\title{
WestVirginiaUniversity
}

THE RESEARCH REPOSITORY @ WVU

Graduate Theses, Dissertations, and Problem Reports

2009

\section{A strength and serviceability assessment of high performance steel Bridge 10462}

Aaron G. Bertoldi

West Virginia University

Follow this and additional works at: https://researchrepository.wvu.edu/etd

\section{Recommended Citation}

Bertoldi, Aaron G., "A strength and serviceability assessment of high performance steel Bridge 10462" (2009). Graduate Theses, Dissertations, and Problem Reports. 4440.

https://researchrepository.wvu.edu/etd/4440

This Thesis is protected by copyright and/or related rights. It has been brought to you by the The Research Repository @ WVU with permission from the rights-holder(s). You are free to use this Thesis in any way that is permitted by the copyright and related rights legislation that applies to your use. For other uses you must obtain permission from the rights-holder(s) directly, unless additional rights are indicated by a Creative Commons license in the record and/ or on the work itself. This Thesis has been accepted for inclusion in WVU Graduate Theses, Dissertations, and Problem Reports collection by an authorized administrator of The Research Repository @ WVU. For more information, please contact researchrepository@mail.wvu.edu. 


\title{
A STRENGTH AND SERVICEABILITY ASSESSMENT OF High PERForMANCE SteEL BRIDGE 10462
}

\author{
Aaron G. Bertoldi \\ Thesis submitted to the \\ College of Engineering and Mineral Resources \\ at West Virginia University \\ in partial fulfillment of the requirements \\ for the degree of \\ Master of Science \\ in \\ Civil and Environmental Engineering
}

Karl E. Barth, Ph. D., Chair

David R. Martinelli, Ph. D.,

Michael G. Barker, Ph. D.

Department of Civil and Environmental Engineering

Morgantown, West Virginia

2009

Keywords: steel bridge, live load deflection, LRFD, high performance steel, bridge serviceability, field testing, HPS $100 \mathrm{~W}$ 


\section{ABSTRACT \\ A Strength and Serviceability Assessment of High Performance Steel Bridge 10462}

\section{Aaron G. Bertoldi}

High performance steels (HPS) were developed through the cooperative efforts of the American Iron and Steel Institute (AISI), the US Navy, and the Federal Highway Administration (FHWA). They offer several advantages over conventional bridge steels including greater yield strengths, improved ductility, increased toughness, and better welding characteristics. The three grades of HPS that are currently available in today's bridge market are HPS 50W, 70W, and 100W. The current steel I-girder flexural capacity equations, however, were specifically developed for girders with nominal yield strengths less than or equal to $70 \mathrm{ksi}$. Because of this fact, the flexural capacities of Igirders incorporating HPS $100 \mathrm{~W}$ have been restricted due to a lack of experimental and/or analytical evidence that supports the applicability of existing equations. In particular, the design flexural capacities of compact and noncompact sections in negative flexure are currently limited to their yield moment capacities $\left(\mathrm{M}_{\mathrm{y}}\right)$ instead of their plastic moment capacities $\left(\mathrm{M}_{\mathrm{p}}\right)$.

The focus of this research project was to experimentally and analytically evaluate the applicability of the current design specifications for I-girders fabricated with HPS 100W. In particular, the strength and serviceability of the Culloden Railroad Overpass (WVDOH Bridge No. 10462) was assessed by conducting static and dynamic load tests. The Culloden Bridge is a three-span-continuous bridge that utilizes HPS 100W in the compression flanges of sections in negative flexure at interior supports. The experimental natural frequency, lateral live load distribution factors, and live load ratings were calculated from field test data and compared with values obtained from an independent design assessment.

The results indicate that the Culloden Bridge performs with adequate strength and serviceability under the current $4^{\text {th }}$ edition of the American Association of Safety and Highway Transportation Officials (AASHTO) specifications (2007 with 2008 interims). The live load deflections obtained from static load tests were found to be less than $\mathrm{L} / 1000$, as well as those determined analytically. Experimental live load deflection distribution factors were found to be larger than AASHTO factors. Conversely, experimental moment distribution factors were found to be less than AASHTO factors. Experimental and design live load ratings were calculated based on the HL-93 design vehicular live load. In all cases, the experimental and design live load rating factors were found to be greater than 1.0; which indicates that the Culloden Bridge has sufficient capacity. 


\section{Acknowledgements}

I would like to thank the West Virginia Department of Transportation for funding this research project and providing the plans for the Culloden Bridge. I would also like to thank my advisor Dr. Karl Barth for his guidance and support throughout my undergraduate and graduate career. The knowledge and experience I gained under his tutelage is invaluable and will never be forgotten. Additional thanks goes to Dr. Michael Barker for lending his bridge testing expertise and guiding me through many rigorous calculations.

Additionally, I would like to thank the graduate students of B-11 who offered moral and technical support, as well as friendship. I would also like to thank my Mom and Dad, and my brother, for continuing to offer their love and support over the last twenty-four years of my life. Lastly, I would like to thank my girlfriend for all of her love, patience, and support during the pursuit of my master's degree. 


\section{Table of Contents}

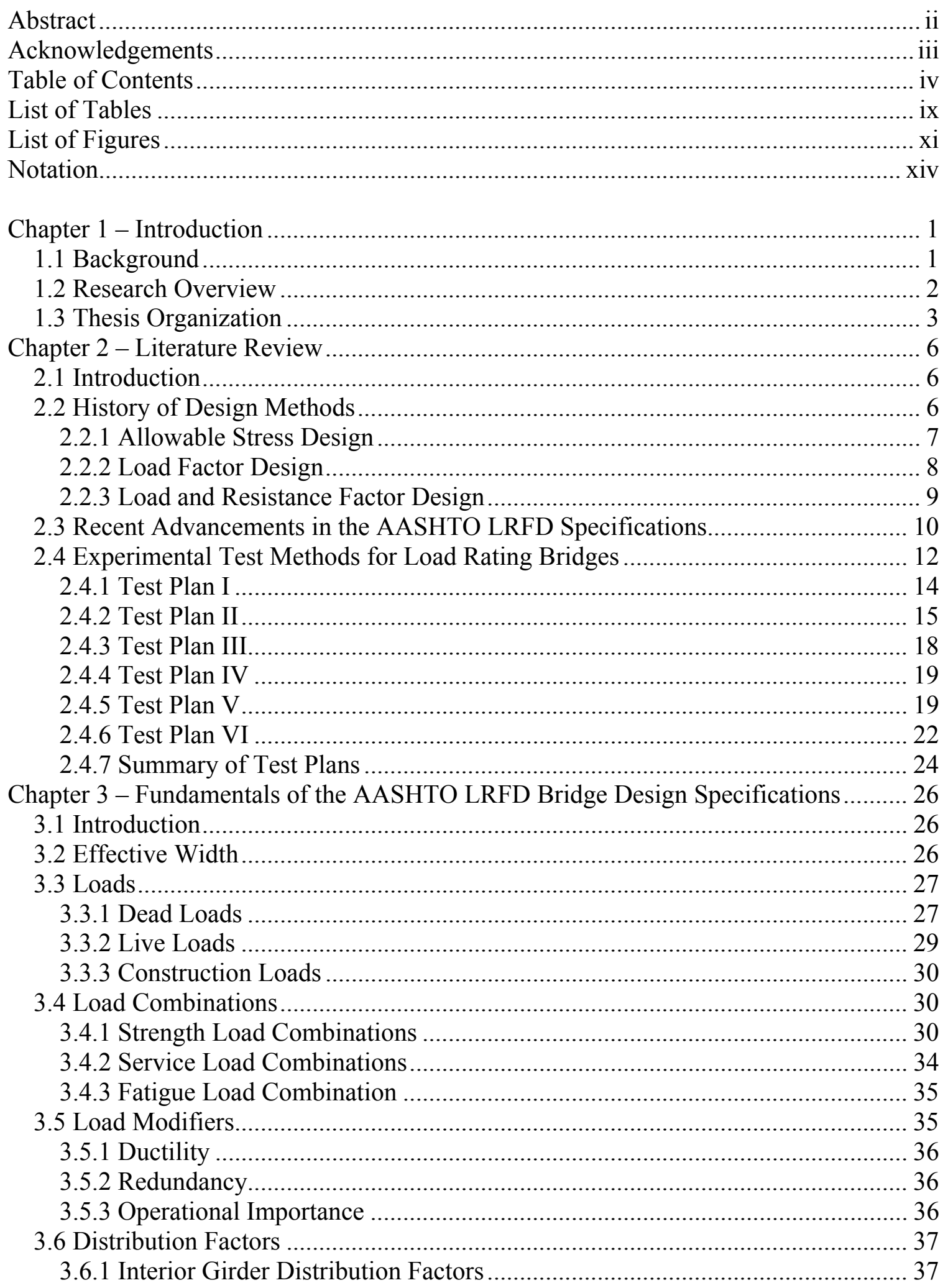


3.6.2 Exterior Girder Distribution Factors.............................................................. 38

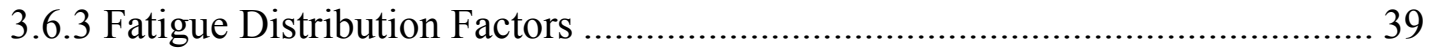

3.6.4 Live Load Deflection Distribution Factor...................................................... 40

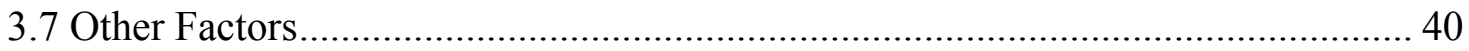

3.7.1 Dynamic Load Allowances........................................................................... 41

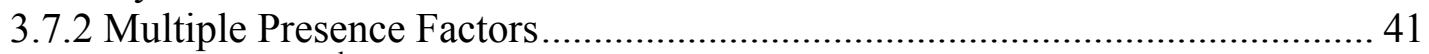

3.8 Summary of the $4^{\text {th }}$ Edition AASHTO LRFD Specifications................................. 42

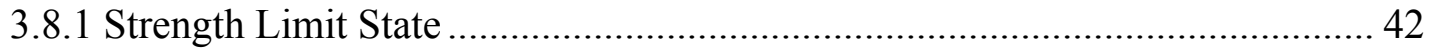

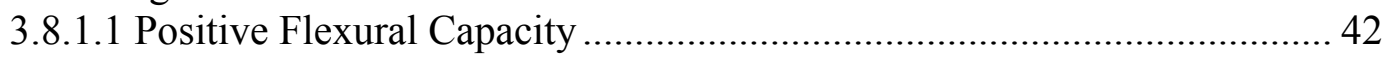

3.8.1.1.1 Compact Sections.......................................................................... 43

3.8.1.1.2 Noncompact Sections..................................................................... 44

3.8.1.2 Negative Flexural Capacity...................................................................... 47

3.8.1.2.1 Flange Local Buckling................................................................. 48

3.8.1.2.2 Lateral-Torsional Buckling ............................................................ 49

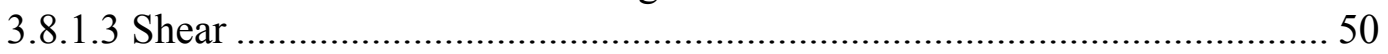

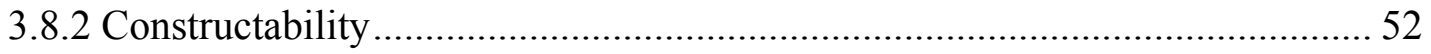

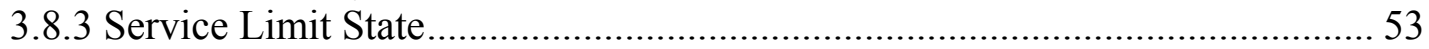

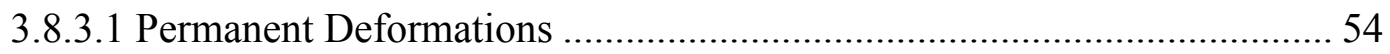

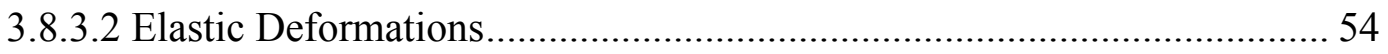

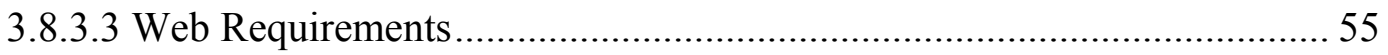

3.8.4 Fatigue and Fracture Limit State.................................................................. 56

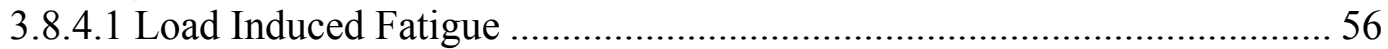

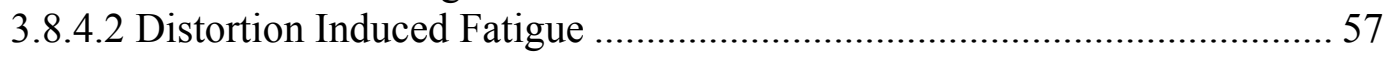

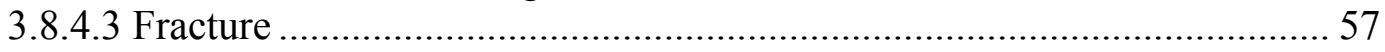

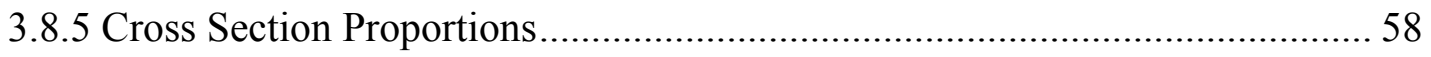

3.8.5.1 Web Proportions …………………………….................................. 58

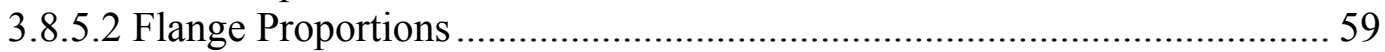

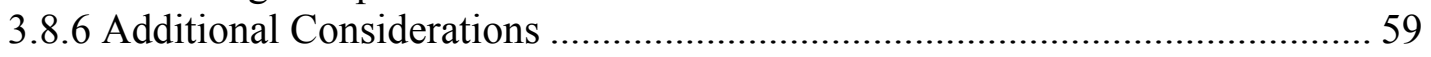

Chapter 4 - Parametric Assessment of AASHTO Specifications for HPS 100W............ 63

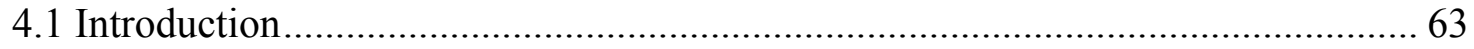

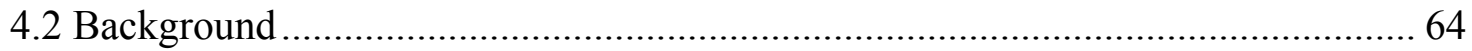

4.3 Negative Flexural Capacity of HPS 100W I-Girders at the Strength Limit State .. 65

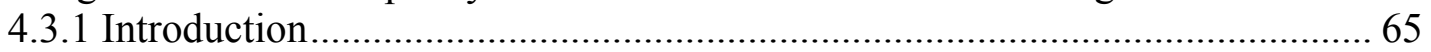

4.3.2 Negative Flexural Capacity per Article 6.10.8 …………………………….... 65

4.3.3 Negative Flexural Capacity per Appendix A .....................................................6 68

4.4 Parametric Study of HPS 100W I-Girders with Finite Element Analysis .............. 73

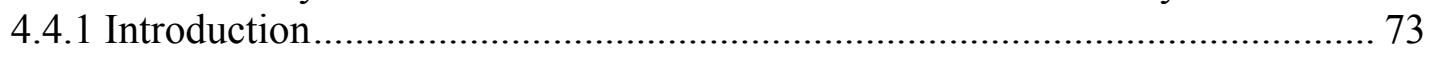

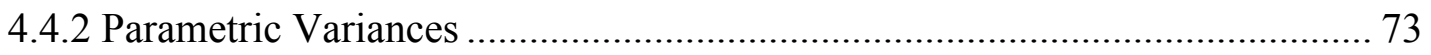

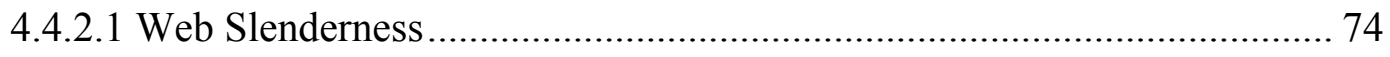

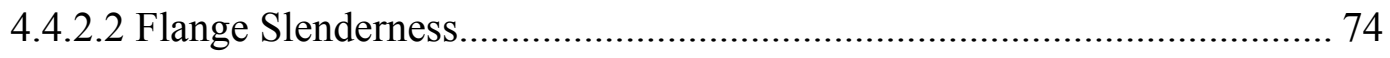

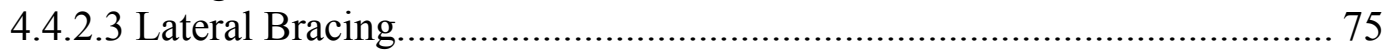

4.4.2.4 Depth of Web in Compression............................................................ 75

4.4.3 Finite Element Analysis Procedure............................................................... 75

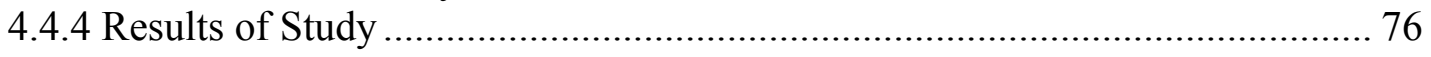

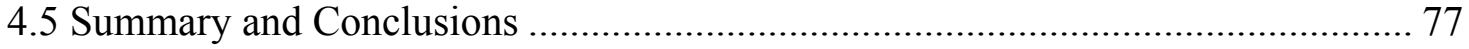

Chapter 5 - Culloden Bridge Design Assessment........................................................... 79 


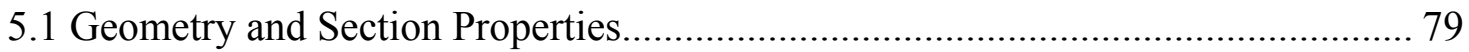

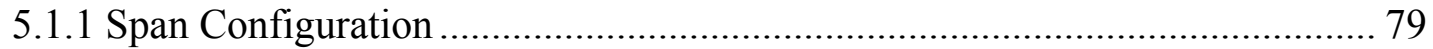

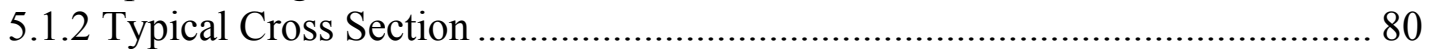

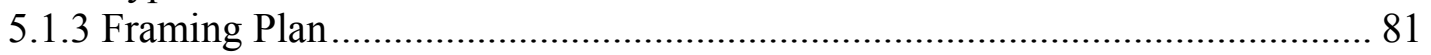

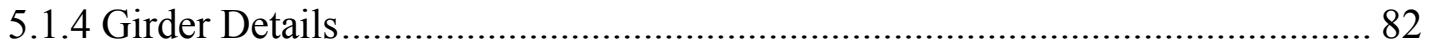

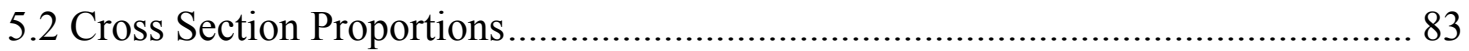

5.2.1 Span to Depth Ratio .................................................................................... 84

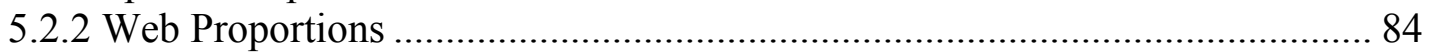

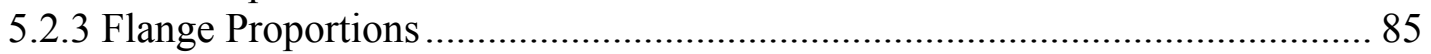

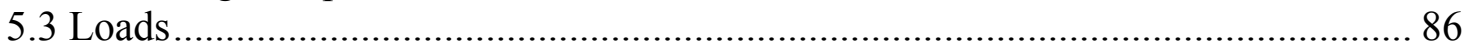

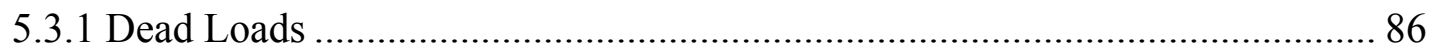

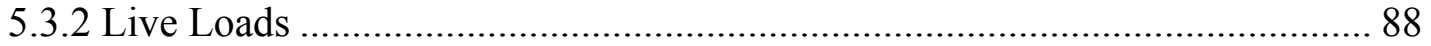

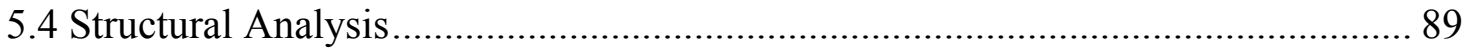

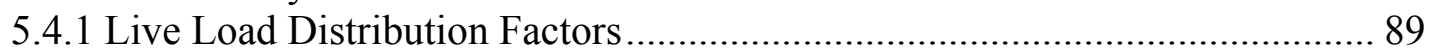

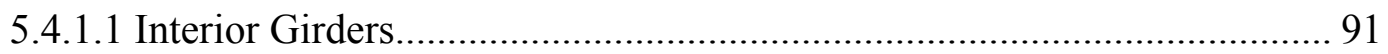

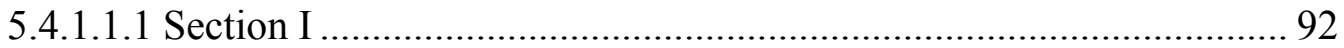

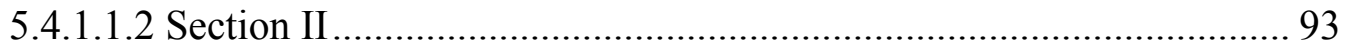

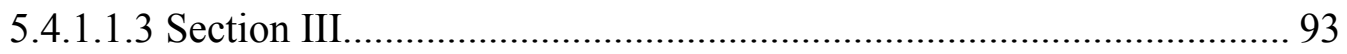

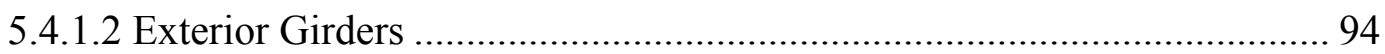

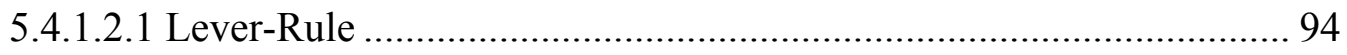

5.4.1.2.2 Lane-Fraction Modification Factor.................................................... 95

5.4.1.2.3 Special Analysis...................................................................... 97

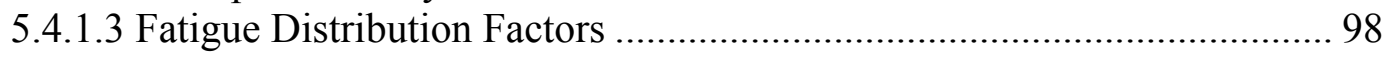

5.4.1.4 Live Load Deflection Distribution Factor.............................................. 99

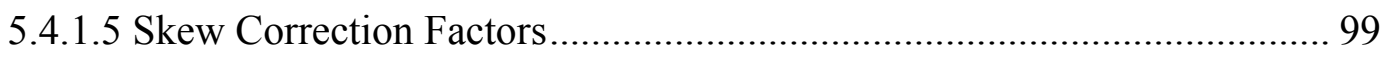

5.4.1.5.1 Moment Correction Factors .......................................................... 100

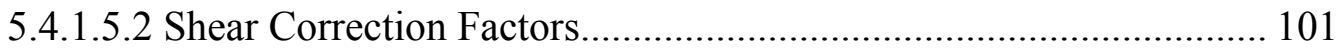

5.4.2 Summary of Distribution Factors................................................................. 101

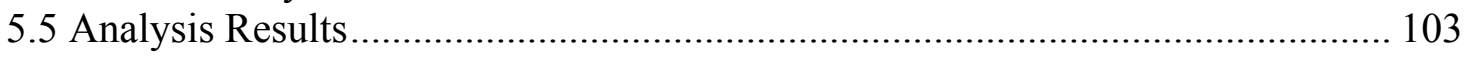

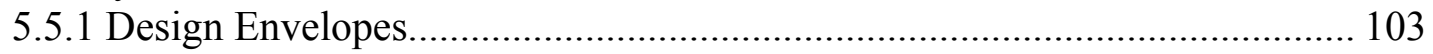

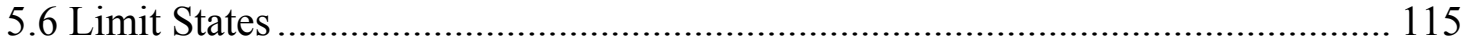

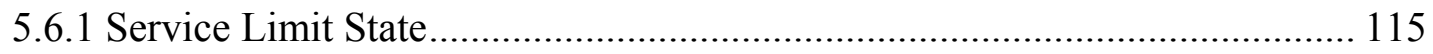

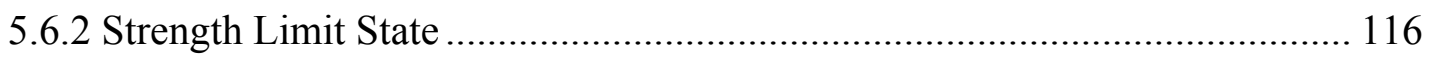

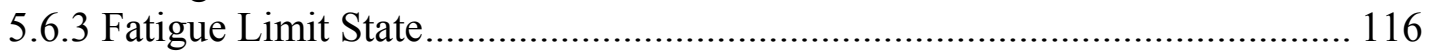

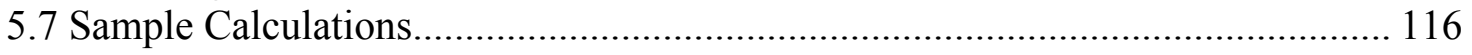

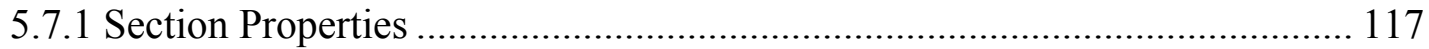

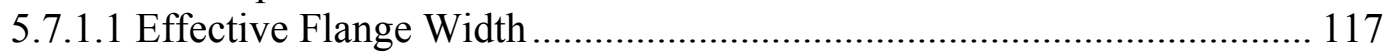

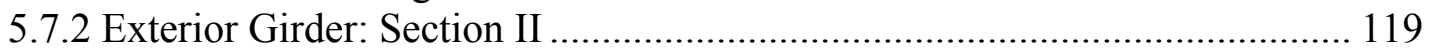

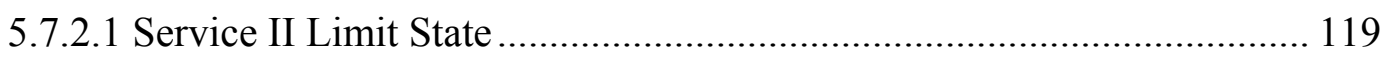

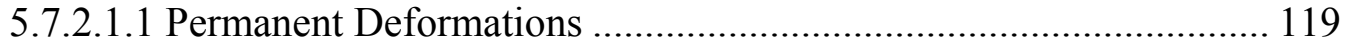

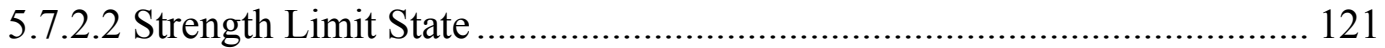

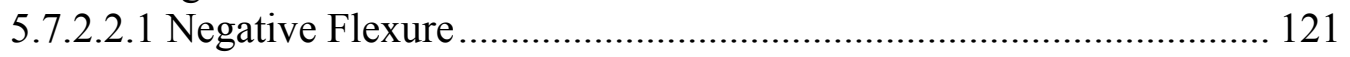

5.7.2.2.1.1 Lateral-Torsional Buckling Capacity...................................... 122

5.7.2.2.1.2 Flange Local Buckling Capacity............................................... 127

5.7.2.2.1.3 Compression Flange Capacity .................................................. 129

5.7.2.2.1.4 Tension Flange Capacity........................................................ 130 


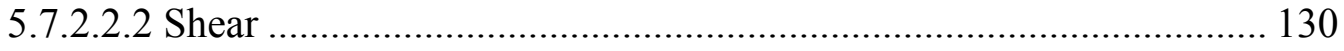

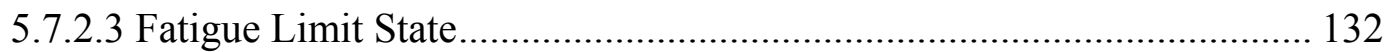

5.7.2.3.1 Load-Induced Fatigue ................................................................ 132

5.7.2.3.2 Special Fatigue Requirement for Webs ......................................... 134

5.7.3 Exterior Girder Check: Section III.......................................................... 136

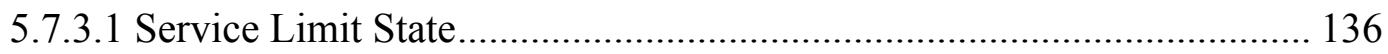

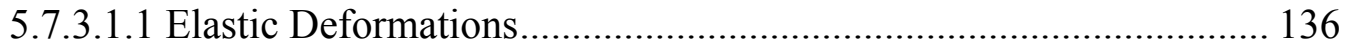

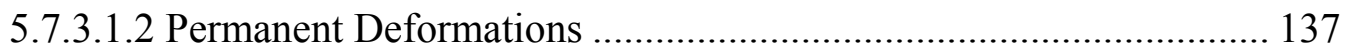

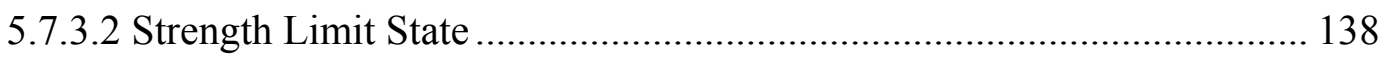

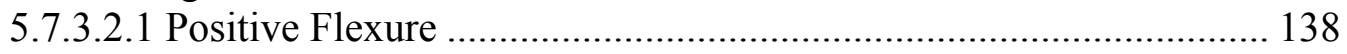

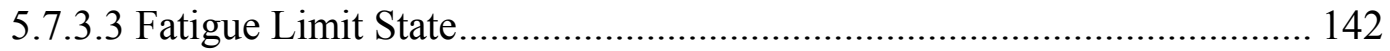

5.7.3.3.1 Load-Induced Fatigue .................................................................. 142

5.7.3.3.2. Special Fatigue Requirement for Webs ......................................... 144

5.7.4 Design Assessment Summary …………………….................................. 145

Chapter 6 -Culloden Bridge Field Test ................................................................... 148

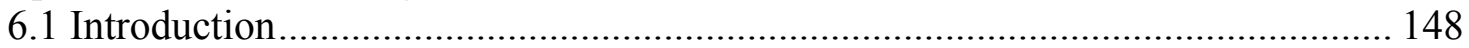

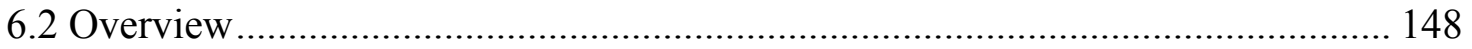

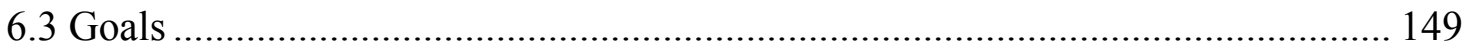

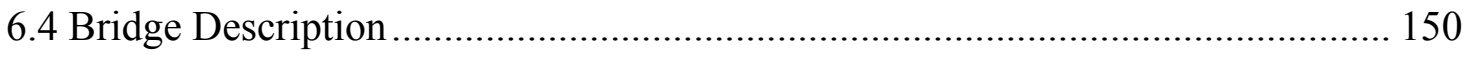

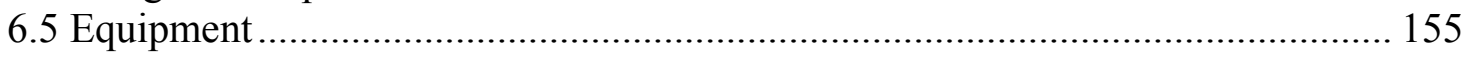

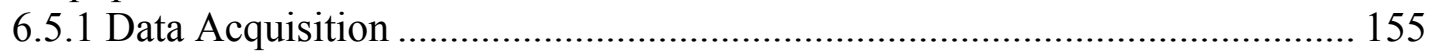

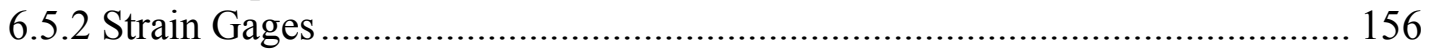

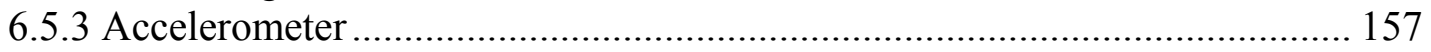

6.5.4 Linear Variable Differential Transducers ................................................. 158

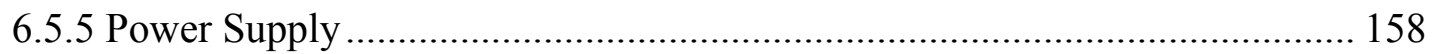

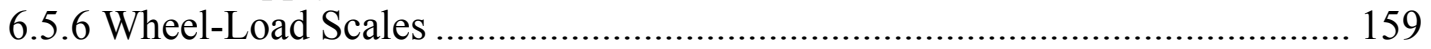

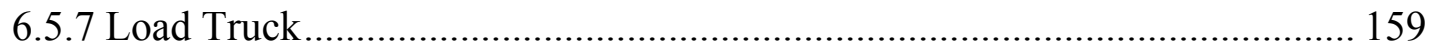

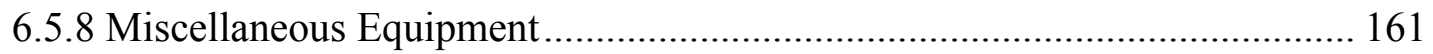

6.6 Determination of Load Truck Placement.............................................................. 162

6.6.1 Influence Surfaces Generated using Finite Element Analysis....................... 162

6.6.2 Lever Rule Load Placement Method ............................................................ 166

6.6.3 Load Placement Used During Physical Testing............................................. 167

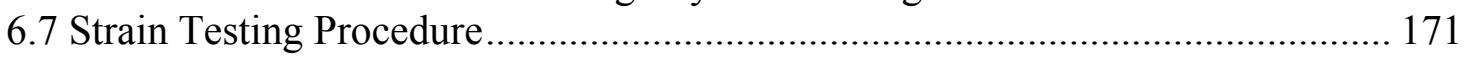

6.8 Deflection Testing Procedure …………………............................................ 174

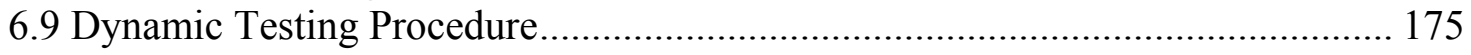

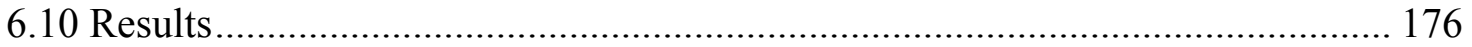

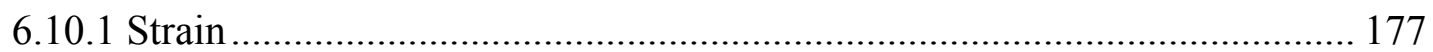

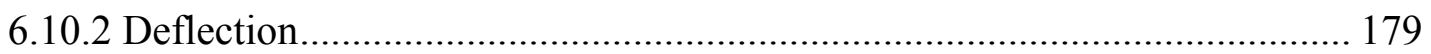

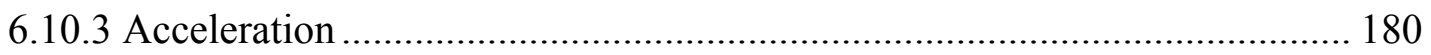

Chapter 7 - Serviceability Assessment of the Culloden Bridge ...................................... 181

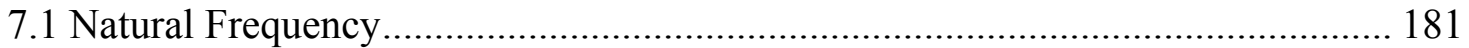

7.1.1 Theoretical Natural Frequency ................................................................... 181

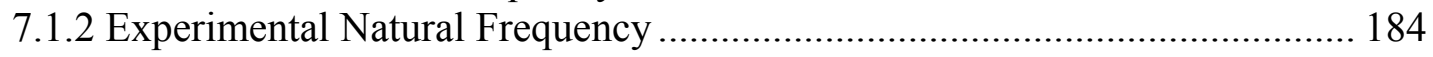

7.1.3 Summary of Natural Frequencies .............................................................. 186

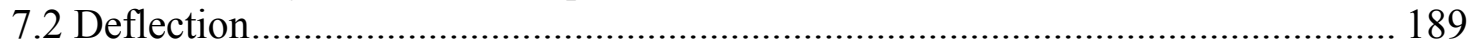

7.2.1 Deflection Field Test Results.................................................................... 189 
7.2.2 Experimental Deflection Distribution Factors ................................................ 194

7.2.3 Summary of Deflection Distribution Factors.................................................. 199

Chapter 8 - Strength Assessment of the Culloden Bridge............................................ 202

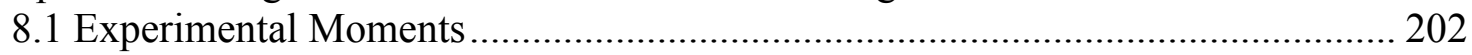

8.1.1 Section I: Experimental Positive Bending Moments ..................................... 203

8.1.2 Section II: Experimental Negative Bending Moments .................................. 213

8.2 Experimental Moment Distribution Factors ……………..................................... 218

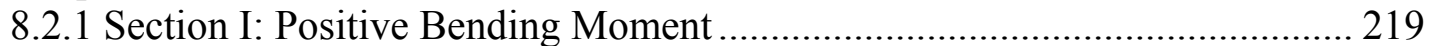

8.2.2 Section II: Negative Bending Moment ................................................. 222

8.2.3 Summary of Moment Distribution Factors ................................................... 224

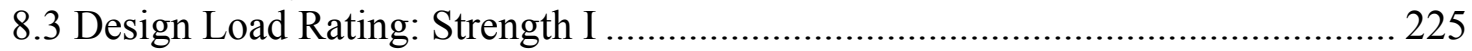

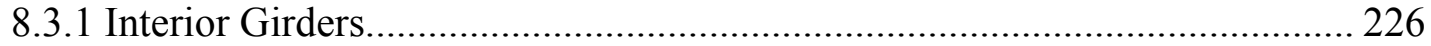

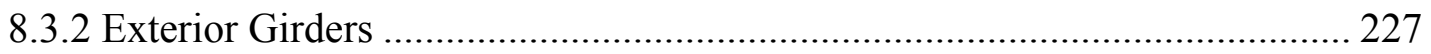

8.4 Design Load Rating: Service II..................................................................... 228

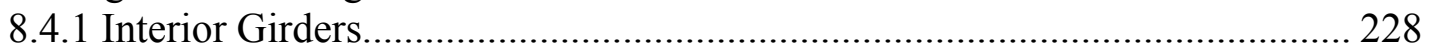

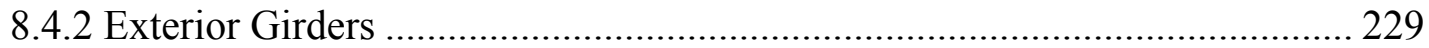

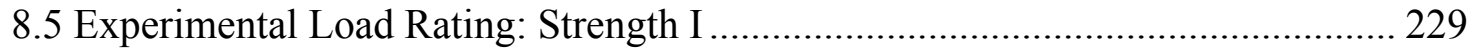

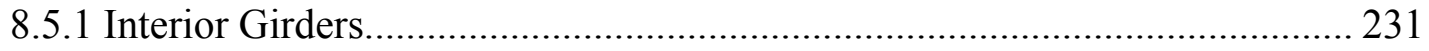

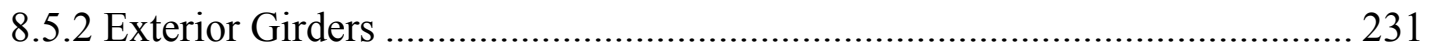

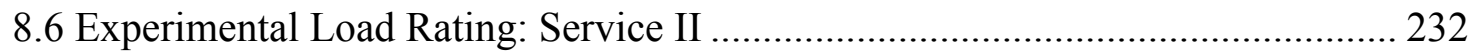

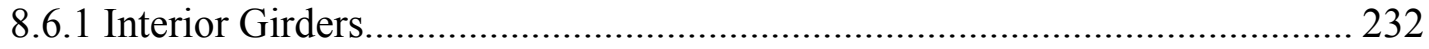

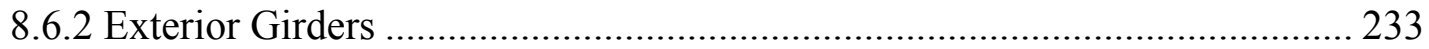

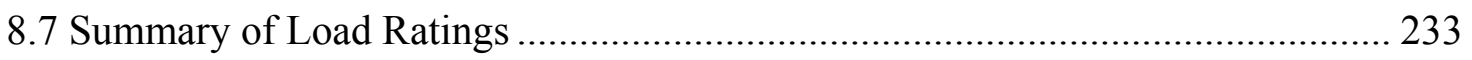

Chapter 9 - Summary and Conclusions................................................................... 235

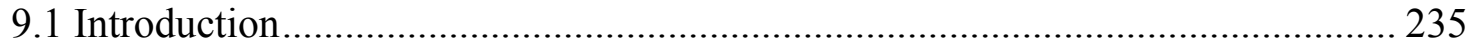

9.2 AASHTO Design Specifications for HPS I-Girders........................................... 235

9.3 Culloden Bridge Design Assessment with Current AASHTO Specifications...... 236

9.4 Strength and Serviceability Field Testing of the Culloden Bridge ........................ 237

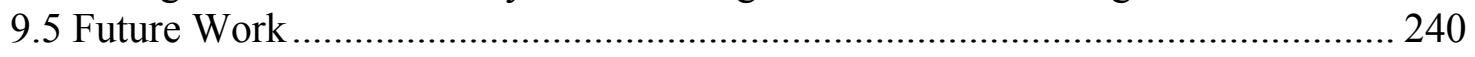

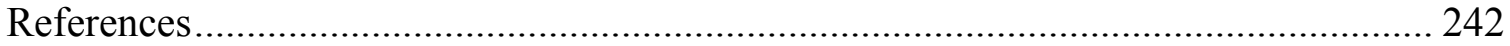

Appendix A: Culloden Bridge Plans...................................................................... 245

Appendix B: Influence Surfaces Generated with Finite Element Modeling .................. 252 


\section{List of Tables}

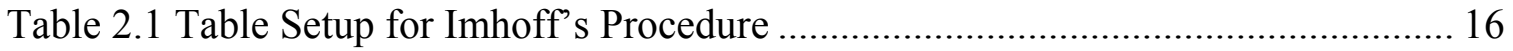

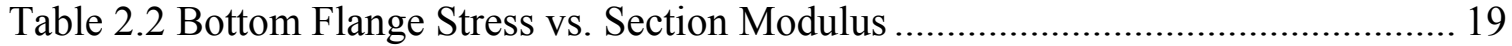

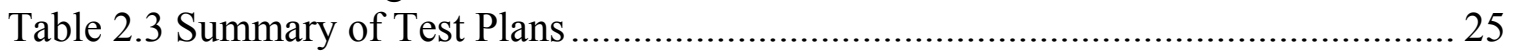

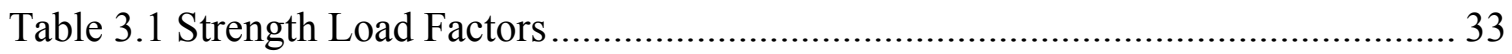

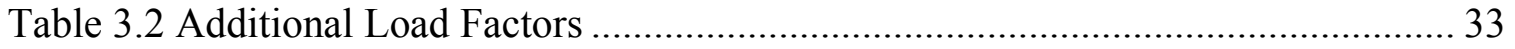

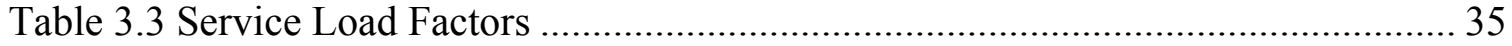

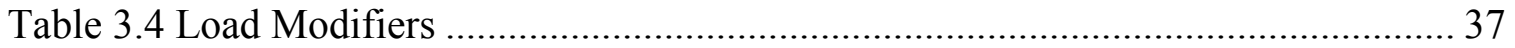

Table 3.5 Dynamic Load Allowance, IM ................................................................... 41

Table 3.6 Multiple Presence Factors............................................................................ 42

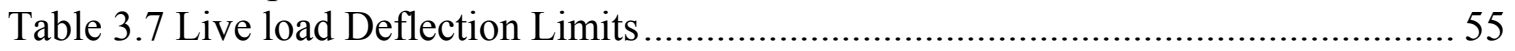

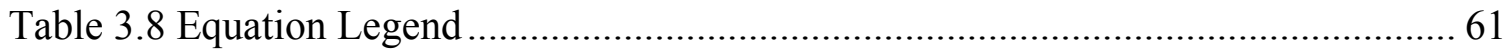

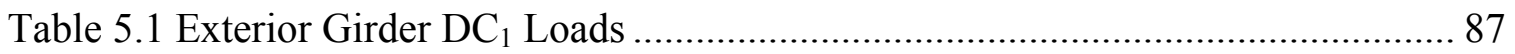

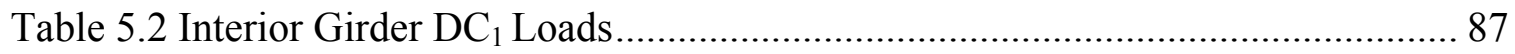

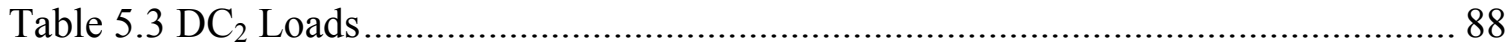

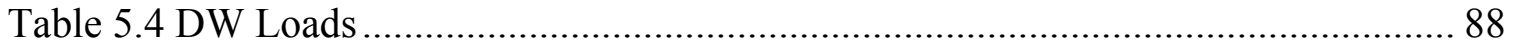

Table 5.5 Moment of Inertia of Steel Section I ........................................................... 90

Table 5.6 Longitudinal Stiffness of Interior Girder Sections ...................................... 91

Table 5.7 Unmodified Moment Distribution Factors ................................................ 95

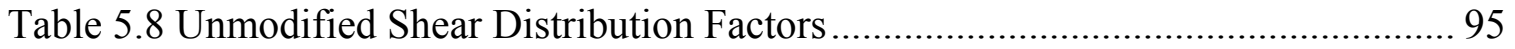

Table 5.9 Modified Moment Distribution Factors .......................................................... 96

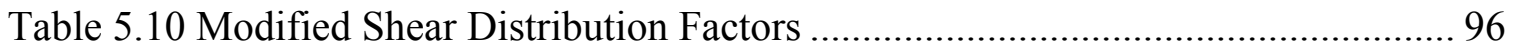

Table 5.11 Special Analysis Distribution Factors........................................................ 98

Table 5.12 Interior Girder Fatigue Moment Distribution Factors ................................ 98

Table 5.13 Interior Girder Fatigue Shear Distribution Factors.................................... 99

Table 5.14 Exterior Girder Fatigue Moment Distribution Factors ................................ 99

Table 5.15 Exterior Girder Fatigue Shear Distribution Factors......................................99

Table 5.16 Interior Girder Skew Correction Factors for Moment ................................. 100

Table 5.17 Exterior Girder Skew Correction Factors for Moment............................... 100

Table 5.18 Interior Girder Skew Correction Factors for Shear ................................... 101

Table 5.19 Exterior Girder Skew Correction Factors for Shear ................................... 101

Table 5.20 Interior Girder - Section I ..................................................................... 102

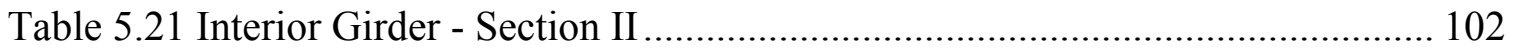

Table 5.22 Interior Girder - Section III.................................................................. 102

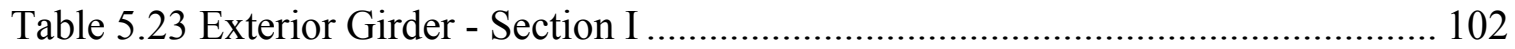

Table 5.24 Exterior Girder - Section II .................................................................. 102

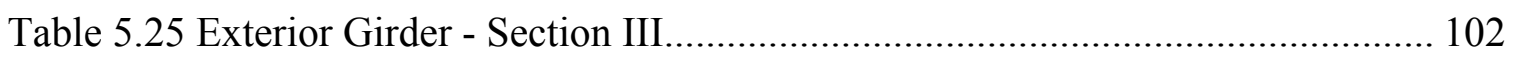

Table 5.26 Unfactored and Undistributed Dead Load Moments (k-ft.) ....................... 110

Table 5.27 Unfactored and Undistributed Live Load Moments (k-ft.)........................ 110

Table 5.28 Unfactored and Distributed Moments (k-ft.) ............................................ 111

Table 5.29 Strength I Load Combination Moments (k-ft.)........................................ 111 
Table 5.30 Service II Load Combination Moments (k-ft.) ........................................ 112

Table 5.31 Factored and Distributed Fatigue Moments (k-ft.) ................................... 112

Table 5.32 Unfactored and Undistributed Shears (kips) ............................................. 113

Table 5.33 Unfactored and Distributed Shears (kips)............................................... 113

Table 5.34 Strength I Load Combination Shears (kips) .......................................... 114

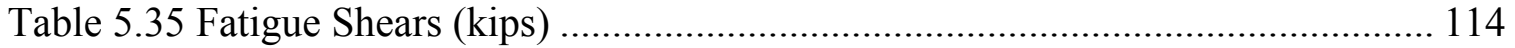

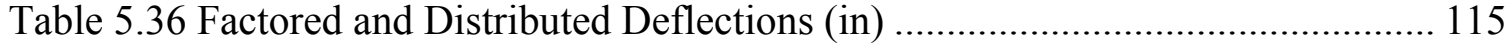

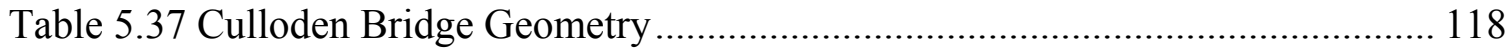

Table 5.38 Exterior Girder Section Properties............................................................ 119

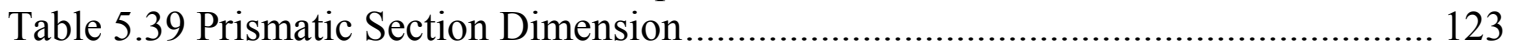

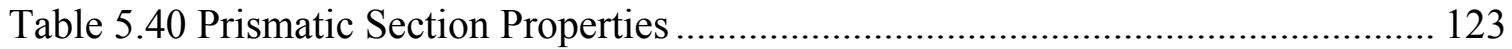

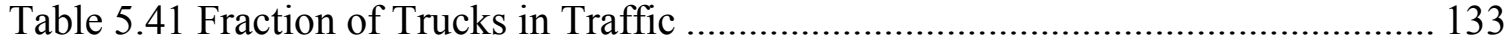

Table 5.42 Summary of Performance Ratios: Exterior Girder Section II...................... 147

Table 5.43 Summary of Performance Ratios: Exterior Girder Section III .................... 147

Table 6.1 Girder 3 Response Due to Incremental Movement of Unit-Load .................. 167

Table 6.2 Truck Placements Measured from North Curb ........................................... 169

Table 7.1 Weighted Average Moment of Inertia .................................................... 182

Table 7.2 Unit Weight of Interior Girder Short-Term Composite Section.................... 183

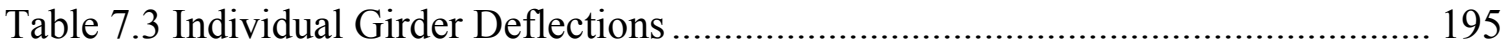

Table 7.4 Superimposed Deflections for Girders 1, 2, \& 3 ........................................ 196

Table 7.5 Superimposed Deflections for Girders 4, 5, 6, \& 7 .................................. 196

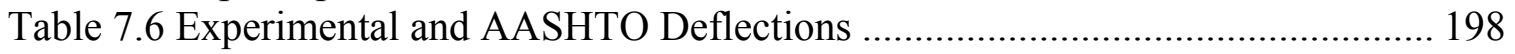

Table 7.7 Percent Difference of Exp. vs. AASHTO Distribution Factors...................... 200

Table 7.8 Percent Difference of Exp. and AASHTO Distribution Factors .................... 201

Table 8.1 Section Properties used in Section I - Positive Moment Calculations............ 204

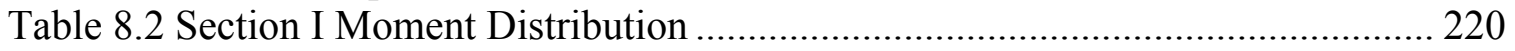

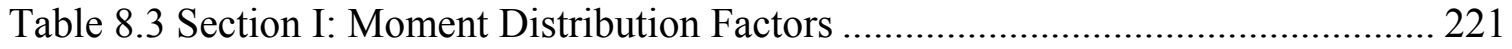

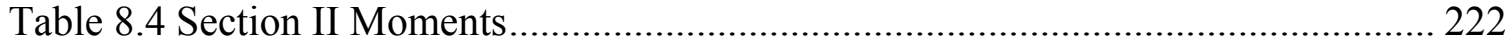

Table 8.5 Section II Moment Distribution Factors .................................................... 223

Table 8.6 Interior Girder Moments and Section Moduli ............................................ 226

Table 8.7 Exterior Girder Moments and Section Moduli ............................................ 226

Table 8.8 Section I: Bottom Flange Stresses (ksi) .................................................... 230

Table 8.9 Section II: Bottom Flange Stresses (ksi) ................................................. 230

Table 8.10 Percent Difference: Strength I - Interior Girder Load Ratings .................... 234

Table 8.11 Percent Difference: Strength I - Exterior Girder Load Ratings ................... 234

Table 8.12 Percent Difference: Service II - Interior Girder Load Ratings ..................... 234

Table 8.13 Percent Difference: Service II - Exterior Girder Load Ratings ................... 234 


\section{List of Figures}

Figure 2.1 Strain Gage Placement using Imhoff's Procedure...................................... 16

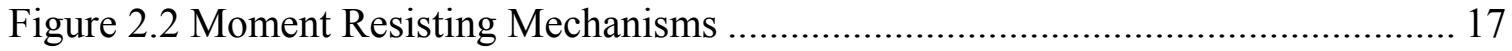

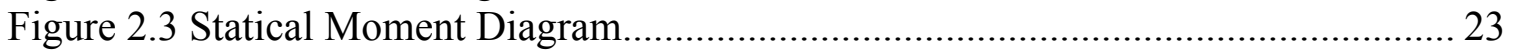

Figure 3.1 Effective Width of a Composite Section ................................................. 27

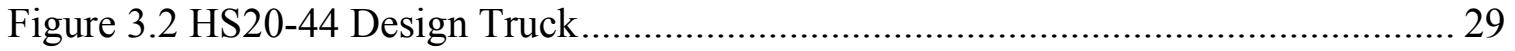

Figure 5.1 Culloden Bridge Span Configuration ....................................................... 80

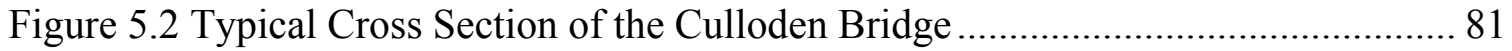

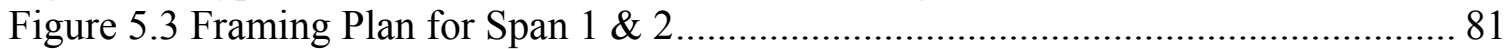

Figure 5.4 Framing Plan for Span $2 \&$ 3 ................................................................. 82

Figure 5.5 I-Girder Section Sizes for Exterior Girders.............................................. 83

Figure 5.6 I-Girder Section Sizes for Interior Girders ............................................ 83

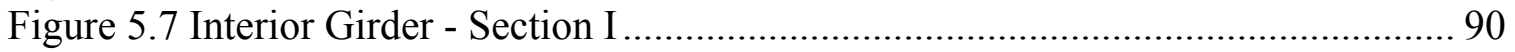

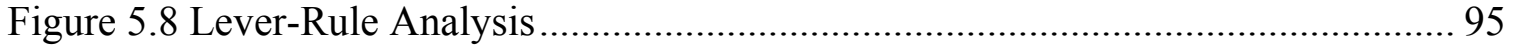

Figure 5.9 Special Analysis Truck Placements.......................................................... 97

Figure 5.10 Moment Envelopes: Exterior Girder ....................................................... 105

Figure 5.11 Fatigue Moment Envelope: Exterior Girder........................................ 106

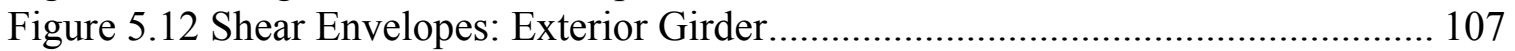

Figure 5.13 Fatigue Shear Envelope: Exterior Girder ............................................. 108

Figure 5.14 Fatigue Shear Envelope: Exterior Girder ............................................ 108

Figure 5.15 Deflection Envelope: Exterior Girder .................................................... 109

Figure 5.16 Fatigue Shear Envelope: Exterior Girder ............................................. 109

Figure 5.17 Effective Flange Width for Exterior Girders........................................ 117

Figure 6.1 Culloden Railroad Overpass (Bridge No. 10462) ..................................... 148

Figure 6.2 Typical Elevation of Culloden Railroad Overpass...................................... 151

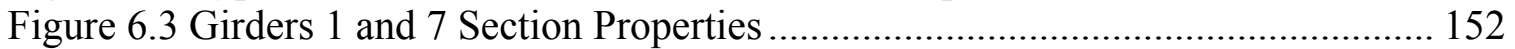

Figure 6.4 Girders 2 thru 6 Section Properties ............................................................ 152

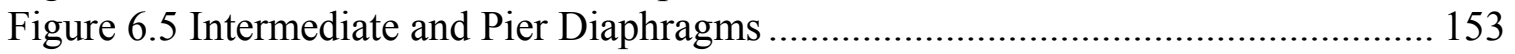

Figure 6.6 Culloden Bridge Framing Plan................................................................. 153

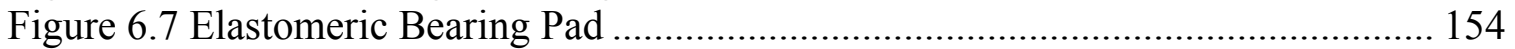

Figure 6.8 Typical Cross Section of the Culloden Bridge .......................................... 154

Figure 6.9 Wireless Base Station .............................................................................. 156

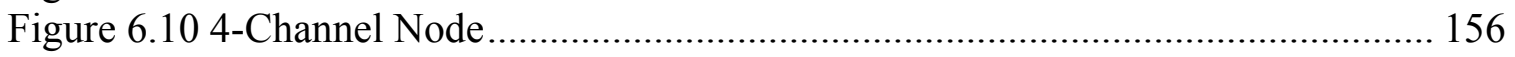

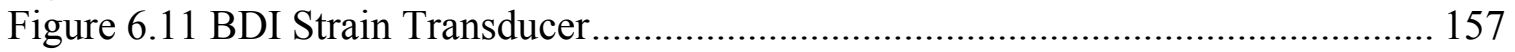

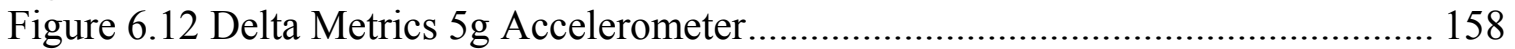

Figure 6.13 RDP Electronics Group DC LVDTs ..................................................... 158

Figure 6.14 Intercomp PT 300 Portable Wheel Load Scale ........................................ 159 
Figure 6.15 WV-DOH Tandem-Axle Dump Truck........................................................ 160

Figure 6.16 WV-DOH Tandem-Axle Dump Truck Wheel Loads .................................. 160

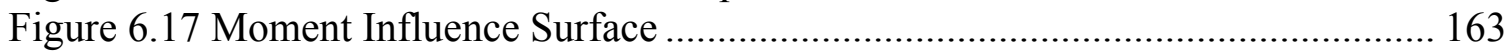

Figure 6.18 2-D Representation of Moment Influence Surface...................................... 164

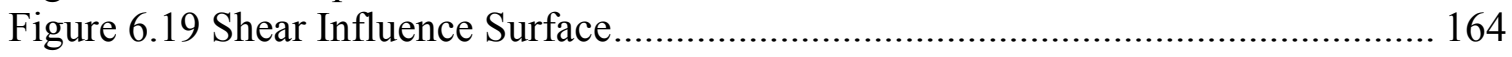

Figure 6.20 2-D Representation of Shear Influence Surface ....................................... 165

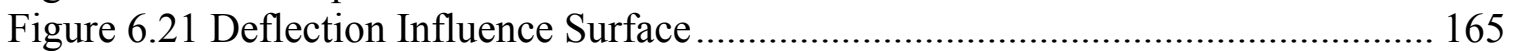

Figure 6.22 2-D Representation of Deflection Influence Surface ................................ 166

Figure 6.23 Truck Placements by Lever Rule ......................................................... 167

Figure 6.24 Truck Placements 1 thru 5 Measured from North Curb .............................. 168

Figure 6.25 Truck Placements 6 thru 10 Measured from North Curb ........................... 169

Figure 6.26 Longitudinal Truck Placement ........................................................... 170

Figure 6.27 Placement of Front-Tire of Load Truck ................................................. 170

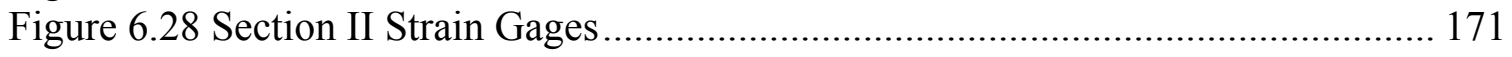

Figure 6.29 Section I Strain Gages ........................................................................ 172

Figure 6.30 Strain Test Sections and Gage Plan..................................................... 173

Figure 6.31 Strain Gage Placements on Web and Flange............................................. 174

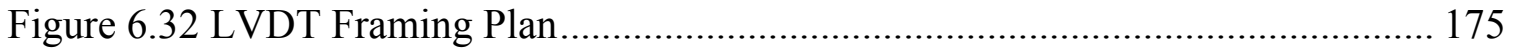

Figure 6.33 LVDT Field Frame ......................................................................... 175

Figure 6.34 Accelerometer Mounted to Top Flange..................................................... 176

Figure 6.35 Girder 4: Negative Bending Strains .................................................. 178

Figure 6.36 Girder 4: Positive Bending Strains ..................................................... 178

Figure 6.37 Truck Placement 5 Deflections …………........................................... 179

Figure 6.38 Dynamic Test Results........................................................................ 180

Figure 7.1 Accelerations from Dynamic Load Test.................................................... 185

Figure 7.2 Fourier Transform Results..................................................................... 186

Figure 7.3 Ontario Bridge Code: Frequency vs. Static Deflection................................. 187

Figure 7.4 Allowable Frequency of the Culloden Bridge.............................................. 188

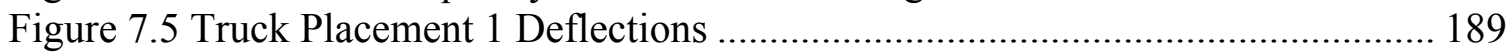

Figure 7.6 Truck Placement 2 Deflections ........................................................... 190

Figure 7.7 Truck Placement 3 Deflections …………............................................. 190

Figure 7.8 Truck Placement 4 Deflections …………................................................ 191

Figure 7.9 Truck Placement 5 Deflections …………….......................................... 191

Figure 7.10 Truck Placement 6 Deflections …………............................................ 192

Figure 7.11 Truck Placement 7 Deflections ………….............................................. 192

Figure 7.12 Truck Placement 8 Deflections ………….............................................. 193

Figure 7.13 Truck Placement 9 Deflections …………............................................. 193

Figure 7.14 Truck Placement 10 Deflections ........................................................... 194

Figure 7.15 Worst-Case Truck Placements for Girders 1, 2, \& 3 ................................. 195

Figure 7.16 Worst-Case Truck Placements for Girders 4, 5, 6, \& 7 .............................. 195

Figure 7.17 Maximum Distribution Factor by Girder ................................................... 197

Figure 7.18 Experimental and AASHTO Deflections .................................................. 199 


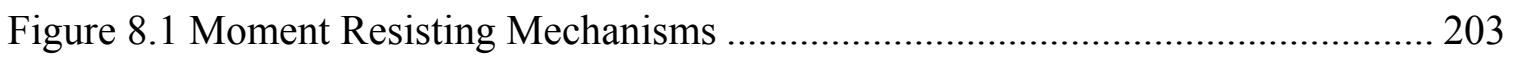

Figure 8.2 Interior Girder - Section I.................................................................. 205

Figure 8.3 Exterior Girder - Section I................................................................. 205

Figure 8.4 Truck Placement 1: Positive Moments....................................................... 208

Figure 8.5 Truck Placement 2: Positive Moments...................................................... 208

Figure 8.6 Truck Placement 3: Positive Moments......................................................... 209

Figure 8.7 Truck Placement 4: Positive Moments..................................................... 209

Figure 8.8 Truck Placement 5: Positive Moments.................................................... 210

Figure 8.9 Truck Placement 6: Positive Moments..................................................... 210

Figure 8.10 Truck Placement 7: Positive Moments................................................... 211

Figure 8.11 Truck Placement 8: Positive Moments ..................................................... 211

Figure 8.12 Truck Placement 9: Positive Moments...................................................... 212

Figure 8.13 Truck Placement 10: Positive Moments................................................. 212

Figure 8.14 Truck Placement 1: Negative Moments ................................................... 213

Figure 8.15 Truck Placement 2: Negative Moments ................................................... 214

Figure 8.16 Truck Placement 3: Negative Moments ………………………….......... 214

Figure 8.17 Truck Placement 4: Negative Moments ……………………………...... 215

Figure 8.18 Truck Placement 5: Negative Moments ................................................ 215

Figure 8.19 Truck Placement 6: Negative Moments .............................................. 216

Figure 8.20 Truck Placement 7: Negative Moments ............................................... 216

Figure 8.21 Truck Placement 8: Negative Moments ................................................... 217

Figure 8.22 Truck Placement 9: Negative Moments …………….............................. 217

Figure 8.23 Truck Placement 10: Negative Moments ................................................ 218

Figure 8.24 Worst Case Truck Placements for Girders 1, 2, \& 3 ................................... 219

Figure 8.25 Worst Case Truck Placements for Girders 4, 5, 6, \& 7 ............................. 219

Figure 8.26 Section I: Maximum AASHTO \& Experimental Distribution Factors ....... 221

Figure 8.27 Section II: Maximum AASHTO \& Experimental Distribution Factors...... 223 


\section{Notation}

$A \quad=$ fatigue detail category constant; area enclosed within centerlines of plates of box members $\left(\mathrm{in}^{2}\right)$

$A_{b f} \quad=$ area of the bottom flange at the abutment $\left(\right.$ in $\left.^{2}\right)$

$A D T T_{S L}=$ single-lane ADTT as specified in Article 3.6.1.4 (trucks)

$A_{f n} \quad=$ sum of the flange area and the area of any cover plates on the side of the neutral axis corresponding to $\mathrm{D}_{\mathrm{n}}\left(\mathrm{in}^{2}\right)$

$A_{\text {steel }} \quad=$ area of steel section $\left(\mathrm{in}^{2}\right)$

$b_{s} \quad=$ effective width of concrete deck (in)

$C \quad=$ ratio of the shear-buckling resistance to the shear yield strength determined with the shear-buckling coefficient, $k$, taken equal to 5.0

$C G \quad=$ distance to the center of gravity of the girder (in)

CP $=$ cover plate factor, 2 if bottom flange is cover plated, 1 if not (Imhoff 1998)

$D \quad=$ web depth (in)

$D_{c} \quad=$ depth of the web in compression in the elastic range. For composite sections, $D_{c}$ shall be determined as specified in Article D6.3.1 (in)

$D_{c p} \quad=$ depth of the web in compression at the plastic moment determined as specified in Article D6.3.2 (in)

$d_{e} \quad=$ the distance between the web of the exterior beam and the interior edge of curb or traffic barrier applicable for $-1.0 \leq d_{e} \leq 5.5$ (ft.)

$D F_{A} \quad=$ analytical distribution factor from Chapter 2 (lanes)

$D F_{E} \quad=$ experimental distribution factor from Chapter 2 (lanes)

$D_{n} \quad=\quad$ larger of the distances from the elastic neutral axis of the cross section to the inside face of either flange. For sections where the neutral axis is at the mid-depth of the web, $D_{n}$

$d_{N A} \quad=$ distance to the neutral-axis (in)

$D_{p} \quad=$ distance from the top of the concrete deck to the neutral axis of the composite section at the plastic moment (in)

$d_{s} \quad=$ distance from the centerline of the closest plate longitudinal stiffener or from the gage line of the closest angle longitudinal stiffener to the inner surface or leg of the compression-flange element (in)

$d_{\text {slab }} \quad=$ depth of concrete slab (in)

$d_{\text {steel }} \quad=$ depth of steel girder (in)

$D_{t} \quad=$ total depth of the composite section (in)

$e \quad=$ eccentricity of a design truck or a design lane load from the center of gravity of the pattern of girders (ft.)

$E \quad=$ modulus of elasticity (ksi)

$E_{b} \quad=$ modulus of elasticity of beam (ksi)

$E_{\text {conc }}=$ modulus of elasticity of concrete $\left(\mathrm{in}^{4}\right)$

$E_{\text {steel }}=$ modulus of elasticity of steel $\left(\mathrm{in}^{4}\right)$ 
$f_{0}=\quad$ stress without consideration of lateral bending at the brace point opposite to the one corresponding to $f_{2}$, calculated from the moment envelope value that produces the largest compression at this point in the flange under consideration, or the smallest tension if this point is never in compression. $f_{0}$ shall be due to the factored loads and shall be taken as positive in compression and negative in tension (ksi)

$f_{1}=\quad$ stress without consideration of lateral bending at the brace point opposite to the one corresponding to $f_{2}$, calculated as the intercept of the most critical assumed linear stress variation passing through $f_{2}$ and either $\mathrm{f}_{\text {mid }}$ or $f_{0}$, whichever produces the smaller value of $C_{b} . f_{l}=f_{0}$ if the entire unbraced length between the brace points is concave in shape; otherwise: $f_{1}=2 f_{\text {mid }}-f_{2} \geq f_{0}(\mathrm{ksi})$

$f_{2} \quad=$ except as noted below, $f_{2}$ is the largest compressive stress without consideration of lateral bending at either end of the unbraced length of the flange under consideration, calculated from the critical moment envelope value. $f_{2}$ shall be due to the factored loads and shall be taken as positive. If the stress is zero or tensile in the flange under consideration at both ends of the unbraced length, $f_{2}$ shall be taken as zero (ksi)

$f_{b u} \quad=$ flange stress calculated without consideration of flange lateral bending determined as specified in Article 6.10.1.6 (ksi)

$f_{c}=$ compression-flange stress at the section under consideration due to the Service II loads calculated without consideration of flange lateral bending (ksi)

$F_{c r} \quad=$ elastic lateral-torsional buckling stress (ksi)

$F_{c r w}=$ nominal bend-buckling resistance for webs with or without longitudinal stiffeners, as applicable, determined as specified in Article 6.10.1.9 (ksi)

$f_{D C l}=$ compression flange stress at the section under consideration, calculated without consideration of flange lateral bending and caused by the factored permanent load applied before the concrete deck has hardened or is made composite (ksi)

$f_{f} \quad=\quad$ flange stress at the section under consideration due to the Service II loads calculated without consideration of flange lateral bending (ksi)

$f_{\ell} \quad=\quad$ flange lateral bending stress at the section under consideration due to the Service II loads determined as specified in Article 6.10.1.6 (ksi)

$f_{\text {mid }}=$ stress without consideration of lateral bending at the middle of the unbraced length of the flange under consideration, calculated from the moment envelope value that produces the largest compression at this point, or the smallest tension if this point is never in compression. fmid shall be due to the factored loads and shall be taken as positive in compression and negative in tension (ksi) 
$f_{n} \quad=$ for sections where yielding occurs first in the flange, a cover plate or the longitudinal reinforcement on the side of the neutral axis corresponding to $D_{n}$, the largest of the specified minimum yield strengths of each component included in the calculation of $A_{f n}$. Otherwise, the largest of the elastic stresses in the flange, cover plate or longitudinal reinforcement on the side of the neutral axis corresponding to $D_{n}$ at first yield on the opposite side of the neutral axis (ksi)

$F_{n c} \quad=$ nominal flexural resistance of the compression flange determined as specified in Article 6.10.7.2.2 (ksi)

$F_{n t} \quad=$ nominal flexural resistance of the tension flange determined as specified in Article 6.10.7.2.2 (ksi)

$f_{s b} \quad=$ natural frequency from the simple beam equation $(\mathrm{Hz})$

$F_{Y} \quad=$ yield stress from Chapter $2(\mathrm{ksi})$

$F_{y c} \quad=$ specified minimum yield strength of the compression flange (ksi)

$F_{y r} \quad=$ compression flange stress at the start of nominal yielding within the cross section, including residual stress effects, but not including compression flange lateral bending, taken as the smaller of $0.7 F_{y c}$ and $F_{y w}$, but not less than $0.5 F_{y c}(\mathrm{ksi})$

$F_{y w} \quad=$ minimum yield strength of the web (ksi)

$g \quad=$ acceleration due to gravity $\left(\mathrm{in} / \mathrm{sec}^{2}\right)$

$h \quad=$ depth between the centerline of the flanges (in)

Haunch $=$ depth of haunch (in)

$I=$ average moment of inertia of the composite girder section $\left(\mathrm{in}^{4}\right)$

$I_{A} \quad=$ analytical impact factor from Chapter 2

$I_{b} \quad=$ average moment of inertia of the composite girder section (in $\left.{ }^{4}\right)$

$I_{\text {conc }}=$ moment of inertia of concrete $\left(\right.$ in $\left.^{4}\right)$

$I_{E} \quad=$ experimental impact factor from Chapter 2

$I_{\text {Exp }} \quad=$ experimental moment of inertia $\left(\right.$ in $\left.^{4}\right)$

$I_{\text {Steel }} \quad=$ moment of inertia of steel $\left(\mathrm{in}^{4}\right)$

$I_{y c}=$ moment of inertia of the compression flange of the steel section about the vertical axis in the plane of the web $\left(\mathrm{in}^{4}\right)$

$I_{y t}=$ moment of inertia of the tension flange of the steel section about the vertical axis in the plane of the web $\left(\right.$ in $\left.^{4}\right)$

$J \quad=$ St. Venant torsional constant (in $\left.{ }^{4}\right)$

$k=$ bend-buckling coefficient for webs with longitudinal stiffeners determined as specified in Article 6.10.1.9.2 which specifies

$K_{g} \quad=$ longitudinal stiffness parameter

$L \quad=$ span length (ft.)

$L_{b} \quad=$ length (in)

$L_{\max } \quad=$ maximum span length (ft.)

$L_{p} \quad=$ limiting unbraced length to achieve the nominal flexural resistance under uniform bending (in)

$L_{r} \quad=\quad$ limiting unbraced length to achieve the nominal onset of yielding in either flange under uniform bending with consideration of compression flange residual stress effects (in) 


\begin{tabular}{|c|c|c|}
\hline$m$ & $=$ & multiple presence factor \\
\hline$M_{0}$ & $=$ & $\begin{array}{l}\text { moment at the brace point opposite to the one corresponding to } M_{2} \text {, } \\
\text { calculated from the moment envelope value that produces the largest } \\
\text { compression at this point in the flange under consideration, or the } \\
\text { smallest tension if this point is never in compression. } M_{0} \text { shall be due to } \\
\text { the factored loads and shall be taken as positive when it causes } \\
\text { compression and negative when it causes tension in the flange under } \\
\text { consideration (in-kip) }\end{array}$ \\
\hline$M_{1}$ & $=$ & $\begin{array}{l}M_{1} \text { moment at the brace point opposite to the one corresponding to } M_{2} \text {, } \\
\text { calculated as the intercept of the most critical assumed linear moment } \\
\text { variation passing through } M_{2} \text { and either } M_{\text {mid }} \text { or } M_{0} \text {, whichever produces } \\
\text { the smaller value of } C_{b} . M_{1}=M_{0} \text { when the variation in the moment along } \\
\text { the entire unbraced length between the brace points is concave in shape: } \\
\text { otherwise: } M_{1}=2 M_{\text {mid }}-M_{2} \geq M_{0} \text { (in-kip) }\end{array}$ \\
\hline$M_{2}$ & $=$ & $\begin{array}{l}\text { except as noted below, largest major-axis bending moment at either end } \\
\text { of the unbraced length causing compression in the flange under } \\
\text { consideration, calculated from the critical moment envelope value. } M_{2} \\
\text { shall be due to the factored loads and shall be taken as positive. If the } \\
\text { moment is zero or causes tension in the flange under consideration at } \\
\text { both ends of the unbraced length, } M_{2} \text { shall be taken as zero (in-kip) }\end{array}$ \\
\hline$M_{B R}$ & $=$ & bearing restraint moment (ft.-kips) \\
\hline$M_{B R}{ }^{A b u t .}$ & $=$ & bearing restraint moment at the abutment (ft.-kips) \\
\hline$M_{B R}$ Crit. Sec. & $=$ & bearing restraint moment at the critical cross section (ft.-kips) \\
\hline$M_{B R}$ Pierl & $=$ & bearing restraint moment at the first pier location (ft.-kips) \\
\hline$M_{B R}{ }^{\text {Pier2 }}$ & $=$ & bearing restraint moment at the second pier location (ft.-kips) \\
\hline$M_{c}$ & $=$ & design load truck moment analyzed at critical sections (ft.-kips) \\
\hline$M_{E}$ & $=$ & experimental load truck moment analyzed at critical sections (ft.-kips) \\
\hline$M_{E}$ & $=$ & $\begin{array}{l}\text { experimental elastic moment with bearing restraint effects removed from } \\
\text { Chapter } 2 \text { (ft.-kips) }\end{array}$ \\
\hline$M_{L E}$ & $=$ & $\begin{array}{l}\text { experimental elastic moment adjusted for longitudinal distribution from } \\
\text { Chapter } 2 \text { (ft.-kips) }\end{array}$ \\
\hline$M_{\text {mid }}$ & $=$ & $\begin{array}{l}\text { major-axis bending moment at the middle of the unbraced length, } \\
\text { calculated from the moment envelope value that produces the largest } \\
\text { compression at this point in the flange under consideration, or the } \\
\text { smallest tension if this point is never in compression (in-kips) }\end{array}$ \\
\hline$M_{n}$ & $=$ & nominal flexural resistance of the section (in-kips) \\
\hline$M_{n c}$ & $=$ & $\begin{array}{l}\text { nominal flexural resistance based on the compression flange determined } \\
\text { as specified in Article A6.3 (in-kips) }\end{array}$ \\
\hline$M_{n t}$ & $=$ & $\begin{array}{l}\text { nominal flexural resistance based on tension yielding determined as } \\
\text { specified in Article A6.4 (in-kips) }\end{array}$ \\
\hline$M_{p}$ & $=$ & $\begin{array}{l}\text { plastic moment of the composite section determined as specified in } \\
\text { Article D6.1 (in-kips) }\end{array}$ \\
\hline & $=$ & analytical RVW Truck Moment (ft.-kips) \\
\hline$M_{T}$ & $=$ & total moment (ft.-kips) \\
\hline$M_{T}$ & $=$ & experimental truck moment; from Chapter 2 (ft.-kips) \\
\hline
\end{tabular}




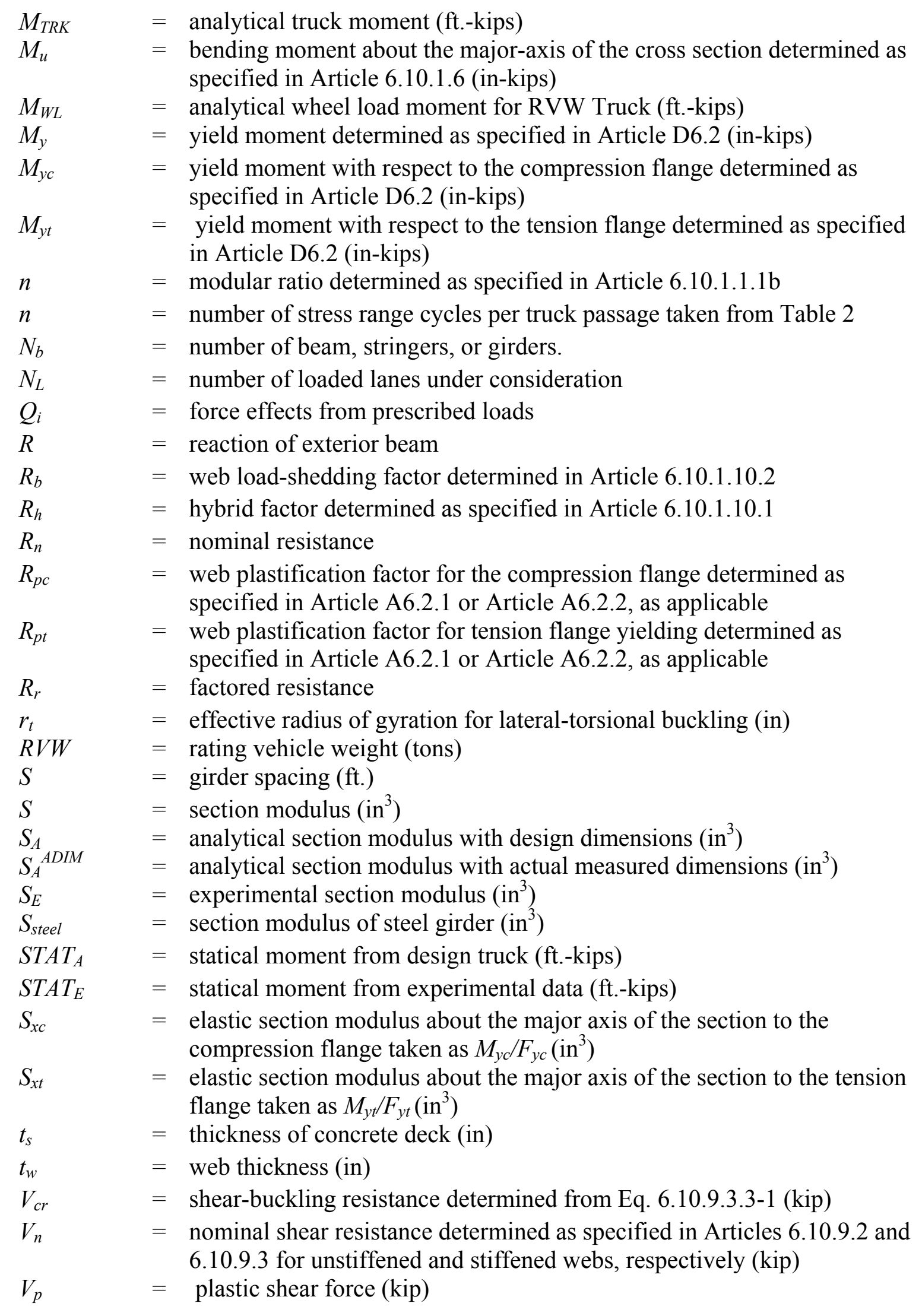




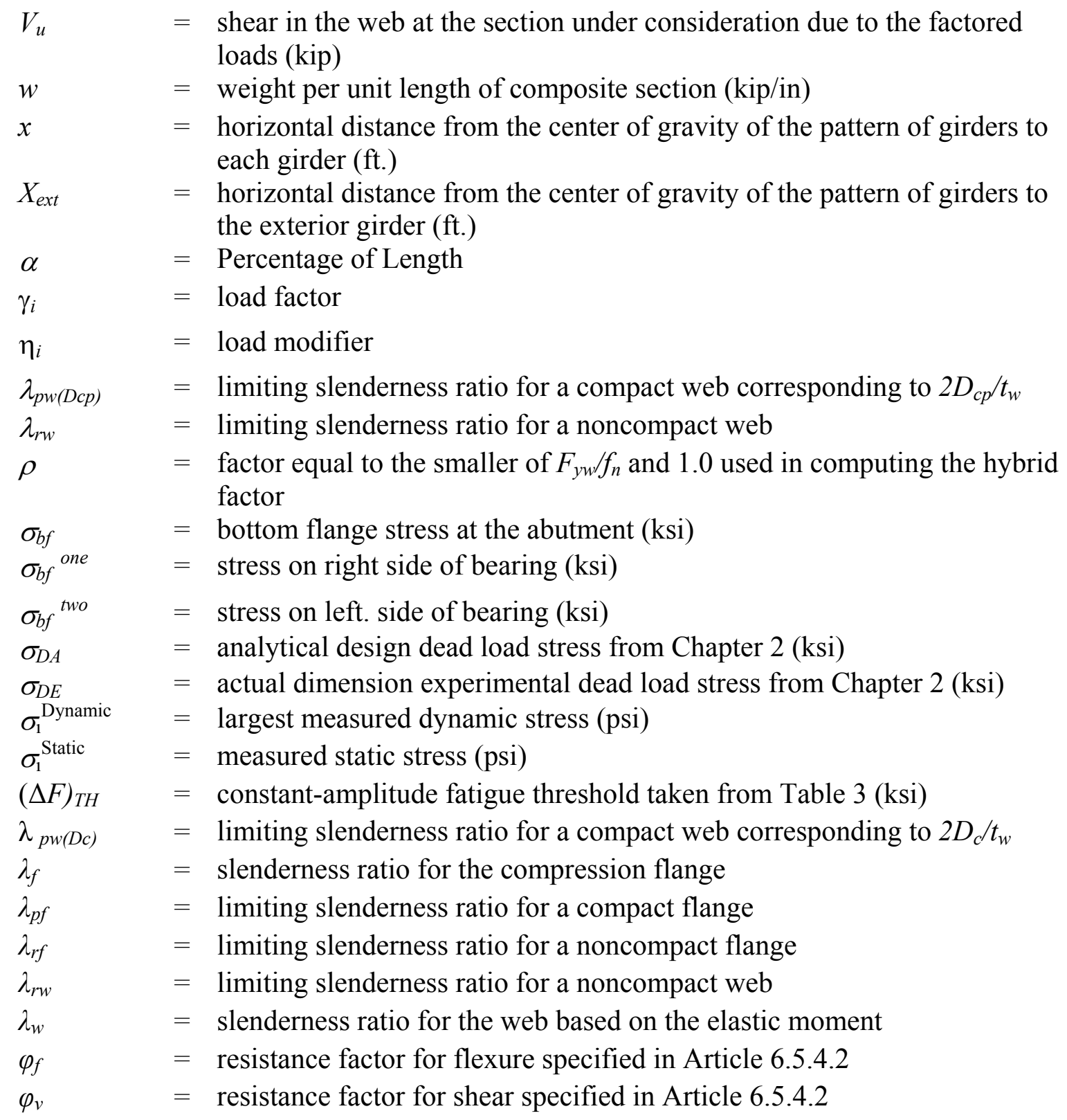




\section{Chapter 1 - Introduction}

\subsection{Background}

The $4^{\text {th }}$ edition of the AASHTO LRFD Bridge Design Specifications limits the negative flexural capacities of steel I-girders, with yield strengths greater than $70 \mathrm{ksi}$, to their yield moment capacities rather than their plastic moment capacities. This limit is imposed due to a lack of experimental and/or analytical evidence supporting the applicability of current flexural capacity equations for high performance steel (HPS). Furthermore, I-girders fabricated from higher strength HPS grades generally require less steel to resist flexural stresses than typical grade steel I-girders. This results in HPS Igirders with smaller moments of inertia and subsequently larger live load deflections. Due to this fact, HPS I-girders are more likely to exceed AASHTO live load deflection limits when optimized for weight.

Live load deflection limits were first introduced at the beginning of the twentieth century in railroad bridges, and later in vehicular bridges, when it was determined from sparse experimental testing that bridges which exhibited satisfactory levels of serviceability maintained deflections that were less than or equal to $\mathrm{L} / 800$; where $\mathrm{L}$ is the span length. An additional limit of L/1000 was later adopted for bridges subject to pedestrian traffic, and although both limits are optional in the current specifications, they are still largely employed by state transportation agencies today (Barth et al. 2002).

Current specifications not only limit flexural capacities and allowable live load deflections of HPS I-girders, but also affect girder economy as well. Previous research has shown that hybrid I-girders utilizing $100 \mathrm{ksi}$ steel may be up to 20-30 percent lighter 
than homogeneous $70 \mathrm{ksi}$ I-girders (Barth, Righman, and Wolfe 2004). In addition to the obvious strength benefits, HPS also exhibits improved weldability, greater levels of toughness, and increased weathering resistance. To realize the cost and weight savings of incorporating HPS into hybrid I-girder designs, further studies must be conducted to merit the removal of current flexural capacity and deflection limits.

\subsection{Research Overview}

The focus of this research is to investigate the current impact of AASHTO specifications on bridges designed with HPS, specifically those employing HPS 100W. This is accomplished by providing an overview of past and current design specifications with emphasis on HPS, performing physical live load testing on a HPS bridge, and by conducting an analytical assessment of a HPS 100W hybrid I-girder bridge.

Current AASHTO specifications are a resultant of significant up-to-date research, organizational revisions, and modified and streamlined equations (AASHTO 2009). One major improvement was the development of unified design equations that are applicable for curved, skewed, and straight steel I-girders. The unified equations are also more accurate than $2^{\text {nd }}$ edition equations, which were considered to be overly conservative in some cases. The $50 \mathrm{ksi}$ limit, which previously determined the applicability of Appendix A, was also increased to $70 \mathrm{ksi}$ in the current specifications; however, it is suggested that this limit should also be increased for steels with yield strengths up to $100 \mathrm{ksi}$.

To ensure that HPS bridges provide adequate levels of strength and serviceability, several levels of field-testing may be used to evaluate structural performance and determine experimental load ratings. Some of the methods described in Chapter 2 were 
used to evaluate a bridge in Culloden, West Virginia, that utilizes HPS 100W in the compression flanges of negative bending regions. Construction of the Culloden Bridge was completed in 2006, making it one of the first bridges in the country fabricated with HPS 100W hybrid I-girders. The overall goal of the Culloden Bridge field test was to evaluate its strength and serviceability performance under prescribed loading conditions. The data obtained from the field test was later used for comparison with an independent design assessment of the bridge conducted with current the AASHTO specifications (AASHTO 2007).

\subsection{Thesis Organization}

This research is presented in nine chapters and three appendices. Chapter Two

discusses past bridge design methodologies and the most recent advancements in the $4^{\text {th }}$ edition of the AASHTO LRFD Bridge Design Specifications (AASHTO 2007). This chapter also presents six levels of field-testing that may be used to experimentally determine load ratings.

Chapter Three provides an overview of current steel I-girder design procedures specified by AASHTO. The loading and structural analysis procedures are outlined first, followed by the different limit state design equations. In addition, a summary of current moment and shear resistance requirements are presented for the strength, service, and fatigue limit states. Lastly, the current web and flange proportional limits are outlined.

Chapter Four provides a parametric assessment of current AASHTO specifications with emphasis on negative flexure equations pertaining to HPS 100W Igirders. 
The current design methods and equations, outlined in Chapters Three and Four, are applied in Chapter Five to an independent design assessment of the Culloden Bridge. The critical locations of the bridge, corresponding to the regions of maximum positive and negative bending, as well as maximum shear, were first identified for analysis. The design capacities of these locations were then evaluated and compared with the force effects induced by strength, service, and fatigue load combinations.

Chapter Six describes the load testing methods and procedures used to field test the Culloden Bridge. A description of the bridge and load test equipment is presented first, followed by the truck placements used during load testing. In conclusion, the strain, deflection, and acceleration results are illustrated in several figures which represent a sample of the results.

Chapter Seven assesses bridge serviceability from the experimental field test data. This includes the results obtained from the dynamic and static load tests. The experimental natural frequency of the bridge was derived from accelerations recorded during dynamic load tests, and was compared with the results of an independent analytical assessment. Lastly, the experimental live load deflections, and respective lateral distribution factors, were determined from the static load test results and compared with AASHTO predicted values.

Experimental moments and lateral distribution factors were calculated and presented in Chapter 8 for interior and exterior girders. Lastly, the experimental and analytical strength and service live load rating factors were calculated and compared at critical positive and negative bending regions of the Culloden Bridge. 
Chapter Nine presents the results of the field test and the independent assessment of the Culloden Bridge utilizing current AASHTO Bridge Design Specifications. In conclusion, closing remarks and a proposal of future work are presented in the final section of Chapter Nine. 


\section{Chapter 2 - Literature Review}

\subsection{Introduction}

This literature review will present a brief history of common design methods

utilized in bridge engineering over the last century. Recent advancements in research and bridge design will then be presented to illustrate ongoing improvements to the current specifications. An overview of experimental bridge testing methods that have been successfully used to test several bridges in the past, including the Culloden Bridge, will be described to conclude this chapter.

\subsection{History of Design Methods}

Three distinct design methods have been utilized over the last one-hundred years. For most of the twentieth century, Allowable Stress Design (ASD), sometimes referred to as Working Stress Design, was the dominant design method used by engineers. It was also very popular when designing truss and arch bridges utilizing pin-connected members. Many of these bridges were statically determinate and easy to analyze because main load carrying members were subject only to axial forces (Tonias 1995).

During the second half of the century, improved materials, quality control, and design methods were becoming available; therefore, it was determined that the shortcomings of ASD should be addressed. This resulted in the introduction of Load Factored Design (LFD) in the 1970s, and like other new design codes, was slow to gain in popularity. The two main conceptual differences between LFD and ASD were the introduction of limit states and the probabilistic factoring of loads. These concepts were 
further expanded upon with the 1986 release of Load and Resistance Factor Design (LRFD). This design method not only factors loads, but also applies probabilistic resistance factors directly to the design capacities of structural members (Tonias 1995).

\subsubsection{Allowable Stress Design}

Allowable stress design (ASD) can be traced back to the 1860 s when it was originally developed as a method for designing metallic structures. At the time, cast iron was one of the most advanced materials available but was short lived and eventually replaced with steel. The most common style of bridge in the late 1800s and early 1900 s was the truss. Although there are many different styles of trusses, most behave by the same fundamental principles. Main load-carrying elements of trusses are either in compression or tension, and usually statically determinant. The analysis procedures utilized to determine forces in truss designs are relatively simple and well suited for ASD (Tonias 1995).

When designing with ASD, it is assumed that the proportional limit of a given material is the maximum permissible stress for that structural element. This was a reasonable limit in the 1800 s when bridge materials were brittle materials and did not have significant reserve capacities beyond their proportional limits. In order to reduce the risk of failure, a factor of safety (F.S.) is applied to the design strength of a member in ASD. This is accomplished by allowing only a fraction of the yield strength to be reached when designing for a specific set of loads. A factor of safety can more generally be defined as the yield strength of a member divided by the stress induced in that member by loads. The name Allowable Stress Design lends itself from the development of 
specifications that allowed certain factors of safety for different types of structures; thus, permitting certain levels of allowable stress.

Eventually, the drawbacks of ASD became evident as the understanding of structures progressed. Some of the shortcomings of ASD are:

- it does not account for combination forces such as shear and moment acting over the same cross section,

- it assumes that the residual stresses in member are initially zero,

- it does not recognize the uncertainty of different loads occurring at the same moment in time,

- factors of safety are only applied to the design capacities of structural members and not to the loads,

- structural capacities are only based on elastic behaviors of isotropic, homogeneous materials,

- it does not embody a reasonable measure of strength, and

- selection of safety factors is subjective and does not provide any reliability in terms of probabilistic failure (Barker and Puckett 1997).

\subsubsection{Load Factor Design}

Load factor design (LFD) was first introduced in the 1970s to address the drawbacks of ASD. There are several design approach differences in LFD that were developed as result of improved materials and a better understanding of structural behavior. One of the major limiting factors of ASD was that it was confined to the yield strength of a given material. However, current research had determined that there is an 
inelastic reserve capacity beyond the yield strength of steel. Two other new concepts introduced in LFD were limit state design and load factoring (Tonias 1995).

The American Institute of Steel Construction (AISC) defines a limit state as a condition which represents the limit of structural usefulness. The two limit states proposed in LFD were service and strength. Within each of these limits states were individual checks pertaining to different design scenarios (i.e. gross section yielding and fracture of the net section). The service limit state is a representation of the performance and behavior of the structure under normal service conditions. The structural behaviors of interest at the service limit state are deflection and vibration. The strength limit state ensures the safety and survival of a structure by evaluating the yield strengths, plastic strengths, buckling capacities, etc. (Tonias 1995).

The development of load factors in LFD was based upon the statistical probabilities of different load combinations occurring at the same time. This replaced the previous ASD method, which treated all loads equally and applied factors of safety accordingly. By introducing statistical variances into bridge design, it was then possible to develop probabilities of failure for a given service life. This allowed engineers to predict probabilities of failure rather than assuming bridges have some arbitrary factor of safety (Tonias 1995).

\subsubsection{Load and Resistance Factor Design}

The $1^{\text {st }}$ edition of Load and Resistance Factored Design for Steel Construction was released in 1986 with a finalized set of load factors that did not exist in the 1978 
LFD. The load factors in the 1978 LFD were initially unverified and research was completed between editions to solidify the factors prescribed in the code (Tonias 1995).

The foremost difference between LFD and LRFD is the application of probabilistically developed resistance factors. Resistance factors are usually less than one and are statistically based on the probability of failure for different types of forces. These probabilities were determined by statistically quantifying uncertainties in material properties, equations, workmanship, quality control, and consequences of failure.

LRFD has several advantages including fairly uniform levels of safety and a rational and consistent method of design. One downside of LRFD, however, is that it once again requires designers to change design philosophies and to have an understating of probability (Barker and Puckett 1997).

\subsection{Recent Advancements in the AASHTO LRFD Specifications}

The AASHTO LRFD Bridge Design Specifications have undergone several revisions over the last three editions. These revisions are based on research that provides more functional and straightforward design procedures and equations. The most recent edition of the specifications was released in 2007 with revisions in several areas of bridge design. AASHTO has described the new specifications as a major step in improved bridge design. Also, because the specifications provide improved bridge analysis procedures, it is expected to lead to bridges exhibiting superior serviceability, enhanced long-term maintainability, and more uniform levels of safety (AASHTO 2009).

Earlier versions of the AASHTO specifications were considered difficult to use because there were a large number of design equations; each with a narrow range of 
applicability. This issue was resolved in the $3^{\text {rd }}$ edition by unifying equations. This meant that fewer equations could be applied to a broader range of designs. In particular, this approach was applied to stability for all I-shapes; including composite I-sections in negative flexure. Straight I-girder design procedures were also simplified in the 3rd edition by streamlining design equations and providing more transparent design procedures (White 2003).

The contribution of the web to the compression flange local buckling (FLB) and lateral-torsional buckling (LTB) capacity of I-girders was somewhat inconsistent in previous editions of the specifications. In older editions, the web was classified as either compact or non-compact. It did not distinguish between compact, non-compact, and slender webs. In addition, previous capacity equations did not distinguish between axial and lateral flange bending stresses. To resolve this issue, research was done to evaluate the webs contribution to the buckling capacity of compression flanges. This was accomplished by modeling the compression flange as a beam-column. The results of this research led to the development of Eq. 2.1, which expresses strength in terms of flange stress computed from elastic analysis. In Eq. 2.1 below, $f_{b u}$ represents the axial stress in the beam-column; while $f l$ is the lateral flange bending stress in the column. The $1 / 3$ term gives an accurate linear approximation of the equivalent beam-column resistance and unifies past equations which were different for curved and straight I-girders.

Eq. 2.1 also predicts the discontinuities of flange compact/non-compact limits and destabilizing effects associated with webs in compression (Hall and Yoo 1996).

$$
f_{b u}+\frac{1}{3} f_{l} \leq \phi_{f} F_{n c}
$$


Additional research was conducted to broaden the applicability of Appendix A. This research showed that the current flexural capacity equations of Appendix A were applicable for girders with yields strengths up to $70 \mathrm{ksi}$. A reasonable method for estimating the elastic first-order lateral flange bending stress was also developed for the new specifications by applying an amplification factor to flanges in compression. The purpose of the amplification factor is to conservatively guard against large unbraced lengths in which second-order flange lateral bending effects are significant.

\subsection{Experimental Test Methods for Load Rating Bridges}

Prior to load testing a bridge, it is important to determine what types of structural behaviors are to be observed and recorded. The first step is to establish the locations of interest to be instrumented. The second step is tailoring the instrumentation to the types of structural behaviors that will be observed at those locations. Next, a detailed load plan should be developed to provide adequate structural response. Some of the factors that may be determined from load testing a bridge are:

- available live load capacity,

- impact,

- bearing restraint forces,

- lateral distribution of forces,

- longitudinal distribution of forces,

- stiffness contributions from barriers, curbs, railings, and other components,

- actual section properties, and

- unintentional composite action (Barker, Imhoff, McDaniel, and Fredrick 1999). 
Six levels of testing are detailed below that may be used to experimentally load rate bridges. The level of accuracy and effort required to perform each test plan increases incrementally with each increase in test plan number. The amount of time and funding available may also play an influential role in determining which test level is best for a particular bridge. There are eight adjustment factors that account for the differences between theoretical and experimental design values (Frederick 1998). These eight adjustment factors are as follows:

$$
\begin{array}{ll}
\frac{R_{b} R_{h} F_{n}-\sigma_{D E}}{R_{b} R_{h} F_{n}-\sigma_{D A}} & \begin{array}{l}
\text { adjustment/correction of the design dead } \\
\text { load vs. the actual dead load computed } \\
\text { with field measured dimensions, }
\end{array} \\
\frac{I_{A}}{I_{E}} & \begin{array}{l}
\text { adjustment for the experimental impact } \\
\text { factor, }
\end{array} \\
\frac{M_{E}}{M_{T}} & \begin{array}{l}
\text { adjustment for bearing restraint force } \\
\text { effects, }
\end{array} \\
\frac{M_{L E}}{M_{E}} & \begin{array}{l}
\text { adjustment for longitudinal redistribution } \\
\text { of moment, }
\end{array} \\
\frac{D F_{A}}{D F_{E}} & \text { adjustment for the experimental } \\
\text { distribution factor, } \\
\frac{M_{L E}}{D F_{E}} \times \frac{M_{R V W}}{M_{T R K}} & \text { adjustment for curbs, parapets, and railings, } \\
\frac{S_{A}{ }^{A D I M}}{S_{A}} & \text { And adjustment for unintentional } \\
\frac{S_{E}}{S_{A}^{A D I M}} & \text { composite action. }
\end{array}
$$


The ratio of experimental to analytical rating factor may be represented from the eight adjustment factors above by the following relationship:

$$
\frac{\text { Exp. Post }}{\text { Ana. Post }}=\left(\frac{R_{b} R_{h} F_{n}-\sigma_{D E}}{R_{b} R_{h} F_{n}-\sigma_{D A}}\right)\left(\frac{I_{A}}{I_{E}}\right)\left(\frac{M_{E}}{M_{T}}\right)\left(\frac{M_{L E}}{M_{E}}\right)\left(\frac{D F_{A}}{D F_{E}}\right)\left(\frac{M_{W L}}{\frac{M_{L E}}{D F_{E}} \frac{M_{R V W}}{M_{T R K}}}\right)\left(\frac{S_{A}{ }^{A D I M}}{S_{A}}\right)\left(\frac{S_{E}}{S_{A}^{A D I M}}\right) \mathbf{E q .} \mathbf{2 . 2}
$$

The following six test plans will present how each of the eight factors is determined from the experimental field test data. A more in depth presentation and derivation of the eight adjustment factors may also be found in Frederick (1998).

\subsubsection{Test Plan I}

Test Plan I may be used to determine the experimental moment capacity and impact factor of a slab on steel I-girder bridge by instrumenting only the most critical girder. The most critical girder is determined analytically by evaluating the longitudinal live load location corresponding to the maximum moment induced in the bridge. That location is then instrumented with a single strain gage on the center of the bottom flange to determine the stress induced during controlled load tests. This test plan is the most basic of the six and will not result in the ability to calculate the experimental section modulus, lateral distribution factors, longitudinal redistribution of moments, contributions from railings and curbs, or the elastic moments with bearing restraint forces removed.

The experimental impact factor is calculated using a single strain gage by running two load tests. The first load test is conducted by statically placing the load at the previously determined critical longitudinal location. The second load test is a dynamic 
test in which the load vehicle is driven over the bridge at normal speeds. The largest strains observed during both load tests are then converted to stress, and the experimental impact factor is calculated by the following equation:

$$
I_{E}=\frac{\sigma_{1}^{\text {Dynamic }}}{\sigma_{1}^{\text {Static }}}
$$

The experimental moment capacity of the bridge may be calculated using either the analytical section modulus, calculated from the original bridge plans, or the section modulus calculated from measured field dimensions. The total moment capacity is calculated as follows:

$$
M_{T}=\sigma_{1} \times S
$$

Although this test plan could theoretically be used to load rate a bridge, it is not recommended due to the lack of testing redundancy.

\subsubsection{Test Plan II}

Test Plan II adds two supplementary strain gages to the previously determined critical girder. The two strain gages are added at the quarter and mid points of the web in addition to the original strain gage placed at the middle of the bottom flange. The additional gages are used to determine the strain profile of the test girder and verify the accuracy of the bottom flange strain. The additional strain gages also make it possible to experimentally verify the section modulus and more accurately predict the total moment capacity of the girder (Imhoff 1998). The experimental stress vs. depth equation is found by developing a numbering system similar to the one shown below in Figure 2.1. It is 
also convenient to set up a spreadsheet resembling Table 2.1, which will later become apparent when applying Imhoff's procedure.

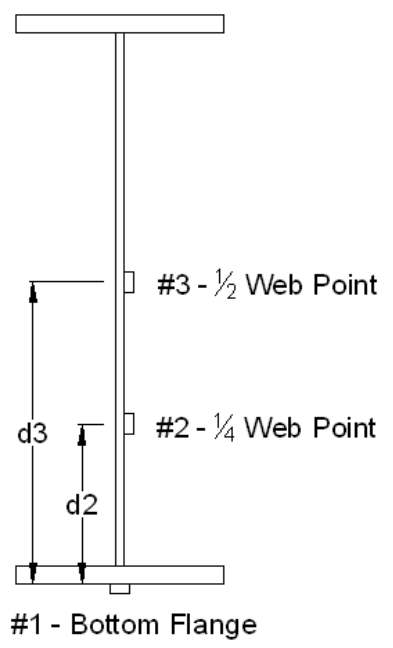

Figure 2.1 Strain Gage Placement using Imhoff's Procedure

Table 2.1 Table Setup for Imhoff's Procedure

\begin{tabular}{|c|c|c|c|c|}
\hline Strain Gage & $\begin{array}{c}\text { Max. Stress } \\
(p s i)\end{array}$ & $\begin{array}{c}\text { Max.Stress } \\
(p s i)\end{array}$ & $\begin{array}{c}\text { Distance to Gage } \\
(\mathrm{in})\end{array}$ & $\begin{array}{c}\sigma_{\mathrm{i}} \times \mathrm{d}_{\mathrm{i}} \\
(\text { (bs } / \mathrm{in})\end{array}$ \\
\hline$\# 1$ & $\sigma_{1}$ & $\sigma_{1}{ }^{2}$ & 0 & $\sigma_{1} \times \mathrm{d}_{1}$ \\
$\# 2$ & $\sigma_{2}$ & $\sigma_{2}{ }^{2}$ & $\mathrm{~d} 2$ & $\sigma_{2} \times \mathrm{d}_{2}$ \\
$\# 3$ & $\sigma_{3}$ & $\sigma_{3}{ }^{2}$ & $\mathrm{~d} 3$ & $\sigma_{3} \times \mathrm{d}_{3}$ \\
\hline
\end{tabular}

After the experimental stresses are obtained from the strain data, a liner regression analysis is used to calculate the linear stress profile of the section. Imhoff's procedure utilizes a least squares approach as shown below.

$$
\left[\begin{array}{cc}
\Sigma \sigma_{i}^{2} & \Sigma \sigma_{i} \\
\Sigma \sigma_{i} & 3
\end{array}\right] \times\left\{\begin{array}{c}
\text { Slope } \\
\text { Intercept }
\end{array}\right\}=\left\{\begin{array}{c}
\Sigma\left(\sigma_{i} \times d_{i}\right) \\
\Sigma d_{i}
\end{array}\right\}
$$

The only unknowns in the two equations above are the slope and intercept values corresponding to the location of the neutral-axis. After solving the system of equations, 
the slope and intercept values are applied to the basic straight-line equation yielding the following results:

$$
\begin{aligned}
& \text { Slope }=\frac{3 \times \Sigma\left(\sigma_{i} \times d_{i}\right)-\Sigma \sigma_{i} \times \Sigma d_{i}}{3 \times \Sigma \sigma_{i}^{2}-\left(\Sigma \sigma_{i}\right)^{2}} \\
& \text { Intercept }=\frac{\Sigma\left(\sigma_{i} \times d_{i}\right)-\Sigma \sigma_{i}^{2} \times \text { Slope }}{\Sigma \sigma_{i}} \\
& d_{i}=\text { Slope } \times \sigma_{i}+\text { Intercept } \\
& \sigma_{i}=\frac{1}{\text { Slope }} \times d_{i}-\frac{\text { Intercept }}{\text { Slope }}
\end{aligned}
$$

The total moment is calculated by breaking the load carrying mechanisms into three parts: the steel girder bending about its own neutral axis $\left(\mathrm{M}_{\mathrm{L}}\right)$, the concrete bending about its own neutral-axis $\left(\mathrm{M}_{\mathrm{u}}\right)$, and the couple induced by the composite action of the deck and girder ( $\mathrm{N}$ x a). Using Eq. 2.10 and Eq. 2.11, the stresses are obtained at the bottom flange and centroid of the girder. These stresses are then used to calculate the contributions of each load carrying mechanism to the total moment shown in Figure 2.2.

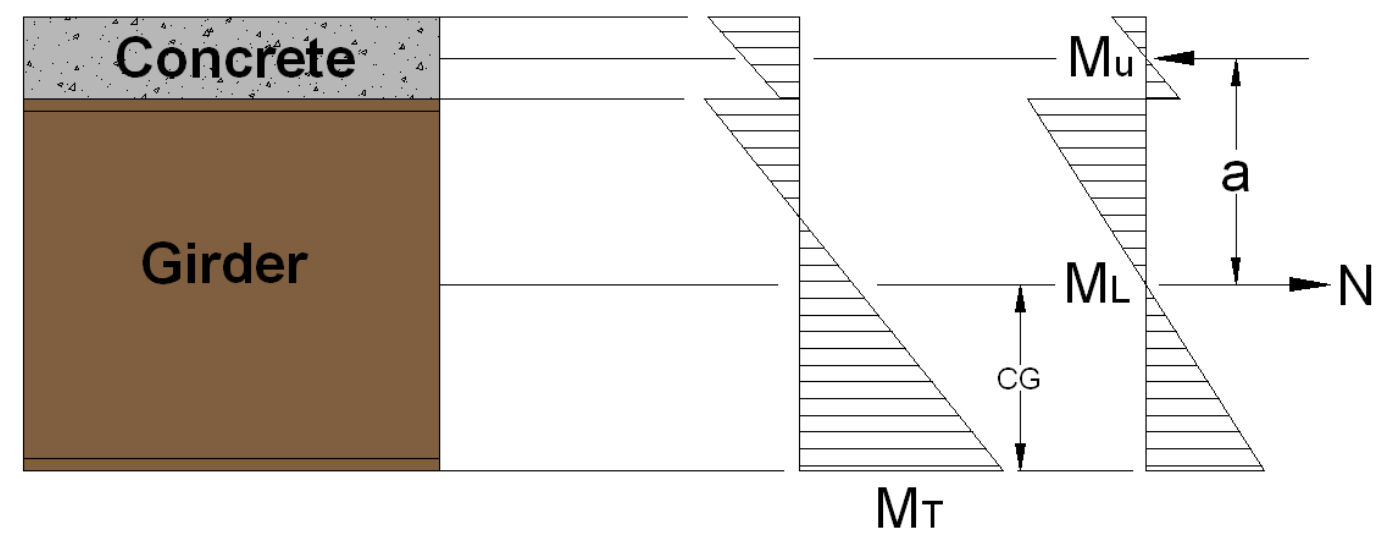

Figure 2.2 Moment Resisting Mechanisms 


$$
\begin{aligned}
& \sigma_{B F}=-\frac{\text { Intercept }}{\text { Slope }} \\
& \sigma_{C G}=\frac{1}{\text { Slope }} \times C G-\frac{\text { Intercept }}{\text { Slope }} \\
& M_{L}=\left(\sigma_{B F}-\sigma_{C G}\right) \times S_{\text {steel }} \\
& M_{u}=\frac{\left(E_{\text {conc }} \times I_{\text {conc }}\right)}{\left(E_{\text {steel }} \times I_{\text {steel }}\right)} \times M_{L} \\
& N a=\left(\sigma_{C G} \times A_{\text {steel }}\right)\left[\left(d_{\text {steel }}-y_{N A}\right)+\text { Haunch }+\frac{d_{\text {slab }}}{2}\right] \\
& M_{T}=M_{u}+M_{L}+N \times a
\end{aligned}
$$

The experimental section modulus is then found by calculating the experimental moment of inertia and dividing by the intercept of the stress profile.

$$
\begin{aligned}
& I_{E x p}=-\left(M_{T}\right) \times \text { Slope } \\
& S_{\text {Exp }}=\frac{I_{\text {Exp }}}{\text { Intercept }}
\end{aligned}
$$

This test plan is more accurate than the first plan, but still lacks the experimental redundancy that would verify the results. However, if funding and time is limited, this test plan may be implemented to successfully load rate a bridge if the load and instrumentation placements correspond with the most critical girder and location.

\subsubsection{Test Plan III}

Test Plan III should produce the same load rating as Test Plan I, but additional gages are used to calculate the experimental lateral distribution factors. Similar to Test 
Plan I, a strain gage is placed on every girder at the center of the bottom flange. The distribution factors are then determined using the following procedure:

1. Develop a table that lists the bottom flange stress versus the section modulus for the respective section based on each critical load placement. There should be a critical load placement for each girder of the bridge unless some placements overlap.

Table 2.2 Bottom Flange Stress vs. Section Modulus

\begin{tabular}{|c|c|c|}
\hline Girder & Analytical Section Modulus & Bottom Flange Stress \\
\hline Critical & $S_{\mathrm{A}}$ & $\sigma_{0}{ }^{\text {eritical }}$ \\
\hline Non-Critical $_{\mathrm{i}}$ & $\mathrm{S}_{\mathrm{i}}$ & $\sigma_{\mathrm{i}}^{{ }^{\text {noncritcal }}}$ \\
\hline Non-Critical $_{\mathrm{i}+1}$ & $\mathrm{~S}_{\mathrm{n}-1}$ & $\sigma_{(\mathrm{n}-1)}{ }^{\text {noncritical }}$ \\
\hline
\end{tabular}

2. Calculate the experimental distribution factor $\left(\mathrm{DF}_{\mathrm{E}}\right)$.

$$
D F_{E}=\frac{\left(\sigma_{0}{ }^{\text {critical }} \times S_{\text {critical }}\right)}{\left({\sigma_{0}}^{\text {critical }} \times S_{A}\right)+\Sigma\left(\sigma_{i}^{\text {non-critical }} \times S_{i}^{\text {non-critical }}\right)}
$$

\subsubsection{Test Plan IV}

Test Plan IV is a combination of the first three test plans in that all girders are gaged with three strain gages at the locations detailed in Test Plan II. This will result in the same load rating as Test Plan II, but may also be used to calculate the distribution factors shown above.

\subsubsection{Test Plan V}

Test Plan V may be used to assess the restraints at pier and abutment bearings. The total moments are then adjusted by removing the axial bearing force effects from the 
experimental strains observed during load testing. To observe bearing restraint force effects, strain gages are placed on the bottom flanges; six inches on both sides of the centers of bearing at the pier, and six inches from the abutment. Not all girders will behave uniformly; therefore, each girder needs to be instrumented. The bearing force of an abutment is then calculated as follows:

$$
\text { Bearing Force }=-A_{b f} \times \sigma_{b f}
$$

The bearing restraint forces at the piers are found by calculating the differences in stress across the bearing supports as shown below.

$$
\text { Bearing Force }=\frac{\left(\sigma_{b f}{ }^{t w o}-\sigma_{b f}^{o n e}\right) \times A_{b f}}{C P}
$$

The axial stresses in the girders, due to bearing force effects, are removed by cutting the bridge at the cross section of interest and summing the force effects from the piers and abutments to obtain the net bearing force. The axial stress is then found as:

$$
\sigma_{\text {axial }}=\frac{\text { Net Bearing Force }}{A_{\text {composite }}}
$$

where:

$$
A_{\text {composite }}=A_{\text {steel }}+\frac{A_{\text {conc }}}{n}
$$

The axial stress in each girder can then be removed from the flexural stress resulting in a net stress shown below.

$$
\sigma=\frac{1}{\text { slope }} \times \frac{d}{2}-\frac{\text { Intercept }}{\text { Slope }}-\sigma_{\text {axial }}
$$


The total moment is then calculated by the three load-carrying mechanism equations specified earlier with axial force effects removed. The adjusted girder stresses are then calculated as:

$$
\sigma_{1}^{\text {Axial Re moved }}=-\frac{\text { Intercept }}{\text { Slope }}-\sigma_{\text {axial }}
$$

and:

$$
\sigma_{C G}^{{ }_{\text {Axial Re }} \text { moved }}=\frac{1}{\text { Slope }} \times \frac{d}{2}-\frac{\text { Intercept }}{\text { Slope }}-\sigma_{\text {axial }}
$$

The bearing restraint moments may also be removed from the total moments at the gaged cross sections to calculate the elastic moments. This is accomplished by first determining the distances to the neutral axes at the sections over the bearing $\left(\mathrm{d}_{\mathrm{NA}}\right)$. The bearing restraint moments are then found by:

$$
M_{B R}=\text { Bearing Force } \times d_{N A}
$$

The bearing restraint moment, at a cross section of interest, may be determined by redistributing the bearing restraint moment calculated above. This is done by applying the ratio of member stiffness to joint stiffness to the moment over the bearing. Assuming a constant moment of inertia in all spans, the distribution can be calculated with the following equation:

$$
\text { Distribution }=\frac{\left(\frac{E \times I}{L}\right)}{\Sigma\left(\frac{E \times I}{L}\right)}
$$

Once the distribution factors have been calculated, the bearing restraint moments at critical cross sections are found by straight-line interpolation. For example, if testing a 
three-span continuous bridge, bearing restraint moments will exist at the two piers. If the critical section lies within the middle span of the bridge, the two bearing restraint moments at the piers are interpolated between. If the critical cross section lies within span one or three, then the pier and abutment restraint moments are used for interpolation. In analytical form, this is presented as:

$$
M_{B R}{ }^{\text {critical section }}=\frac{M_{B R-\text { Pier } 1}+M_{B R-P i e r 2}}{2}
$$

and:

$$
M_{B R}{ }^{\text {critical section }}=\frac{M_{B R-P i e r 1}+M_{B R-A b u t m e n t}}{2}
$$

The elastic moment at the critical cross section, with axial and bearing moment force effects removed, is then found as follows:

$$
M_{E}=M_{T}^{\text {Axial Re moved }}-M_{B R}{ }^{\text {Critical Section }}
$$

\subsubsection{Test Plan VI}

Test plan VI may be employed to obtain all previously mentioned factors as well as the experimental elastic moment diagrams. This is achieved by simultaneously placing strain gages on pre-determined critical-cross sections and on both sides of the pier bearing. For continuous multi-span bridges, the gage placements consist of three gages for each negative moment cross section to determine the elastic moment previously defined in Test Plan V. Gages placed in the negative bending regions over the pier bearings must be at least one girder depth away from the centers of bearing. This is done to remove the gages from the effects of bearing stiffeners and cross-frame diaphragms at 
the pier. To calculate the elastic longitudinal adjustment factors, the following procedures are used:

1. Calculate and plot the elastic moments for the critical sections to construct the moment diagram. The moments over the piers may be linearly extrapolated from the values obtained at one girder depth away from the piers.

2. Calculate the statical moments as discussed in Frederick (1998):

$$
\begin{aligned}
& \operatorname{STAT}_{A}={M_{c}}^{2}-(1-\alpha) \times{M_{c}}^{1}-(\alpha) \times M_{c}{ }^{3} \\
& \operatorname{STAT}_{E}={M_{E}}^{2}-(1-\alpha) \times{M_{E}}^{1}-(\alpha) \times{M_{E}}^{3}
\end{aligned}
$$

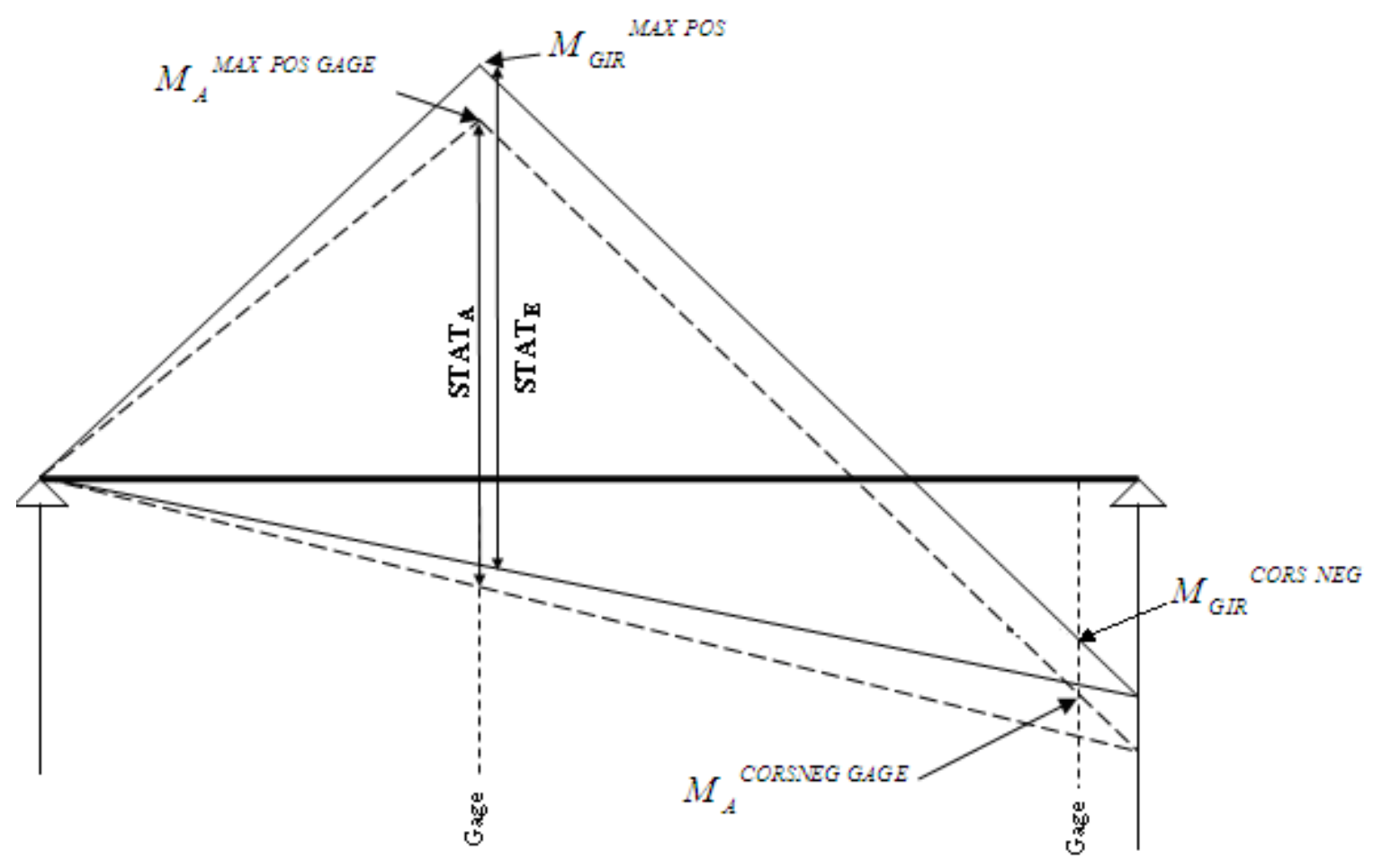

Figure 2.3 Statical Moment Diagram 
3. Calculate the elastic longitudinal adjustment moments from the following equation:

$$
M_{L E}=\frac{S T A T_{E}}{S T A T_{A}} \times M_{c}^{2}
$$

This test plan removes many of the unwanted force effects within the experimental data. In addition, Test Plan VI may be used to produce the most accurate rating of the six plans.

\subsubsection{Summary of Test Plans}

The adjustment factors obtained from each test plan are summarized below in Table 2.3. Test Plan I is the most basic of the plans but lacks the experimental redundancy that verifies the strain observed in the bottom flange. Test Plan II verifies the strain obtained from Test Plan I by utilizing Imhoff's procedure, but lacks global redundancy. Test Plan III employs a single gage on the bottom flange of each girder in order to determine lateral load distribution. Test Plan IV may be used verify stresses and lateral distributions throughout all cross sections. Test Plan V accounts for bearing restraint force effects and details how to remove them from the experimental data. Test Plan VI encompasses all of the previous plans and may also be used to calculate the longitudinal distribution of moments and unintended system stiffness. 
Table 2.3 Summary of Test Plans

\begin{tabular}{|c|c|c|c|c|c|c|}
\hline F actor & Plan I & Plan II & Plan III & Plan IV & Plan V & Plan VI \\
\hline Impact Factor & Yes & Yes & Yes & Yes & Yes & Yes \\
\hline Experimental Dead Load & Yes & Yes & Yes & Yes & Yes & Yes \\
\hline $\begin{array}{l}\text { Un-intended or Additional } \\
\text { Composite Action }\end{array}$ & No & Yes & No & Yes & Yes & Yes \\
\hline Lateral Distribution & No & No & Yes & Yes & Yes & Yes \\
\hline Bearing Restraint & No & No & No & No & Yes & Yes \\
\hline Longitudinal Distribution & No & No & No & No & No & Yes \\
\hline $\begin{array}{c}\text { Unaccounted System } \\
\text { Stiffness }\end{array}$ & No & No & No & No & No & Yes \\
\hline
\end{tabular}




\section{Chapter 3 - Fundamentals of the AASHTO LRFD Bridge Design Specifications}

\subsection{Introduction}

The LFD method was replaced in 1994 with the LRFD version of AASHTO Bridge Design Specifications; however, significant research has been conducted since then to further improve upon the 1994 methods and equations. This was achieved by unifying equations for a broader range of design considerations and by developing more accurate capacity equations. The new equations were first presented in the $3^{\text {rd }}$ edition (2003) of the specifications and remained mostly unchanged in the 2007 release of the $4^{\text {th }}$

edition. Interim revisions were made to the $4^{\text {th }}$ edition in 2008 and 2009 , and will be included in the current assessment of the specifications within this chapter.

\subsection{Effective Width}

The theoretical effective flange width is defined as the width of the deck in which the longitudinal stress is assumed to be uniformly distributed. In reality the stress is not uniformly distributed and the actual stress distribution for a composite section is shown in Figure 3.1. For interior girders, the effective deck width may be taken as the distance between girders. For an exterior girder, this simplifies to $1 / 2$ the interior girder spacing plus the overhang deck width. 


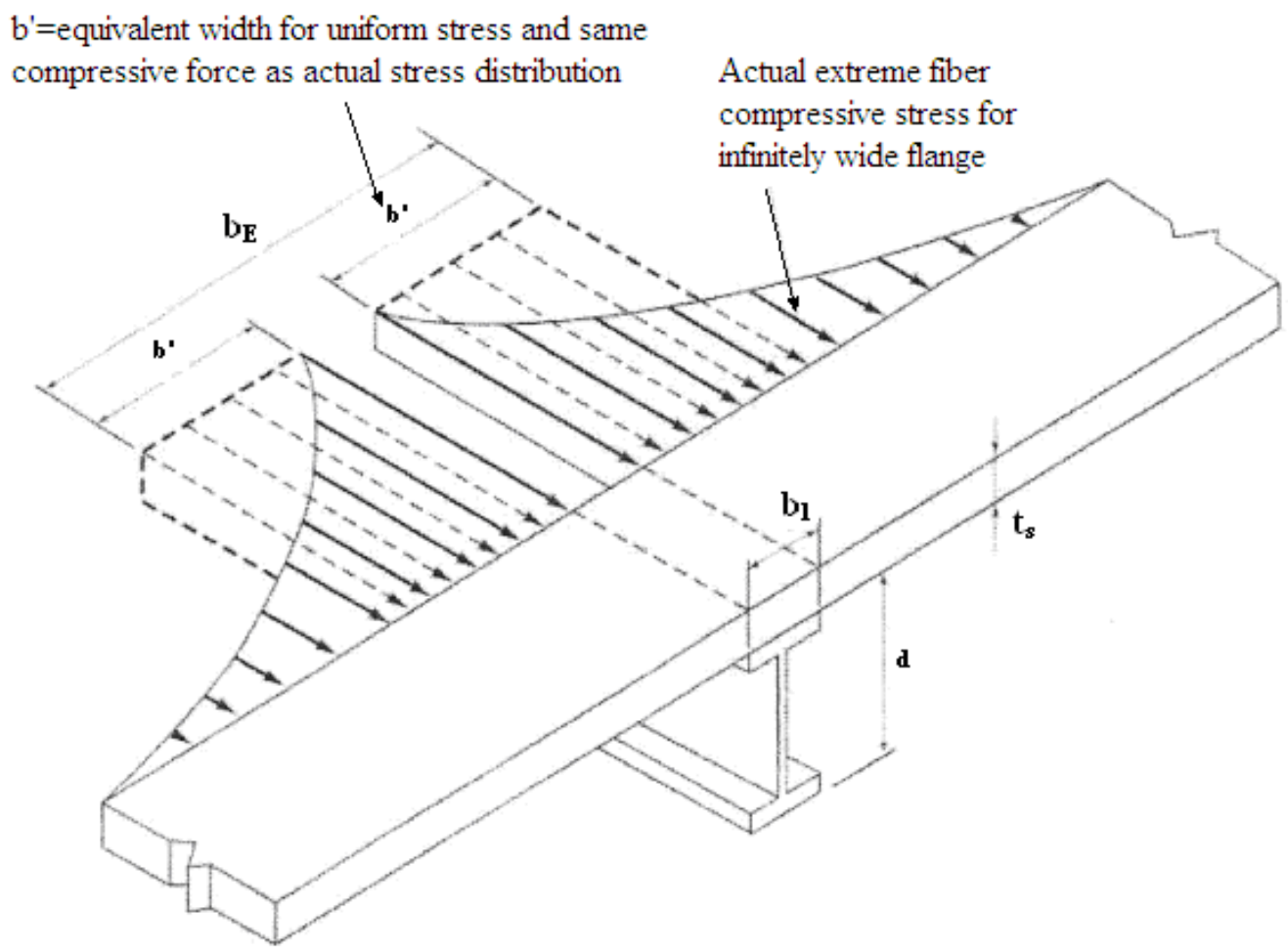

Figure 3.1 Effective Width of a Composite Section

\subsection{Loads}

Bridge design loads are classified as either permanent or transient. Permanent loads are always present and generally do not vary in magnitude over time. Conversely, transient loads, also referred to as live loads, have the ability to act on any location of the structure and at varying magnitudes and times. Both types of loads are broken up into their respective categories and detailed below.

\subsubsection{Dead Loads}

Gravitational dead loads can be broken into non-composite dead loads $\left(\mathrm{DC}_{1}\right)$, and composite dead loads $\left(\mathrm{DC}_{2}\right.$ and $\left.\mathrm{DW}\right) . \quad \mathrm{DC}_{1}$ loads account for all superstructure materials exerting a force on the girders prior to the hardening of the concrete deck. For a typical 
slab-on-steel I-girder bridge, this will include the weights of the girders, concrete deck, stay-in-place forms, haunches, overhang tapers, and steel diaphragms. These loads are applied to the non-composite section consisting only of the steel girders prior to the concrete reaching 75 percent of its compressive strength. $\mathrm{DC}_{2}$ loads act on the composite section after the concrete has hardened and includes the weights of curbs, barriers, sidewalks, railings, etc. DW is the weight of the future wearing surfaces and utilities also acting on the composite section. $\mathrm{DC}_{2}$ and $\mathrm{DW}$ loads act only on the long-term composite section.

Composite action may be defined as the sharing of forces between structural elements. Slab on steel I-girder bridges transfer forces through shear connectors placed along the length of the bridge. These connectors allow the deck and girders to act as one composite section. The resultant composite section has a higher section modulus than if the steel girder was considered by itself. The composite section of a bridge is determined by transforming the area of the deck, within the effective width, into an equivalent area of steel by applying the modular ratio $(n)$. This ratio is typically 7 or 8 , for normal strength concretes, and the short-term composite section is determined by dividing the area of the concrete by the modular ratio $(n)$. The long-term composite section is found by dividing the effective area of concrete by three times the modular ratio (3n). The long-term modular ratio is higher because creep and cracks form within the concrete over its extended service life. This reduces the load carrying contributions of the deck to the composite section. 


\subsubsection{Live Loads}

The design vehicular live load is applied to the short-term composite section of the bridge. AASHTO denotes this load as HL-93 and it is the combination of a design truck, or tandem, plus the design lane load. The design truck is a 72-kip three-axle vehicle with an 8-kip front axle and two 32-kip rear axles. The front axle is spaced at a distance of $14 \mathrm{ft}$. from the first rear axle, and the two rear axles have a variable spacing of 14 to $30 \mathrm{ft}$. In the transverse direction, wheels are spaced at $6 \mathrm{ft}$. on center. The second design live load, designated as a tandem axle load, is 50-kips and consists of two 25-kip axles spaced longitudinally at $4 \mathrm{ft}$. This axle load also has a $6 \mathrm{ft}$. transverse wheel spacing like the design truck. The design lane load is $640 \mathrm{lbs} / \mathrm{ft}$. and is applied over $10 \mathrm{ft}$. transverse width within a $12 \mathrm{ft}$. design lane. This load is placed only to produce maximum force effects and need not be continuous over the entire structure.
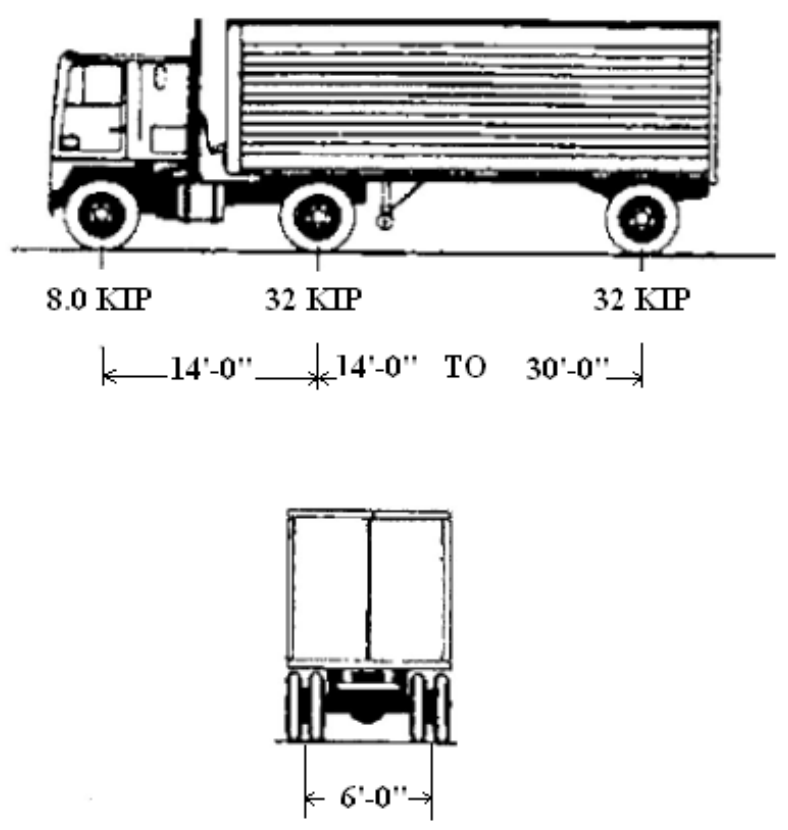

Figure 3.2 HS20-44 Design Truck 


\subsubsection{Construction Loads}

Construction loads are accounted for to protect the structure from damage and possible collapse during different phases of construction. In some cases, constructability may control the design; therefore, it must not be neglected. Construction loads typically consist of deck overhang forms, deck overhangs, screed rails, railings, walkways, and the finishing machine. The weight of the deck overhangs are typically assumed to be distributed partially to the overhang brackets and partially to the exterior girders. During construction, the deck of the bridge is cast in sequences to minimize cracking. The positive dead load bending regions are cast and cured first, followed by the negative bending regions. By allowing the girders to rotate over their supports prior to casting the negative bending regions, residual stresses within the deck are minimized.

\subsection{Load Combinations}

Several load combinations are utilized to statistically account for the probability of different load combinations occurring at the same point in time. Each limit state has prescribed load factors that can be found in Tables 3.4.1-1 and 3.4.1-2 of the AASHTO specifications. The total factored force effects are defined by AASHTO as:

$$
Q=\Sigma \eta_{i} \gamma_{i} Q_{i}
$$

Eq. 3.1

\subsubsection{Strength Load Combinations}

The strength limit state ensures the safety and stability of bridges undergoing statistically significant load combinations. The HL-93 live load, described in Section 
3.3.1, is applied during the strength limit state and consists of:

- a design truck or tandem with a 33 percent dynamic load allowance, and

- a design lane load.

The Strength I load combination is used to check structural members and components of a bridge under normal loading conditions. It applies load factors of 1.25, 1.5 , and 1.75 to the non composite dead loads $\left(\mathrm{DC}_{1}\right)$, composite dead loads $\left(\mathrm{DC}_{2}\right)$, and live loads (LL), respectively. The Strength I load combination is also used to check construction loads with load factors of 1.25 and 1.50 applied to dead and live loads, respectively. Wind loads are factored by a minimum of 1.25 and all other load factors are taken equal to 1.0 .

The Strength II load combination is used to check the strength of the bridge undergoing permit loads. Permit loads are generally heavier and have more axles than the HL-93 load but are less likely; therefore, the LL factor is reduced to 1.35. All other load factors are the same as the Strength I load factors with wind loads (WS and WL) effectively neglected.

The Strength III load combination is used to ensure the bridge maintains adequate strength under an applied $55 \mathrm{mph}$ wind load acting only on the structure. Non composite and composite dead loads are again factored by 1.25 and 1.5 , respectively. The force exerted by the wind load is factored by 1.4 after the bridge has entered service and 1.25 during construction. The composite dead load factor may also be reduced from 1.5 to 1.25 during construction checks. 
Generally speaking, long span bridges have higher dead-to-live load force effect ratios than typical bridges with span lengths less than $200 \mathrm{ft}$. This poses a problem because resistance factors were calibrated by sampling smaller span bridges. This issue was addressed with the Strength IV load combination by factoring all permanent loads by 1.5. This effectively eliminated the need for new resistance factors for longer span bridges. Wind and live load force effects are also neglected in the Strength IV load combination; however, in some instances this load combination may control certain stages of construction.

The Strength V load combination is used to check the strength of the bridge under 55 mph winds with traffic. It applies a 1.25 load factor to $\mathrm{DC}_{1}, 1.5$ to $\mathrm{DC}_{2}, 1.35$ to $\mathrm{LL}$, 0.4 to WS, and 1.0 to WL. When checking construction, the load factor for $\mathrm{DC}_{2}$ may by reduce from 1.5 to 1.25. The strength load factors are summarized below in Table 3.2 and Table 3.3. The load factors $\left(\gamma_{\mathrm{p}}\right)$ listed in Table 3.4.1-2 of the AASHTO specifications vary for different types of loads and are presented below in Table 3.2. 
Table 3.1 Strength Load Factors

\begin{tabular}{|c|c|c|c|c|c|c|c|c|c|}
\hline $\begin{array}{c}\text { Load } \\
\text { Combination } \\
\text { Limit State }\end{array}$ & $\begin{array}{l}D C \\
D D \\
D W \\
E H \\
E V \\
E S \\
E L \\
\underline{P S} \\
\underline{C R} \\
\underline{S H}\end{array}$ & $\begin{array}{l}L L \\
I M \\
C E \\
B R \\
P L \\
L S\end{array}$ & $W A$ & $W S$ & $W L$ & $F R$ & $T U$ & $T G$ & $S E$ \\
\hline $\begin{array}{l}\text { STRENGTH I } \\
\text { (unless noted) }\end{array}$ & $\gamma_{p}$ & 1.75 & 1.00 & - & - & 1.00 & $0.50 / 1.20$ & $\gamma_{T G}$ & $\gamma_{S E}$ \\
\hline STRENGTH II & $\gamma_{p}$ & 1.35 & 1.00 & - & - & 1.00 & $0.50 / 1.20$ & $\gamma_{T G}$ & $\gamma_{S E}$ \\
\hline $\begin{array}{l}\text { STRENGTH } \\
\text { III }\end{array}$ & $\gamma_{p}$ & - & 1.00 & 1.40 & - & 1.00 & $0.50 / 1.20$ & $\gamma_{T G}$ & $\gamma_{S E}$ \\
\hline $\begin{array}{l}\text { STRENGTH } \\
\text { IV }\end{array}$ & $\gamma_{p}$ & - & 1.00 & - & - & 1.00 & $0.50 / 1.20$ & - & - \\
\hline STRENGTH V & $\gamma_{p}$ & 1.35 & 1.00 & 0.40 & 1.0 & 1.00 & $0.50 / 1.20$ & $\gamma_{T G}$ & $\gamma_{S E}$ \\
\hline
\end{tabular}

Table 3.2 Additional Load Factors

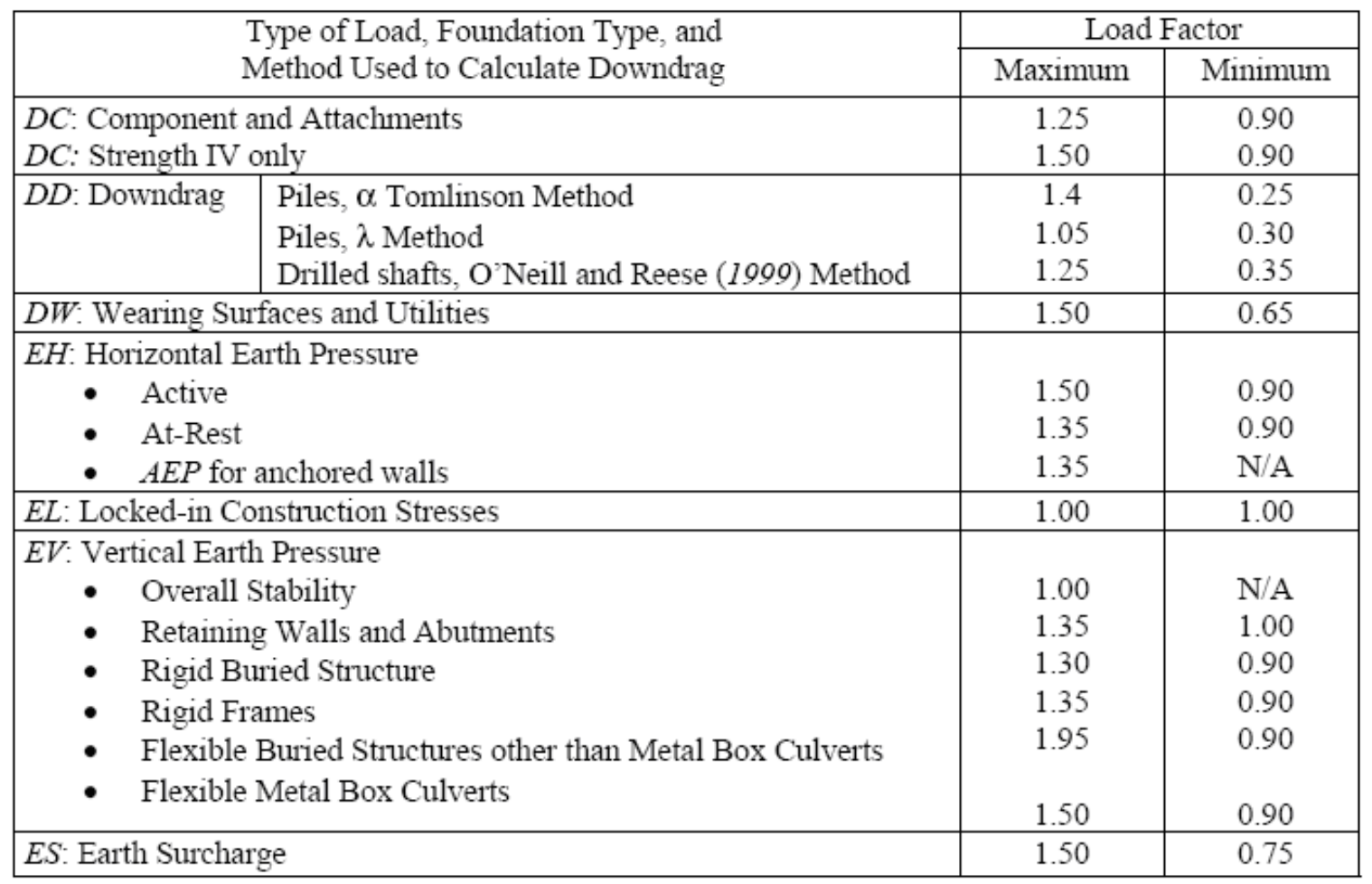




\subsubsection{Service Load Combinations}

The service limit state is used to control cracking of concrete bridge members and components by checking service level stresses and deflections. These stresses are primarily caused by large permanent and/or elastic deformations. The Service I load combination is used to control cracks and check deflections under normal operational use. All load factors are taken as 1.0 except for wind acting on the structure which has a load factor of 0.3. If the owner invokes the optional live load deflection criteria specified in Article 2.5.2.6.2, the deflection should be taken as the larger deflection induced by:

- the design truck alone, or

- 25 percent of the design truck plus the design lane load.

The Service II load combination is used to evaluate web stresses to protect against cracking in the deck due to permanent deformations. Flange stresses are limited to a percentage of their design strength to protect the web from premature yielding or buckling that could cause permanent deformations. The load factors for the Service II load combination are 1.0 for all dead loads and 1.3 for live loads. A summary of service load factors are tabulated in Table 3.3. 
Table 3.3 Service Load Factors

\begin{tabular}{|c|c|c|c|c|c|c|c|c|c|}
\hline $\begin{array}{c}\text { Load } \\
\text { Combination } \\
\text { Limit State }\end{array}$ & $\begin{array}{l}D C \\
D D \\
D W \\
E H \\
E V \\
E S \\
E L \\
\underline{P S} \\
\underline{C R} \\
\underline{S H}\end{array}$ & $\begin{array}{l}L L \\
I M \\
C E \\
B R \\
P L \\
L S\end{array}$ & $W A$ & $W S$ & $W L$ & $F R$ & $T U$ & $T G$ & $S E$ \\
\hline SERVICE I & 1.00 & 1.00 & 1.00 & 0.30 & 1.0 & 1.00 & $1.00 / 1.20$ & $\gamma_{T G}$ & $\gamma_{S E}$ \\
\hline SERVICE II & 1.00 & 1.30 & 1.00 & - & - & 1.00 & $1.00 / 1.20$ & - & - \\
\hline
\end{tabular}

\subsubsection{Fatigue Load Combination}

Fatigue damage is generally load or distortion induced and may result in cracks that typically form around welded and/or bolted connections. The fatigue load combination is used to combat cracking by limiting the stress range produced by the fatigue truck over a specified design life. The fatigue load is specified in Article 3.6.1.4.1 as a single HS20-44 design truck with a constant rear axle spacing of 30 feet and a load factor of 0.75 . A survey of bridges with fatigue damage concluded that this truck configuration is responsible for a majority of load induced damages on highway bridges. At the fatigue limit state, the fatigue truck factor is 0.75 and the dynamic load allowance is 15 percent.

\subsection{Load Modifiers}

Load modification factors account for material properties, redundancies in design, and the structural importance. They range from 0.95 to 1.05 and are multiplied to obtain a single load modification factor. 


\subsubsection{Ductility}

At the strength and extreme event limit state, it is important that the bridge show signs of inelastic behavior before failure. This ensures adequate protection against brittle failure within structural elements and joints. Brittle behavior is unfavorable because the load carrying capacity of structural members and joints are exceeded at the elastic limit. Ductile behavior is characterized by large inelastic deformations that provide warning signs of structural failure prior to reaching inelastic capacity. The ductility factor $\left(\eta_{D}\right)$ is between 0.95 and 1.05 for the strength and extreme event limit states shown below in Table 3.4. This modification factor is applied to the factored loads to obtain an ultimate design load.

\subsubsection{Redundancy}

A structural system is redundant if the failure of a member within that system does not cause the total collapse of the entire system. These types of bridges should be implemented when possible to protect against catastrophic failure. Structural systems that lack redundancies contain members which are referred to as failure-critical. If a failure-critical member is loaded in excess of its ultimate capacity, the entire structural system fails. The redundancy load modifiers $\left(\eta_{R}\right)$ for various degrees of structural redundancy are presented below in Table 3.4.

\subsubsection{Operational Importance}

The impacts of a bridges failure on society, national security, and national defense is assessed when selecting the operational importance factor $\left(\eta_{I}\right)$. Each bridge must be 
uniquely classified when choosing the importance load modifier. Bridges that lie on highly traveled corridors in metropolitan areas are considered operationally important to travelers and commerce. Bridges on interstate highways could potentially be used to maneuver military equipment and personnel; thus, have a higher operational importance.

Table 3.4 Load Modifiers

\begin{tabular}{|l|l|}
\hline \multicolumn{2}{|l|}{ Ductility } \\
\hline Non-ductile components and connections & $\eta_{D} \geq 1.05$ \\
\hline Conventional designs and details & $\eta_{D}=1.00$ \\
\hline Components with more ductility & $\eta_{D} \geq 0.95$ \\
\hline Redundancy & \\
\hline Non-redundant members & $\eta_{R} \geq 1.05$ \\
\hline Conventional levels of redundancy & $\eta_{R}=1.00$ \\
\hline Exceptional levels of redundancy & $\eta_{R} \geq 0.95$ \\
\hline Operational Importance & \\
\hline Important bridges & $\eta_{I} \geq 1.05$ \\
\hline Typical bridges & $\eta_{I}=1.00$ \\
\hline Relatively less important bridges & $\eta_{I} \geq 0.95$ \\
\hline
\end{tabular}

\subsection{Distribution Factors}

Distribution factors are used to reduce a three-dimensional analysis into a twodimensional analysis referred to as a line-girder analysis. Several equations and methods are outlined in Section 4.6.2.2 of the AASHTO specifications and are presented below.

\subsubsection{Interior Girder Distribution Factors}

Moment and shear distribution factors for interior girders are outlined in Tables 4.6.2.2.2b-1 and 4.6.2.2.3a-1 of the AASHTO specifications. The distribution factors for 
moment and shear, with a single lane loaded, are as follows:

$$
\begin{aligned}
& D F_{\text {moment }}=0.06+\left(\frac{S}{14}\right)^{0.4}\left(\frac{S}{L}\right)^{0.3}\left(\frac{K_{g}}{12.0 L t_{s}^{3}}\right)^{0.1} \\
& D F_{\text {shear }}=0.36+\frac{S}{25.0}
\end{aligned}
$$

These equations are applicable for the following ranges:

- $3.5 \leq S \leq 16$ (ft.)

- $4.5 \leq t_{s} \leq 12.0$ (in)

- $20 \leq L \leq 240$ (ft.)

- $\quad N_{b} \geq 4$

- $10,000 \leq K_{g} \leq 7,000,000$

When two or more design lanes are loaded the distribution factors become:

$$
\begin{aligned}
& D F_{\text {moment }}=0.075+\left(\frac{S}{9.5}\right)^{0.6}\left(\frac{S}{L}\right)^{0.2}\left(\frac{K_{g}}{12.0 L t_{s}^{3}}\right)^{0.1} \\
& D F_{\text {shear }}=0.20+\frac{S}{12.0}-\left(\frac{S}{35}\right)^{2.0}
\end{aligned}
$$

Eq. 3.4

Eq. 3.5

Multiple presence factors were included in the derivation of the approximate distribution factor equations; therefore, they need not be applied again.

\subsubsection{Exterior Girder Distribution Factors}

Moment and shear distribution factors for exterior girders are determined from Tables 4.6.2.2.2d-1 and 4.6.2.2.3b-1 of the AASHTO specifications. For a single lane 
loaded, distribution factors are determined using the lever rule. The lever-rule assumes that the deck is simply-supported between adjacent girders and load distribution is found by statically summing moments about adjacent girders. To determine the distribution

factors for two lanes loaded, a correction factor is applied to the distribution factors found from the interior girder. The correction factor is calculated as follows:

$$
\begin{aligned}
& e_{\text {moment }}=0.77+\frac{d_{e}}{9.1} \\
& e_{\text {shear }}=0.6+\frac{d_{e}}{10}
\end{aligned}
$$

The distribution factors above do not account for cross-frames and diaphragms; therefore, commentary C4.6.2.2.2d specifies a special analysis procedure. The equation suggested in the commentary is an interim provision until further research can produce a more representative factor. This equation is typically used for determining approximate load distributions on a system of piles and is as follows:

$$
R=\frac{N_{L}}{N_{b}}+\frac{X_{e x t} \sum e}{\sum N^{N_{L}} \sum}
$$

Multiple presence factors must be applied to the reactions obtained with this equation to arrive at the correct distribution factors.

\subsubsection{Fatigue Distribution Factors}

The fatigue limit state applies one design truck; therefore, all factors must be converted to equivalent single lane loaded distribution factor as specified in Article 3.6.1.4.3b. Distribution factors obtained from approximate equations, the lever-rule, and 
the special analysis for interior and exterior girder are divided by the appropriate multiple presence factor to obtain the fatigue distribution factors.

\subsubsection{Live Load Deflection Distribution Factor}

When choosing to invoke the optional live load deflection criterion of the specifications, all lanes should be loaded to produce the maximum possible deflection. The short-term composite section stiffness is considered when calculating deflection. For straight bridges, this is simply the composite section obtained from the effective width and modular ratio. For skewed bridges, a right cross section may be used. For curved and curved skewed bridges, a radial cross section should be used when determining composite stiffness. Additionally, all girders are assumed to deflect equally as stated in Article 2.5.2.6.2. The live load distribution factor is then found as:

$$
D F=m \frac{N_{L}}{N_{B}}
$$

Eq. 3.9

\subsection{Other Factors}

The suspension of a vehicle may become excited as it travels across a bridge; thus, the force it exerts on the bridge will be increased as the suspension reacts to deck joints, approach slabs, and other bumps in the roadway. To compensate for this in design, dynamic load allowance factors, also referred to as impact factors, are applied to the design vehicular live loads. The probability of multiple design loads acting on the bridge at the same time is also calculated and applied to the distribution factors. These probability factors are referred to as multiple presence factors in the AASHTO specifications. 


\subsubsection{Dynamic Load Allowances}

The dynamic load allowance is applied to vehicular live loads to account for the excitation of the vehicle's suspension as it drives across the bridge. The dynamic load allowance is 15 percent for the fatigue limit state, 75 percent when applying loads to deck joints, and 33 percent for all other limit states. This equates to impact factors of 1.15 , 1.75 , and 1.33 , respectively.

Table 3.5 Dynamic Load Allowance, IM

\begin{tabular}{|l|c|}
\hline \multicolumn{1}{|c|}{ Component } & IM \\
\hline Deck Joints - All Limit States & $75 \%$ \\
\hline All Other Components & \\
- Fatigue and Fracture Limit State & $15 \%$ \\
- All Other Limit States & $33 \%$ \\
\hline
\end{tabular}

\subsubsection{Multiple Presence Factors}

Multiple presence factors account for the probability of several design lanes being loaded simultaneously. The interior girder distribution factors already account for multiple presence; therefore, it is not necessary to reapply the factors. However, the lever rule and special analysis method used to calculate exterior girder distribution factors do not account for multiple presence; therefore, it must be applied to the girder reactions obtained from these methods. For the fatigue limit state, only one design lane is loaded, therefore, multiple presence must be removed from previously calculated distribution factors. 


\section{Table 3.6 Multiple Presence Factors}

\begin{tabular}{|c|c|}
\hline $\begin{array}{c}\text { Number } \\
\text { of lanes } \\
\text { loaded }\end{array}$ & $\begin{array}{c}\text { Multiple } \\
\text { Presence } \\
\text { Factors, m }\end{array}$ \\
\hline 1 & 1.2 \\
\hline 2 & 1.0 \\
\hline 3 & 0.85 \\
\hline$>3$ & 0.65 \\
\hline
\end{tabular}

\subsection{Summary of the $4^{\text {th }}$ Edition AASHTO LRFD Specifications}

\subsubsection{Strength Limit State}

The equations for positive and negative flexure, as well as shear, are presented below for the strength limit state. To ensure adequate capacity over the design service life of a bridge, these equations must be satisfied. If the bridge does not meet all of the requirements of this limit state the structural integrity of the structure may be at risk and should be reevaluated.

\subsubsection{Positive Flexural Capacity}

Article 6.10.6.2.2 of the AASHTO specifications classifies composite sections in positive flexure as compact or non-compact. Compact sections must satisfy the following limits:

- minimum yield strengths of the flanges do not exceed $70 \mathrm{ksi}$.

- web satisfies the proportional limit of:

$$
\frac{D}{t_{w}} \leq 150
$$


- section satisfies the web slenderness limit of:

$$
\frac{2 D_{c p}}{t_{w}} \leq 3.76 \sqrt{\frac{E}{F_{y c}}}
$$

Eq. 3.11

The top flange of a composite section generally meets the flange slenderness

limits because it is continuously braced by the deck. Compact and non-compact sections must also meet the ductility requirements specified in Article 6.10.7.3 of the specifications and are as follows:

$$
D_{p} \leq 0.42 D_{t}
$$

\subsection{Compact Sections}

At the strength limit state, positive flexural sections must satisfy the following equation:

$$
M_{u}+\frac{1}{3} f_{l} S_{x t} \leq \phi_{f} M_{n}
$$

The lateral flange bending effects are effectively neglected at the strength limit state because the deck is assumed to resist all lateral forces; therefore, $f_{l}$ will be zero in the subsequent calculations.

To ensure that the bridge deck does not prematurely crush before the composite section reaches its plastic moment capacity, Article 6.10.7.1.2 limits the distance from the top of the concrete to the plastic neutral axis to 10 percent of the total depth of the composite section. This precaution is taken to preserve the ductility of the composite 
section and is expressed as:

$$
D_{p} \leq 0.1 D_{t}
$$

Eq. 3.14

If the above condition is met, then the nominal flexural resistance is equal to the plastic moment capacity; otherwise, the nominal flexural resistance is limited to:

$$
M_{n}=M_{p}\left(1.07-0.7 \frac{D_{p}}{D_{t}}\right)
$$

The nominal flexural resistance for continuous spans must also satisfy the following limit except when the span under consideration, and all adjacent spans, satisfies the requirement of Article B6.2 which is:

$$
M_{n} \leq 1.3 R_{h} M_{y}
$$

\subsection{Noncompact Sections}

Noncompact sections are limited to their yield strength capacities and must satisfy the following:

\section{Compression Flange:}

$$
f_{b u} \leq \phi_{f} F_{n c}
$$

Tension Flange:

$$
f_{b u}+\frac{1}{3} f_{l} \leq \phi_{f} F_{n t}
$$

The nominal compression flange flexural resistance $\left(F_{n c}\right)$ is calculated as follows:

$$
F_{n c}=R_{b} R_{h} F_{y c}
$$

The web load-shedding factor $\left(R_{b}\right)$ accounts for the redistribution of stress from the web to the compression flange during web-bend buckling. This increase of stress in the flange 
ultimately reduces the flexural capacity of the cross section. The web load-shedding factor may be taken as 1.0 when:

- checking constructability,

- the section is composite, in positive flexure, and the web satisfies:

$$
\frac{D}{t_{w}} \leq 150
$$

- one or more longitudinal stiffeners are provided and:

$$
\frac{D}{t_{w}} \leq 0.95 \sqrt{\frac{E k}{F y c}}
$$

- or the webs satisfy:

$$
\frac{2 D_{c}}{t_{w}} \leq \lambda_{r w}
$$

otherwise:

$$
R_{b}=1-\left(\frac{a_{w c}}{1200+300 a_{w c}}\right)\left(\frac{2 D_{c}}{t_{w}}-\lambda_{r w}\right) \leq 1.0
$$

in which:

$$
\lambda_{r w}=5.7 \sqrt{\frac{E}{F_{y c}}}
$$

where:

$$
a_{w c}=\frac{2 D_{c} t_{w}}{b_{f c} t_{f c}}
$$


for all sections except composite longitudinally-stiffened sections in positive flexure in which:

$$
a_{w c}=\frac{2 D_{c} t_{w}}{b_{f c} t_{f c}+b_{s} t_{s}\left(1-f_{D C 1} / F_{y c}\right) / 3 n}
$$

and if:

$\frac{d_{s}}{D_{c}} \geq 0.4$

then:

$$
k=\frac{5.17}{\left(d_{s} / D\right)^{2}} \geq \frac{9}{\left(D_{c} / D\right)^{2}}
$$

otherwise:

$$
k=\frac{11.64}{\left(\frac{D_{c}-d_{s}}{D}\right)^{2}}
$$

For composite sections, $D_{c}$ shall be determined as specified in Article D6.3.1 which specifies:

$$
D_{c}=\left(\frac{-f_{c}}{\left|f_{c}\right|+f_{t}}\right) d-t_{f c} \geq 0
$$

The hybrid girder factor $\left(R_{h}\right)$ may be taken as 1.0 for all homogeneous cross sections, and sections with web strengths higher than flange strengths; otherwise:

$$
R_{h}=\frac{12+\beta\left(3 \rho-\rho^{3}\right)}{12+2 \beta}
$$

in which:

$$
\beta=\frac{2 D_{n} t_{w}}{A_{f n}}
$$




\subsubsection{Negative Flexural Capacity}

Sections in negative flexure are considered compact, or noncompact, if meeting the proportional limits of Article 6.10.6.2.3 which specify:

- the specified minimum yield strengths of the flanges do not exceed $70.0 \mathrm{ksi}$.

- the web satisfies the noncompact slenderness limit:

$$
\frac{2 D_{c}}{t_{w}} \leq 5.7 \sqrt{\frac{E}{F_{y c}}}
$$

- the flanges satisfy the following ratio:

$$
\frac{I_{y c}}{I_{y t}} \geq 0.3
$$

Article 6.10 .8 of the AASHTO Specifications distinguishes between various bracing conditions when considering flange strength at the strength limit state. Discretely braced flanges in compression at the strength limit state must satisfy the following inequality:

$$
f_{b u}+\frac{1}{3} f_{l} \leq \phi_{f} F_{n c}
$$

Discretely braced flanges in tension at the strength limit state must satisfy the following:

$$
f_{b u}+\frac{1}{3} f_{l} \leq \phi_{f} F_{n t}
$$

Continuously braced flanges in tension or compression at the strength limit state are limited to:

$$
f_{b u} \leq \phi_{f} R_{h} F_{y f}
$$


The nominal flexural resistance of the compression flange is controlled by the smaller of the flange local buckling (FLB) strength or the lateral-torsional buckling (LTB) strength specified in Articles 6.10.8.2.2 and 6.10.8.2.3., respectively.

\subsection{Flange Local Buckling}

The flange local buckling strength, detailed in Article 6.10.8.2.2 of the specifications, is as follows:

$$
\begin{aligned}
& \text { If } \lambda_{f} \leq \lambda_{p f} \text {, then: } \\
& F_{n c}=R_{b} R_{h} F_{y c}
\end{aligned}
$$

otherwise:

$$
F_{n c}=\left[1-\left(\frac{F_{y r}}{R_{h} F_{y c}}\right)\left(\frac{\lambda_{f}-\lambda_{p f}}{\lambda_{r f}-\lambda_{p f}}\right)\right] R_{b} R_{h} F_{y c}
$$

in which:

$$
\begin{aligned}
& \lambda_{f}=\frac{b_{f c}}{2 t_{f c}} \\
& \lambda_{p f}=0.38 \sqrt{\frac{E}{F_{y c}}} \\
& \lambda_{r f}=0.56 \sqrt{\frac{E}{F_{y r}}}
\end{aligned}
$$




\subsection{Lateral-Torsional Buckling}

The lateral-torsional buckling strength of a prismatic compression flange shall be taken as:

$$
\begin{aligned}
& \text { If } L_{b} \leq L_{p} \text { then: } \\
& F_{n c}=R_{b} R_{h} F_{y c} \\
& \text { If } L_{p}<L_{b} \leq L_{r} \text { then: } \\
& F_{n c}=C_{b}\left[1-\left(\frac{F_{y r}}{R_{h} F_{y c}}\right)\left(\frac{L_{b}-L_{p}}{L_{r}-L_{p}}\right)\right] R_{b} R_{h} F_{y c} \leq R_{b} R_{h} F_{y c} \\
& \text { If } L_{b} \geq L_{r} \text { then: } \\
& F_{n c}=F_{c r} \leq R_{b} R_{h} F_{y c}
\end{aligned}
$$

in which:

$$
\begin{aligned}
& L_{p}=1.0 r_{t} \sqrt{\frac{E}{F_{y c}}} \\
& L_{r}=\pi r_{t} \sqrt{\frac{E}{F_{y r}}}
\end{aligned}
$$

The moment gradient modifier $\left(C_{b}\right)$ may be calculated as follows:

for unbraced cantilevers and for members where $f_{\text {mid }} / f_{2}>1$ or $f_{2}=0$ :

$C_{b}=1.0$

for all other cases:

$$
C_{b}=1.75-1.05\left(\frac{f_{1}}{f_{2}}\right)+0.3\left(\frac{f_{1}}{f_{2}}\right)^{2} \leq 2.3
$$


The elastic lateral-torsional buckling stress is then found as:

$$
F_{c r}=\frac{C_{b} R_{b} \pi^{2} E}{\left(\frac{L_{b}}{r_{t}}\right)^{2}}
$$

And the effective radius of gyration for lateral-torsional buckling is found as:

$$
r_{t}=\frac{b_{f_{c}}}{\sqrt{12\left(1+\frac{1}{3} \frac{D_{c} t_{w}}{b_{f_{c}} t_{f c}}\right)}}
$$

\subsubsection{Shear}

Straight and curved web panels must satisfy Article 6.10.9.1 at the strength limit state. AASHTO specifications state that the maximum shear induced by the factored loads must be less than the nominal shear strength. This limit is presented below as:

$$
V_{u} \leq \phi_{v} V_{n}
$$

Eq. 3.51

The web panels of hybrid and non-hybrid I-girders are classified as stiffened or unstiffened. Web panels are considered to be stiffened if they meet the following criteria:

- no longitudinal stiffeners, and with transverse stiffeners, and spaced not to exceed $3 D$, or

- with one or more longitudinal stiffeners, and with transverse stiffeners, spaced not to exceed $1.5 D$ 
If webs do not meet the above requirements they are considered unstiffened. The nominal shear strength is then determined with Article 6.10.9.2 of the AASHTO specifications as:

$$
V_{n}=V_{c r}=C V_{p}
$$

where:

$$
V_{p}=0.58 F_{y w} D t_{w}
$$

The value of $C$ is then determined using AASHTO equations 6.10.9.3.2-4, 6.10.9.3.2-5, or 6.10.9.3.2-6, as follows:

$$
\begin{aligned}
& \text { If: } \frac{D}{t_{w}} \leq 1.12 \sqrt{\frac{E k}{F_{y w}}}, \text { then: } \\
& C=1.0 \\
& \text { If: } 1.12 \sqrt{\frac{E k}{F_{y w}}} \leq \frac{D}{t_{w}} \leq 1.40 \sqrt{\frac{E k}{F_{y w}}}, \text { then: } \\
& C=\frac{1.12}{\frac{D}{t_{w}}} \sqrt{\frac{E k}{F_{y w}}} \\
& \text { If: } \frac{D}{t_{w}} \geq 1.40 \sqrt{\frac{E k}{F_{y w}}}, \text { then: } \\
& C=\frac{1.57}{\left(\frac{D}{t_{w}}\right)^{2}} \sqrt{\frac{E k}{F_{y w}}}
\end{aligned}
$$

Eq. 3.58 
Transversely and longitudinally-stiffened webs, as well as sections that are only transversely stiffened, are separated into categories of interior panels and end panels. Interior web panels must be proportioned such that:

$$
\frac{2 D t_{w}}{\left(b_{f c} t_{f c}+b_{f t} t_{f t}\right)} \leq 2.5
$$

The shear resistance is then found as:

$$
V_{n}=V_{p}\left[C+\frac{0.87(1-C)}{\sqrt{1+\left(\frac{d_{0}}{D}\right)^{2}}}\right]
$$

The nominal resistance of an end web panel is equivalent to that of an un-stiffened web presented earlier.

\subsubsection{Constructability}

During construction, the yielding of main load carrying members is not permitted except in the webs of hybrid girders. The proper construction load factors are specified in Article 3.4.2 of the AASHTO specifications and are applied to construction loads when checking flange nominal yielding, flexural resistance, and web-bend buckling. Discretely braced compression flanges must satisfy the following limits:

Nominal Flange Yielding:

$$
f_{b u}+f_{l} \leq \phi_{f} R_{h} F_{y c}
$$

Flexural Resistance:

$$
f_{b u}+\frac{1}{3} f_{l} \leq \phi_{f} F_{n c}
$$


Web Bend-Buckling:

$f_{b u} \leq \phi_{f} F_{c r w}$

Eq. 3.63

where:

$$
f_{l} \leq 0.6 F_{y t}
$$

Eq. 3.64

Discretely and continuously braced tension flanges must also satisfy the following requirements for critical stages of construction:

Discretely Braced Tension Flanges:

$$
f_{b u}+f_{l} \leq \phi_{f} R_{h} F_{y t}
$$

Continuously Braced Tension and Compression Flanges:

$$
f_{b u} \leq \phi_{f} R_{h} F_{y f}
$$

\subsubsection{Service Limit State}

The Service limit state is employed to preserve the bridge deck such that acceptable levels of rideability and minimal deck deterioration are present over a useful service life. Decks which are subject to loads that cause permanent deformations and/or cracks will have a reduced service life and may rapidly deteriorate once damage is incurred. To protect the deck from premature failure, web yielding and bend-buckling capacities are checked at the Service II load combination. The owner of the bridge may also choose to limit elastic deflections to ensure that excessive deformations do not damage the bridge. 


\subsubsection{Permanent Deformations}

At the Service II limit state, lateral flange bending effects are applied to the top and bottom flanges. The Service II load combination is applied to the short-term or longterm composite section, as appropriate, assuming the deck is fully effective for both positive and negative flexure. The stress is then found based on the composite section and earlier specified load factors. Flanges must satisfy the equations below to ensure premature web yielding and bend-buckling do not occur prior to flange strength development.

Top Flange of Composite Sections:

$$
f_{f} \leq 0.95 R_{h} F_{y f}
$$

Bottom Flange of Composite Sections:

$$
f_{f}+\frac{f_{l}}{2} \leq 0.95 R_{h} F_{y f}
$$

Both Flanges of Composite Sections:

$$
f_{f}+\frac{f_{l}}{2} \leq 0.80 R_{h} F_{y f}
$$

\subsubsection{Elastic Deformations}

Live load deflection limits are optional in the $4^{\text {th }}$ edition of the AASHTO specifications; however, suggested limits are presented in Article 2.5.2.6. If deflection is checked, it shall be taken as the largest deflection induced by:

- the design truck plus impact, or

- 25 percent of the design truck with impact plus the design lane load. 
When evaluating live load deflection, all girders are assumed to deflect equally and all design lanes are to be loaded. The short-term composite section, along with any structurally continuous portions of the bridge, may be included in the total stiffness of the structure when determining deflection. The suggested deflection limits from Article 2.5.2.6.2 of the specifications are as follows:

Table 3.7 Live load Deflection Limits

\begin{tabular}{|l|c|l|}
\hline Vehicular loads only: & Span/800 & Eq. 3.70 \\
\hline Vehicular and/or pedestrian loads: & Span/1000 & Eq. 3.71 \\
\hline Vehicular loads on cantilever arms: & Span/300 & Eq. 3.72 \\
\hline $\begin{array}{l}\text { Vehicular and/or pedestrian loads on } \\
\text { cantilever arms: }\end{array}$ & Span/375 & Eq. 3.73 \\
\hline
\end{tabular}

\subsubsection{Web Requirements}

Web bend-buckling may cause accelerated deck deterioration and possible rupture due to plastic deformations. To ensure that webs have adequate web bend-buckling capacities, the following equation must be satisfied for the Service II load combination.

$$
f_{c} \leq F_{c r w}
$$

where:

$$
F_{c r w}=\frac{0.9 E k}{\left(\frac{D}{t_{w}}\right)^{2}}
$$

Composite sections in positive flexure, and proportioned such that $\mathrm{D} / \mathrm{t}_{\mathrm{w}} \leq 150$, need not be checked for web bend-buckling. 


\subsubsection{Fatigue and Fracture Limit State}

Fatigue is specified in AASHTO as load-induced or distortion-induced, and is outlined in Articles 6.6.1.2 and 6.6.1.3, respectively. Restrictions are placed on certain connection details which are described and illustrated in Table 6.6.1.2.3-1, Table

6.6.1.2.3-2, and Figure 6.6.1.2.3-1. The fatigue limit state is based on design life and limits the live load stress ranges of details to prevent crack growth.

\subsubsection{Load Induced Fatigue}

The live load stress range may be computed for flexural members, with shear connectors provided throughout their length, by using the short-term composite section assuming that the concrete deck is effective in both positive and negative bending. Residual stresses are not considered when determining stress ranges and these provisions shall be applied only to details subjected to a net applied tensile stress. In regions where permanent loads produce compression, fatigue shall be considered only if the compressive stress is less than twice the maximum tensile live load stress resulting from the fatigue load combination specified in Table 3.4.1-1. For load-induced fatigue considerations, each detail shall satisfy the following:

$$
\begin{aligned}
& \gamma(\Delta f) \leq(\Delta F)_{n} \\
& (\Delta F)_{n}=\left(\frac{A}{N}\right)^{\frac{1}{3}} \geq \frac{1}{2}(\Delta F)_{T H}
\end{aligned}
$$

in which:

$$
N=(365)(75) n(A D T T)_{S L}
$$




\subsubsection{Distortion Induced Fatigue}

Article 6.6.1.3 outlines several detail requirements that are used to satisfy distortion-induced fatigue. These connection details are outlined such that sufficient load paths exist to transmit all intended and unintended forces through transverse, lateral, and longitudinal members. The load paths shall be provided by either welding or bolting to the compression and tension flanges of the cross section where:

- connecting cross-frames or diaphragms are attached to transverse connection plates or to transverse stiffeners functioning as connection plates,

- internal or external cross-frames or diaphragms are attached to transverse connection plates or to transverse stiffeners functioning as connection plates, or

- floor beams are attached to transverse connection plates or to transverse stiffeners functioning as connection plates.

In the absence of better information, the welded, or bolted connection, should be designed to resist a 20.0-kip lateral load for straight, non-skewed bridges. To control buckling and elastic flexing of the web, the provision of Article 6.10.5.3 specifies that:

$$
V_{u} \leq V_{c r}
$$

Eq. 3.79

\subsubsection{Fracture}

Primary longitudinal members subject to tension forces under the strength limit states are required by Article 6.6.2 to meet Charpy V-notch toughness requirements. Structural members that are considered to be fracture-critical must also meet Charpy Vnotch requirements. Several temperature zones are specified in Table 6.6.2-1 in which 
applicable minimum service temperatures are listed. Table 6.6.2-2 of the specifications presents the corresponding fracture toughness requirements.

\subsubsection{Cross Section Proportions}

Several cross section proportional limits were developed from many years of construction and fabrication experience and are outlined in Article 6.10.2 of the specifications. These limits are designed to restrict any pre-service damage to components of the bridge superstructure. They were also developed as precautionary measures to safeguard against damage during handling, distortion due to welding, and adverse structural behavior.

\subsubsection{Web Proportions}

Girders with large profiles and thin webs are hard to handle during construction. To address this issue, Articles 6.10.2.1.1 and 6.10.2.1.2 limit the girder depth to thickness ratio to:

Without Longitudinal Stiffeners:

$$
\frac{D}{t_{w}} \leq 150
$$

With Longitudinal Stiffeners:

$$
\frac{D}{t_{w}} \leq 300
$$




\subsubsection{Flange Proportions}

Article 6.10.2.2 specifies that compression and tension flanges shall be proportioned such that:

$$
\begin{aligned}
& \frac{b_{f}}{2 t_{f}} \leq 12 \\
& b_{f} \geq D / 6 \\
& t_{f} \geq 1.1 t_{w} \\
& 0.1 \leq \frac{I_{y c}}{I_{y t}} \leq 10
\end{aligned}
$$

The following justifications are made for each of the flange proportion limits:

- Eq. 3.82 ensures that excessive distortion will not take place when the flange is welded to the web.

- Eq. 3.83 ensures that webs can develop post buckling shear resistance due to tension field action.

- Eq. 3.84 requires the flange thickness to be 10 percent larger than the web thickness to ensure that the flange will be able to resist web shear buckling.

- Eq. 3.85 ensures that the section does not behave like a T-section and increases handleability during construction.

\subsubsection{Additional Considerations}

The $4^{\text {th }}$ edition AASHTO LRFD Bridge Design Specifications was considered for strength, service, and fatigue limits states, but was limited to the applicable scope of this research. Several other important sections of the specifications, such as Appendices B,C, 
and D must also be investigated to fully address I-girder superstructure design.

Additional design consideration must also be made for shear connectors, transverse stiffeners, bearings, diaphragms, deck design, etc. 
Table 3.8 Equation Legend

\begin{tabular}{|c|c|}
\hline $\begin{array}{l}\text { Chapter } 3 \\
\text { Equation }\end{array}$ & $\begin{array}{c}\text { AASHTO } 4^{\text {th }} \text { Ed. } \\
\text { Equation }\end{array}$ \\
\hline Eq. 3.1 & $1.3 .2 .1-1$ \\
\hline Eq. 3.2 & Table 4.6.2.2.2b-1 \\
\hline Eq. 3.3 & Table 4.6.2.2.3a-1 \\
\hline Eq. 3.4 & Table 4.6.2.2.2b-1 \\
\hline Eq. 3.5 & Table 4.6.2.2.3a-1 \\
\hline Eq. 3.6 & Table 4.6.2.2.2d-1 \\
\hline Eq. 3.7 & Table 4.6.2.2.3b-1 \\
\hline Eq. 3.8 & $\mathrm{C} 4.6 .2 .2 .2 \mathrm{~d}-1$ \\
\hline Eq. 3.9 & 2.5.2.6.2 \\
\hline Eq. 3.10 & $6.10 .2 .1 .1-1$ \\
\hline Eq. 3.11 & $6.10 .6 .2 .2-1$ \\
\hline Eq. 3.12 & $6.10 .7 .3-1$ \\
\hline Eq. 3.13 & $6.10 .7 .1 .1-1$ \\
\hline Eq. 3.14 & 6.10.7.1.2-1 \\
\hline Eq. 3.15 & $6.10 .7 .1 .2-2$ \\
\hline Eq. 3.16 & $6.10 .7 .1 .2-3$ \\
\hline Eq. 3.17 & 6.10.7.2.1-1 \\
\hline Eq. 3.18 & 6.10.7.2.1-2 \\
\hline Eq. 3.19 & $6.10 .7 .2 .2-1$ \\
\hline Eq. 3.20 & 6.10.2.1.1-1 \\
\hline Eq. 3.21 & $6.10 .1 .10 .2-1$ \\
\hline Eq. 3.22 & $6.10 .1 .10 .2-2$ \\
\hline Eq. 3.23 & $6.10 .1 .10 .2-3$ \\
\hline Eq. 3.24 & $6.10 .1 .10 .2-4$ \\
\hline Eq. 3.25 & $6.10 .1 .10 .2-5$ \\
\hline Eq. 3.26 & $6.10 .1 .10 .2-6$ \\
\hline Eq. 3.28 & $6.10 .1 .9 .2-1$ \\
\hline Eq. 3.29 & $6.10 .1 .9 .2-2$ \\
\hline Eq. 3.30 & D6.3.1-1 \\
\hline Eq. 3.31 & $6.10 .1 .10 .1-1$ \\
\hline Eq. 3.32 & $6.10 .1 .10 .1-2$ \\
\hline Eq. 3.33 & $6.10 .6 .2 .3-1$ \\
\hline Eq. 3.34 & 6.10.6.2.3-2 \\
\hline Eq. 3.35 & 6.10.8.1.1-1 \\
\hline Eq. 3.36 & 6.10.8.1.2-1 \\
\hline Eq. 3.37 & 6.10.8.1.3-1 \\
\hline Eq. 3.38 & 6.10.8.2.2-1 \\
\hline Eq. 3.39 & $6.10 .8 .2 .2-2$ \\
\hline Eq. 3.40 & $6.10 .8 .2 .2-3$ \\
\hline Eq. 3.41 & $6.10 .8 .2 .2-4$ \\
\hline Eq. 3.42 & $6.10 .8 .2 .2-5$ \\
\hline
\end{tabular}




\begin{tabular}{|c|c|}
\hline $\begin{array}{l}\text { Chapter } 3 \\
\text { Equation }\end{array}$ & $\begin{array}{l}\text { AASHTO } 4^{\text {th }} \text { Ed. } \\
\text { Equation }\end{array}$ \\
\hline Eq. 3.43 & 6.10.8.2.3-1 \\
\hline Eq. 3.44 & $6.10 .8 .2 .3-2$ \\
\hline Eq. 3.45 & $6.10 .8 .2 .3-3$ \\
\hline Eq. 3.46 & $6.10 .8 .2 .3-4$ \\
\hline Eq. 3.47 & $6.10 .8 .2 .3-5$ \\
\hline Eq 3.48 & $6.10 .8 \cdot 2.3-7$ \\
\hline Eq. 3.49 & $6.10 .8 .2 .3-8$ \\
\hline Eq. 3.50 & $6.10 .8 .2 .3-9$ \\
\hline Eq. 3.51 & $6.10 .9 .1-1$ \\
\hline Eq. 3.52 & $6.10 .9 .2-1$ \\
\hline Eq. 3.53 & $6.10 .9 .2-2$ \\
\hline Eq. 3.54 & $6.10 .9 .3 .2-4$ \\
\hline Eq. 3.55 & $6.10 .9 \cdot 3.2-5$ \\
\hline Eq. 3.56 & $6.10 .9 .3 .2-5$ \\
\hline Eq. 3.57 & $6.10 .9 .3 .2-6$ \\
\hline Eq. 3.58 & $6.10 .9 .3 .2-6$ \\
\hline Eq. 3.59 & $6.10 .9 .3 .2-1$ \\
\hline Eq. 3.60 & $6.10 .9 \cdot 3 \cdot 2-2$ \\
\hline Eq. 3.61 & $6.10 .3 .2 .1-1$ \\
\hline Eq. 3.62 & $6 \cdot 10.3 \cdot 2.1-2$ \\
\hline Eq. 3.64 & 6.10.1.6-1 \\
\hline Eq. 3.63 & $6.10 .3 \cdot 2 \cdot 1-3$ \\
\hline Eq. 3.65 & $6.10 .3 .2 .2-1$ \\
\hline Eq. 3.66 & $6.10 .3 .2 .3-1$ \\
\hline Eq. 3.67 & 6.10.4.2.2-1 \\
\hline Eq. 3.68 & $6.10 .4 .2 .2-2$ \\
\hline Eq. 3.69 & $6.10 .4 .2 .2-3$ \\
\hline Eq. 3.70 & 2.5 .2 .6 .2 \\
\hline Eq. 3.71 & 2.5.2.6.2 \\
\hline Eq. 3.72 & 2.5 .2 .6 .2 \\
\hline Eq. 3.73 & 2.5.2.6.2 \\
\hline Eq. 3.74 & $6.10 .4 .2 .2-4$ \\
\hline Eq. 3.76 & $6.6 .1 .2 .2-1$ \\
\hline Eq. 3.77 & $6.6 .1 .2 .5-1$ \\
\hline Eq. 3.78 & $6.6 \cdot 1 \cdot 2.5-2$ \\
\hline Eq. 3.79 & $6.10 .5 .3-1$ \\
\hline Eq. 3.80 & $6.10 .2 .1 .1-1$ \\
\hline Eq. 3.81 & $6.10 .2 .1 .2-1$ \\
\hline Eq. 3.82 & $6.10 .2 .2-1$ \\
\hline Eq. 3.83 & $6.10 .2 .2-2$ \\
\hline Eq. 3.84 & $6.10 .2 .2-3$ \\
\hline Eq. 3.84 & $6.10 .2 .2-4$ \\
\hline
\end{tabular}




\section{Chapter 4 - Parametric Assessment of AASHTO Specifications for HPS 100W}

\subsection{Introduction}

The $4^{\text {th }}$ edition of the AASHTO specifications currently limits steel I-girders, with yield strengths greater then $70 \mathrm{ksi}$, to their respective yield moment capacities instead of their plastic moment capacities (AASHTO 2008). In doing so, economical HPS 100W steel I-girders cannot be realized because they are not applicable in Appendix A. The focus of this chapter is to evaluate the current design specifications that are applicable for HPS 100W Hybrid I-girders, as well as those in Appendix A which are currently not applicable, to determine if the current limits may safely be removed.

In previous editions of the AASHTO specifications, $50 \mathrm{ksi}$ was the limit that governed the applicability of the plastic moment equations. When HPS 70W became readily available in 1994, it faced the same problems that HPS $100 \mathrm{~W}$ encounters today. At the time, a limited amount of experimental and analytical data was available for HPS 70W; therefore, the structural behavior was unverified and excluded from Appendix A. Experimental and analytical tests were performed by Barth et al. (2000), Fahnstock and Sause (2001), and Yakel et al. (2002) which determined that compact sections incorporating HPS 70W were capable of reaching their plastic moment capacities. Additional work was done by Fahnstock and Sause (2001) to determine the applicability of $1^{\text {st }}$ and $2^{\text {nd }}$ edition negative flexural capacity equations for homogeneous HPS $100 \mathrm{~W}$ Igirders in negative flexure. However, only two homogenous HPS 100W I-girders were experimentally tested; therefore, additional experiments and analytical assessments are necessary to reinforce the findings of Fahnstock and Sause. 


\subsection{Background}

High strength steels are generally considered to be less ductile than lower grade steels. The ability of a material to deform plastically, prior to reaching its rupture strength, is dependent upon the yield ratio of that material (YR). The yield ratio can be defined as the ratio of a material's yield strength to its ultimate strength. It is also a good representation of a material's ductility. A low yield ratio indicates a high level of ductility, while a yield ratio approaching 1.00 indicates a brittle material. Grade 50 steel has a $\mathrm{YR}=0.77$ and deforms plastically after it surpasses its yield strength. This is a desirable material trait for bridges because it provides warning signs prior to catastrophic failure. One of the major concerns associated with HPS $100 \mathrm{~W}$ is that it has a YR $=0.90$. Materials with yield ratios closer to 1.00 exhibit brittle behavior and are more likely to fracture, without warning, than plastically deform (Barth et al. 2007).

Research was conducted by Fahnstock and Sause (2001) to determine if the $1^{\text {st }}$ and $2^{\text {nd }}$ editions of the AASHTO specifications could accurately predict design capacities of homogeneous HPS 100W I-girders. However, the scope of this research was limited to only a compact girder, and a girder with compact flanges and a noncompact web. The compact girder was able to reach its plastic moment capacity, while the girder with compact flanges and a noncompact web came within 3 percent of its design flexural capacity (Barth et al. 2007). Further research is necessary to verify that $4^{\text {th }}$ Edition equations are capable of predicting the flexural capacities of sections fabricated with HPS 100W. 


\subsection{Negative Flexural Capacity of HPS 100W I-Girders at the Strength Limit State}

\subsubsection{Introduction}

High strength steels are commonly incorporated into hybrid girder designs at regions of high stress. In continuous span bridges, regions of high stress are generally located in the compression flanges of negative bending regions over piers. The $4^{\text {th }}$ edition of the specifications outlines two separate design methods for determining the negative flexural capacities of steel I-girders. The first method is found in Article 6.10.8 which limits the flexural capacity of the negative bending section to the yield moment. The second method is found in Appendix A, which allows I-girders with compact and noncompact webs to utilize their inelastic capacities (AASHTO 2008).

\subsubsection{Negative Flexural Capacity per Article 6.10.8}

HPS 100W violates the first provision of Appendix A; therefore, all HPS 100W bridges must currently be designed with the provisions of Article 6.10.8, which limits the negative flexural capacity to the yield moment. At the strength limit state, discretely braced flanges in compression must meet the following:

$$
f_{b u}+\frac{1}{3} f_{l} \leq \phi_{f} F_{n c}
$$

Discretely braced flanges in tension at the strength limit state must satisfy the following:

$$
f_{b u}+\frac{1}{3} f_{l} \leq \phi_{f} F_{n t}
$$

Eq. 4.2 
Continuously braced flanges in tension or compression, at the strength limit state, must also satisfy:

$$
f_{b u} \leq \phi_{f} R_{h} F_{y f}
$$

Eq. 4.3

The nominal flexural resistance, governed by the compression flange, is the smaller of the flange local buckling (FLB) strength, or the lateral-torsional buckling (LTB) strength specified in Articles 6.10.8.2.2 and 6.10.8.2.3., respectively. The flange local buckling strength, detailed in Article 6.10.8.2.2 of the specifications, is as follows:

$$
\begin{aligned}
& \text { If } \lambda_{f} \leq \lambda_{p f}: \\
& F_{n c}=R_{b} R_{h} F_{y c}
\end{aligned}
$$

otherwise:

$$
F_{n c}=\left[1-\left(\frac{F_{y r}}{R_{h} F_{y c}}\right)\left(\frac{\lambda_{f}-\lambda_{p f}}{\lambda_{r f}-\lambda_{p f}}\right)\right] R_{b} R_{h} F_{y c}
$$

in which:

$$
\begin{aligned}
& \lambda_{f}=\frac{b_{f c}}{2 t_{f c}} \\
& \lambda_{p f}=0.38 \sqrt{\frac{E}{F_{y c}}} \\
& \lambda_{r f}=0.56 \sqrt{\frac{E}{F_{y r}}}
\end{aligned}
$$

The lateral-torsional buckling strength of prismatic compression flanges, detailed in Article 6.10 .8 .2 .3 of the specifications, shall be taken as:

$$
\begin{aligned}
& \text { If } L_{b} \leq L_{p}: \\
& F_{n c}=R_{b} R_{h} F_{y c}
\end{aligned}
$$




$$
\begin{aligned}
& \text { If } L_{p}<L_{b} \leq L_{r}: \\
& F_{n c}=C_{b}\left[1-\left(\frac{F_{y r}}{R_{h} F_{y c}}\right)\left(\frac{L_{b}-L_{p}}{L_{r}-L_{p}}\right)\right] R_{b} R_{h} F_{y c} \leq R_{b} R_{h} F_{y c} \\
& \text { If } L_{b} \geq L_{r}: \\
& F_{n c}=F_{c r} \leq R_{b} R_{h} F_{y c}
\end{aligned}
$$

Eq. 4.11

in which:

$$
\begin{gathered}
L_{p}=1.0 r_{t} \sqrt{\frac{E}{F_{y c}}} \\
L_{r}=\pi r_{t} \sqrt{\frac{E}{F_{y r}}}
\end{gathered}
$$

The moment gradient modifier $\left(C_{b}\right)$ may be calculated as follows:

for unbraced cantilevers and for members where $f_{\text {mid }} / f_{2}>1$ or $f_{2}=0$ :

$$
C_{b}=1.0
$$

for all other cases:

$$
C_{b}=1.75-1.05\left(\frac{f_{1}}{f_{2}}\right)+0.3\left(\frac{f_{1}}{f_{2}}\right)^{2} \leq 2.3
$$

The elastic lateral-torsional buckling stress is then found as:

$$
F_{c r}=\frac{C_{b} R_{b} \pi^{2} E}{\left(\frac{L_{b}}{r_{t}}\right)^{2}}
$$


The effective radius of gyration for lateral-torsional buckling is then found as follows:

$$
r_{t}=\frac{b_{f c}}{\sqrt{12\left(1+\frac{1}{3} \frac{D_{c} t_{w}}{b_{f c} t_{f c}}\right)}}
$$

\subsubsection{Negative Flexural Capacity per Appendix A}

Appendix A may be utilized for straight I-girder bridges if they are proportioned such that:

- the specified minimum yield strengths of the flanges do not exceed $70.0 \mathrm{ksi}$,

- the web satisfies the noncompact slenderness limit:

$$
\frac{2 D_{c}}{t_{w}} \leq 5.7 \sqrt{\frac{E}{F_{y c}}}
$$

- the flanges satisfy the following ratio:

$$
\frac{I_{y c}}{I_{y t}} \geq 0.3
$$

Sections with discretely braced compression flanges at the strength limit state must meet the following:

$$
M_{u}+\frac{1}{3} f_{l} S_{x c} \leq \phi_{f} M_{n c}
$$

Sections with discretely braced tension flanges at the strength limit state must meet the following:

$$
M_{u}+\frac{1}{3} f_{l} S_{x t} \leq \phi_{f} M_{n t}
$$


Sections with continuously braced compression flanges at the strength limit state must meet the following:

$$
M_{u} \leq \phi_{f} R_{p c} M_{y c}
$$

Sections with continuously braced tension flanges at the strength limit state must meet the following:

$$
M_{u} \leq \phi_{f} R_{p t} M_{y t}
$$

Appendix A differentiates between compact and noncompact web sections when

evaluating the web plastification factors. For webs to be classified as compact, they must meet the following:

$$
\frac{2 D_{c p}}{t_{w}} \leq \lambda_{p w\left(D_{c o)}\right.}
$$

in which:

$$
\lambda_{p w\left(D_{c o)}\right.}=\frac{\sqrt{\frac{E}{F_{y c}}}}{\left(0.54 \frac{M_{p}}{R_{h} M_{y}}-0.09\right)^{2}} \leq \lambda_{r w}\left(\frac{D_{c p}}{D_{c}}\right)
$$

and:

$$
\lambda_{r w}=5.7 \sqrt{\frac{E}{F_{y c}}}
$$

The web plastification factors for compact webs are then found by:

$$
R_{p c}=\frac{M_{p}}{M_{y c}}
$$




$$
R_{p t}=\frac{M_{p}}{M_{y t}}
$$

Webs that do not satisfy the requirements for compactness, but may still be classified as noncompact, must satisfy the following:

$$
\lambda_{w} \leq \lambda_{r w}
$$

where:

$$
\lambda_{w}=\frac{2 D_{c}}{t_{w}}
$$

and:

$$
\lambda_{r w}=5.7 \sqrt{\frac{E}{F_{y c}}}
$$

The web plastification factors for noncompact webs are then found by:

$$
\begin{aligned}
& R_{p c}=\left[1-\left(1-\frac{R_{h} M_{y c}}{M_{p}}\right)\left(\frac{\lambda_{w}-\lambda_{p w\left(D_{c}\right)}}{\lambda_{r w}-\lambda_{p w\left(D_{c}\right)}}\right)\right] \frac{M_{p}}{M_{y c}} \leq \frac{M_{p}}{M_{y c}} \\
& R_{p t}=\left[1-\left(1-\frac{R_{h} M_{y t}}{M_{p}}\right)\left(\frac{\lambda_{w}-\lambda_{p w\left(D_{c}\right)}}{\lambda_{r w}-\lambda_{p w\left(D_{c}\right)}}\right)\right] \frac{M_{p}}{M_{y t}} \leq \frac{M_{p}}{M_{y t}}
\end{aligned}
$$

where:

$$
\lambda_{p w\left(D_{c}\right)}=\lambda_{p w\left(D_{c p}\right)}\left(\frac{D_{c}}{D_{c p}}\right) \leq \lambda_{r w}
$$

Similar to Article 6.10 .8 of the specifications, Appendix A limits the nominal flexural capacity to either the flange local buckling (FLB) capacity or lateral-torsional buckling 
(LTB) capacity. The flexural capacity based on the flange local buckling capacity is as follows:

$$
\begin{aligned}
& \text { If } \lambda_{f} \leq \lambda_{p f} \text { then: } \\
& M_{n c}=R_{p c} M_{y c}
\end{aligned}
$$

otherwise:

$$
M_{n c}=\left[1-\left(1-\frac{F_{y y} S_{x c}}{R_{p c} M_{y c}}\right)\left(\frac{\lambda_{f}-\lambda_{p f}}{\lambda_{r f}-\lambda_{p f}}\right)\right] R_{p c} M_{y c}
$$

in which:

$$
\begin{aligned}
& \lambda_{f}=\frac{b_{f c}}{2 t_{f c}} \\
& \lambda_{p f}=0.38 \sqrt{\frac{E}{F_{y c}}} \\
& \lambda_{r f}=0.95 \sqrt{\frac{E k_{c}}{F_{y r}}}
\end{aligned}
$$

for built-up sections:

$$
k_{c}=\frac{4}{\sqrt{\frac{D}{t_{w}}}} \quad 0.35 \leq k_{c} \leq 0.76
$$

for rolled shapes:

$\mathrm{k}_{\mathrm{c}}=0.76$

The lateral-torsional buckling capacity, for prismatic lengths, shall be taken as:

$$
\begin{aligned}
& \text { If } L_{b} \leq L_{p}: \\
& M_{n c}=R_{p c} M_{y c}
\end{aligned}
$$


If $L p<L_{b} \leq L_{r}$ :

$M_{n c}=C_{b}\left[1-\left(1-\frac{F_{y r} S_{x c}}{R_{p c} M_{y c}}\right)\left(\frac{L_{b}-L_{p}}{L_{r}-L_{p}}\right)\right] R_{p c} M_{y c} \leq R_{p c} M_{y c}$

Eq. 4.41

If $L_{b}>L_{r}$ :

$M_{n c}=F_{c r} S_{x c} \leq R_{p c} M_{y c}$

Eq. 4.42

where:

$F_{c r}=\frac{C_{b} \pi^{2} E}{\left(L_{b} / r_{t}\right)^{2}} \sqrt{1+0.078 \frac{J}{S_{x c} h}\left(L_{b} / r_{t}\right)^{2}}$

Eq. 4.43

and if $M_{m i d} / M_{2}>1$, or $M_{2}=0$ :

$C_{b}=1.0$

for all other cases:

$C_{b}=1.75-1.05\left(\frac{M_{1}}{M_{2}}\right)+0.3\left(\frac{M_{1}}{M_{2}}\right)^{2} \leq 2.3$

Eq. 4.44

and:

$L_{r}=1.95 r_{t} \frac{E}{F_{y r}} \sqrt{\frac{J}{S_{x c} h}} \sqrt{1+\sqrt{1+6.76\left(\frac{F_{y r}}{E} \frac{S_{x c} h}{J}\right)^{2}}}$

Eq. 4.45

where:

$J=\frac{D t_{w}{ }^{3}}{3}+\frac{b_{f c} t_{f c}^{3}}{3}\left(1-0.63 \frac{t_{f c}}{b_{f c}}\right)+\frac{b_{f c} t_{f t}^{3}}{3}\left(1-0.63 \frac{t_{f t}}{b_{f t}}\right)$

Eq. 4.46

and:

$$
r_{t}=\frac{b_{f_{c}}}{\sqrt{12\left(1+\frac{1}{3} \frac{D_{c} t_{w}}{b_{f_{c}} t_{f_{c}}}\right)}}
$$


Sections with flange transitions within their unbraced lengths may be analyzed using the smallest section properties within the unbraced length. This will result in a conservative LTB capacity; however, a more refined approach may be adopted which utilizes the weighted average of the section properties to more accurately model the stiffness of the member. If a flange transition takes place at a distance less than 20 percent of the unbraced length away from a brace point with the smaller moment, then the member may be treated as prismatic; however, if the flange transition lies outside this length, one of the methods mentioned above must be used to determine LTB capacity. Lastly, the nominal tension flange capacity is specified in Appendix A as follows:

$$
M_{n t}=R_{p t} M_{y t}
$$

Eq. 4.48

\subsection{Parametric Study of HPS 100W I-Girders with Finite Element Analysis}

\subsubsection{Introduction}

Three-dimensional finite element analysis (FEA) was performed for a suite of hybrid girders with 100 ksi flanges and 70 ksi webs by Barth, Righman, and Wolfe (2007). The results of the analysis were compared with the predicted moment capacities from the $2^{\text {nd }}$ and $3^{\text {rd }}$ editions of the AASHTO specifications.

\subsubsection{Parametric Variances}

Several parameters were varied in order to produce a matrix of theoretical girders that could be used to determine the applicability of the AASHTO specifications (Barth et al. 2007). The parameters varied were web slenderness, flange slenderness, lateral bracing, and percentage of web depth in compression. The $3^{\text {rd }}$ edition of the specifications has two sets of equations for determining the negative flexure capacity. 
The first set of equations is presented in Article 6.10.8. The second set is presented in Appendix A (Barth et al. 2007). Girders were designed to target key web slenderness values embedded within the two sets equations. All girders had a constant span-to-depth ratio of 30 , cross section aspect ratio of 4, HPS 70W webs, and HPS 100W flanges. Shear resistance was provided by transverse stiffeners for sections that were found to be insufficient (Barth et al. 2007).

\subsubsection{Web Slenderness}

Web slenderness values were varied to target the applicability of specific moment capacity equations within the specifications. The compact limit of Appendix A was targeted first. Girders that meet the requirements of a compact section can theoretically reach their plastic moment capacities. The second limit targeted was the noncompact limit, which is the minimum slenderness limit for the applicability of Appendix A equations. Sections that meet this requirement, but not the compact limit, have capacities greater than the yield moment, but less than the plastic moment. Several girders were also designed to target the maximum allowable web slenderness permitted by Section 6.10.2. The last targeted web slenderness was an intermediate value used to evaluate the strength prediction equations between limits (Barth et al. 2007).

\subsubsection{Flange Slenderness}

Flange slenderness values were varied to correspond to the compact and noncompact limits of Article 6.10.8, and the noncompact limit of Appendix A. The 
compact limits are the same for Article 6.10.8 and Appendix A; however, the noncompact limit is different in Appendix A (Barth et al. 2007).

\subsubsection{Lateral Bracing}

Lateral brace lengths greatly affect the lateral-torsional buckling capacities of the girders. Much like the flanges, Appendix A and Article 6.10.8 also define brace lengths as compact or noncompact. These limits vary depending on which of the above sections the LTB capacity is being determined (Barth et al. 2007).

\subsubsection{Depth of Web in Compression}

The ratio of web depth in compression to total web depth $\left(\mathrm{D}_{\mathrm{cp}} / \mathrm{D}\right)$ has been shown to affect the behavior of I-girders; therefore, two key values were used to examine the effects of this phenomenon. The two values selected were 0.50 , which represents a doubly symmetric section, and 0.65 , which is a typical upper range value found in practical girder designs (Barth et al. 2007).

\subsubsection{Finite Element Analysis Procedure}

The finite element analysis of HPS hybrid I-girders was accomplished by modeling the girders in three-point bending. The models were assumed to be simplysupported at the points of contraflexure. These points were located at a distance $0.20 \mathrm{~L}$ away from the supports. The support reaction was treated as a concentrated load at the midpoint of the modeled girder and was used to develop that maximum bending capacity (Barth et al. 2007). 
ABAQUS has non-linear capabilities; therefore, nonlinear material properties of $100 \mathrm{ksi}$ steel were used in the models. These material properties were determined from experimental values obtained at Lehigh University. They were:

- Young's Modulus $=29,000 \mathrm{ksi}$

- $\quad$ Yield Ratio $=0.91$

- $\quad$ Strain Hardening Modulus $=93.7 \mathrm{ksi}$

The $70 \mathrm{ksi}$ web properties were modeled with values obtained from experimental tests done by the FHWA. These values were:

- $\quad$ Young's Modulus $=29,000 \mathrm{ksi}$

- $\quad$ Yield Ratio $=0.83$

- Strain Hardening Modulus $=72 \mathrm{ksi}$

Residual stresses and geometric imperfections, within mill tolerances, were also incorporated into the model (Barth et al. 2007).

\subsubsection{Results of Study}

The negative bending capacity equations of the $2^{\text {nd }}$ and $3^{\text {rd }}$ editions of the AASHTO specifications were reasonably close or exceeded by all of the girders modeled in ABAQUS. Flexural capacity ratios were determined from the moment capacities predicted with the $2^{\text {nd }}$ and $3^{\text {rd }}$ editions of the specifications with respect to the FEA predicted capacities. These were denoted as $\mathrm{M}_{\mathrm{n} 2 \mathrm{nd}} / \mathrm{M}_{\mathrm{FEA}}$, and $\mathrm{M}_{\mathrm{n} 3 \mathrm{nd}} / \mathrm{M}_{\mathrm{FEA}}$, respectively (Barth et al. 2007). 
The average flexural capacity ratio, determined with $3^{\text {rd }}$ edition equations, was 0.88 ; with a high of 1.03 and a low of 0.76 . Therefore, the $3^{\text {rd }}$ edition equations were found to under-predict the flexural capacity of HPS hybrid girders by an average of 12 percent. A small percentage of FEA girders did not reach their predicted flexural capacities, but were within 3 percent. The girders that did not meet the predicted moment capacities had noncompact lateral brace lengths; and many had compact compression flanges. The girders which were found to be the most underestimated by $3^{\text {rd }}$ edition equations had slender brace lengths. These girders exceeded capacity by an average of 18 percent (Barth et al. 2007).

The average flexural capacity ratio, determined with the $2^{\text {nd }}$ edition capacity equations, was $0.71 ; 17$ percent lower than the average computed using the $3^{\text {rd }}$ edition equations. The maximum and minimum reported ratios were 0.99 and 0.37 , respectively. Under some circumstances, the $2^{\text {nd }}$ edition equations were found to drastically underestimate bending capacity. A large percentage of underestimated girders had noncompact compression flanges and compact or noncompact lateral bracing lengths. The average bending capacity ratio for girders meeting this criterion was $0.46 ; 54$ percent lower than predicted by AASHTO (Barth et al. 2007).

\subsection{Summary and Conclusions}

The $4^{\text {th }}$ edition of the AASHTO specifications limits the negative bending moment capacities of HPS 100W I-girders to their yield moments instead of their plastic moments. The negative bending moment capacity equations of the $3^{\text {rd }}$ edition were 
unchanged in the $4^{\text {th }}$ edition; therefore, any conclusions made from the $3^{\text {rd }}$ edition may be applied to the current specifications.

The moment capacities resulting from the FEA of each girder met or exceeded the capacities predicted with the equations provided in the $3^{\text {rd }}$ edition of the AASHTO specifications. In most cases, the $3^{\text {rd }}$ edition flexural capacities were found to be accurate, yet conservative assessments of the FEA flexural capacities; thus, the limit placed on the yield strength of HPS $100 \mathrm{~W}$ can safely removed in the $4^{\text {th }}$ edition of the AASHTO specifications (Barth et al. 2007). 


\section{Chapter 5 - Culloden Bridge Design Assessment}

\subsection{Geometry and Section Properties}

The span configurations and structural layout of the Culloden Bridge are outlined below in the subsequent sections. They were obtained from the as-built plans provided by the West Virginia Department of Highways in Charleston, West Virginia.

\subsubsection{Span Configuration}

The Culloden Bridge consists of three continuous spans (54 ft., $80 \mathrm{ft} ., 54 \mathrm{ft}$.) with integral abutments and elastomeric bearing pads at interior supports. There were several site constrictions related to the bridge's proximity to the railroad, and governed by CSX, that affected the layout of the bridge. Two requirements were wall piers and a minimum vertical clearance of $23 \mathrm{ft}$. between the top of the railroad tracks and the bottom of the girders in the middle span. Wall piers were chosen because CSX requires pier locations that fall within $25 \mathrm{ft}$. of track centerlines to be designed and reinforced against collision. This can be accomplished by either independently constructing crash walls around piers or by designing piers that meet CSX heavy construction standards. In the case of the Culloden Bridge, $3 \mathrm{ft}$. thick and $54 \mathrm{ft}$. long wall piers were selected to resist collision forces. 


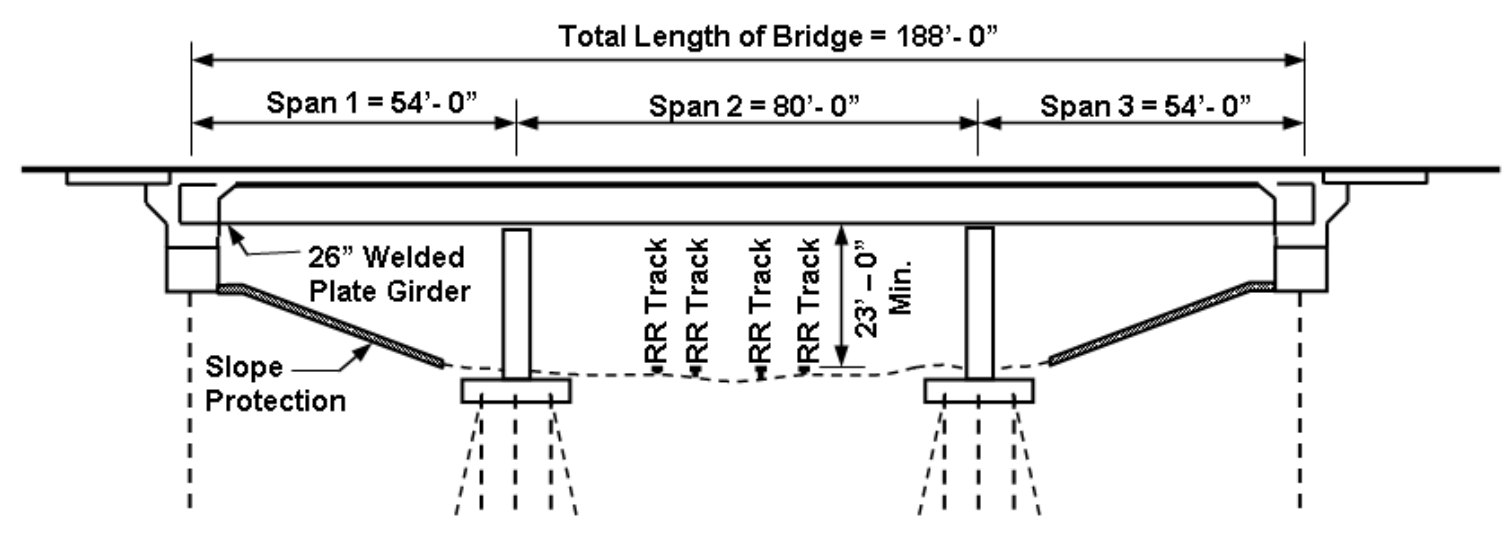

Figure 5.1 Culloden Bridge Span Configuration

\subsubsection{Typical Cross Section}

A typical cross section of the Culloden Bridge is shown below. There are two 12$\mathrm{ft}$. traffic lanes and two shoulders measuring $8 \mathrm{ft}$. and $15 \mathrm{ft}-11 \mathrm{in}$. The north and south overhangs of the bridge incorporate continuous barriers and railings. The northern overhang also supports an additional 8 in. by $5 \mathrm{ft}$. sidewalk. The total deck thickness is 8 in. and includes a $1 / 4$ in. integral wearing surface and overhangs of $3.5 \mathrm{ft}$. The girders are spaced at $8 \mathrm{ft}$. intervals and the total clear roadway width is $47 \mathrm{ft}$. $-11 \mathrm{in}$. This clear roadway width will conservatively be rounded up to $48 \mathrm{ft}$.; therefore, all subsequent calculations are based upon 4 design lanes of traffic. 


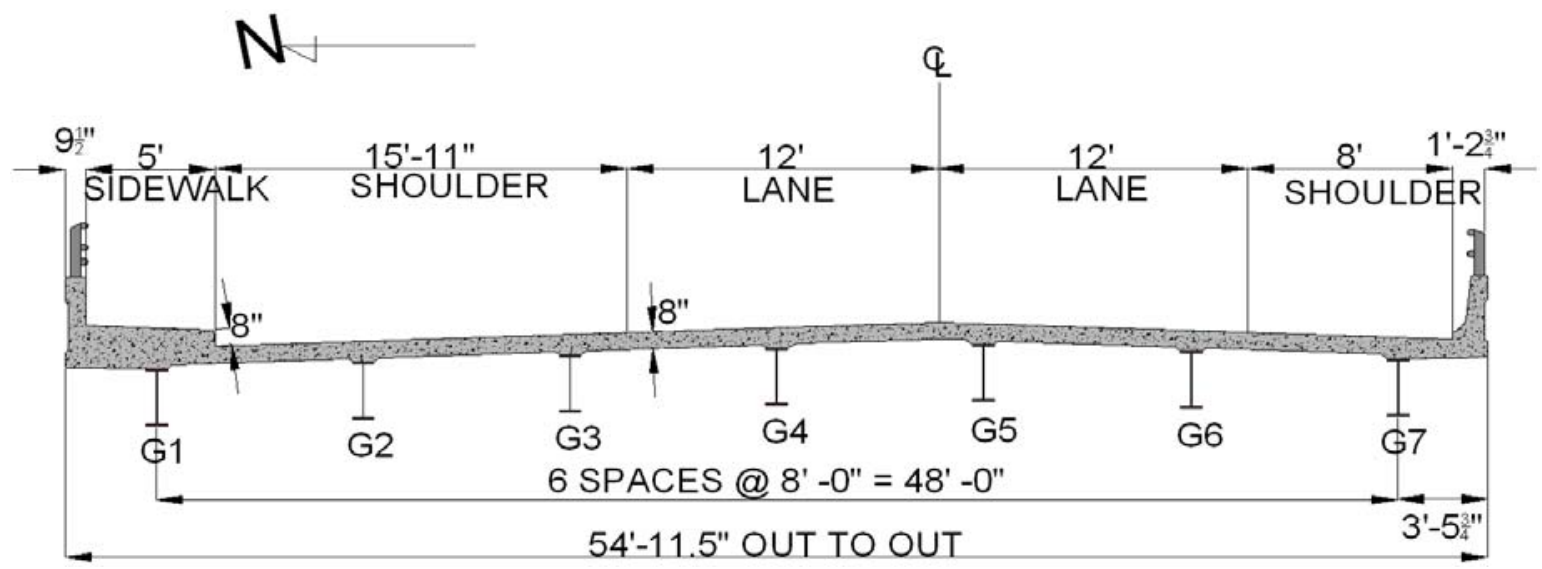

Figure 5.2 Typical Cross Section of the Culloden Bridge

\subsubsection{Framing Plan}

The framing plan, shown in Figure 5.3 and Figure 5.4, illustrates the locations of the intermediate and pier diaphragms. The plan is not symmetric about the bridge longitudinal centerline; therefore, the framing plan is illustrated below by cutting the bridge at the longitudinal centerline.

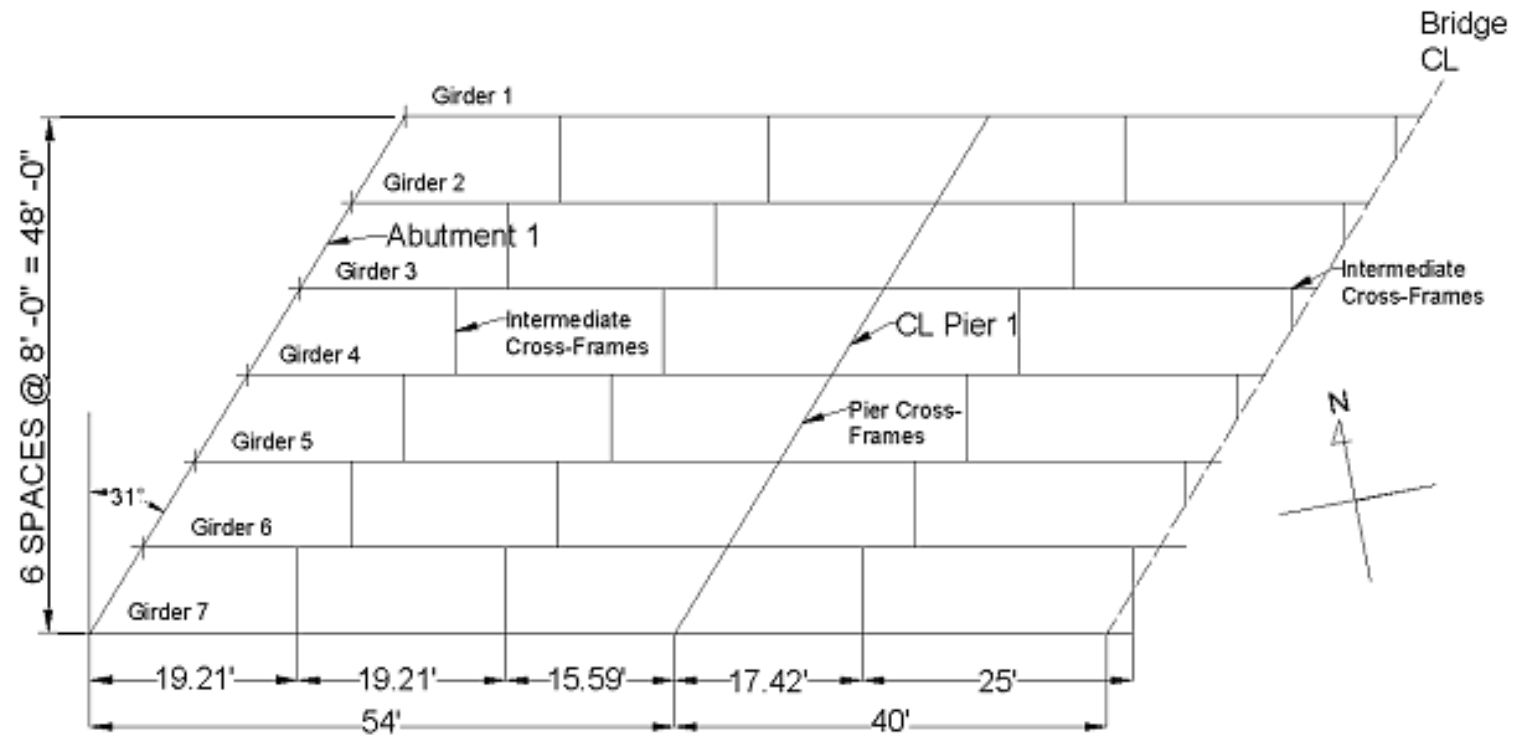

Figure 5.3 Framing Plan for Span 1 \& 2 


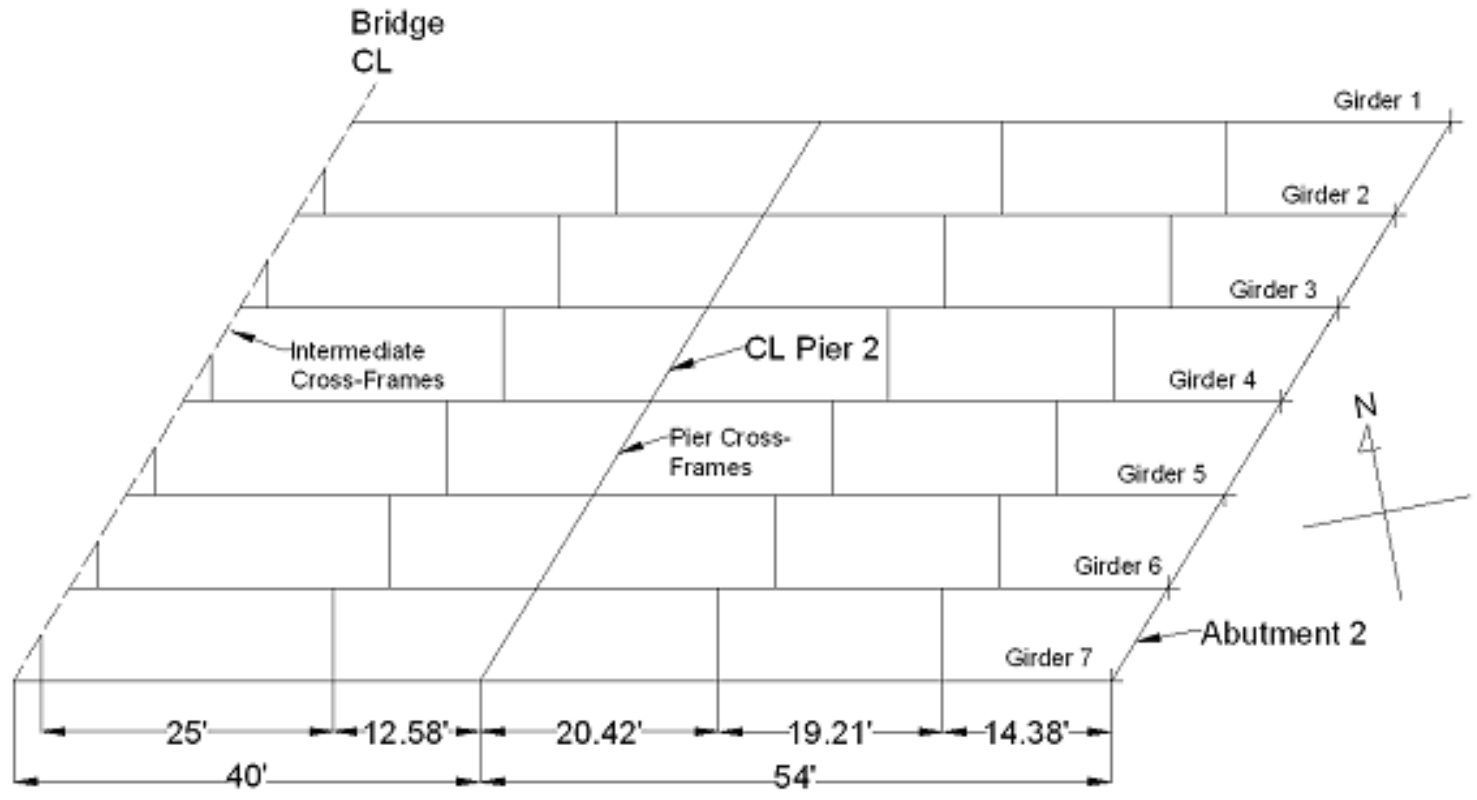

Figure 5.4 Framing Plan for Span $2 \& 3$

\subsubsection{Girder Details}

Three girder section sizes were used to resist bending stresses at critical positive and negative bending regions of the bridge. The first cross section is located in the positive bending regions of the first and third spans. The second cross section is located in the negative bending regions over the piers. The third cross section is in the positive bending region of the second span. This section is spliced to the second cross section with gusset plates and high strength bolts. The flange and web geometries of the exterior and interior girders, as well as their respective yield strengths, are shown below in Figure 5.5 and Figure 5.6. Each girder is proportioned symmetrically about the longitudinal centerline of the bridge; thus, only half of each girder is illustrated below. 


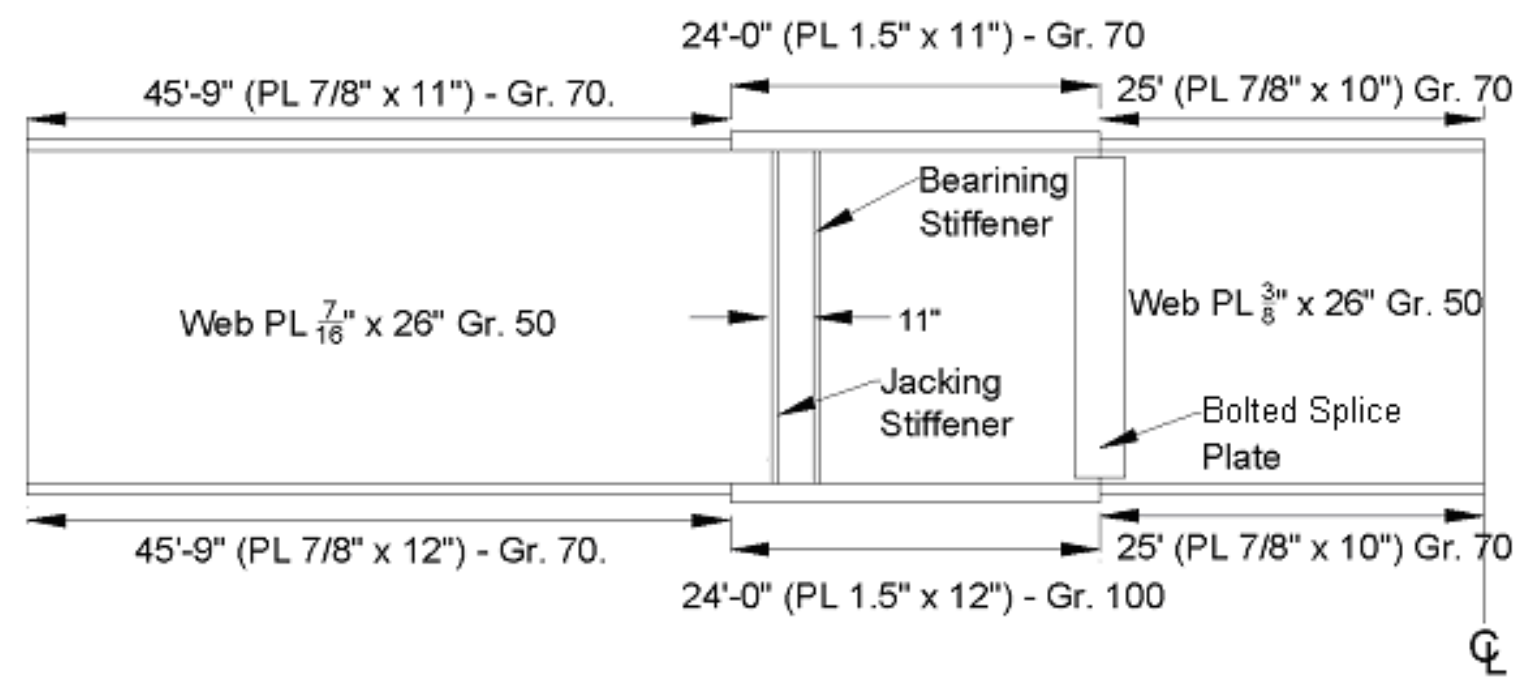

Figure 5.5 I-Girder Section Sizes for Exterior Girders

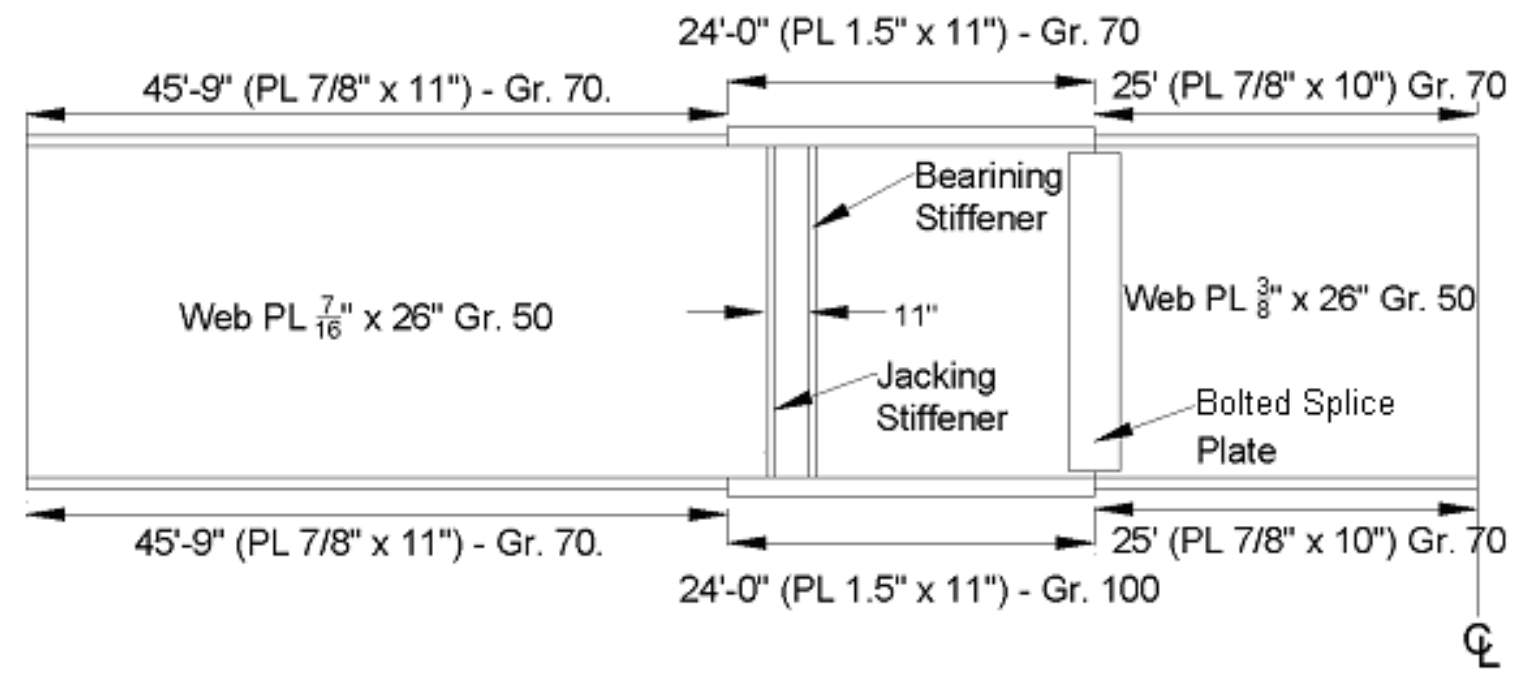

Figure 5.6 I-Girder Section Sizes for Interior Girders

\subsection{Cross Section Proportions}

The AASHTO specifications limit several I-girder proportions based on fabrication, construction, and design experience. The girder proportions of the Culloden Bridge were checked against the AASHTO limits and are presented below. 


\subsubsection{Span to Depth Ratio}

Span-to-depth ratios are optional in the current AASHTO specifications;

therefore, it is generally up to the owner of the bridge to invoke the criterion of Article 2.5.2.6.3. The Culloden Bridge is a three-span continuous bridge; therefore, the minimum suggested girder depth is $0.027 \mathrm{~L}$.

$$
\begin{array}{ll}
\text { Span 1: } 0.027 \times 54 f t=1.458 f t=17.5 \mathrm{in} & \text { Eq. } \mathbf{5 . 1} \\
\text { Span 2: } 0.027 \times 80 f t=2.16 f t=25.9 \mathrm{in} & \text { Eq. } \mathbf{5 . 2}
\end{array}
$$

The Culloden Bridge has a minimum I-girder depth of 27.75 inches; therefore, all girder cross sections meet the suggested span-to-depth ratio.

\subsubsection{Web Proportions}

The Culloden Bridge does not have longitudinal stiffeners; thus, the suggested minimum web thickness is:

$$
\begin{aligned}
& \frac{D}{t_{w}} \leq 150 \\
& \frac{27.75 \mathrm{in}}{0.375 \mathrm{in}}=74 \leq 150 \quad \therefore \text { Limit Satisfied }
\end{aligned}
$$

The Culloden Bridge satisfies the above limit; however, the National Steel Bridge Alliance (NSBA) recommends a minimum web thickness of 0.4375 in.; with 0.50 in. preferred. This thickness is recommended to ensure that web bend-buckling is not a problem at the Service limit state. 


\subsubsection{Flange Proportions}

Article 6.10.2.2 specifies that compression and tension flanges shall be proportioned such that:

$$
\begin{aligned}
& \frac{b_{f}}{2 t_{f}} \leq 12 \\
& b_{f} \geq D / 6 \\
& t_{f} \geq 1.1 t_{w} \\
& 0.1 \leq \frac{I_{y c}}{I_{y t}} \leq 10 \\
& b_{f c} \geq L / 85
\end{aligned}
$$

Eq. 5.6

Eq. 5.7

Eq. 5.8

Based on the parameters of the above equations, the most critical cross section

dimensions for each proportions check were chosen from interior or exterior girders.

$$
\begin{aligned}
& \frac{b_{f}}{2 t_{f}}=\frac{11 \text { in }}{2(0.875 \text { in })} \\
& 4.81 \text { in } \leq 12 \text { in } \quad \therefore \text { Limit Satisfied } \\
& D / 6=\frac{27.75 \text { in }}{6} \\
& 4.625 \text { in } \leq 11 \text { in } \quad \therefore \text { Limit Satisfied } \\
& \left(t_{f}\right)_{\min } \geq 1.1\left(t_{w}\right)=1.1(0.375 \text { in })=0.4125 \text { in } \\
& 0.875 \text { in } \geq 0.4125 \text { in } \quad \therefore \text { Limit Satisfied }
\end{aligned}
$$




$$
\begin{aligned}
& \frac{I_{y c}}{I_{y t}}=\frac{0.875 \mathrm{in}(11 \mathrm{in})^{3}}{0.875 \mathrm{in}(12 \mathrm{in})^{3}}=0.917 \\
& 0.1 \leq 0.917 \leq 10 \quad \therefore \text { Limit Satisfied } \\
& L / 85=\frac{(69.75 \mathrm{ft}) 12 \mathrm{in} / \mathrm{ft}}{85} \\
& 9.847 \mathrm{in} \leq 11 \mathrm{in} \quad \therefore \text { Limit Satisfied }
\end{aligned}
$$

\subsection{Loads}

The loads applicable in this design evaluation were superstructure dead loads and vehicular live loads. Water, wind, ice, earthquake, earth pressure, temperature, friction, collision, and blast loadings were not considered in this design assessment.

\subsubsection{Dead Loads}

The dead loads applied in superstructure design are denoted as $\mathrm{DC}_{1}, \mathrm{DC}_{2}$, and DW; as previously specified in Chapter $3 . \mathrm{DC}_{1}$ is determined by estimating the weights of the materials acting on the non-composite I-girders. This includes the weights of the girders, deck, haunches, overhang tapers, and a 5 percent increase in steel that accounts for miscellaneous details and diaphragms. The unit weights of steel and concrete were assumed to be $490 \mathrm{lbs} / \mathrm{ft}^{3}{ }^{3}$ and $150 \mathrm{lbs} / \mathrm{ft}^{3}{ }^{3}$. The stay-in-place (SIP) forms were also assumed to be $15 \mathrm{lbs} / \mathrm{ft}^{2}$. 


\section{Table 5.1 Exterior Girder DC 1 Loads}

\begin{tabular}{|c|c|c|}
\hline & & $\begin{array}{c}\text { ist. Load } \\
(\mathrm{kip} / \mathrm{ft})\end{array}$ \\
\hline Concrete Deck (inlcuding WWS) & $(8 \mathrm{in} / 12) \times 7.5 \mathrm{ft} \times 0.15 \mathrm{kips} / \mathrm{cf}=$ & 0.750 \\
\hline Concrete Haunch Section I & $(11 \mathrm{in} / 12) \times(2 \mathrm{in} / 12) \times 0.15 \mathrm{kips} / \mathrm{cf}=$ & 0.023 \\
\hline Concrete Haunch Section II & $(11 \mathrm{in} / 12) \times(2 \mathrm{in} / 12) \times 0.15 \mathrm{kips} / \mathrm{cf}=$ & 0.023 \\
\hline Concrete Haunch Section III & $(10 \mathrm{in} / 12) \times(2 \mathrm{in} / 12) \times 0.15 \mathrm{kips} / \mathrm{cf}=$ & 0.021 \\
\hline Concrete Overhang Taper I & $1 / 2 \times(3.5 \mathrm{ft}-(5.5 \mathrm{in} / 12)) \times(2 \mathrm{in} / 12) \times 0.15 \mathrm{kips} / \mathrm{cf}=$ & 0.038 \\
\hline Concrete Overhang Taper II & $1 / 2 \times(3.5 \mathrm{ft}-(5.5 \mathrm{in} / 12)) \times(2 \mathrm{in} / 12) \times 0.15 \mathrm{kips} / \mathrm{cf}=$ & 0.038 \\
\hline Concrete Overhang Taper III & $1 / 2 \times(3.5 \mathrm{ft}-(5 \mathrm{in} / 12)) \times(2 \mathrm{in} / 12) \times 0.15 \mathrm{kips} / \mathrm{cf}=$ & 0.039 \\
\hline Steel Girder Section I & $(31.5 \mathrm{in} 2 / 144) \times 0.49 \mathrm{kips} / \mathrm{cf}=$ & 0.107 \\
\hline Steel Girder Section II & $(45.875 \mathrm{in} 2 / 144) \times 0.49 \mathrm{kips} / \mathrm{cf}=$ & 0.156 \\
\hline Steel Girder Section III & $(27.25 \mathrm{in} 2 / 144) \times 0.49 \mathrm{kips} / \mathrm{cf}=$ & 0.093 \\
\hline $5 \%$ Misc. Steel Section I & $5 \% \times(31.5 \mathrm{in} 2 / 144) \times 0.49 \mathrm{kips} / \mathrm{cf}=$ & 0.005 \\
\hline $5 \%$ Misc. Steel Section II & $5 \% \times(45.875 \mathrm{in} 2 / 144) \times 0.49 \mathrm{kips} / \mathrm{cf}=$ & 0.008 \\
\hline $5 \%$ Misc. Steel Section III & $5 \% \times(27.25 \mathrm{in} 2 / 144) \times 0.49 \mathrm{kips} / \mathrm{cf}=$ & 0.005 \\
\hline Stay in Place Forms Section I & $6.58 \mathrm{ft} \times 0.015 \mathrm{kips} / \mathrm{sf}=$ & 0.099 \\
\hline Stay in Place Forms Section II & $6.58 \mathrm{ft} \times 0.015 \mathrm{kips} / \mathrm{sf}=$ & 0.099 \\
\hline Stay in Place Forms Section III & $6.67 \mathrm{ft} \times 0.015 \mathrm{kips} / \mathrm{sf}=$ & 0.100 \\
\hline \multirow[t]{3}{*}{ 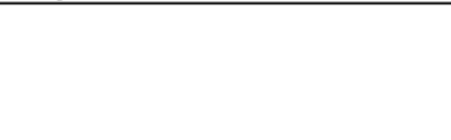 } & \multirow{2}{*}{\begin{tabular}{c|c} 
Total Section I= & Total Section II = \\
\cline { 2 - 3 } & Tot
\end{tabular}} & 1.022 \\
\hline & & 1.074 \\
\hline & Total Section III = & 1.007 \\
\hline
\end{tabular}

\section{Table 5.2 Interior Girder $\mathrm{DC}_{1}$ Loads}

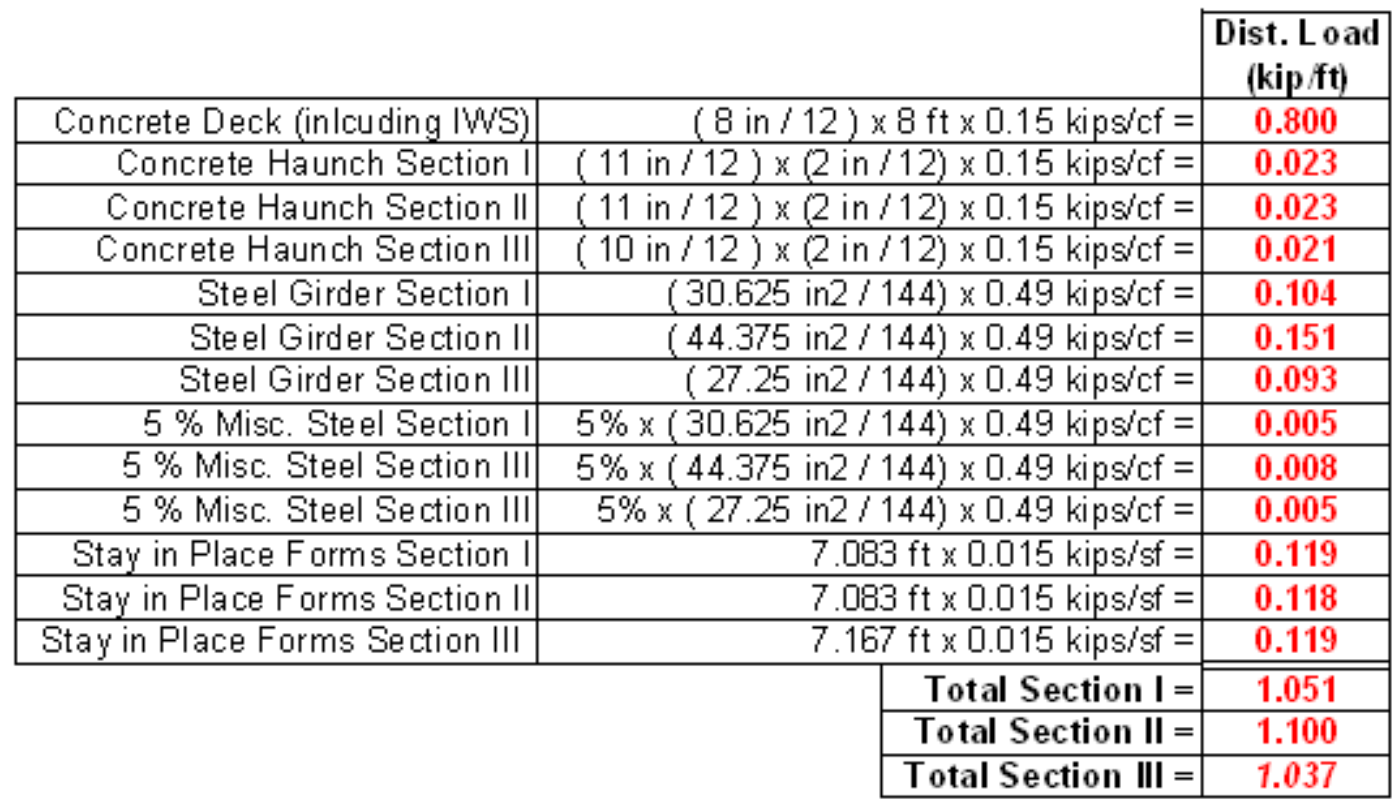

The $\mathrm{DC}_{2}$ loads act on the long-term composite section in which it is assumed that

the concrete has hardened and acts compositely with the girders. The $\mathrm{DC}_{2}$ loads include 
the weights of curbs, barriers, sidewalks, and railings. The total $\mathrm{DC}_{2}$ load is assumed to be evenly distributed to all girders, and for the Culloden Bridge, is comprised of a sidewalk and two-Type F Barriers with a unit weight of $305 \mathrm{lbs} / \mathrm{ft}$. The Culloden Bridge also incorporates continuous railings; however, their weights were considered to be negligible for this design assessment.

Table 5.3 $\mathrm{DC}_{2}$ Loads

\begin{tabular}{|r|r|c|}
\cline { 3 - 3 } \multicolumn{2}{l|}{} & $\begin{array}{c}\text { Dist. Load } \\
\text { (kip/ft) }\end{array}$ \\
\hline Concrete Sidewalk & $2 \times 0.305 \mathrm{kips} / \mathrm{ft}=$ & 0.610 \\
\hline & Total DC $\mathrm{C}_{2}$ Per Girder $=$ & 0.1590 \\
\hline
\end{tabular}

The DW loads include the weights of the future wearing surfaces (FWS) and the utilities acting on the long-term composite section. The FWS was assumed to be 25 $\mathrm{lbs} / \mathrm{ft}^{2}$ and was equally distributed to all girders.

Table 5.4 DW Loads

\begin{tabular}{|l|c|c|}
\multicolumn{2}{l|}{} & $\begin{array}{c}\text { Dist. Load } \\
\text { (kip } f \mathbf{f t})\end{array}$ \\
\hline Wearing Surface & $48 \mathrm{ft} \times 0.025 \mathrm{kips} / \mathrm{sf}=$ & 1.200 \\
\hline Total DW Per Girder $=$ & 0.171 \\
\hline
\end{tabular}

\subsubsection{Live Loads}

The AASHTO specified live loads were applied to the short-term composite sections using the analysis program CONSYS ${ }^{\mathrm{TM}}$ to produce influence lines and develop force envelopes. The CONSYS load library conveniently contains all of the current AASHTO design loads that may be applied individually, or in combinations specified by 
limit state. The following loads were applied to develop live load force envelopes:

- HS20-44 truck

- lane load

- tandem

- double truck

- double tandem

- special negative bending load combinations

- live load deflection combination

o design truck plus impact, or

o 25 percent of the design truck plus impact taken together with the design lane load.

\subsection{Structural Analysis}

Approximate analysis methods, described in Section 4 of the AASHTO specifications, were utilized in the design evaluation of the Culloden Bridge. A linegirder analysis was performed by applying lateral live load distribution factors to produce shear, moment, and deflection envelopes.

\subsubsection{Live Load Distribution Factors}

To determine the interior girder distribution factors using the approximate AASHTO equations, the longitudinal stiffness parameter $\left(K_{g}\right)$ was determined for each section. 


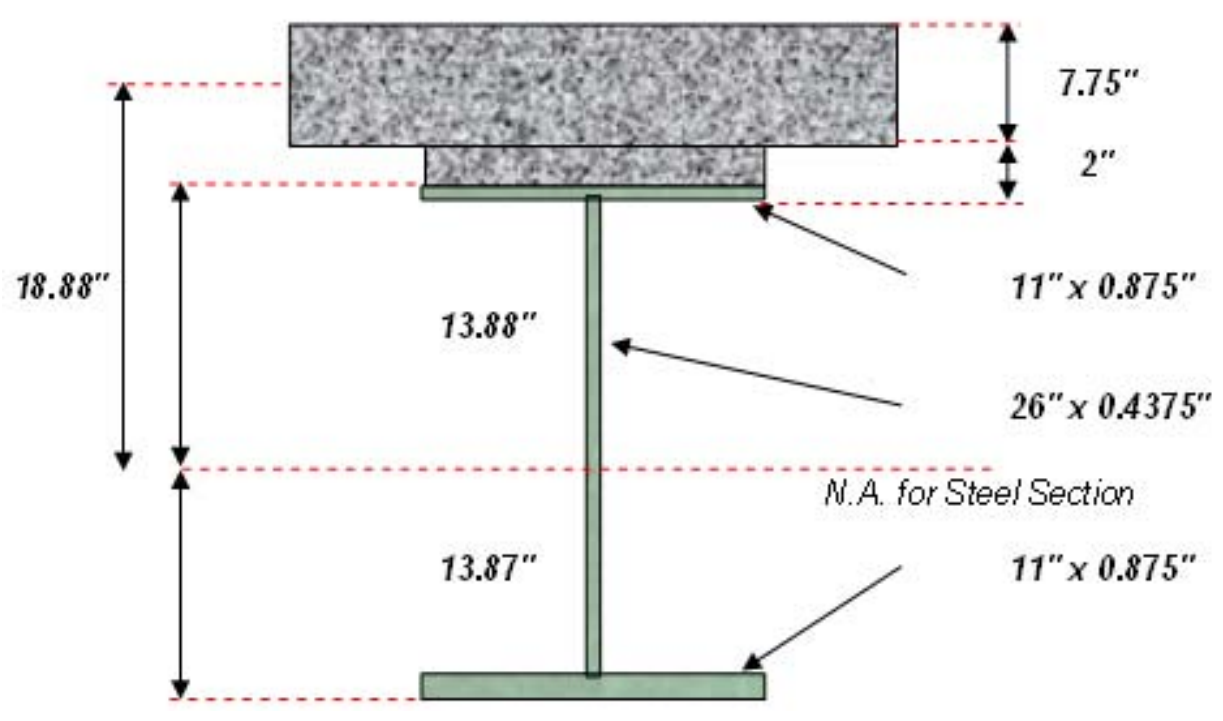

Figure 5.7 Interior Girder - Section I

Table 5.5 Moment of Inertia of Steel Section I

\begin{tabular}{|r|c|c|c|c|c|c|}
\cline { 2 - 7 } \multicolumn{1}{c|}{} & A & d & Ad & Ad $^{2}$ & $\mathbf{I}_{0}$ & I \\
\hline Top Flange: 11" $\times 0.875 "$ & 9.6 & 27.3 & 262.9 & 7180.0 & 0.6 & 7180.6 \\
\hline Web: 26" $\times 0.4375 "$ & 11.4 & 13.9 & 157.8 & 2189.9 & 640.8 & 2830.7 \\
\hline Bottom Flange: 11" $\times 0.875 "$ & 9.6 & 0.4 & 4.2 & 1.8 & 0.6 & 2.5 \\
\hline Sum: & 30.6 & Sum: & 424.9 & \multicolumn{3}{c}{$10013.7 \mathrm{in}^{4}$}
\end{tabular}

The moment of inertia above was calculated with $d$ measured from a datum point taken from the bottom of the bottom flange. The correct moment of inertia is found by measuring $d$ from the neutral axis of the section; therefore, the above value was adjusted for the correct neutral axis location. The distance to the neutral axis from the previous datum point was found as:

$$
\begin{aligned}
& d_{s}=\frac{\Sigma A d}{\Sigma A} \\
& d_{s}=\frac{424.9 \mathrm{in}^{2}}{30.6 \mathrm{in}}=13.9 \mathrm{in}
\end{aligned}
$$


The correct moment of inertia about the neutral axis is then found as:

$$
\begin{aligned}
& I_{N A}=I_{\text {Bot.Flange }}-\left(d_{s} \times \Sigma A d\right) \\
& I_{N A}=10,013.7 \mathrm{in}^{4}-\left(13.9 \mathrm{in} \times 424.9 \mathrm{in}^{3}\right)=4120.1 \mathrm{in}^{4}
\end{aligned}
$$

The distance between the centroid of the steel section and the centroid of the slab $\left(e_{g}\right)$ must also be determined to calculate the longitudinal stiffness.

$$
\begin{aligned}
& e_{g}=D_{\text {steel }}-d_{s}+\text { Haunch }-t_{\text {top flange }}+\frac{\text { Struc. Slab Thickness }}{2} \\
& e_{g}=[26+(2) 0.875]-13.9+2-0.875+\frac{0.75}{2}=18.9 \text { in }
\end{aligned}
$$

The longitudinal stiffness is then found as:

$$
\begin{aligned}
& K_{g}=n\left(I+A e_{g}{ }^{2}\right) \\
& K_{g}=8\left(4120.1+(30.6)(18.9)^{2}\right)=120,291 \mathrm{in}^{4}
\end{aligned}
$$

The longitudinal stiffness values of the other sections were also determined and are tabulated below in Table 5.6.

Table 5.6 Longitudinal Stiffness of Interior Girder Sections

\begin{tabular}{|c|c|}
\cline { 2 - 2 } \multicolumn{1}{c|}{} & $\begin{array}{c}\mathrm{Kg} \\
\left(\mathrm{in}^{4}\right)\end{array}$ \\
\hline Section I & 120,292 \\
\hline Section II & 181,562 \\
\hline Section III & 107,405 \\
\hline
\end{tabular}

\subsubsection{Interior Girders}

As previously mentioned in Chapter 3 , multiple presence factors were taken into account when the approximate distribution factor equations were derived; therefore, they 
need not be applied again. In addition, the equations for moment and shear are different and also change for one lane loaded, and two or more lanes loaded. The approximate moment distribution factors vary with each section change; however, the shear distribution factors remain constant throughout all spans, thus, will only be calculated once.

\subsection{Section I}

The moment and shear distribution factors for section I of an interior girder are as follows:

Bending Moment (Table 4.6.2.2.2b-1):

One lane loaded:

$$
\begin{aligned}
& D F=0.06+\left(\frac{S}{14}\right)^{0.4}\left(\frac{S}{L}\right)^{0.3}\left(\frac{K_{g}}{12.0 L t_{s}^{3}}\right)^{0.1} \\
& D F=0.06+\left(\frac{8}{14}\right)^{0.4}\left(\frac{8}{854}\right)^{0.3}\left(\frac{120,292}{12.0(54)(7.75)^{3}}\right)^{0.1}=0.471 \text { lanes }
\end{aligned}
$$

Two or more lanes loaded:

$$
\begin{aligned}
& D F=0.075+\left(\frac{S}{9.5}\right)^{0.6}\left(\frac{S}{L}\right)^{0.2}\left(\frac{K_{g}}{12.0 L t_{s}^{3}}\right)^{0.1} \\
& D F=0.075+\left(\frac{8}{9.5}\right)^{0.6}\left(\frac{8}{54}\right)^{0.2}\left(\frac{120,292}{12.0(54)(7.75)^{3}}\right)^{0.1}=0.637 \text { lanes }
\end{aligned}
$$

Shear (Table 4.6.2.2.3a-1):

One lane loaded:

$$
\begin{aligned}
& D F=0.36+\frac{S}{25.0} \\
& D F=0.36+\frac{8}{25.0}=0.680 \text { lanes }
\end{aligned}
$$


Two or more lanes loaded:

$$
D F=0.20+\frac{S}{12.0}-\left(\frac{S}{35}\right)^{2.0}
$$

$$
D F=0.20+\frac{8}{12.0}-\left(\frac{8}{35}\right)^{2.0}=0.814 \text { lanes }
$$

\subsection{Section II}

The moment distribution factors for Section II of an interior girder are as follows:

One lane loaded:

$$
\begin{aligned}
& D F=0.06+\left(\frac{S}{14}\right)^{0.4}\left(\frac{S}{L}\right)^{0.3}\left(\frac{K_{g}}{12.0 L t_{s}^{3}}\right)^{0.1} \\
& D F=0.06+\left(\frac{8}{14}\right)^{0.4}\left(\frac{8}{854}\right)^{0.3}\left(\frac{181,562}{12.0(54)(7.75)^{3}}\right)^{0.1}=0.453 \text { lanes }
\end{aligned}
$$

Two or more lanes loaded:

$$
\begin{aligned}
& D F=0.075+\left(\frac{S}{9.5}\right)^{0.6}\left(\frac{S}{L}\right)^{0.2}\left(\frac{K_{g}}{12.0 L t_{s}^{3}}\right)^{0.1} \\
& D F=0.075+\left(\frac{8}{9.5}\right)^{0.6}\left(\frac{8}{54}\right)^{0.2}\left(\frac{181,562}{12.0(54)(7.75)^{3}}\right)^{0.1}=0.624 \text { lanes }
\end{aligned}
$$

\subsection{Section III}

The moment distribution factors for Section III are as follows:

One lane loaded:

$$
\begin{aligned}
& D F=0.06+\left(\frac{S}{14}\right)^{0.4}\left(\frac{S}{L}\right)^{0.3}\left(\frac{K_{g}}{12.0 L t_{s}^{3}}\right)^{0.1} \\
& D F=0.06+\left(\frac{8}{14}\right)^{0.4}\left(\frac{8}{854}\right)^{0.3}\left(\frac{107,405}{12.0(54)(7.75)^{3}}\right)^{0.1}=0.407 \text { lanes }
\end{aligned}
$$




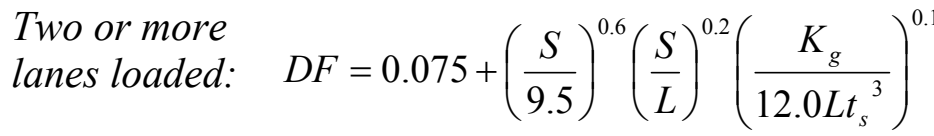

Eq. 5.20

$$
D F=0.075+\left(\frac{8}{9.5}\right)^{0.6}\left(\frac{8}{54}\right)^{0.2}\left(\frac{107,405}{12.0(54)(7.75)^{3}}\right)^{0.1}=0.569 \text { lanes }
$$

\subsubsection{Exterior Girders}

The approximate distribution factor equations utilized above are only applicable for interior girders. AASHTO specifies three different methods for approximating the distribution factors for exterior girders. These methods are detailed below in the subsequent sections.

\subsection{Lever-Rule}

For one lane loaded, Tables 4.6.2.2.2d-1 and 4.6.2.2.3b-1 of the AASHTO specifications state that the distribution factors for moment and shear are to be found using the Lever Rule. The exterior girder reaction, due to a pair of 1-kip unit loads illustrated below, was found to be 0.66 by summing the moments about the adjacent interior girder. The one-lane-loaded multiple presence factor $(m=1.2)$ and the exterior girder reaction were then multiplied together to arrive at a distribution factor of 0.791 lanes. 


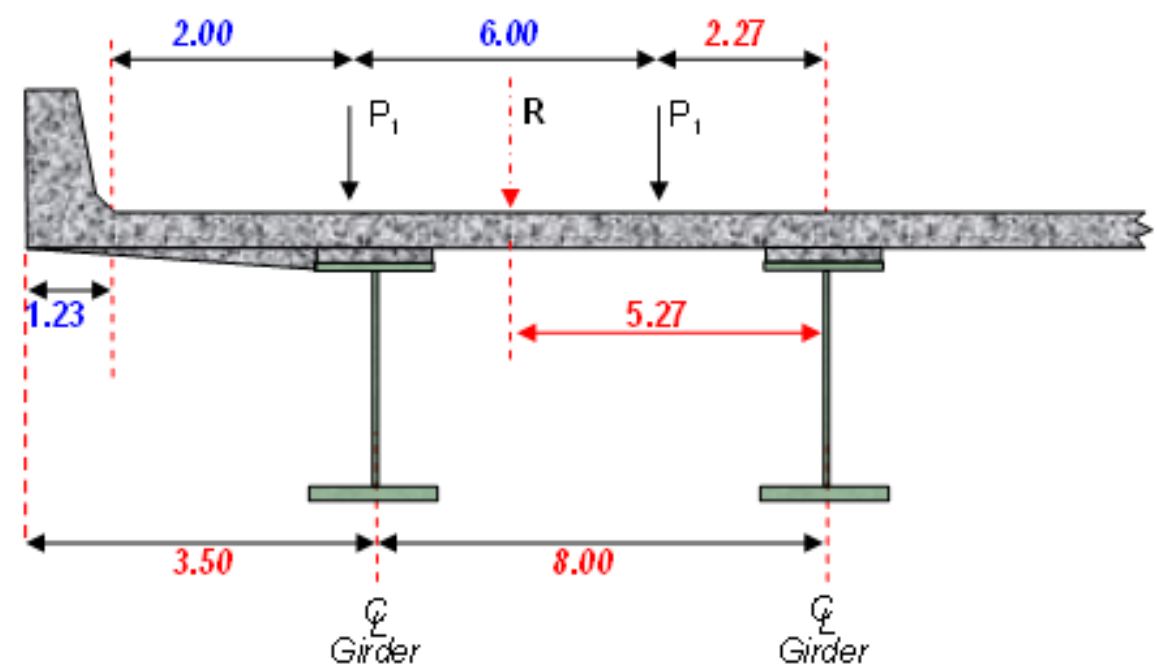

Figure 5.8 Lever-Rule Analysis

\subsection{Lane-Fraction Modification Factor}

When two or more lanes are loaded, an approximate distribution factor for an exterior girder may be found by multiplying the interior girder distribution factor by a modification factor $(e)$. The approximate unmodified distribution factors for an interior girder are listed in the tables below.

Table 5.7 Unmodified Moment Distribution Factors

\begin{tabular}{|c|c|c|}
\hline \multirow{2}{*}{ Section I } & 0.471 & one lane loaded \\
\cline { 2 - 3 } & 0.637 & two lanes loaded \\
\hline \multirow{2}{*}{ Section II } & 0.453 & one lane loaded \\
\cline { 2 - 3 } & 0.624 & two lanes loaded \\
\hline \multirow{2}{*}{ Section III } & 0.407 & one lane loaded \\
\cline { 2 - 3 } & 0.569 & two lanes loaded \\
\hline
\end{tabular}

Table 5.8 Unmodified Shear Distribution Factors

\begin{tabular}{|l|l|l|}
\hline \multirow{2}{*}{ Sections I, II, \& III } & 0.680 & one lane loaded \\
\cline { 2 - 3 } & 0.814 & two lanes loaded \\
\hline
\end{tabular}


The modification factors are a function of the distance between the web of the exterior girder and the edge of the curb or barrier $\left(d_{e}\right)$. The moment and shear modification factors are applied to the unmodified interior girder distribution factors and found below.

Bending Moment (Table 4.6.2.2.2d-1):

$\begin{aligned} & \text { Two or more } \\ & \text { lanes loaded: }\end{aligned} \quad e=0.77+\frac{d_{e}}{9.1}$

$$
e=0.77+\frac{2.27}{9.1}=1.019
$$

\section{Table 5.9 Modified Moment Distribution Factors}

\begin{tabular}{|c|c|c|}
\hline Section I & 0.649 & two lanes loaded \\
\hline Section II & 0.636 & two lanes loaded \\
\hline Section III & 0.580 & two lanes loaded \\
\hline
\end{tabular}

Shear (Table 4.6.2.2.3b-1):

Two or more

lanes loaded:

$$
\begin{aligned}
& e=0.6+\frac{d_{e}}{10} \\
& e=0.6+\frac{2.27}{10}=0.827
\end{aligned}
$$

Table 5.10 Modified Shear Distribution Factors

\begin{tabular}{|c|c|c|}
\hline Section I & 0.562 & two lanes loaded \\
\hline Section II & 0.674 & two lanes loaded \\
\hline Section III & 0.674 & two lanes loaded \\
\hline
\end{tabular}




\subsection{Special Analysis}

The distribution factors obtained from the approximate equations do not account for cross-frame contributions; therefore, Commentary C4.6.2.2.2d specifies a special analysis procedure that assumes the entire deck of the bridge rotates as a rigid body about the transverse centerline of the girder system. The reactions found by this method must also be multiplied by the appropriate multiple presence factors to calculate the exterior girder distribution factors shown in Table 5.11.

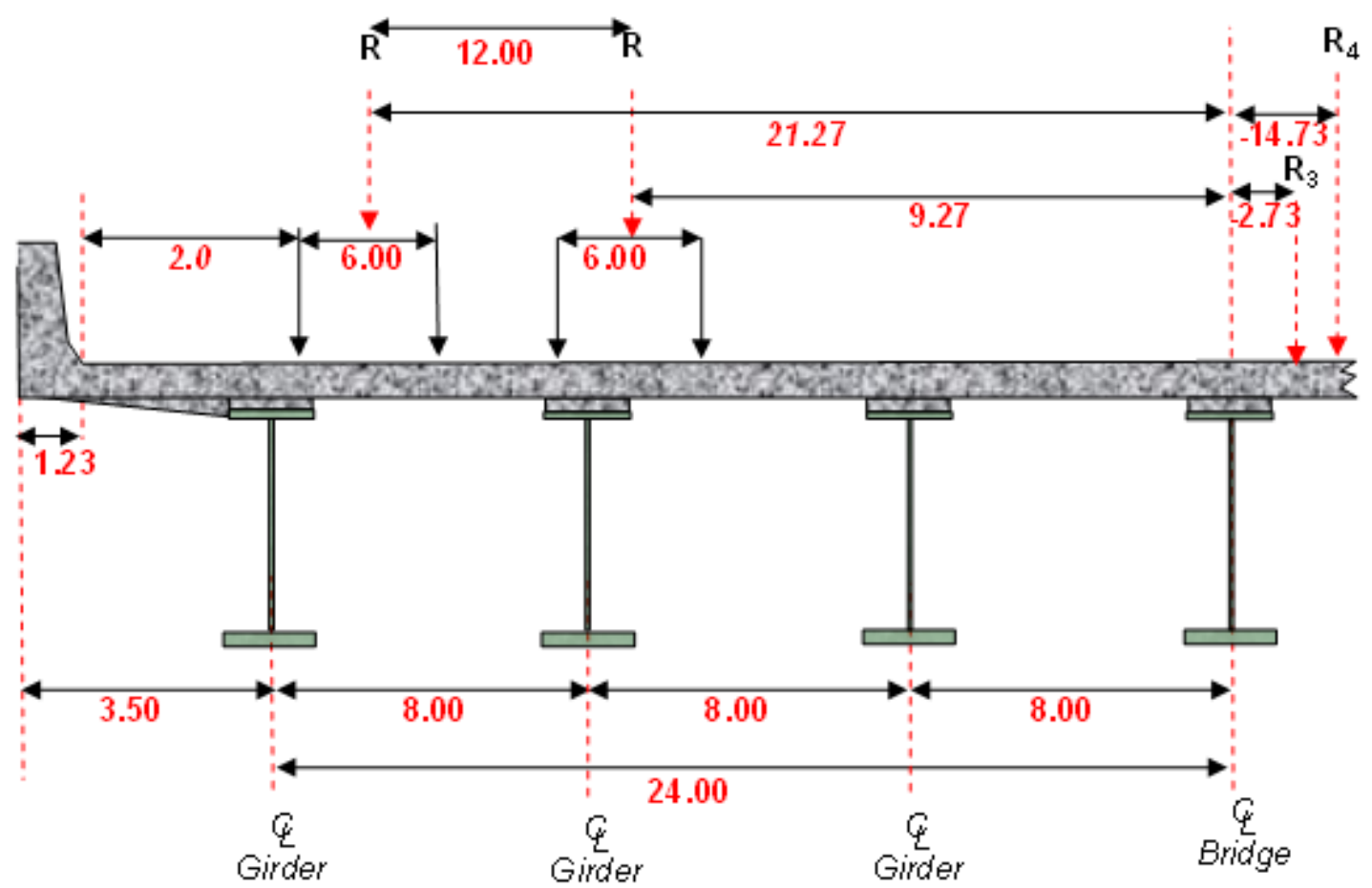

Figure 5.9 Special Analysis Truck Placements 
Reaction

Equation:

$$
R=\frac{N_{L}}{N_{b}}+\frac{X_{e x t} \sum^{N_{L}} e}{\sum x^{2}}
$$

One lane

loaded:

$$
R_{1}=\frac{1}{7}+\frac{24 \times \Sigma(21.7)}{2 \times\left(8^{2}+16^{2}+24^{2}\right)}=0.428
$$

Two lanes

loaded:

$$
R_{2}=\frac{2}{7}+\frac{24 \times(21.7+9.27)}{2 \times\left(8^{2}+16^{2}+24^{2}\right)}=0.695
$$

Three lanes

loaded:

$$
R_{3}=\frac{3}{7}+\frac{24 \times(21.7+9.27-2.73)}{2 \times \Sigma\left(8^{2}+16^{2}+24^{2}\right)}=0.801
$$

Four lanes

loaded:

$$
R_{4}=\frac{4}{7}+\frac{24 \times \Sigma(21.7+9.27-2.73-14.73)}{2 \times \Sigma\left(8^{2}+16^{2}+24^{2}\right)}=0.747
$$

\section{Table 5.11 Special Analysis Distribution Factors}

\begin{tabular}{|l|l|l|}
\hline \multirow{4}{*}{ Sections I, II, \& III } & 0.513 & One lane loaded \\
\cline { 2 - 3 } & 0.695 & Two lanes loaded \\
\cline { 2 - 3 } & 0.681 & Three lanes loaded \\
\cline { 2 - 3 } & 0.485 & Four lanes loaded \\
\hline
\end{tabular}

\subsubsection{Fatigue Distribution Factors}

The fatigue load consists of 75 percent of a single HS20-44 design truck; therefore, all distribution factors must be converted to a single-lane-loaded distribution factor as specified in Article 3.6.1.4.3b. Distribution factors obtained from the approximate equations, Lever Rule, and special analysis are divided by the appropriate multiple presence factor to obtain the fatigue distribution factors for one lane loaded.

\section{Table 5.12 Interior Girder Fatigue Moment Distribution Factors}

\begin{tabular}{|c|c|c|}
\hline Sections I & 0.393 & one lane loaded \\
\hline Sections II & 0.378 & one lane loaded \\
\hline Sections III & 0.340 & one lane loaded \\
\hline
\end{tabular}




\section{Table 5.13 Interior Girder Fatigue Shear Distribution Factors}

\begin{tabular}{|l|l|l|}
\hline Sections I, II, \& III & 0.567 & one lane loaded \\
\hline
\end{tabular}

\section{Table 5.14 Exterior Girder Fatigue Moment Distribution Factors}

\begin{tabular}{|l|l|l|}
\hline \multirow{2}{*}{ Sections I, II, \& III } & 0.659 & one lane loaded - lever \\
\cline { 2 - 4 } & 0.428 & one lane loaded - special \\
\hline
\end{tabular}

\section{Table 5.15 Exterior Girder Fatigue Shear Distribution Factors}

\begin{tabular}{|l|l|l|}
\hline \multirow{2}{*}{ Sections I, II, \& III } & 0.659 & one lane loaded - lever \\
\cline { 2 - 3 } & 0.428 & one lane loaded - special \\
\hline
\end{tabular}

\subsubsection{Live Load Deflection Distribution Factor}

When checking live load deflections, all design lanes are to be loaded to produce maximum deflections. Additionally, all girders are assumed to deflect equally as stated in Article 2.5.2.6.2. The live load deflection distribution factor for the Culloden Bridge is found below as:

$$
\begin{aligned}
& D F=m_{N_{L}} \frac{N_{L}}{N_{B}} \\
& D F=0.65\left(\frac{4}{7}\right)=0.371 \text { lanes }
\end{aligned}
$$

\subsubsection{Skew Correction Factors}

The moment and shear distribution factors determined above must be corrected for skew by applying adjustment factors. Skew adjustment factors are applicable for bridges with skew angles between $30^{\circ}$ and $60^{\circ}$, respectively. If the skew angle is less than $30^{\circ}$, the skew correction factor is to be taken as 1.0. If the skew angle is greater than $60^{\circ}$, the correction factor is to be calculated with a maximum skew angle of $60^{\circ}$. 


\subsection{Moment Correction Factors}

The Culloden Bridge is skewed at an angle of $31^{\circ} 00^{\prime} 10^{\prime \prime}$, which corresponds to the following skew correction factor for moment:

$$
\begin{aligned}
& c_{1}=0.25\left(\frac{K_{g}}{12 L t_{s}^{3}}\right)^{0.25}\left(\frac{S}{L}\right)^{0.5} \\
& c_{1}=0.25\left(\frac{120,292}{12(54)(7.75)^{3}}\right)^{0.25}\left(\frac{8}{54}\right)^{0.5}=0.0294 \\
& S C F=1-c_{1} \tan (\theta)^{1.5} \\
& S C F=1-0.0294 \tan \left(31^{\circ} 10^{\prime \prime}\right)^{1.5}=0.986
\end{aligned}
$$

The skew correction factors for moment are presented for interior and exterior girders in the tables below. In this case, the factors are dependent upon the longitudinal stiffness parameter $K_{g}$.

Table 5.16 Interior Girder Skew Correction Factors for Moment

\begin{tabular}{|l|c|c|}
\cline { 2 - 3 } \multicolumn{1}{c|}{} & $\mathrm{c}_{1}$ & Moment \\
\hline Section I & 0.029 & 0.986 \\
\hline Section II & 0.025 & 0.988 \\
\hline Section III & 0.018 & 0.992 \\
\hline
\end{tabular}

Table 5.17 Exterior Girder Skew Correction Factors for Moment

\begin{tabular}{|l|c|c|}
\cline { 2 - 3 } \multicolumn{1}{c|}{} & $\mathrm{c}_{1}$ & Moment \\
\hline Section I & 0.030 & 0.986 \\
\hline Section II & 0.025 & 0.988 \\
\hline Section III & 0.018 & 0.992 \\
\hline
\end{tabular}




\subsection{Shear Correction Factors}

The shear distribution factors calculated above are also multiplied by the skew correction factor presented in Table 4.6.2.2.3c-1 of the AASHTO specifications. The correction factor for Section I of an interior girder is as follows:

$$
\begin{aligned}
& S C F=1+0.20\left(\frac{12 L t_{s}^{3}}{K_{g}}\right)^{0.3} \tan (\theta) \\
& S C F=1+0.20\left(\frac{12(54)(7.75)^{3}}{120,292}\right)^{0.3} \tan \left(31^{\circ} 10^{\prime \prime}\right)=1.158
\end{aligned}
$$

The skew correction factor for shear increases the distribution factors for all sections of the Culloden Bridge. The corrected distribution factors for interior and exterior girders are presented in the tables below.

Table 5.18 Interior Girder Skew Correction Factors for Shear

\begin{tabular}{|l|c|c|}
\cline { 2 - 3 } \multicolumn{1}{c|}{} & $c_{1}$ & Sh ear \\
\hline Section I & 0.029 & 1.158 \\
\hline Section II & 0.025 & 1.149 \\
\hline Section III & 0.018 & 1.178 \\
\hline
\end{tabular}

Table 5.19 Exterior Girder Skew Correction Factors for Shear

\begin{tabular}{|c|c|c|}
\cline { 2 - 3 } \multicolumn{1}{c|}{} & $c_{1}$ & Shear \\
\hline Section I & 0.030 & 1.156 \\
\hline Section II & 0.025 & 1.146 \\
\hline Section III & 0.018 & 1.175 \\
\hline
\end{tabular}

\subsubsection{Summary of Distribution Factors}

Distribution factors were calculated for all three sections of interior and exterior girders. These factors were then multiplied by the appropriate skew correction factors and are summarized in the tables below. 
Table 5.20 Interior Girder - Section I

\begin{tabular}{|l|l|}
\hline Bending Moment & 0.628 \\
\hline Shear & 0.943 \\
\hline Fatigue: Bending Moment & 0.387 \\
\hline Fatigue: Shear & 0.656 \\
\hline Deflection & 0.371 \\
\hline
\end{tabular}

Table 5.21 Interior Girder - Section II

\begin{tabular}{|l|l|}
\hline Bending Moment & 0.616 \\
\hline Shear & 0.936 \\
\hline Fatigue: Bending Moment & 0.373 \\
\hline Fatigue: Shear & 0.651 \\
\hline Deflection & 0.371 \\
\hline
\end{tabular}

Table 5.22 Interior Girder - Section III

\begin{tabular}{|l|l|}
\hline Bending Moment & 0.564 \\
\hline Shear & 0.960 \\
\hline Fatigue: Bending Moment & 0.337 \\
\hline Fatigue: She ar & 0.668 \\
\hline Deflection & 0.371 \\
\hline
\end{tabular}

Table 5.23 Exterior Girder - Section I

\begin{tabular}{|l|c|}
\hline Bending Moment & 0.780 \\
\hline Shear & 0.913 \\
\hline Fatigue: Bending Moment & 0.650 \\
\hline Fatigue: Shear & 0.761 \\
\hline Deflection & 0.371 \\
\hline
\end{tabular}

Table 5.24 Exterior Girder - Section II

\begin{tabular}{|l|c|}
\hline Bending Moment & 0.781 \\
\hline Shear & 0.906 \\
\hline Fatigue: Bending Moment & 0.651 \\
\hline Fatigue: Shear & 0.755 \\
\hline Deflection & 0.371 \\
\hline
\end{tabular}

Table 5.25 Exterior Girder - Section III

\begin{tabular}{|l|c|}
\hline Bending Moment & 0.689 \\
\hline Shear & 0.929 \\
\hline Fatigue: Bending Moment & 0.653 \\
\hline Fatigue: Shear & 0.774 \\
\hline Deflection & 0.371 \\
\hline
\end{tabular}




\subsection{Analysis Results}

When assessing design forces, composite sections are considered un-cracked in positive and negative flexure regions of the bridge. Each load, and the corresponding section it acts upon, is detailed below:

- $\mathrm{DC}_{1}$ Loads: Steel Section Only

- $\mathrm{DC}_{2}$ and DW: Long-Term Composite Section with modular ratio of 3n

- Live loads: Short-Term Composite Section with modular ratio of $n$

\subsubsection{Design Envelopes}

The design envelopes for an exterior girder illustrate the maximum moments and shears at tenth points along the bridge. The HL-93 load consists of a design tandem, or design truck with variable axle spacing, in combination with a design lane load. A special negative moment load case is also employed between points of dead load contraflexure. It consists of 90 percent of two design trucks spaced such that the lead axle of the second truck and the rear axle of the first truck are $50 \mathrm{ft}$. apart. The 32-kip axles are spaced at a constant $14 \mathrm{ft}$., and the two trucks are placed in adjacent spans. An additional 90 percent of the design lane load is also applied to this load case, but may be spaced discontinuously to maximize negative flexure. The appropriate dynamic load allowance and distribution factors were also applied to the aforementioned loads; however, the DC1, DC2, and DW moments are un-factored and un-distributed in the envelope figures below.

A second set of moment and shear envelopes were also generated for the fatigue limit state. The fatigue truck acts on the short-term composite section and is multiplied 
by a load factor of 0.75 , and dynamic load allowance of 1.15 . The appropriate distribution factors were also applied to the factored fatigue moments and shears.

The optional live load deflection limit was also checked by obtaining the maximum deflection from the following:

- a design truck plus impact, or

- $25 \%$ of the design truck plus impact, and the design lane load.

The maximum deflections were obtained by simultaneously placing loads in all design lanes and applying the corresponding multiple presence factor. The maximum deflections at each tenth-point are illustrated in Figures 5.14. 


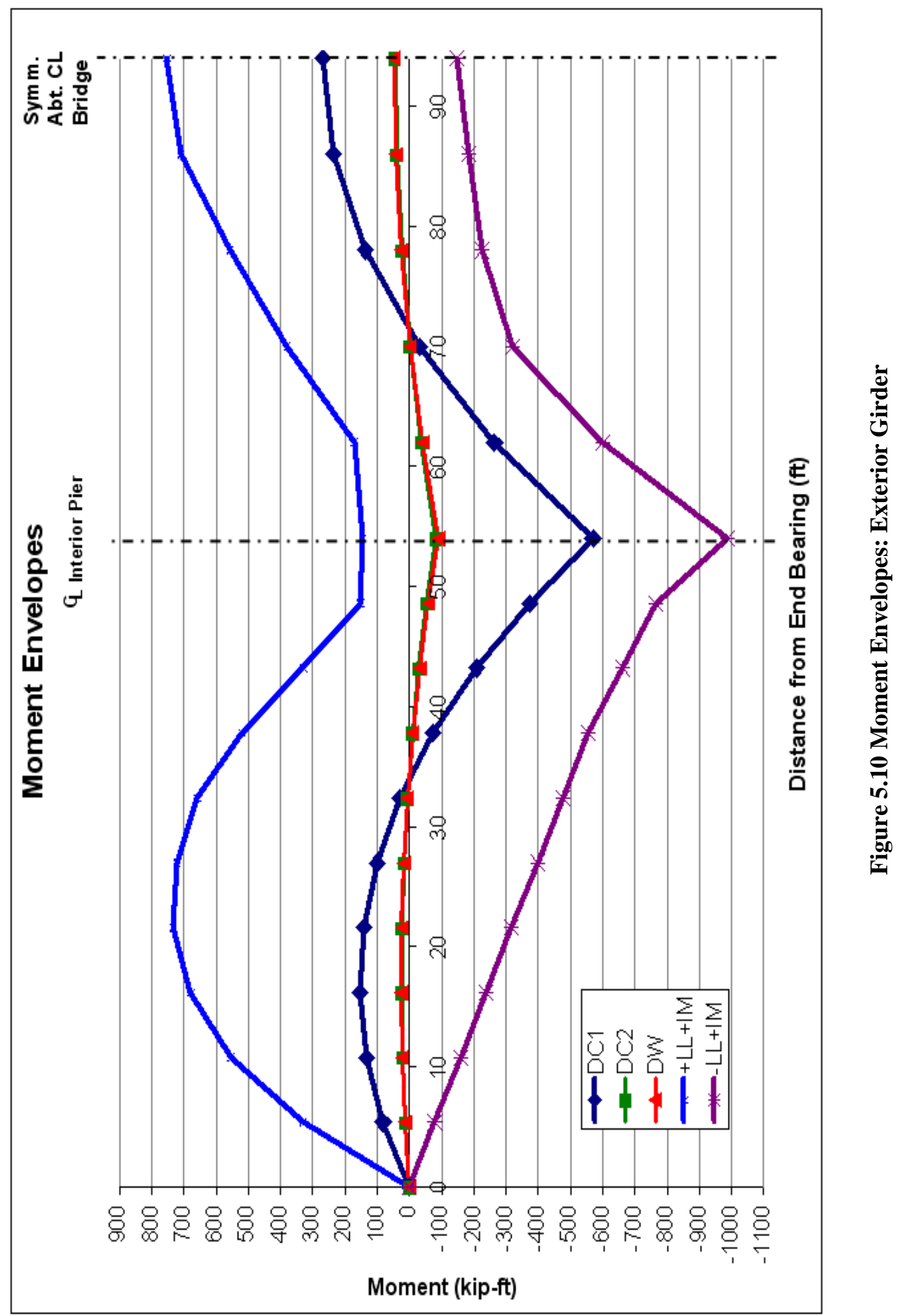




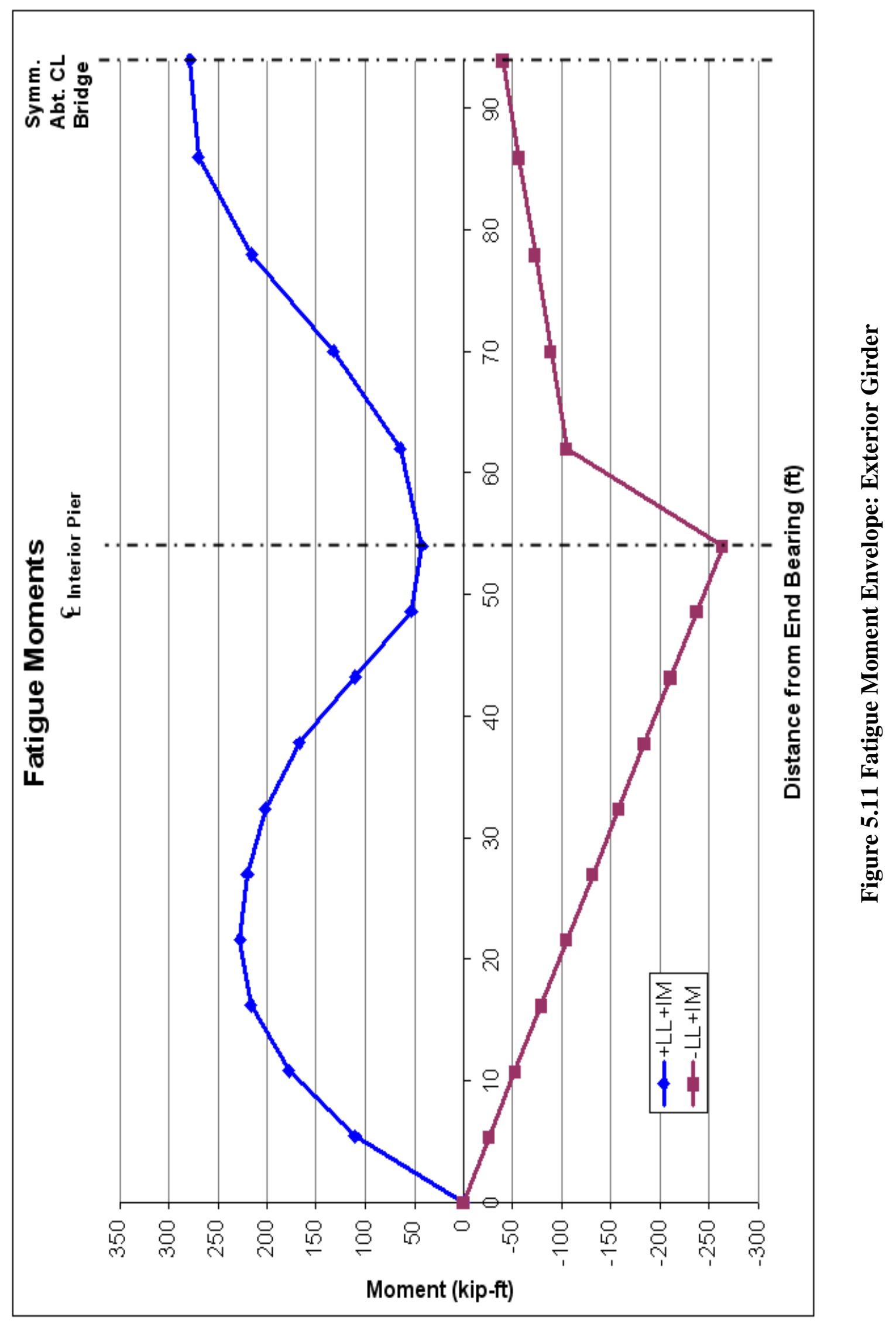




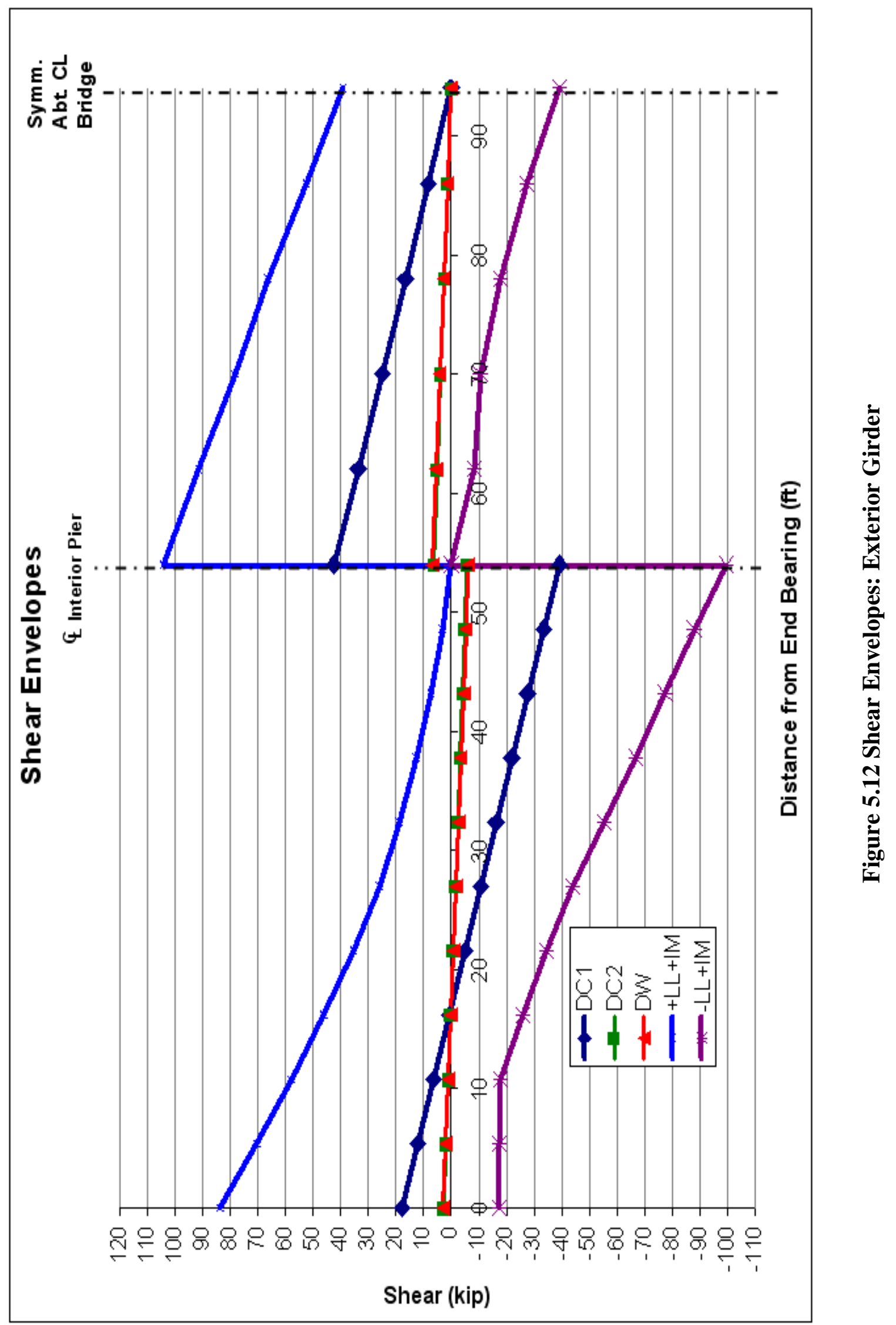




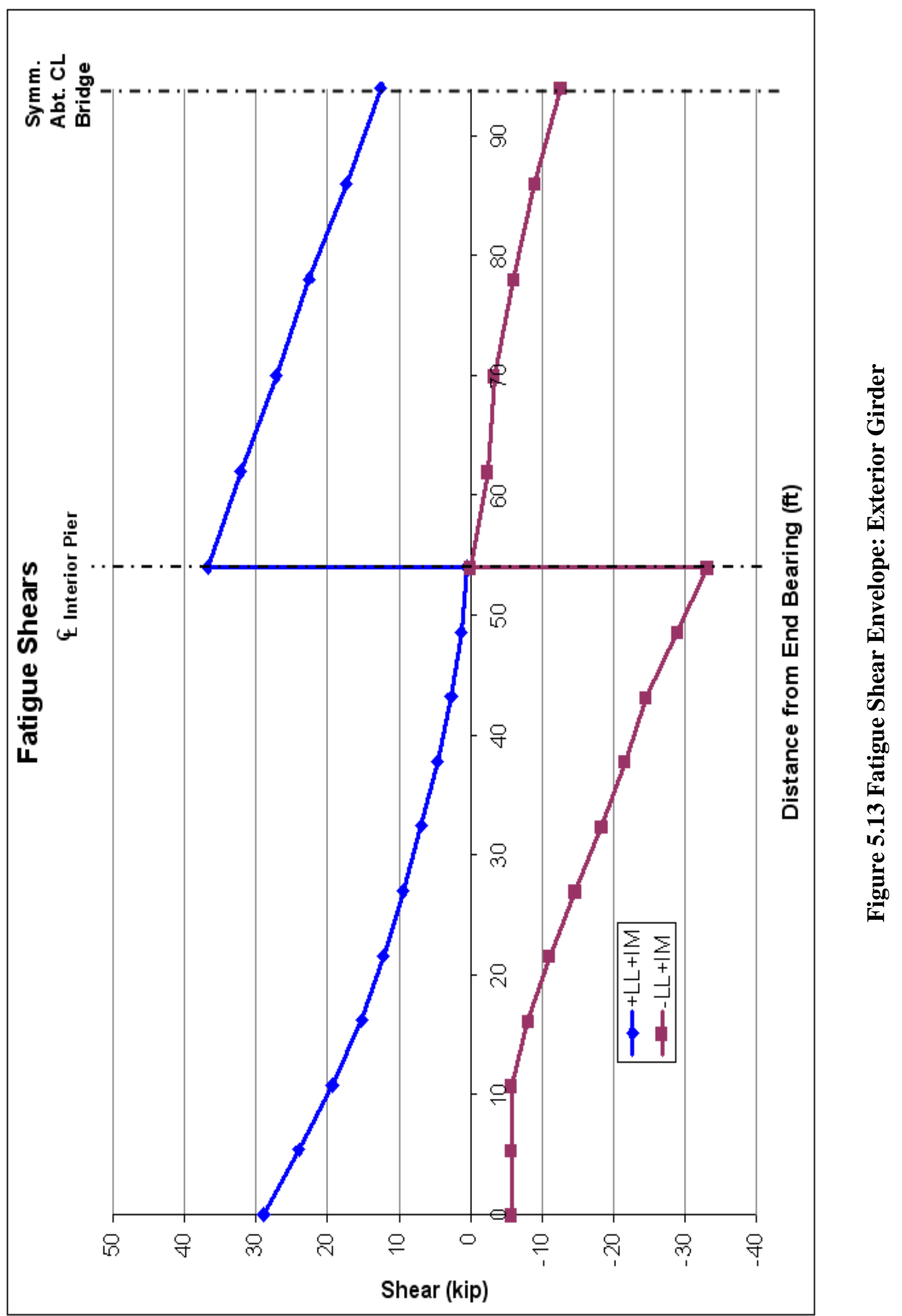




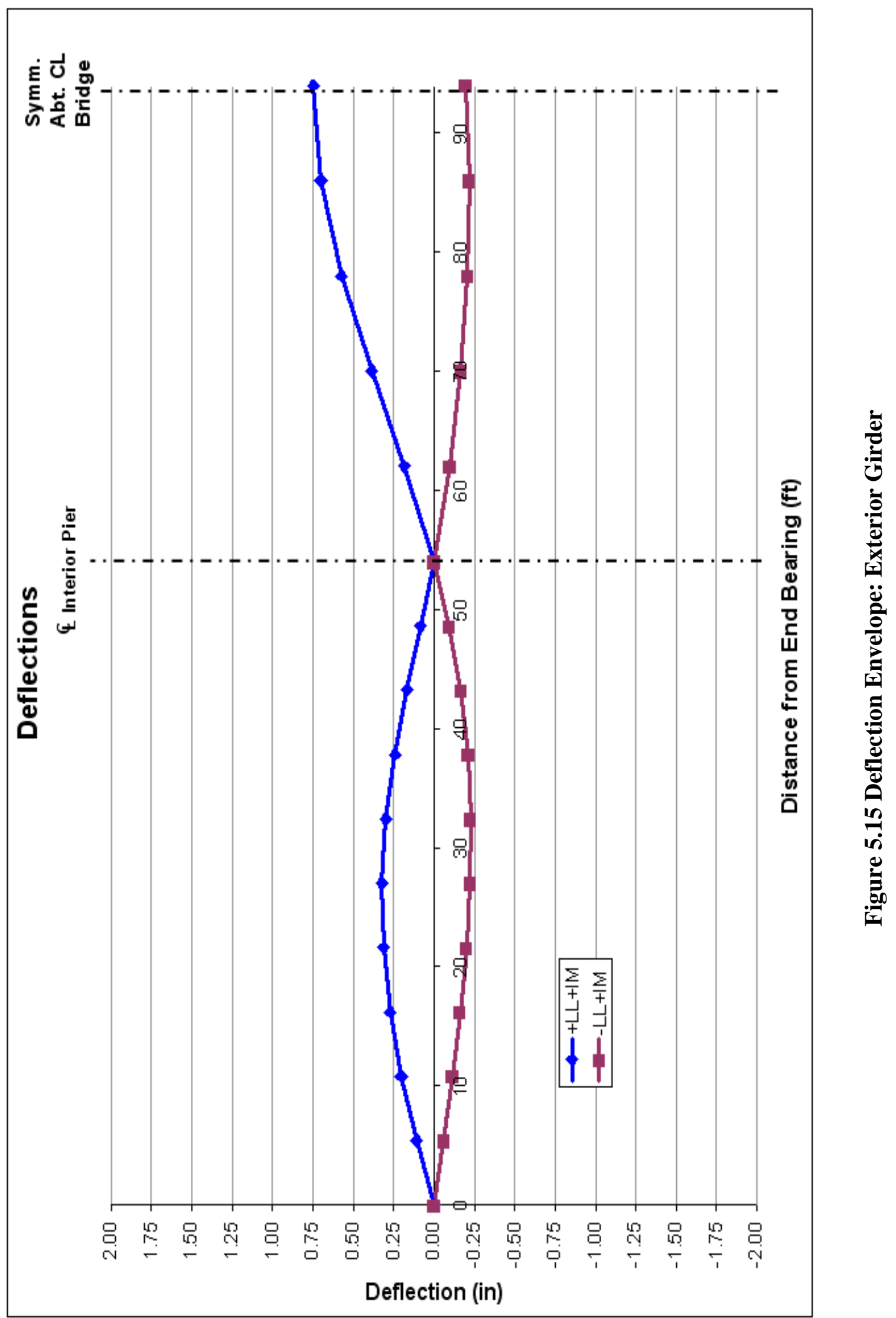


Table 5.26 Unfactored and Undistributed Dead Load Moments (k-ft.)

\begin{tabular}{|c|c|c|c|}
\hline & $\begin{array}{l}\text { Non- } \\
\text { Com. }\end{array}$ & $\begin{array}{l}\text { Com. } \\
\text { Dead }\end{array}$ & $\begin{array}{c}\text { Wearing } \\
\text { Surf. }\end{array}$ \\
\hline 1/10 Pt. & DC1 & $\overline{D C 2}$ & DW \\
\hline 0 & 0 & 0 & 0 \\
\hline 0.1 & 81 & 13 & 13 \\
\hline 0.2 & 132 & 20 & 22 \\
\hline 0.3 & 152 & 24 & 25 \\
\hline 0.4 & 141 & 22 & 24 \\
\hline 0.5 & 100 & 16 & 18 \\
\hline 0.6 & 28 & 6 & 6 \\
\hline 0.7 & -75 & -10 & -10 \\
\hline 0.8 & -208 & -30 & -32 \\
\hline 0.9 & -373 & -54 & -58 \\
\hline 1 & -569 & -83 & -90 \\
\hline 1.1 & -265 & -38 & -40 \\
\hline 1.2 & -31 & -2 & -2 \\
\hline 1.3 & 135 & 24 & 25 \\
\hline 1.4 & 235 & 39 & 42 \\
\hline 1.5 & 268 & 44 & 47 \\
\hline
\end{tabular}

Table 5.27 Unfactored and Undistributed Live Load Moments (k-ft.)

\begin{tabular}{|c|c|c|c|c|c|c|c|c|c|c|}
\hline \multirow[b]{2}{*}{ 1/10 Pt. } & \multicolumn{2}{|c|}{ Truck Load } & \multicolumn{2}{|c|}{ Lane Load } & \multicolumn{2}{|c|}{ Tandem } & \multicolumn{2}{|c|}{ Double Truck } & \multicolumn{2}{|c|}{ Double Tandem } \\
\hline & Pos. & Neg. & Pos. & Neg. & Pos. & Neg. & Pos. & Neg. & Pos. & Neg. \\
\hline 0 & 0 & 0 & 0 & 0 & 0 & 0 & 0 & 0 & 0 & 0 \\
\hline 0.1 & 261 & -57 & 77 & -26 & 224 & -42 & 0 & 0 & 5 & 0 \\
\hline 0.2 & 433 & -113 & 135 & -53 & 382 & -85 & 0 & 0 & 11 & 0 \\
\hline 0.3 & 523 & -170 & 174 & -79 & 478 & -127 & 0 & 0 & 16 & 0 \\
\hline 0.4 & 561 & -227 & 194 & -105 & 515 & -170 & 0 & 0 & 22 & 0 \\
\hline 0.5 & 548 & -284 & 196 & -132 & 505 & -212 & 0 & 0 & 27 & 0 \\
\hline 0.6 & 500 & -340 & 180 & -158 & 457 & -254 & 0 & 0 & 32 & 0 \\
\hline 0.7 & 392 & -397 & 144 & -185 & 368 & -297 & 0 & 0 & 38 & 0 \\
\hline 0.8 & 242 & -454 & 90 & -211 & 249 & -339 & 0 & -454 & 43 & -548 \\
\hline 0.9 & 99 & -511 & 48 & -268 & 110 & -382 & 0 & -585 & 49 & -616 \\
\hline 1 & 110 & -567 & 39 & -377 & 87 & -424 & 0 & -773 & 0 & -688 \\
\hline 1.1 & 115 & -276 & 42 & -195 & 134 & -218 & 0 & -496 & 8 & -338 \\
\hline 1.2 & 288 & -233 & 86 & -94 & 301 & -184 & 0 & -273 & 16 & -245 \\
\hline 1.3 & 482 & -190 & 166 & -74 & 439 & -150 & 0 & 0 & 24 & 0 \\
\hline 1.4 & 602 & -147 & 228 & -74 & 529 & -116 & 0 & 0 & 32 & 0 \\
\hline 1.5 & 634 & -104 & 248 & -74 & 558 & -82 & 0 & 0 & 40 & 0 \\
\hline
\end{tabular}


Table 5.28 Unfactored and Distributed Moments (k-ft.)

\begin{tabular}{|c|c|c|c|c|c|c|c|c|}
\hline \multirow[b]{2}{*}{ 1/10 Pt. } & \multicolumn{2}{|c|}{ Vehicle } & \multirow[b]{2}{*}{$\begin{array}{l}\text { Special } \\
\text { Neq. }\end{array}$} & \multirow[b]{2}{*}{$\begin{array}{c}\text { Standard } \\
\text { Neq. }\end{array}$} & \multirow[b]{2}{*}{$\begin{array}{r}1.33 \times \text { Vehicle } \\
\text { + Lane positive }\end{array}$} & \multirow{2}{*}{$\begin{array}{c}\text { Moment } \\
\text { Distribution } \\
\text { Factors }\end{array}$} & \multirow[b]{2}{*}{ Pos. } & \multirow[b]{2}{*}{ Neq. } \\
\hline & Pos. & Neg. & & & & & & \\
\hline 0 & 0 & 0 & 0 & 0 & 0 & 0.780 & 0 & 0 \\
\hline 0.1 & 261 & -57 & -24 & -102 & 424 & 0.780 & 331 & -79 \\
\hline 0.2 & 433 & -113 & -47 & -204 & 711 & 0.780 & 554 & -159 \\
\hline 0.3 & 523 & -170 & -71 & -306 & 870 & 0.780 & 678 & -238 \\
\hline 0.4 & 561 & -227 & -95 & -407 & 941 & 0.780 & 734 & -318 \\
\hline 0.5 & 548 & -284 & -119 & -509 & 925 & 0.780 & 721 & -397 \\
\hline 0.6 & 500 & -340 & -142 & -611 & 844 & 0.780 & 658 & -476 \\
\hline 0.7 & 392 & -397 & -166 & -713 & 666 & 0.780 & 519 & -556 \\
\hline 0.8 & 249 & -454 & -846 & -815 & 421 & 0.781 & 329 & -661 \\
\hline 0.9 & 110 & -511 & -979 & -947 & 194 & 0.781 & 152 & -766 \\
\hline 1 & 110 & -567 & -1265 & -1131 & 186 & 0.781 & 145 & -988 \\
\hline 1.1 & 134 & -276 & -770 & -562 & 220 & 0.781 & 172 & -601 \\
\hline 1.2 & 301 & -233 & -412 & -404 & 485 & 0.781 & 379 & -321 \\
\hline 1.3 & 482 & -190 & -67 & -326 & 808 & 0.689 & 556 & -225 \\
\hline 1.4 & 602 & -147 & -67 & -269 & 1028 & 0.689 & 709 & -186 \\
\hline 1.5 & 634 & -104 & -67 & -212 & 1092 & 0.689 & 752 & -146 \\
\hline
\end{tabular}

Table 5.29 Strength I Load Combination Moments (k-ft.)

\begin{tabular}{|c|c|c|c|c|c|c|c|}
\hline \multirow[b]{2}{*}{ 1/10 Pt. } & \multirow{2}{*}{$\begin{array}{l}1.25 \\
\text { DC1 }\end{array}$} & \multirow{2}{*}{$\begin{array}{l}1.25 \\
D C 2\end{array}$} & \multirow[b]{2}{*}{$1.5 \mathrm{DW}$} & \multicolumn{2}{|c|}{$1.75(\mathrm{LL}+1 \mathrm{M})$} & \multicolumn{2}{|c|}{ Strength I } \\
\hline & & & & Pos. & Neg. & Pos. & Neg. \\
\hline 0 & 0 & 0 & 0 & 0 & 0 & 0 & 0 \\
\hline 0.1 & 102 & 16 & 20 & 578 & -139 & 716 & -1 \\
\hline 0.2 & 165 & 26 & 33 & 970 & -278 & 1194 & -54 \\
\hline 0.3 & 190 & 30 & 38 & 1186 & -417 & 1444 & -159 \\
\hline 0.4 & 177 & 28 & 36 & 1284 & -556 & 1524 & -315 \\
\hline 0.5 & 125 & 20 & 26 & 1262 & -695 & 1434 & -523 \\
\hline 0.6 & 35 & 7 & 9 & 1151 & -834 & 1202 & -783 \\
\hline 0.7 & -94 & -12 & -16 & 908 & -972 & 787 & -1094 \\
\hline 0.8 & -261 & -37 & -48 & 575 & -1156 & 230 & -1501 \\
\hline 0.9 & -466 & -68 & -87 & 265 & -1338 & -356 & -1959 \\
\hline 1 & -712 & -104 & -134 & 254 & -1729 & -696 & -2679 \\
\hline 1.1 & -331 & -47 & -61 & 300 & -1052 & -138 & -1491 \\
\hline 1.2 & -38 & -2 & -3 & 663 & -563 & 619 & -606 \\
\hline 1.3 & 169 & 29 & 38 & 974 & -394 & 1210 & -157 \\
\hline 1.4 & 293 & 48 & 63 & 1240 & -325 & 1644 & 80 \\
\hline 1.5 & 335 & 56 & 71 & 1316 & -256 & 1777 & 204 \\
\hline
\end{tabular}


Table 5.30 Service II Load Combination Moments (k-ft.)

\begin{tabular}{|c|c|c|c|c|c|c|c|}
\hline \multirow[b]{2}{*}{ 1/10 Pt. } & \multirow{2}{*}{$\begin{array}{l}1.00 \\
\text { DC1 }\end{array}$} & \multirow{2}{*}{$\begin{array}{l}1.00 \\
D C 2\end{array}$} & \multirow{2}{*}{$\begin{array}{l}1.00 \\
\text { DW }\end{array}$} & \multicolumn{2}{|c|}{$1.30(\mathrm{LL}+\mid \mathrm{M})$} & \multicolumn{2}{|c|}{ Service II } \\
\hline & & & & Pos. & Neg. & Pos. & Neg. \\
\hline 0 & 0 & 0 & 0 & 0 & 0 & 0 & 0 \\
\hline 0.1 & 81 & 13 & 13 & 430 & -103 & 537 & 4 \\
\hline 0.2 & 132 & 20 & 22 & 721 & -206 & 895 & -32 \\
\hline 0.3 & 152 & 24 & 25 & 881 & -310 & 1083 & -108 \\
\hline 0.4 & 141 & 22 & 24 & 954 & -413 & 1141 & -225 \\
\hline 0.5 & 100 & 16 & 18 & 937 & -516 & 1071 & -382 \\
\hline 0.6 & 28 & 6 & 6 & 855 & -619 & 895 & -580 \\
\hline 0.7 & -75 & -10 & -10 & 675 & -722 & 580 & -817 \\
\hline 0.8 & -208 & -30 & -32 & 427 & -859 & 158 & -1129 \\
\hline 0.9 & -373 & -54 & -58 & 197 & -994 & -288 & -1479 \\
\hline 1 & -569 & -83 & -90 & 189 & -1284 & -553 & -2027 \\
\hline 1.1 & -265 & -38 & -40 & 223 & -782 & -119 & -1124 \\
\hline 1.2 & -31 & -2 & -2 & 492 & -418 & 458 & -452 \\
\hline 1.3 & 135 & 24 & 25 & 723 & -292 & 907 & -108 \\
\hline 1.4 & 235 & 39 & 42 & 921 & -241 & 1236 & 74 \\
\hline 1.5 & 268 & 44 & 47 & 978 & -190 & 1337 & 169 \\
\hline
\end{tabular}

Table 5.31 Factored and Distributed Fatigue Moments (k-ft.)

\begin{tabular}{|c|c|c|c|c|c|}
\hline \multirow[b]{2}{*}{ 1/10 Pt. } & \multicolumn{2}{|c|}{$0.75(\mathrm{LL}+\mid \mathrm{M})$} & \multirow{2}{*}{$\begin{array}{l}\text { Fatigue } \\
\text { Moment }\end{array}$} & \multicolumn{2}{|c|}{ Fatigue I } \\
\hline & pos. & neg. & & Pos. & Neg. \\
\hline 0 & 0 & 0 & 0.650 & 0 & 0 \\
\hline 0.1 & 170 & -40 & 0.650 & 111 & -26 \\
\hline 0.2 & 274 & -81 & 0.650 & 178 & -53 \\
\hline 0.3 & 333 & -121 & 0.650 & 216 & -79 \\
\hline 0.4 & 350 & -162 & 0.650 & 228 & -105 \\
\hline 0.5 & 339 & -202 & 0.650 & 220 & -132 \\
\hline 0.6 & 311 & -243 & 0.650 & 202 & -158 \\
\hline 0.7 & 257 & -283 & 0.650 & 167 & -184 \\
\hline 0.8 & 169 & -324 & 0.651 & 110 & -211 \\
\hline 0.9 & 82 & -364 & 0.651 & 53 & -237 \\
\hline 1 & 65 & -405 & 0.651 & 42 & -264 \\
\hline 1.1 & 99 & -162 & 0.651 & 65 & -105 \\
\hline 1.2 & 204 & -137 & 0.651 & 133 & -89 \\
\hline 1.3 & 330 & -111 & 0.653 & 216 & -73 \\
\hline 1.4 & 413 & -86 & 0.653 & 270 & -56 \\
\hline 1.5 & 426 & -61 & 0.653 & 278 & -40 \\
\hline
\end{tabular}


Table 5.32 Unfactored and Undistributed Shears (kips)

\begin{tabular}{|c|c|c|c|c|c|c|c|c|c|}
\hline \multirow[b]{2}{*}{ 1/10 Pt. } & \multirow{2}{*}{$\begin{array}{l}\text { Non- } \\
\text { Com. } \\
\text { Dead } \\
\text { DC1 }\end{array}$} & \multirow{2}{*}{$\begin{array}{l}\text { Com. } \\
\text { Dead } \\
\text { DC2 }\end{array}$} & \multirow{2}{*}{$\begin{array}{c}\begin{array}{c}\text { Wearing } \\
\text { Surf. }\end{array} \\
\text { DW }\end{array}$} & \multicolumn{2}{|c|}{ Truck Load } & \multicolumn{2}{|c|}{ Lane Load } & \multicolumn{2}{|c|}{ Tandem } \\
\hline & & & & Pos. & Neg. & Pos. & Neg. & Pos. & Neg. \\
\hline 0 & 18 & 3 & 3 & 57 & -11 & 16 & -5 & 48 & -8 \\
\hline 0.1 & 12 & 2 & 2 & 48 & -11 & 13 & -5 & 42 & -8 \\
\hline 0.2 & 7 & 1 & 1 & 40 & -11 & 10 & -6 & 35 & -10 \\
\hline 0.3 & 1 & 0 & 0 & 32 & -13 & 7 & -7 & 29 & -16 \\
\hline 0.4 & -5 & -1 & -1 & 25 & -21 & 5 & -8 & 24 & -22 \\
\hline 0.5 & -11 & -2 & -2 & 18 & -28 & 4 & -10 & 19 & -28 \\
\hline 0.6 & -16 & -2 & -3 & 13 & -36 & 3 & -12 & 14 & -33 \\
\hline 0.7 & -22 & -3 & -4 & 8 & -44 & 2 & -15 & 9 & -38 \\
\hline 0.8 & -28 & -4 & -4 & 4 & -51 & 1 & -18 & 5 & -42 \\
\hline 0.9 & -33 & .5 & -5 & 2 & -57 & 1 & -21 & 2 & -46 \\
\hline 1 & -39 & 6 & -6 & 65 & -63 & 28 & -26 & 49 & -49 \\
\hline 1 & 43 & 6 & 7 & 65 & -63 & 28 & -26 & 49 & -49 \\
\hline 1.1 & 34 & 5 & 5 & 59 & -5 & 23 & -2 & 45 & -4 \\
\hline 1.2 & 25 & 4 & 4 & 51 & -5 & 18 & -3 & 41 & -7 \\
\hline 1.3 & 17 & 3 & 3 & 43 & -11 & 14 & -4 & 36 & -12 \\
\hline 1.4 & 8 & 1 & 1 & 35 & -18 & 10 & -5 & 30 & -17 \\
\hline 1.5 & 0 & 0 & 0 & 26 & -26 & 8 & -8 & 23 & -23 \\
\hline
\end{tabular}

Table 5.33 Unfactored and Distributed Shears (kips)

\begin{tabular}{|c|c|c|c|c|c|c|c|}
\hline \multirow[b]{2}{*}{ 1/10 Pt. } & \multicolumn{2}{|c|}{ Vehicle } & \multicolumn{2}{|c|}{$1.33 \times$ Vehicle } & \multirow{2}{*}{$\begin{array}{c}\text { Shear } \\
\text { Distribution }\end{array}$} & \multirow[b]{2}{*}{ Pos. } & \multirow[b]{2}{*}{ Neg. } \\
\hline & Pos. & Neg. & Pos. & Neg. & & & \\
\hline 0 & 57 & -11 & 91 & -19 & 0.913 & 84 & -17 \\
\hline 0.1 & 48 & -11 & 77 & -19 & 0.913 & 70 & -17 \\
\hline 0.2 & 40 & -11 & 63 & -20 & 0.913 & 58 & -18 \\
\hline 0.3 & 32 & -16 & 50 & -28 & 0.913 & 46 & -26 \\
\hline 0.4 & 25 & -22 & 39 & -38 & 0.913 & 35 & -34 \\
\hline 0.5 & 19 & -28 & 28 & -48 & 0.913 & 26 & -44 \\
\hline 0.6 & 14 & -36 & 21 & -61 & 0.913 & 19 & -55 \\
\hline 0.7 & 9 & -44 & 14 & -73 & 0.913 & 13 & -67 \\
\hline 0.8 & 5 & -51 & 8 & -85 & 0.906 & 7 & -77 \\
\hline 0.9 & 2 & -57 & 4 & -97 & 0.906 & 3 & -88 \\
\hline 1 & 65 & -63 & 115 & -110 & 0.906 & 0 & -99 \\
\hline 1 & 65 & -63 & 115 & -110 & 0.906 & 104 & 0 \\
\hline 1.1 & 59 & -5 & 101 & -9 & 0.906 & 91 & -8 \\
\hline 1.2 & 51 & -7 & 86 & -12 & 0.906 & 78 & -10 \\
\hline 1.3 & 43 & -12 & 71 & -19 & 0.929 & 66 & -18 \\
\hline 1.4 & 35 & -18 & 56 & -29 & 0.929 & 52 & -27 \\
\hline 1.5 & 26 & -26 & 42 & -42 & 0.929 & 39 & -39 \\
\hline
\end{tabular}


Table 5.34 Strength I Load Combination Shears (kips)

\begin{tabular}{|c|c|c|c|c|c|c|c|}
\hline \multirow[b]{2}{*}{ 1/10 Pt. } & \multirow{2}{*}{$\begin{array}{l}1.25 \\
\text { DC1 }\end{array}$} & \multirow{2}{*}{$\begin{array}{l}1.25 \\
D C 2\end{array}$} & \multirow[b]{2}{*}{$1.5 \mathrm{DW}$} & \multicolumn{2}{|c|}{$1.75(\mathrm{LL}+\mid \mathrm{M})$} & \multicolumn{2}{|c|}{ Strength I } \\
\hline & & & & Pos. & Neg. & Pos. & Neg. \\
\hline 0 & 22 & 3 & 4 & 146 & -30 & 177 & 0 \\
\hline 0.1 & 15 & 2 & 3 & 123 & -30 & 144 & -10 \\
\hline 0.2 & 8 & 1 & 2 & 101 & -32 & 112 & -20 \\
\hline 0.3 & 1 & 0 & 0 & 81 & -45 & 82 & -44 \\
\hline 0.4 & -6 & -1 & -1 & 62 & -60 & 54 & -68 \\
\hline 0.5 & -13 & -2 & -2 & 46 & -77 & 28 & -94 \\
\hline 0.6 & -20 & -3 & -4 & 33 & -97 & 6 & -124 \\
\hline 0.7 & -27 & -4 & -5 & 22 & -117 & -14 & -154 \\
\hline 0.8 & -34 & -5 & -7 & 13 & -135 & -33 & -182 \\
\hline 0.9 & -42 & 6 & -8 & 6 & -154 & -50 & -210 \\
\hline 1 & 53 & 8 & 10 & 182 & -174 & 254 & -103 \\
\hline 1.1 & 42 & 6 & 8 & 160 & -15 & 217 & 42 \\
\hline 1.2 & 31 & 5 & 6 & 137 & -18 & 179 & 24 \\
\hline 1.3 & 21 & 3 & 4 & 116 & -31 & 144 & -3 \\
\hline 1.4 & 10 & 2 & 2 & 92 & -48 & 106 & -34 \\
\hline 1.5 & 0 & 0 & 0 & 69 & -69 & 69 & -69 \\
\hline
\end{tabular}

Table 5.35 Fatigue Shears (kips)

\begin{tabular}{|c|c|c|c|c|c|}
\hline \multirow[b]{2}{*}{ 1/10 Pt. } & \multicolumn{2}{|c|}{$0.75(\mathrm{LL}+\| \mathrm{M})$} & \multirow{2}{*}{$\begin{array}{l}\text { Fatigue } \\
\text { Moment }\end{array}$} & \multicolumn{2}{|c|}{ Fatigue I } \\
\hline & Pos. & Neg. & & Pos. & Neg. \\
\hline 0 & 38 & -7 & 0.761 & 29 & -6 \\
\hline 0.1 & 32 & -7 & 0.761 & 24 & -6 \\
\hline 0.2 & 25 & -7 & 0.761 & 19 & -6 \\
\hline 0.3 & 20 & -11 & 0.761 & 15 & -8 \\
\hline 0.4 & 16 & -15 & 0.761 & 12 & -11 \\
\hline 0.5 & 12 & -19 & 0.761 & 9 & -15 \\
\hline 0.6 & 9 & -24 & 0.761 & 7 & -18 \\
\hline 0.7 & 6 & -28 & 0.761 & 5 & -22 \\
\hline 0.8 & 4 & -32 & 0.755 & 3 & -25 \\
\hline 0.9 & 2 & -38 & 0.755 & 1 & -29 \\
\hline 1 & 49 & -44 & 0.755 & 1 & -33 \\
\hline 1 & 49 & -44 & 0.755 & 37 & 0 \\
\hline 1.1 & 43 & -3 & 0.755 & 32 & -2 \\
\hline 1.2 & 36 & -4 & 0.755 & 27 & -3 \\
\hline 1.3 & 29 & -8 & 0.774 & 23 & -6 \\
\hline 1.4 & 22 & -12 & 0.774 & 17 & -9 \\
\hline 1.5 & 16 & -16 & 0.774 & 13 & -13 \\
\hline
\end{tabular}


Table 5.36 Factored and Distributed Deflections (in)

\begin{tabular}{|c|c|c|c|c|c|}
\hline \multicolumn{6}{|c|}{ Optional Live-Load Deflection (in) } \\
\hline \multirow[b]{2}{*}{ 1/10 Pt. } & \multicolumn{2}{|c|}{$(\mathrm{LL}+\mid \mathrm{M})$} & \multirow[b]{2}{*}{ D.F. } & \multicolumn{2}{|c|}{ Deflection } \\
\hline & pos. & neg. & & pos. & neg. \\
\hline 0 & 0.000 & 0.000 & 0.371 & 0.000 & 0.000 \\
\hline 0.1 & 0.293 & $-0.160 \mid$ & 0.371 & 0.109 & -0.059 \\
\hline 0.2 & 0.545 & $|-0.306|$ & 0.371 & 0.203 & -0.114 \\
\hline 0.3 & 0.732 & $\mid-0.439$ & 0.371 & 0.272 & -0.163 \\
\hline 0.4 & 0.838 & $\mid-0.545$ & 0.371 & 0.311 & -0.203 \\
\hline 0.5 & 0.865 & -0.599 & 0.371 & 0.321 & -0.222 \\
\hline 0.6 & 0.798 & $\mid-0.612$ & 0.371 & 0.296 & -0.227 \\
\hline 0.7 & 0.652 & -0.572 & 0.371 & 0.242 & -0.212 \\
\hline 0.8 & 0.452 & $\mid-0.452$ & 0.371 & 0.168 & -0.168 \\
\hline 0.9 & 0.226 & -0.253 & 0.371 & 0.084 & -0.094 \\
\hline 1 & 0.000 & 0.000 & 0.371 & 0.000 & 0.000 \\
\hline 1.1 & 0.492 & $\mid-0.266$ & 0.371 & 0.183 & -0.099 \\
\hline 1.2 & 1.037 & -0.452 & 0.371 & 0.385 & -0.168 \\
\hline 1.3 & 1.543 & -0.559 & 0.371 & 0.573 & -0.207 \\
\hline 1.4 & 1.889 & -0.585 & 0.371 & 0.701 & -0.217 \\
\hline 1.5 & 2.008 & -0.532 & 0.371 & 0.746 & -0.198 \\
\hline
\end{tabular}

\subsection{Limit States}

\subsubsection{Service Limit State}

The Service limit state is employed to ensure adequate bridge performance and serviceability over a design service life. The Service I and II load combinations correspond to the loads that induce stresses and deformations observed during typical service conditions. The Service I load combination is used when calculating live load deflection. Live load deflections may be limited to avoid adverse structural or physiological effects associated with excessive deformations. The Service II load combination is intended to protect the structure against localized yielding that could potentially cause permanent deformations. By limiting permanent deformations, bridge rideability is maintained and undesirable affects associated with localized yielding and web-bend buckling are avoided. 


\subsubsection{Strength Limit State}

The Strength limit state ensures that stability is maintained under statistically significant load combinations that the bridge is expected to experience during its design life. The Strength I load combination will be evaluated for the Culloden Bridge to ensure adequate capacity is provided to resist bending moments and shears

\subsubsection{Fatigue Limit State}

Crack formation and propagation is prevented over the design life of a bridge by limiting the stress range produced by the fatigue load. The AASHTO specifications classify several types of structural details that must be checked for fatigue. The fatigue limit state was checked at the mid-span and over the interior piers to ensure that acceptable stress ranges were not exceeded.

\subsection{Sample Calculations}

Sample calculations are presented for the two most critical locations of the Culloden Bridge. The first location is the maximum negative bending region, Section II, over the pier. The second location, Section III, is located at the middle of the second span and corresponds to the maximum positive bending region of the bridge. Section I is located in the maximum positive bending region of the first span, however, force effects are smaller than Section III; therefore, it will not be presented hereafter. The approximate line-girder analysis procedure theoretically predicts larger moment distribution factors for exterior girders; therefore, only exterior girders are considered in the subsequent calculations. All load modifiers $\left(\eta_{i}\right)$ were taken equal to 1.00 for this design assessment. 
The stress calculations in the subsequent calculations adopt a positive sign convention for tensile forces and negative for compressive forces. All numbers presented in the following sections are rounded for simplicity; however, the answers reported are resultant of unrounded numbers.

\subsubsection{Section Properties}

\subsubsection{Effective Flange Width}

The 4th edition of the AASHTO specifications states that the effective flange width is to be taken as $1 / 2$ the girder spacing plus the width of the deck overhang. The Culloden Bridge has I-girders spaced at $8 \mathrm{ft}$. intervals and a deck overhang width of 3.5 ft. This equates to an effective width of $90 \mathrm{in}$.

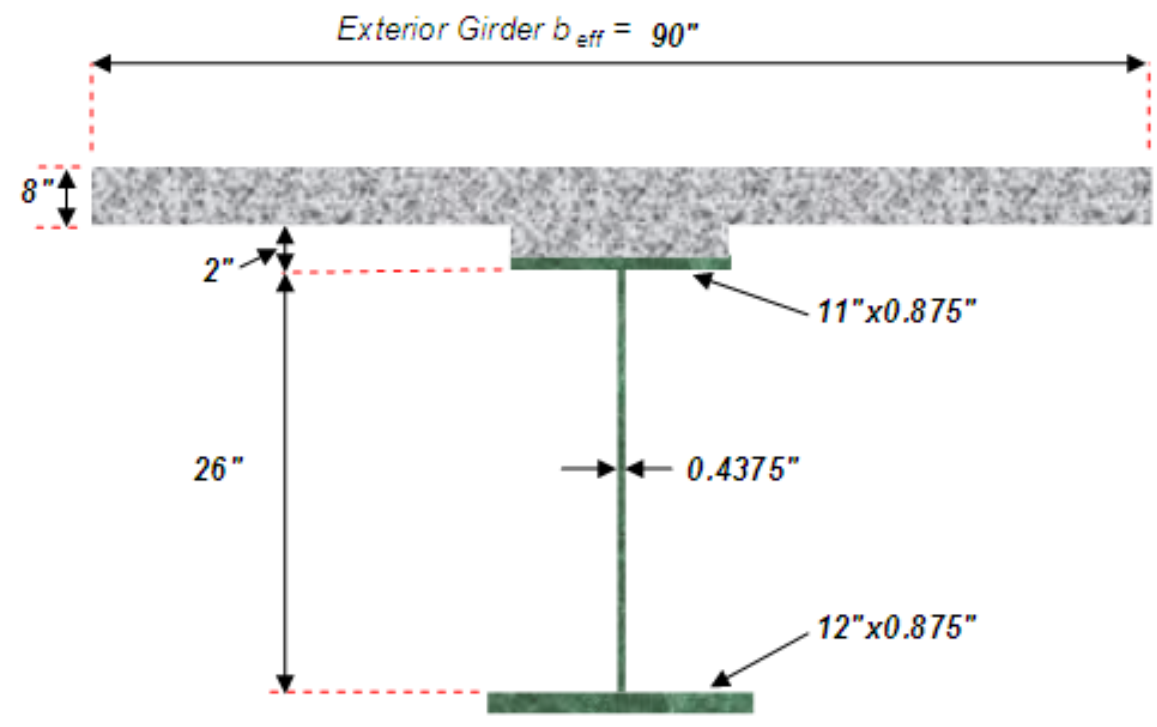

Figure 5.17 Effective Flange Width for Exterior Girders

The previously specified bridge geometries were used to calculate the noncomposite, composite short-term, and composite long-term section moduli for each 
section. The top longitudinal rebar cover was measured from the top of the deck to the C.G. of the rebar. The bottom rebar cover was taken as the distance between the bottom of the deck and the C.G. of the rebar. The Culloden Bridge plans specify 4,000 psi concrete in the deck; therefore, the modular ratio $(n)$ was taken as 8 when calculating the short-term composite sections in the tables below. The long-term composite sections were determined using the long-term modular ratio $3 n=24$. In the negative bending region, the non-composite section plus the longitudinal reinforcement was considered when determining short and long-term stresses. The AASHTO specifications do not require a reduction of longitudinal reinforcement area when determining dead load stresses; however, it was conservatively divided by 3 to adjust for creep and cracks in the long-term section.

\section{Table 5.37 Culloden Bridge Geometry}

\begin{tabular}{|c|c|}
\hline Girder Spacing & 8 \\
\hline Ov erhang & 3.5 \\
\hline Overhang Thickness & 8 \\
\hline Span Length 1 & 54.00 \\
\hline Span Length 2 & 80.00 \\
\hline Span Av erage & 67.00 \\
\hline Number of Girders & 7 \\
\hline Clear Roadway Width & 48.00 \\
\hline Design Lanes & 4 \\
\hline Total Slab Thickness & 8 \\
\hline IWS & 0.25 \\
\hline Top Reinf. Cover Sec. I \& III & 2.75 \\
\hline Top Reinf. Cover Sec.ll & 2.875 \\
\hline Bottom Reinf. Cov er I \& III & 1.313 \\
\hline Bottom Reinf. Cov er II & 1.313 \\
\hline
\end{tabular}


Table 5.38 Exterior Girder Section Properties

\begin{tabular}{|c|c|c|c|c|}
\hline & \multirow{2}{*}{ Steel Section } & \multicolumn{2}{|c|}{ Section Modulus } & \multirow{2}{*}{$I_{x w}$, in ${ }^{4}$} \\
\hline & & $S x_{t g p}$, in $^{3}$ & $S x_{\text {bot }}$, in ${ }^{3}$ & \\
\hline \multirow{5}{*}{$\begin{array}{c}\text { Section I } \\
\text { Positive Bending }\end{array}$} & Steel & 300 & 316 & 4272 \\
\hline & Steel + reinf & 408 & 318 & 4959 \\
\hline & Steel + reinf/3 & 333 & 316 & 4500 \\
\hline & short term $(\mathrm{n})$ & 122358 & 480 & 13281 \\
\hline & long term (3n) & 1999 & 441 & 10017 \\
\hline \multirow{5}{*}{$\begin{array}{c}\text { Section II } \\
\text { Negative Bending }\end{array}$} & Steel & 479 & 510 & 7161 \\
\hline & Steel + reinf & 842 & 577 & 9930 \\
\hline & Steel + reinf $/ 3$ & 595 & 538 & 8197 \\
\hline & short term $(n)$ & 8229 & 705 & 18822 \\
\hline & long term $(3 n)$ & 1871 & 647 & 13950 \\
\hline \multirow{3}{*}{$\begin{array}{c}\text { Section III } \\
\text { Positive Bending }\end{array}$} & Steel & 267 & 267 & 3710 \\
\hline & short term (n) & -22837 & 409 & 11543 \\
\hline & long term (3n) & 2145 & 375 & 8866 \\
\hline
\end{tabular}

\subsubsection{Exterior Girder: Section II}

\subsubsection{Service II Limit State}

To maintain bridge rideability, the Service II limit state ensures that permanent deformations are controlled. This is achieved by limiting the flexural stresses such that localized yielding and buckling do not occur. Bridge decks that incorporate shear studs throughout their length are assumed to be fully composite in positive and negative flexure at the service limit state; therefore, the short-term and long-term composite sections will be used in stress calculations.

\subsection{Permanent Deformations}

The hybrid girder factor accounts for non-homogeneous cross sections in which portions of the built-up section may fail prior to others. The hybrid girder factor for 
Section II of the Culloden Bridge was determined as follows:

$$
\begin{aligned}
& D_{n}=15.71 \mathrm{in} . \\
& A_{f n}=b_{f c} \times t_{f c}
\end{aligned}
$$

$$
A_{f n}=12 \times 1.5=18 \mathrm{in}^{2}
$$

$$
\beta=\frac{2 D_{n} t_{w}}{A_{f n}}
$$

$$
\beta=\frac{2 \times 15.71 \times 0.4375}{18}=0.763
$$

$$
\begin{aligned}
& \rho=\frac{F_{y w}}{F_{y c}} \\
& \rho=\frac{50.0 \mathrm{ksi}}{100 \mathrm{ksi}}=0.50
\end{aligned}
$$

$$
\begin{aligned}
& R_{h}=\frac{12+\beta\left(3 \rho-\rho^{3}\right)}{12+2 \beta} \\
& R_{h}=\frac{12+0.763\left[3(0.50)-(0.50)^{3}\right]}{12+2(0.763)}=0.965
\end{aligned}
$$

Eq. 5.31

The top and bottom flange stresses, due to the Service II load combination, were then checked. Lateral flange bending effects were neglected because the deck is considered composite at the service limit state.

\section{Top Flange:}

$$
f_{f}=\eta\left[\frac{1.0\left(M_{D C 1}\right)}{S_{\text {steel }}}+\frac{1.0\left(M_{D C 2}+M_{D W}\right)}{S_{L T}}+\frac{1.3\left(M_{L L+I M}\right)}{S_{S T}}\right]
$$




$$
\begin{aligned}
& f_{f}=1.0\left[\frac{1.0(569)}{479}+\frac{1.0[(83)+(90)]}{1871}+\frac{1.3(988)}{8229}\right] 12 \\
& f_{f}=17.24 \text { ksi tension } \\
& f_{f} \leq 0.95 R_{h} F_{y f} \\
& 0.95 R_{h} F_{y f}=0.95(0.965)(70)=64.17 \mathrm{ksi} \\
& 17.25 \mathrm{ksi} \leq 64.17 \mathrm{kips} \quad \therefore \text { OK }(\text { Ratio }=0.268) \\
& \text { Bottom Flange: } \\
& f_{f}=1.0\left[\frac{1.0(569)}{510}+\frac{1.0[(83)+(-90)]}{647}+\frac{1.3(988)}{705}\right] 12 \\
& f_{f}=38.48 \text { ksi compression } \\
& f_{f}+\frac{f_{l}}{2} \leq 0.95 R_{h} F_{y f} \quad \therefore \text { OK }(\text { Ratio }=0.420) \\
& 0.95 R_{h} F_{y f}=0.95(0.965)(100)=91.675 \mathrm{ksi} \\
& 38.48 \text { ksi }+0 \leq 91.675 \mathrm{ksi}
\end{aligned}
$$

Article 6.10.4.2.2 specifies that the compression flange must not exceed the nominal web bend-buckling resistance; however, composite negative bending sections checked at the strength limits state with Article 6.10.8 need not be checked.

\subsubsection{Strength Limit State}

\subsection{Negative Flexure}

The Culloden Bridge incorporates $100 \mathrm{ksi}$ steel in the bottom flanges of Section II over the pier; thus, Appendix A is not applicable and Article 6.10.8 of the AASHTO 
specifications will be utilized to determine compression flange capacity. The compression flange capacity of Section II is limited to the smaller of the lateral-torsional buckling capacity and the local web-bend buckling capacity. For composite sections in negative flexure, the following relationship must be satisfied:

Discretely Braced Compression Flanges:

$$
f_{b u}+\frac{1}{3} f_{l} \leq \phi_{f} F_{n c}
$$

Discretely Braced Tension Flanges:

$$
f_{b u}+\frac{1}{3} f_{l} \leq \phi_{f} F_{n t}
$$

Continuously Braced Tension or Compression Flanges:

$$
f_{b u} \leq \phi_{f} R_{h} F_{y f}
$$

The lateral flange bending stress $\left(f_{l}\right)$ is assumed to be zero for all strength calculations as it need not be checked once the deck and girders have become composite.

\subsection{Lateral-Torsional Buckling Capacity}

The lateral-torsional buckling capacity was analyzed at four critical girder locations. From these four locations it was determined that the most critical unbraced length was west of the western most pier. The total unbraced length at this location is 245 inches. A flange transition lies 108 inches from the cross-frame at the pier and 137 inches from the next intermediate cross-frame. This equates to a flange transition 44 percent of the unbraced length away from the pier cross-frame. Commentary 6.10.8.2.3 states that for unbraced lengths containing a transition to a smaller section at a distance greater than 20 percent of the unbraced length from the cross-frame with the smaller 
moment, the lateral-torsional buckling resistance should be taken as the smaller resistance $\left(F_{n c}\right)$ within the unbraced length. In this case, the flange transition is a distance equivalent to 56 percent of the unbraced length away from the cross-frame with the smaller moment. The commentary also states that the most accurate lateral-torsional buckling capacity is found by converting the non-prismatic member into an equivalent prismatic member based on the weighted average of the two sections. A conservative LTB capacity may also be determined by using the smaller of the two sections; however, a weighted average approach was adopted in the subsequent LTB calculations.

An equivalent prismatic beam was determined by multiplying each section by its respective percentage of unbraced length. Section II makes up 44 percent of the unbraced length while Section I makes 56 percent. The equivalent prismatic beam dimensions are shown below in Table 5.39 and the section moduli in Table 5.40.

Table 5.39 Prismatic Section Dimension

\begin{tabular}{|c|c|c|c|c|c|c|}
\cline { 2 - 7 } \multicolumn{1}{c|}{} & \multicolumn{2}{c|}{ Web (in) } & \multicolumn{2}{c|}{ Top Flange (in) } & \multicolumn{2}{c|}{ Bottom Flange (in) } \\
\cline { 2 - 7 } \multicolumn{1}{c|}{} & Depth & Thickness & Width & Thickness & Width & Thickness \\
\hline Prismatic Beam & 26 & 0.4375 & 11 & 1.15 & 12 & 1.15 \\
\hline
\end{tabular}

Table 5.40 Prismatic Section Properties

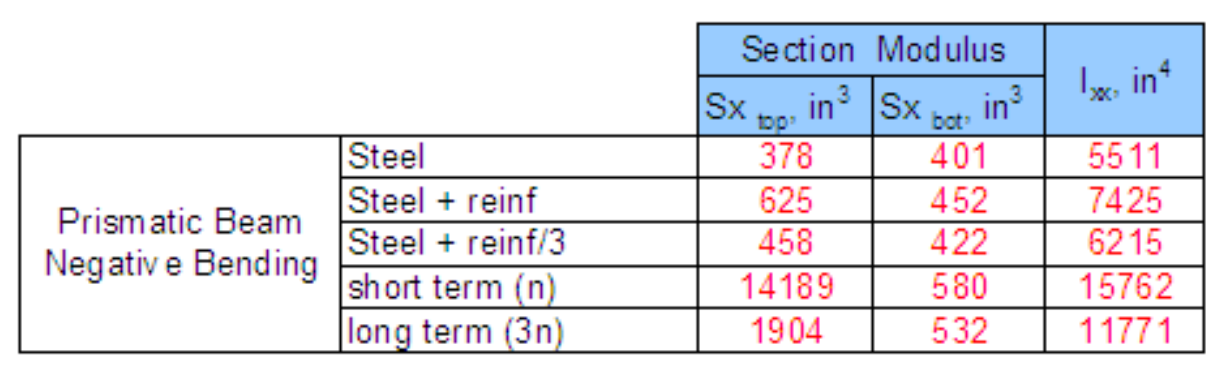


The flexural stresses induced by the Strength I load combination were found at the critical negative bending section using the actual sections properties at that location. The prismatic section properties were only used to determine the LTB capacity of the critical unbraced length. The maximum bending stresses in the top and bottom flanges were then found as:

Top Flange:

$$
\begin{aligned}
& f_{b u}=\eta\left[\frac{1.25\left(M_{D C 1}\right)}{S_{\text {steel }}}+\frac{1.25\left(M_{D C 2}\right)}{S_{r e \text { inf } / 3}}+\frac{1.5\left(M_{D W}\right)}{S_{r e \text { inf } / 3}}+\frac{1.75\left(M_{L L+I M}\right)}{S_{r e \text { inf }}}\right] \text { Eq. } 5.38 \\
& f_{b u}=1.0\left[\frac{1.25(569)}{479}+\frac{1.25(83)}{595}+\frac{1.5(90)}{595}+\frac{1.75(988)}{842}\right] 12 \\
& f_{b u}=47.28 \text { ksi tension }
\end{aligned}
$$

Bottom Flange:

$$
\begin{aligned}
& f_{b u}=1.0\left[\frac{1.25(569)}{510}+\frac{1.25(83)}{538}+\frac{1.5(90)}{538}+\frac{1.75(988)}{577}\right] 12 \\
& f_{b u}=58.02 \text { ksi compression }
\end{aligned}
$$

The depth of the web in compression $\left(D_{c}\right)$ was previously determined from the elastic section properties of the prismatic beam as $15.26 \mathrm{in}$. The effective radius of gyration for lateral-torsional buckling was then determined as follows:

$$
r_{t}=\frac{b_{f c}}{\sqrt{12\left(1+\frac{1}{3} \frac{D_{c} t_{w}}{b_{f c} t_{f c}}\right)}}
$$




$$
r_{t}=\frac{12}{\sqrt{12\left(1+\frac{1}{3} \frac{(15.26)(0.4375)}{(12)(1.15)}\right)}}=3.22 \mathrm{in} .
$$

The limiting unbraced length $\left(L_{p}\right)$ to achieve the nominal flexural resistance of $R_{b} R_{h} F_{y c}$ under uniform bending was found as:

$$
\begin{aligned}
& L_{p}=1.0 r_{t} \sqrt{\frac{E}{F_{y c}}} \\
& L_{p}=1.0(3.22) \sqrt{\frac{29000 \mathrm{ksi}}{83 k s i}}=60.02 \mathrm{in} .
\end{aligned}
$$

The compression flange stress at the onset of nominal yielding $\left(F_{y r}\right)$ within the prismatic cross section is to be taken as the smaller of $0.7 F_{y c}$ and $F_{y w}$, but not less than $0.5 F_{y c}$.

$$
\begin{aligned}
& F_{y r}=\min \left(0.7 F_{y c}, F_{y c}\right) \geq 0.5 F_{y c} \\
& F_{y r}=\min [0.7(83 \mathrm{ksi}), 50 \mathrm{ksi}] \geq 0.5(83 \mathrm{ksi})=50 \mathrm{ksi}
\end{aligned}
$$

The unbraced length $\left(L_{r}\right)$ in which either flange is considered to have reached its respective yield strength under uniform bending, was calculated as:

$$
\begin{aligned}
& L_{r}=\pi r_{t} \sqrt{\frac{E}{F_{y r}}} \\
& L_{r}=\pi(3.22 \mathrm{in}) \sqrt{\frac{29000 \mathrm{ksi}}{50 \mathrm{ksi}}}=243.21 \mathrm{in} .
\end{aligned}
$$

Article 6.10.8.2.3 states that $C_{b}$ shall be taken equal to 1.0 when determining $F_{c r}$ for unbraced lengths incorporating flange transitions outside of the 20 percent requirement; however, because an equivalent prismatic section is being assessed, the moment gradient 
modifier should be calculated to obtain an accurate lateral-torsional buckling capacity. The dead and live load moments were found at the mid and intermediate diaphragms within the unbraced length to determine the stresses $f_{\text {mid }}, f_{0}$, and $f_{l}$. The variation in moment over the pier is considered to be concave; therefore, $f_{l}=f_{0}$. The moment gradient modifier and critical stress were then found as:

$$
\begin{aligned}
& C_{b}=1.75-1.05\left(\frac{f_{1}}{f_{2}}\right)+0.3\left(\frac{f_{1}}{f_{2}}\right)^{2} \leq 2.3 \\
& C_{b}=1.75-1.05\left(\frac{22.41}{58.02}\right)+0.3\left(\frac{22.41}{58.02}\right)^{2}=1.39 \leq 2.3 \\
& F_{c r}=\frac{C_{b} R_{b} \pi^{2} E}{\left(\frac{L_{b}}{r_{t}}\right)^{2}} \\
& F_{c r}=\frac{(1.39)(1.0)(3.14)^{2}(29000 \mathrm{ksi})}{\left(\frac{245 \mathrm{in} .}{3.22 \mathrm{in} .}\right)^{2}}=68.45 \mathrm{ksi}
\end{aligned}
$$

The limiting unbraced length required to achieve the onset of nominal yielding in either flange under uniform bending, $L_{r}$, is less than $L_{b}$; therefore, the nominal compression flange strength is equal to $F_{c r}$.

$$
\begin{aligned}
& F_{n c}=F_{c r} \leq R_{b} R_{h} F_{y c} \\
& F_{n c}=68.45 \mathrm{ksi} \leq(1.0)(0.971)(83 \mathrm{ksi})=80.593 \mathrm{ksi}
\end{aligned}
$$

therefore:

$$
F_{n c}=68.45 \mathrm{ksi}
$$




\subsection{Flange Local Buckling Capacity}

The compression flange proportions were evaluated and classified as compact, non-compact, or slender. The compression flange slenderness was then found as:

$$
\begin{aligned}
& \lambda_{f}=\frac{b_{f c}}{2 t_{f c}} \\
& \lambda_{f}=\frac{12}{2(1.5)}=4.00
\end{aligned}
$$

The limiting slenderness ratio for a compact flange is:

$$
\begin{aligned}
& \lambda_{p f}=0.38 \sqrt{\frac{E}{F_{y c}}} \\
& \lambda_{p f}=0.38 \sqrt{\frac{29000}{100}}=6.47
\end{aligned}
$$

The limiting slenderness ratio for a noncompact flange is:

$$
\begin{aligned}
& \lambda_{r f}=0.56 \sqrt{\frac{E}{F_{y r}}} \\
& \lambda_{r f}=0.56 \sqrt{\frac{29000 k s i}{50 k s i}}=13.49
\end{aligned}
$$

Because $\lambda_{f}$ is less than $\lambda_{p f}$, the flange may be considered compact for the subsequent capacity calculations. The web load-shedding factor $\left(R_{b}\right)$ accounts for the shedding of compressive stresses to the flange after the web-buckling limit has been exceeded. The web load-shedding factor was calculated as follows:

$$
R_{b}=1-\left(\frac{a_{w c}}{1200+300 a_{w c}}\right)\left(\frac{2 D_{c}}{t_{w}}-\lambda_{r w}\right) \leq 1.0
$$


where:

$$
a_{w c}=\frac{2 D_{c} t_{w}}{b_{f_{c}} t_{f c}}
$$

Eq. 5.50

If the web satisfies the noncompact limit specified in Article 6.10.1.10.2, $R_{b}$ is to be taken as 1.0 .

$$
\begin{aligned}
& \frac{2 D_{c}}{t_{w}} \leq \lambda_{r w} \\
& \frac{2(15.71 \mathrm{in})}{0.4375 \mathrm{in} .}=71.79 \leq 106.42 \\
& \text { therefore: } \\
& R_{b}=1.0
\end{aligned}
$$

The hybrid girder factor $\left(R_{h}\right)$ is applied to built-up sections in which webs and flanges have different yield strengths. Typically, higher yield strength steels are utilized in flanges, while lower strength steels are used in webs. This improves economy but reduces the total section capacity because the web may yield prior to the flanges. The hybrid girder factor was calculated as follows:

$$
R_{h}=\frac{12+\beta\left(3 \rho-\rho^{3}\right)}{12+2 \beta}
$$

in which:

$$
\begin{aligned}
& \beta=\frac{2 D_{n} t_{w}}{A_{f n}} \\
& \beta=\frac{2(15.71 \mathrm{in})(0.4375 \mathrm{in} .)}{18.00 \mathrm{in}^{2}}=0.763
\end{aligned}
$$


and:

$$
\begin{aligned}
& \rho=\min \left[\left(F_{y w} / f_{n}\right), 1.0\right] \\
& \rho=\min [(50 / 100), 1.0]=0.50
\end{aligned}
$$

Eq. 5.54

The hybrid girder factor is then taken as:

$$
R_{h}=\frac{12+0.763\left[3(0.50)-(0.50)^{3}\right]}{12+2(0.763)}=0.965
$$

The compression flange was previously determined to be compact; therefore, the nominal compression flange strength due to local buckling resistance was found as:

$$
\begin{aligned}
& F_{n c}=R_{b} R_{h} F_{y c} \\
& F_{n c}=(1.0)(0.965)(100 \mathrm{ksi})=96.47 \mathrm{ksi}
\end{aligned}
$$

Eq. 5.55

\subsection{Compression Flange Capacity}

The nominal flexural capacity of the critical section analyzed above was controlled by the lateral-torsional buckling capacity. At the strength limit state, sections in negative flexure must satisfy the following relationship:

$$
\begin{aligned}
& f_{b u}+\frac{1}{3} f_{l} \leq \phi_{f} F_{n c} \\
& 58.023 k s i+0 k s i \leq 1.0(68.45 k s i) \\
& 58.023 k s i \leq 71.90 k s i \quad \therefore \text { OK }(\text { Ratio }=0.847)
\end{aligned}
$$


The flexural capacity of the compression flange is within 15 percent of the ultimate stress; therefore, the girders in the negative flexure region of the bridge have adequate capacity

\subsection{Tension Flange Capacity}

At the strength limit state, continuously braced tension flanges must satisfy the following:

$$
\begin{aligned}
& f_{b u} \leq \phi_{f} R_{h} F_{y f} \\
& 47.28 \mathrm{ksi} \leq 1.0(0.965)(70 \mathrm{ksi}) \\
& 47.28 \mathrm{ksi} \leq 67.55 \mathrm{ksi} \quad \therefore \text { OK }(\text { Ratio }=0.820)
\end{aligned}
$$

\subsection{Shear}

The shear resistance was determined with the provisions of Article 6.10.9.2 of the specifications for an unstiffened web. Intermediate diaphragms are spaced throughout the bridge; however, they will be neglected unless the nominal shear capacity of an unstiffened web is exceeded in the following calculations. The reaction force at the interior bearing support produced the largest shearing force throughout the bridge; therefore, Section II was evaluated as the critical section. The abutment reaction force was also significant; however, this section need not be checked because the web dimensions and strength properties are the same as Section II. At the strength limit state, curved and straight web panels must meet the following requirement:

$$
V_{u} \leq \phi_{v} V_{n}
$$

Eq. 5.58 
where:

$$
\begin{aligned}
& V_{n}=V_{c r}=C V_{p} \\
& \text { and, } \\
& V_{p}=0.58 F_{y w} D t_{w}
\end{aligned}
$$

The ratio of shear-buckling resistance to shear yield strength $(C)$ is determined by evaluating the following equation with $k$ set equal to 5 :

$$
\begin{aligned}
& \text { If: } \\
& \frac{D}{t_{w}} \leq 1.12 \sqrt{\frac{E k}{F_{y w}}} \\
& C=1.0 \\
& \frac{26 \mathrm{in} .}{0.4375 \mathrm{in} .} \leq 1.12 \sqrt{\frac{(29000 \mathrm{ksi})(5)}{50 k s i}} \\
& 59.429 \leq 60.314 \\
& \text { therefore: } \\
& \text { C }=1.0
\end{aligned}
$$

The plastic shearing force was then calculated based on the yield strength and area of the web panel. The shear capacity of the unstiffened web was calculated and compared with the ultimate shear induced by the Strength I load combination.

$$
\begin{aligned}
& V_{p}=0.58(50 \text { ksi })(26 \text { in. })(0.4375 \text { in. })=329.875 \text { kips } \\
& \text { therefore, } \\
& V_{n}=1.0(329.875 \text { kips })=329.875 \text { kips } \\
& V_{u}=254 \text { kips } \leq 329.88 \text { kips } \quad \therefore \text { OK }(\text { Ratio }=0.770)
\end{aligned}
$$


The shear capacity of an unstiffened web provides adequate resistance; therefore, no further analysis is necessary.

\subsubsection{Fatigue Limit State}

\subsection{Load-Induced Fatigue}

The Culloden Bridge has skewed and perpendicular diaphragms spaced at varying intervals throughout its length. The diaphragms are bolted to stiffeners which are welded to the top and bottom flanges. The fatigue of the base metal at weld locations in the tension flange was checked by applying the fatigue load truck. The fatigue truck was factored by 0.75 and multiplied by an impact factor of 1.15 percent. The short-term composite section was used to determine the stress range because shear studs were provided throughout the bridge length. The stress range $(\Delta f)$ induced by the fatigue truck at the pier diaphragm was determined as:

$$
\begin{aligned}
& \Delta f=\frac{\left(+M_{L L+I M}\right) c}{I_{S T}}+\frac{\left|-M_{L L+I M}\right| c}{I_{S T}} \\
& \Delta f=\frac{(42 \times 12)(0.787)}{18,822}+\frac{|-264 \times 12|(0.787)}{18,822}=0.153 \mathrm{ksi}
\end{aligned}
$$

The frequency of the fatigue load was determined by estimating the average daily truck traffic (ADTT). For the Culloden Bridge, the single lane average daily truck traffic was found by first estimating the ADTT based on commentary 3.6.1.4.2 of the specifications. This was based on the assumption that the average daily traffic (ADT) is 20,000 vehicles and that a certain fraction of those vehicles are trucks. The fractions of 
trucks in traffic are specified for the following highway classifications:

Table 5.41 Fraction of Trucks in Traffic

\begin{tabular}{|c|c|}
\hline Class of Highway & $\begin{array}{c}\text { Fraction of } \\
\text { Trucks in Traffic }\end{array}$ \\
\hline Rural Interstate & 0.20 \\
\hline Urban Interstate & 0.15 \\
\hline Other Rural & 0.15 \\
\hline Other Urban & 0.10 \\
\hline
\end{tabular}

The Culloden Bridge is located on a rural portion of US Route 60 between Charleston and Huntington West Virginia; therefore, it will be considered Other Rural. The ADTT was then calculated as:

$$
\begin{aligned}
& A D T T=\text { Truck Fraction } \times A D T \\
& A D T T=0.15 \times 20,000 \text { vehicles }=3,000 \text { trucks per day }
\end{aligned}
$$

The average single lane daily truck traffic was then estimated as:

$$
A D T T_{S L}=p \times A D T T
$$

where:

$$
p=0.80 \text { for bridges with three or more design lanes }
$$

$$
A D T T_{S L}=0.80 \times 3,000=2,400 \text { trucks per day }
$$

The design life of the bridge was assumed to be 75 years and the cycles per truck passage ( $n$ ) were then obtained from Table 6.6.1.5-2 of the specifications.

$$
\begin{aligned}
& N=(365 \text { Days } / \text { Year })(\text { Bridge Life })(n)\left(A D T T_{S L}\right) \\
& N=(365)(75)(1.50)(2,400)=98,550,000 \text { cycles }
\end{aligned}
$$


For load induced fatigue considerations, each detail must satisfy the following:

$$
\begin{aligned}
& \gamma(\Delta f) \leq(\Delta F)_{n} \\
& \text { where, } \\
& (\Delta F)_{n}=\left(\frac{A}{N}\right)^{\frac{1}{3}} \geq \frac{1}{2}(\Delta F)_{T H}
\end{aligned}
$$

The diaphragms are connected with fillet welds normal to the direction of stress in the top flange; therefore, the connections are categorized as C' and the constant amplitude fatigue threshold $\left(\Delta F_{T H}\right)$ was taken as $12.0 \mathrm{ksi}$ as specified in Table 6.6.1.2.5-3. The nominal fatigue resistance of the connection was then found as:

$$
\begin{aligned}
& (\Delta F)_{n}=\left(\frac{44 \times 10^{8}}{9.855 \times 10^{7}}\right)^{\frac{1}{3}} \geq \frac{1}{2}(12.0) \\
& (\Delta F)_{n}=3.5475 \mathrm{ksi} \leq 6 \mathrm{ksi}
\end{aligned}
$$

therefore:

$$
(\Delta F)_{n}=6.0 \mathrm{ksi}
$$

then:

$$
\gamma(\Delta f)=0.153 k s i \leq 6.0 k s i \quad \therefore \text { OK }(\text { Ratio }=0.217)
$$

\subsection{Special Fatigue Requirement for Webs}

Webs with transverse stiffeners are more prone to fatigue cracks; therefore, they shall satisfy the following requirement:

$$
V_{u} \leq \phi_{v} V_{n}
$$


The shear induced by the fatigue load at Section II is equal to the sum of the dead load shears plus twice the fatigue live load shear. Dynamic effects and distribution factors were also applied to the fatigue shears below.

$$
V_{u}=(-39.4)+(-5.84)+(-6.28)+2(-33.1)=-117.64 k i p s
$$

The panel adjacent to the pier support is 245 inches long and governed by the cross-frame spacing. The shear buckling capacity of an unstiffened panel is specified as:

$$
V_{n}=V_{c r}=C V_{p}
$$

Eq. 5.70

The shear-buckling coefficient $(k)$ was found first in order to determine $C$. This was calculated as follows:

$$
\begin{aligned}
& k=5+\frac{5}{\left(\frac{d_{0}}{D}\right)^{2}} \\
& k=5+\frac{5}{\left(\frac{245}{26}\right)^{2}}=5.056
\end{aligned}
$$

If:

$$
\frac{D}{t_{w}} \leq 1.12 \sqrt{\frac{E k}{F_{y w}}}
$$

Eq. 5.72

then:

$C=1.0$

$\frac{26}{0.4375} \leq 1.12 \sqrt{\frac{(29,000)(5.056)}{50}}$

$59.43 \leq 60.65$ 
therefore:

$C=1.0$

The shear buckling capacity of the panel was then found as:

$V_{p}=0.58(50)(26)(0.4375)=329.88$ kips

then:

$V_{c r}=C V_{p}=1.0(329.88)=329.88 \mathrm{kips}$

thus:

$V_{u}=\mid-117.64$ kips $\mid \leq 329.88$ kips $\quad \therefore$ OK $($ Ratio $=0.357)$

\subsubsection{Exterior Girder Check: Section III}

\subsubsection{Service Limit State}

In addition to the Service II load combination, the Service I load combination was also evaluated for live load deflection as specified in Article 6.10.4.1.

\subsection{Elastic Deformations}

Article 2.5.2.6 of the AASHTO specifications states that bridges should be designed to avoid undesirable structural or psychological effects caused by live load deflections. The optional live load deflection limit for a bridge subject to pedestrian and vehicular traffic is $\mathrm{L} / 1000$. The maximum mid-span deflection was obtained from the previously specified live load combination of truck, tandem, and lane load. These loads were factored and multiplied by the appropriate dynamic allowance and distribution factors. The program CONSYS was utilized to determine the maximum undistributed and unfactored deflections within Section III of the Culloden Bridge. The maximum unfactored and un-distributed live load deflection at the mid-span of the bridge was reported 
as $1.77 \mathrm{in.}$ After applying the distribution and dynamic allowance factors, 0.371 and 1.33 respectively, the maximum deflection was reduced to 0.746 in. The maximum allowable deflection, specified above as L/1000, was then found as:

$$
\begin{aligned}
\Delta_{\max } & =\frac{L}{1000} \\
\Delta_{\max } & =\frac{80 f t^{*} 12^{\mathrm{in} / f t}}{1000}=0.96 \text { in } \geq 0.746 \text { in } \therefore \mathrm{OK}(\text { Ratio }=0.910)
\end{aligned}
$$

\subsection{Permanent Deformations}

Determine $R_{h}$ :

$$
\begin{aligned}
& D_{n}=27.38 \mathrm{in} \\
& A_{f n}=10 \times 0.875=8.75 \mathrm{in}^{2} \\
& \beta=\frac{2 \times 27.380 \times 0.375}{8.75}=2.347 \\
& \rho=\frac{50.0 \mathrm{ksi}}{70 \mathrm{ksi}}=0.714 \\
& R_{h}=\frac{12+2.347\left[3(0.714)-(0.714)^{3}\right]}{12+2(2.347)}=0.969
\end{aligned}
$$

The top and bottom flange stresses induced by the Service II load combination were then found and checked as follows:

$$
\begin{aligned}
& \text { Top Flange: } \\
& f_{f}=1.0\left[\frac{1.0(268)}{267}+\frac{1.0(44+47)}{2145}-\frac{1.3(752)}{22836}\right] 12=-12.02 \mathrm{ksi} \text { comp. } \\
& 0.95 R_{h} F_{y f}=0.95(0.969)(70)=64.43 \mathrm{ksi} \\
& 12.02 \mathrm{ksi} \leq 64.43 \mathrm{ksi} \quad \therefore \text { OK }(\text { Ratio }=0.187)
\end{aligned}
$$


Bottom Flange:

$$
\begin{aligned}
& f_{f}=1.0\left[\frac{1.0(268)}{267}+\frac{1.0(44+47)}{375}+\frac{1.3(752)}{409}\right] 12=43.65 \mathrm{ksi} \text { ten. } \\
& 0.95 R_{h} F_{y f}=0.95(0.969)(70)=64.43 \mathrm{ksi} \\
& 43.65 \mathrm{ksi}+0 \leq 64.43 \mathrm{ksi} \quad \therefore \text { OK }(\text { Ratio }=0.677)
\end{aligned}
$$

Article 6.10.4.2.2 also specifies that the compression flange must not exceed the nominal web bend-buckling resistance; however, composite positive bending sections that meet the web proportion requirements of $D / t_{w}<150$ need not be checked.

$$
\frac{D}{t_{w}}=\frac{26}{0.375}=69.333 \leq 150
$$

Therefore, no further calculations are needed at the Service II limit state.

\subsubsection{Strength Limit State}

\subsection{Positive Flexure}

Composite sections in positive flexure are classified as compact or noncompact in Article 6.10.6.2.2 of the specifications. The girder geometry of the cross section is used to determine this classification and a compact section must satisfy the following limits:

- $\quad$ specified minimum yield strength of the flanges do not exceed $70 \mathrm{ksi}$

- the web satisfies the proportional limit of:

$$
\frac{D}{t_{w}} \leq 150
$$

- The section satisfies the web slenderness limit of:

$$
\frac{2 D_{c p}}{t_{w}} \leq 3.76 \sqrt{\frac{E}{F_{y c}}}
$$


To determine if a composite section qualifies as compact, the plastic neutral axis (PNA) must first be determined. This is accomplished by determining the plastic force contributed by each component of the composite cross section. The forces for each component were found as follows:

Plastic force acting in the slab:

$$
\begin{aligned}
P_{s} & =0.85 f^{\prime} c b_{\text {eff }} t_{s} \\
P_{s} & =0.85(4)(90)(7.75)=2,371.5 \mathrm{kips}
\end{aligned}
$$

Plastic force acting in the compression flange:

$$
\begin{aligned}
& P_{c}=F_{y c} b_{c} t_{c} \\
& P_{c}=(70)(10)(0.875)=613 \text { kips }
\end{aligned}
$$

Plastic forces acting in the web:

$$
\begin{aligned}
P_{w} & =F_{y w} D t_{w} \\
P_{w} & =(50)(26)(0.375)=488 \mathrm{kips}
\end{aligned}
$$

Plastic forces acting in the tension flange:

$$
\begin{aligned}
P_{t} & =F_{y t} b_{t} t_{t} \\
P_{t} & =(70)(10)(0.875)=613 \mathrm{kips}
\end{aligned}
$$

From observation, $P_{t}+P_{w}+P_{c} \leq P s$; therefore, the distance to the plastic neutral axis was calculated as follows:

$$
\begin{aligned}
& \bar{Y}=t_{s}\left(\frac{P_{w}+P_{t}+P_{c}}{P_{s}}\right) \\
& \bar{Y}=7.75\left(\frac{488+613+613}{2371.5}\right)=5.596 \text { in. from top of deck }
\end{aligned}
$$


The distance from the centroid of each force-resisting mechanism to the PNA was then found and used to calculate the plastic moment.

$$
\begin{aligned}
& M_{p}=\left(\frac{\bar{Y}^{2} P_{s}}{2 t_{s}}\right)+\left(P_{c} d_{c}+P_{t} d_{t}+P_{w} d_{w}\right) \\
& M_{p}=\left(\frac{(5.596)^{2}(2371.5)}{2(7.75)}\right)+[(613)(3.7)+(613)(30.6)+(488)(17.1)] \\
& M_{p}=34,167 k i p-i n=2,847 k i p-f t
\end{aligned}
$$

Because the PNA is located in the deck, the depth of web in compression $\left(D_{c p}\right)$ is zero. Section compactness was then checked for the composite positive bending section from Eq. 5.75 and Eq. 5.76 .

$$
\begin{aligned}
& \frac{26}{0.375}=69.333 \leq 150 \quad \therefore \text { OK } \\
& \frac{2(0)}{0.375} \leq 3.76 \sqrt{\frac{29,000}{70}} \\
& 0 \leq 150 \quad \therefore \text { OK }
\end{aligned}
$$

The composite section meets the requirements of a compact section, therefore, the nominal moment capacity can now be found. To ensure the deck does not prematurely crush before the section reaches its plastic moment capacity, the following limit must be checked:

$$
\begin{aligned}
& D_{p} \leq 0.1 D_{t} \\
& 5.596 \leq 0.1(36.625) \\
& 5.596 \leq 3.663 \quad \therefore \quad \text { NOT OK }(\text { Ratio }=1.528)
\end{aligned}
$$


Therefore, the flexural capacity must be increased to protect the deck from prematurely cracking. Nevertheless, the nominal moment capacity was found as:

$$
\begin{aligned}
& M_{n}=M_{p}\left(1.07-0.7 \frac{D_{p}}{D_{t}}\right) \\
& M_{n}=2,847 \mathrm{kip}-f t\left[1.07-0.7\left(\frac{5.596}{36.625}\right)\right]=2,742 \mathrm{kip}-f t
\end{aligned}
$$

In continuous span bridges, the flexural resistance must also satisfy the following criteria:

$$
M_{n} \leq 1.3 R_{h} M_{y}
$$

Eq. $\mathbf{5 . 8 4}$

The yield moment of the composite section was determined with Appendix D6.2.2 of the specifications. Within Appendix D, the additional moment capacity of the composite section is found by removing the dead load stresses from the yield strength of the flange. This allows the yield moment to be determined by summing the dead load. Based on the Strength I load combination, the additional moment capacity was found as follows:

$$
\begin{aligned}
& F_{y c}=\frac{M_{D C 1}}{S_{N C}}+\frac{M_{D C 2}+M_{D W}}{S_{L T}}+\frac{M_{A D}}{S_{S T}} \\
& M_{A D}=\left[F_{y c}-\left(\frac{M_{D C 1}}{S_{N C}}+\frac{M_{D C 2}+M_{D W}}{S_{L T}}\right)\right] S_{S T} \\
& M_{A D}=\left[70-\left(\frac{1.25(268)}{267}+\frac{1.25(43)+1.5(47)}{375}\right) 12\right] 409 \\
& M_{A D}=20,819 \mathrm{kip}-\mathrm{in} \\
& M_{A D}=1,735 \mathrm{kip}-\mathrm{ft}
\end{aligned}
$$


The yield moment was then found using from the following equation:

$$
\begin{aligned}
& M_{y}=1.25 M_{D C 1}+1.25 M_{D C 2}+1.5 M_{D W}+M_{A D} \\
& M_{y}=1.25(268)+1.25(43)+1.5(47)+1,735=2,195 \mathrm{kip}-f t \\
& M_{y}=2,195 \mathrm{kip}-f t
\end{aligned}
$$

The above-mentioned criteria can now be checked:

$$
\begin{aligned}
& M_{n} \leq 1.3(0.969)(2195)=2,772 \mathrm{kip}-f t \\
& 2,742 \mathrm{kip}-f t \leq 2,772 \mathrm{kip}-f t \\
& \text { therefore: } \\
& M_{n}=2,742 \mathrm{kip}-f t
\end{aligned}
$$

Eq. $\mathbf{5 . 8 8}$

At the strength limit state, compact sections must satisfy the following equation:

$$
\begin{aligned}
& M_{u}+\frac{1}{3} f_{l} S_{x t} \leq \phi_{f} M_{n} \\
& 1,777 \leq 1.0(2,742) \\
& 1,777 \text { kip }-f t \leq 2,742 \mathrm{kip}-f t \quad \therefore \text { OK }(\text { Ratio }=0.648)
\end{aligned}
$$

Eq. 5.89

\subsubsection{Fatigue Limit State}

\subsection{Load-Induced Fatigue}

By observation, it was concluded that the largest stress range was induced at the intermediate diaphragm at the mid-span of Section III. The diaphragm is bolted to a connection-plate that is welded to the top and bottom flanges of the girder. The fatigue of the base metal at the weld in the tension flange was assessed by calculating the stress 
range induced by the fatigue load truck. The stress range was determined as follows:

$$
\Delta f=\frac{(280.7 \times 12)(27.38)}{11,543}+\frac{|-44.8 \times 12|(27.38)}{11,543}=9.27 \mathrm{ksi}
$$

The frequency of the average daily truck traffic determined in the previous section was used in the subsequent calculations. For load-induced fatigue, each detail must satisfy the following:

$$
\gamma(\Delta f) \leq(\Delta F)_{n}
$$

where:

$$
(\Delta F)_{n}=\left(\frac{A}{N}\right)^{\frac{1}{3}} \geq \frac{1}{2}(\Delta F)_{T H}
$$

The diaphragm is connected by a fillet-weld normal to the direction of stress in the flange; therefore, the connection is categorized as C'. Thus, the constant amplitude fatigue threshold $\Delta F_{T H}$ was taken as $12.0 \mathrm{ksi}$ as specified in Table 6.6.1.2.5-3. The nominal fatigue resistance of the connection was then found as:

$$
\begin{aligned}
& (\Delta F)_{n}=\left(\frac{44 \times 10^{8}}{9.855 \times 10^{7}}\right)^{\frac{1}{3}} \geq \frac{1}{2}(12.0) \\
& (\Delta F)_{n}=3.5475 \mathrm{ksi} \leq 6 \mathrm{ksi}
\end{aligned}
$$

therefore:

$$
\begin{aligned}
& \Delta F_{n}=6.0 \mathrm{ksi} \\
& \gamma(\Delta f)=9.27 \mathrm{ksi} \leq 6.0 \mathrm{ksi} \quad \therefore \text { NOT OK }(\text { Ratio }=1.55)
\end{aligned}
$$




\subsection{Special Fatigue Requirement for Webs}

To control cracking in webs with transverse stiffeners, the following limit shall be satisfied:

$$
\begin{aligned}
& V_{u} \leq \phi_{v} V_{n} \\
& V_{u}=(0)+(0)+(0)+2(12.6)=25.2 \mathrm{kips}
\end{aligned}
$$

The controlling panel length is 200 inches long and is governed by the diaphragm spacing. The shear buckling capacity of this panel is specified as:

$$
V_{n}=V_{c r}=C V_{p}
$$

The shear-buckling coefficient $(k)$ must first be found in order to determine $C$. It was calculated as follows:

$$
\begin{aligned}
& k=5+\frac{5}{\left(\frac{d_{0}}{D}\right)^{2}} \\
& k=5+\frac{5}{\left(\frac{300}{26}\right)^{2}}=5.037 \\
& \text { If }: \\
& \frac{D}{t_{w}} \leq 1.12 \sqrt{\frac{E k}{F_{y w}}}
\end{aligned}
$$

then:

$C=1.0$

$\frac{26}{0.375} \leq 1.12 \sqrt{\frac{(29,000)(5.037)}{50}}$

$69.33 \geq 60.54$ 
If:

$\frac{D}{t_{w}} \leq 1.40 \sqrt{\frac{E k}{F_{y w}}}$

Eq. 5.94

then:

$C=\frac{1.12}{\frac{D}{t_{w}}} \sqrt{\frac{E k}{F_{y w}}}$

Eq. 5.95

$69.33 \leq 1.40 \sqrt{\frac{(29,000)(5.037)}{50}}=75.675$

therefore:

$C=\frac{1.12}{\left(\frac{26}{0.375}\right)} \sqrt{\frac{(29,000)(5.037)}{50}}=0.873$

then:

$V_{p}=0.58(50)(26)(0.375)=282.8$ kips

and:

$V_{c r}=C V_{p}=0.873(282.75)=246.9$ kips

therefore:

$V_{u}=25.2$ kips $\leq 246.9$ kips $\quad \therefore$ OK $($ Ratio $=0.102)$

\subsubsection{Design Assessment Summary}

The service, strength, and fatigue limit states were assessed for critical positive and negative bending sections of the Culloden Bridge. The Service II limit state was evaluated for Section II in the negative bending region at the pier. To protect the integrity and rideability of the deck, the Service II limit state restricts flange stresses to 95 
percent of their yield capacity to protect against inelastic deformations. The top and bottom flanges of the Culloden Bridge satisfied this requirement by 73 and 58 percent, respectively. The Service I limit state was applied when checking the live load deflection. Section III was the most critical with a maximum theoretical deflection of 0.746 in.; 9 percent less than the maximum allowable deflection 0.960 in.

The shear and moment capacities of Sections II and III of the Culloden Bridge were evaluated at the Strength I limit state. When determining shear capacity, it was conservatively assumed that the web was unstiffened although stiffeners were provided at the diaphragm connections. The shear resistances of Sections II and III were found to exceed the Strength I induced shears by 23 and 90 percent, respectively. The moment capacities of Sections II and III were also found to exceed the maximum Strength I induced moments by 15 and 35 percent, respectively. However, Section III did not satisfy the requirements Article 6.10.7.1.2 which ensures the deck in a composite section does not prematurely crush prior to the girder reaching its plastic moment capacity. The Culloden Bridge has shallow girders that led to this limit being exceeded by 54 percent, however, the maximum Strength I moment only induces 65 percent of the design flexural stress of the girder; therefore, it is likely that the girder will never undergo inelastic behavior under the prescribed loads and the deck will maintain adequate serviceability. The fatigue limit state was evaluated for diaphragm connections and the web. In Section II, the weld base metal strength at the diaphragm connection was found to exceed the load induced fatigue stress by 78 percent. The web at this location was also found to exceed its necessary capacity by 64 percent. The fatigue of the weld base metal for the diaphragm connection at the mid-span of the Bridge was also checked for Section III. 
The fatigue truck induced a live load stress range of $9.27 \mathrm{ksi}$ at the location of the weld in the tension flange. The allowable stress range for a $C^{\prime}$ detail is only $6 \mathrm{ksi}$; therefore, the fatigue resistance of the weld base metal at this location is exceeded by 55 percent.

Table 5.42 Summary of Performance Ratios: Exterior Girder Section II

\begin{tabular}{|c|c|c|c|}
\hline \multirow{2}{*}{ Service II } & Permanent & Top Flange & 0.268 \\
\cline { 3 - 4 } & Deformations & Bottom Flange & 0.420 \\
\hline \multirow{3}{*}{ Strength I } & Negative & Top Flange & 0.847 \\
\cline { 3 - 4 } & Flexure & Bottom Flange & 0.820 \\
\cline { 3 - 4 } & Shear & Web & 0.770 \\
\hline \multirow{2}{*}{ Fatigue } & Load Induced & Top Flange & 0.217 \\
\cline { 2 - 4 } & Special for Web & Web & 0.357 \\
\hline
\end{tabular}

Table 5.43 Summary of Performance Ratios: Exterior Girder Section III

\begin{tabular}{|c|c|c|c|}
\hline Service I & Elastic & 1.50 L Point & 0.910 \\
\hline \multirow{2}{*}{ Service II } & Permanent & Top Flange & 0.187 \\
\cline { 3 - 4 } & Deformations & Bottom Flange & 0.677 \\
\hline Strength I & Positive Flexure & Bottom Flange & 0.648 \\
\hline \multirow{2}{*}{ Fatigue } & Load Induced & Top Flange & 1.550 \\
\cline { 2 - 4 } & Special for Web & Web & 0.102 \\
\hline
\end{tabular}




\section{Chapter 6 -Culloden Bridge Field Test}

\subsection{Introduction}

The Culloden Bridge (WVDOH Bridge No. 10462) is a three-span continuous bridge that carries two lanes of traffic on US Route 60 . The bridge was instrumented and field tested over a $2 \frac{1}{2} 2$-day period. The main objectives of the test were to determine bending moments, deflections, and dynamic responses. The bridge has staggered diaphragms, integral abutments, elastomeric bearings, continuously composite sections, and a high level of skew that makes it of particular interest for comparison with the AASHTO specifications.

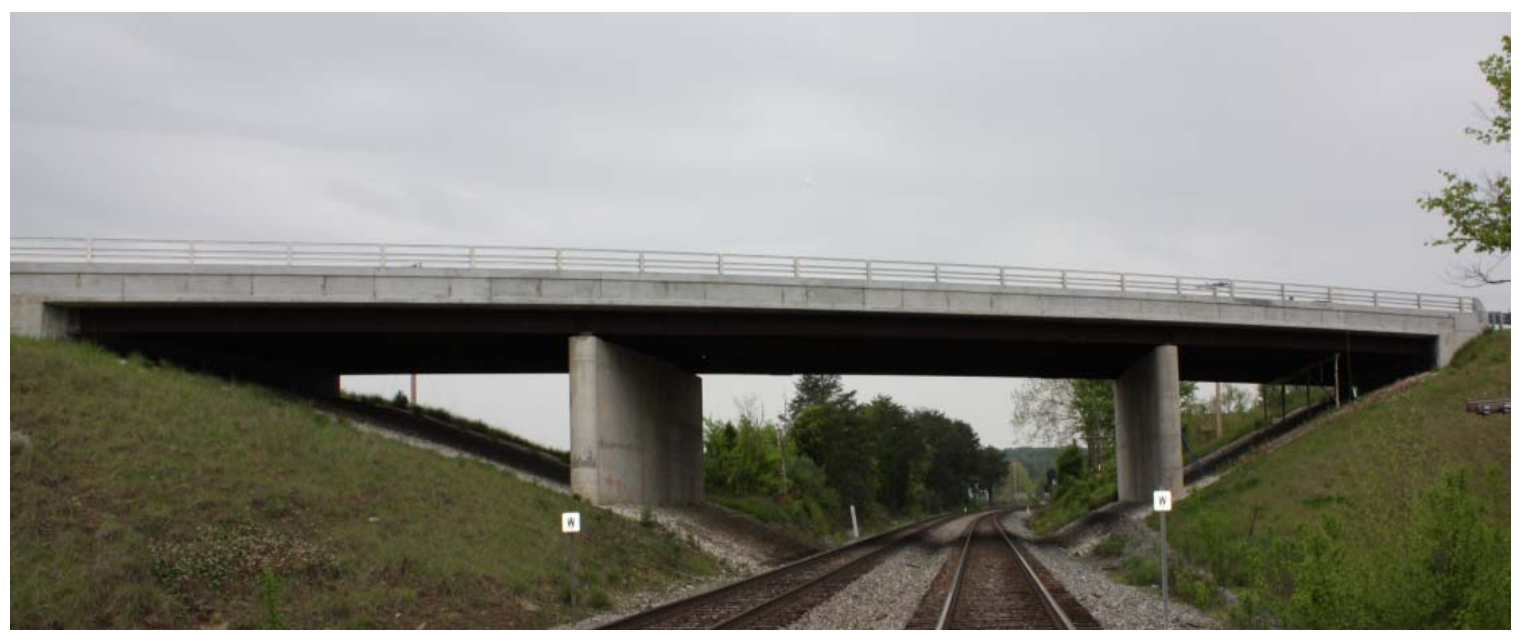

Figure 6.1 Culloden Railroad Overpass (Bridge No. 10462)

\subsection{Overview}

The focus of this project was to experimentally and analytically evaluate design code applicability for girders fabricated from $100 \mathrm{ksi}$ steel. Specifically, field testing of the Culloden Bridge was conducted to assess the accuracy and consistency of the current 
AASHTO specifications for HPS 100W I-girders. The Culloden Bridge incorporates HPS $100 \mathrm{~W}$ in the compression flanges of the negative bending regions; making it one of the first bridges in the United States to utilize this steel.

During the first full day of testing, the maximum negative bending region over the pier was instrumented with strain gages. While this was taking place, a rigid frame was also constructed to support LVDTs. The second day was used to load test and move the strain gages between positive and negative bending locations. This was accomplished without much difficulty because reusable strain transducers were used in tandem with a wireless data acquisition system.

Several static load truck placements were selected to maximize live load effects on each of the seven girders. These placements corresponded to maximum bending moment and deflection locations that were determined from influence surfaces and with the Lever Rule. After static load testing had been completed, dynamic load tests were performed by exciting the suspension of the load truck as it drove over the bridge.

\subsection{Goals}

Investigators conducted controlled load testing of the bridge with the following goals in mind:

- assess general structural performance,

- determine live load distribution factors,

- calculate live load rating factors,

- evaluate live load deflections, and

- observe dynamic behavior of the superstructure. 
The results of this field test are later used to evaluate the overall performance of HPS 100W Bridges by comparing the experimental results with the AASHTO specifications. When performing field tests, it is decidedly difficult to match measured responses with intended structural performance. Many factors affect the final structural response such as:

- actual structural properties and dimensions,

- lateral live load distribution,

- longitudinal distribution,

- impact,

- bearing restraint,

- additional/unintended composite action, and

- curb, railing, and skew effects.

\subsection{Bridge Description}

The Culloden Bridge, pictured in Figure 6.2, is a three-span (54 ft., $80 \mathrm{ft} ., 54 \mathrm{ft}$.) continuous bridge on the border of Cabell and Putnam Counties. It carries local traffic on US Route 60 , parallel to Interstate 64 , making it a secondary route. The bridge's construction was completed in 2006. 


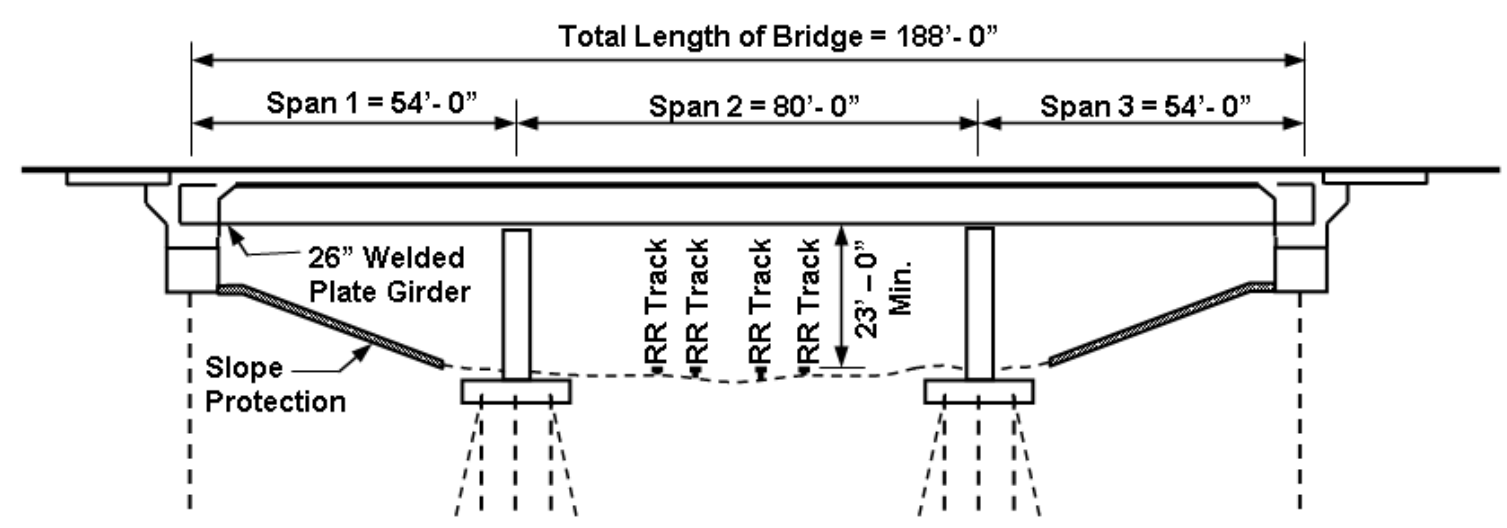

Figure 6.2 Typical Elevation of Culloden Railroad Overpass

The Culloden Bridge is comprised of seven weathering steel hybrid I-girders with 50 ksi webs, and 70-100 ksi flanges. The interior girders, shown in Figure 6.4, are symmetric about their neutral-axis throughout all three-spans, whereas the exterior girders have slightly larger bottom flanges in spans one and three. The design utilizes three different cross sections to resist positive and negative bending moments through out the bridge. The first section transition takes place $45 \mathrm{ft} .-9$ in. from the abutment and was accomplished with splice welds. A second transition takes place $69 \mathrm{ft} .-9$ in. from the abutment and consists of bolted splice plates ranging in thicknesses from $3 / 8$ " to $5 / 8$ ". Shear studs are provided throughout the entire length of the bridge, therefore, the bridge may be considered composite in both positive and negative bending regions. 


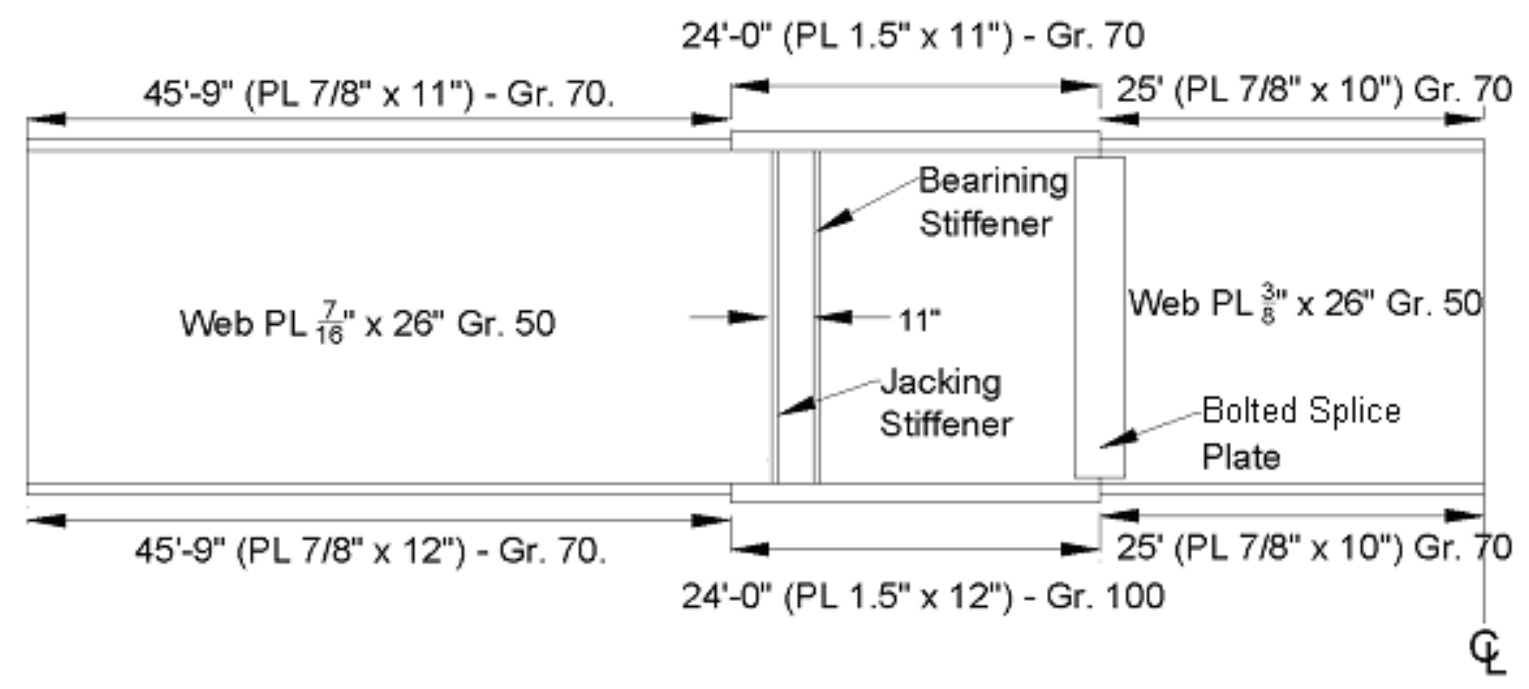

Figure 6.3 Girders 1 and 7 Section Properties

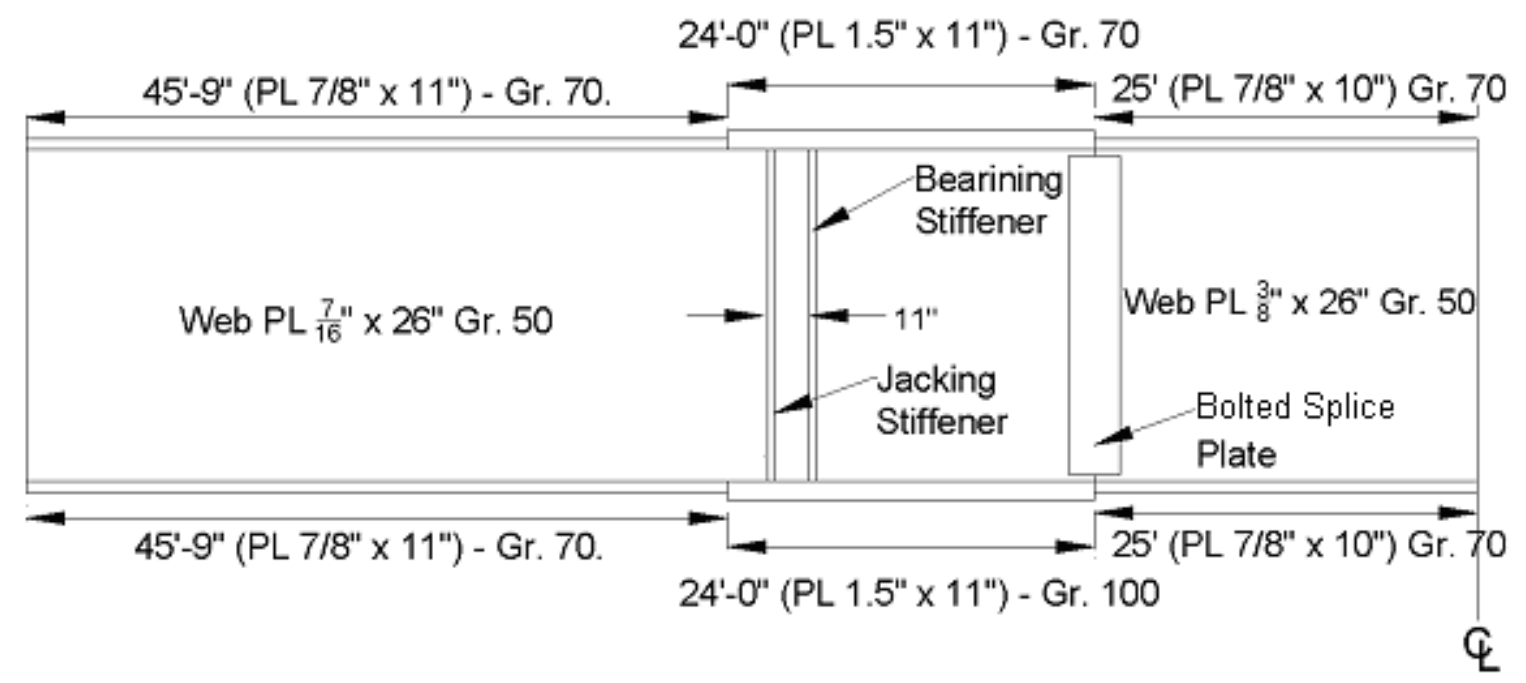

Figure 6.4 Girders 2 thru 6 Section Properties

The Culloden Bridge is skewed at an angle of $31^{\circ} 00^{\prime} 10^{\prime \prime}$ at the abutments and interior supports. Staggered diaphragms run perpendicular to the longitudinal centerline of the bridge (Figure 6.5), while the diaphragms at the supports are skewed (Figure 6.6). The diaphragms in all three spans of the bridge are comprised of C15 x 33.9 channel sections bolted to $1 / 2 "$ stiffeners. 


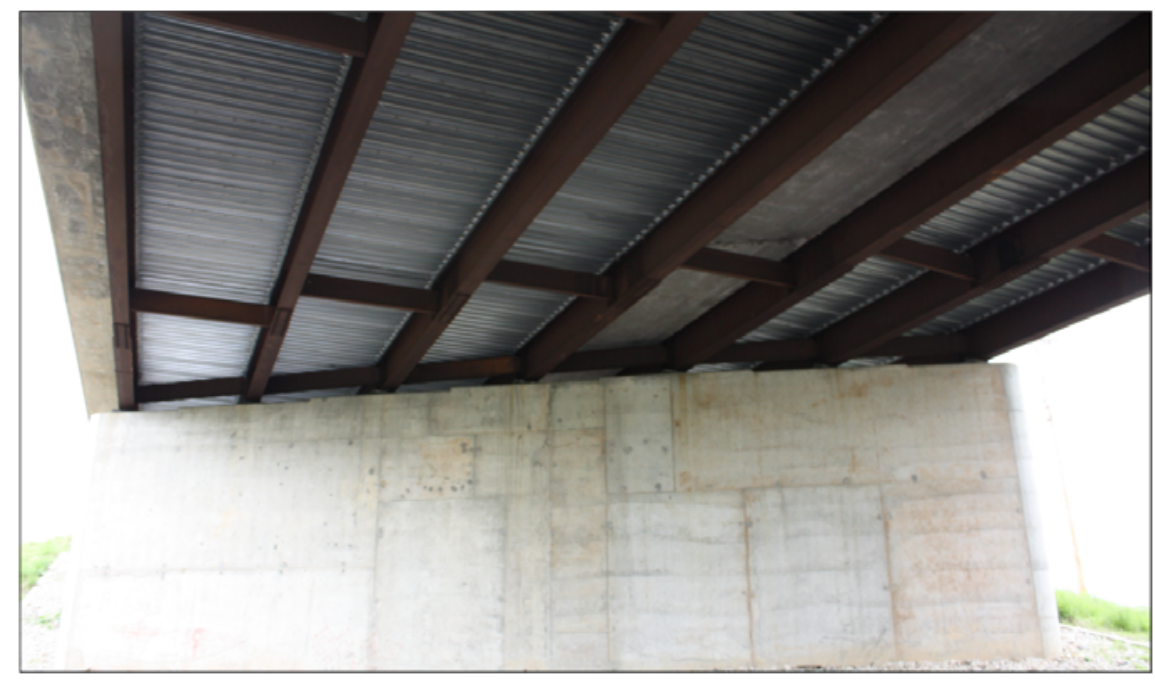

Figure 6.5 Intermediate and Pier Diaphragms

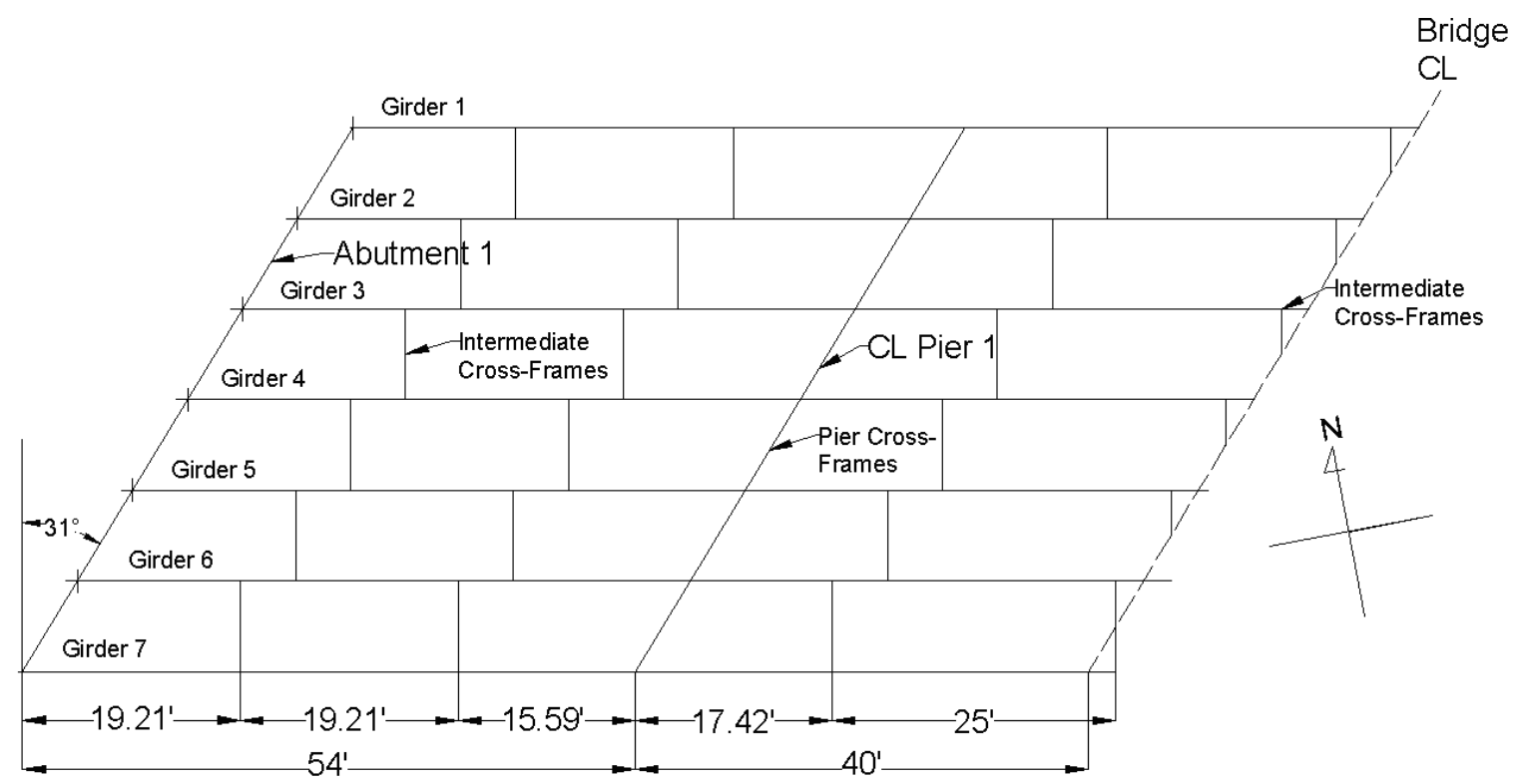

Figure 6.6 Culloden Bridge Framing Plan

The bridge carries two 12-ft. lanes of traffic and accommodates two shoulders; 8 $\mathrm{ft}$. and $16 \mathrm{ft}$., as well as a 5-ft. sidewalk. The bearings are $16.5 \mathrm{in.} \mathrm{x} 11 \mathrm{in}$. and $16.5 \mathrm{in} . \mathrm{x}$ 13 in. elastomeric bearing pads with a total thickness of 3 in. The pads are comprised of 3/8 in. thick elastomeric layers with 6-11 gage steel laminates. Each pad rests on a 
beveled steel sole-plate that typically tapers from 1.95 " to 2.05 " in order to accommodate the superelevation of the deck.

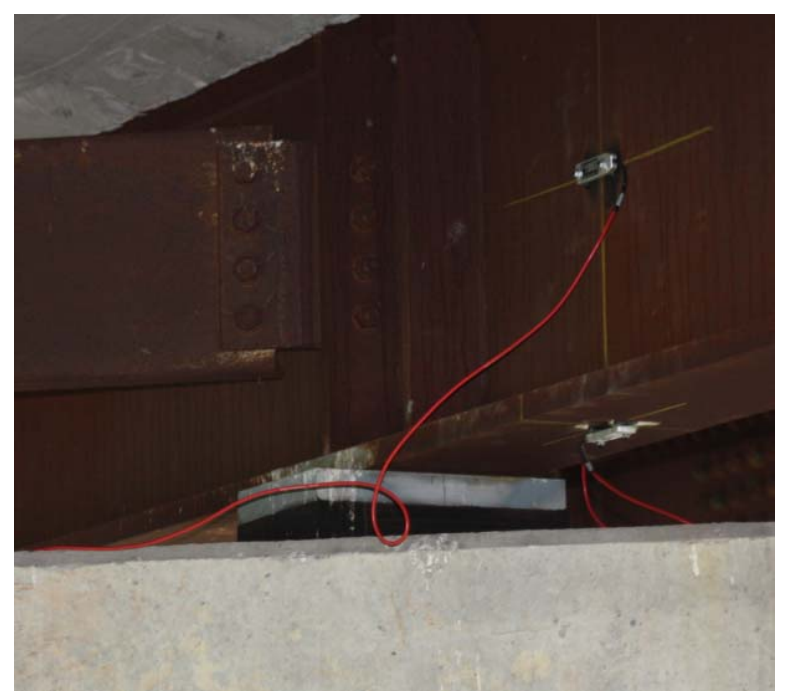

Figure 6.7 Elastomeric Bearing Pad

The reinforced concrete deck is approximately 8 -inches thick and supports an additional 8-in. thick sidewalk on the north overhang. Two-parapets, with built-in continuous railings, also run the full length of the bridge on the north and south overhangs.

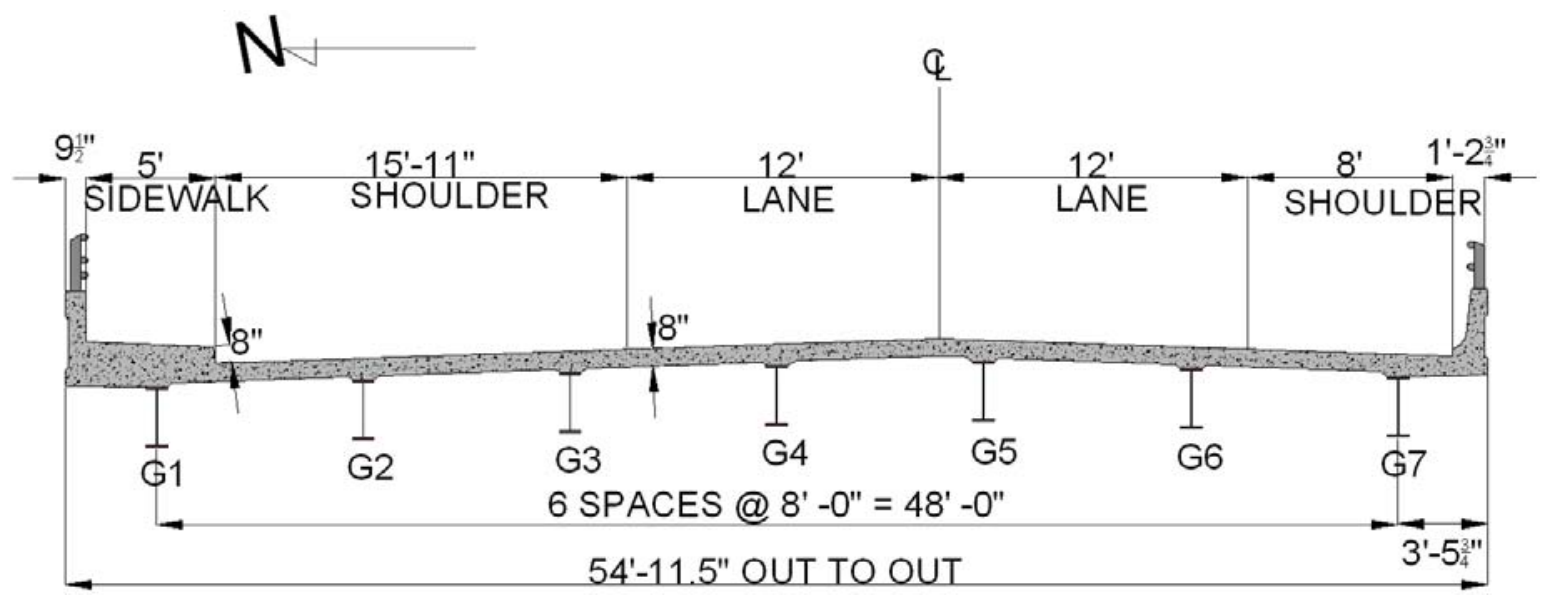

Figure 6.8 Typical Cross Section of the Culloden Bridge 


\subsection{Equipment}

\subsubsection{Data Acquisition}

Strains, deflections, and accelerations were collected and recorded by a suite of wireless instruments, devices, and software from Bridge Diagnostics, Incorporated (BDI). The BDI wireless system can accommodate several different types of instruments and incorporates 4-channel nodes and a wireless base station. Each instrument generally comes equipped with BDI's "Intelliducer" chip that allows it to identify itself within the software. This eliminates confusion during post-processing when trying to distinguish between data collected by various gages. The instruments used during this field test were BDI strain transducers, RDP LVDTs, and a Delta Metrics accelerometer.

The wireless base station is used to monitor real-time wireless broadband signals that are transmitted over several hundred feet from the 4-channel nodes. The nodes also monitor and power the instruments when online. The base station is capable of taking readings at 500 samples per second $(500 \mathrm{~Hz})$ and has an expandable channel capacity ranging from 4 to 128 channels; expandable in multiples of four.

This test system saves a lot of time because it requires no wiring between the base station and the instruments. The nodes and base station are powered by rechargeable 9.6V Makita Ni-MH batteries that can last up to six hours under continuous use. The BDI software also has a standby function that allows users to put all or some of the nodes to sleep for a given amount of time. This allows users to run tests all day on a single battery charge without having to spend valuable time retrieving the nodes to replace batteries. 


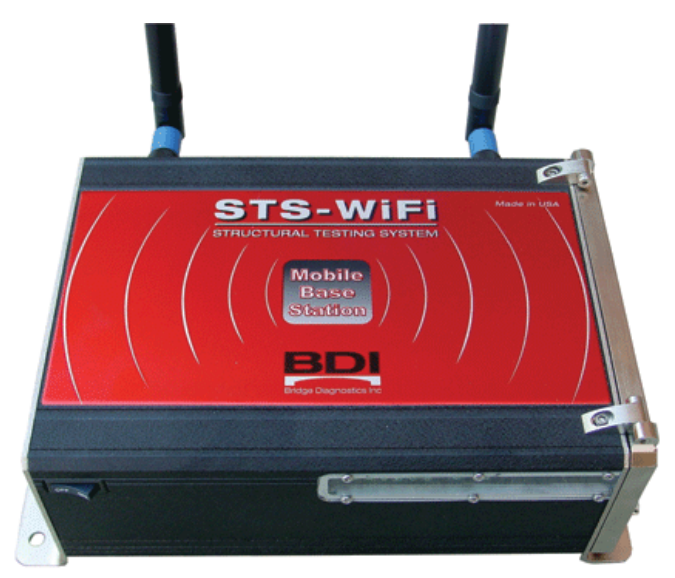

Figure 6.9 Wireless Base Station

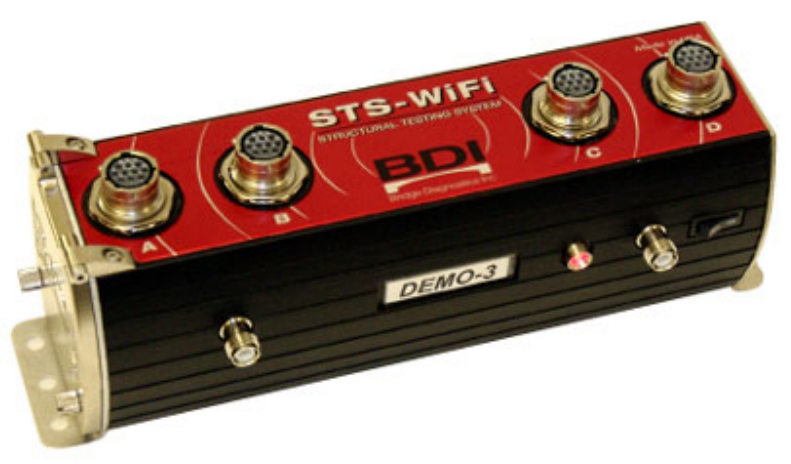

Figure 6.10 4-Channel Node

\subsubsection{Strain Gages}

The strain gages selected for the field test were BDI's re-useable strain transducers (Figure 6.11). They are ideal for field-testing because they require minimal surface preparation and take very little time to install. The gages have a temperature range of $-60^{\circ} \mathrm{F}$ to $+250^{\circ} \mathrm{F}$ and connect to the nodes with military style quick connect plugs requiring no solder. Each gage has a range of \pm 2000 me with an accuracy of \pm 2 percent. Reusable mounting studs were glued to the bridge with an instant adhesive and mounted with a jig to ensure proper stud spacing. The jig also reduced the risk of damaging the gages while tightening the nuts. The mounting studs fit through two holes on either end 
of the gage and tightened with two 7/16-in. nuts. The recommended adhesive was Loctite 410 Black Toughened Adhesive with an accelerator: Loctite Tak Pak 7452. The gage locations were first marked using a yellow construction crayon and then prepped with a hand grinder to remove rust. An acetone soaked rag was then used to remove any residue and dust. The adhesive was then applied to the bottom of the transducer tabs and pressed against the girder at the marked gage locations. After a brief moment, the gage was pulled back off the girder and the adhesive accelerator was quickly sprayed onto the two adhesive spots left on the girder from the tabs. The gage was then reapplied to the same location and held in place for approximately 15 seconds until secure.

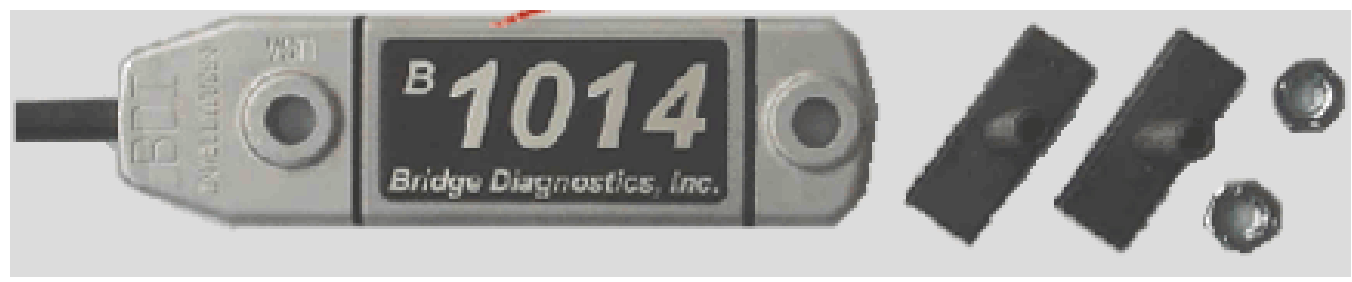

Figure 6.11 BDI Strain Transducer

\subsubsection{Accelerometer}

In order to observe the dynamic behavior of the bridge, a Delta Metrics accelerometer (Figure 6.12) was mounted to Girder 4 on the underside of the top flange. It has a frequency range of 0 to $300 \mathrm{~Hz}$ and a maximum acceleration capacity of $5 \mathrm{~g}$ 's. Its operational temperature range is $-40^{\circ} \mathrm{F}$ to $250^{\circ} \mathrm{F}$. 


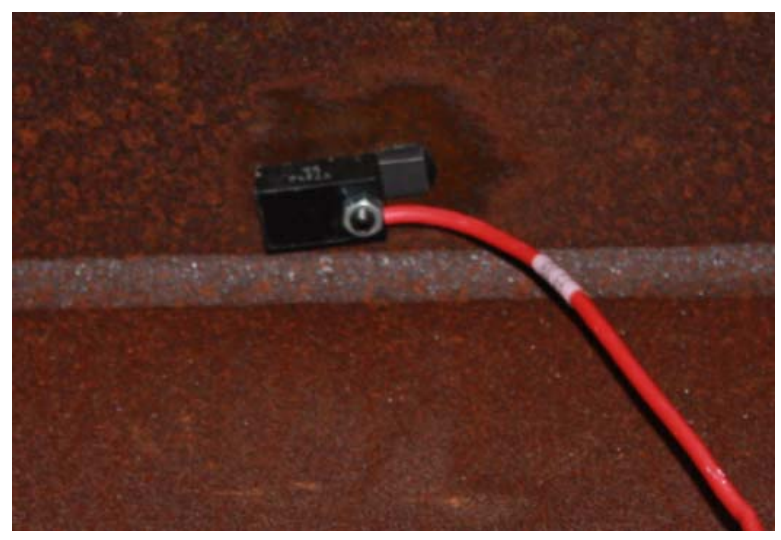

Figure 6.12 Delta Metrics 5g Accelerometer

\subsubsection{Linear Variable Differential Transducers}

Deflections were simultaneously recorded at the theoretical maximum positive bending region of the first-span using 7-LVDTs. The LVDTs were provided by BDI and manufactured by RDP Electronics Group. They have a range of \pm 1 inch, an accuracy of $\pm 0.1 \%$, and an operating temperature range of $-58^{\circ} \mathrm{F}$ to $158^{\circ} \mathrm{F}$.

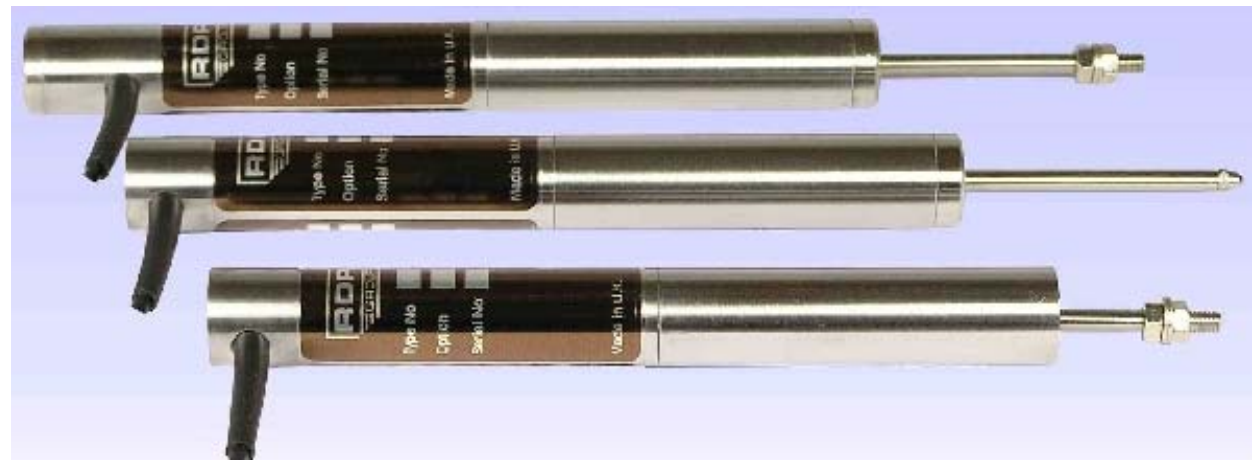

Figure 6.13 RDP Electronics Group DC LVDTs

\subsubsection{Power Supply}

Power was supplied with a Honda gasoline generator in tandem with an APC battery back up and surge protection system. This fail safe ensured that no data would be lost or corrupted due to power loss or surge. 


\subsubsection{Wheel-Load Scales}

The load truck's wheels were weighed prior to load testing so that it would later be possible to compare the load test data with AASHTO prediction equations. Each wheel load was determined with an Intercomp PT300 scale with a 25,000-pound capacity and 20-pound sensitivity.

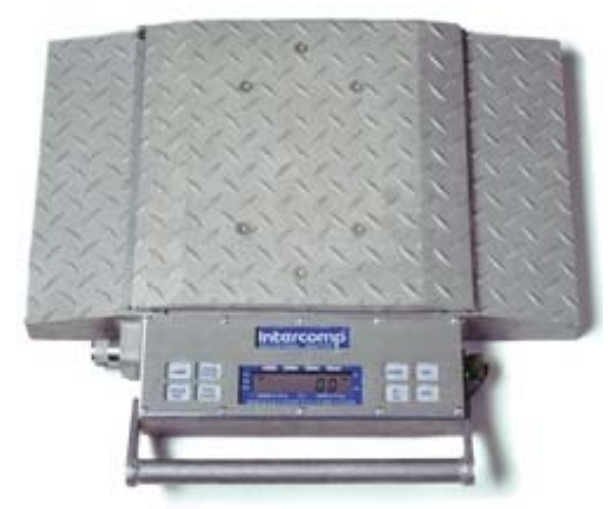

Figure 6.14 Intercomp PT 300 Portable Wheel Load Scale

\subsubsection{Load Truck}

A fully loaded tandem-axle dump truck was provided by the West Virginia Department of Highways (WVDOH) to induce various structural behaviors. This type of truck was chosen due to its similarity to the AASHTO HS-20 design load truck. The truck was weighed and measured prior to static load tests with the Intercomp scales and a tape measure. The weight of each wheel load was recorded in a flat parking lot and is shown below in Figure 6.16. 


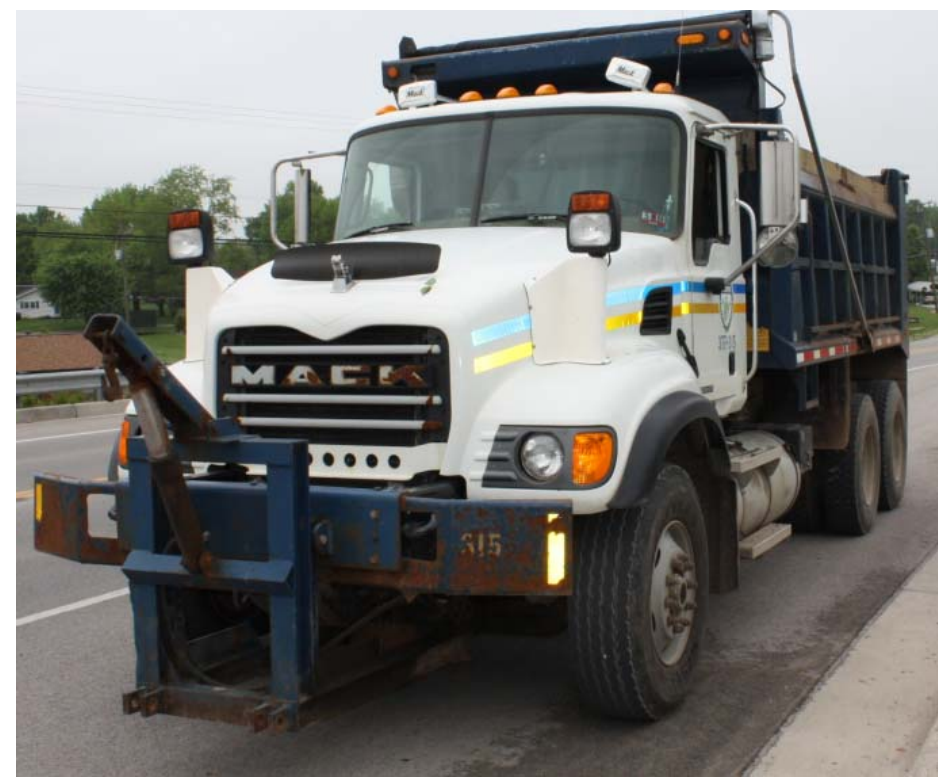

Figure 6.15 WV-DOH Tandem-Axle Dump Truck

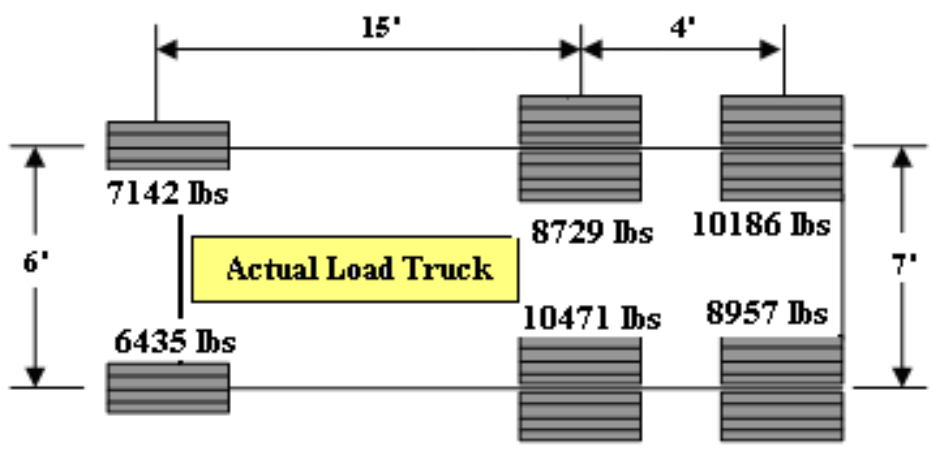

Figure 6.16 WV-DOH Tandem-Axle Dump Truck Wheel Loads 


\subsubsection{Miscellaneous Equipment}

The placement of the strain transducers required the use of several pieces of equipment shown below:

- $20 \mathrm{ft}$. extension ladder,

- extension cord,

- square,

- measuring tape,

- grinder, and

- $\quad$ socket set.

The tools required to construct the LVDT frame were:

- $10 \mathrm{ft}$. step ladder,

- sledge hammer,

- plumb bob,

- cordless drill and saw, and

- bubble-level.

Due to inclement weather and line-of-sight restrictions, the base station and computer were placed under the bridge; thus, it was impossible for the person running the software to know the position of the load truck. To resolve this issue, Cobra Walkie Talkies were used to communicate when to start and stop the data acquisition system. 


\subsection{Determination of Load Truck Placement}

Worst-case truck placements were determined for each girder prior to load testing. This was accomplished by performing a FEA of the bridge and with the Lever Rule. Both methods are detailed in the subsequent sections and were taken into account when placing the load truck during field tests.

\subsubsection{Influence Surfaces Generated using Finite Element Analysis}

A three-dimensional finite element (FE) model of the Culloden Bridge was constructed with the program FEMAPTM, and compiled and analyzed within the program

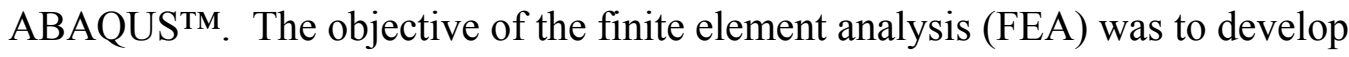
influence surfaces that could be used to determine truck placements that maximized the force effects in each of the seven girders. A 32-kip unit-load was placed incrementally at tenth-points along the bridge. The stresses were evaluated at two locations in the web and one location in the bottom by programming the input files to output stresses for user defined elements. Shears and deflections were also separately written to output files with each incremental move of the unit-load. Microsoft Excel ${ }^{\mathrm{TM}}$ spreadsheets were built to convert the ABAQUS output files into a usable format. Once all of the values were input into the spreadsheets, the moments in each girder were calculated from the stresses at each tenth-point. The moments, shears, and deflections were then compiled and plotted in three-dimensional graphs to generate influence surfaces for the bridge. The 3-D influence surfaces for moment, shear, and deflection at the $0.40 \mathrm{~L}_{1}$ point in Girder 3 can be seen in the figures below. 2-D representations of the 3-D graphs were also created to 
better observe the exact locations of maximum influence. The influence surfaces were then used to determine worst-case truck placements based on peak influence coefficients.

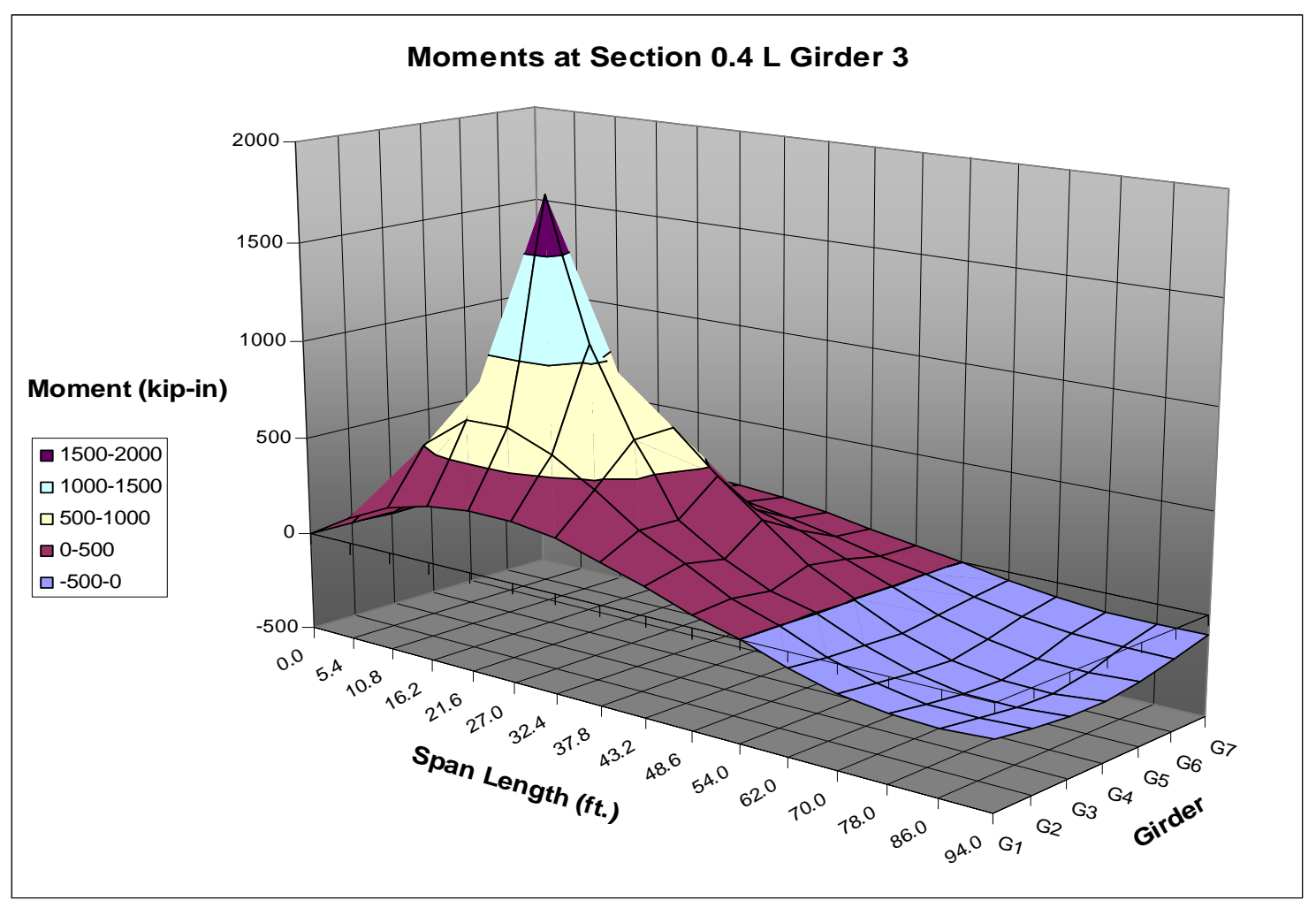

Figure 6.17 Moment Influence Surface 


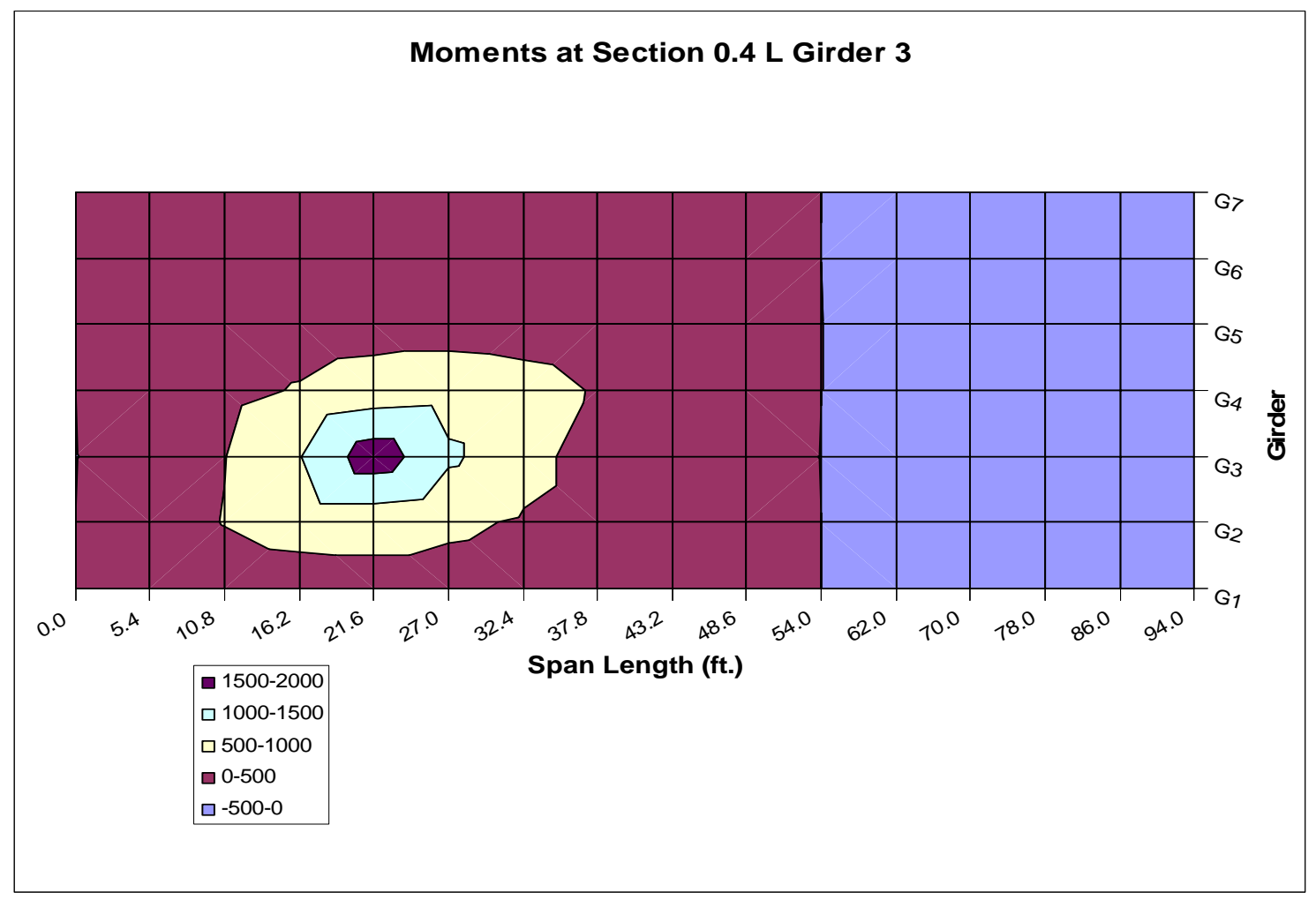

Figure 6.18 2-D Representation of Moment Influence Surface

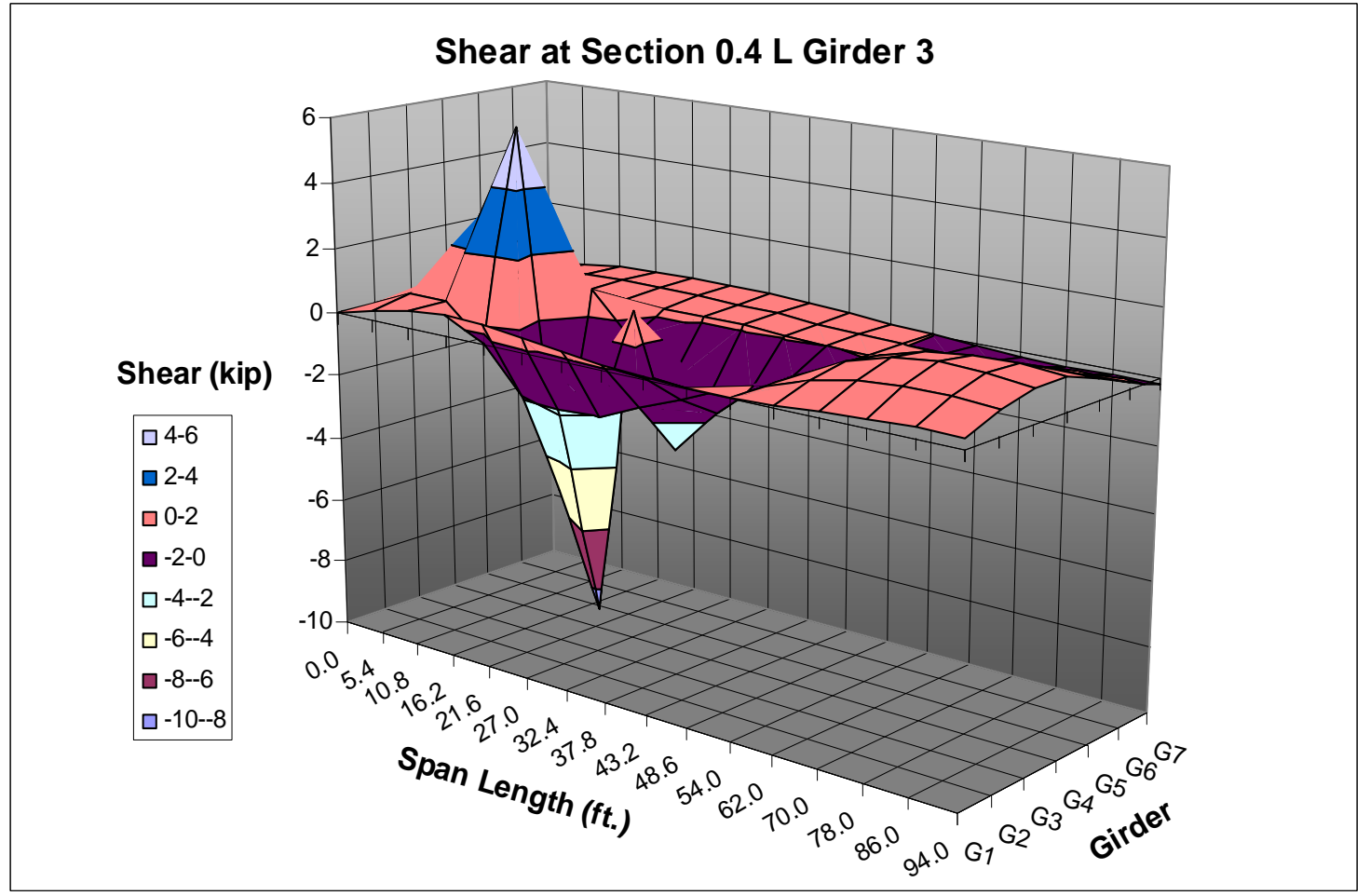

Figure 6.19 Shear Influence Surface 


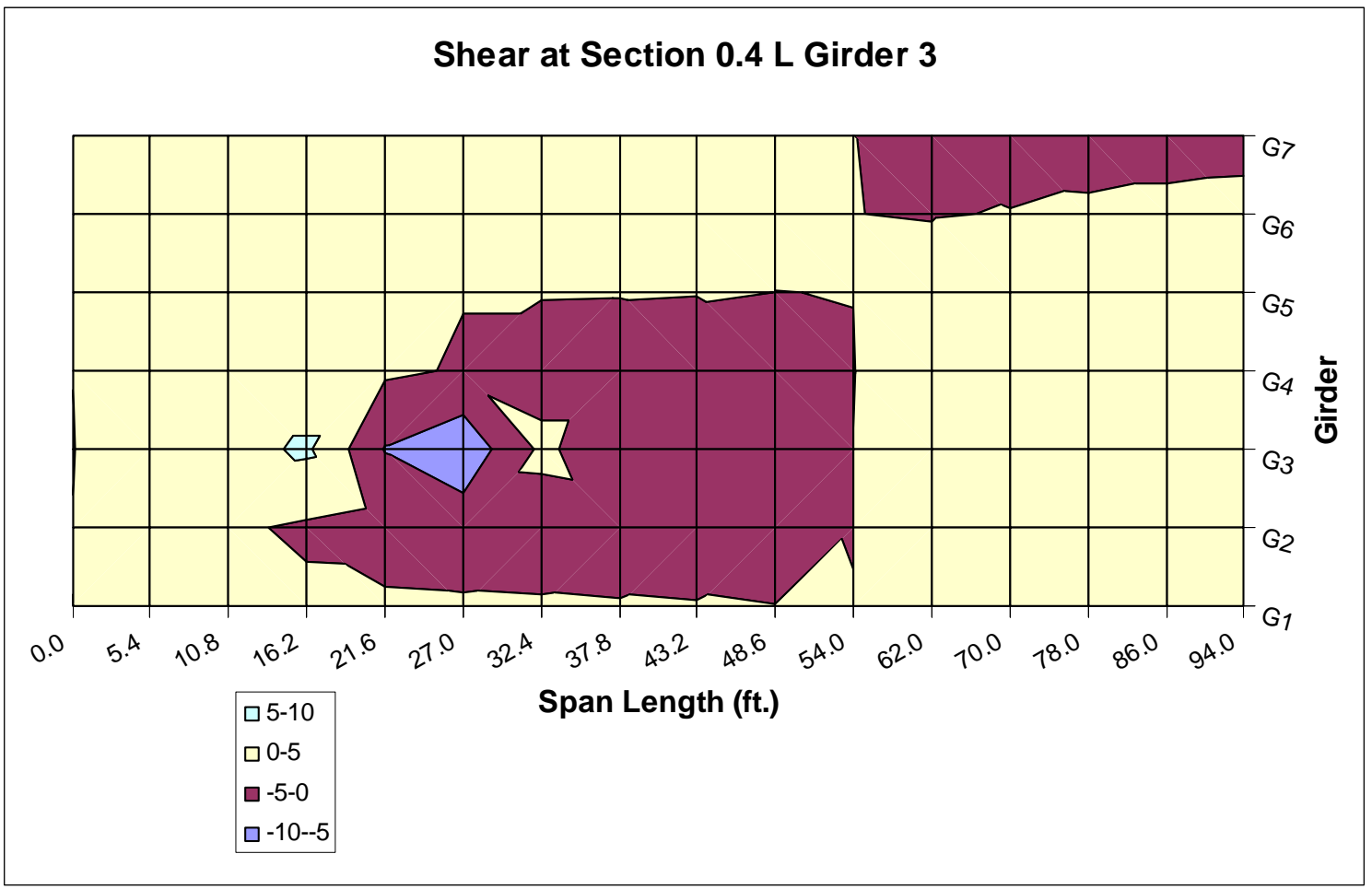

Figure 6.20 2-D Representation of Shear Influence Surface

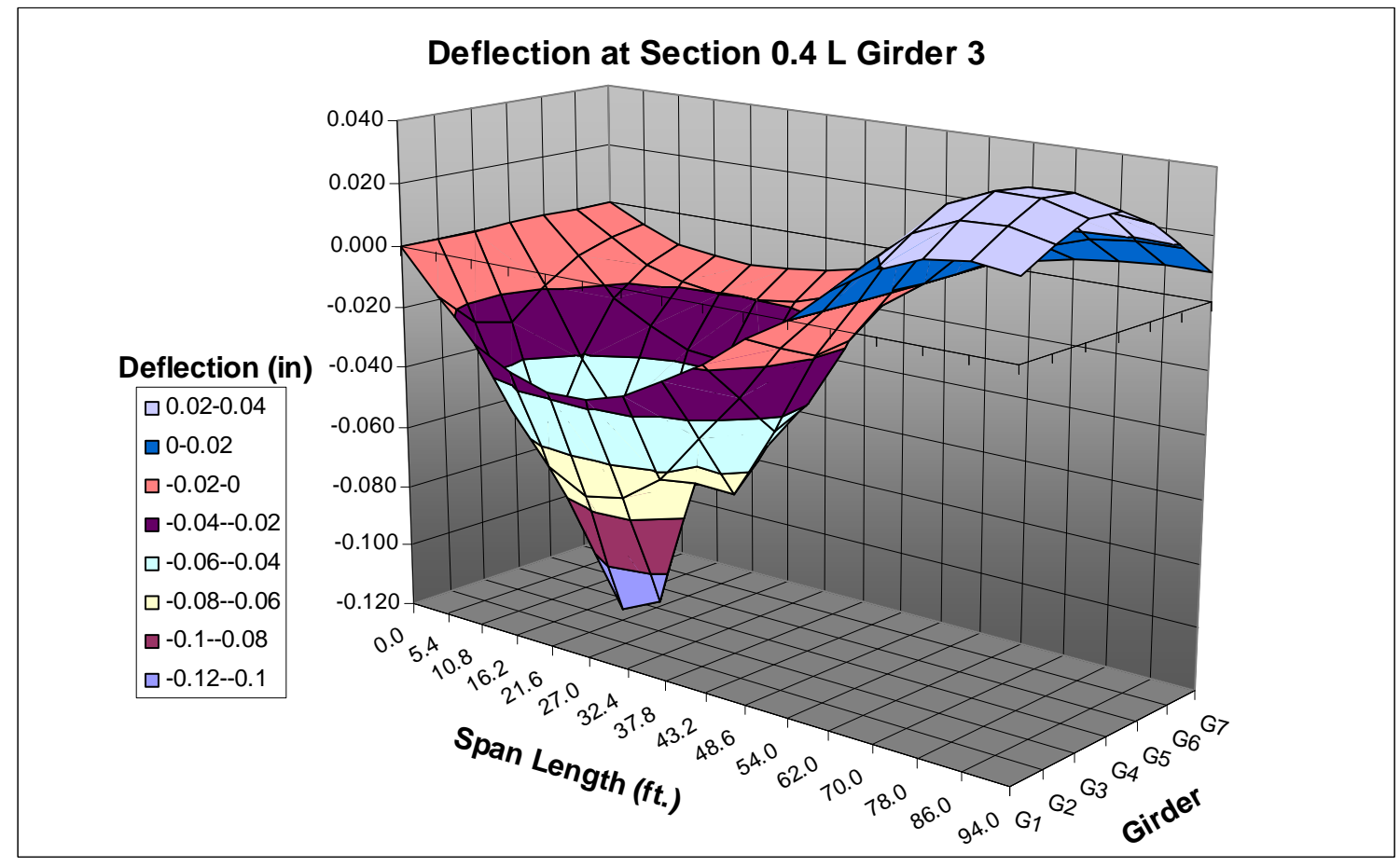

Figure 6.21 Deflection Influence Surface 


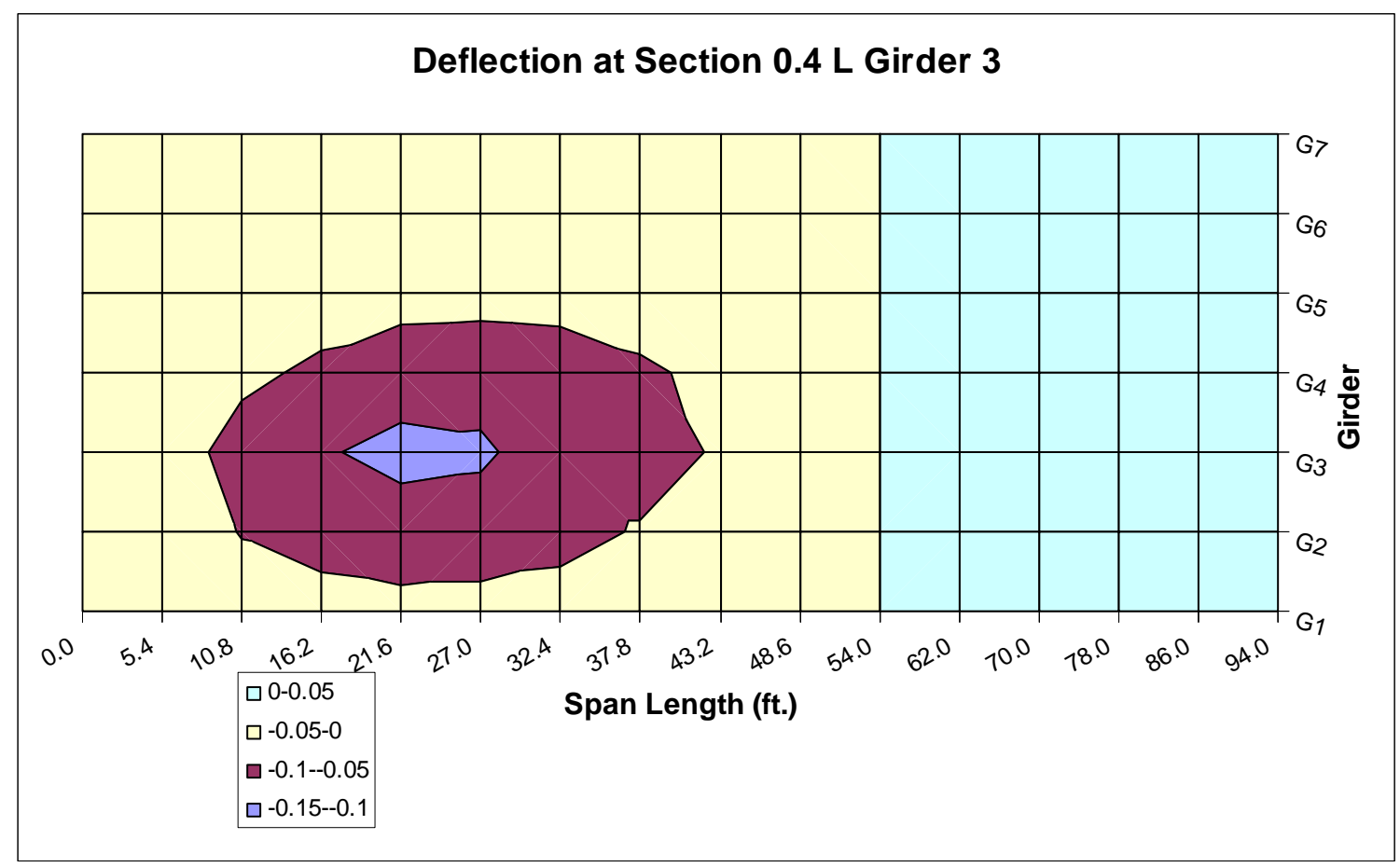

Figure 6.22 2-D Representation of Deflection Influence Surface

\subsubsection{Lever Rule Load Placement Method}

The Lever Rule was also used to estimate worst-case lateral truck placements for each of the 7 girders. HS-20 truck dimensions were used to space 1-kip unit loads laterally across the bridge deck. The Lever Rule assumes that the bridge deck behaves as a simply supported beam between adjacent girders. To obtain each girder reaction, the sum of the moments is taken about one of the adjacent girders. Equilibrium equations and the principle of superposition make it possible to determine the maximum response of each girder due to several unit loads acting simultaneously. For interior girders, multiple trucks were able to contribute to each of the worst-case loadings. A distance of 4 $\mathrm{ft}$. was maintained between trucks, based upon AASHTO spacing requirements, and $2 \mathrm{ft}$. between tires and curbs. The Lever Rule is also used in the AASHTO specifications to 
determine lateral live load distribution factors for shear and moment, but in this case, was also used to estimate worst-case truck placements.

Table 6.1 Girder 3 Response Due to Incremental Movement of Unit-Load

\begin{tabular}{|c|c|c|c|c|c|c|c|c|c|c|c|c|}
\hline \multicolumn{12}{|c|}{ Girder 3} & \multirow[b]{3}{*}{ Total R3 } \\
\hline \multicolumn{3}{|c|}{ Tire 1, Span 1} & \multicolumn{3}{|c|}{ Tire 2, Span 2} & \multicolumn{3}{|c|}{ Tire 3, Span 2} & \multicolumn{3}{|c|}{ Tire 4, Span 3} & \\
\hline Location & R1 & R2 & Location & R2 & R3 & Location & R2 & R3 & Location & \begin{tabular}{|l|} 
R33 \\
\end{tabular} & R4 & \\
\hline 4.28 & 0.47 & 0.53 & 2.28 & 0.72 & 0.28 & 6.28 & 0.22 & 0.78 & 4.28 & 0.47 & 0.53 & 1.53 \\
\hline 5.28 & 0.34 & 0.66 & 3.28 & 0.59 & 0.41 & 7.28 & 0.09 & 0.91 & 5.28 & 0.34 & 0.66 & 1.66 \\
\hline 6.00 & 0.25 & 0.75 & 4.00 & 0.50 & 0.50 & 8.00 & 0.00 & 1.00 & 6.00 & 0.25 & 0.75 & 1.75 \\
\hline 6.28 & 0.22 & 0.78 & 4.28 & 0.47 & 0.53 & & & & & & & \\
\hline 7.28 & 0.09 & 0.91 & 5.28 & 0.34 & 0.66 & & & & & & & \\
\hline 8.00 & 0.00 & 1.00 & 6.00 & 0.25 & 0.75 & & & & & & & \\
\hline
\end{tabular}

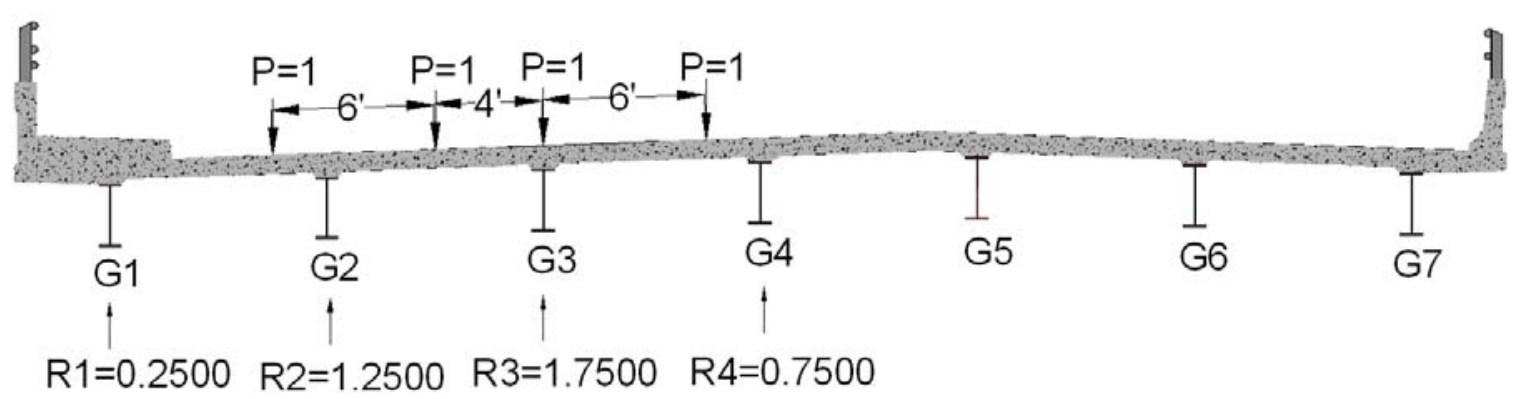

Figure 6.23 Truck Placements by Lever Rule

\subsubsection{Load Placement Used During Physical Testing}

The truck placements used during physical testing of the Culloden Bridge were based on FEA, the Lever Rule, and previous load testing experience. The original truck placement plan called for twelve separate truck runs to maximize each girder response; however, when these locations were being marked on the bridge deck it was noticed that two of the truck runs nearly overlapped and one was not possible. The two overlapping locations were merged to form one; reducing the total number of truck placements to ten. Each truck placement in Figure 6.24 and Figure 6.25 was measured from the edge of the 
north curb to the front left tire. Landscaping paint was used to mark the deck such that the two rear driver's side tires straddled the $0.40 \mathrm{~L}_{1}$ and $0.60 \mathrm{~L}_{1}$ points. The lateral locations of each truck placement are presented in Table 6.2. The critical longitudinal locations are also illustrated in Figure 6.26.

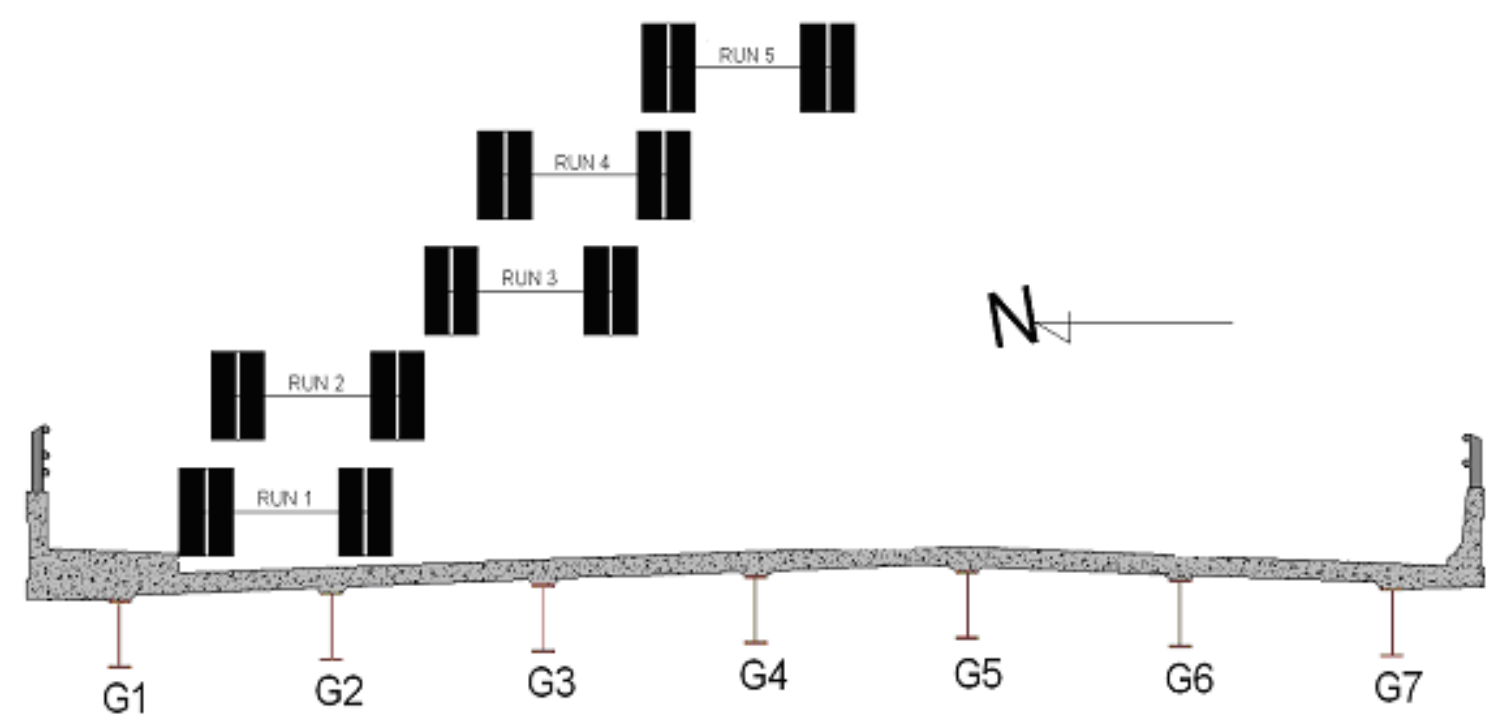

Figure 6.24 Truck Placements 1 thru 5 Measured from North Curb 


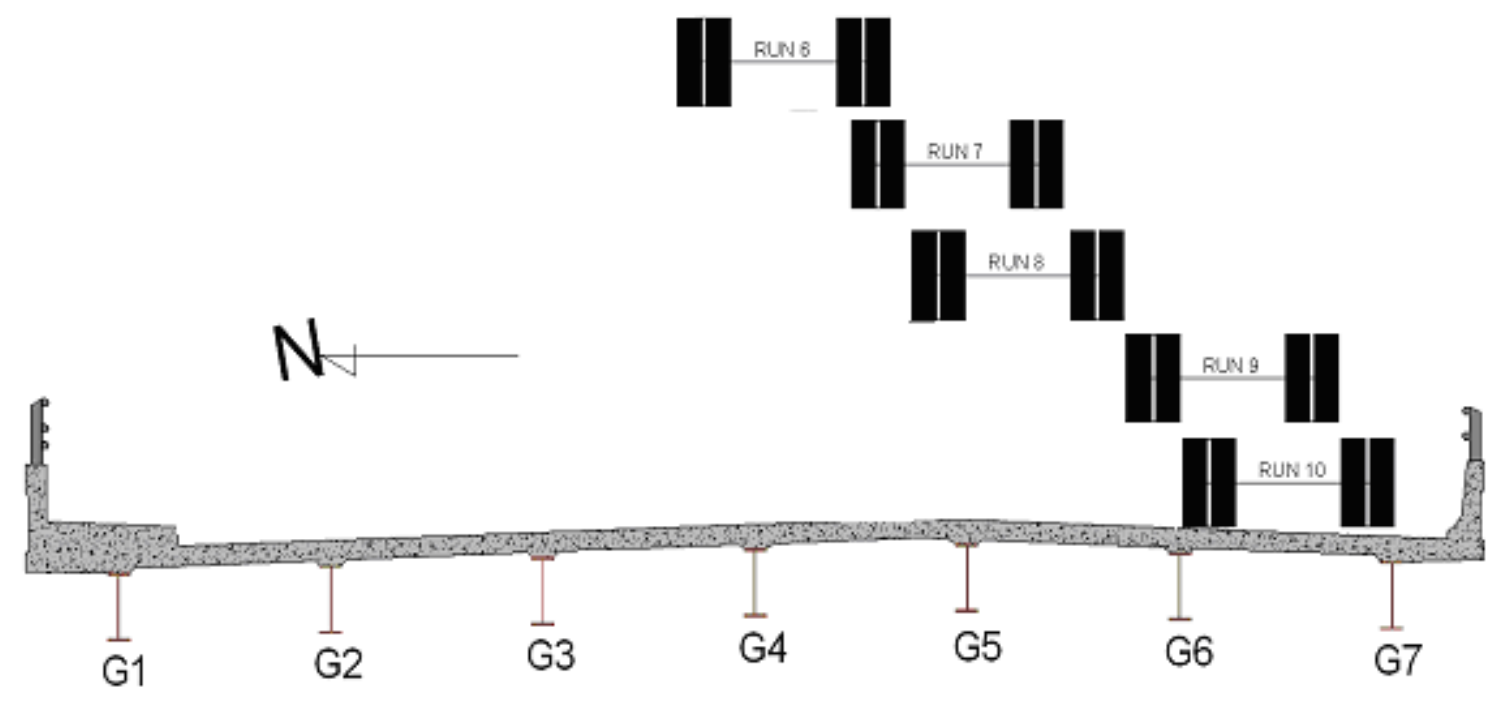

Figure 6.25 Truck Placements 6 thru 10 Measured from North Curb

Table 6.2 Truck Placements Measured from North Curb

\begin{tabular}{|c|c|}
\hline Run & $\begin{array}{c}\text { Distance } \\
\text { (ft.) }\end{array}$ \\
\hline 1 & 1 \\
\hline 2 & 2.67 \\
\hline 3 & 10.75 \\
\hline 4 & 12.67 \\
\hline 5 & 18.75 \\
\hline 6 & 20.75 \\
\hline 7 & 26.75 \\
\hline 8 & 28.75 \\
\hline 9 & 36.75 \\
\hline 10 & 38.75 \\
\hline
\end{tabular}




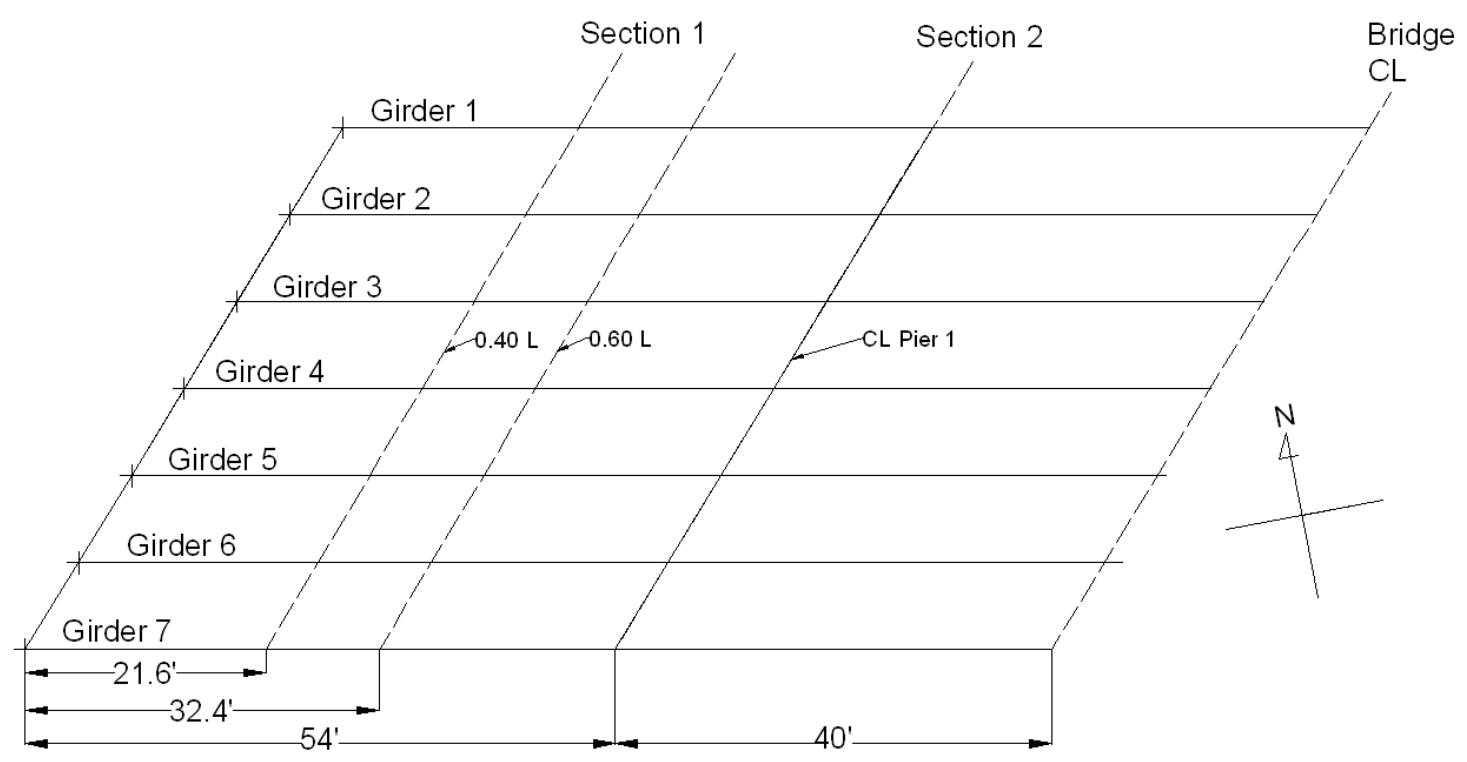

Figure 6.26 Longitudinal Truck Placement

When evaluating strain, the truck was instructed to stop and place its rear tandem axles at two locations on the bridge. The first location was at $0.40 \mathrm{~L}_{1}(21$ '-7') and the second was at $0.60 \mathrm{~L}_{1}\left(31^{\prime}-2\right.$ ') from the centers-of-bearing of the west abutment. The placement of the rear tandem-axles was accomplished by marking where the driver's front tire should stop to correctly place the rear axles of the truck.

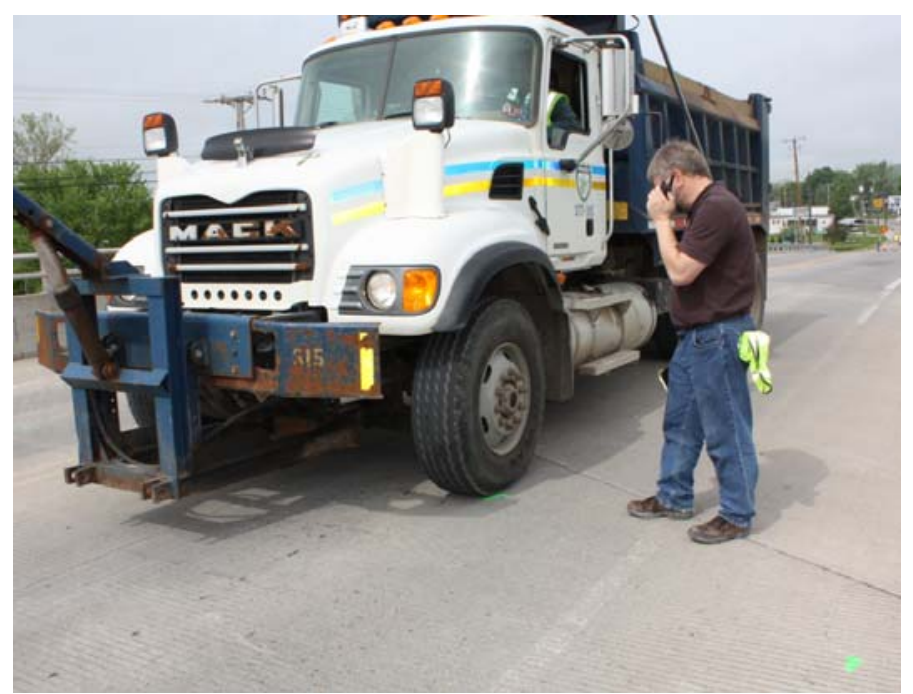

Figure 6.27 Placement of Front-Tire of Load Truck 


\subsection{Strain Testing Procedure}

Strain gages were placed to observe the maximum positive and negative bending moments within the first span of the bridge. The first region instrumented was Section II (Figure 6.28). Strain gages were placed one girder depth (29 in.) from the centers-ofbearing at the pier. This was done to limit bearing and cross-frame affects on the flexural strain readings. The second region tested was Section I, which was located at distance of $0.40 \mathrm{~L}_{1}(21.6 \mathrm{ft}$.) from the west abutment (Figure 6.29).

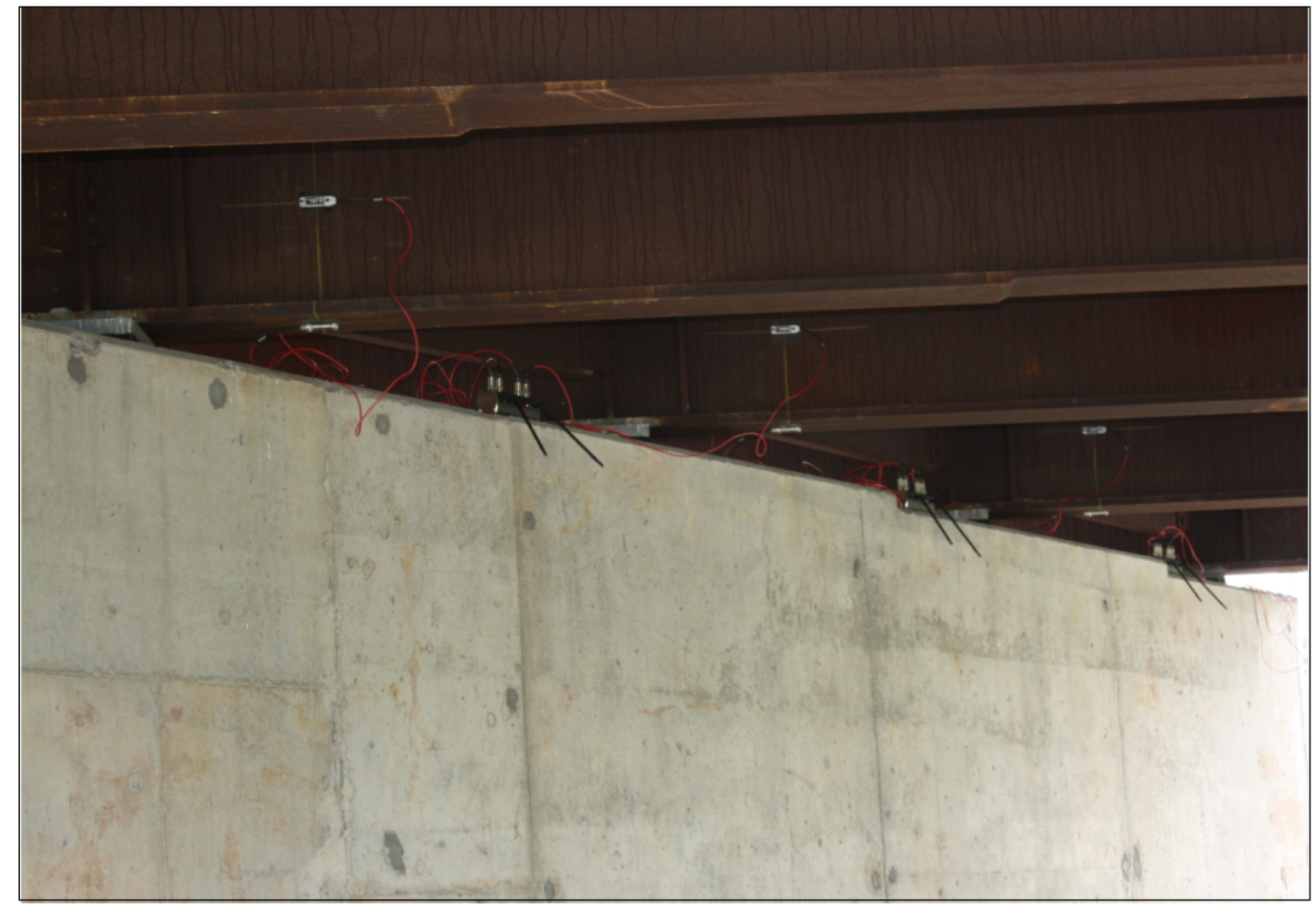

Figure 6.28 Section II Strain Gages 


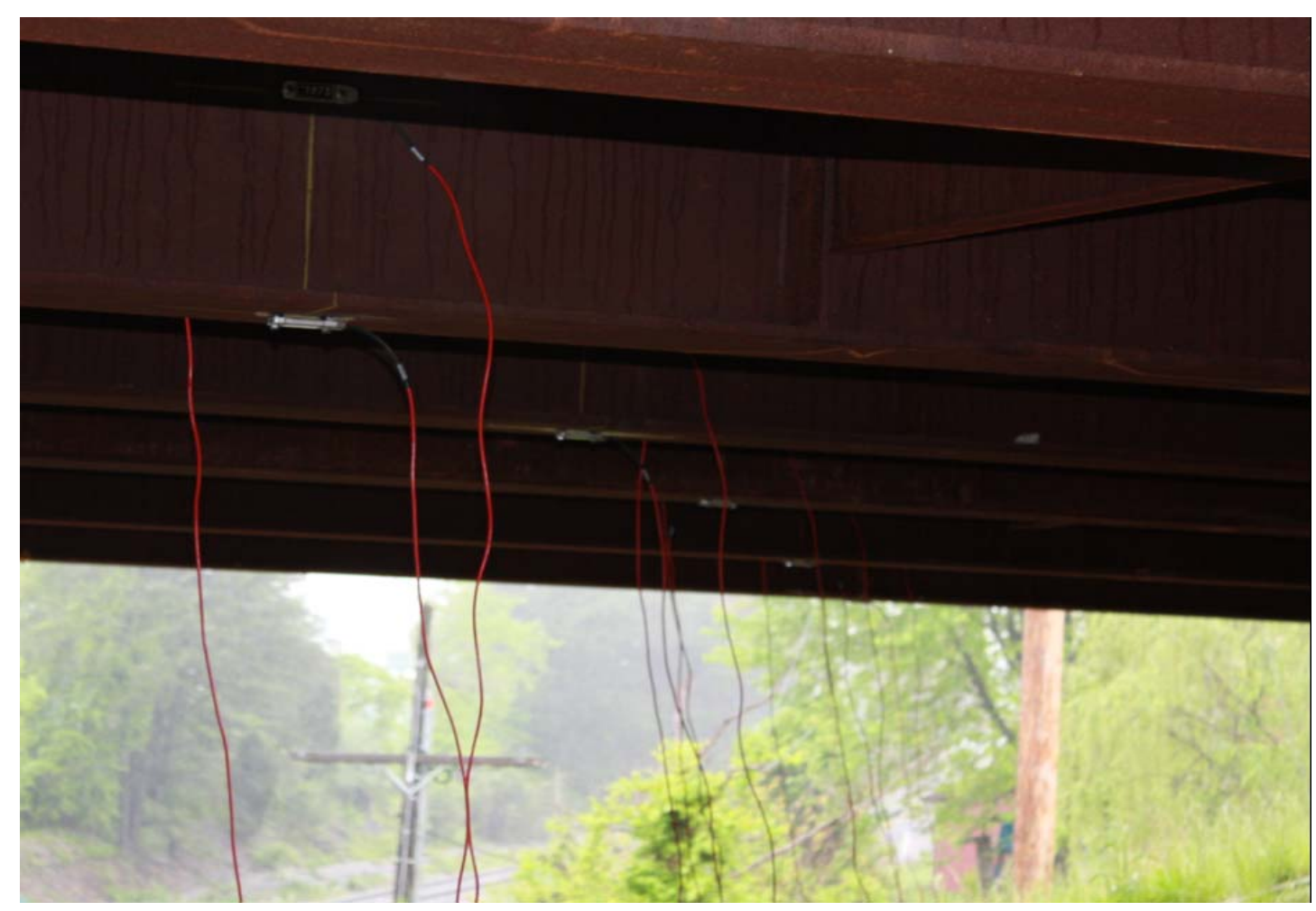

Figure 6.29 Section I Strain Gages

Three strain gages were mounted to each girder to simultaneously record strains induced by the load truck. Two of the gages were mounted on opposite sides of the web to obtain the average strain across the thickness of the web. The third gage was mounted to the middle of the bottom flange as shown below in Figure 6.31. During lab verification of the strain gages, it was discovered that the strain readings would wander for approximately the first ten minutes. After ten minutes, the strain readings became more stable as the gages warmed up. On the day of the load tests, the gages were allowed to warm up for approximately 30 minutes prior to taking any readings. The strains recorded during load tests were used to generate strain profiles, which in turn, were used to produce stress profiles. The stress profiles were then used to calculate the total moments induced in each girder. Due to a small change in the original load plan, there 
were only enough strain gages to fully instrument 6 of 7 girders. It was determined that Girder 1 was the least critical girder because of its location under the sidewalk.

Nevertheless, Girder 1 was outfitted with 2 gages; one on the web and one on the bottom flange.

To observe the maximum theoretical strains at both test sections, the load truck was slowly driven onto the bridge and instructed to stop at the locations specified above. After a few seconds of recording static strain readings, the truck was moved to a second location. Again, static strain readings were recorded for several seconds. The truck was then driven off the bridge and the test was stopped and reset for the next truck placement.

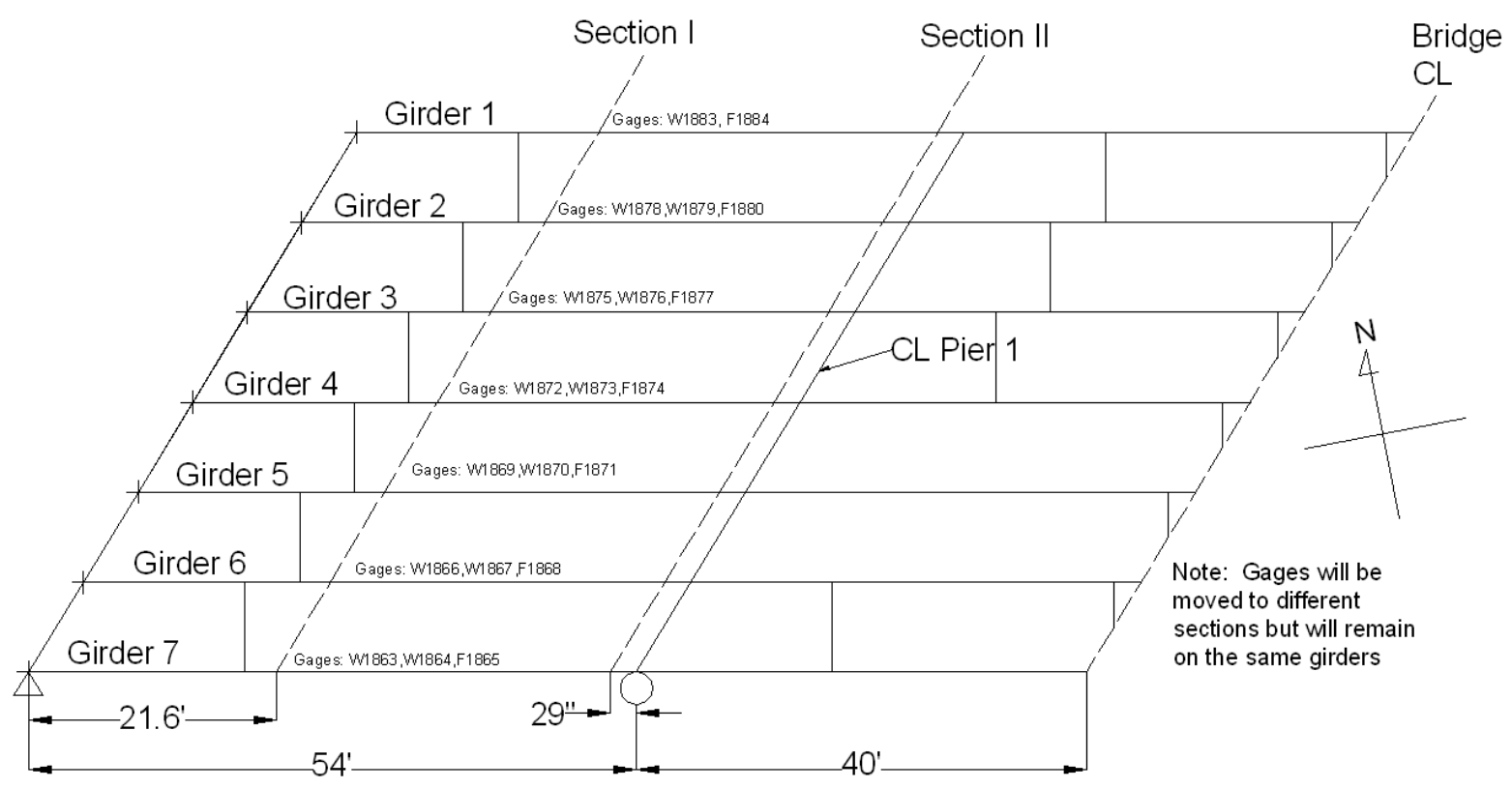

Figure 6.30 Strain Test Sections and Gage Plan 


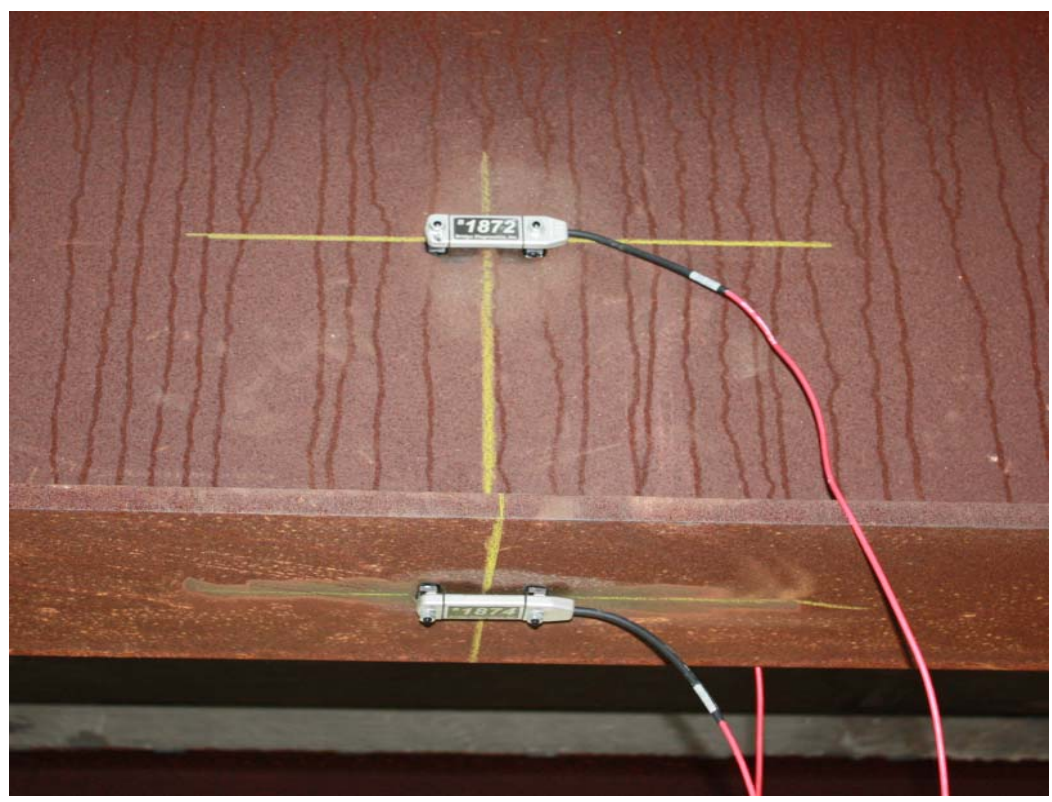

Figure 6.31 Strain Gage Placements on Web and Flange

\subsection{Deflection Testing Procedure}

The load placements and procedures utilized during strain testing were also used during deflection testing. A temporary frame was constructed from 4 x $4 \mathrm{~s}, 2 \times 6 \mathrm{~s}$, and 2 $\mathrm{x} 4 \mathrm{~s}$ as shown below in Figure 6.32 and 6.33. The LVDTs were mounted to $2 \mathrm{x} 4$ 's that were then mounted to the frame. Each LVDT was individually oriented on the frame to provide proper initial plunger displacement. This was necessary because the LVDTs have an outward over-travel of 0.39 " and an inward over-travel of 0.12 ". This means that the first 0.39 inches of deflection does not produce a voltage change, therefore, cannot be translated into deflection within the testing software. The same is true for the inward over-travel. Once the plunger has become fully depressed, the first 0.12 inches of rebound do not translate into deflection as no voltage change has taken place. 


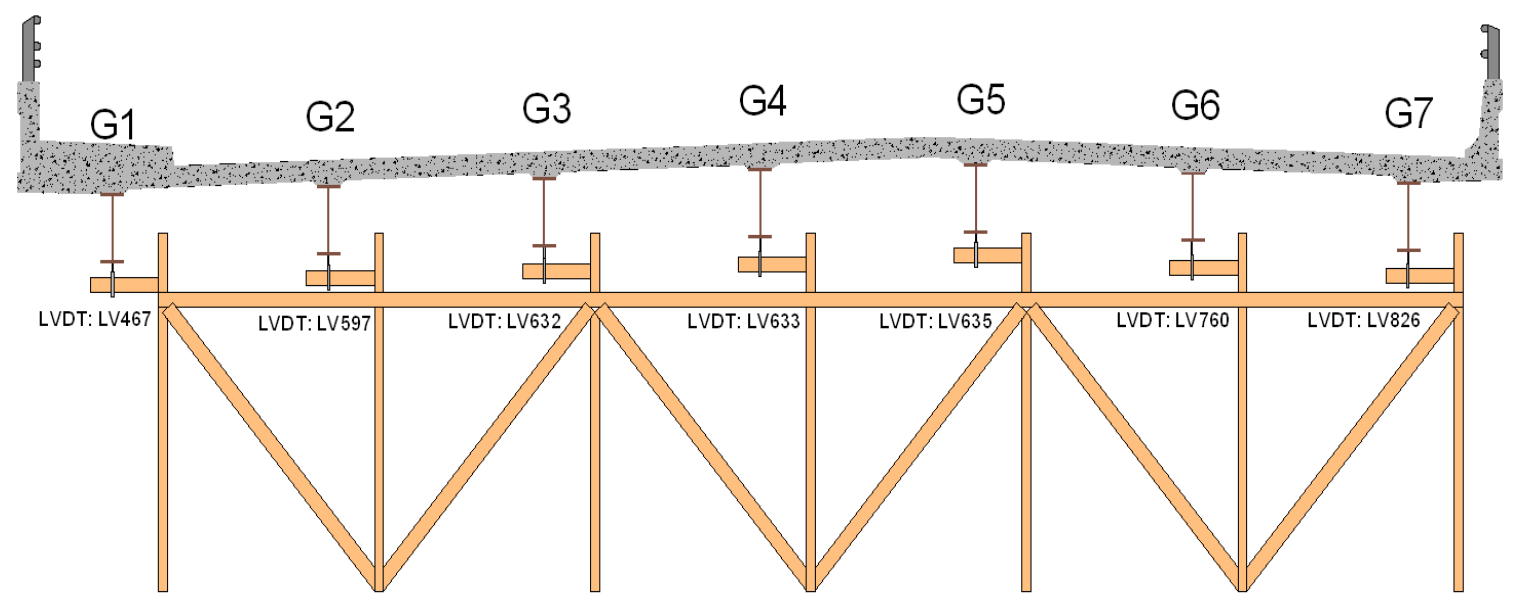

Figure 6.32 LVDT Framing Plan

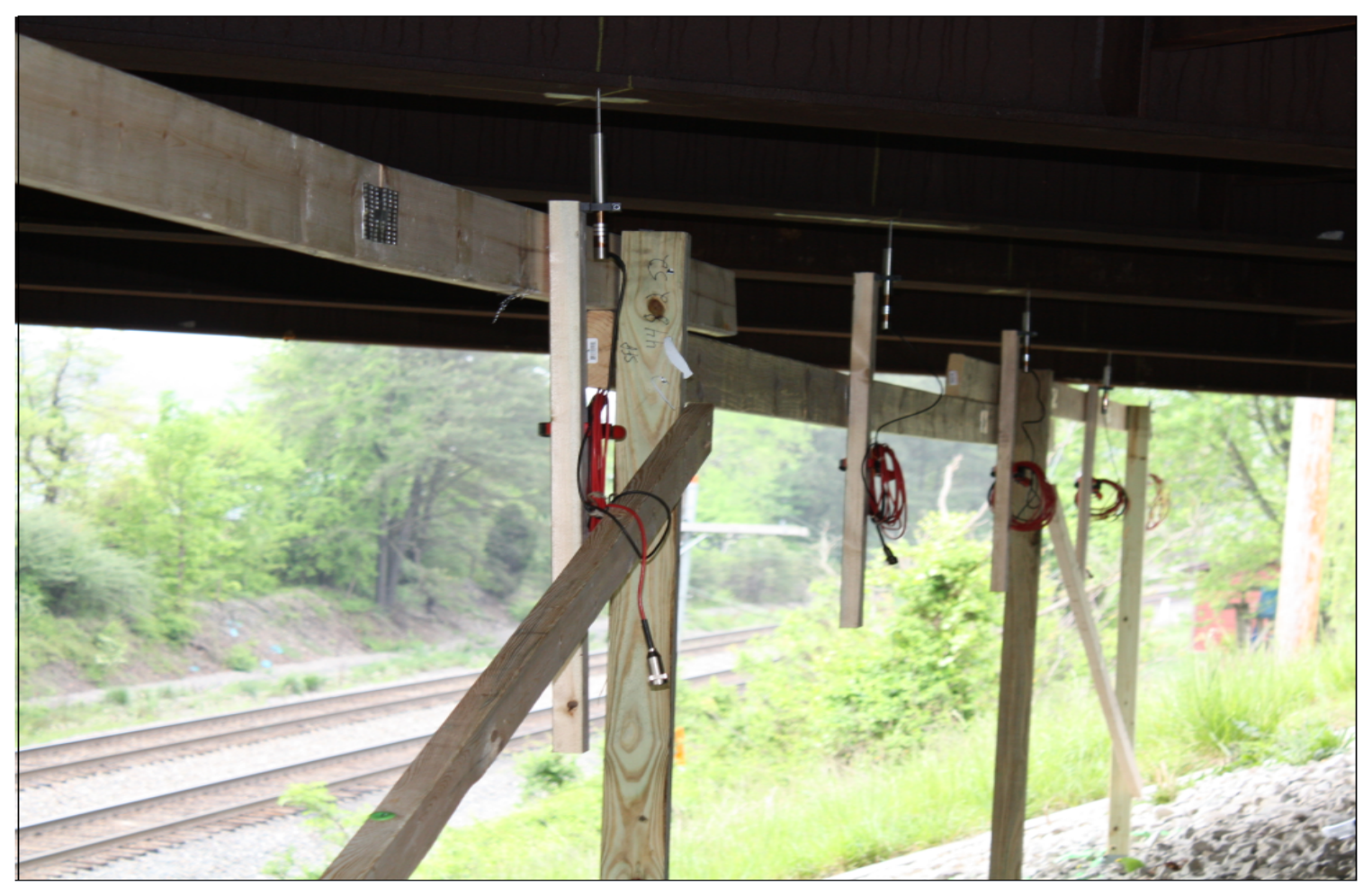

Figure 6.33 LVDT Field Frame

\subsection{Dynamic Testing Procedure}

Previous dynamic tests have shown that load trucks need to reach at least $25 \mathrm{mph}$ to induce adequate forced vibrations (Davis 2003). Dynamic load testing of the Culloden Bridge was accomplished by accelerating the load truck to approximately $40 \mathrm{mph}$. As 
the truck entered the first span, the driver was instructed to aggressively apply his brakes at the approximate location of the accelerometer (Figure 6.34). The dynamic response of the truck's suspension produced forced vibrations within the superstructure. The driver then exited the bridge allowing the remaining forced vibrations to dampen. The remaining free-vibrations were then recorded and used to determine the fundamental frequency of the bridge.

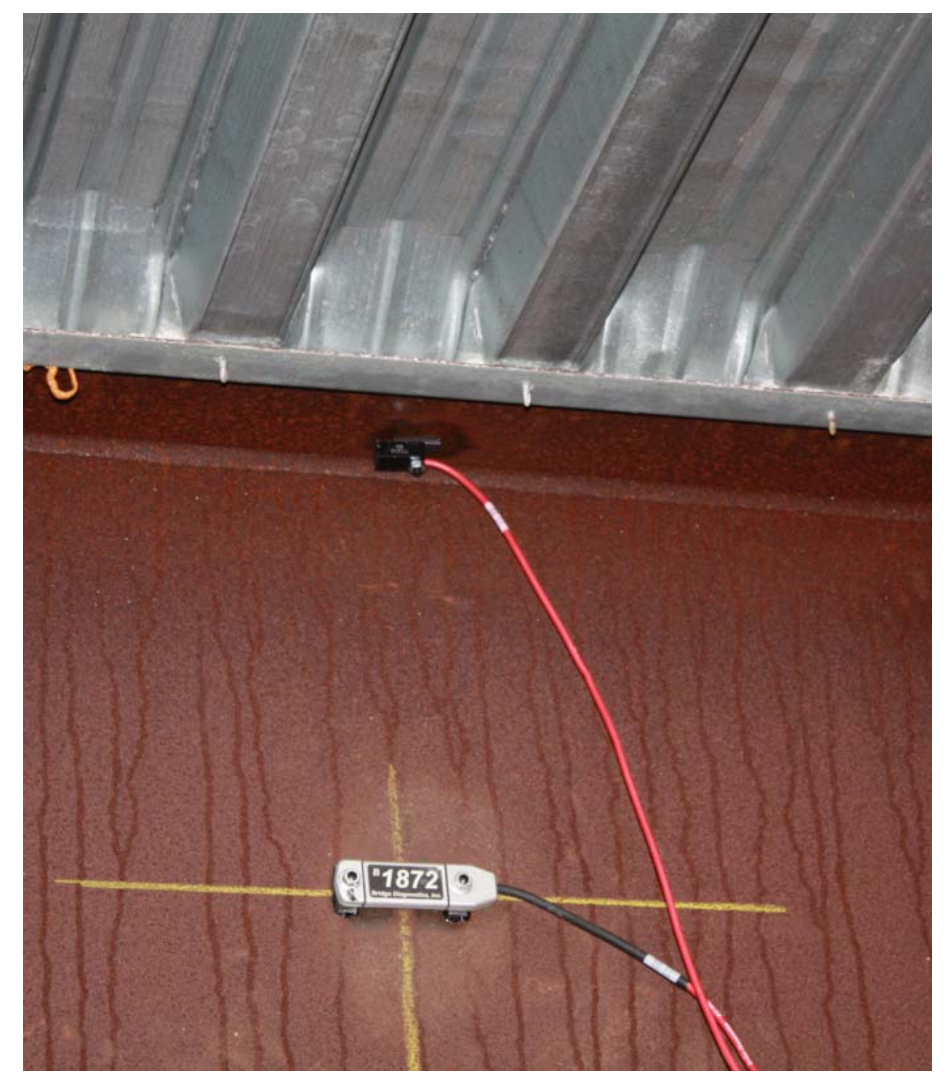

Figure 6.34 Accelerometer Mounted to Top Flange

\subsection{Results}

The data recorded from each load test was saved and uploaded into Excel ${ }^{\mathrm{TM}}$ spreadsheets for analysis. Separate spreadsheets were generated for strains, deflections, and accelerations. Strains were recorded at the maximum positive and negative bending 
regions of the first span, while deflections and accelerations were only recorded at the maximum positive bending region of the first span.

\subsubsection{Strain}

Strain gages were placed on both sides of the web to obtain an average web strain at the points of maximum positive and negative bending. The strains in Figure 6.35 correspond with the worst-case truck placement for Girder 4 . The strains are negative, indicating that the gages were placed in compression. The approximate locations of constant strain in the figures below represent the periods of time that the load truck was stopped at $0.40 \mathrm{~L}_{1}$ and $0.60 \mathrm{~L}_{1}$. As the truck drove over the first pier, the strains decreased slightly then rapidly increased as the truck approached the middle of the second span. When the truck traveled across the third span of the bridge, a small positive strain was recorded indicating negative bending.

The strains exhibited in Figure 6.36 were recorded at the maximum positive bending region of Girder 4. The strains were positive at this location because the gages were placed in tension below the neutral axis of the girder. Like Figure 6.35, constant strains indicate when the truck stopped at the predetermined locations of maximum influence. In addition, negative bending was again indicated by the small negative strain recorded when the truck traveled across the second span. 


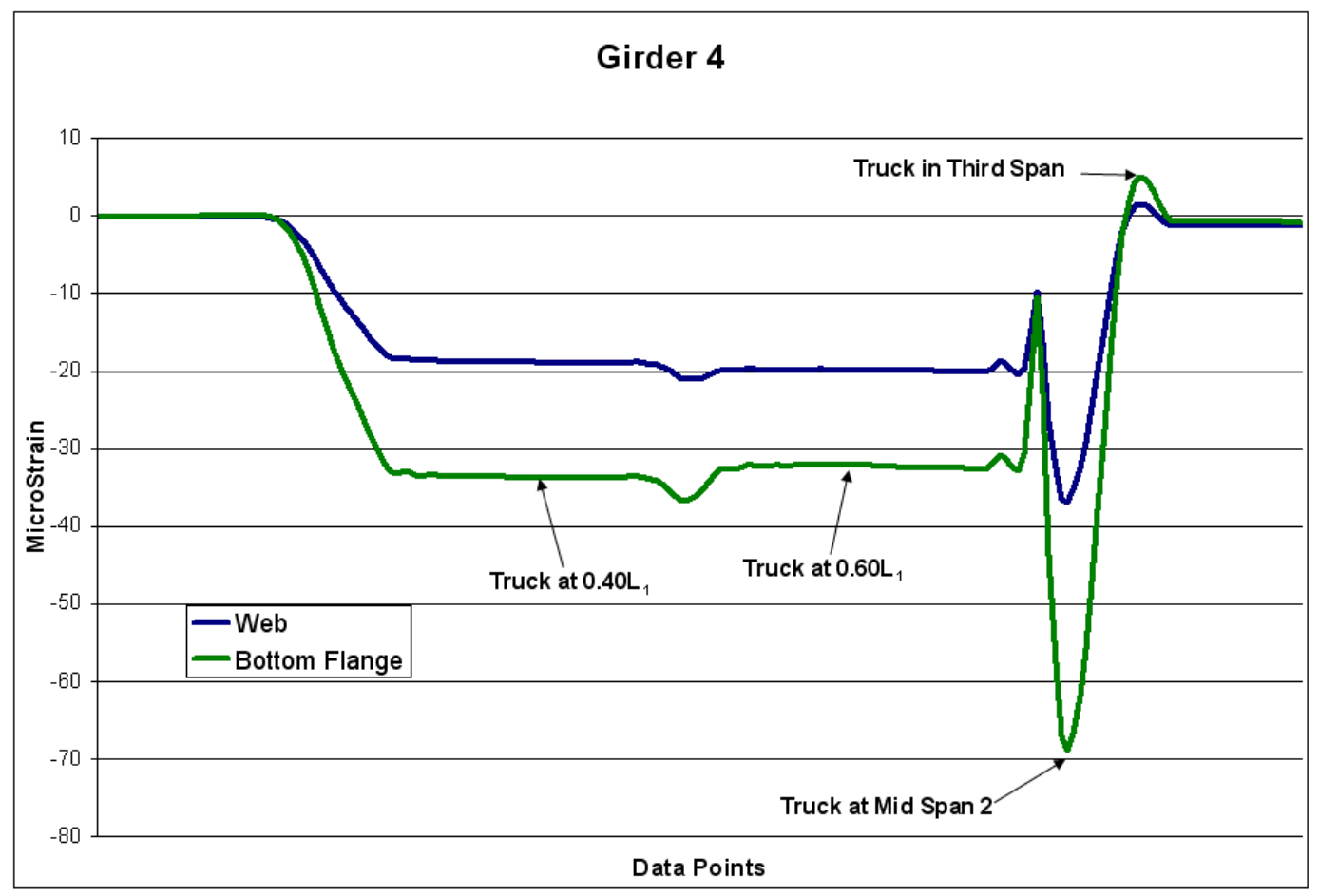

Figure 6.35 Girder 4: Negative Bending Strains

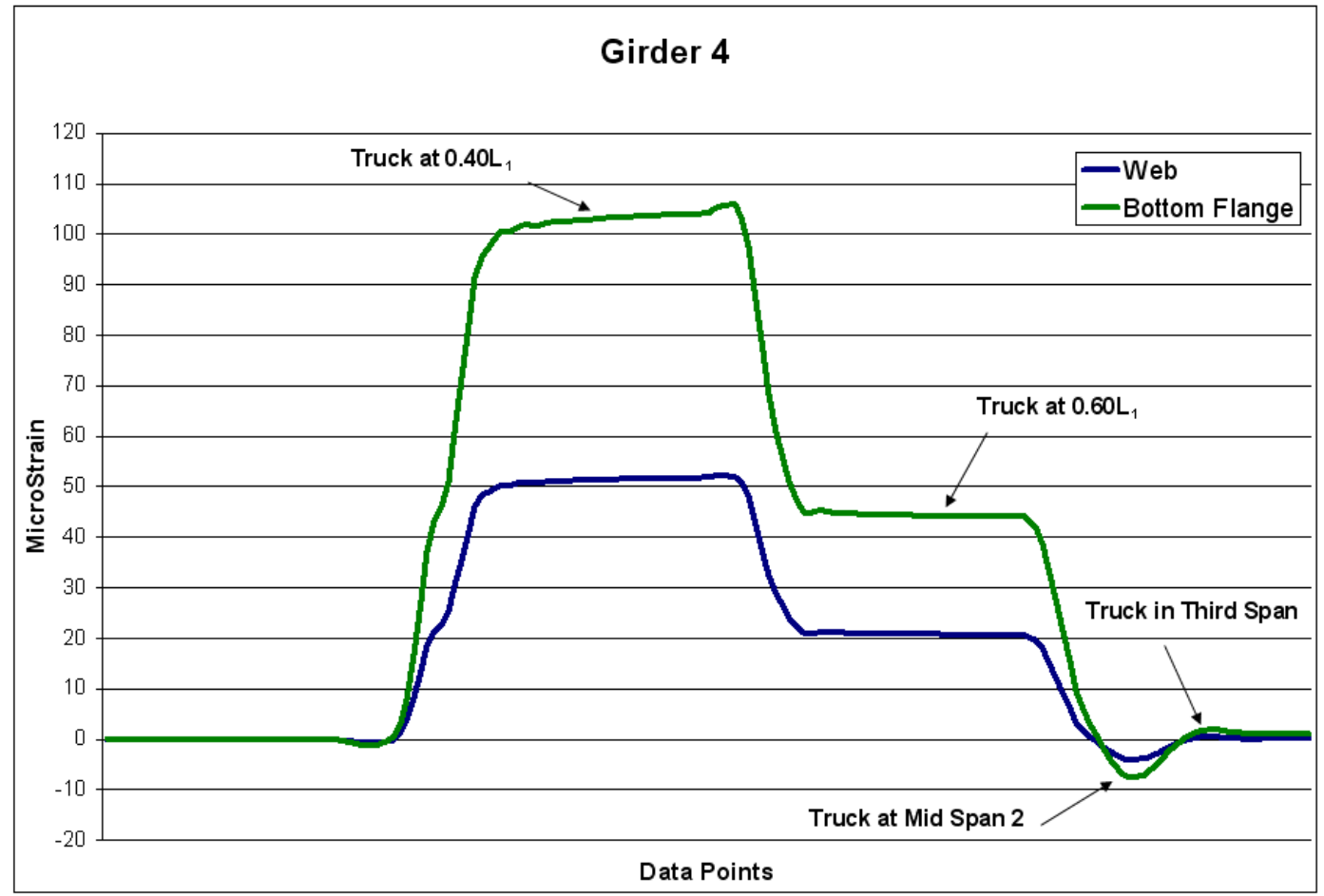

Figure 6.36 Girder 4: Positive Bending Strains 


\subsubsection{Deflection}

The maximum positive bending location in the first span was instrumented with 7-LVDTs in order to simultaneously observe deflections in all girders. During each run, the load truck stopped at the $0.40 \mathrm{~L}_{1}$ point. This location corresponds to the theoretical point of maximum deflection in the first span of the bridge. Figure 6.37 represents the deflections due to the worst-case truck placement for Girder 4. It is clearly shown that the largest deflection did indeed take place when the truck stopped over the $0.40 \mathrm{~L}_{1}$ point. As the truck entered the second span, a positive deflection was recorded indicating uplift of the first span. A very small negative deflection was also recorded when the truck continued onto the third span of the bridge.

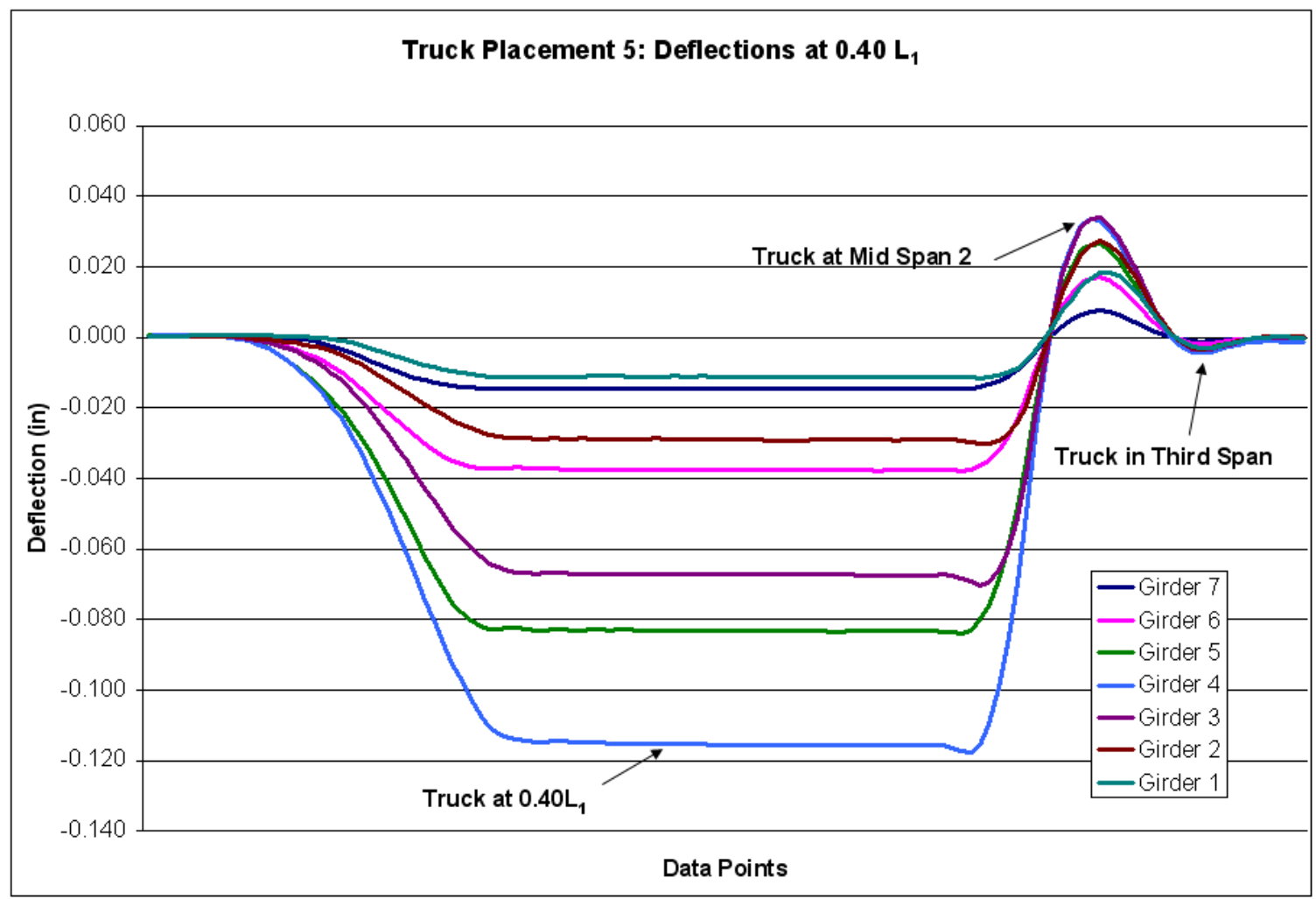

Figure 6.37 Truck Placement 5 Deflections 


\subsubsection{Acceleration}

Three dynamic tests were conducted which produced two sets of useable data. To excite the bridge, the load truck accelerated to a speed between 35 and $40 \mathrm{mph}$. Upon reaching the $0.40 \mathrm{~L}_{1}$ point of the first span, the truck locked its brakes; exciting the suspension of the truck and inducing forced vibrations within the superstructure of the bridge. The forced vibrations can be seen damping out in Figure 6.38, followed by the free vibrations that were used to determine the first fundamental frequency of the bridge. The two red lines in Figure 6.38 represent the points when the truck entered and exited the bridge superstructure. This was important to know when performing the Fourier Series Analysis to determine the natural frequency of the bridge.

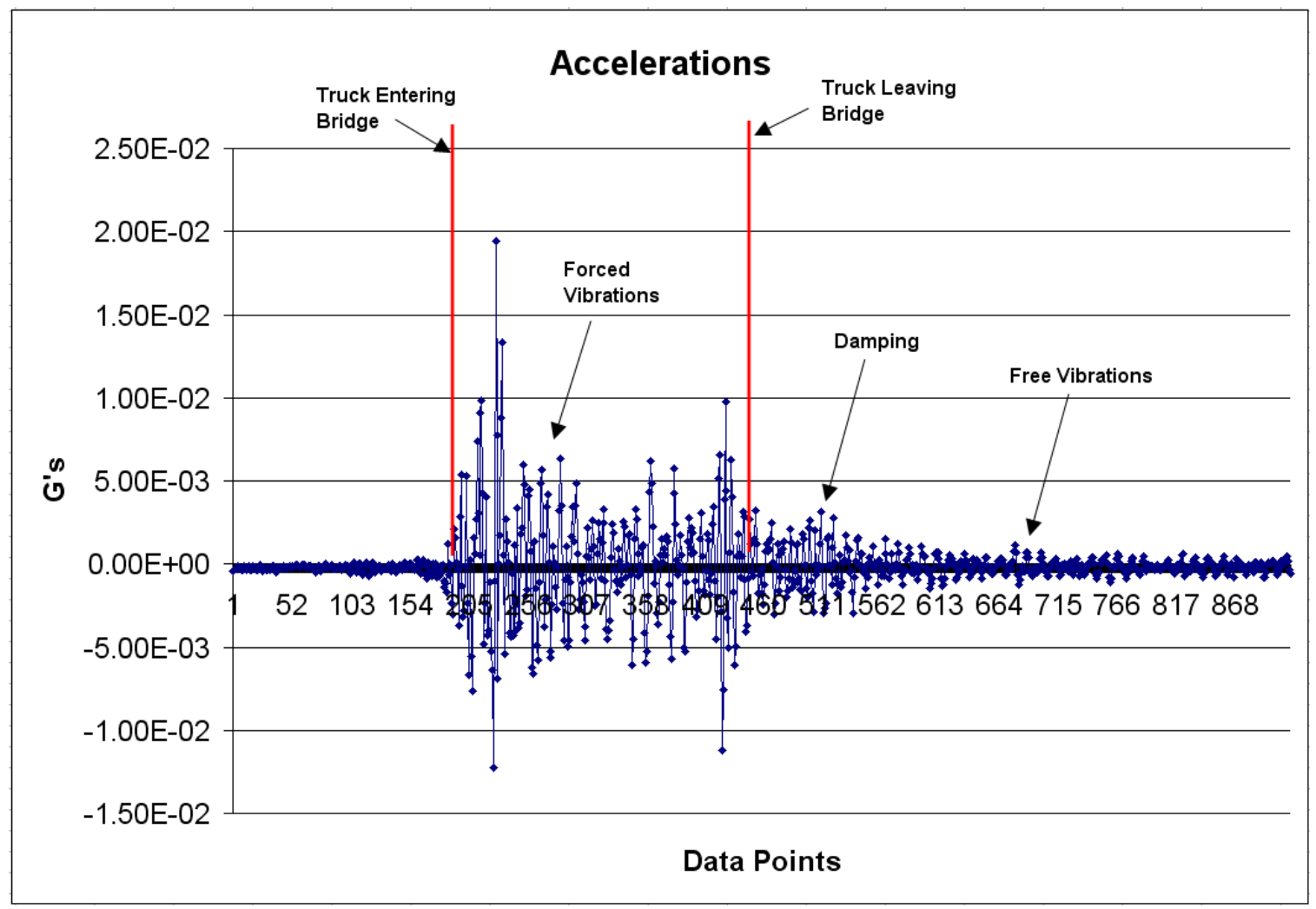

Figure 6.38 Dynamic Test Results 


\section{Chapter 7 - Serviceability Assessment of the Culloden Bridge}

\subsection{Natural Frequency}

\subsubsection{Theoretical Natural Frequency}

Significant work was conducted by Barth and Wu to develop a natural frequency equation that accurately predicts the fundamental frequencies of continuous span steel Igirder bridges (Barth and $\mathrm{Wu} 2007)$. Finite element models were generated for a suite of bridges and then analyzed for comparison with experimental field test results. This was accomplished by developing a FEA procedure which utilizes the commercial software ABAQUSTM. In this analysis, the concrete deck was modeled as uncracked as tests have shown that, in the elastic range, deck cracking has little effect on the global behavior of the bridge. The parameters considered to influence the predicted natural frequency are:

- span arrangements,

- $\quad$ span lengths,

- material properties,

- inclusion of parapets, and

- span-to-depth ratios.

Several natural frequency equations have been developed empirically from data collected through theoretical research and field-tests. Other researchers have developed equations with the Rayleigh-Ritz method, finite element analysis, and other approximate methods (Barth and $\mathrm{Wu} 2007$ ). The most basic method is derived from the simple-beam equation and may be used to determine the natural frequency of a single-span bridge; 
however, it has not been shown to accurately predict the natural frequency of continuous span bridges.

The following equation was then developed by Barth and $\mathrm{Wu}$ to predict the natural frequency of continuous span bridges by applying a modification factor to the original simple-beam frequency equation.

$$
\begin{aligned}
& f=\lambda^{2} f_{s b} \\
& \text { where: } \\
& \lambda^{2}=a \frac{I^{c}}{L^{b}{ }_{\text {max }}} \\
& \mathrm{a}=0.88, \mathrm{~b}=-0.033, \text { and } \mathrm{c}=0.0333 \text { for } 3 \text { or more spans }
\end{aligned}
$$

The average moment of inertia was calculated by using the weighted average approach shown below in Table 7.1. The percentages of girder length for each section were found and applied to the corresponding moment of inertia for the short-term

\begin{tabular}{|c|c|c|c|c|}
\hline & $\begin{array}{l}\text { Total } \\
\text { Length }\end{array}$ & \begin{tabular}{|c|}
$\%$ of Total \\
Length
\end{tabular} & $\mathrm{I}_{\text {int }}$ & $I_{\text {ext }}$ \\
\hline & $\mathrm{ft}$ & $\%$ & in $^{4}$ & in $^{4}$ \\
\hline Section I & 91.5 & $49 \%$ & 12,791 & 13,281 \\
\hline Section II & 48 & $26 \%$ & 18,054 & 18,822 \\
\hline Section III & 50 & $27 \%$ & 11,684 & 15,762 \\
\hline & \multirow{2}{*}{\multicolumn{2}{|c|}{$\begin{array}{r}\text { Wt. Avg Sum: } \\
\text { Wt. Avg Tot: }\end{array}$}} & 13,943 & 175,462 \\
\hline & & & \multicolumn{2}{|c|}{14.377} \\
\hline
\end{tabular}
composite section. In doing so, an equivalent prismatic beam was realized and used to calculate the natural frequency of the bridge.

Table 7.1 Weighted Average Moment of Inertia

Because the field test data was obtained from an interior girder, the unit weight of the short-term composite section at $0.40 \mathrm{~L}_{1}$ was used in the subsequent calculations. The unit 
weight of the composite section in the table below was determined from the effective area of deck and the self-weight of the girder.

\section{Table 7.2 Unit Weight of Interior Girder Short-Term Composite Section}

\begin{tabular}{|c|c|}
\hline \multicolumn{2}{|c|}{ Interior Girder Unit Weight } \\
\hline Component & $(\mathrm{lb} / \mathrm{in})$ \\
\hline Effec. Deck & 66.67 \\
\hline Girder & 8.68 \\
\hline T otal: & 75.35 \\
\cline { 2 - 2 }
\end{tabular}

The natural frequency of the Culloden Bridge was then estimated by the simplebeam equation as:

$$
f_{s b}=\frac{3.142}{2\left(960^{2}\right)} \sqrt{\frac{(29,000,000)(14,377)(386)}{75.35}}=2.491 \mathrm{~Hz}
$$

The coefficient $\lambda^{2}$ was then determined and applied to the simple-beam frequency to determine the correct natural frequency for a three-span bridge.

$$
\begin{aligned}
& \lambda^{2}=0.88\left(\frac{14,377^{(0.033)}}{80^{(-0.033)}}\right)=1.395 \\
& f=1.395(2.491)=3.474 \mathrm{~Hz}
\end{aligned}
$$

The parametric study conducted by Barth and Wu revealed that natural frequencies are up to 10 percent higher when parapets are included in the natural frequency analysis. As such, they suggest applying a correction factor to the frequency obtained from the previous equation. This parapet correction factor was found as:

$$
\text { factor }=\frac{1.34}{L^{-0.0054} I^{0.024}}
$$




$$
\text { factor }=\frac{1.34}{(80)^{-0.0054}(14,377)^{0.024}}=1.09
$$

By applying the parapet factor, the corrected natural frequency of the Culloden Bridge was found as:

$$
f=1.09(3.474)=3.789 \mathrm{~Hz}
$$

\subsubsection{Experimental Natural Frequency}

Experimental accelerations were recorded during dynamic loading tests from the accelerometer mounted on Girder 4. The accelerometer was mounted to the top flange at the $0.40 \mathrm{~L}_{1}$ point of the first span. The load truck was driven onto the bridge and instructed to slam on the brakes as it reached this point. Accelerations were recorded as the truck approached the bridge, during the excitation of the suspension, and after the truck had left the bridge. Accelerations were also recorded for several seconds after the truck had left the bridge to observe the free vibrations which are used to determine the natural frequency. The first dynamic truck run was not captured by the data acquisition system; however, good results were obtained from the second and third runs. The accelerations recorded during the second run are shown below in Figure 7.1. 


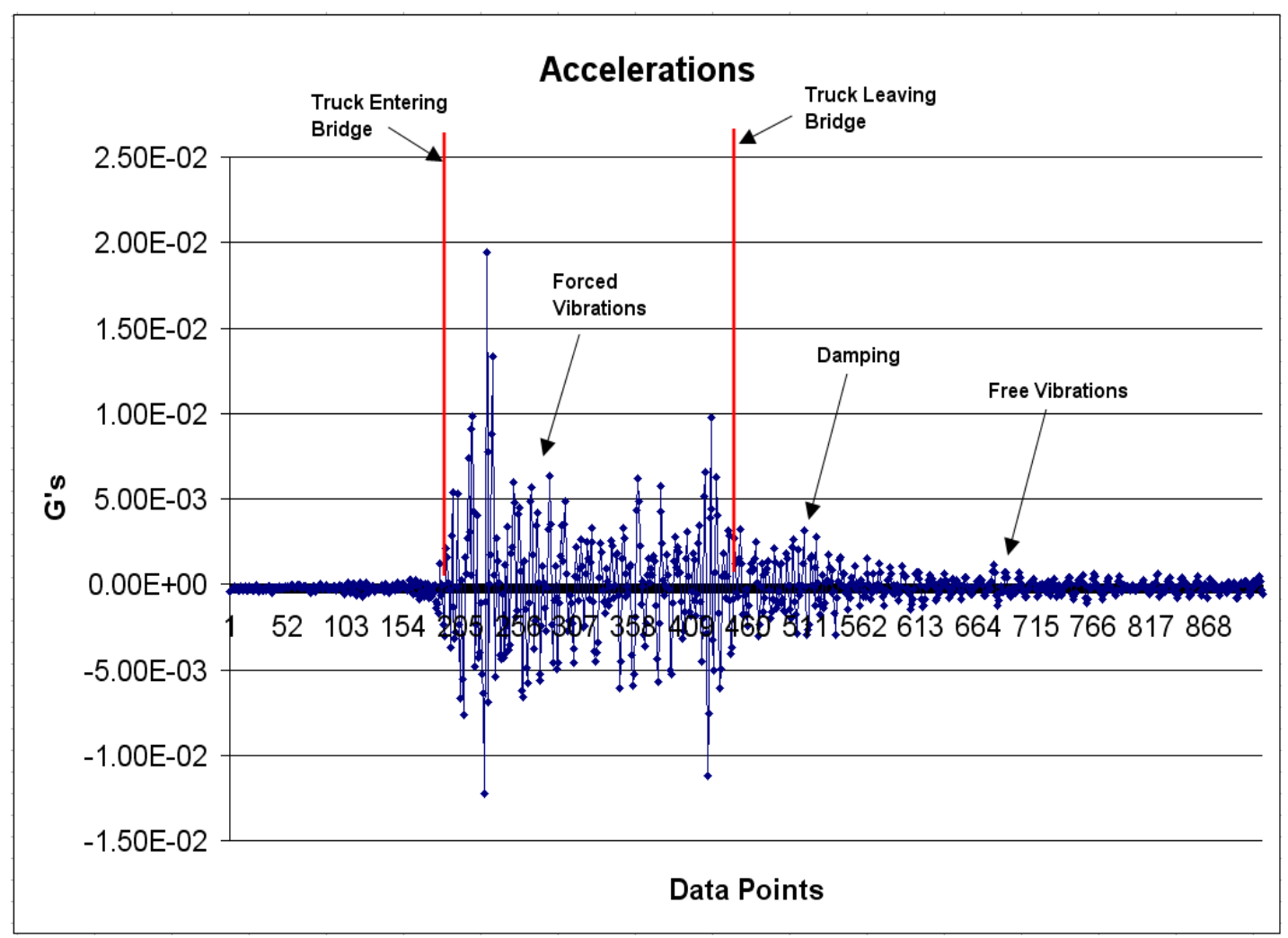

Figure 7.1 Accelerations from Dynamic Load Test

The natural frequency of the Culloden Bridge was determined from the acceleration data by performing a Fourier Transform. Excel ${ }^{\mathrm{TM}}$ was used to calculate the complex coefficients of the Fourier Transform from the time series data. Excel ${ }^{\mathrm{TM}}$ requires that the number of samples in the time series data be a power of 2 . The total number of data points recorded during the second dynamic load test was 2730; however, there were approximately 600 free vibration data points that could be used in the analysis. Based on the power of 2 requirement, the number of points analyzed was $2^{9}$; or 512 data points. The Excel ${ }^{\mathrm{TM}}$ function was calculated in time steps of 0.020 seconds, which corresponds to a sampling rate of $50.0 \mathrm{~Hz}$. The natural frequency was determined by observing the first spike in amplitude in Figure 7.2 below. The first spike in amplitude 
takes place at $3.906 \mathrm{~Hz}$ along the $\mathrm{x}$-axis; thus, the experimental natural frequency of the Culloden Bridge is $3.906 \mathrm{~Hz}$.

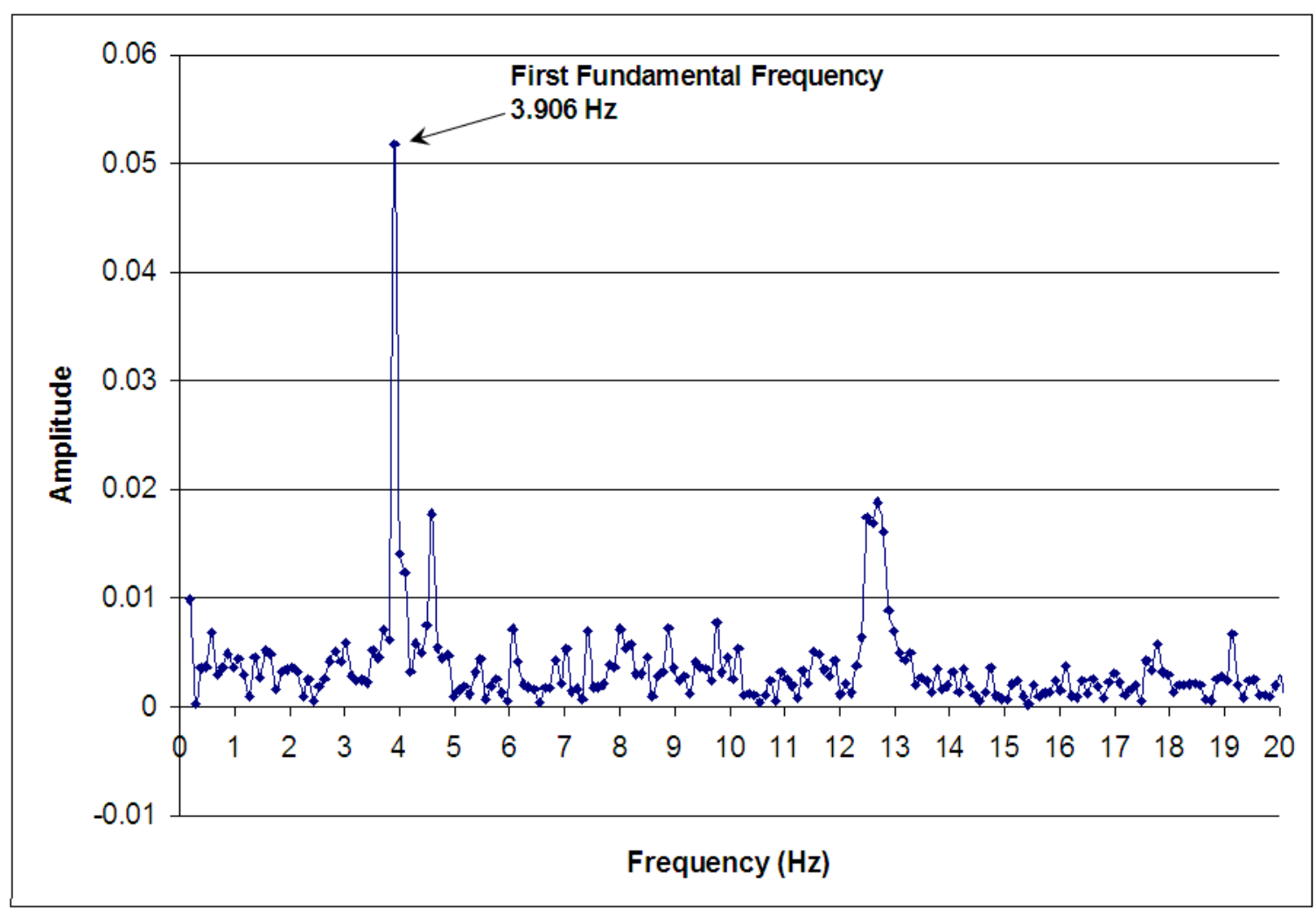

Figure 7.2 Fourier Transform Results

\subsubsection{Summary of Natural Frequencies}

The experimental natural frequency was determined to be $3.906 \mathrm{~Hz}$. This is clearly illustrated by the first sharp spike in Figure 7.2, which corresponds to the large amplitude of the Fourier Coefficient. The theoretical natural frequency, predicted by the Barth and Wu equation, was found to be $3.789 \mathrm{~Hz}$. This equates to a 3 percent difference between experimental and theoretical natural frequencies and verifies both the field data and the theoretical prediction equation. 
The current AASHTO specifications do not directly limit vibrations, but rather indirectly limit live load deflections. On the contrary, the Ontario and Canadian Bridge Codes suggest a serviceability limit based on the maximum static deflection, the level of pedestrian traffic, and the first flexural frequency. Figure 7.3 demonstrates the acceptable ranges of static deflection, with respect to first flexural frequency, for various levels of pedestrian traffic.

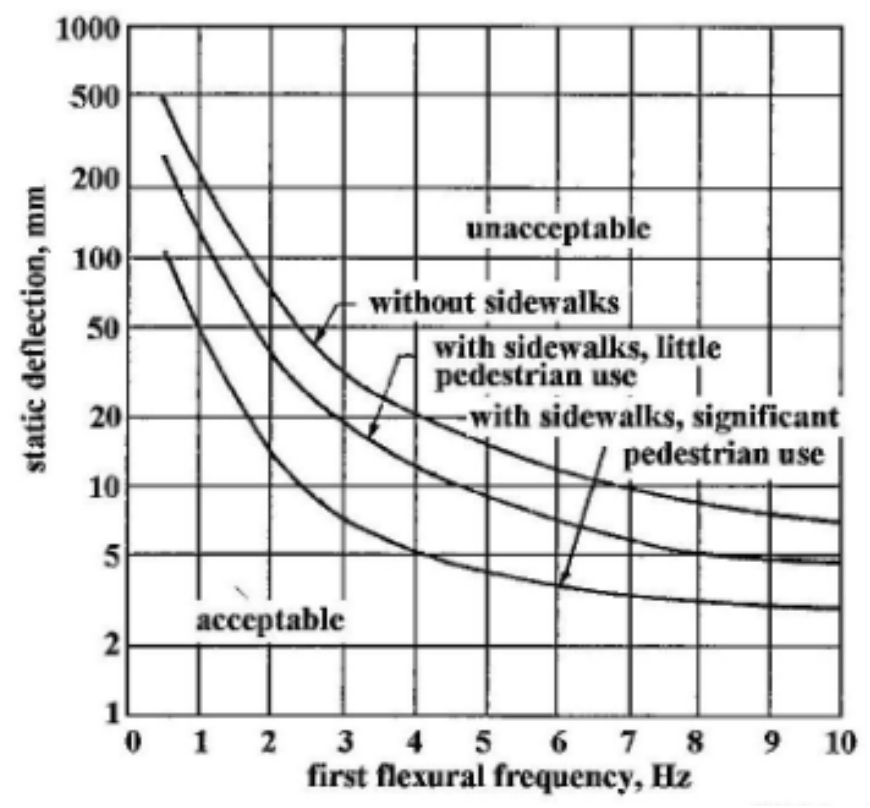

Figure 7.3 Ontario Bridge Code: Frequency vs. Static Deflection

The maximum static deflection in the Ontario and Canadian Code is calculated by applying a factored load truck plus impact. The static deflection caused by this load case is determined at the center of the sidewalk, at the inside face of the barrier wall, or below a railing for bridges with no sidewalks (Ministry of Transportation 1991). The static deflection of the Culloden Bridge was determined by applying a single HS20-44 load truck in CONSYS. On the Culloden Bridge, the sidewalk is located over an exterior girder, therefore, the static deflection was found with exterior girder section properties. 
The unfactored static deflection due to the HS20-44 load was found to be 2.00 in. The live load deflection distribution factor was also recalculated for a single load and was found to be 0.171 lanes. By applying Service I load factors, impact, and the live load deflection distribution factor, the deflection was found to be 0.454 inches $(11.53 \mathrm{~mm})$. The Culloden Bridge has little pedestrian traffic; therefore, the maximum acceptable first flexural to be approximately $4.25 \mathrm{~Hz}$.

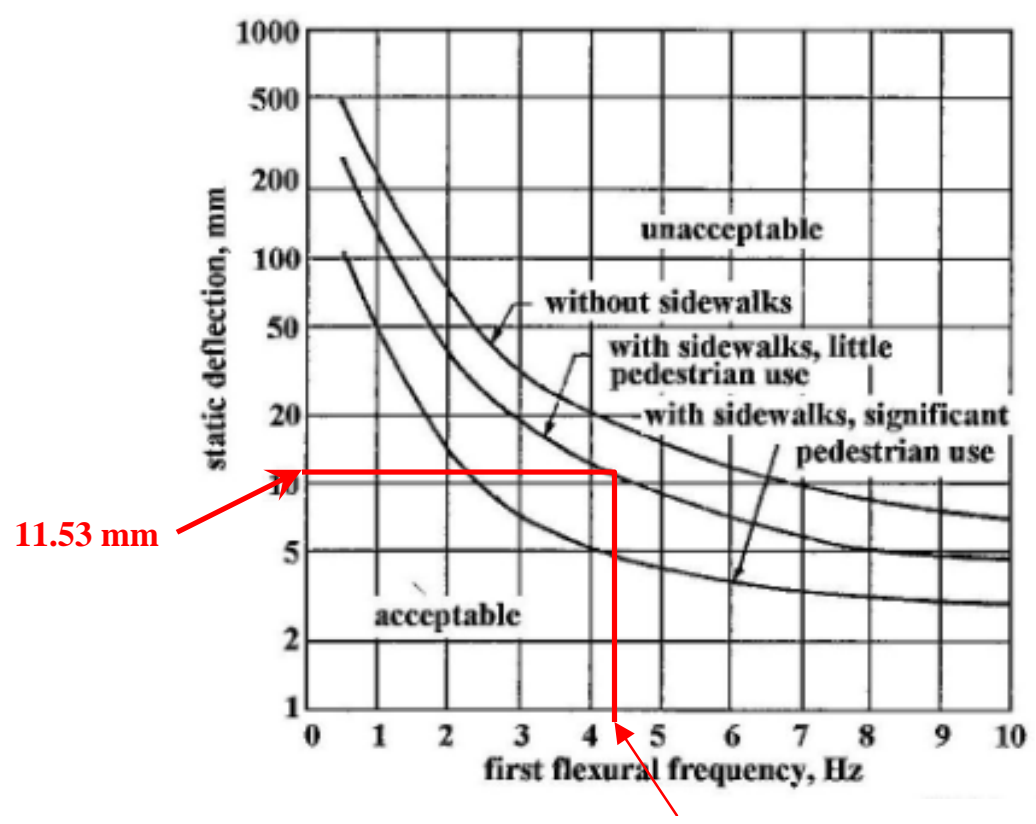

$4.25 \mathrm{~Hz}$

Figure 7.4 Allowable Frequency of the Culloden Bridge

The largest natural frequency was found from the experimental data as $3.906 \mathrm{~Hz}$; therefore, based on the Canadian and Ontario Bridge Codes, the first flexural frequency of the Culloden Bridge is 8 percent less than the allowable frequency of $4.25 \mathrm{~Hz}$. If the Culloden Bridge was more heavily traveled by pedestrians, the allowable natural frequency would have been reduced to $2.25 \mathrm{~Hz}$; placing the experimental natural frequency outside of the acceptable range. 


\subsection{Deflection}

\subsubsection{Deflection Field Test Results}

Each girder was instrumented with a LVDT and load tested to produce maximum deflections. Truck placements were measured from the edge of the north curb as previously presented in Figure 6.24 and Figure 6.25. The load test results are presented below with several points of interest illustrated in Figure 7.5. The two points along the bottom of the graph demonstrate when the load truck stopped at $0.40 \mathrm{~L}_{1}$ and $0.60 \mathrm{~L}_{1}$. This was done to observe static deflections and minimize the affects of impact. The third point illustrates when the truck was in the second span of the bridge causing uplift in the first span. When the truck reached the opposite end span, the deflection in the first span was again upward. This was caused by an uplift of the middle span as the load truck entered the opposite end-span.

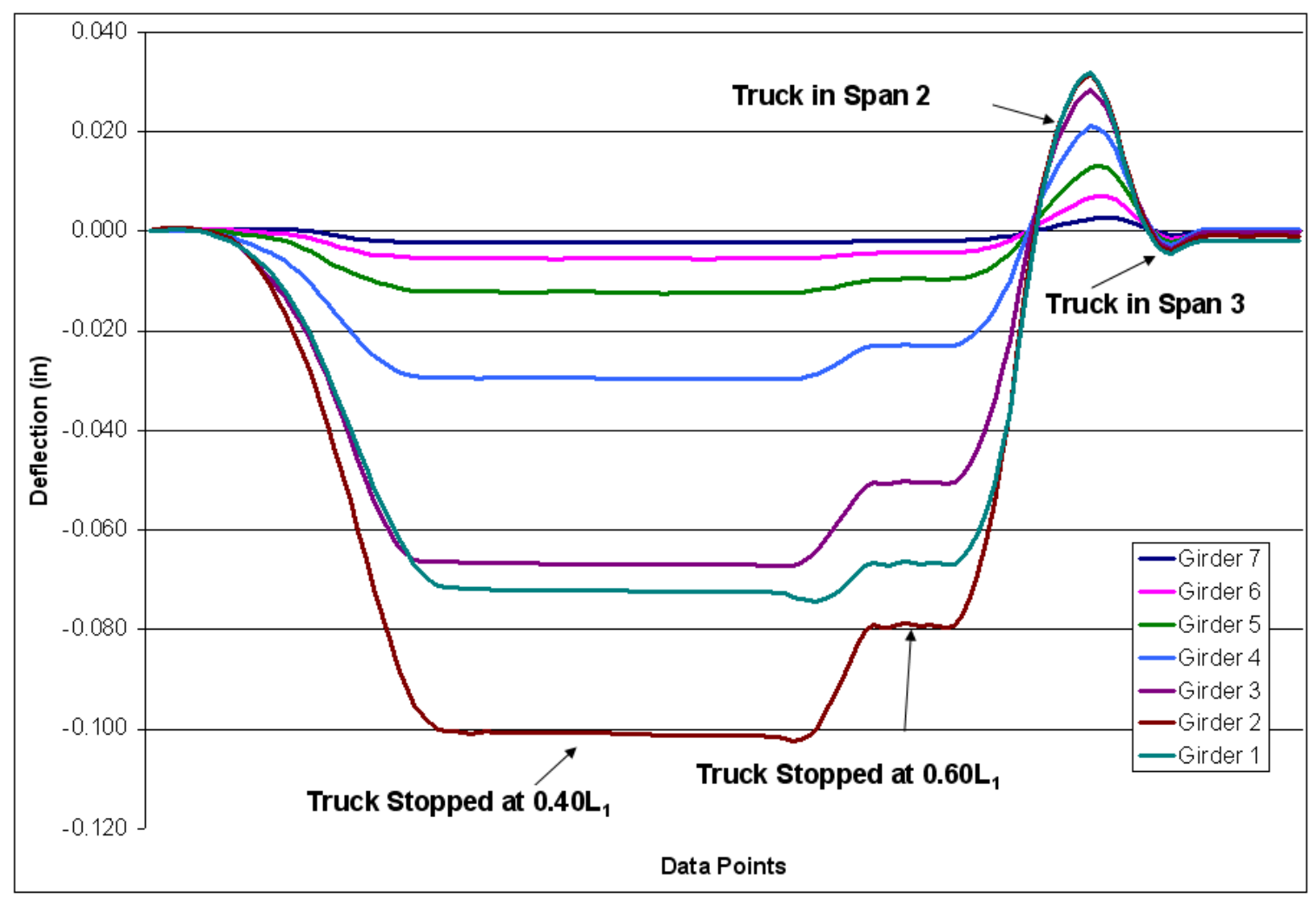

Figure 7.5 Truck Placement 1 Deflections 


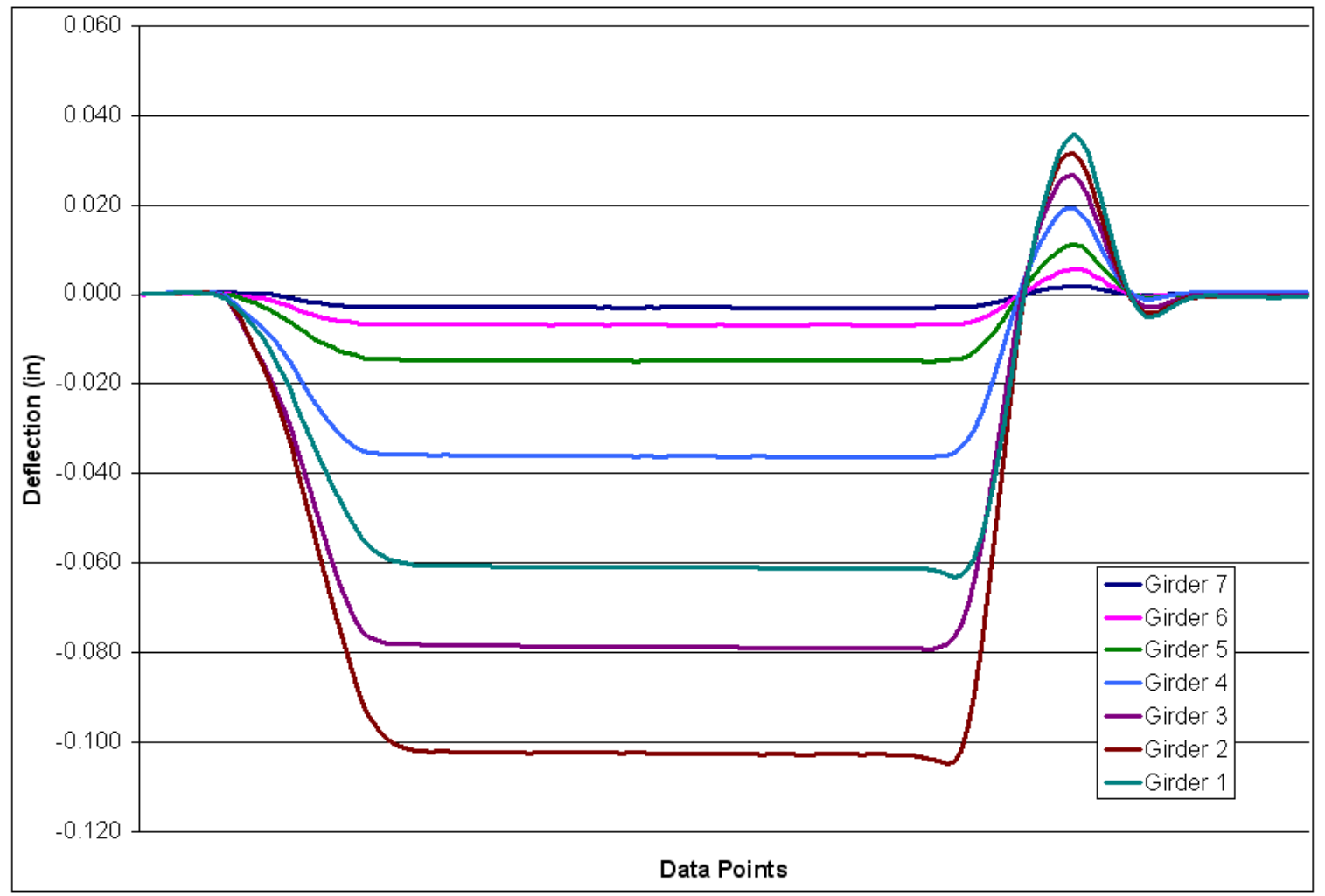

Figure 7.6 Truck Placement 2 Deflections

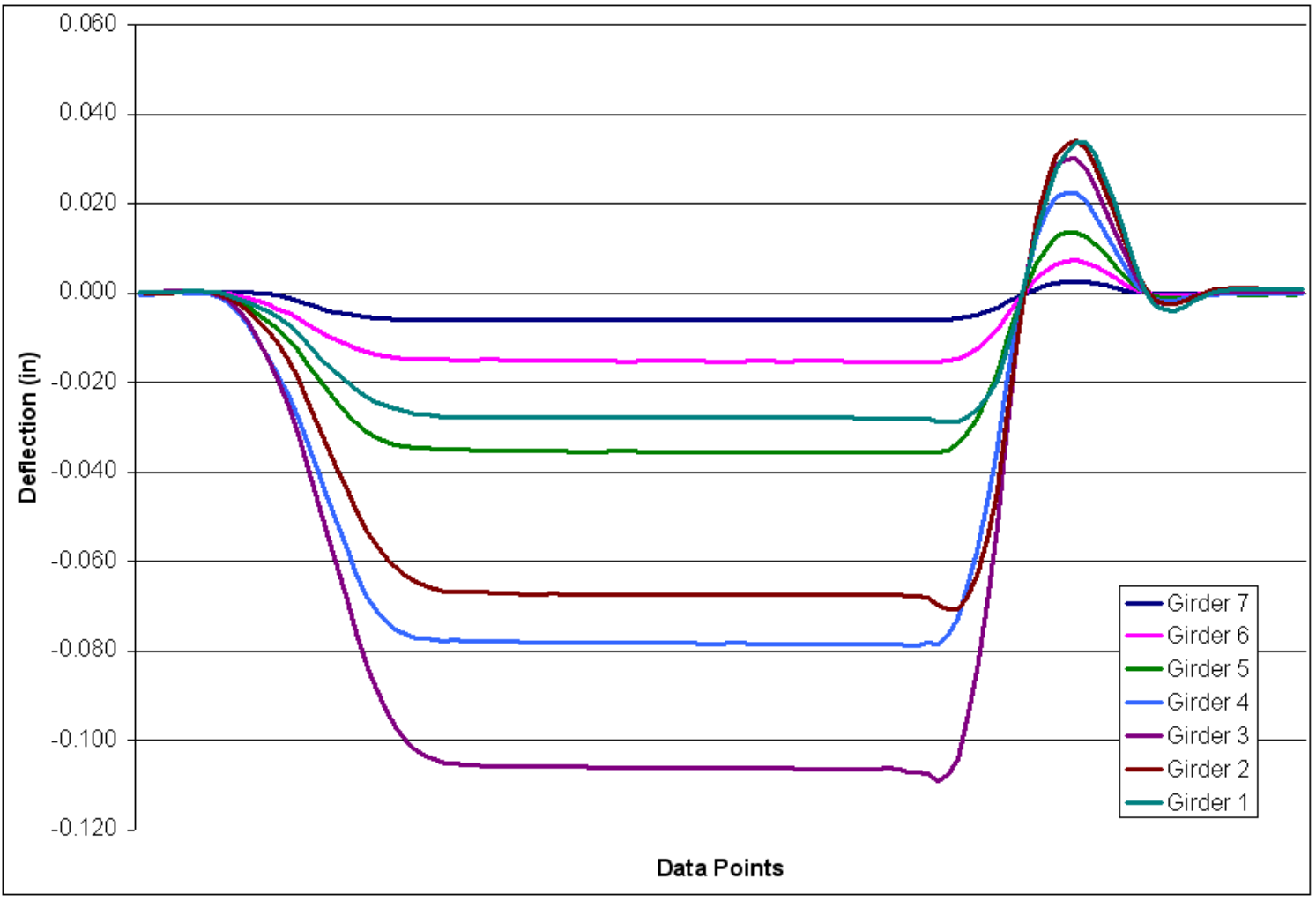

Figure 7.7 Truck Placement 3 Deflections 


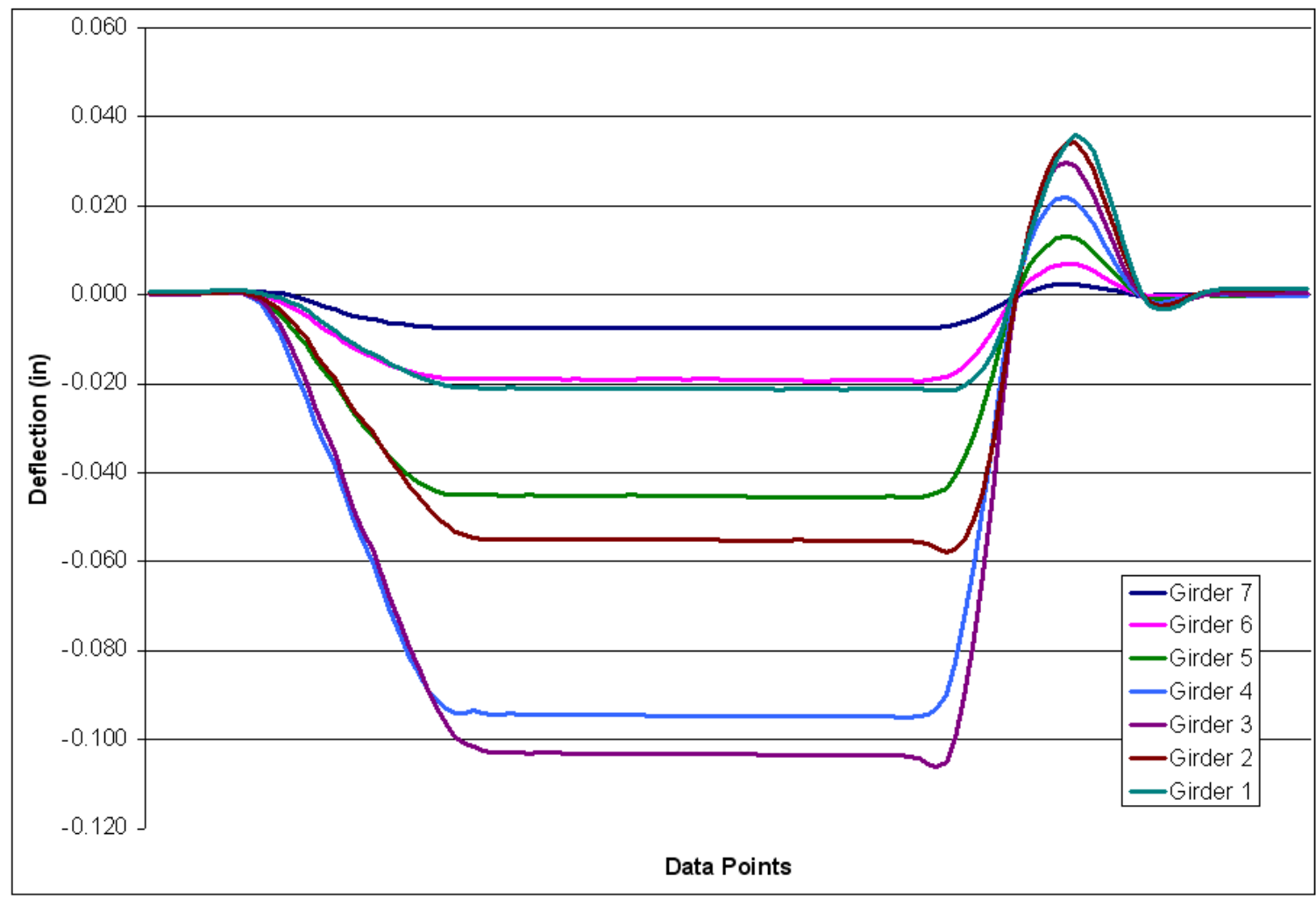

Figure 7.8 Truck Placement 4 Deflections

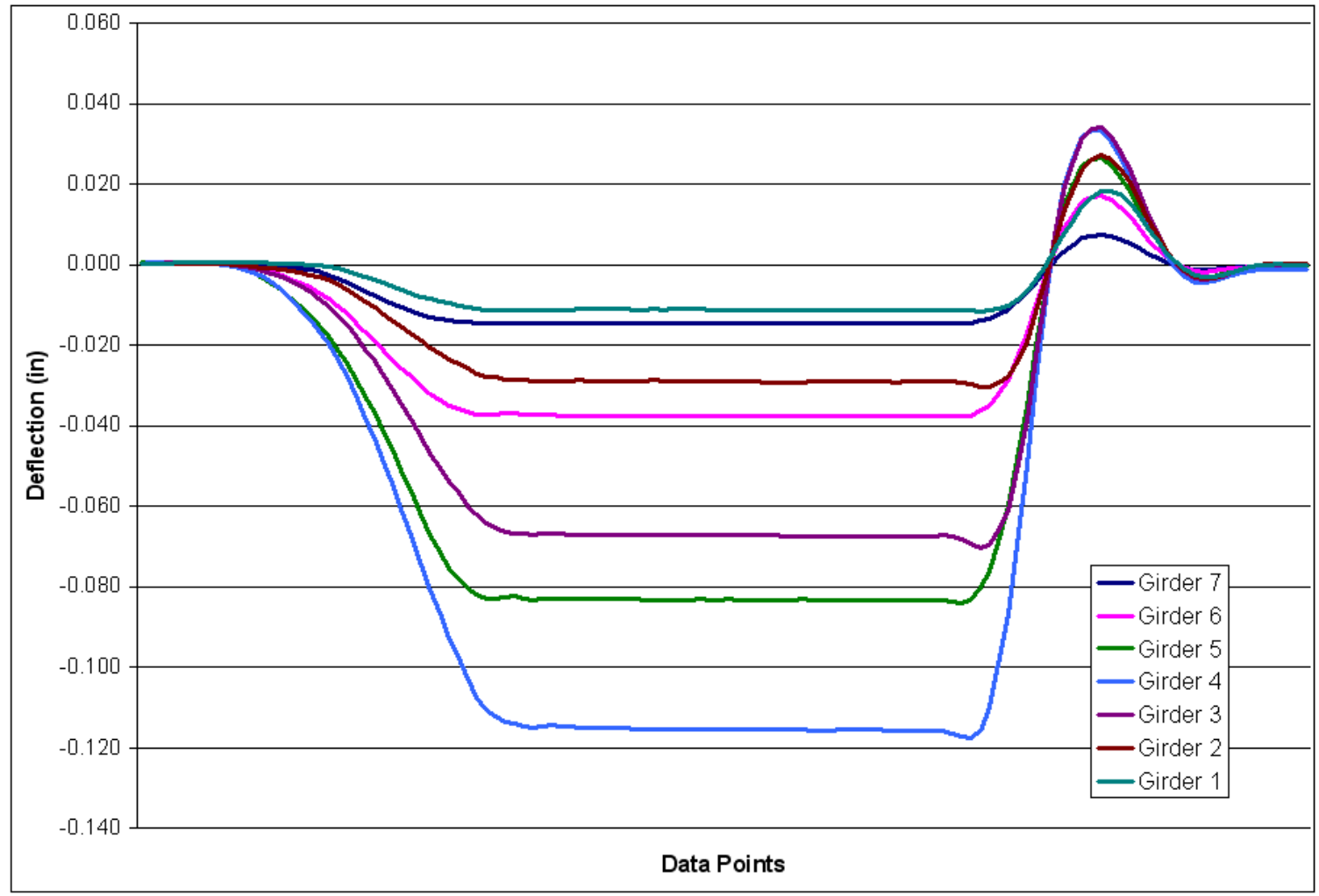

Figure 7.9 Truck Placement 5 Deflections 


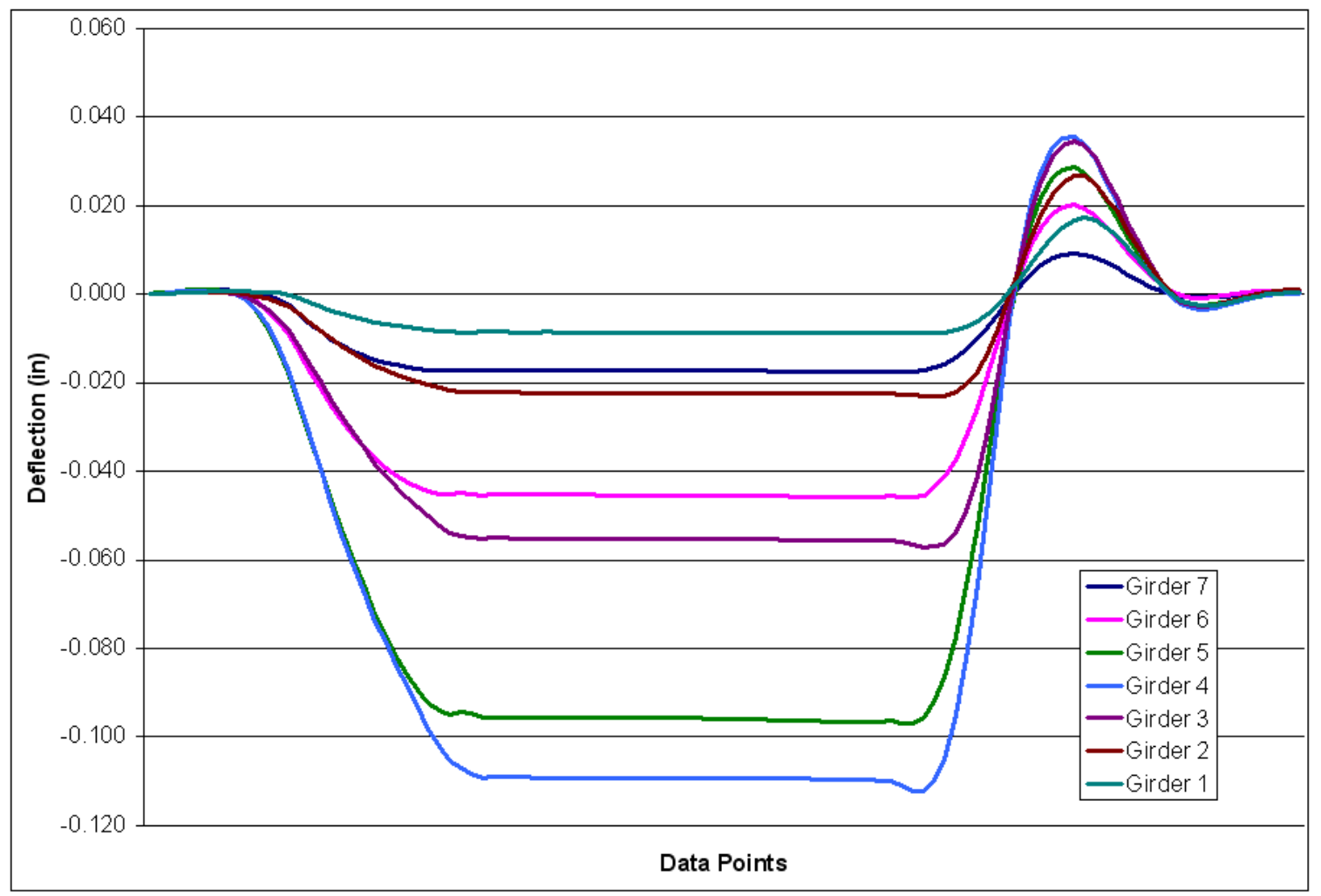

Figure 7.10 Truck Placement 6 Deflections

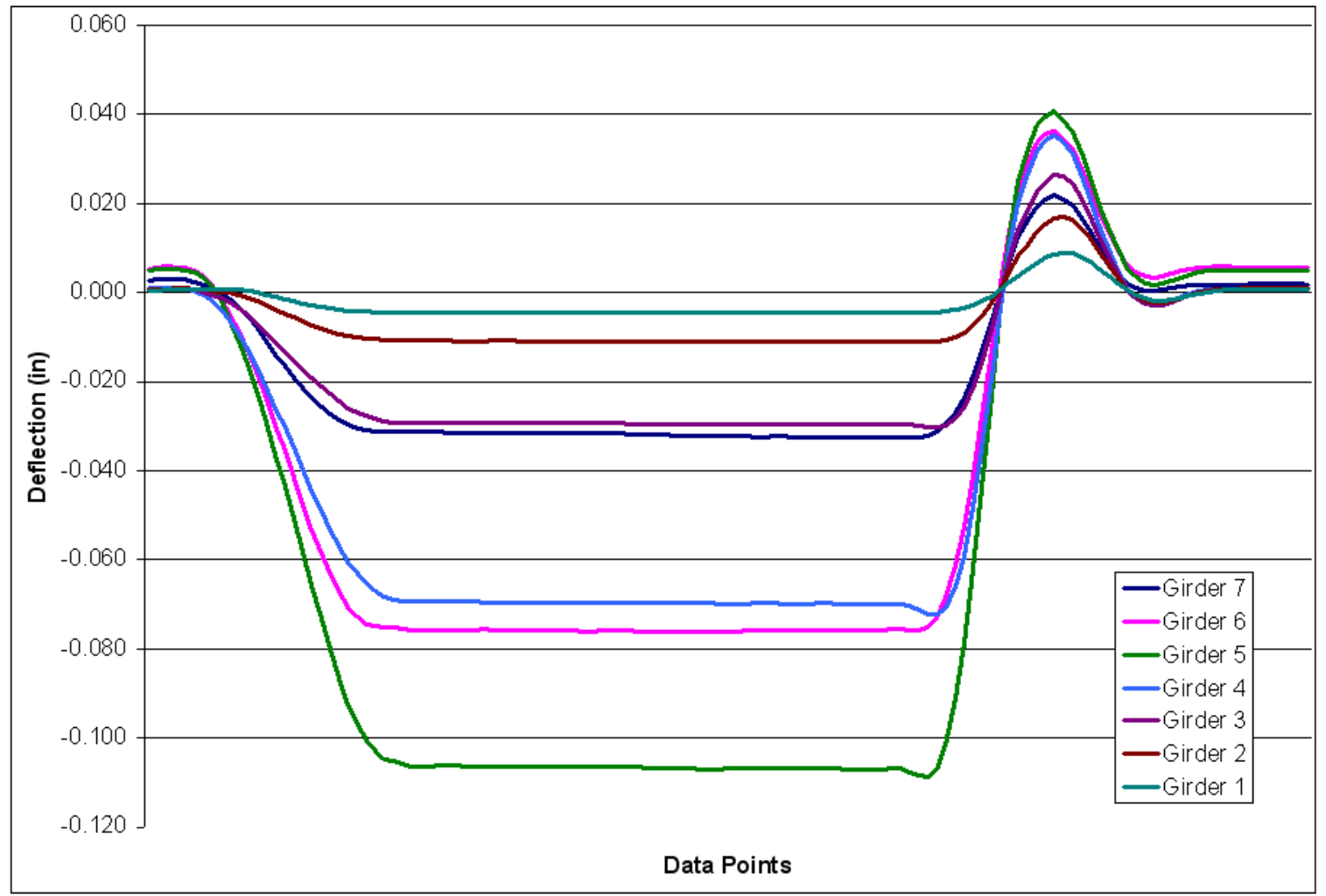

Figure 7.11 Truck Placement 7 Deflections 


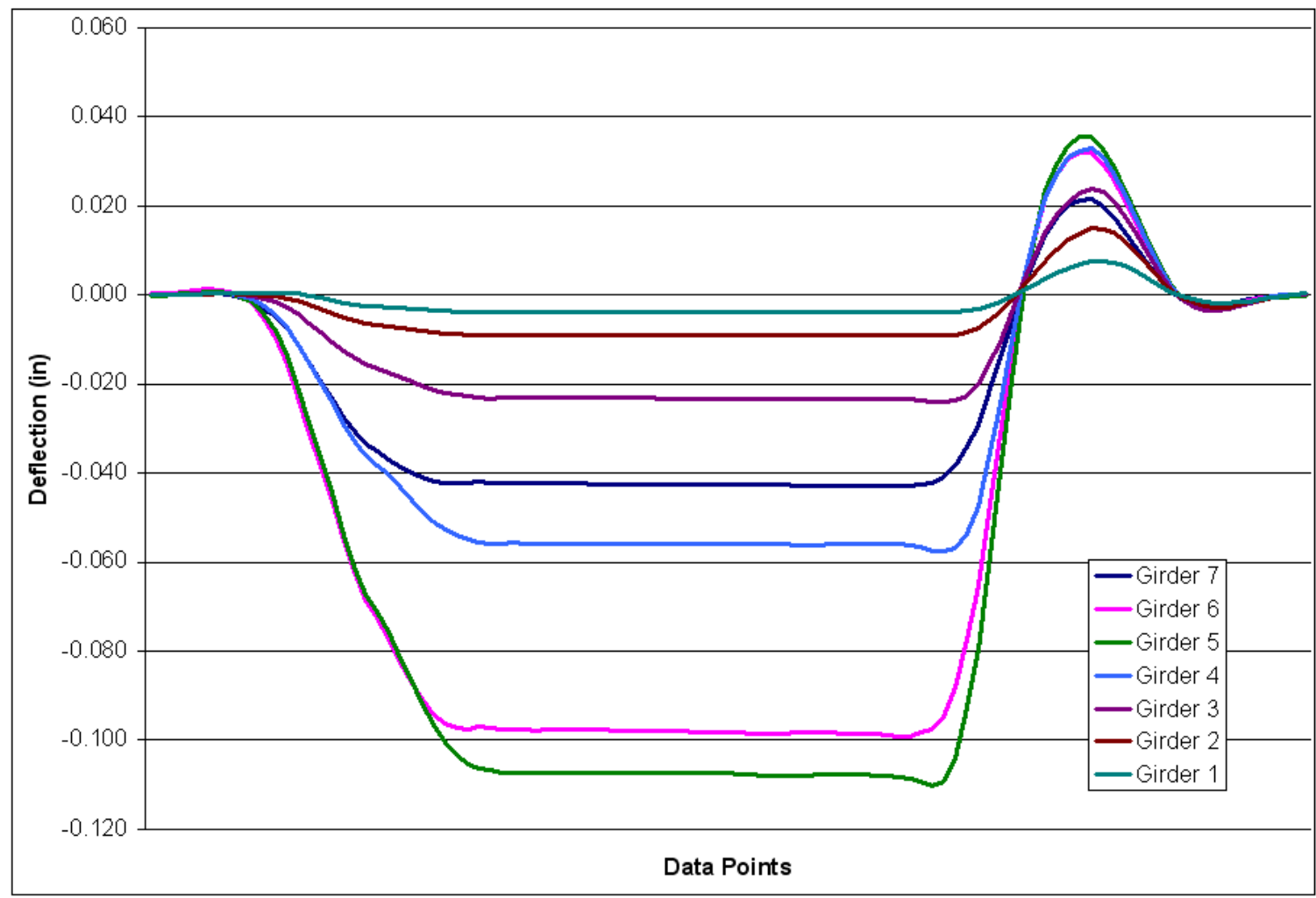

Figure 7.12 Truck Placement 8 Deflections

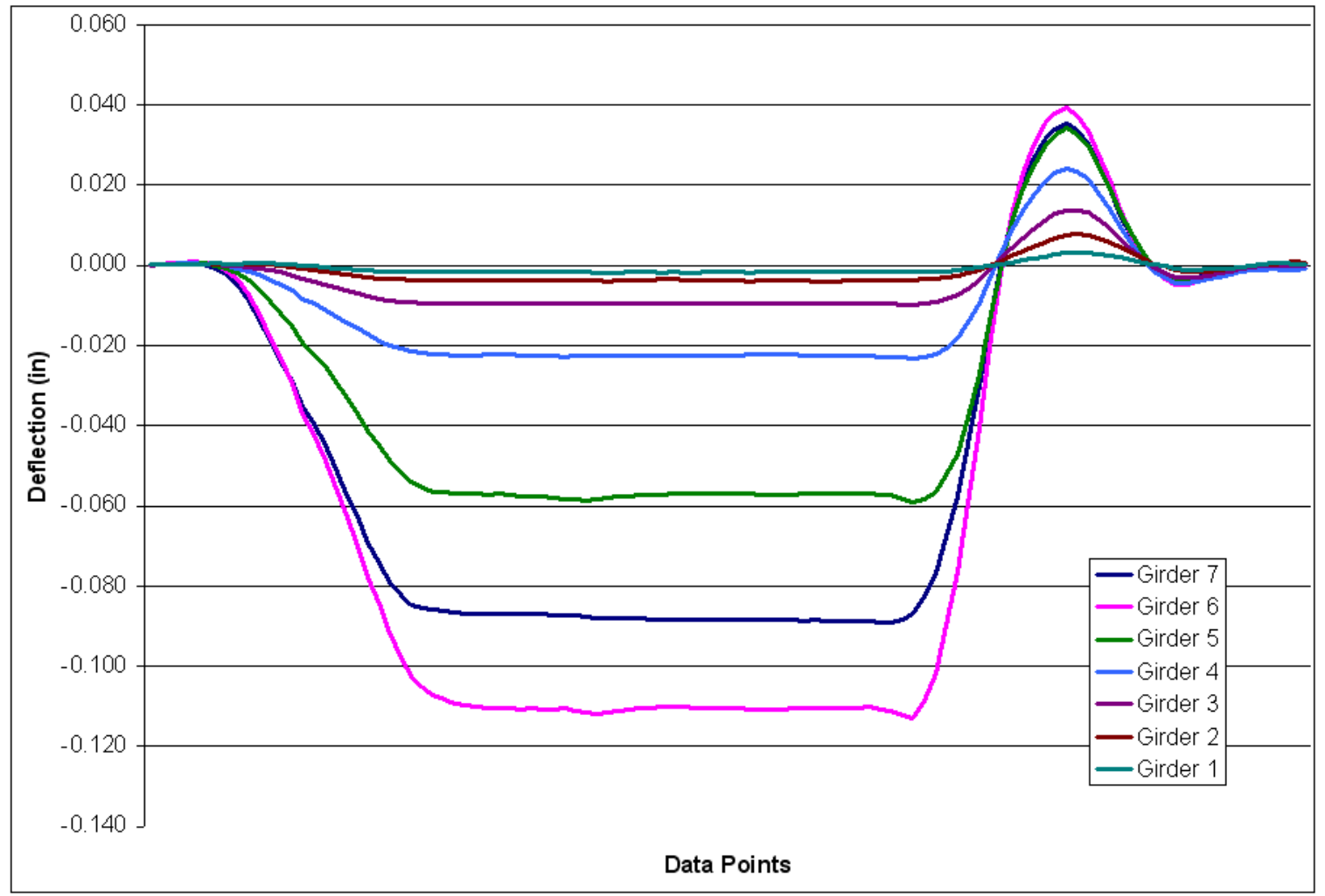

Figure 7.13 Truck Placement 9 Deflections 


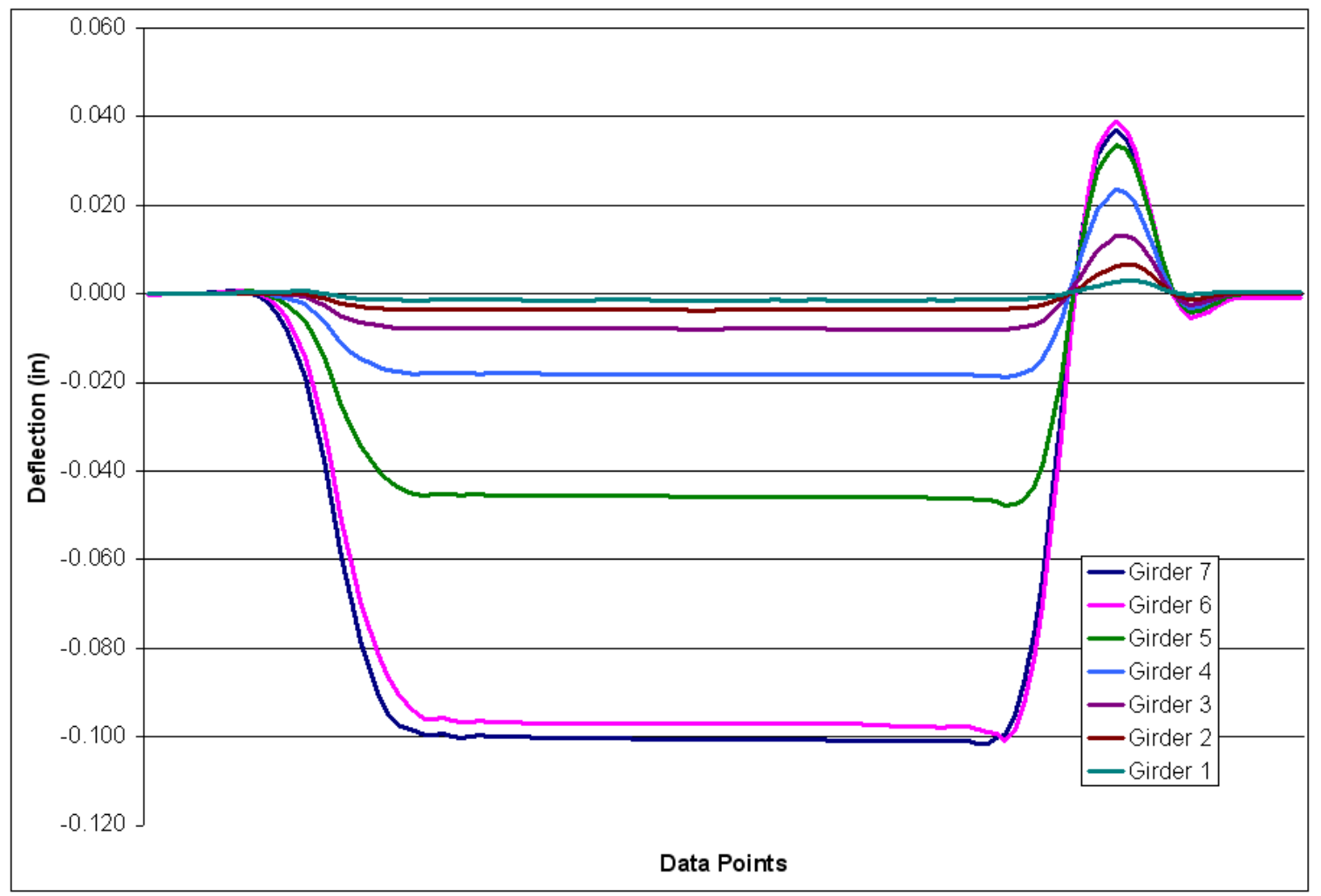

Figure 7.14 Truck Placement 10 Deflections

\subsubsection{Experimental Deflection Distribution Factors}

Live load deflection distribution factors were experimentally determined by superimposing truck placements to produce maximum deflections in each girder. AASHTO requires that $2 \mathrm{ft}$. be maintained between truck tires and curbs, tires and barriers, and $4 \mathrm{ft}$. between adjacent trucks. Truck placements meeting this criterion were used to determine maximum girder deflections. Girders 1, 2, and 3 were found to deflect most from superimposed truck placements 1, 3, 6, and 8, while Girders 4, 5, 6, and 7 deflected most from superimposed truck placements 3, 5, 8, and 10 . 


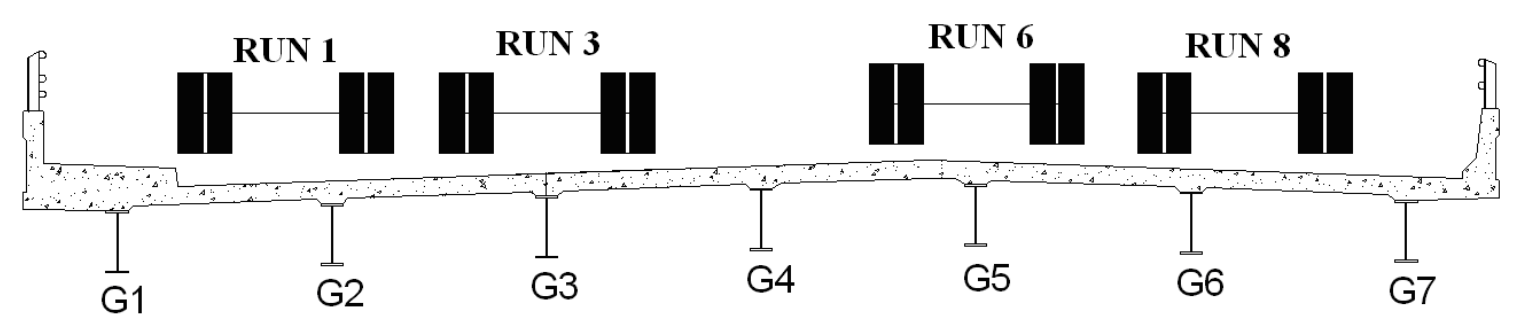

Figure 7.15 Worst-Case Truck Placements for Girders 1, 2, \& 3

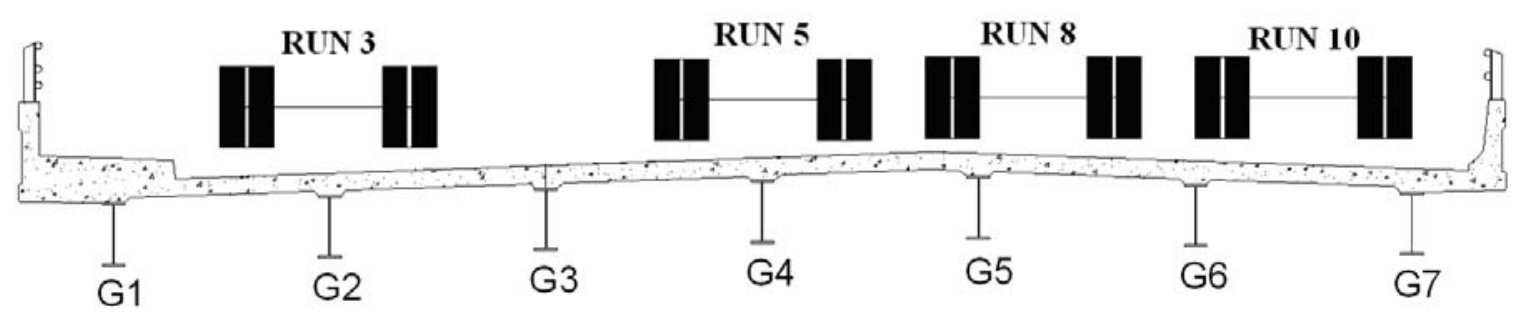

Figure 7.16 Worst-Case Truck Placements for Girders 4, 5, 6, \& 7

The maximum deflections were obtained for each girder by superimposing the load truck placements shown in the figures above. Deflections recorded from each truck placement are tabularized below, and critical truck placements are summed to determine the maximum live load deflections for each girder.

Table 7.3 Individual Girder Deflections

\begin{tabular}{|c|c|c|c|c|c|c|c|}
\cline { 2 - 7 } \multicolumn{1}{c|}{} & \multicolumn{7}{c|}{ Deflection (in) } \\
\cline { 2 - 8 } \multicolumn{1}{c|}{} & Girder 1 & Girder 2 & Girder 3 & Girder 4 & Girder 5 & Girder 6 & Girder 7 \\
\hline Truck Placement 1 & -0.074 & -0.102 & -0.067 & -0.030 & -0.012 & -0.008 & -0.003 \\
\hline Truck Placement 2 & -0.063 & -0.105 & -0.079 & -0.036 & -0.015 & -0.007 & -0.003 \\
\hline Truck Placement 3 & -0.029 & -0.071 & -0.109 & -0.079 & -0.036 & -0.015 & -0.006 \\
\hline Truck Placement 4 & -0.022 & -0.058 & -0.106 & -0.095 & -0.046 & -0.019 & -0.008 \\
\hline Truck Placement 5 & -0.011 & -0.030 & -0.070 & -0.118 & -0.084 & -0.038 & -0.015 \\
\hline Truck Placement 6 & -0.009 & -0.023 & -0.057 & -0.112 & -0.097 & -0.046 & -0.018 \\
\hline Truck Placement 7 & -0.005 & -0.011 & -0.030 & -0.072 & -0.109 & -0.076 & -0.033 \\
\hline Truck Placement 8 & -0.004 & -0.009 & -0.024 & -0.058 & -0.110 & -0.099 & -0.043 \\
\hline Truck Placement 9 & -0.002 & -0.004 & -0.010 & -0.023 & -0.059 & -0.113 & -0.089 \\
\hline Truck Placement 10 & -0.002 & -0.004 & -0.008 & -0.019 & -0.048 & -0.101 & -0.101 \\
\hline
\end{tabular}


Table 7.4 Superimposed Deflections for Girders 1, 2, \& 3

\begin{tabular}{|c|c|c|c|c|c|c|c|}
\cline { 2 - 8 } \multicolumn{1}{c|}{} & \multicolumn{9}{c|}{ Deflection (in.) } \\
\cline { 2 - 8 } \multicolumn{1}{c|}{} & Girder 1 & Girder 2 & Girder 3 & Girder 4 & Girder 5 & Girder 6 & Girder 7 \\
\hline Truck Placement 1 & -0.074 & -0.102 & -0.067 & -0.030 & -0.012 & -0.005 & -0.002 \\
\hline Truck Placement 3 & -0.029 & -0.070 & -0.109 & -0.078 & -0.036 & -0.015 & -0.006 \\
\hline Truck Placement 6 & -0.009 & -0.023 & -0.057 & -0.112 & -0.097 & -0.046 & -0.018 \\
\hline Truck Placement 8 & -0.004 & -0.009 & -0.024 & -0.058 & -0.110 & -0.098 & -0.042 \\
\hline Sum: & $-\mathbf{0 . 1 1 5}$ & $-\mathbf{0 . 2 0 4}$ & -0.256 & $\mathbf{- 0 . 2 7 8}$ & $\mathbf{- 0 . 2 5 5}$ & $\mathbf{- 0 . 1 6 4}$ & $-\mathbf{0 . 0 6 8}$ \\
\cline { 2 - 8 }
\end{tabular}

Table 7.5 Superimposed Deflections for Girders 4, 5, 6, \& 7

\begin{tabular}{|c|c|c|c|c|c|c|c|}
\cline { 2 - 8 } \multicolumn{1}{c|}{} & \multicolumn{7}{c|}{ Deflection (in.) } \\
\cline { 2 - 8 } \multicolumn{1}{c|}{} & Girder 1 & Girder 2 & Girder 3 & Girder 4 & Girder 5 & Girder 6 & Girder 7 \\
\hline Truck Placement 3 & -0.029 & -0.070 & -0.109 & -0.078 & -0.036 & -0.015 & -0.006 \\
\hline Truck Placement 5 & -0.011 & -0.030 & -0.070 & -0.110 & -0.076 & -0.035 & -0.013 \\
\hline Truck Placement 8 & -0.004 & -0.009 & -0.024 & -0.058 & -0.110 & -0.098 & -0.042 \\
\hline Truck Placement 10 & -0.001 & -0.004 & -0.008 & -0.018 & -0.047 & -0.099 & -0.101 \\
\hline Sum: & $\mathbf{- 0 . 0 4 5}$ & $-\mathbf{0 . 1 1 3}$ & $\mathbf{0 . 2 1 1}$ & -0.264 & -0.269 & -0.247 & $-\mathbf{0 . 1 6 3}$ \\
\cline { 2 - 8 }
\end{tabular}

The maximum experimental deflection distribution factors were determined for interior and exterior girders with the following equation:

$$
D F=\frac{\max \left(m \times \Delta_{\text {sup erimposed }}\right)}{\Delta_{100 \% \text { Load Truck }}}
$$

The deflections due to $1,2,3$, and 4 lanes loaded were multiplied by their respective multiple presence factor and divided by the theoretical deflection from an undistributed load truck determined with CONSYS ${ }^{\mathrm{TM}}$. The maximum experimental deflection of an interior girder was due to truck placements 3, 5, and 8 acting on Girder 4 . This resulted in the following live load deflection distribution factor:

$$
D F_{\text {Interior }}=\frac{0.85(0.078+0.110+0.058)}{0.380}=0.550 \text { lanes }
$$

The maximum exterior girder deflection was due to truck placements 8 and 10 acting on 
Girder 7. This equated to the following distribution factor:

$$
D F_{\text {Exterior }}=\frac{1.00(|-0.042|+|-0.101|)}{|-0.370|}=0.388 \text { lanes }
$$

The optional live load deflection criterion specifies that all design lanes are to be loaded when determining the maximum deflection. The Culloden Bridge has 4 design lanes and 7 girders; therefore, the AASHTO distribution factor was calculated as follows:

$$
\begin{aligned}
& D F=m\left(\frac{N_{L}}{N_{B}}\right) \\
& D F=0.65\left(\frac{4}{7}\right)=0.371 \text { lanes }
\end{aligned}
$$

Eq. 7.5

The results of the experimental and AASHTO distribution factors, with and without multiple presence factors taken into account, are shown in Figure 7.17.

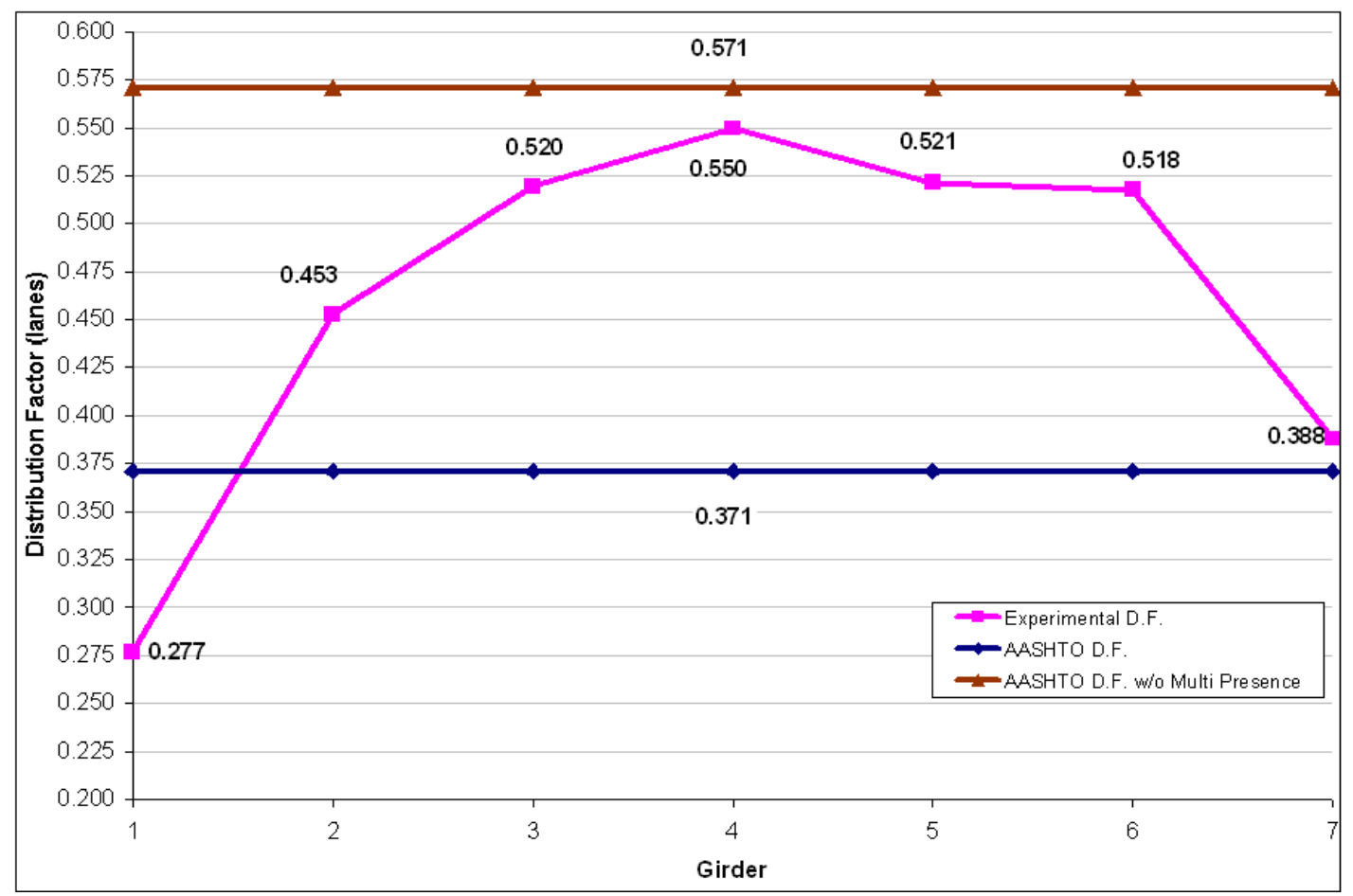

Figure 7.17 Maximum Distribution Factor by Girder 
AASHTO and experimental distribution factors were further compared by using CONSYS ${ }^{\mathrm{TM}}$ to determine girder deflections induced by the Service I load combination at the $0.40 \mathrm{~L}_{1}$ point of interior and exterior girders. AASHTO distribution factors, with impact, were applied to CONSYS ${ }^{\mathrm{TM}}$ deflections and compared with each girder's experimental deflection. The experimental deflections were also multiplied by impact for comparison with the already factored AASHTO values. A third set of AASHTO deflections were also compared to illustrate AASHTO deflections with multiple presence removed from the applied distribution factors. The three sets of deflections were then plotted in Figure 7.18 to illustrate the differences between experimental deflections, AASHTO deflections, and AASHTO deflections without multiple presence.

\section{Table 7.6 Experimental and AASHTO Deflections}

\begin{tabular}{|r|c|c|c|c|c|c|c|}
\cline { 2 - 8 } \multicolumn{1}{c|}{} & \multicolumn{7}{c|}{ Deflections (in.) } \\
\cline { 2 - 8 } \multicolumn{1}{c|}{} & Girder 1 & Girder 2 & Girder 3 & Girder 4 & Girder 5 & Girder 6 & Girder 7 \\
\hline Experimental Truck & 0.153 & 0.271 & 0.341 & 0.351 & 0.357 & 0.328 & 0.217 \\
\hline AASHTO Loading & 0.311 & 0.326 & 0.326 & 0.326 & 0.326 & 0.326 & 0.311 \\
\hline AASHTO Loading w/o MP & 0.478 & 0.502 & 0.502 & 0.502 & 0.502 & 0.502 & 0.478 \\
\hline
\end{tabular}




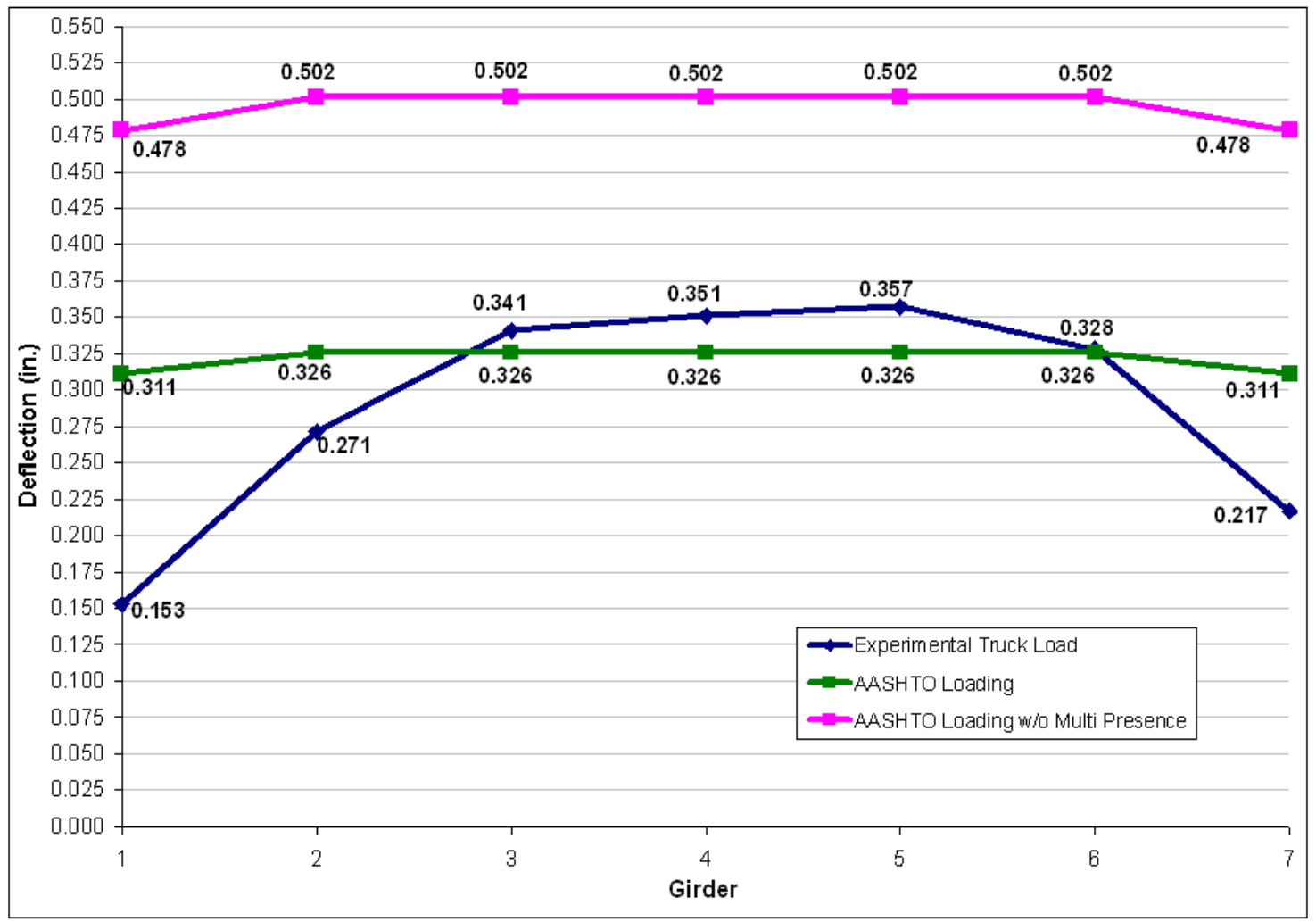

Figure 7.18 Experimental and AASHTO Deflections

\subsubsection{Summary of Deflection Distribution Factors}

On average, the experimental distribution factors were 14.34 percent higher than the AASHTO distribution factors; with the highest experimental distribution factor being 32.5 percent higher than AASHTO, and the lowest being 37.69 percent lower than AASHTO. During deflection testing it was not possible to maximize exterior girder deflections due to their proximity to curbs, barriers and sidewalks; thus, their distribution factors were considerably less than the interior girder distribution factors. Girder 1 was located under a sidewalk making it impossible to reach with the load truck such that the axle was straddling the girder. Girder 7 was also not fully loaded because of a $2 \mathrm{ft}$. required clearance between tire and barrier. The interior girders were effectively tested because it was possible to place the load truck to maximize deflections. The average 
experimental distribution factor for an interior girder was $27.26 \%$ higher than the AASHTO distribution factor.

Table 7.7 Percent Difference of Exp. vs. AASHTO Distribution Factors

\begin{tabular}{|c|c|c|c|}
\hline \multirow{2}{*}{ Girder } & \multicolumn{2}{|c|}{ Dist. Factor (lanes) } & \\
\cline { 2 - 3 } & Exp. & AASHTO & $\%$ Diff. \\
\hline Girder 1 & 0.277 & 0.371 & $-34.07 \%$ \\
\hline Girder 2 & 0.453 & 0.371 & $18.05 \%$ \\
\hline Girder 3 & 0.520 & 0.371 & $28.59 \%$ \\
\hline Girder 4 & 0.550 & 0.371 & $32.50 \%$ \\
\hline Girder 5 & 0.521 & 0.371 & $28.85 \%$ \\
\hline Girder 6 & 0.518 & 0.371 & $28.32 \%$ \\
\hline Girder 7 & 0.388 & 0.371 & $4.33 \%$ \\
\hline \multicolumn{3}{|c|}{$\begin{array}{c}\text { Overall Avg: } \\
\text { Avg Interior: }\end{array}$} & $15.22 \%$ \\
Avg Exterior: & $-14.87 \%$ \\
\hline
\end{tabular}

When checking live load deflection, all design lanes are to be loaded to maximize effects. The maximum deflection is then multiplied by the deflection distribution factor which includes multiple presence. However, applying multiple presence in this case is unfounded because the specifications specifically state that all design lanes are loaded; therefore, multiple presence factors should be neglected. To compare, experimental and AASHTO distribution factors, with multiple presence excluded, were tabulated in Table 7.7 and plotted in Figure 7.8. Exterior girders were not included in the table because they could not be fully loaded during field tests. The girders adjacent to the exterior girders also yielded somewhat lower experimental distribution factors because of truck placement limitations. Girder 4 was located at the transverse mid-point of the cross section; thus, it was possible to maximize deflections with the truck placements outlined in Figure 7.16. When compared with AASHTO, Girder 4 was only $3.85 \%$ less than the AASHTO distribution factor without multiple presence effects. 
Table 7.8 Percent Difference of Exp. and AASHTO Distribution Factors

\begin{tabular}{|c|c|c|c|}
\hline & \multicolumn{2}{|c|}{ Dist. Factor (lanes) } & \\
\cline { 2 - 3 } Girder & Exp. & $\begin{array}{c}\text { AASHTO } \\
\text { w/o M.P. }\end{array}$ & \% Diff. \\
\hline Girder 2 & 0.453 & 0.571 & $-26.07 \%$ \\
\hline Girder 3 & 0.520 & 0.571 & $-9.86 \%$ \\
\hline Girder 4 & 0.550 & 0.571 & $-3.85 \%$ \\
\hline Girder 5 & 0.521 & 0.571 & $-9.46 \%$ \\
\hline Girder 6 & 0.518 & 0.571 & $-10.28 \%$ \\
\hline \multicolumn{3}{|c}{ Avg Interior : $-11.90 \%$} \\
\hline
\end{tabular}




\section{Chapter 8 - Strength Assessment of the Culloden Bridge}

\subsection{Experimental Moments}

The maximum positive and negative bending regions of an end-span were instrumented with three stain gages; one in the center of each bottom flange, and two at the mid-point of each web. Gages were placed on each side of the web to account for torsion in the web during load testing. To correct for web torsion effects, the two web strain values were averaged. Stresses were then determined by multiplying the web and flange strains by the modulus of elasticity for steel $(29,000 \mathrm{ksi})$. Once the stresses were

determined, the bending moments induced by the load truck were found by the equations below previously introduced in Chapter 2 .

$$
\begin{aligned}
& M_{L}=\left(\sigma_{B F}-\sigma_{C G}\right) \times S_{\text {steel }} \\
& M_{u}=\frac{\left(E_{\text {conc }} \times I_{\text {conc }}\right)}{\left(E_{\text {steel }} \times I_{\text {steel }}\right)} \times M_{L} \\
& N a=\left(\sigma_{C G} \times A_{\text {steel }}\right)\left[\left(d_{\text {steel }}-y_{N A}\right)+\text { Haunch }+\frac{d_{\text {slab }}}{2}\right] \\
& M_{T}=M_{u}+M_{L}+N \times a
\end{aligned}
$$




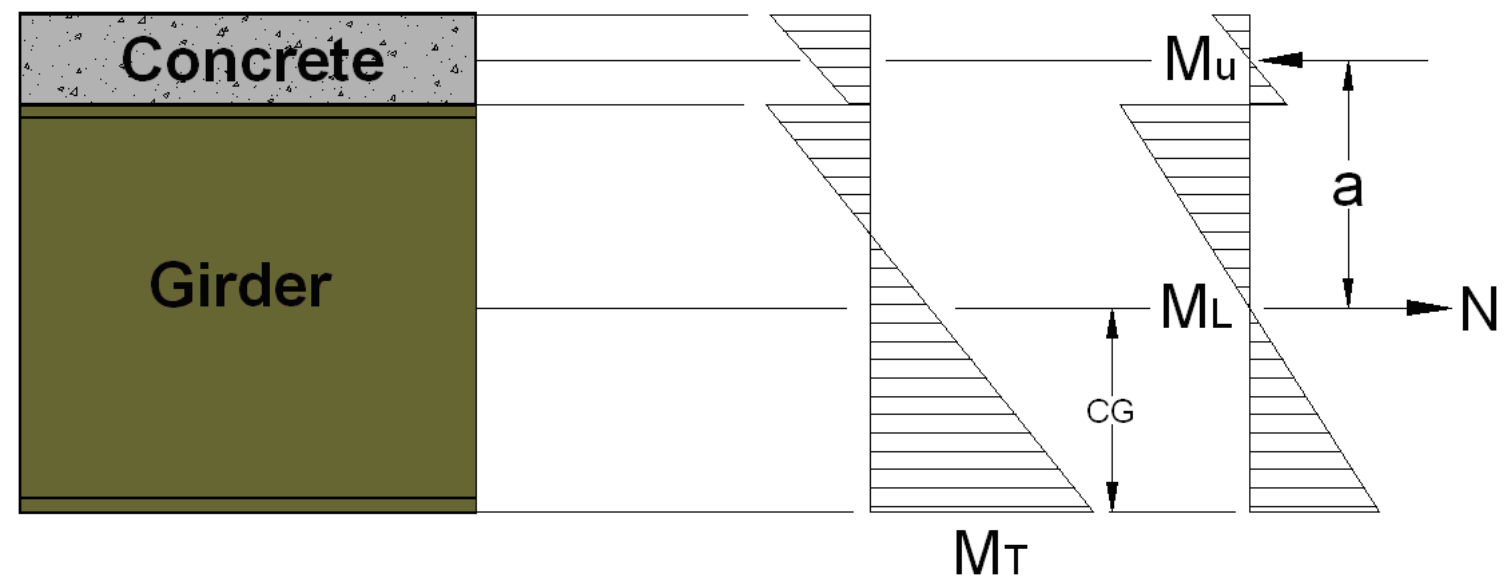

Figure 8.1 Moment Resisting Mechanisms

\subsubsection{Section I: Experimental Positive Bending Moments}

The bottom flanges of interior and exterior girders are slightly different in

Sections I and II; therefore, their section properties were calculated independently of each other and are presented below in Table 8.1. The AASHTO specifications allow the shortterm composite sections to be used in the positive and negative bending regions at the service limit state; therefore, the deck was assumed to be uncracked and fully composite across the effective width when determining the experimental bending moments. The effective flange widths are also slightly different between interior and exterior girders. The interior girders have an effective flange width of 96 in., while exterior girders have an effective flange width of 90 in. as shown in Figure 8.2 and Figure 8.3, respectively. 
Table 8.1 Section Properties used in Section I - Positive Moment Calculations

\begin{tabular}{|c|c|c|}
\hline & \multicolumn{2}{|c|}{ SECTION I } \\
\hline & Ext. Girders & Int. Girders \\
\hline $\mathrm{E}_{\mathrm{STL}}=$ & 29000 & 29000 \\
\hline$f_{c}^{\prime}=$ & 4000 & 4000 \\
\hline $\mathrm{E}_{\text {CONC }}=$ & 3605 & 3605 \\
\hline$b_{e=}=$ & 90 & 96 \\
\hline $\mathrm{h}=$ & 2 & 2 \\
\hline Struc.Slab t = & 7.75 & 7.75 \\
\hline$b_{\mathrm{t}}=$ & 11 & 11 \\
\hline$t_{t}=$ & $7 / 8$ & $7 / 8$ \\
\hline$t_{w}=$ & $7 / 16$ & $7 / 16$ \\
\hline $\mathrm{D}_{\mathrm{w}}=$ & 26 & 26 \\
\hline$b_{b}=$ & 12 & 11 \\
\hline$t_{b j}=$ & $7 / 8$ & $7 / 8$ \\
\hline$F_{y t}=$ & 70 & 70 \\
\hline $\mathrm{F}_{\mathrm{yw}}=$ & 50 & 50 \\
\hline$F_{y 0}=$ & 100 & 100 \\
\hline $\mathrm{d}_{\mathrm{STL}}=$ & 28 & 28 \\
\hline$A_{\text {sec. } 1}=$ & 31.500 & 30.625 \\
\hline $\mathrm{y}_{\mathrm{NA}}=$ & 13.502 & 13.875 \\
\hline$I_{\text {section } \mid}=$ & 4271.586 & 4117.923 \\
\hline$S_{\text {top }}=$ & 299.802 & 296.787 \\
\hline$S_{\text {bottom }}=$ & 316.367 & 296.787 \\
\hline$I_{\text {CONC }}=$ & 3491.133 & 3723.875 \\
\hline
\end{tabular}




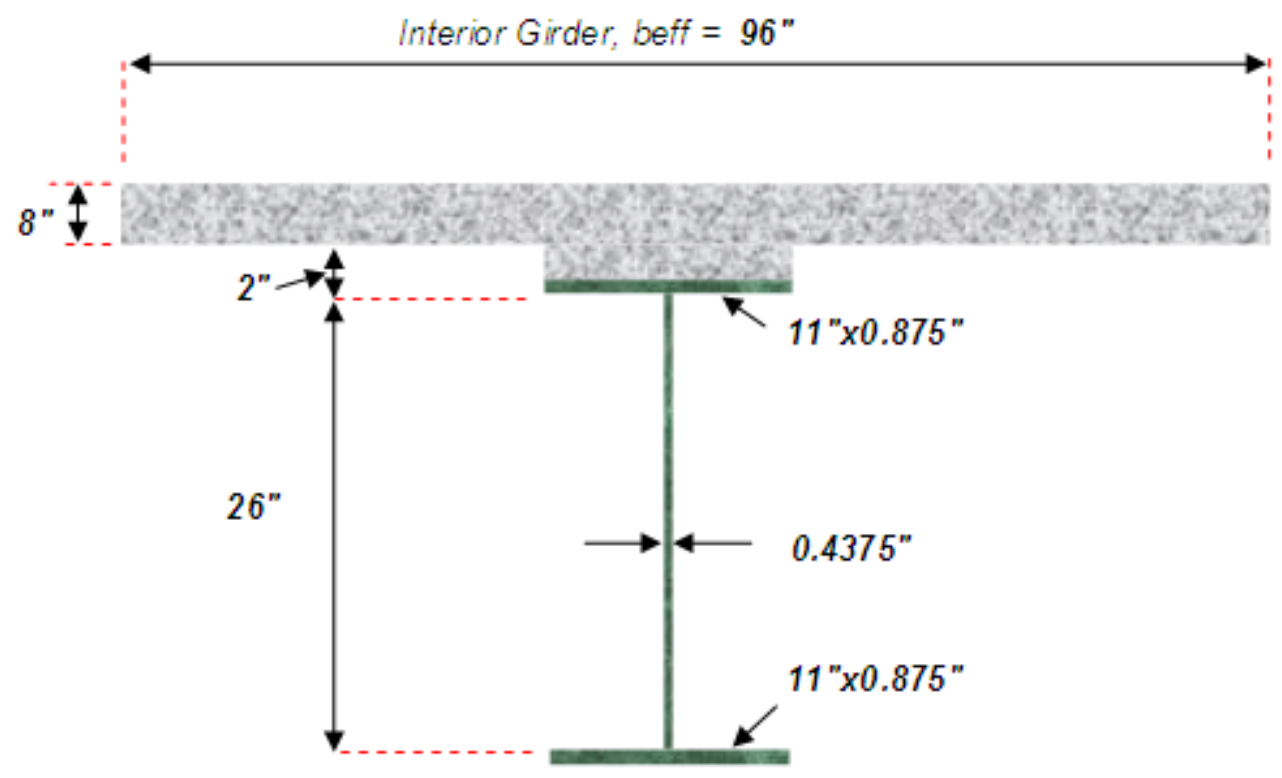

Figure 8.2 Interior Girder - Section I

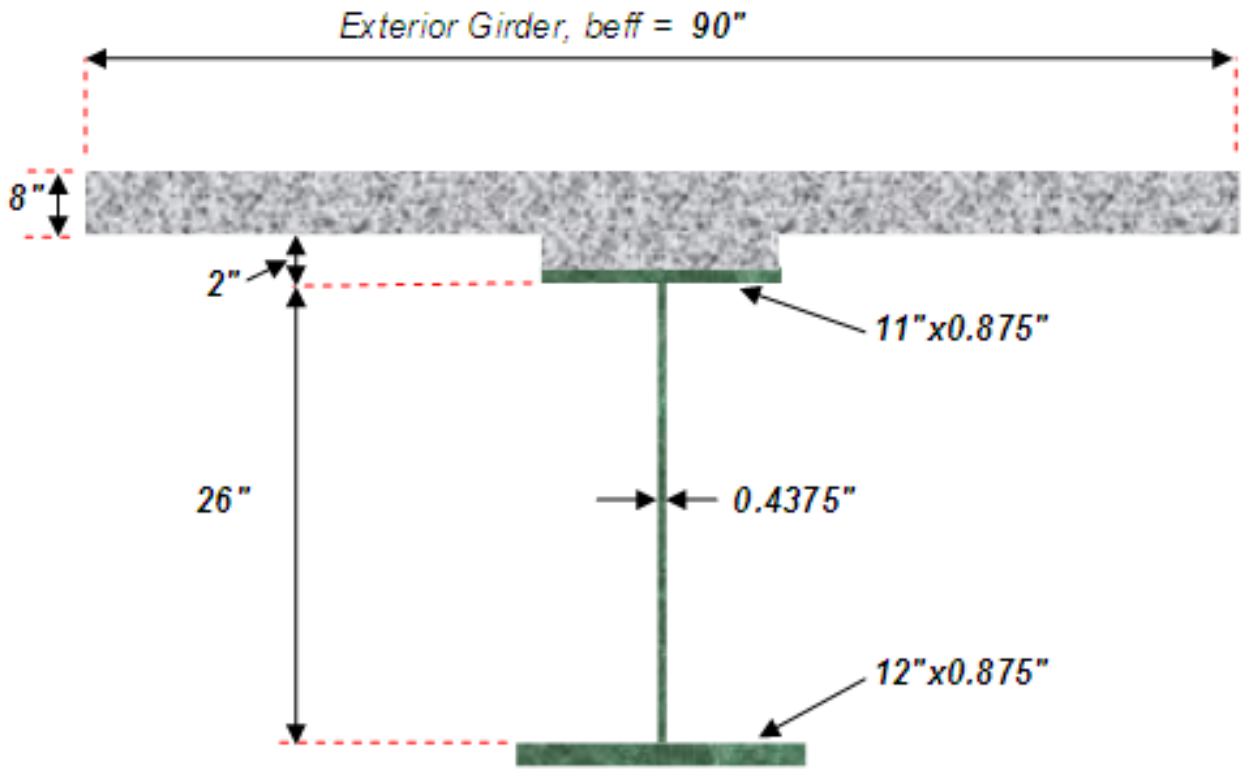

Figure 8.3 Exterior Girder - Section I 
Sample moment calculations are presented below from the data collected during truck placement 1 . This truck placement corresponds to the location that induced the maximum positive moment in Girder 2 and was calculated as follows:

$$
\begin{aligned}
& \sigma_{B F}=\varepsilon_{b f} E_{\text {steel }} \\
& \sigma_{B F}=\left(98.19 \times 10^{-6}\right)(29,000)=2.84 \mathrm{ksi} \\
& \sigma_{C G}=\left(\frac{\varepsilon_{w 1}+\varepsilon_{w 2}}{2}\right) E_{\text {steel }} \\
& \sigma_{C G}=\left[\frac{\left(63.58 \times 10^{-6}\right)+\left(41.11 \times 10^{-6}\right)}{2}\right] 29,000=1.518 \mathrm{ksi} \\
& M_{L}=[(2.848)-(1.518)] \times 296.78=394.6 \mathrm{kip}-\text { in } \\
& E_{\text {conc }}=57,000 \sqrt{f^{\prime}}{ }_{c} \\
& E_{\text {conc }}=57,000 \sqrt{4}=3,605 \mathrm{ksi} \\
& M_{u}=\frac{(3,605 \times 3724)}{(29,000 \times 4118)} \times(394.6)=44.4 \mathrm{kip}-\text { in } \\
& N a=[1.518 \times 30.625] \times\left[(28-13.875)+2+\frac{7.75}{2}\right]=918.16 \mathrm{kip}-\text { in } \\
& M_{T}=44.4+394.6+918.16=1357.16 \mathrm{kip}-\text { in } \\
& M_{T}=113.09 \mathrm{kip}-f t
\end{aligned}
$$

The calculations above were performed for each girder and truck placement and then plotted in Excel ${ }^{\mathrm{TM}}$. Several key points are noted in Figure 8.4. The first point represents when the load truck was stopped for several seconds at $0.40 \mathrm{~L}_{1}$ tenth-point. 
This was done to allow vibrations to dampen out of the superstructure that could potentially affect the strain readings. As the truck pulled away from the $0.40 \mathrm{~L}_{1}$ point, the moment increased momentarily in Girder 1 before decreasing. This means that the theoretical influence point of maximum moment was slightly past the $0.40 \mathrm{~L}_{1}$ point for Girder 1. The most likely reasons for this are the fixity at the integral abutments and the bridge skew. A second indication that the skew influenced the strain readings is that Girder 3 also had a momentary peak just prior to the truck stopping at the $0.40 \mathrm{~L}_{1}$ point. This was expected because the $0.40 \mathrm{~L}_{1}$ point for each girder varies with the skew. In other words, Girder 1 has a $0.40 \mathrm{~L}_{1}$ point $9.61 \mathrm{ft} .\left(16 \mathrm{ft} . \mathrm{x} \tan 31^{\circ}\right)$ past the $0.40 \mathrm{~L}_{1}$ point of Girder 3 measured from a line drawn perpendicular to the longitudinal centerline of the bridge.

The second point in Figure 8.4 is when the load truck was stopped at the $0.60 \mathrm{~L}_{1}$ point. The third point is a small negative moment that was recorded as the load truck crossed the second span of the bridge. The fourth point represents when the load truck entered the third span and produced uplift in the second span which, in turn, resulted in a positive moment in the instrumented span. 


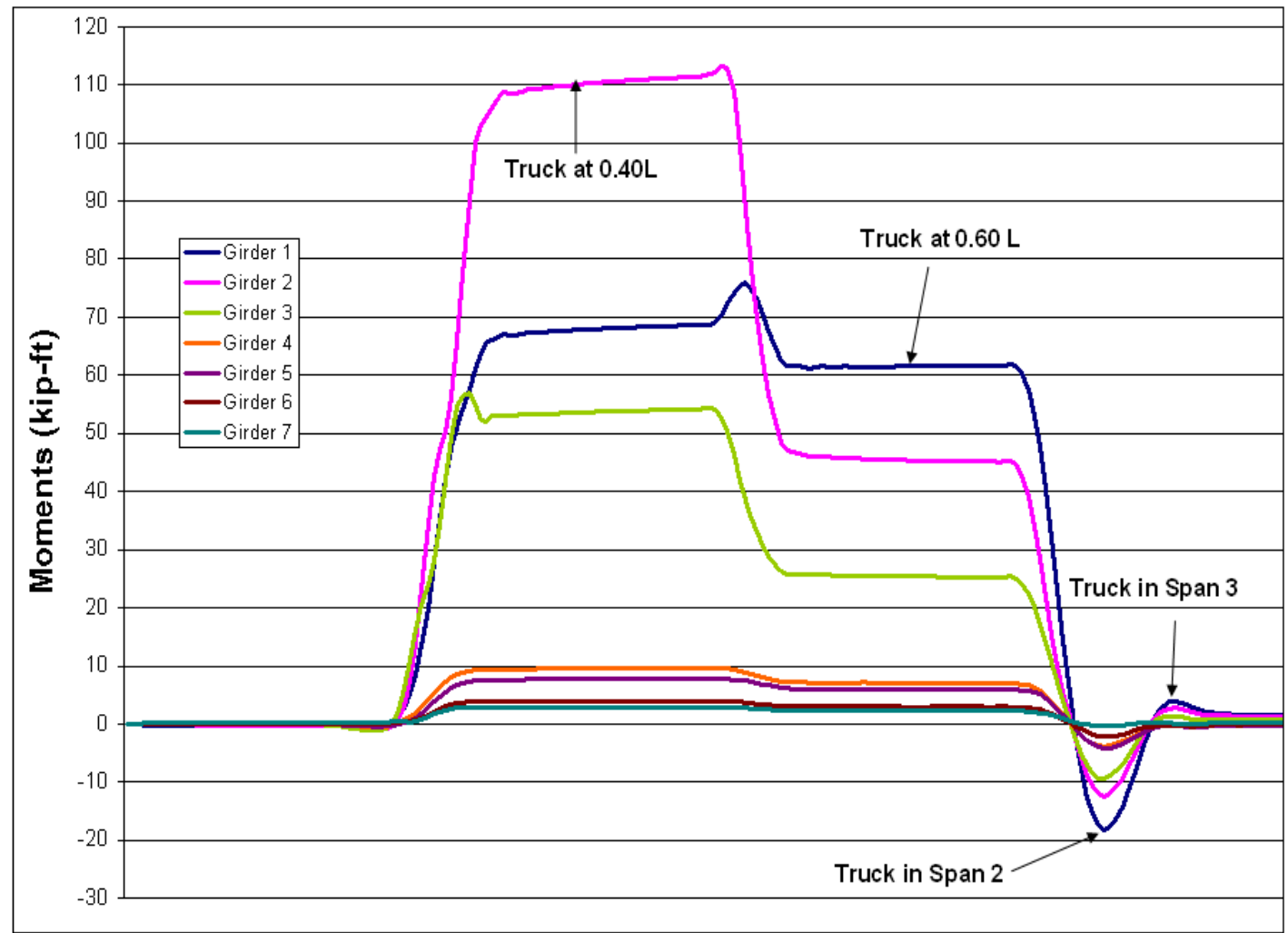

Figure 8.4 Truck Placement 1: Positive Moments

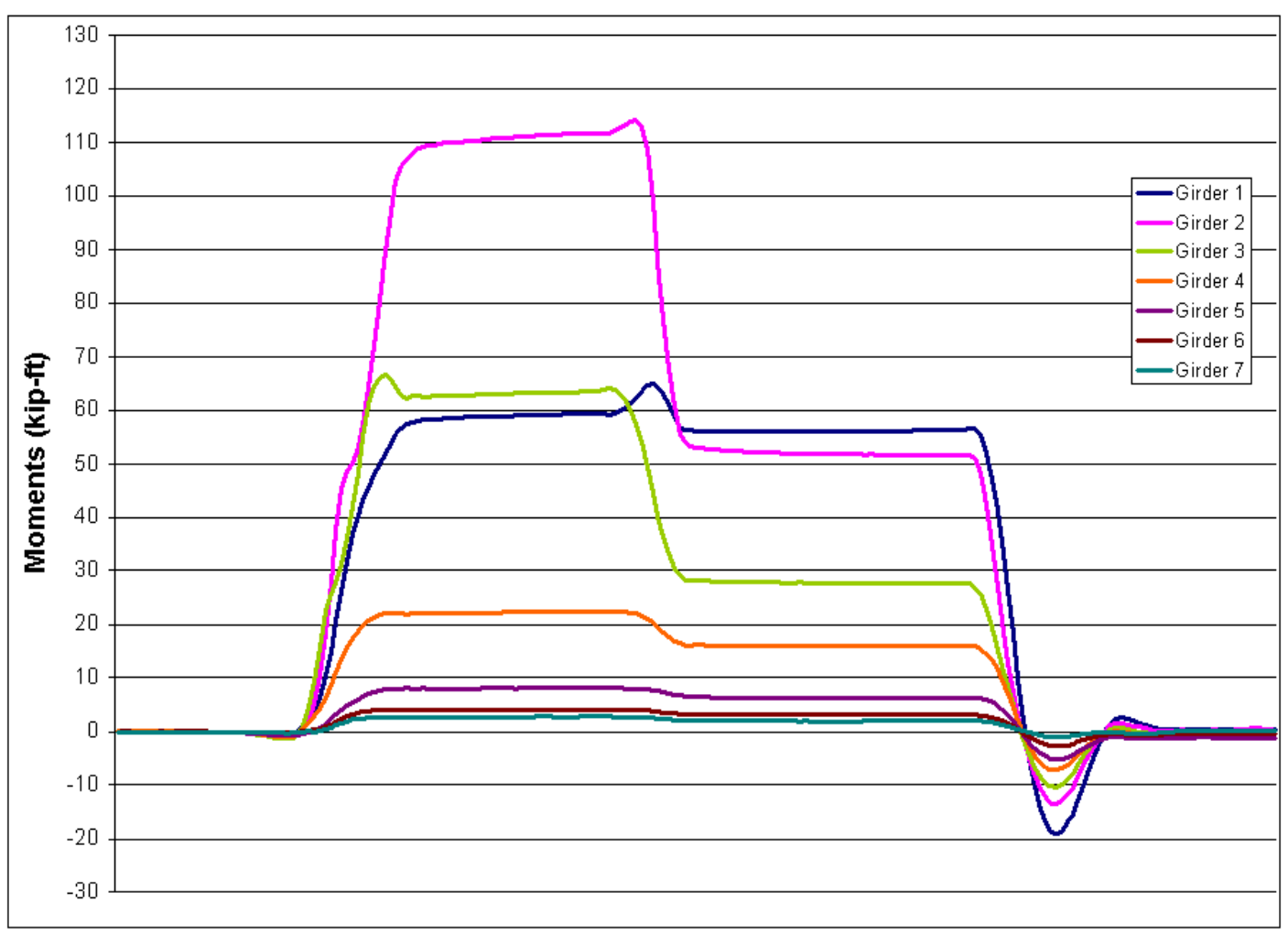

Figure 8.5 Truck Placement 2: Positive Moments 


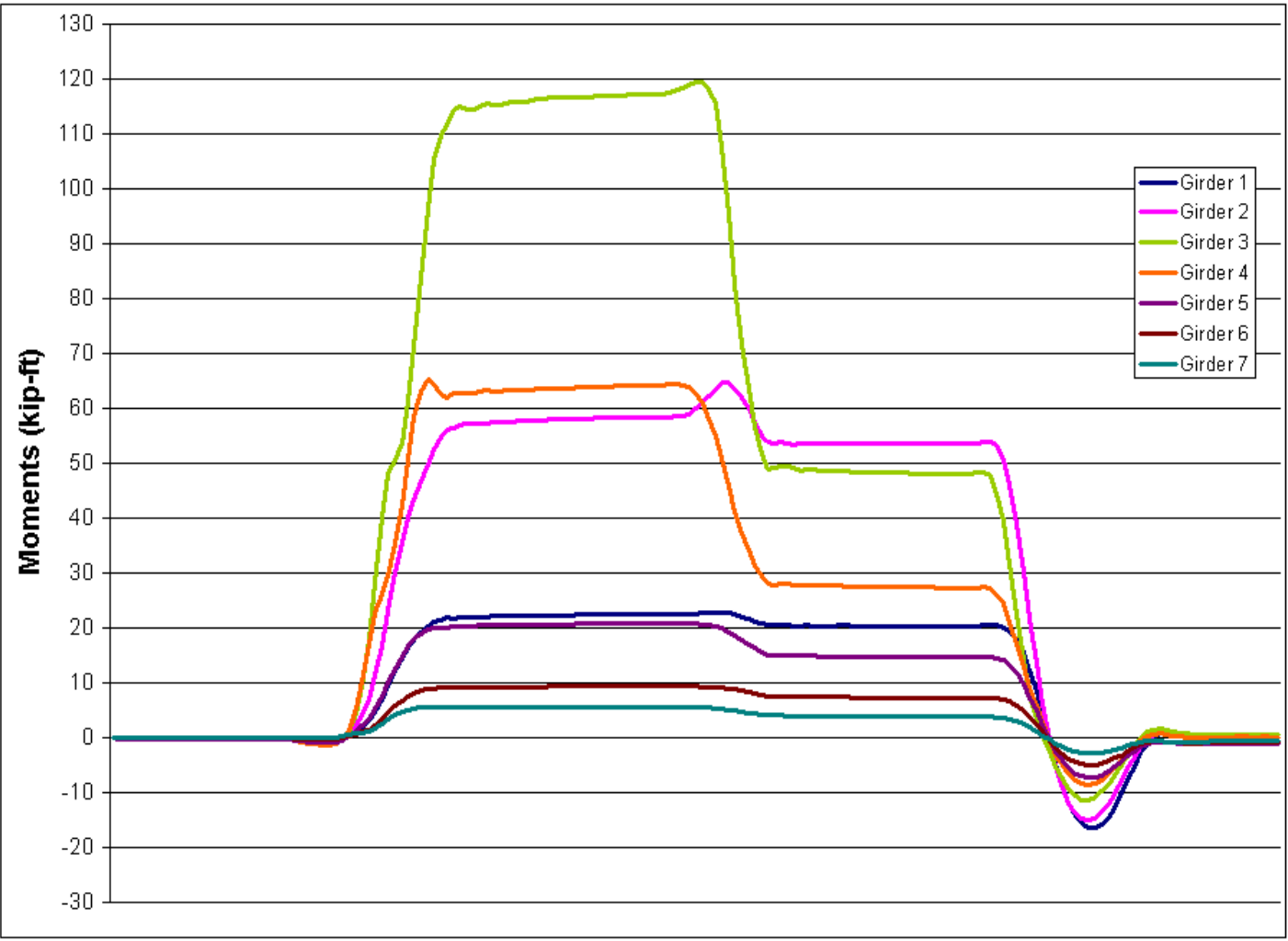

Figure 8.6 Truck Placement 3: Positive Moments

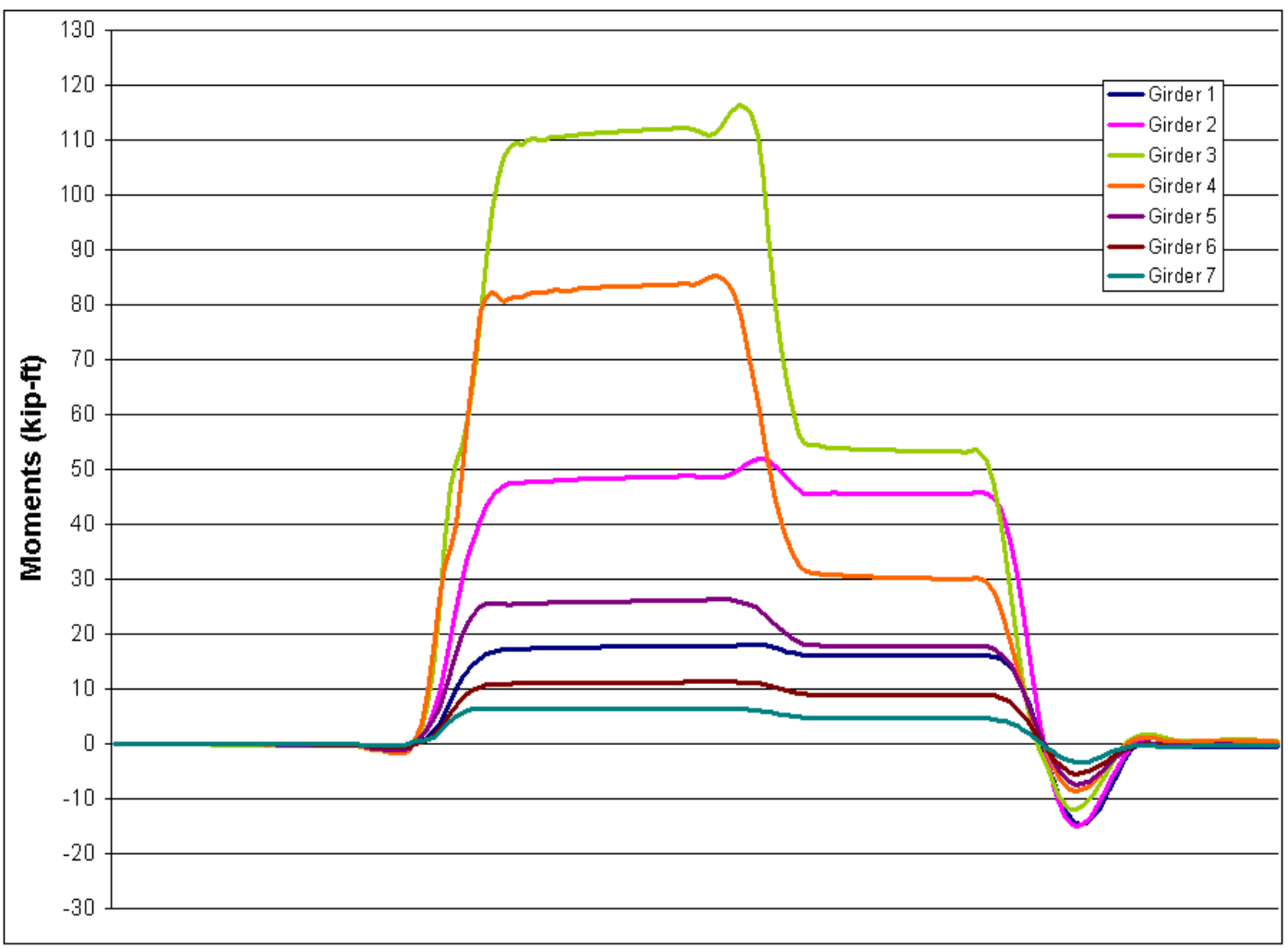

Figure 8.7 Truck Placement 4: Positive Moments 


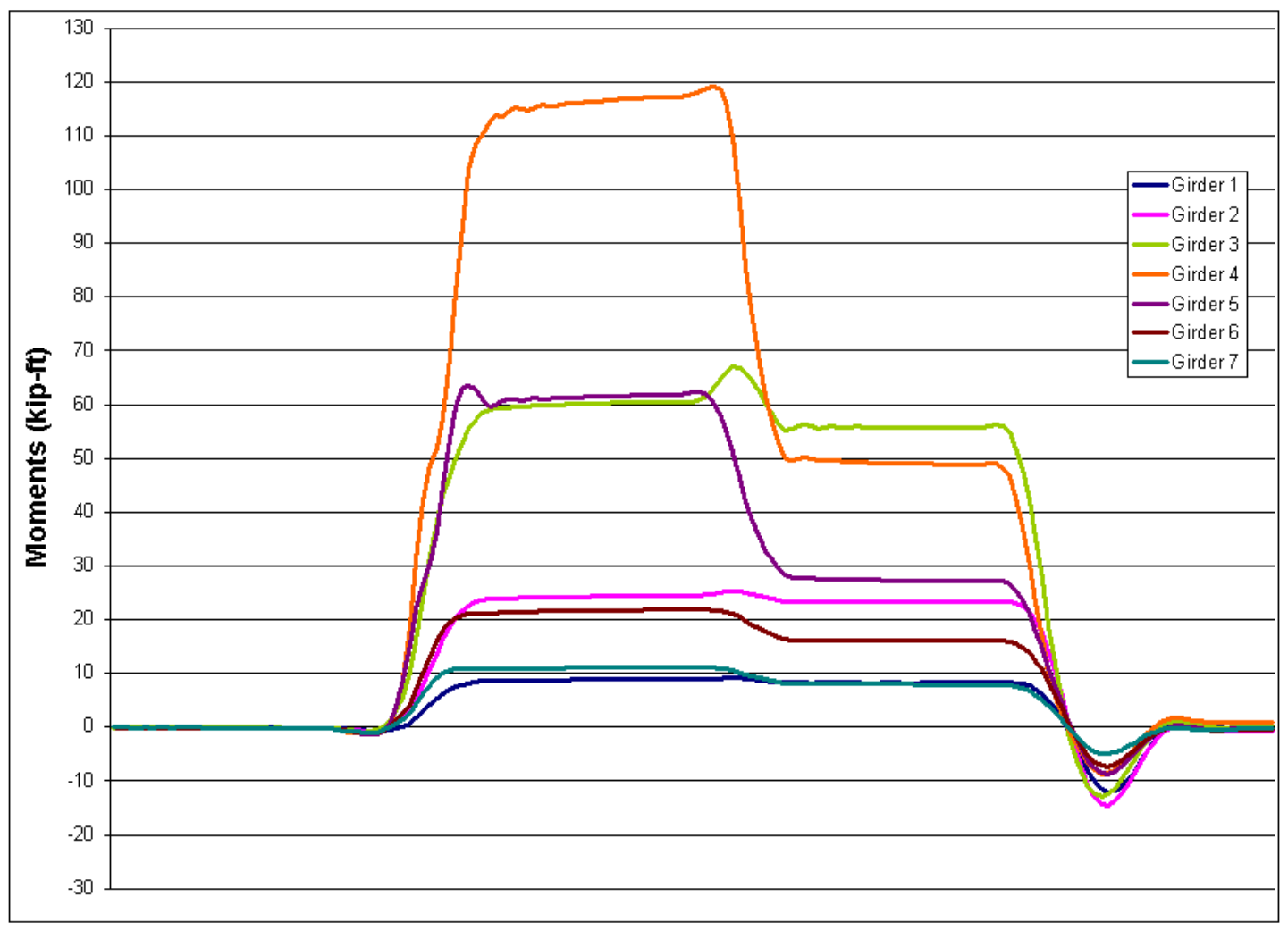

Figure 8.8 Truck Placement 5: Positive Moments

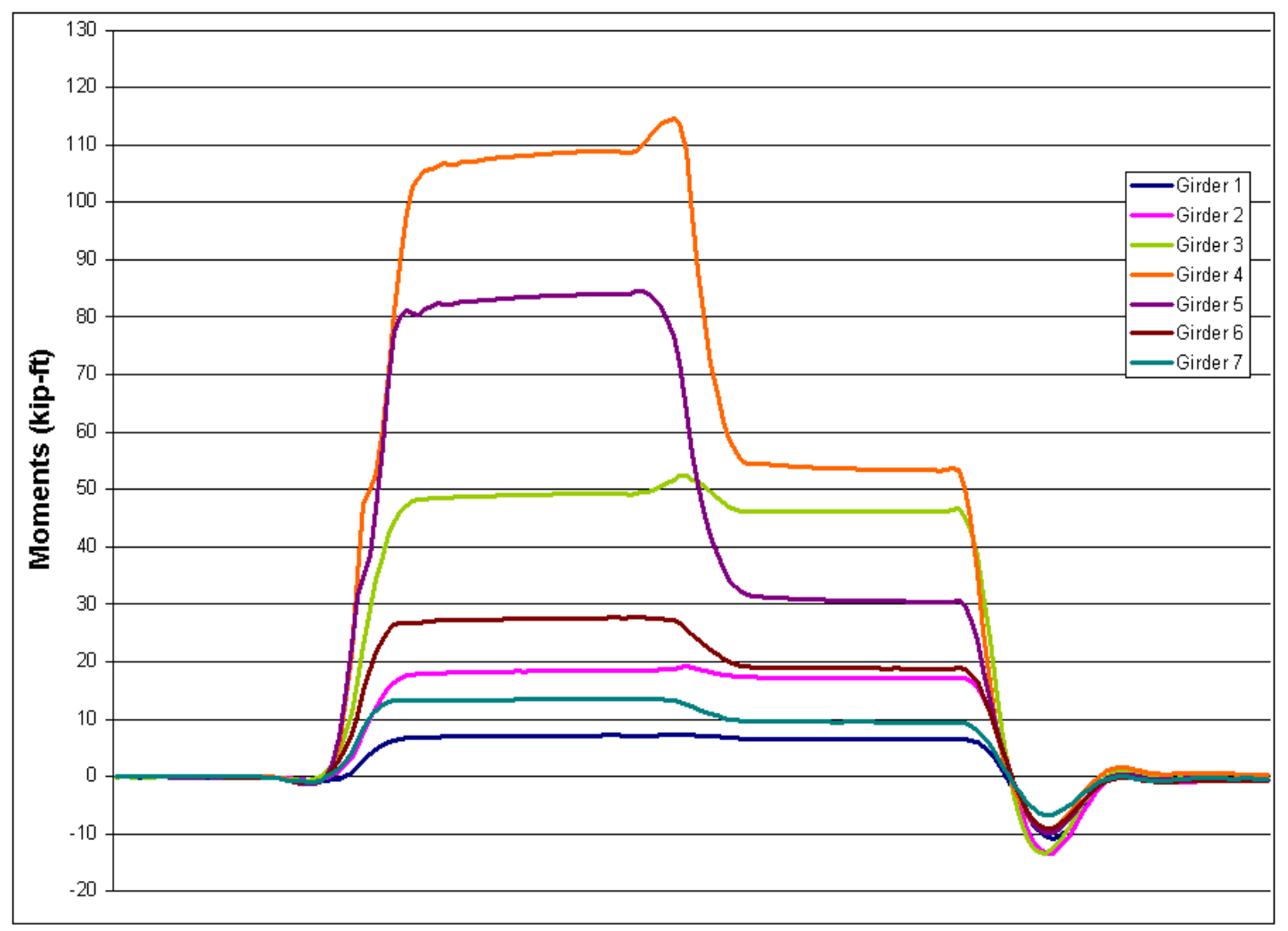

Figure 8.9 Truck Placement 6: Positive Moments 


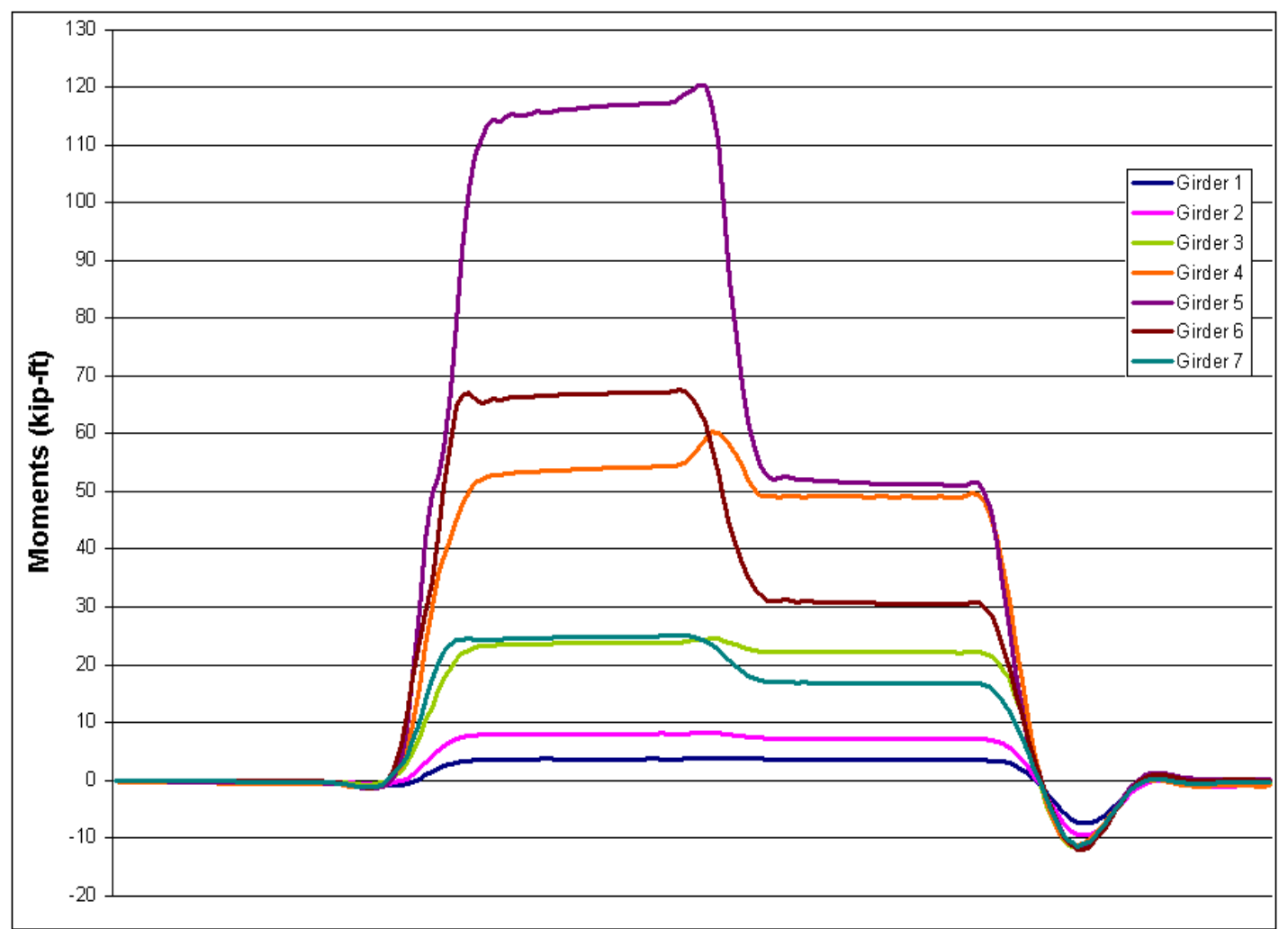

Figure 8.10 Truck Placement 7: Positive Moments

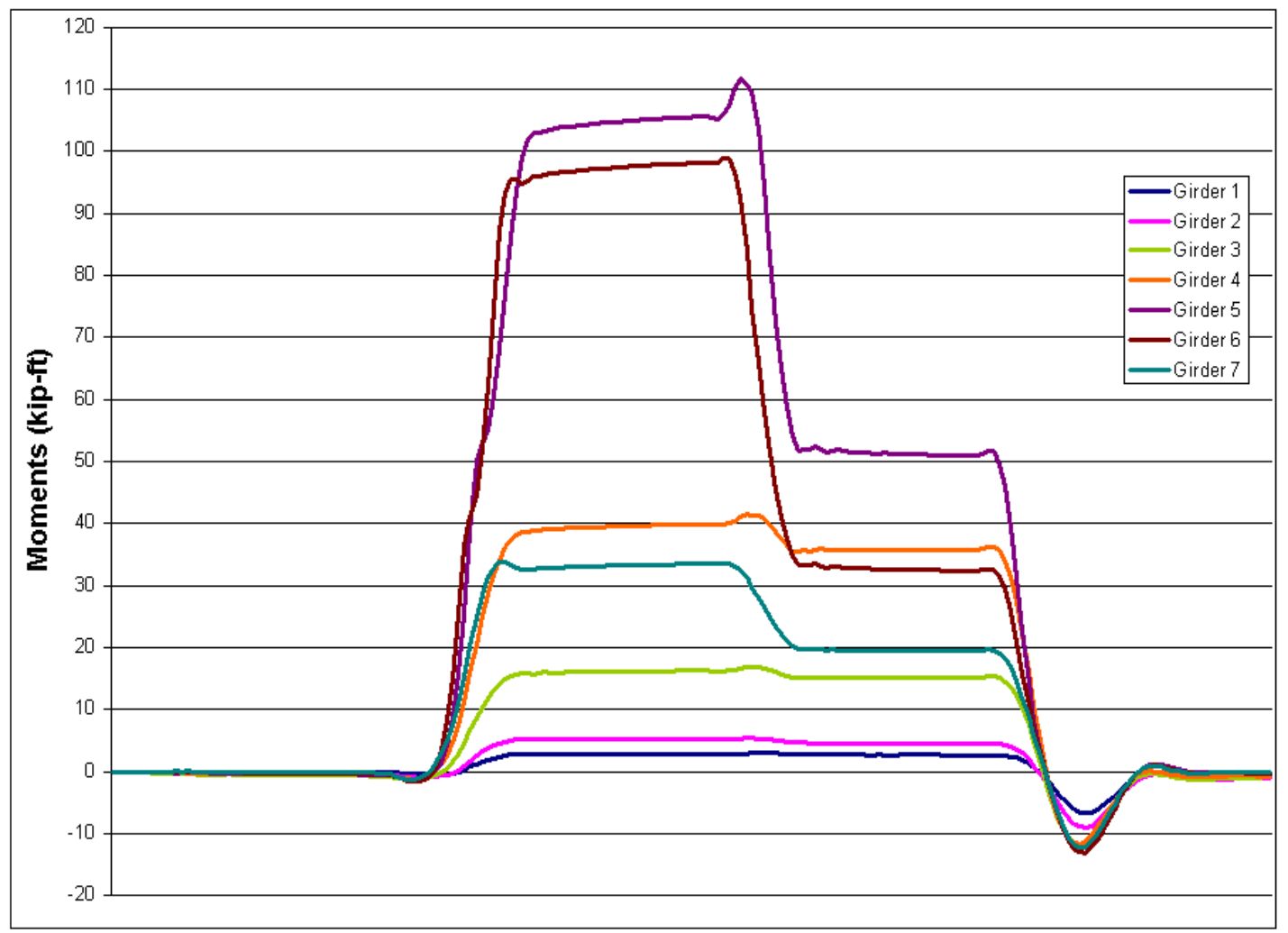

Figure 8.11 Truck Placement 8: Positive Moments 


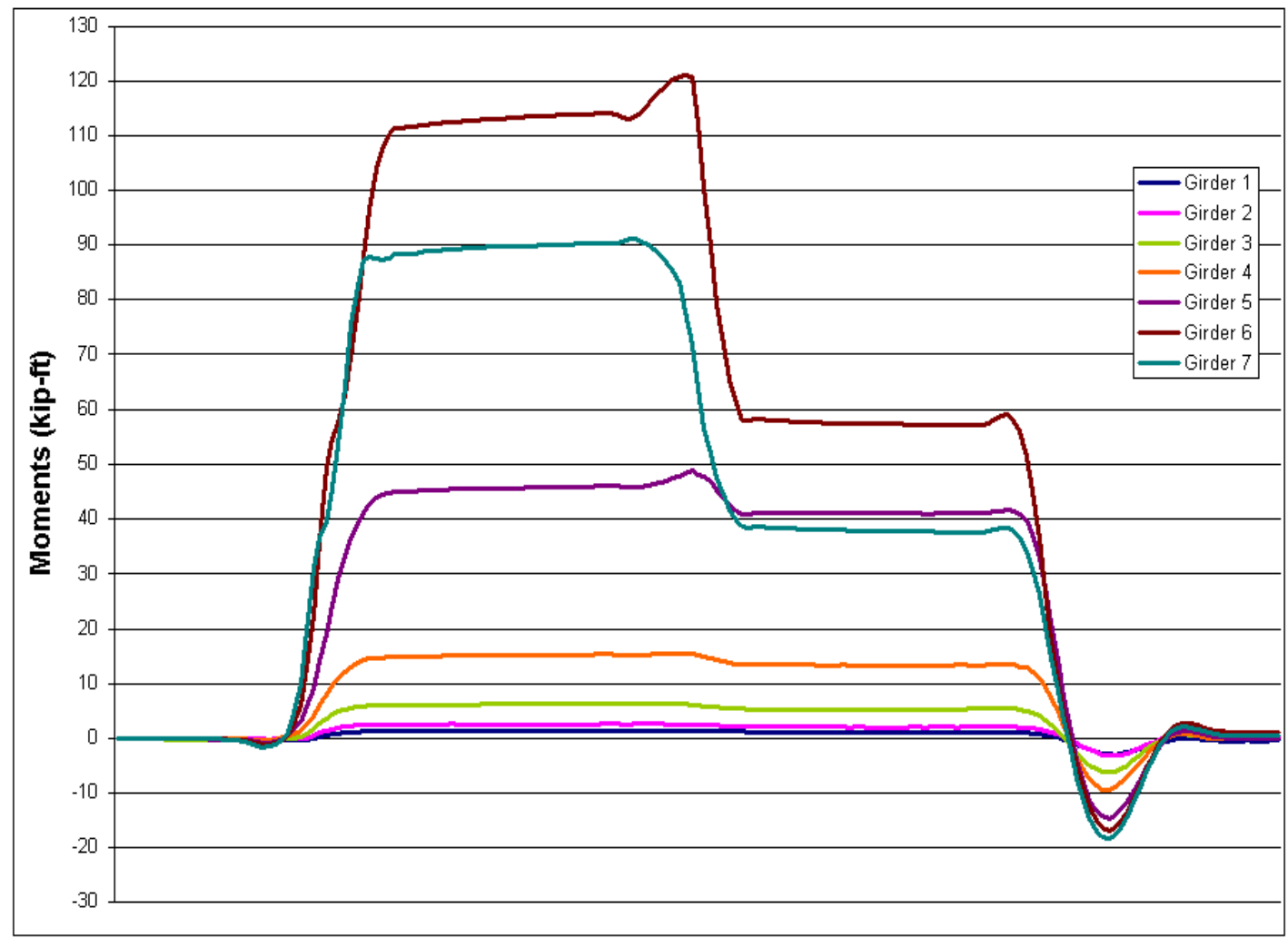

Figure 8.12 Truck Placement 9: Positive Moments

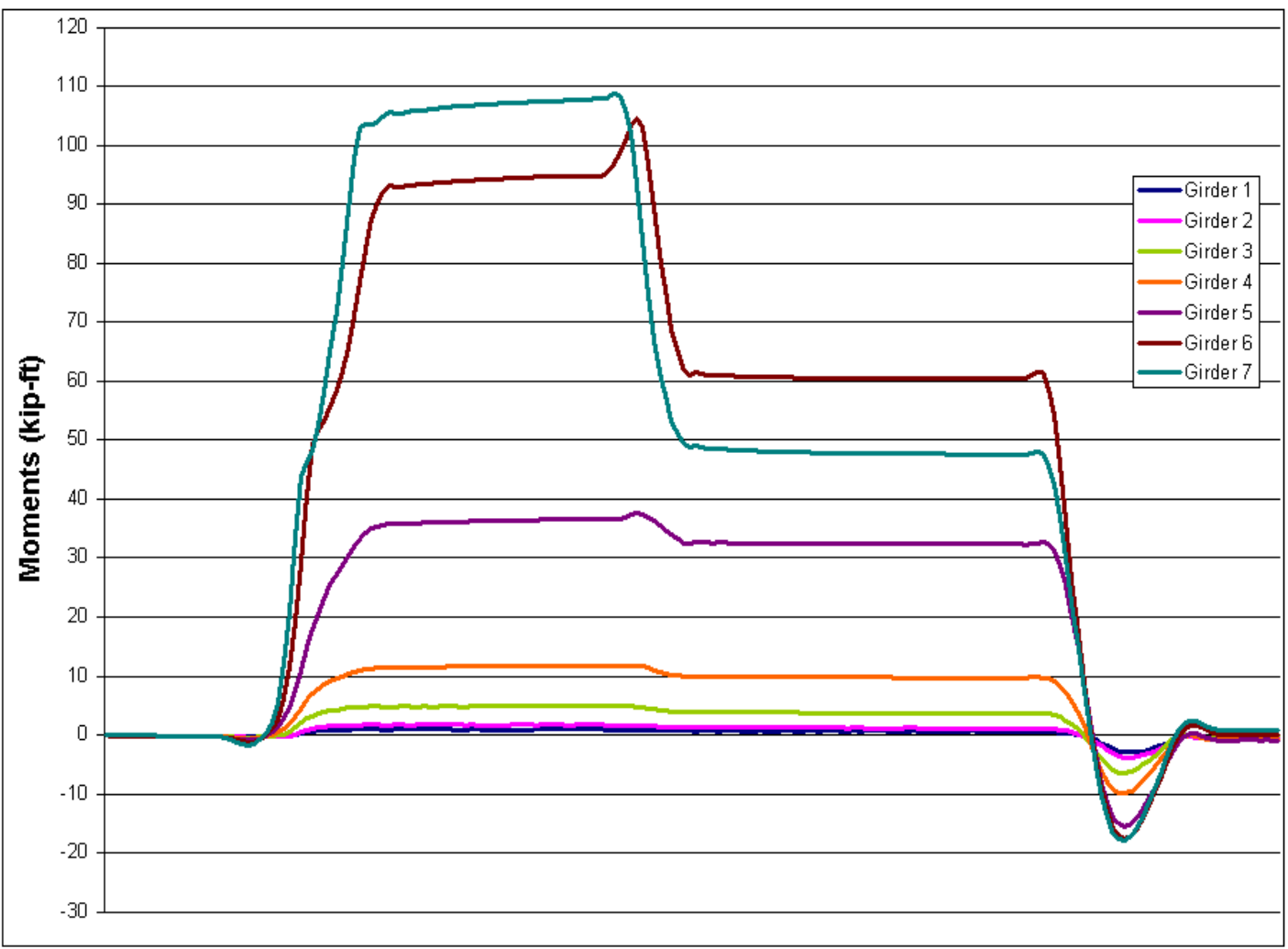

Figure 8.13 Truck Placement 10: Positive Moments 


\subsubsection{Section II: Experimental Negative Bending Moments}

The calculations outlined above were also used to determine the maximum negative bending moments at the gaged locations over the pier. Like Figure 8.4, Figure 8.14 also has several points that illustrate moments induced by the load truck as it traveled across the bridge. The data obtained during truck placement 3 , in Figure 8.16, is incomplete because the truck driver stopped and turned around on the bridge, however, much of the data was still valid and was used in subsequent calculations.

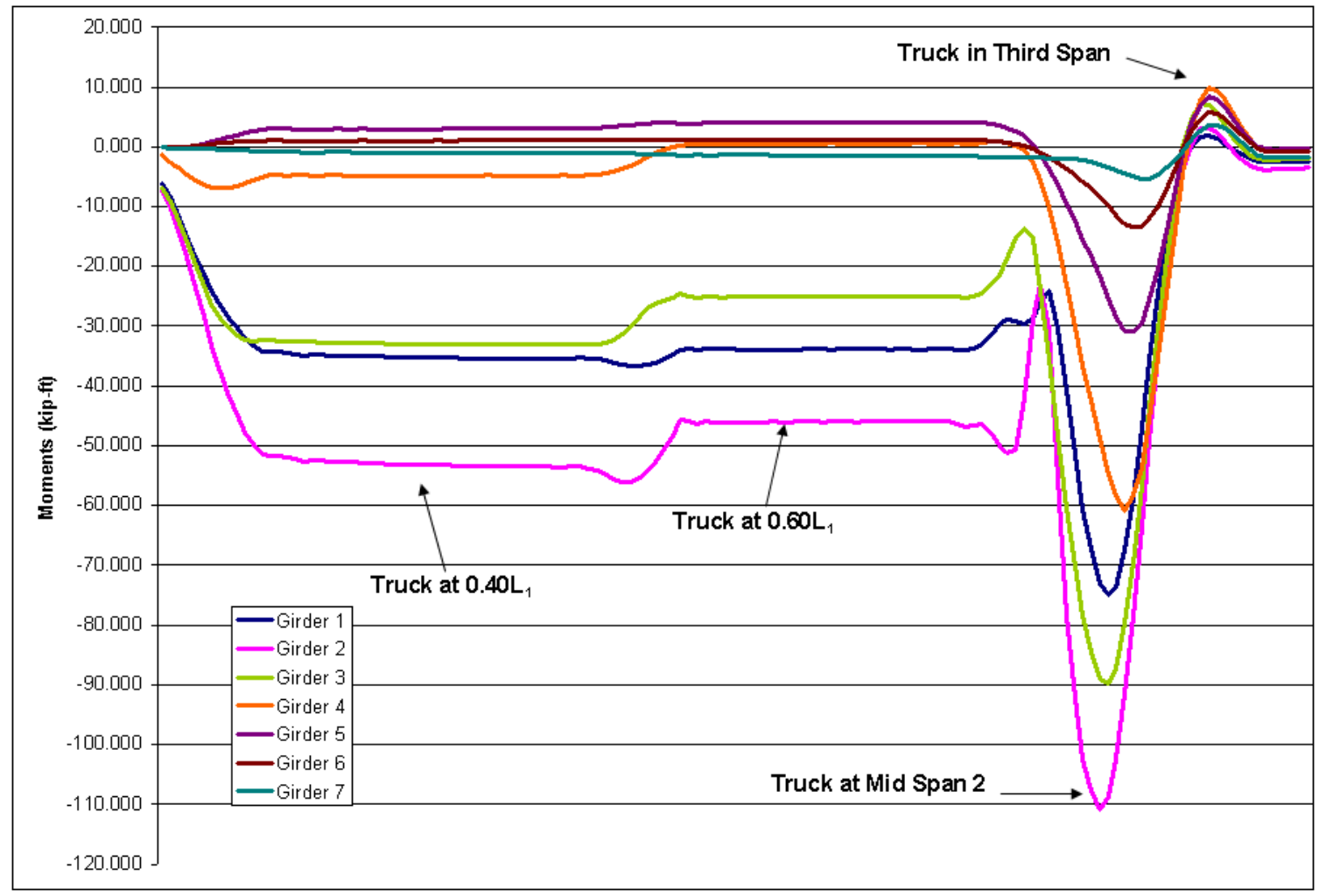

Figure 8.14 Truck Placement 1: Negative Moments 


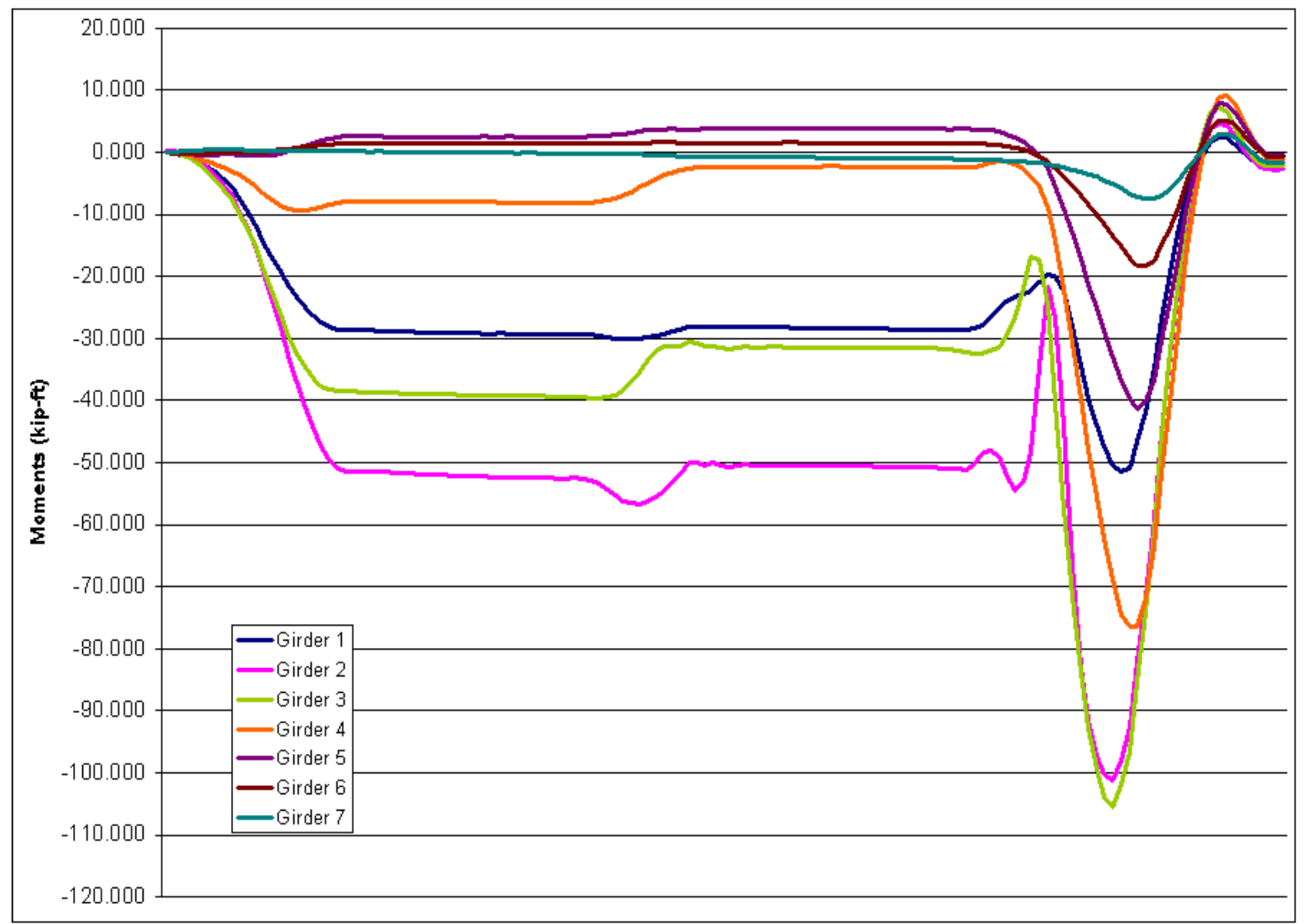

Figure 8.15 Truck Placement 2: Negative Moments

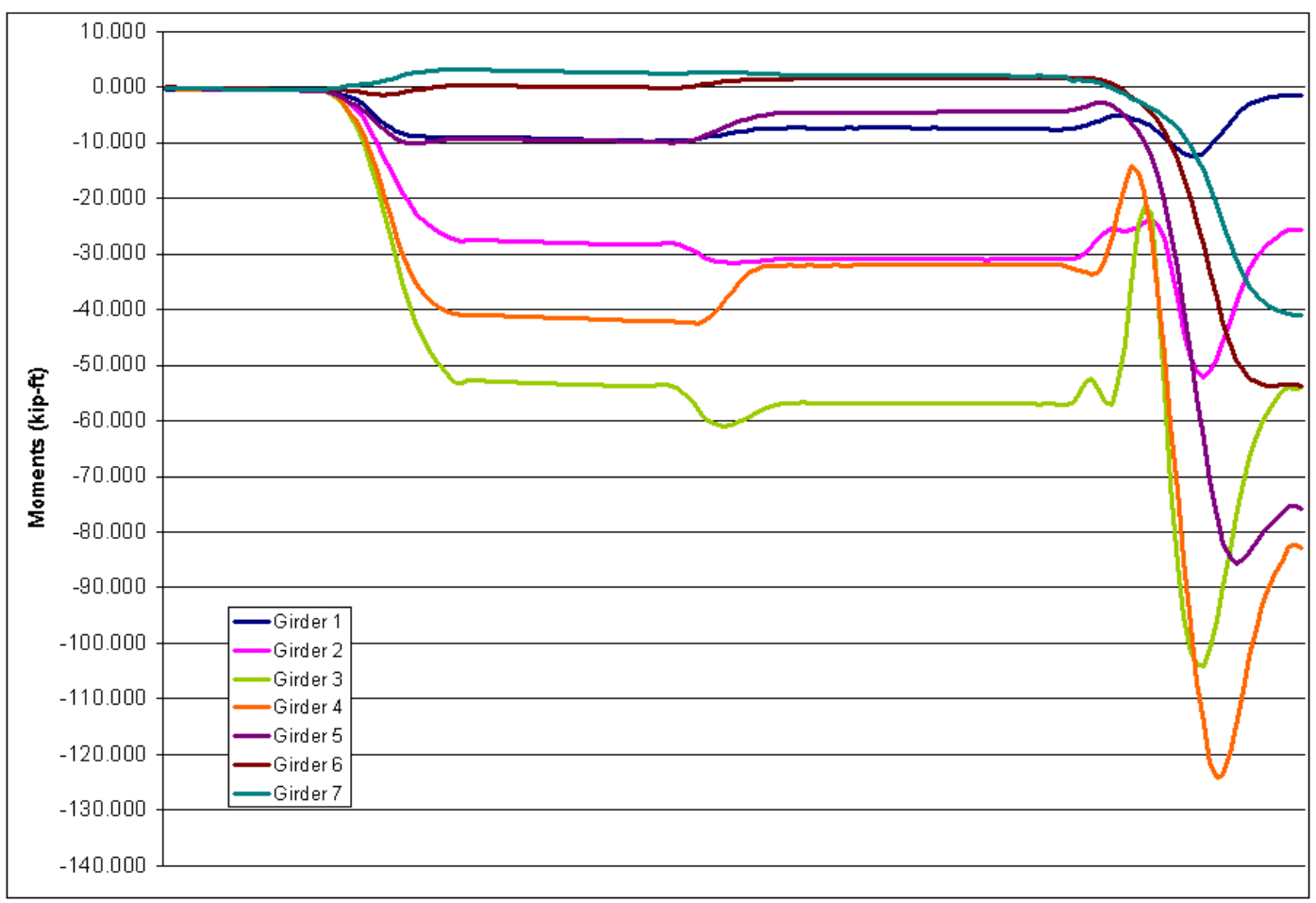

Figure 8.16 Truck Placement 3: Negative Moments 


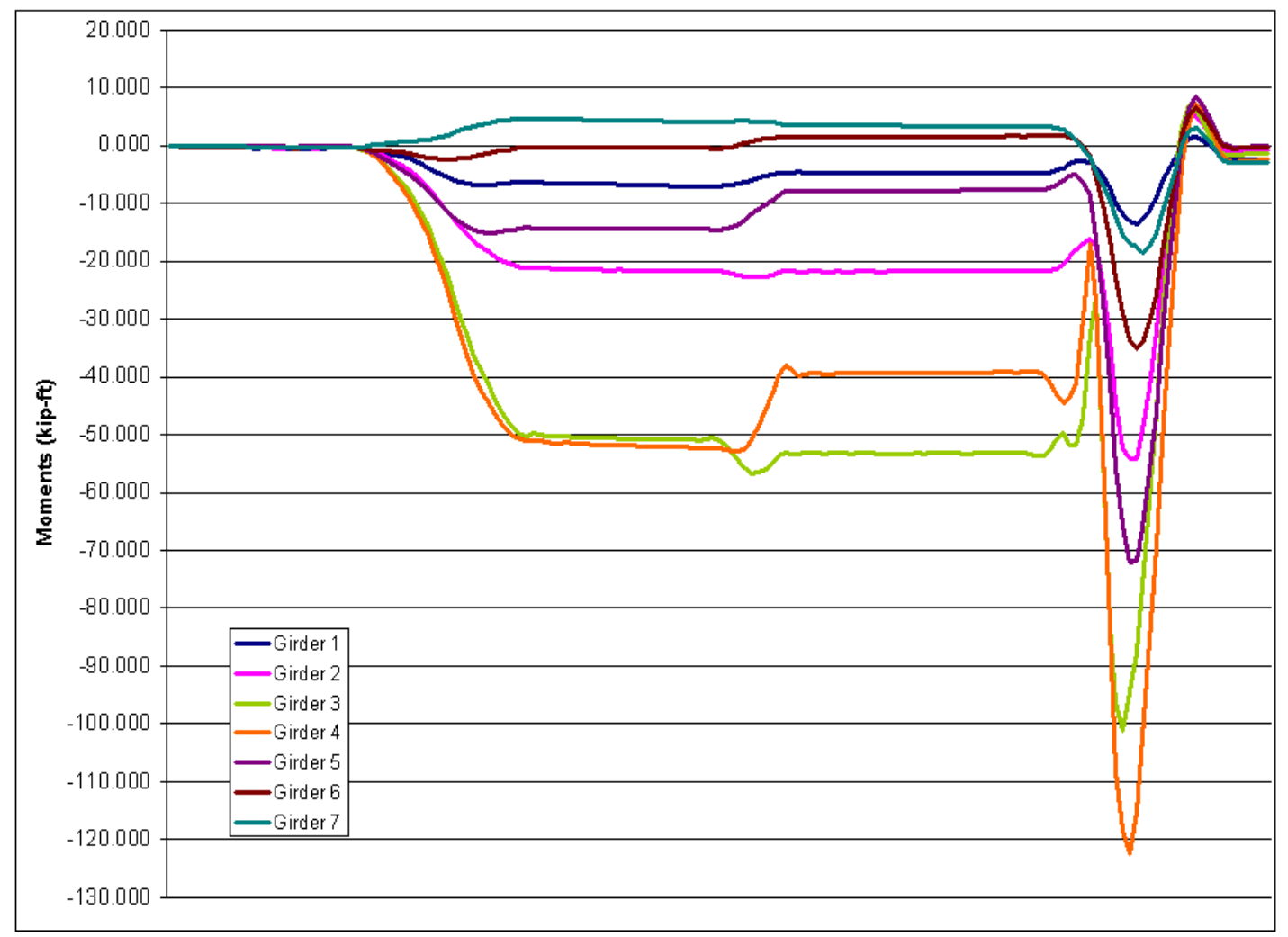

Figure 8.17 Truck Placement 4: Negative Moments

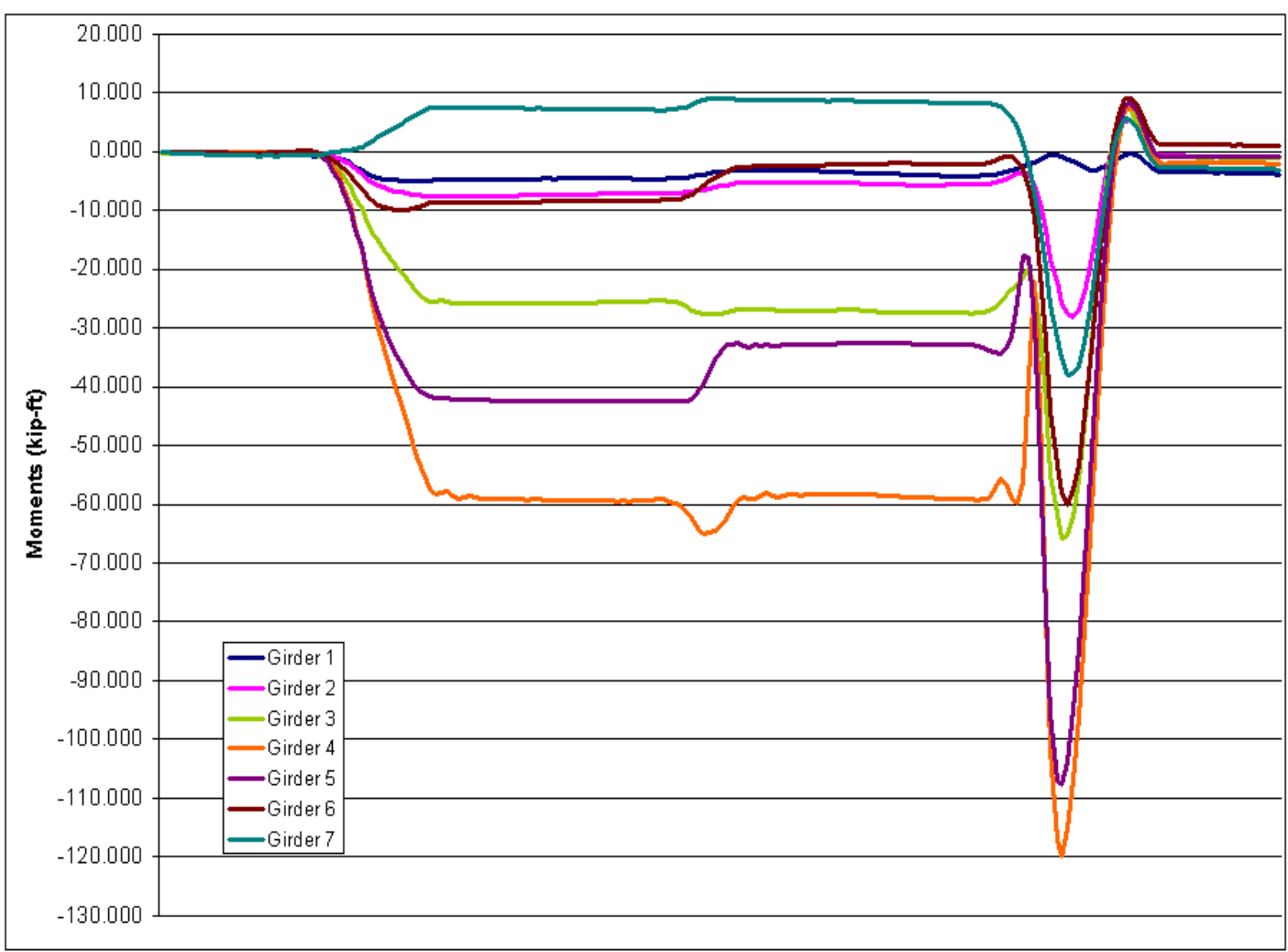

Figure 8.18 Truck Placement 5: Negative Moments 


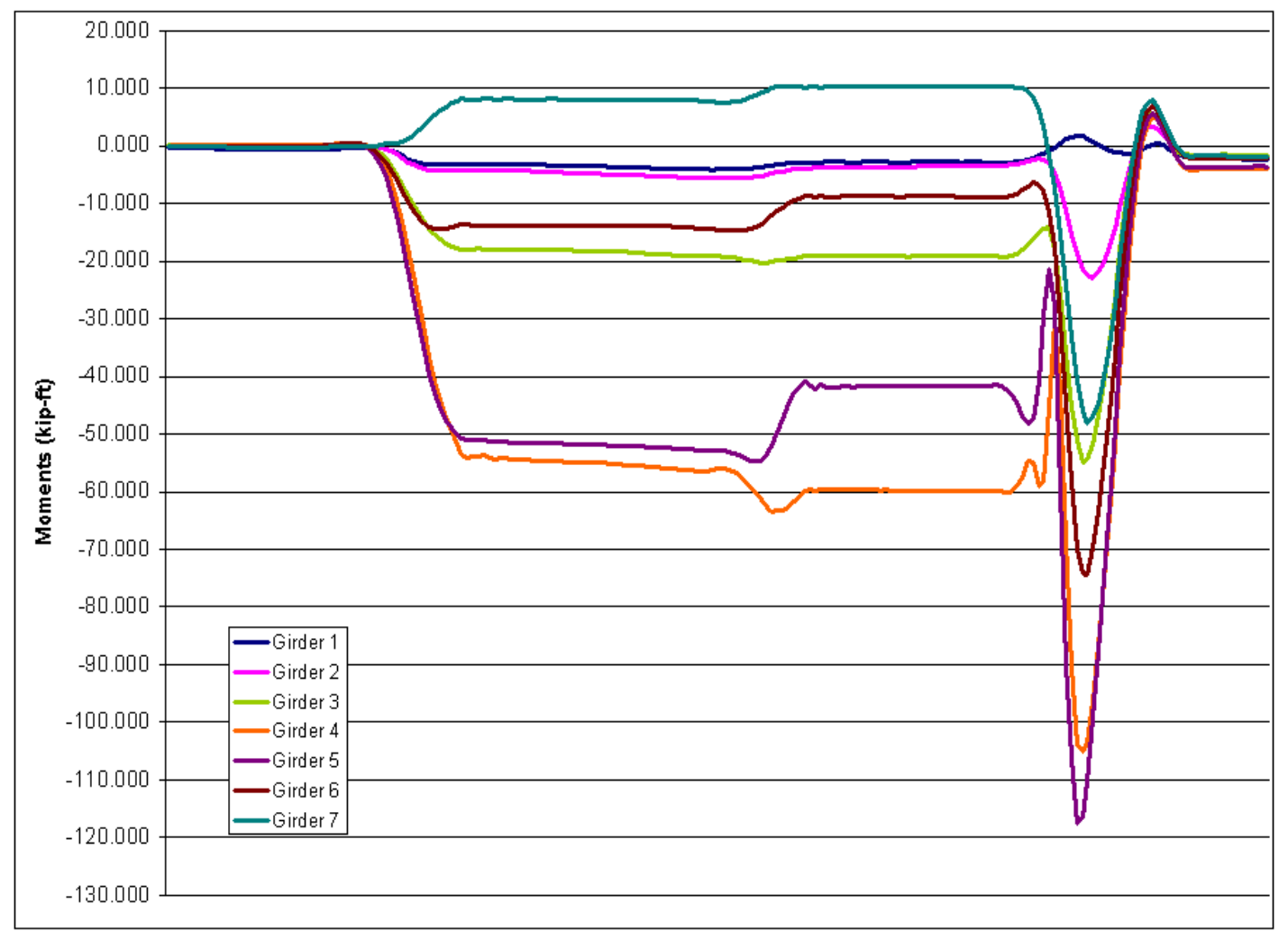

Figure 8.19 Truck Placement 6: Negative Moments

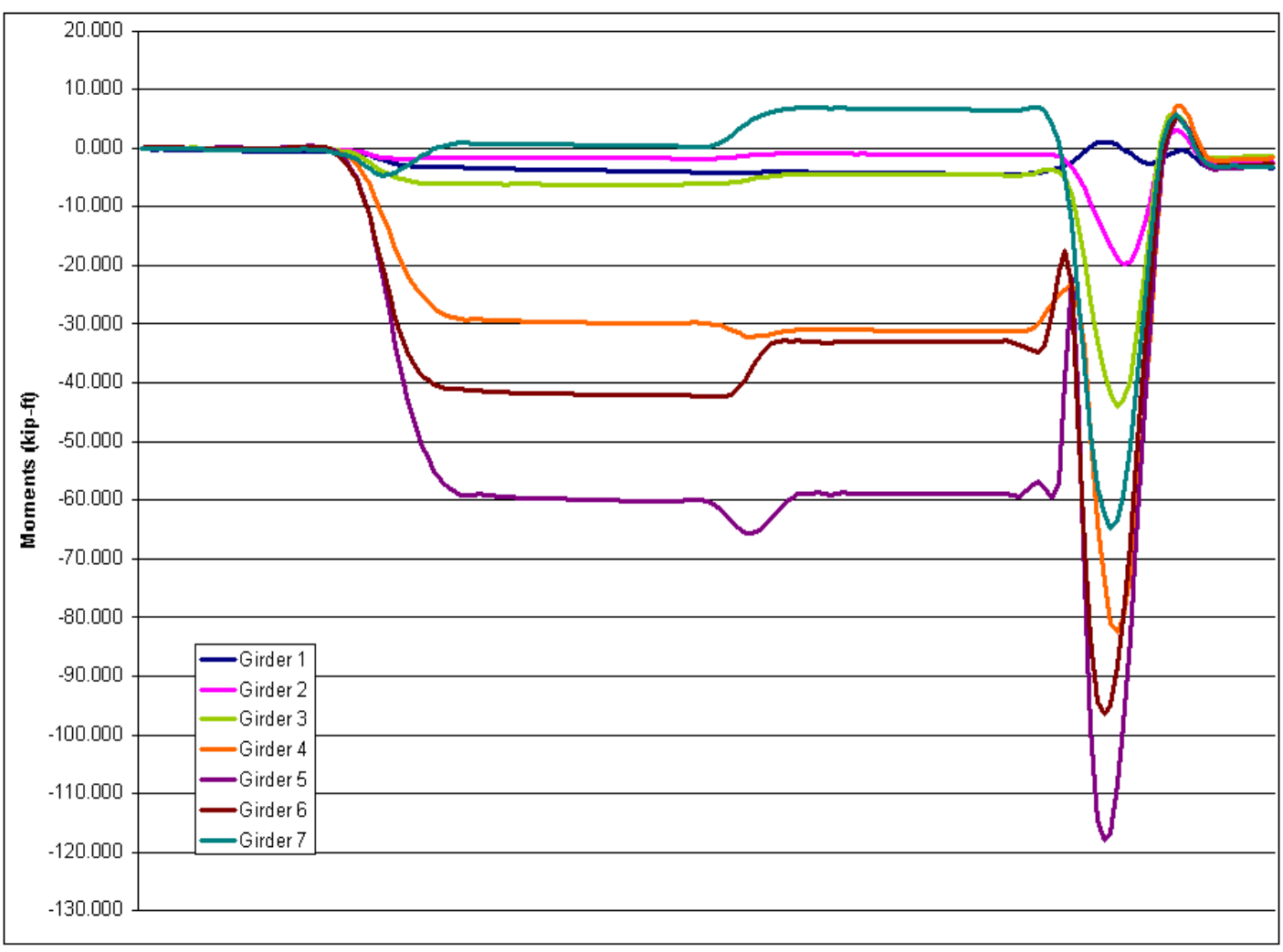

Figure 8.20 Truck Placement 7: Negative Moments 


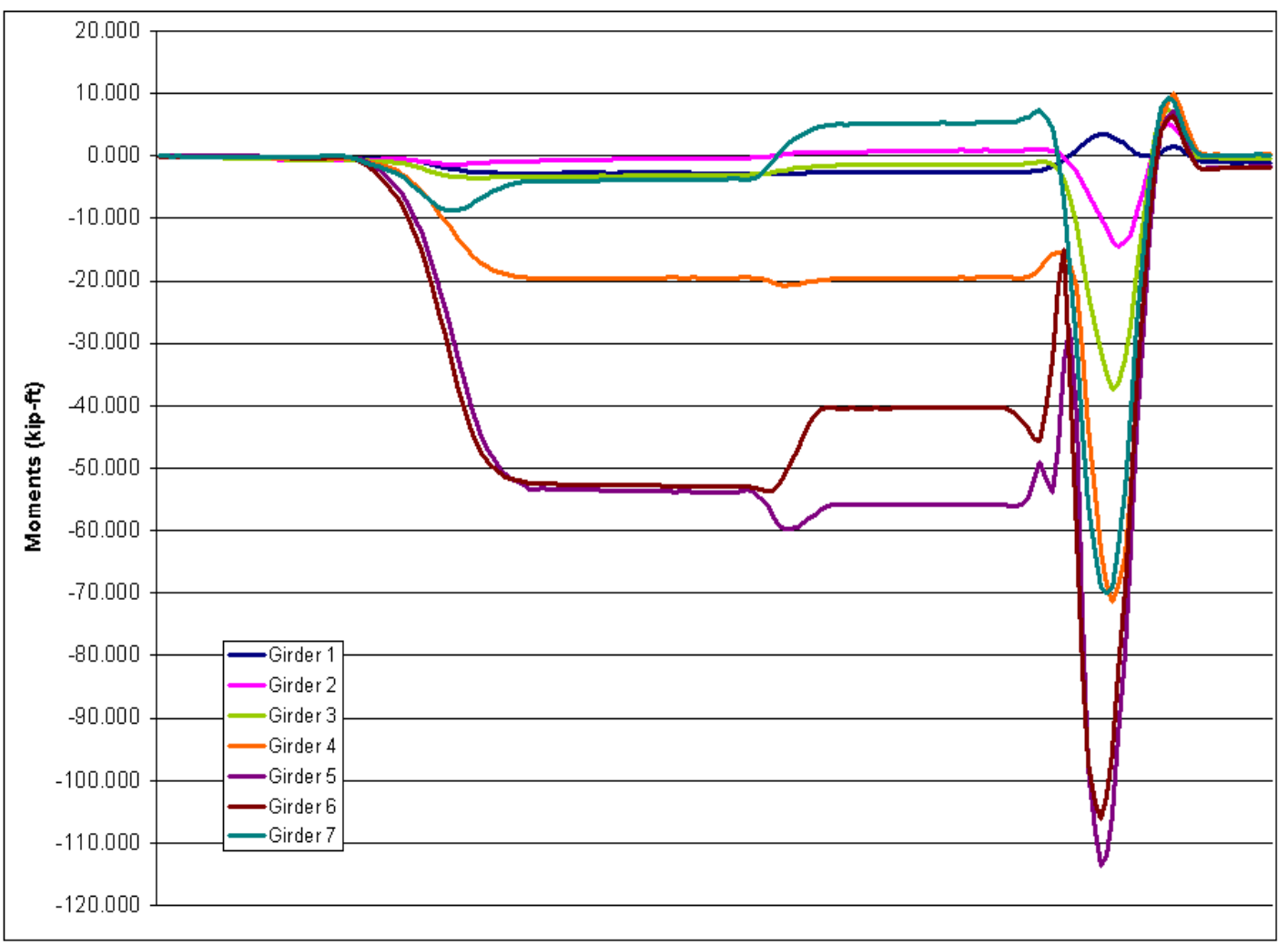

Figure 8.21 Truck Placement 8: Negative Moments

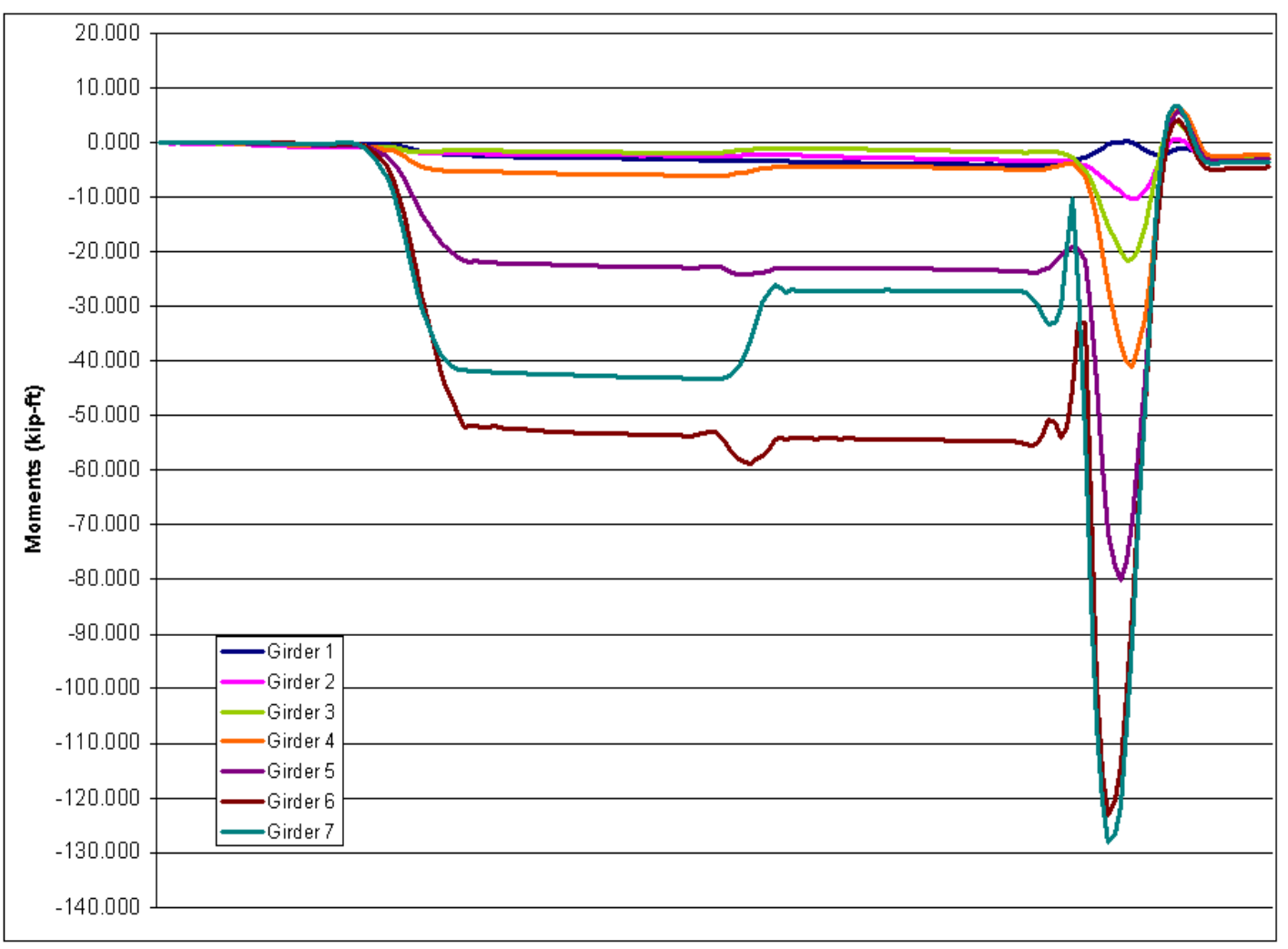

Figure 8.22 Truck Placement 9: Negative Moments 


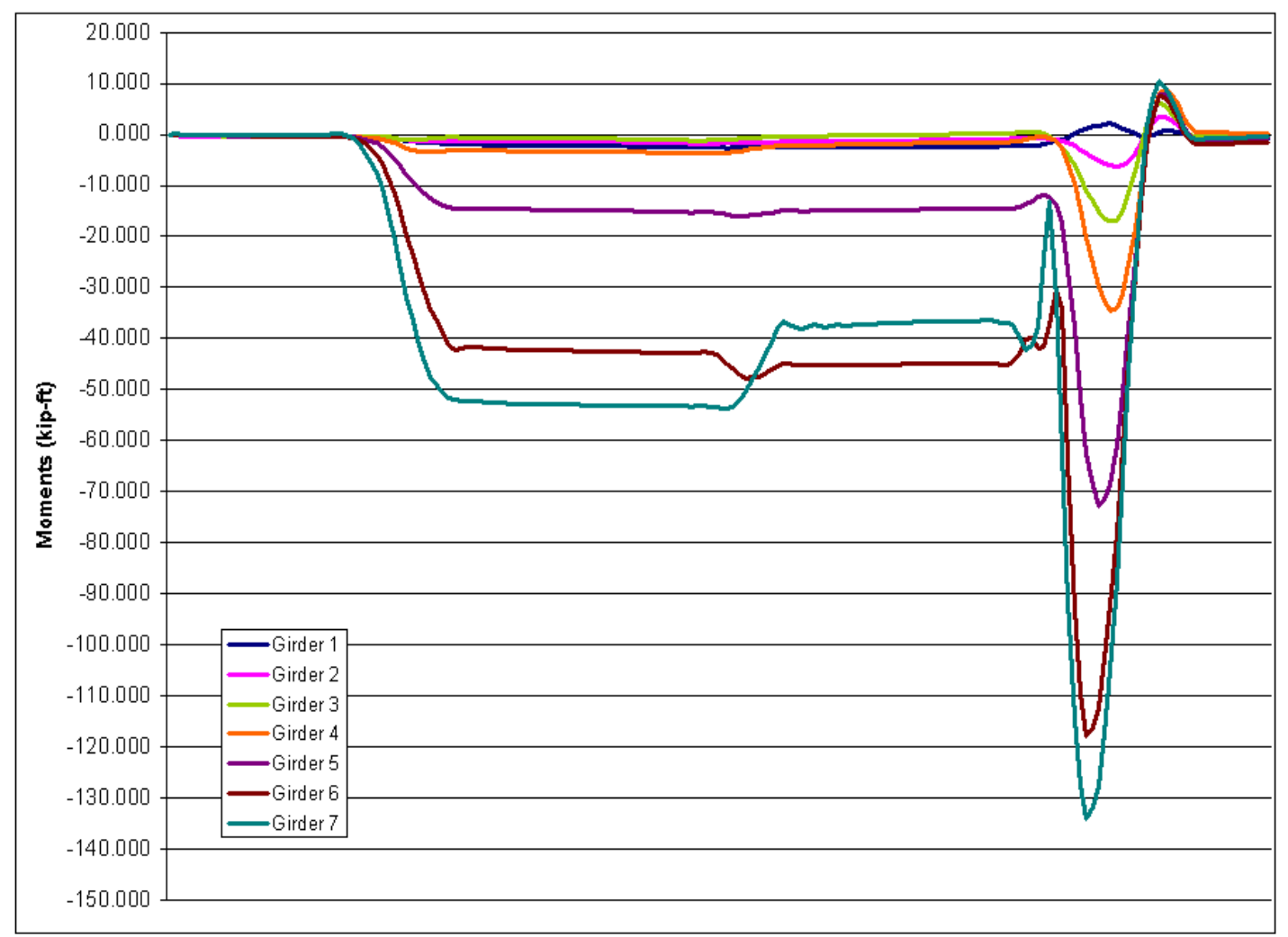

Figure 8.23 Truck Placement 10: Negative Moments

\subsection{Experimental Moment Distribution Factors}

The experimental moment distribution factors were determined for interior and exterior girders for comparison with AASHTO predicted distribution factors. To determine the maximum moment distribution factor for a particular girder, the load truck must be placed to produce maximum force effects in that girder. The maximum superimposed moment, with multiple presence effects, is then divided by the un-factored and undistributed theoretical moment due to the load truck used during field tests. The multiple presence factors were applied based on the number of design lanes superimposed in the distribution calculation; thus, the experimental moment distribution 
factor equation is written as:

$$
D . F .=m \frac{M_{\text {max sup erimposed }}}{M_{100 \% \text { load truck }}}
$$

The worst case truck placements for each girder are shown in Figure 8.24 and Figure 8.25. The truck locations were governed by the AASHTO truck spacing requirements that require a minimum of $4 \mathrm{ft}$. between adjacent truck tires and $2 \mathrm{ft}$. between tires and curbs/barriers.

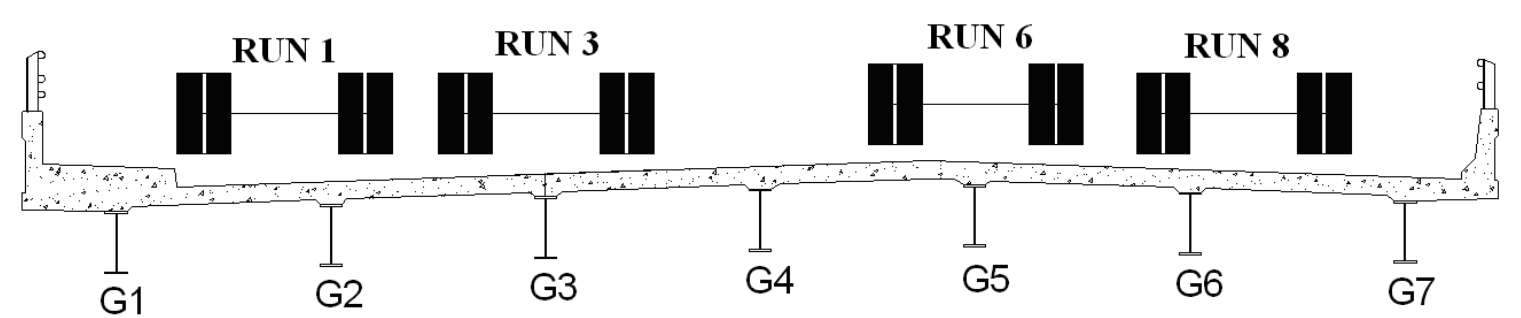

Figure 8.24 Worst Case Truck Placements for Girders 1, 2, \& 3

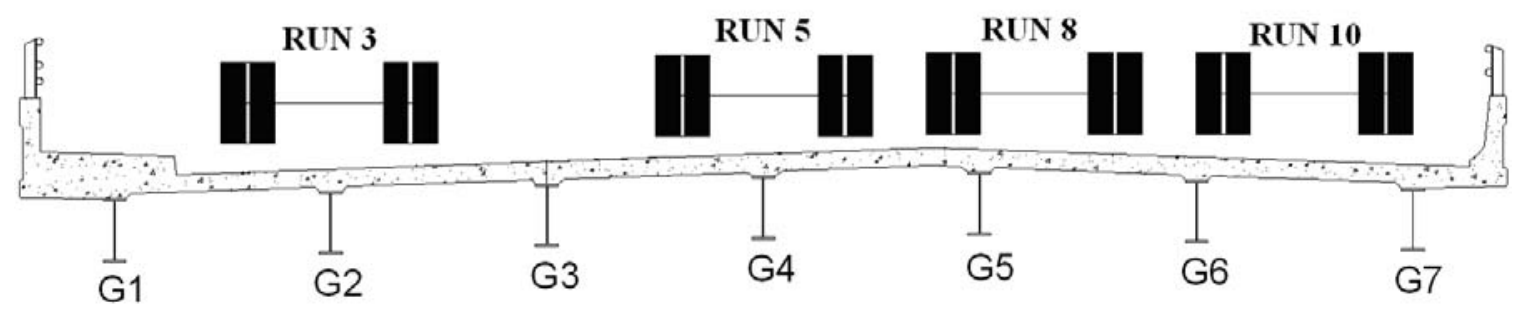

Figure 8.25 Worst Case Truck Placements for Girders 4, 5, 6, \& 7

\subsubsection{Section I: Positive Bending Moment}

The positive moments induced by each truck placement are shown in Table 8.2. By the principle of superposition, they were used to calculate the maximum moment distribution factors for each girder. The undistributed and un-factored moments induced 
by the load truck for interior and exterior girders were found from CONSYS ${ }^{\mathrm{TM}}$ as 329.2 kip-ft. and 330.0 kip-ft., respectively.

Table 8.2 Section I Moment Distribution

\begin{tabular}{|c|c|c|c|c|c|c|c|}
\cline { 2 - 8 } \multicolumn{1}{c|}{} & \multicolumn{7}{c|}{ Section I Momen ts (kip-ft) } \\
\cline { 2 - 8 } \multicolumn{1}{c|}{} & Girder 1 & Girder 2 & Girder 3 & Girder 4 & Girder 5 & Girder 6 & Girder 7 \\
\hline Truck Placement 1 & 70.2 & 113.1 & 52.6 & 9.5 & 7.8 & 3.9 & 2.9 \\
\hline Truck Placement 2 & 62.2 & 114.0 & 57.3 & 22.0 & 8.1 & 4.0 & 2.7 \\
\hline Truck Placement 3 & 22.6 & 59.9 & 119.4 & 62.8 & 20.7 & 9.3 & 5.5 \\
\hline Truck Placement 4 & 18.0 & 50.2 & 116.2 & 79.0 & 26.0 & 11.2 & 6.4 \\
\hline Truck Placement 5 & 9.0 & 24.7 & 62.8 & 119.1 & 60.5 & 21.8 & 11.1 \\
\hline Truck Placement 6 & 7.2 & 18.8 & 51.8 & 58.9 & 76.8 & 27.2 & 13.2 \\
\hline Truck Placement 7 & 3.8 & 8.2 & 24.4 & 59.1 & 120.3 & 61.8 & 24.2 \\
\hline Truck Placement 8 & 2.8 & 5.3 & 16.6 & 41.1 & 111.7 & 92.6 & 32.5 \\
\hline Truck Placement 9 & 1.2 & 2.5 & 6.3 & 15.5 & 48.4 & 121.2 & 77.9 \\
\hline Truck Placement 10 & 0.9 & 1.7 & 4.9 & 11.7 & 36.7 & 96.8 & 108.6 \\
\hline
\end{tabular}

Based on the moments tabularized above, and the undistributed truck moments from CONSYS ${ }^{\mathrm{TM}}$, the moment distribution factor for Girder 1 was found for a single lane load

as:

$$
D F_{\exp }=1.2\left(\frac{70.2}{330.0}\right)=0.255 \text { lanes }
$$

The remaining three truck placements were superimposed incrementally to determine the maximum experimental moment distribution factor for each girder. For Girder 1, the maximum moment distribution factor was a resultant of two lanes loaded and was calculated as follows:

$$
\text { Dist }_{4}=1.00\left(\frac{70.2+22.6}{330.0}\right)=0.281 \text { lanes }
$$

This process was repeated for Girders 2 thru 7 to determine that maximum moment distribution factor for each girder. The distribution factors for each girder, with respect to 
the number of lanes loaded, are shown in Table 8.3. The maximum distribution factor for each girder is listed at the bottom of the table and plotted against the AASHTO design distribution factors in Figure 8.27.

Table 8.3 Section I: Moment Distribution Factors

\begin{tabular}{|c|c|c|c|c|c|c|c|c|}
\hline $\begin{array}{l}\text { Lanes } \\
\text { Loaded }\end{array}$ & MP & Girder 1 & Girder 2 & Girder 3 & Girder 4 & Girder 5 & Girder 6 & Girder 7 \\
\hline 1 & 120 & 0.255 & 0.412 & 0.192 & 0.434 & 0.407 & 0.353 & 0.395 \\
\hline 2 & 1.00 & 0.281 & 0.182 & 0.363 & 0.487 & 0.523 & 0.575 & 0.427 \\
\hline 3 & 0.85 & 0.258 & 0.049 & 0.134 & 0.576 & 0.539 & 0.545 & 0.392 \\
\hline 4 & 0.65 & 0.203 & 0.010 & 0.033 & 0.463 & 0.453 & 0.435 & 0.311 \\
\hline & $\mathrm{Ma}$ & 0.281 & 0412 & 0.363 & 0.576 & 0.539 & 0.575 & 0.427 \\
\hline
\end{tabular}

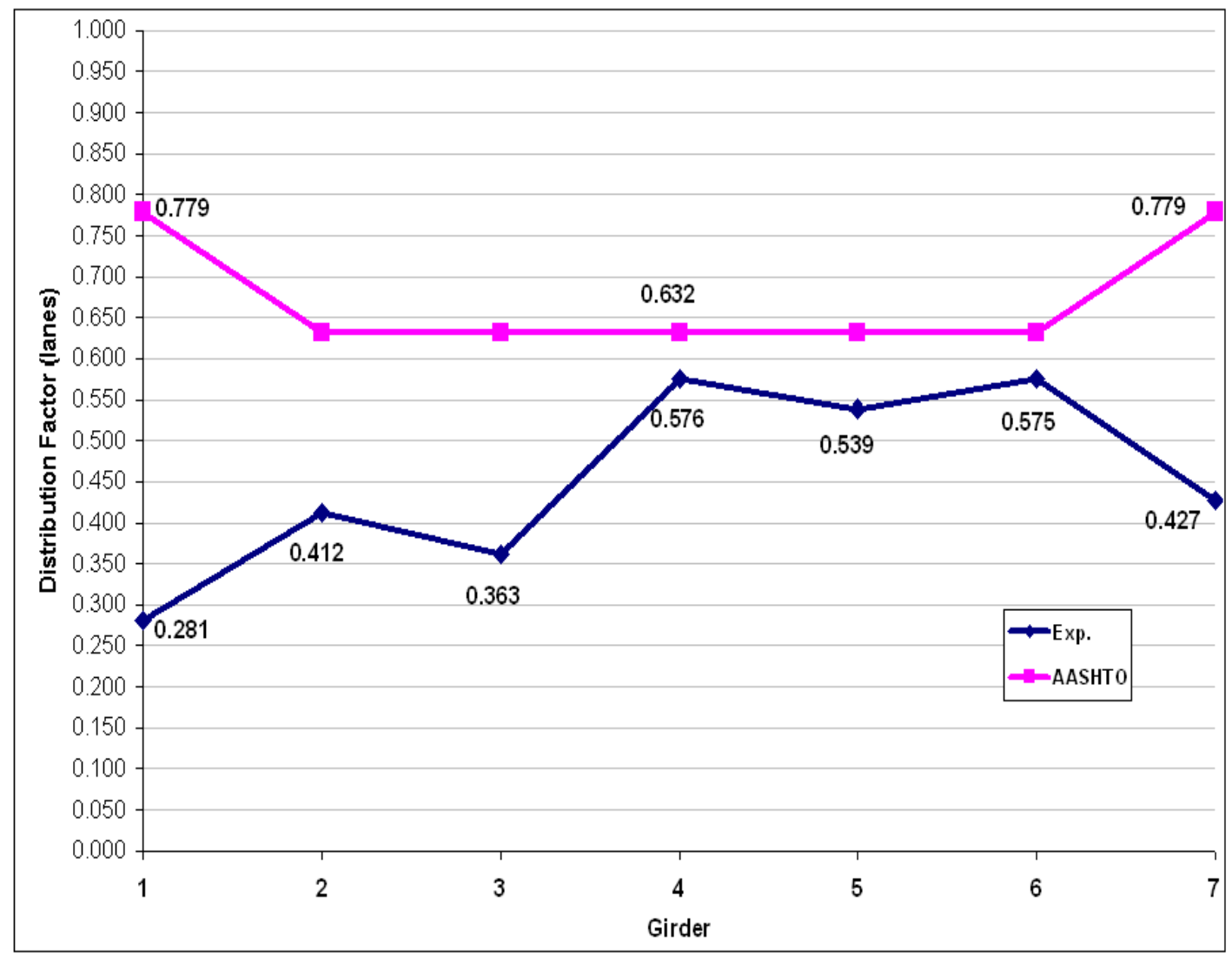

Figure 8.26 Section I: Maximum AASHTO \& Experimental Distribution Factors 
The maximum experimental distribution factor was determined from the worstcase loading for Girder 4 as 0.576 lanes. For an interior girder, AASHTO methods predicted a maximum moment distribution factor of 0.632 lanes; equating to an 8.86 percent difference between maximum experimental and design distribution factors. Girders 1 through 3 were found to have experimental distribution factors less than AASHTO and the other load tested girders. This was due to the unintentional composite action between the deck, sidewalk, railings, and parapets, as well as the inaccessibility of Girders 1 and 2 due to the sidewalk.

\subsubsection{Section II: Negative Bending Moment}

The methods used to determine the experimental moment distribution factors above were also employed in the negative bending region. The moments induced by the load truck are presented in Table 8.4. Example calculations are not repeated within this section; however, the experimental distribution factors are presented in Table 8.5 and Figure 8.27. The undistributed and un-factored moments for interior and exterior girders were found from CONSYS ${ }^{\mathrm{TM}}$ as $-364.8 \mathrm{kip}-\mathrm{ft}$. and -371.9 kip-ft., respectively.

Table 8.4 Section II Moments

\begin{tabular}{|c|c|c|c|c|c|c|c|}
\cline { 2 - 8 } \multicolumn{1}{c|}{} & Girder 1 & Girder 2 & Girder 3 & Girder 4 & Girder 5 & Girder 6 & Girder 7 \\
\hline Truck Placement 1 & -35.2 & -51.8 & -33.0 & -4.9 & 3.0 & 1.0 & -0.9 \\
\hline Truck Placement 2 & -29.2 & -52.3 & -39.2 & -8.0 & 2.5 & 1.4 & 0.0 \\
\hline Truck Placement 3 & -9.5 & -28.1 & -53.5 & -41.6 & -9.6 & 0.1 & 2.7 \\
\hline Truck Placement 4 & -6.6 & -21.4 & -50.4 & -51.6 & -14.3 & -0.4 & 4.5 \\
\hline Truck Placement 5 & -4.5 & -7.3 & -25.7 & -59.4 & -42.4 & -8.5 & 7.2 \\
\hline Truck Placement 6 & -3.6 & -4.9 & -18.3 & -55.2 & -51.9 & -13.8 & 8.1 \\
\hline Truck Placement 7 & -3.7 & -1.6 & -6.2 & -29.7 & -59.9 & -41.9 & 0.5 \\
\hline Truck Placement 8 & -2.8 & -0.6 & -3.2 & -19.6 & -53.6 & -52.7 & -4.0 \\
\hline Truck Placement 9 & -2.9 & -2.4 & -1.8 & -5.9 & -22.7 & -53.3 & -42.8 \\
\hline Truck Placement 10 & -2.2 & -1.3 & -0.7 & -3.3 & -14.7 & -42.4 & -52.9 \\
\hline
\end{tabular}


Table 8.5 Section II Moment Distribution Factors

\begin{tabular}{|c|c|c|c|c|c|c|c|c|}
\hline $\begin{array}{l}\text { Lanes } \\
\text { Loaded }\end{array}$ & MP & Girder 1 & Girder 2 & Girder 3 & Girder 4 & Girder 5 & Girder 6 & Girder 7 \\
\hline 1 & 120 & 0.235 & 0.258 & 0.293 & 0.394 & 0.374 & 0.388 & 0.433 \\
\hline 2 & 1.00 & 0.221 & 0.134 & 0.263 & 0.502 & 0.607 & 0.614 & 0.547 \\
\hline 3 & 0.85 & 0.184 & 0.044 & 0.119 & 0.716 & 0.661 & 0.657 & 0.545 \\
\hline 4 & 0.65 & 0.135 & 0.018 & 0.056 & 0.583 & 0.643 & 0.570 & 0.454 \\
\hline & $\mathrm{Ma}$ & 0.235 & 0.258 & 0.293 & 0.716 & 0.661 & 0.657 & 0.547 \\
\hline
\end{tabular}

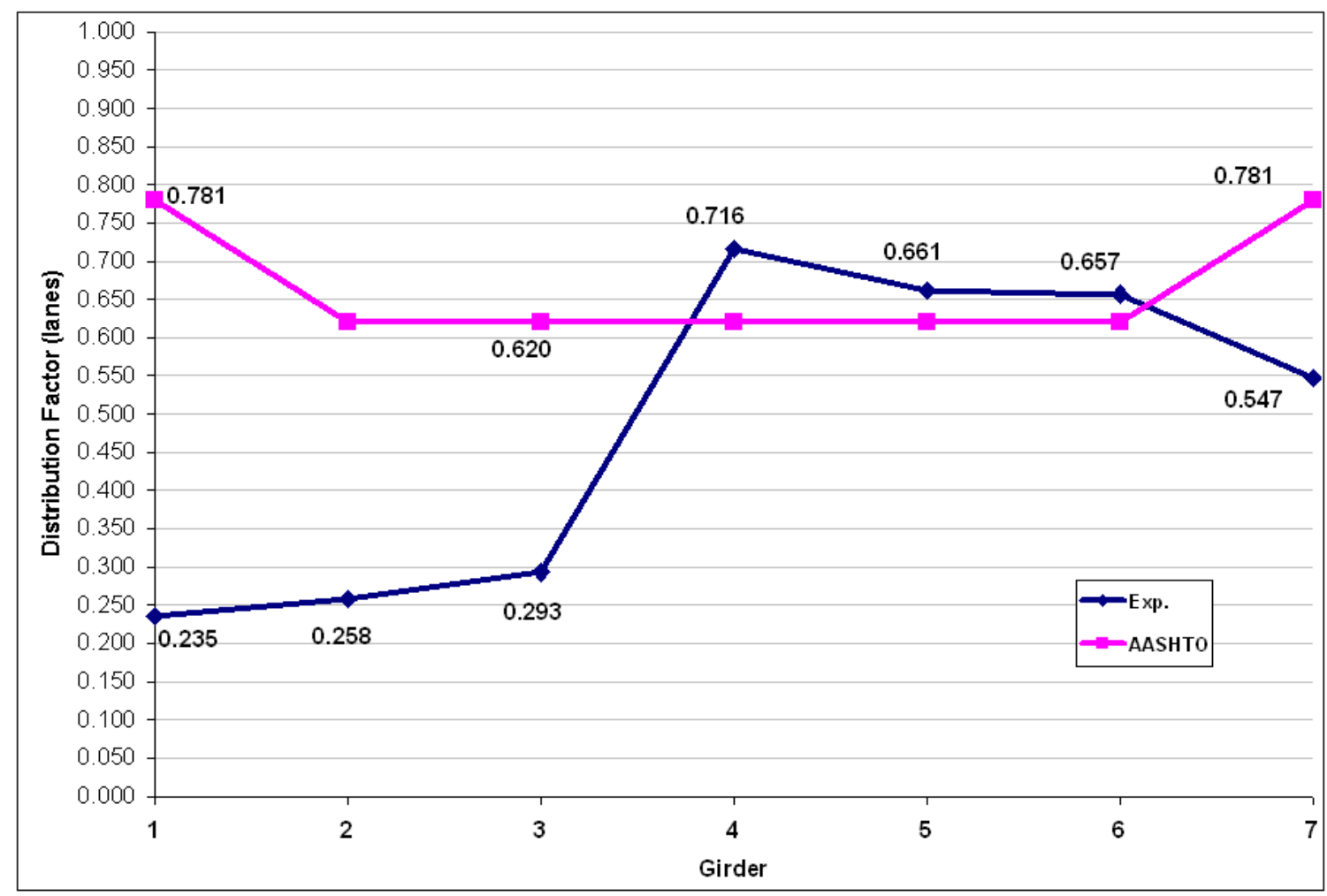

Figure 8.27 Section II: Maximum AASHTO \& Experimental Distribution Factors

The maximum experimental distribution factor for the negative bending region was found by superimposing three truck placements on Girder 4. This resulted in a distribution factor of 0.716 lanes; 13.41 percent higher than the maximum AASHTO predicted distribution factor for an interior girder. Similar to the results of the positive bending region, Girders 1 through 3 yielded distribution factors that were much less than 
AASHTO and the other load tested girders. Again, unintentional composite action and truck placement restrictions limited the responses of these girders and ultimately resulted in reduced experimental distribution factors.

\subsubsection{Summary of Moment Distribution Factors}

Load testing of Section I resulted in a maximum experimental moment distribution factor of 0.576 lanes. AASHTO methods predicted a maximum distribution factor of 0.632 lanes for an interior girder; equating to an 8.86 percent difference. Thus, it can be concluded that AASHTO conservatively predicts the maximum moment distribution factor for an interior girder in the positive bending region of the Culloden Bridge. Conversely, the maximum experimental moment distribution factor for Section II was found to be 0.716 lanes, while AASHTO methods resulted in a maximum distribution factor of 0.620 lanes for an interior girder; therefore, AASHTO underpredicts moment distribution in the negative bending region of the Culloden Bridge.

In both the positive and negative bending regions, AASHTO over-predicts the exterior girder distribution factors by as much as 70 percent. This was due to limited truck placements because of sidewalks, overhangs, parapets, and AASHTO truck placement requirements. Bridges with larger overhangs and no sidewalks should also be investigated to conclude that these factors did indeed play a role in the resulting distribution factors for the Culloden Bridge. 


\subsection{Design Load Rating: Strength I}

The design load ratings were individually calculated for interior and exterior girders. The moment envelopes were developed with CONSYS ${ }^{\mathrm{TM}}$ to determine the maximum force effects at $0.40 \mathrm{~L}_{1}$ and $1.00 \mathrm{~L}_{1}$ points. In regions of negative flexure, four unbraced lengths were analyzed; however, only the most critical unbraced length is presented below. The negative flexural capacity for exterior girders was determined by transforming the non-prismatic unbraced length into an equivalent prismatic member by taking a weighted average approach. This was not necessary for interior girders because they were found to have adequate negative flexural capacity using conventional methods. The Strength I and Service II load combinations, from the $4^{\text {th }}$ edition of the AASHTO specifications, were used to load rate the bridge. The Strength I load ratings were found from the following equations:

$$
\begin{aligned}
& R F_{\text {Strength } I-P o s}=\frac{1}{1.75 M_{L L+I M}}\left[\phi_{f} M_{n}-1.25 M_{D C 1}-1.25 M_{D C 2}-1.5 M_{D W}\right] \\
& R F_{\text {Strength I-Neg }}=\frac{S_{\text {steel }+ \text { reinf }}}{1.75 M_{L L+I M}}\left[\phi_{f} F_{n c}-\frac{1.25 M_{D C 1}}{S_{N C}}-\frac{1.25 M_{D C 2}}{S_{\text {steel }+ \text { reinf } / 3}}-\frac{1.5 M_{D W}}{S_{\text {steel }+ \text { re inf } / 3}}\right]
\end{aligned}
$$

In regions of positive flexure, the girders and deck were considered composite for Strength I and Service II load ratings. In regions of negative flexure, the girders plus the longitudinal reinforcement were considered composite for Strength I load ratings; however, the girder plus the deck was considered composite for Service II load ratings. The moments and section moduli used in the design load rating calculations are presented below in Tables 8.6 and 8.7. 
Table 8.6 Interior Girder Moments and Section Moduli

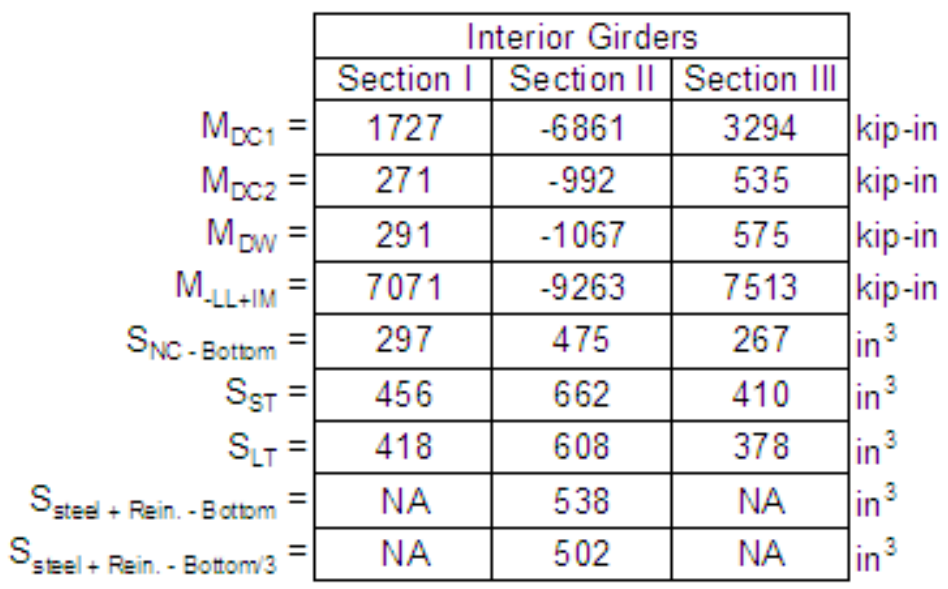

Table 8.7 Exterior Girder Moments and Section Moduli

\begin{tabular}{|c|c|c|c|c|}
\hline & Section I & Section II & Section III & \\
\hline$M_{D C 1}=$ & 1697 & -6833 & 3214 & kip-in \\
\hline$M_{D C 2}=$ & 268 & -1000 & 526 & kip-in \\
\hline$M_{D W}=$ & 288 & -1076 & 566 & kip-in \\
\hline$M_{-L L+M}=$ & 8803 & -11854 & 9027 & kip-in \\
\hline$S_{\mathrm{NC}} \cdot$ Bottom $=$ & 316 & 510 & 267 & in $^{3}$ \\
\hline$S_{S T}=$ & 480 & 705 & 409 & in $^{3}$ \\
\hline$S_{L T}=$ & 441 & 647 & 375 & in $^{3}$ \\
\hline$S_{\text {steal }+ \text { Ren. - Bottom }}=$ & NA & 577 & NA & $\operatorname{in}^{3}$ \\
\hline 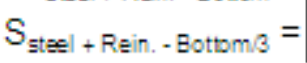 & NA & 538 & NA & in $^{3}$ \\
\hline
\end{tabular}

\subsubsection{Interior Girders}

The Strength I design load ratings for an interior girder were found as follows:

Section I - Positive Bending:

$$
\begin{aligned}
& R F_{\text {Strength I-Pos }}=\frac{1}{1.75(7,071)}[1.0(36,367)-1.25(1,727)-1.25(271)-1.5(291)] \\
& R F_{\text {Strength I-Pos }}=2.70
\end{aligned}
$$


Section II - Negative Bending:

$$
\begin{aligned}
& R F_{\text {Strength I-Neg }}=\frac{538}{1.75(9,263)}\left[1.0(72.21)-\frac{1.25(6,862)}{475}-\frac{1.25(886)}{502}-\frac{1.5(953)}{502}\right] \\
& R F_{\text {Strength I-Neg }}=1.61
\end{aligned}
$$

Section III - Positive Bending:

$$
\begin{aligned}
& R F_{\text {Strengthl-Pos }}=\frac{1}{1.75(7,513)}[1.0(32,819)-1.25(3,294)-1.25(535)-1.5(575)] \\
& R F_{\text {StrengthI-Pos }}=2.07
\end{aligned}
$$

\subsubsection{Exterior Girders}

The Strength I design load ratings for an exterior girders were found as follows:

Section I - Positive Bending:

$$
\begin{aligned}
& R F_{\text {Strengthl-Pos }}=\frac{1}{1.75(8,802)}[1.0(37,312)-1.25(1,697)-1.25(268)-1.5(288)] \\
& R F_{\text {StrengthI-Pos }}=2.23
\end{aligned}
$$

Section II - Negative Bending (Prismatic Section):

$$
\begin{aligned}
& R F_{\text {Strengthl-Neg }}=\frac{577}{1.75(11,854)}\left[1.0(68.45)-\frac{1.25(6,833)}{510}-\frac{1.25(1,000)}{538}-\frac{1.5(1,076)}{538}\right] \\
& R F_{\text {StrengthI-Neg }}=1.29
\end{aligned}
$$

Section III - Positive Bending:

$$
\begin{aligned}
& R F_{\text {Strengthl-Pos }}=\frac{1}{1.75(9,027)}[1.0(32,760)-1.25(3,214)-1.25(526)-1.5(566)] \\
& R F_{\text {Strengthl-Pos }}=1.72
\end{aligned}
$$




\subsection{Design Load Rating: Service II}

The Service II load ratings were also determined from the moment envelopes generated with CONSYSTM as were found with the following equations:

$$
\begin{aligned}
& R F_{\text {Service II-Pos }}=\frac{1}{1.3 M_{L L+I M}}\left[0.95 \phi_{f} M_{n c}-M_{D C 1}-M_{D C 2}-M_{D W}\right] \\
& R F_{\text {Service II-Neg }}=\frac{S_{\text {short-term }}}{1.3 M_{L L+I M}}\left[0.95 \phi_{f} F_{n c}-\frac{M_{D C 1}}{S_{N C}}-\frac{M_{D C 2}}{S_{\text {long-term }}}-\frac{M_{D W}}{S_{\text {long-term }}}\right] \text { Eq. 8.8 }
\end{aligned}
$$

\subsubsection{Interior Girders}

The Service II load ratings for interior girders were found as follows:

Section I - Positive Bending:

$$
\begin{aligned}
& \left.R F_{\text {Service II-Pos }}=\frac{1}{1.3(7,071)}[(0.95)(1.0)(36,367)-1727-271-291)\right] \\
& R F_{\text {Service II-Pos }}=3.51
\end{aligned}
$$

Section II - Negative Bending:

$$
\begin{aligned}
& R F_{\text {Service II-Neg }}=\frac{662}{1.3(9,263)}\left[(0.95)(1.0)(72.21)-\frac{6,861}{475}-\frac{992}{608}-\frac{1,067}{608}\right] \\
& R F_{\text {Service II-Neg }}=2.79
\end{aligned}
$$

Section III - Positive Bending:

$$
\begin{aligned}
& R F_{\text {Service II-Pos }}=\frac{1}{1.3(7,513)}[(0.95)(1.0)(32,819)-3,294-535-575] \\
& R F_{\text {Service II-Pos }}=2.74
\end{aligned}
$$




\subsubsection{Exterior Girders}

The Service II load ratings for exterior girders were found as follows:

Section I - Positive Bending:

$$
\begin{aligned}
& R F_{\text {Service II-Pos }}=\frac{1}{1.3(8,803)}[(0.95)(1.0)(37,312)-1,697-268-288] \\
& R F_{\text {Service II-Pos }}=2.90
\end{aligned}
$$

Section II - Negative Bending (Prismatic Section):

$$
\begin{aligned}
& R F_{\text {Service I-Neg }}=\frac{705}{1.3(11,854)}\left[0.95(1.0)(68.45)-\frac{6,833}{510}-\frac{1,000}{647}-\frac{1,076}{647}\right] \\
& R F_{\text {Service II-Neg }}=2.21
\end{aligned}
$$

Section III - Positive Bending:

$$
\begin{aligned}
& R F_{\text {Service II-Pos }}=\frac{1}{1.3(9,027)}[(0.95)(1.0)(32,761)-3,214-526-566] \\
& R F_{\text {Service II-Pos }}=2.29
\end{aligned}
$$

\subsection{Experimental Load Rating: Strength I}

The Strength I experimental load ratings for positive and negative bending sections were found from the following equations:

$$
R F_{\text {EXP-Strength I-Pos }}=\frac{\phi_{f} F_{n}-\left(\frac{1.25 M_{D C 1}}{S_{N C}}+\frac{1.25 M_{D C 2}}{S_{L T}}+\frac{1.5 M_{D W}}{S_{L T}}\right)}{1.75 \times \sigma_{B F \operatorname{Max}}\left(\frac{M_{H L-93}}{M_{E X P \text { Truck }} \times 1.33}\right)(1+I M)}
$$




$$
R F_{\text {EXP-Strength I-Neg }}=\frac{\phi_{f} F_{n}-\left(\frac{1.25 M_{D C 1}}{S_{N C}}+\frac{1.25 M_{D C 2}}{S_{\text {steel }+ \text { rein } / 3}}+\frac{1.5 M_{D W}}{S_{\text {steel }+ \text { rein } / 3}}\right)}{1.75 \times \sigma_{B F \operatorname{Max}}\left(\frac{M_{H L-93}}{M_{E X P \text { Truck }} \times 1.33}\right)(1+I M)}
$$

The section moduli used to determine the design load ratings were also used to determine the experimental load ratings in the subsequent calculations. Strains recorded during load tests were not affected by impact because the load truck was either static or traveling at crawl speeds; therefore, impact was applied to the experimental moments to be consistent with design. In the negative bending region only the experimental load rating for the most critical unbraced length is presented below. Due to the frequent train traffic under the mid-span of the Culloden Bridge, Section III was not instrumented; therefore, experimental load rating factors are not presented for this section. The maximum bottom flange stresses induced be each load truck placement, and used in the subsequent calculations, are presented below in Table 8.8 and Table 8.9.

Table 8.8 Section I: Bottom Flange Stresses (ksi)

\begin{tabular}{|c|c|c|c|c|c|c|}
\hline Girder 1 & Girder 2 & Girder 3 & Girder 4 & Girder 5 & Girder 6 & Girder 7 \\
\hline 1.695 & 2.848 & 1.339 & 1.609 & 0.540 & 0.231 & 0.123 \\
\hline 0.549 & 1.515 & 3.062 & 3.071 & 1.584 & 0.550 & 0.253 \\
\hline 0.171 & 0.474 & 1.338 & 1.067 & 2.915 & 2.351 & 0.758 \\
\hline 0.069 & 0.134 & 0.434 & 0.304 & 0.951 & 2.465 & 2.556 \\
\hline 2.484 & 4.971 & 6.174 & 6.051 & 5.990 & 5.597 & 3.691 \\
\hline
\end{tabular}

Table 8.9 Section II: Bottom Flange Stresses (ksi)

\begin{tabular}{|c|c|c|c|c|c|c|}
\hline Girder 1 & Girder 2 & Girder 3 & Girder 4 & Girder 5 & Girder 6 & Girder 7 \\
\hline-1.045 & -1.835 & -1.460 & -0.512 & -0.058 & 0.028 & 0.035 \\
\hline-0.102 & -0.508 & -0.886 & -1.999 & -1.799 & -0.963 & -0.510 \\
\hline 0.022 & -0.304 & -0.824 & -1.059 & -1.893 & -1.761 & -1.052 \\
\hline 0.045 & -0.161 & -0.515 & -0.349 & -1.044 & -1.950 & -2.018 \\
\hline-1.080 & -2.808 & -3.684 & -3.919 & -4.794 & -4.646 & -3.546 \\
\hline
\end{tabular}




\subsubsection{Interior Girders}

The maximum Strength I experimental load rating for an interior girders was found from Girder 3 as:

Section I - Positive Bending:

$$
\begin{aligned}
R F_{\text {EXP-Strength I-Pos }}=\frac{(1.0)(79.82)-\left(\frac{1.25(1,727)}{297}+\frac{1.25(271)}{418}+\frac{1.5(291)}{418}\right)}{(1.75)(6.17)\left(\frac{7,071}{2,885 \times 1.33}\right)(1.33)} \\
R F_{\text {EXP-Strength I-Pos }}=2.67
\end{aligned}
$$

Section II - Negative Bending:

$$
\begin{aligned}
R F_{\text {EXP-Strength I-Neg }}=\frac{(1.0)(72.21)-\left(\frac{1.25|-6,861|}{475}+\frac{1.25|-992|}{502}+\frac{1.5|-1,067|}{502}\right)}{(1.75)\left|(-4.79)\left(\frac{-9,263}{-4,331 \times 1.33}\right)\right|(1.33)} \\
R F_{\text {EXP-Strength I-Neg }}=2.70
\end{aligned}
$$

\subsubsection{Exterior Girders}

The maximum Strength I experimental load rating for an exterior girder was found from Girder 7 as follows:

Section I - Positive Bending:

$$
\begin{aligned}
R F_{E X P-S t r e n g t h ~ I-P o s} & =\frac{1.0(77.66)-\left(\frac{1.25(1,697)}{316}+\frac{1.25(268)}{441}+\frac{1.5(288)}{441}\right)}{(1.75)(3.69)\left(\frac{8,803}{1,893 \times 1.33}\right)(1.33)} \\
R F_{\text {EXP-Strength I-Pos }} & =2.30
\end{aligned}
$$


Section II - Negative Bending:

$$
\begin{aligned}
R F_{\text {EXP-Strength I-Neg }} & =\frac{1.0(72.10)-\left(\frac{1.25|-6,833|}{510}+\frac{1.25|-1.000|}{538}+\frac{1.5|-1,076|}{538}\right)}{(1.75)\left|(-3.55)\left(\frac{-11,854}{-3,116 \times 1.33}\right)\right|(1.33)} \\
R F_{\text {EXP-Strength } I-\text { Neg }} & =1.96
\end{aligned}
$$

\subsection{Experimental Load Rating: Service II}

The Service II experimental load ratings were found from the equation below. Again, impact was applied to the maximum experimental moment to be consistent with the design moment.

$$
R F_{E X P-\text { Service II }}=\frac{0.95 \phi_{f} F_{n}-\left(\frac{M_{D C 1}}{S_{N C}}+\frac{M_{D C 2}}{S_{L T}}+\frac{M_{D W}}{S_{L T}}\right)}{1.3 \times \sigma_{B F \operatorname{Max}}\left(\frac{M_{H L-93}}{M_{E X P \text { Truck }} \times 1.33}\right)(1+I M)}
$$

\subsubsection{Interior Girders}

The maximum Service II experimental load rating, determined from Girder 3, was found as follows:

Section I - Positive Bending:

$$
\begin{aligned}
R F_{\text {EXP-Service II }} & =\frac{0.95(1.0)(79.82)-\left(\frac{1,727}{297}+\frac{271}{418}+\frac{291}{418}\right)}{(1.3)(6.17)\left(\frac{7,071}{2,885 \times 1.33}\right)(1.33)} \\
R F_{\text {EXP-Service II }} & =3.49
\end{aligned}
$$


Section II - Negative Bending:

$$
\begin{aligned}
R F_{\text {EXP-Service II }}=\frac{0.95(1.0)(72.21)-\left(\frac{|-6,861|}{475}+\frac{|-992|}{608}+\frac{|-1,067|}{608}\right)}{(1.3)\left|(-4.79)\left(\frac{-9,263}{-4,331 \times 1.33}\right)\right|(1.33)} \\
R F_{\text {EXP-Service II }}=3.81
\end{aligned}
$$

\subsubsection{Exterior Girders}

The maximum Service II experimental load rating, determined from Girder 7, was found as follows:

Section I - Positive Bending:

$$
\begin{aligned}
R F_{\text {EXP-Service II }}=\frac{0.95(1.0)(77.66)-\left(\frac{1,697}{316}+\frac{268}{441}+\frac{288}{441}\right)}{(1.3)(3.69)\left(\frac{8,802}{1,893 \times 1.33}\right)(1.33)} \\
R F_{\text {EXP-Service II }}=3.01
\end{aligned}
$$

Section II-Negative Bending:

$$
\begin{aligned}
R F_{\text {EXP-Service II }}=\frac{0.95(1.0)(68.45)-\left(\frac{|-6,833|}{510}+\frac{|-1,000|}{647}+\frac{|-1,076|}{647}\right)}{(1.3)\left|(-3.55)\left(\frac{-11,854}{-3,116 \times 1.33}\right)\right|(1.33)} \\
R F_{\text {EXP-Service II }}=2.76
\end{aligned}
$$

\subsection{Summary of Load Ratings}

The design and experimental load ratings, and the percent differences between them, are summarized in the tables below for interior and exterior girders. In most cases, 
the experimental load ratings were greater than the design load ratings. This was expected because the design load ratings do not account for the structurally continuous portions of the bridge such as the sidewalk, barriers, and railings.

Table 8.10 Percent Difference: Strength I - Interior Girder Load Ratings

\begin{tabular}{|c|c|c|c|}
\cline { 2 - 4 } \multicolumn{1}{c|}{} & Design & Exp. & $\%$ Diff. \\
\hline Section I & 2.70 & 2.67 & 1.21 \\
\hline Section II & 1.61 & 2.70 & 67.79 \\
\hline Section III & 2.07 & - & - \\
\hline
\end{tabular}

Table 8.11 Percent Difference: Strength I - Exterior Girder Load Ratings

\begin{tabular}{|c|c|c|c|}
\cline { 2 - 4 } \multicolumn{1}{c|}{} & Design & Exp. & $\%$ Diff. \\
\hline Section I & 2.23 & 2.30 & 3.08 \\
\hline Section II & 1.29 & 1.96 & 52.30 \\
\hline Section III & 1.72 & - & - \\
\hline
\end{tabular}

Table 8.12 Percent Difference: Service II - Interior Girder Load Ratings

\begin{tabular}{|c|c|c|c|}
\cline { 2 - 4 } \multicolumn{1}{c|}{} & Design & Exp. & $\%$ Diff. \\
\hline Section I & 3.51 & 3.49 & 0.55 \\
\hline Section II & 2.79 & 3.81 & 36.50 \\
\hline Section III & 2.74 & - & - \\
\hline
\end{tabular}

Table 8.13 Percent Difference: Service II - Exterior Girder Load Ratings

\begin{tabular}{|c|c|c|c|}
\cline { 2 - 4 } \multicolumn{1}{c|}{} & Design & Exp. & $\%$ Diff. \\
\hline Section I & 2.90 & 3.01 & 3.71 \\
\hline Section II & 2.21 & 2.76 & 24.89 \\
\hline Section III & 2.29 & - & - \\
\hline
\end{tabular}




\section{Chapter 9 - Summary and Conclusions}

\subsection{Introduction}

The objective of this research was to evaluate HPS bridge performance and serviceability through analytical assessments and field tests. Current and past design methodologies were presented in Chapter 2, followed by an overview of recent editions of the AASHTO LRFD Bridge Design Specifications with focus on HPS and serviceability in Chapters 3 and 4 . In addition to past design methodologies, Chapter 2 also presents several levels of field-testing used to evaluate bridge serviceability and develop load ratings. The Culloden Bridge design assessment was presented in Chapter 5, followed by the field test in Chapter 6. Lastly, the strength and serviceability of the Culloden Bridge was evaluated by comparing experimental and theoretical values determined with the AASHTO specifications in Chapters 7 and 8.

\subsection{AASHTO Design Specifications for HPS I-Girders}

The $4^{\text {th }}$ edition of the AASHTO LRFD Bridge Design Specifications limits the flexural capacity of HPS 100W I-girders to their yield moment capacities rather than their plastic moment capacities. Although further analysis and testing is necessary to verify the flexural behavior of HPS, the findings of Barth, Wolfe, and Righman lay the necessary groundwork for the future removal of the current limit. The results of their FE parametric study show that the current AASHTO design equations conservatively predict the design flexural capacity of HPS girders.

Work was also conducted to develop more accurate flexural capacity equation for compression flange behavior in steel I-girders. This consisted of modeling compression 
flanges as beam-columns and accounting for the web's contribution to the flexural capacity of the compression flange. An empirical 1/3 factor was developed, through a large number of tests, to linearly approximate the web/flange behavioral instability during flexure.

The live load deflection limit, L/800, was originally introduced to control bridge serviceability. If the L/800 limit is to be justified as a serviceability limit, than further analysis and tests are necessary to merit its applications. Furthermore, several other limits already exist in the specifications to ensure serviceability. The second live load deflection limit, L/1000, is used to avoid undesirable physiological effects; however, studies by Wright and Walker have shown that vibrations in tandem with deflection are the cause of undesirable physiological effects. Hybrid girders that utilize the benefits of HPS are generally shallower than their lower grade steel counterparts and deflect more. Although live load deflection limits are optional in AASHTO, many state agencies still employ them which ultimately affects the economy of girders designed with HPS. In conclusion, live load deflection limits should be relaxed for HPS bridge designs pending further studies that merit their use or modification.

\subsection{Culloden Bridge Design Assessment with Current AASHTO Specifications}

The Culloden Bridge was reevaluated with the $4^{\text {th }}$ edition of the AASHTO Specifications with focus on the Strength I, Service II, and Fatigue limit states. The critical sections of the bridge were checked for cross section proportions, flexure, shear, fatigue, permanent deformations, and elastic deformations. From observation, the two 
critical sections were determined to be Section II; over the pier, and Section III; at the middle of second span.

Sections II and III of an exterior girder were evaluated and presented in Chapter

5. Both sections were found to satisfy AASHTO limit states except Section III which violated fatigue. AASHTO limits the live load fatigue stress range to half the constant amplitude fatigue threshold, or $6 \mathrm{ksi}$. In the case of the Culloden Bridge, the stress range was determined to be $9.27 \mathrm{ksi}$ at the connection plate weld for the diaphragm in Section III; exceeding the limit for a C' connection.

All of the cross section proportions met AASHTO requirements; however, the National Steel Bridge Alliance (NSBA) recommends a minimum web thickness of 7/16", with a minimum of a 1/2" preferred to combat web bend-buckling at the service limit state. Section III of the Culloden Bridge has a web thickness of $3 / 8$ ", which is smaller than the suggested limit.

The maximum live load deflection was determined with the program CONSYS ${ }^{\mathrm{TM}}$ as $0.746 \mathrm{in}$. This deflection includes distribution factors and impact. The maximum allowable deflection for a bridge with sidewalks is equal to $\mathrm{L} / 1000$ and was determined to be $0.960 \mathrm{in}$. Therefore, the Culloden Bridge has a maximum theoretical deflection that is 9 percent less than the maximum deflection allowed by AASHTO.

\subsection{Strength and Serviceability Field Testing of the Culloden Bridge}

The strength and serviceability of the Culloden Bridge were evaluated experimentally through field tests and compared with theory using the AASHTO specifications. The serviceability assessment consisted of determining the natural 
frequency, and the lateral live load deflection distribution factors. The strength assessment focused on the lateral distribution of moments and the load ratings of the Culloden Bridge.

The experimental natural frequency was determined by performing a Fourier analysis of the acceleration data obtained through dynamic load tests. The natural frequency was also calculated from an equation developed by Barth and $\mathrm{Wu}$ for comparison with the experimental value (Barth and $\mathrm{Wu}$ 2007). The experimental natural frequency was determined to be $3.906 \mathrm{~Hz}$. The theoretical natural frequency was found to be $3.789 \mathrm{~Hz}$. This represents a 3 percent difference between the two values. The Ontario and Canadian bridge design codes present acceptable limits of vibration based on the maximum static deflection and the first flexural frequency. The limits are narrowed into categories of bridges without sidewalks, with little used sidewalks, and with significantly used sidewalks. The Culloden Bridge's sidewalk is not used significantly; therefore, the maximum acceptable frequency, with a static deflection of 0.403 in., is about $4.5 \mathrm{~Hz}$. In conclusion, both the experimental and the theoretical natural frequencies are acceptable by this standard.

The maximum experimental deflection was determined at the $0.40 \mathrm{~L}_{1}$ point by superimposing 4 load trucks and summing the deflections recorded in each girder. By observation, the largest experimental deflection (with impact) occurred in Girder 5 and was 0.357 in. However, the experimental load truck weighed 51.92 kips and the controlling AASHTO load truck weighs 72 kips. This equates to a 39 percent difference and, when accounted for, increases the maximum experimental deflection to $0.497 \mathrm{in}$. The maximum theoretical deflection was determined at the $0.40 \mathrm{~L}_{1}$ point with 
CONSYS ${ }^{\mathrm{TM}}$. It was then multiplied by impact and the live load deflection distribution factor which includes multiple presence. This resulted in a maximum theoretical deflection of $0.326 \mathrm{in}$. This theoretical deflection is 52 percent less than the maximum experimental deflection, however, if you remove multiple presence from the live load deflection distribution factor the maximum theoretical deflection is $0.501 \mathrm{in}$. This results in a maximum theoretical deflection that is 1 percent larger than the maximum experimental deflection. The theoretical deflection was expected to be slightly larger because the theoretical deflection does not account for the additionally system stiffness provided by curbs, railings, sidewalks, etc.

The live load deflection distribution factors were also determined by superimposing load truck placements used during field tests. The experimental distribution factors of each girder were then compared with the distribution factors determined with AASHTO. On average, the experimental distribution factors were 15 percent higher than AASHTO predicted values.

The moment distribution factors were found for each girder with 1, 2, 3, and 4 lanes loaded by incrementally superimposing load trucks. Each distribution factor was then compared with the AASHTO predicted factor for each number of lanes loaded. The experimental moment distribution factors for the positive bending region were found to be an average 8.9 percent less than AASHTO predicted values. The negative bending region over the pier was found to have experimental moment distributions an average of 13 percent greater than AASHTO distribution factors. Therefore, AASHTO conservatively predicts the moment distribution factors for Section I, but under predicts moment distribution factors for Section II. 
Design and experimental load ratings were determined to assess the live load capacity of the Culloden Bridge. The average experimental Strength I rating for Section I of an interior girder was only 1 percent less than the design, while the exterior girder experimental rating was 3 percent higher than design. The experimental Strength I load ratings for Section II were found to be 68 and 52 percent conservative for interior and exterior girders, respectively. At the Service II limit state, Section I of the interior and exterior girders had rating factors that were only 0.5 and 4 percent different, respectively. At Section II, the percent difference jumped up to 37 and 25 percent for interior and exterior girders. In conclusion, all design and experimental ratings were found to be greater than 1.00; indicating that the Culloden Bridge has sufficient capacity.

\subsection{Future Work}

Research indicates that AASHTO flexural capacity equations may be used to accurately predict plastic moment capacities of $100 \mathrm{ksi}$ steel I-girders. To merit the removal of current limitations placed on these equations it is suggested that future field tests, finite element modeling, and controlled lab testing be performed for a suite of HPS I-girders. Parameters should be varied to meet key slenderness and bracing limits within the current specifications.

Limiting live load deflections does not guarantee that bridges will exhibit favorable serviceability characteristics over their design lives. Further investigations should be made into the parameters that effect damage done by elastic and permanent deflections. Deflection limits are currently used to control bridge vibrations; however, past studies have shown that a bridge's natural frequency, and not deflection, should be 
limited to control vibrations. To effectively control bridge vibrations, a natural frequency provision should be implemented in the AASHTO specifications capable of producing accurate and consistent results for various bridge types, spans, bearings, etc.

Additionally, the inclusion of multiple presence in live load deflection distribution factors should be examined to merit removal when investigating maximum live load deflections. 


\section{References}

AASHTO. 1996. LRFD Bridge Design Specifications, $1^{\text {st }}$ Edition, American Association of State Highway and Transportation Officials, Washington, D.C.

AASHTO. 2001. LRFD Bridge Design Specifications, $2^{\text {nd }}$ Edition, American Association of State Highway and Transportation Officials, Washington, D.C.

AASHTO. 2003. LRFD Bridge Design Specifications, $3^{\text {rd }}$ Edition, American Association of State Highway and Transportation Officials, Washington, D.C.

AASHTO. 2007. AASHTO LRFD Bridge Design Specifications, Customary U.S. Units, 4th Edition, with 2008 Interim Revisions, American Association of State Highway and Transportation Officials, Washington, D.C.

AASHTO. 2009. AASHTO LRFD Bridge Design Specifications, Customary U.S. Units, 4th Edition, with 2008 and 2009 Interim Revisions, AASHTO Bookstore. [Online] https://bookstore.transportation.org/Item_details.aspx?id=879

ABAQUS. 2002. ABAQUS/Standard User Manual, Version 6.3. Hibbit, K., \& Sorensen, Inc., USA

American Iron and Steel Institute. 2009. Steel Bridge Design Handbook, Example 1: Three-Span Continuous Straight Composite Girder. National Steel Bridge Alliance. [Online] http://www.steelbridges.org/pdfs/DesignExample1.pdf

Barker, M.G., Gandiaga, L., Staebler, J. 2008. "Serviceability Limits and Economical Steel Bridge Design, Interim Report Prepared for Mountain Plains Consortium." University of Wyoming, Laramie, WY, June.

Barker, M.G., Imhoff, C.A., McDaniel, W.T., and Fredrick, T.L. 1999. "Field Testing and Load Rating Procedures for steel Girder Bridges.” Report 97-3, MCHRP, Missouri Department of Transportation, May.

Barker, R.M., Puckett, J.A. 1997. Design of Highway Bridges. John Wiley \& Sons, Inc., New York, NY.

Barth, K.E., Bergman, A., \& Roeder, C.W. 2002. "Improved Live load Deflection Criteria for Steel Bridges." National Cooperative Highway Research Program Web Document 46 (Project 20-7[133]), November.

Barth, K.E., Davalos, J.F., Chiarello, M., \& Zou, B. 2008. "Evaluation of Live load Distribution Factors for Composite Bridges by Finite Element and Explicit Solutions.” Unpublished Article, West Virginia University. 
Barth, K.E., Righman, J.E., \& Wolfe, L.B. 2007. "Assessment of AASHTO LRFD Specifications for Hybrid HPS 100W Steel I-Girders.” Journal of Bridge Engineering, American Society of Civil Engineers, Reston, VA, Vol. 12, No. 3, pp. 380-388.

Barth, K. E., D. W. White, and B. M. Bobb. (2000). "Negative Bending Resistance of HPS70W Girders", Journal of Constructional Steel Research, Elsevier, 53(1), 1-31.

Barth, K.E., Wu, H. 2007. "Development of Improved Natural Frequency Equations for Continuous Span Steel I-Girder Bridges.” Engineering Structures, Vol. 29, No. 12, pp. 3432-3442.

Davis, J.D. 2003. "Serviceability Field Testing of Hybrid HPS Bridge A6101.” Master's Thesis, University of Missouri, Columbia, MO, July.

Fahnstock, L.A. and Sause, R. 2001. "Strength and Ductility of HPS-100W I-Girders in Negative Flexure." Journal of Bridge Engineering, American Society of Civil Engineers, Reston, VA, Vol. 6, No. 4.

Frederick, T.L. 1998. "Experimental Load Rating of an Existing Slab on Girder Bridge." Master's Thesis, University of Missouri, Columbia, MO, May.

Freeman, L.B. 2005. "Development of an Optimized Short-Span Steel Bridge Package." Master's Thesis, West Virginia University, Morgantown, WV.

Hall, D. H., and C. H. Yoo. 1996. "I-Girder Curvature Study." Interim Report, NCHRP Project 12-38 submitted to NCHRP, Transportation Research Board, Washington, DC, pp. 1-72 (or see Appendix A of NCHRP Report 424: Improved Design Specifications for Horizontally Curved Steel Highway Bridges, pp. 49-74).

Imhoff, C.M. 1998. "Testing and Modeling of Bridge R-289.” Master's Thesis, University of Missouri, Columbia, MO, August.

Leap Software, Inc. 2006. CONSYSTM AASHTO Standard and LRFD Live and Static Load Analysis User Manual, Version 1.3.1.

Ministry of Transportation: Quality and Standards Division. (1991). Ontario Highway Bridge Design Code/Commentary, ( $3^{\text {rd }}$ ed.). Toronto, Ontario, Canada.

Oesch, E.R. 2003. "Strength and Performance Field Testing of Hybrid HPS Bridge A6101." Master's Thesis, University of Missouri, Columbia, December.

Tonias, D.E. 1995. Bridge Engineering: Design, Rehabilitation, and Maintenance of Modern Highway Bridges. McGraw-Hill, New York, NY. 
Vuchi, A. 2005. "Graphical User Interface for Three-Dimensional FE Modeling of Composite Steel Bridges.” Master's Thesis, West Virginia University, Morgantown, WV.

White, D. W. 2003. "New LRFD Provisions for the Flexural Design of Steel I-Girder Bridges." Steel Bridge Design Workshop, NSBA Steel Bridge Symposium, November, 2003.

White, D. W. 2004. "Unified Flexural Resistance Equations for Stability Design of Steel I-Section Members-Overview." Structural Engineering, Mechanics and Materials Report No. 24a, School of Civil and Environmental Engineering, Georgia Institute of Technology, Atlanta, GA.

White, D. W., and Grubb, M.A. 2005. "Unified Resistance Equations for Design of Curved and Tangent Steel Bridge I-Girders." Proceedings of the 2005 TRB Bridge Engineering Conference, Transportation Research Board, Washington, DC, July 2005.

Wu, H. 2003. "Influence of Live load Deflections on Superstructure Performance of Slab on Steel Stringer Bridges." Doctoral Dissertation, West Virginia University, Morgantown., WV.

Yakel, A. J., Mans, P., and Azizinamini, A. (2002). "Flexural Capacity and Ductility of HPS-70W Bridge Girders,” Engineering Journal, AISC, 39(1), p 38-51. 
Appendix A: Culloden Bridge Plans 


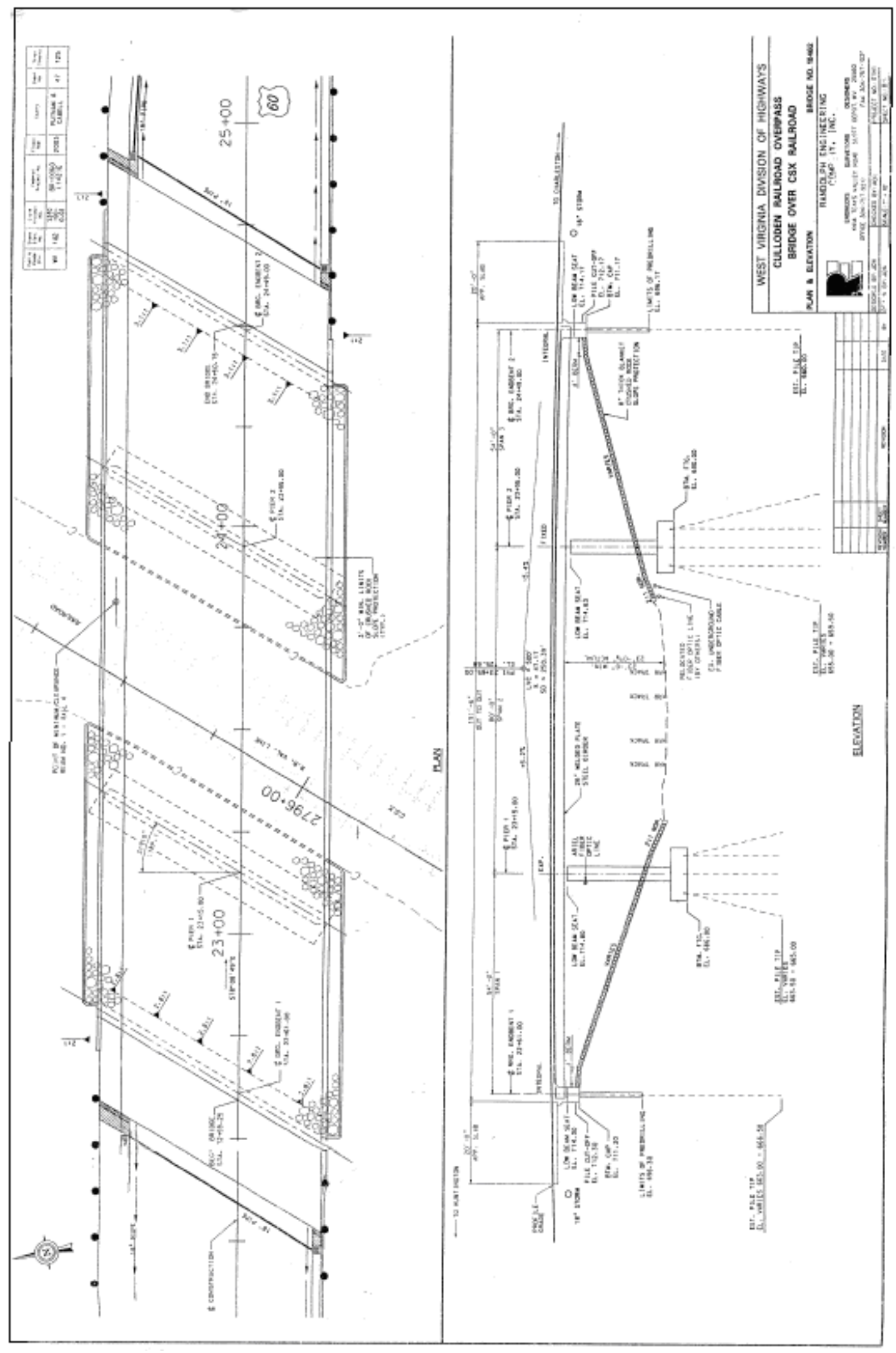




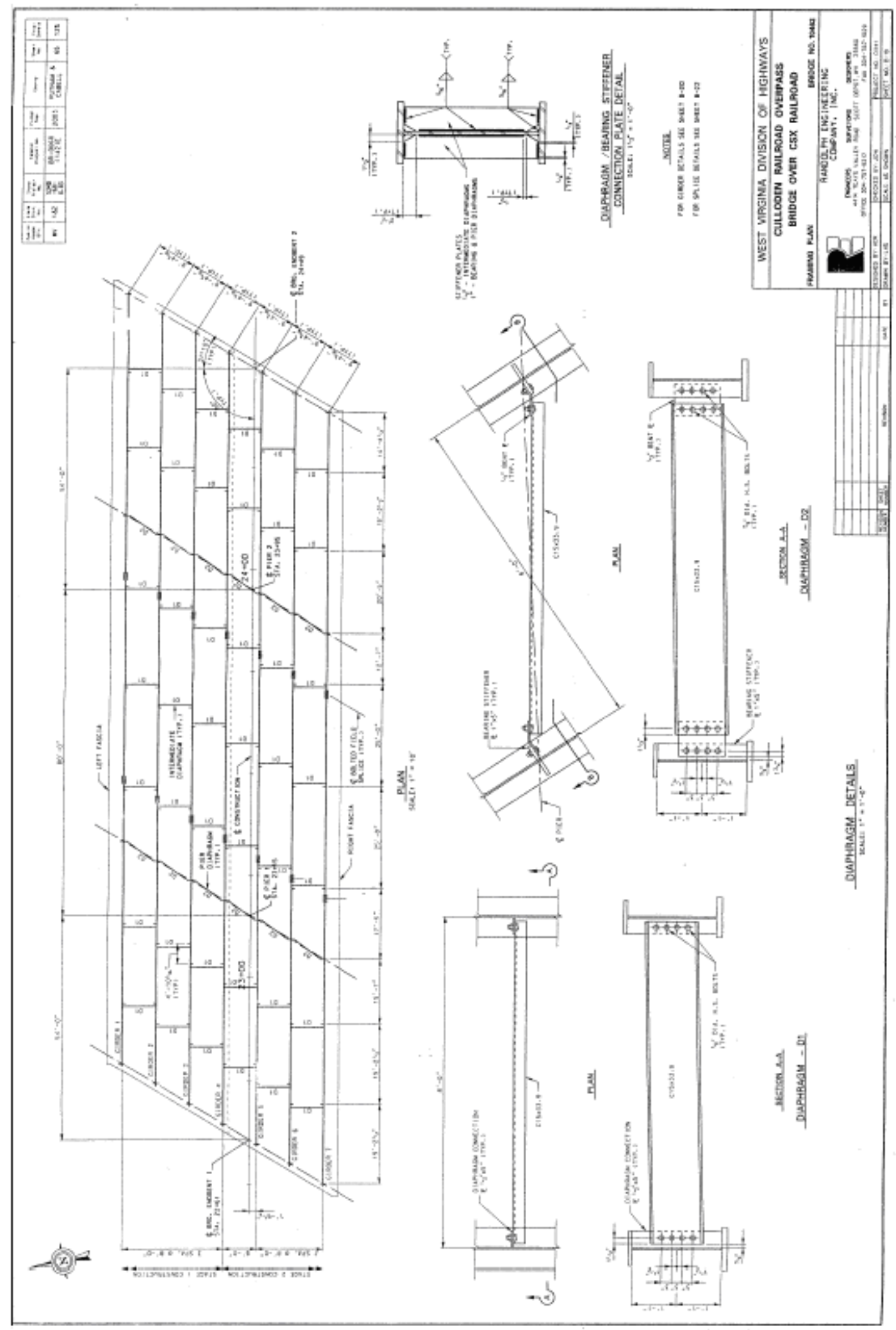




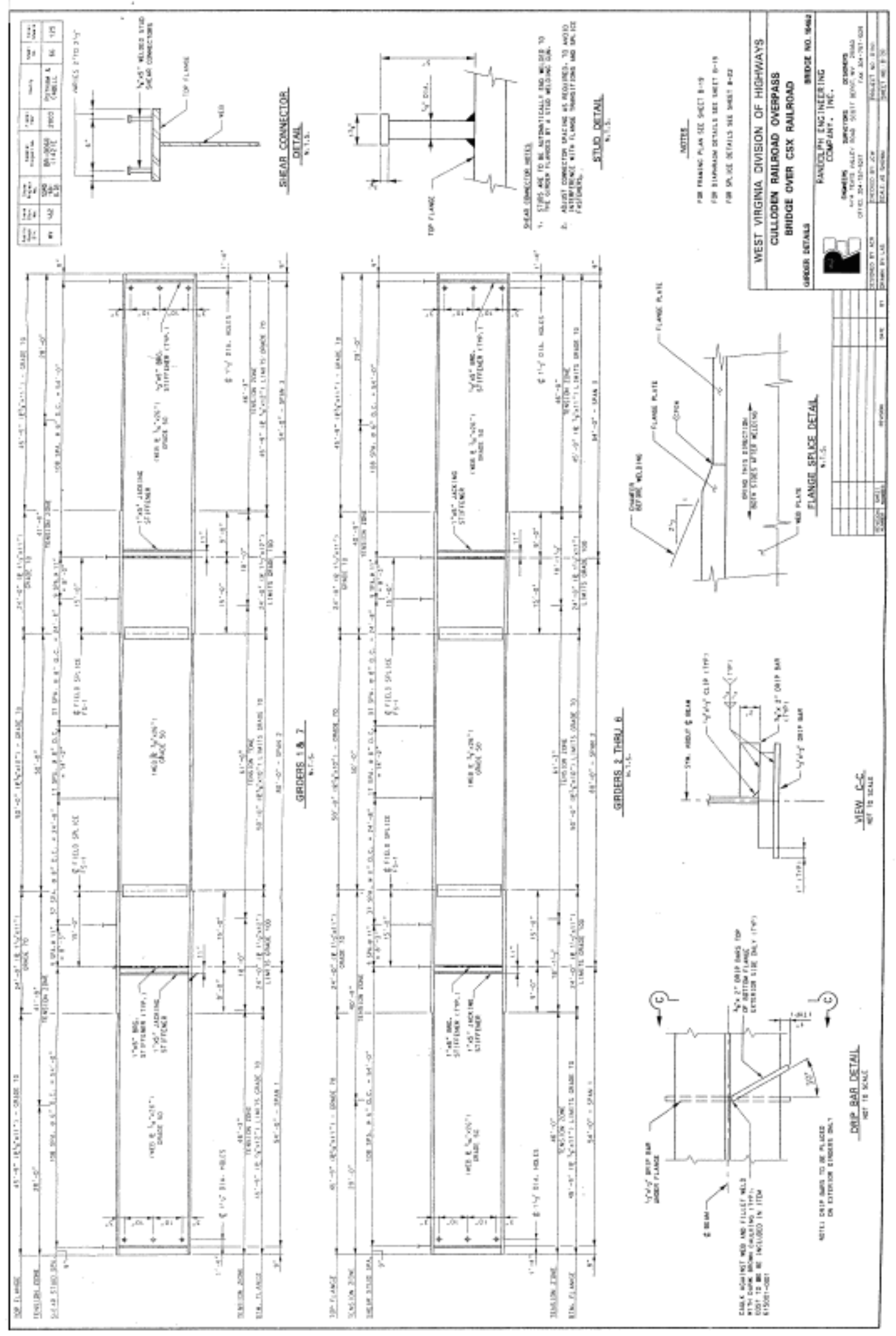




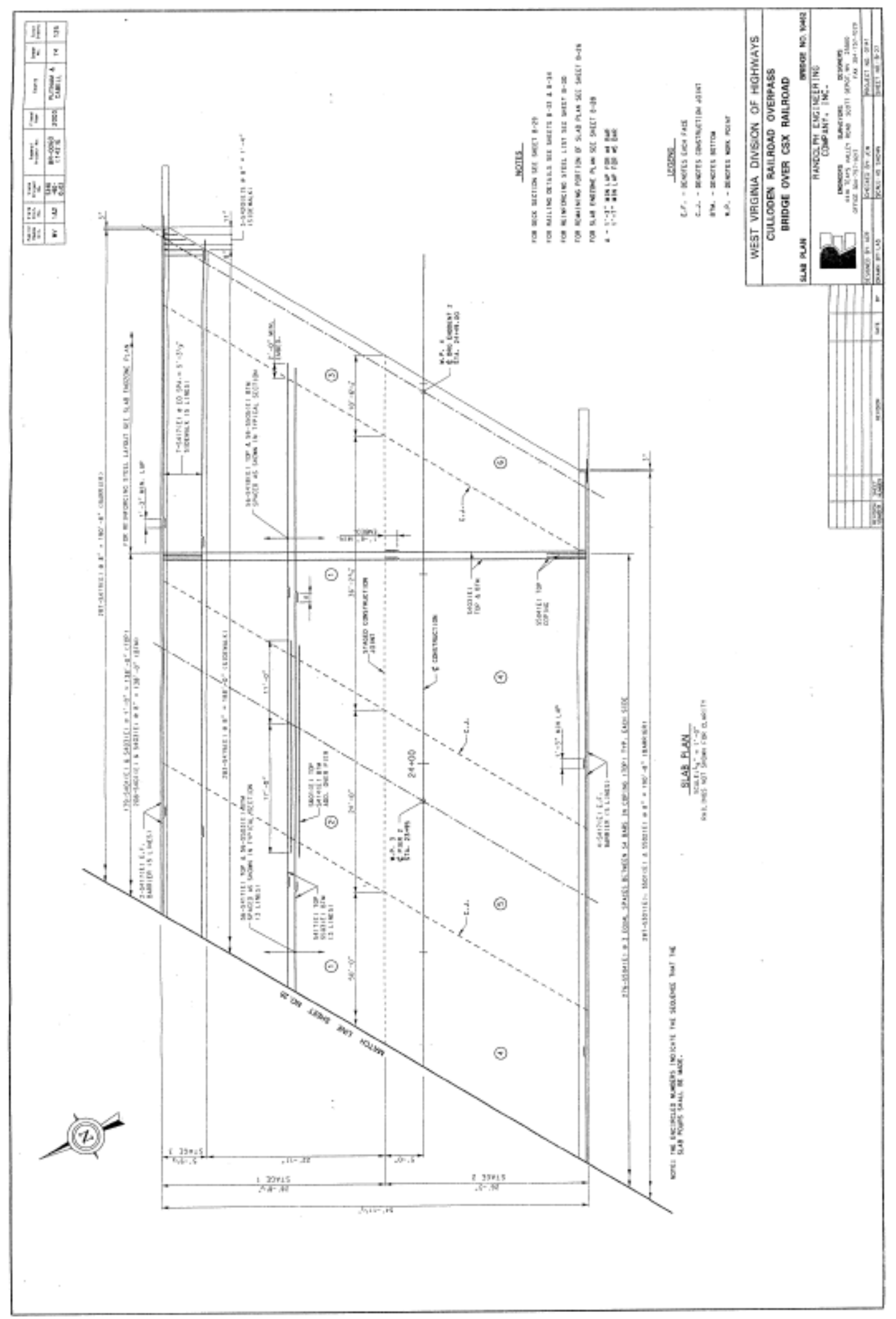




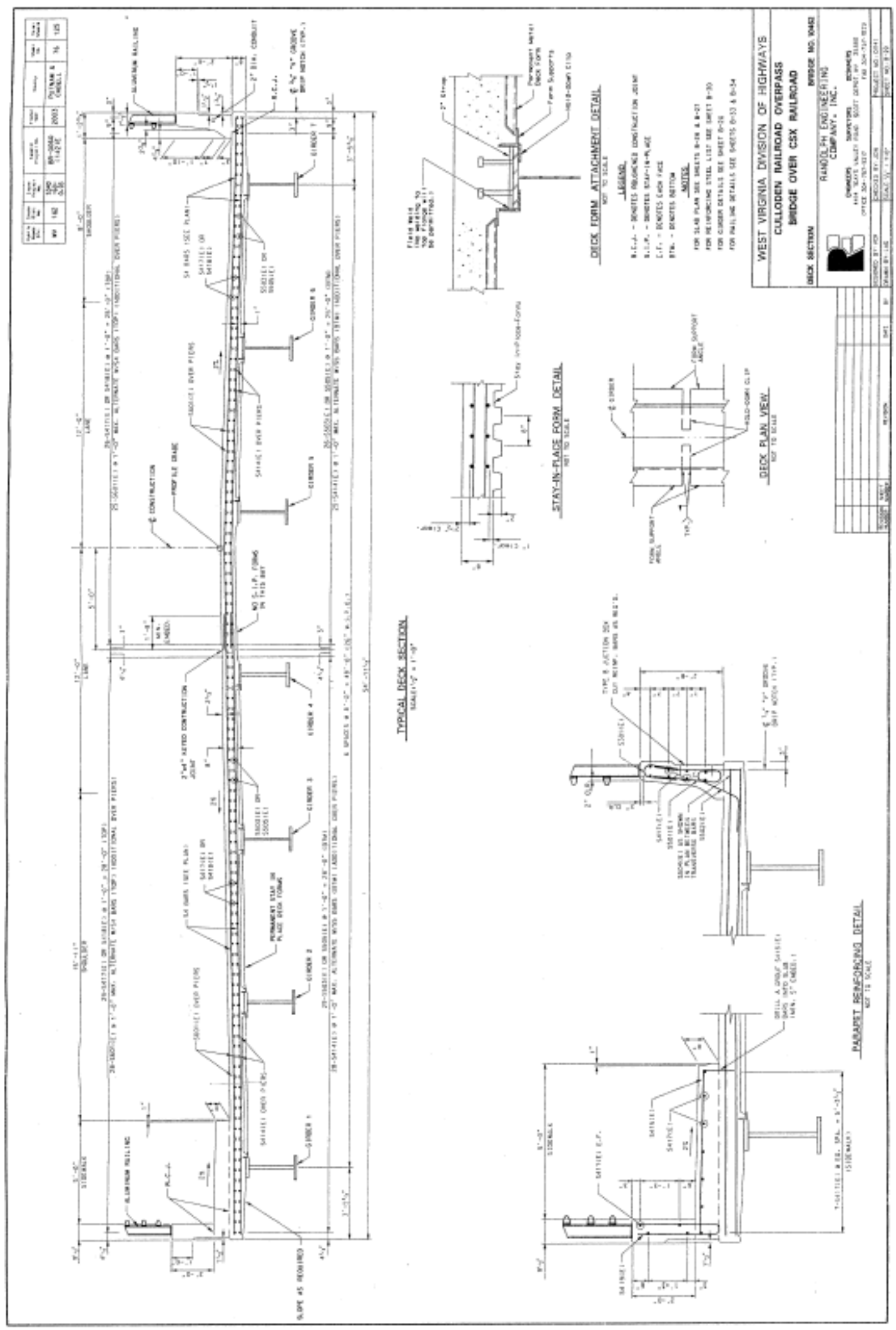




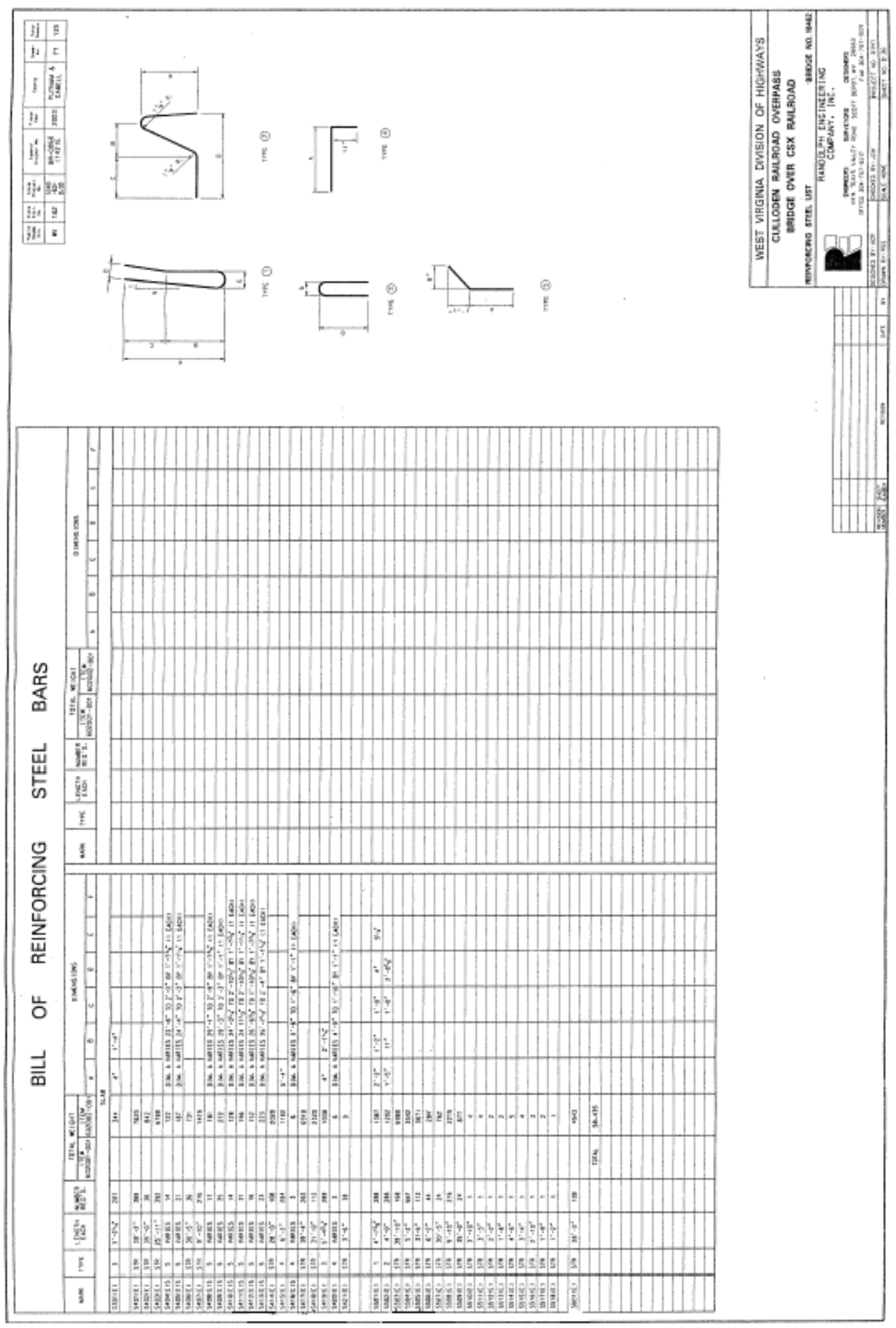


Appendix B: Influence Surfaces Generated with Finite Element Modeling 

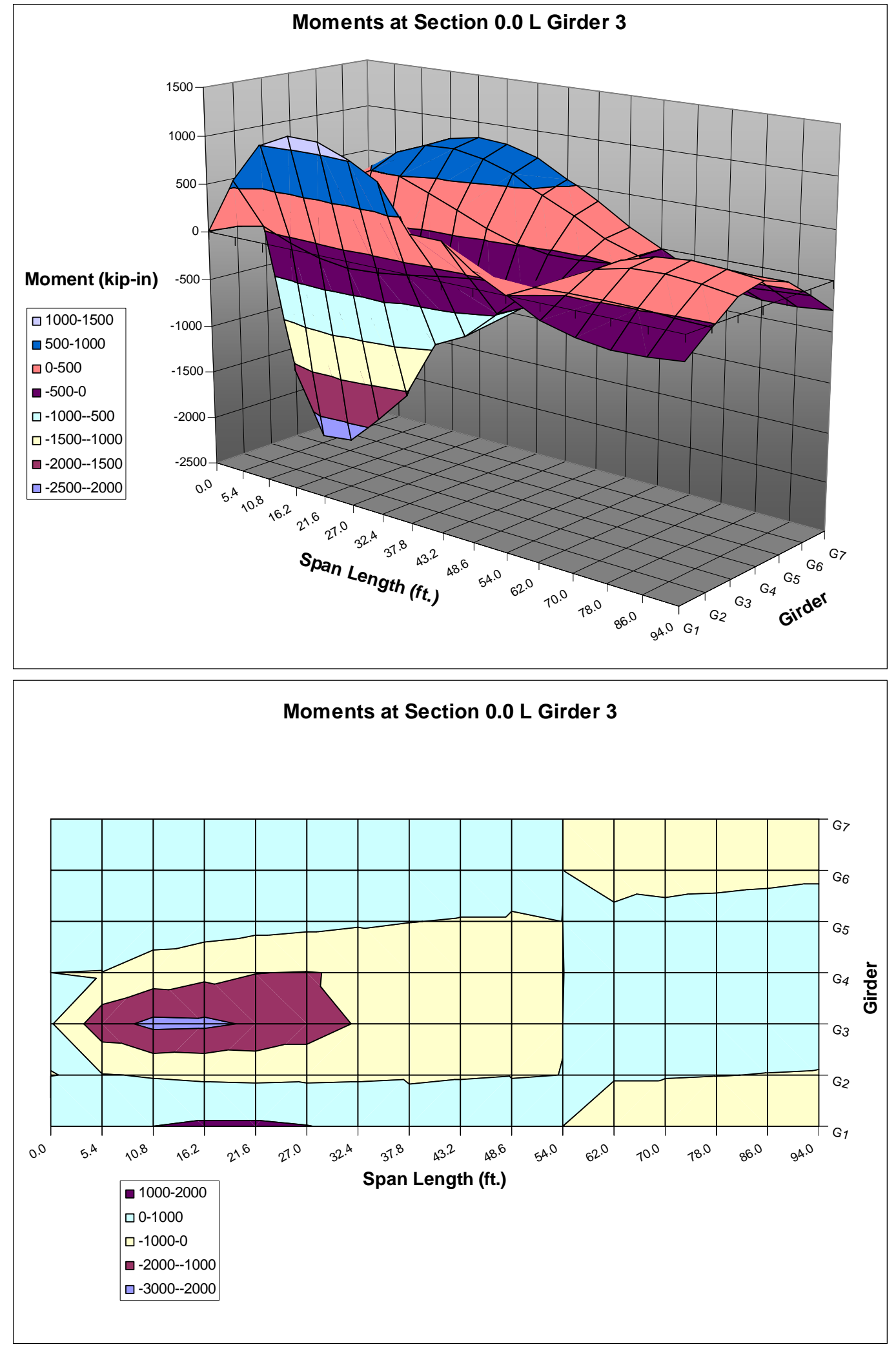

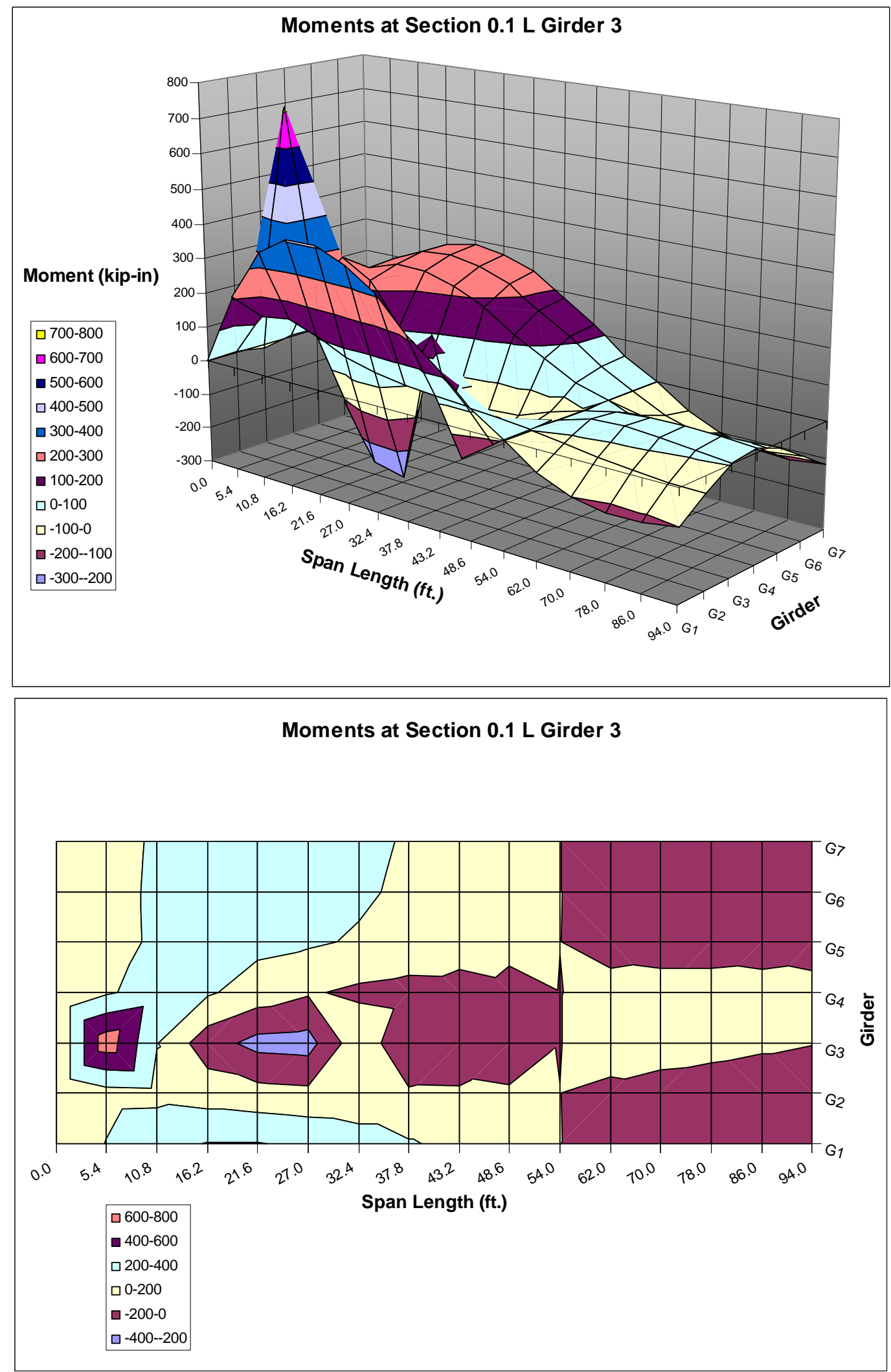

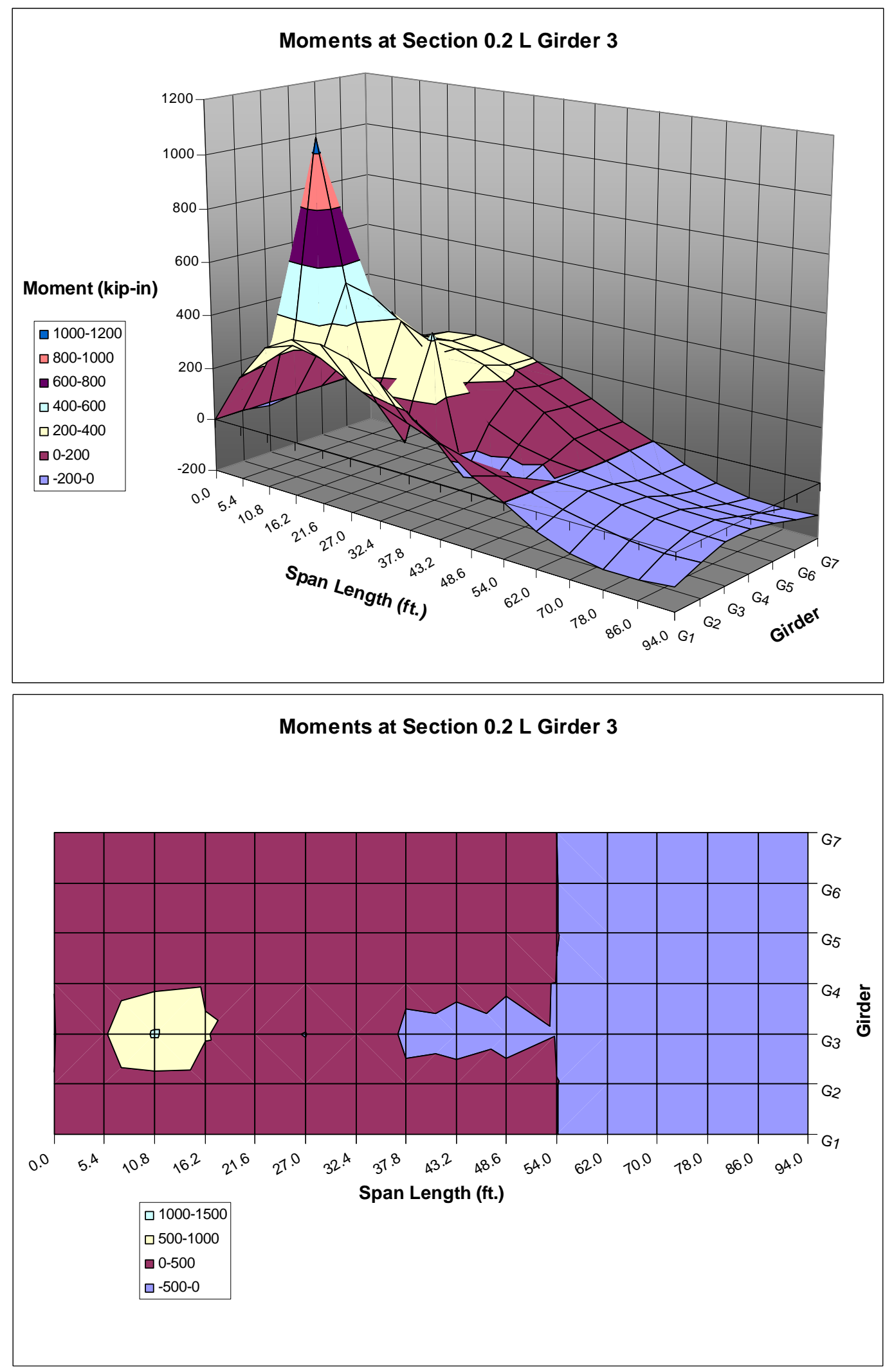

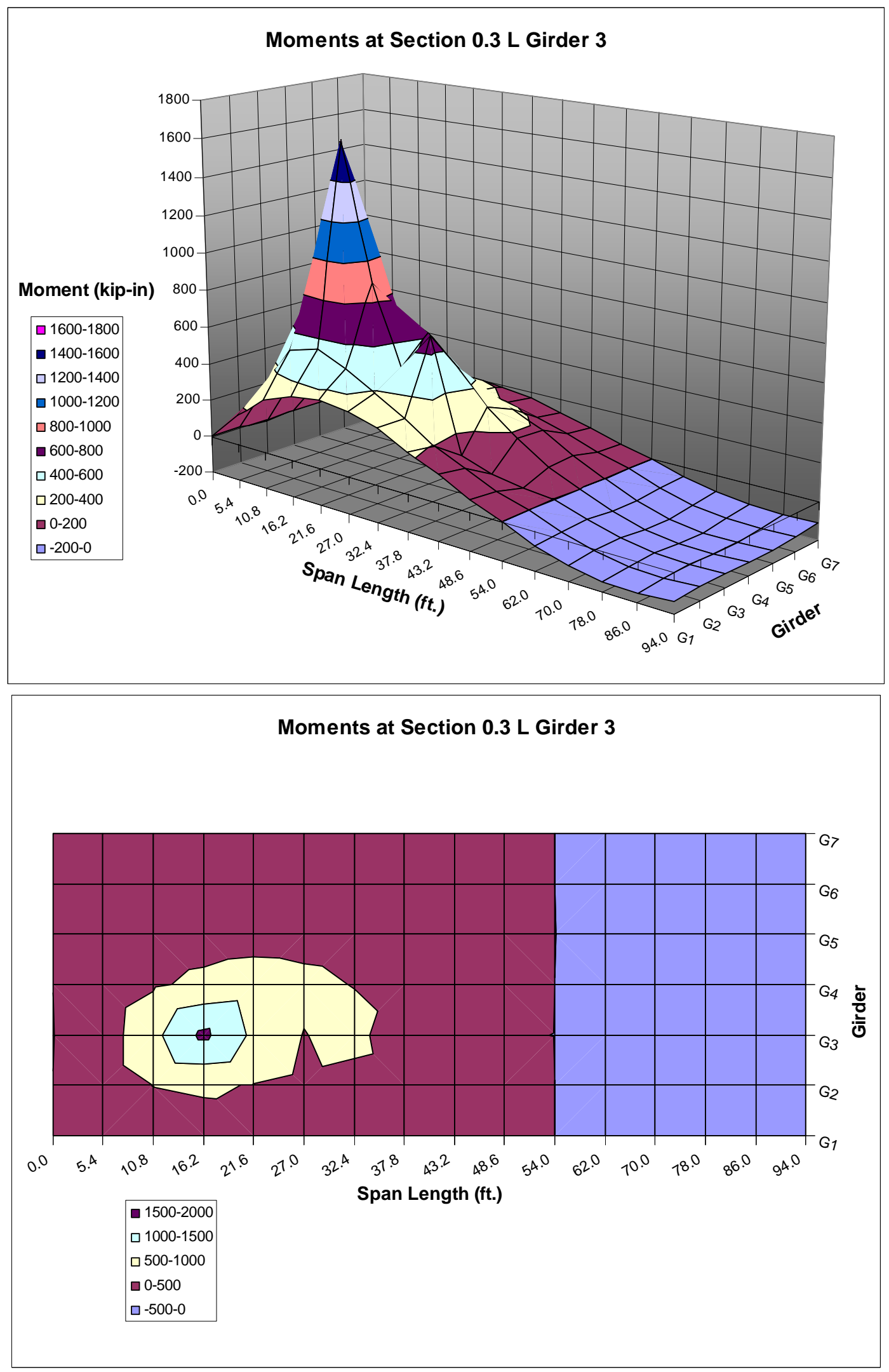

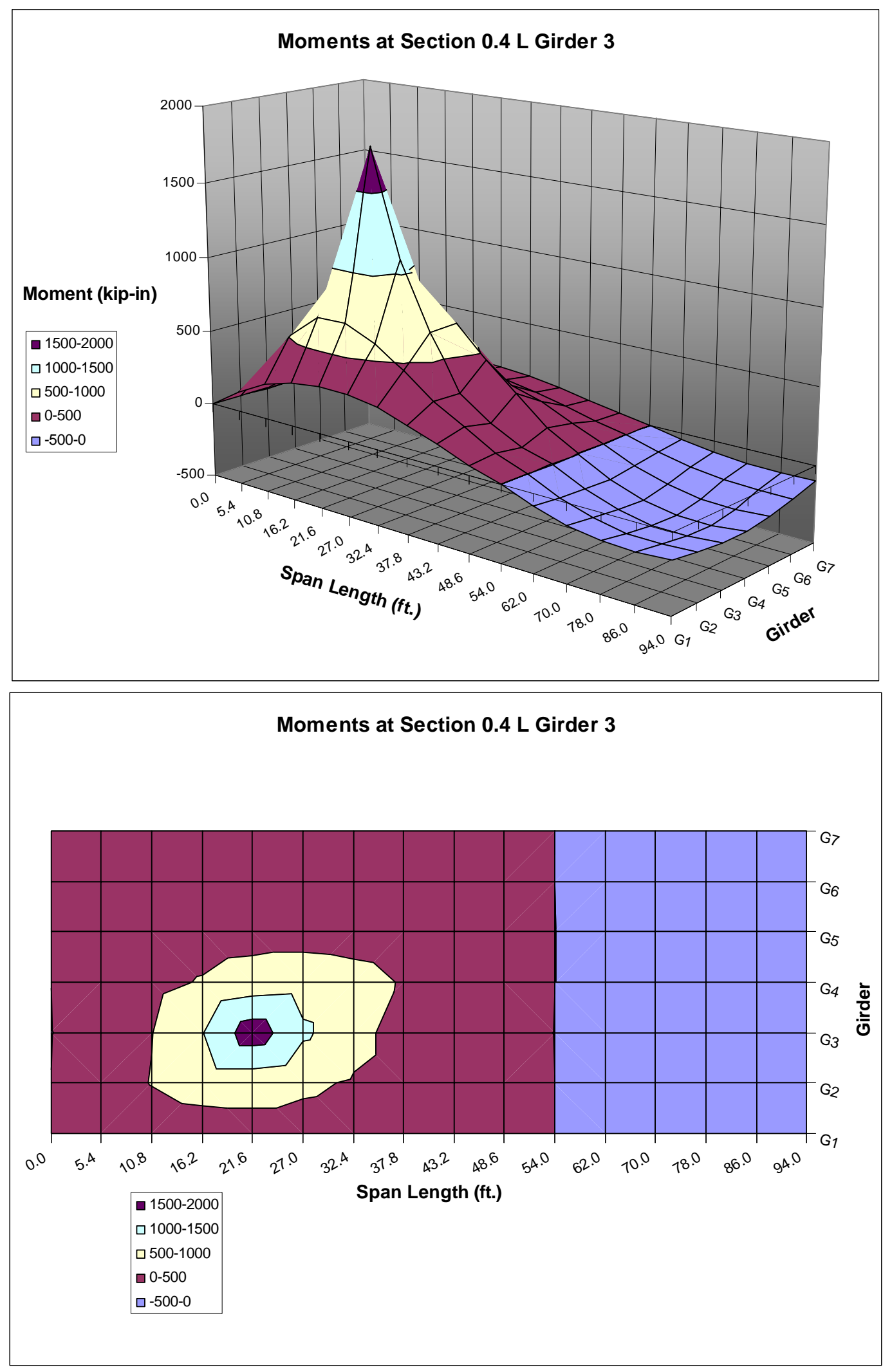

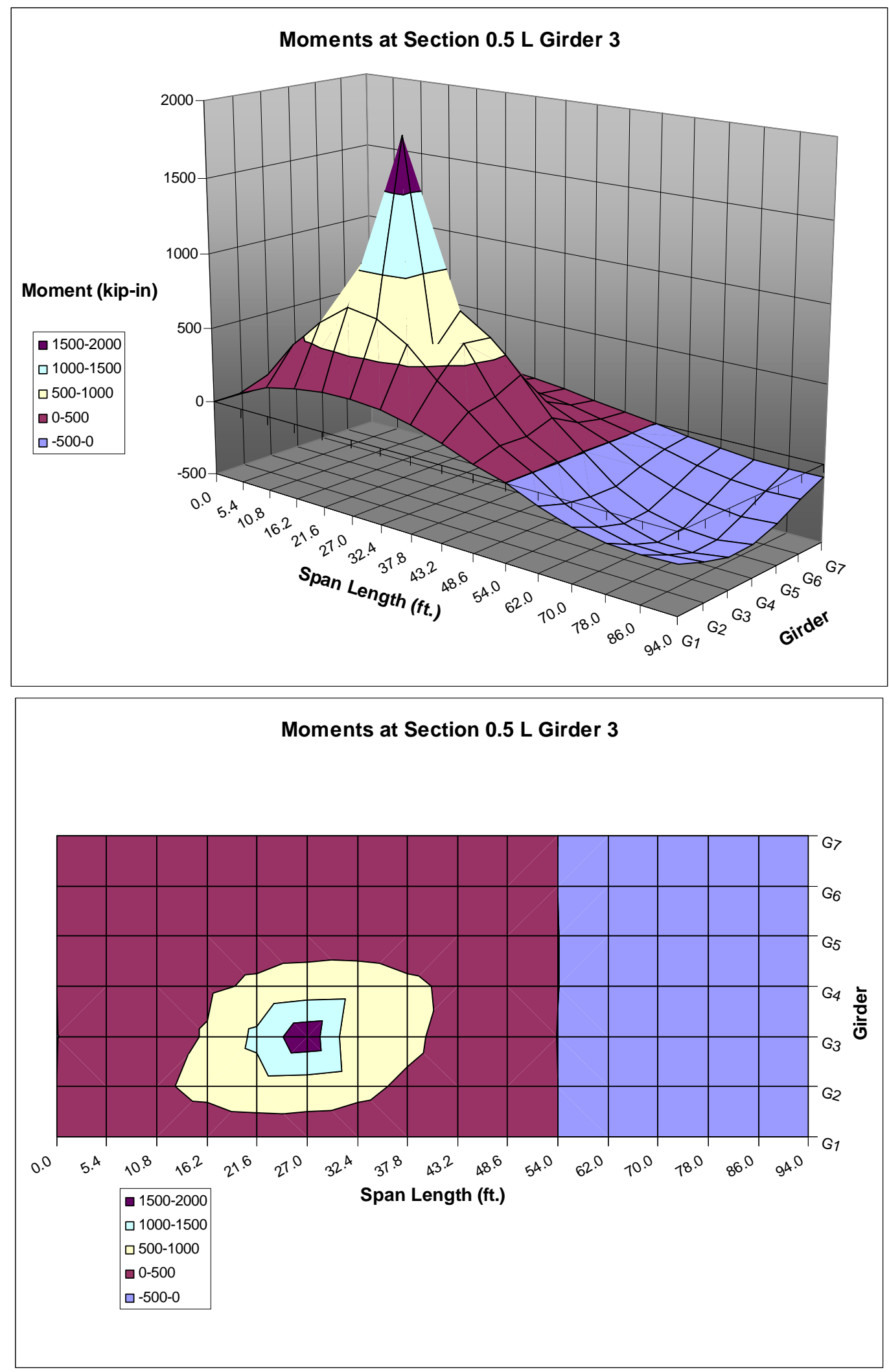

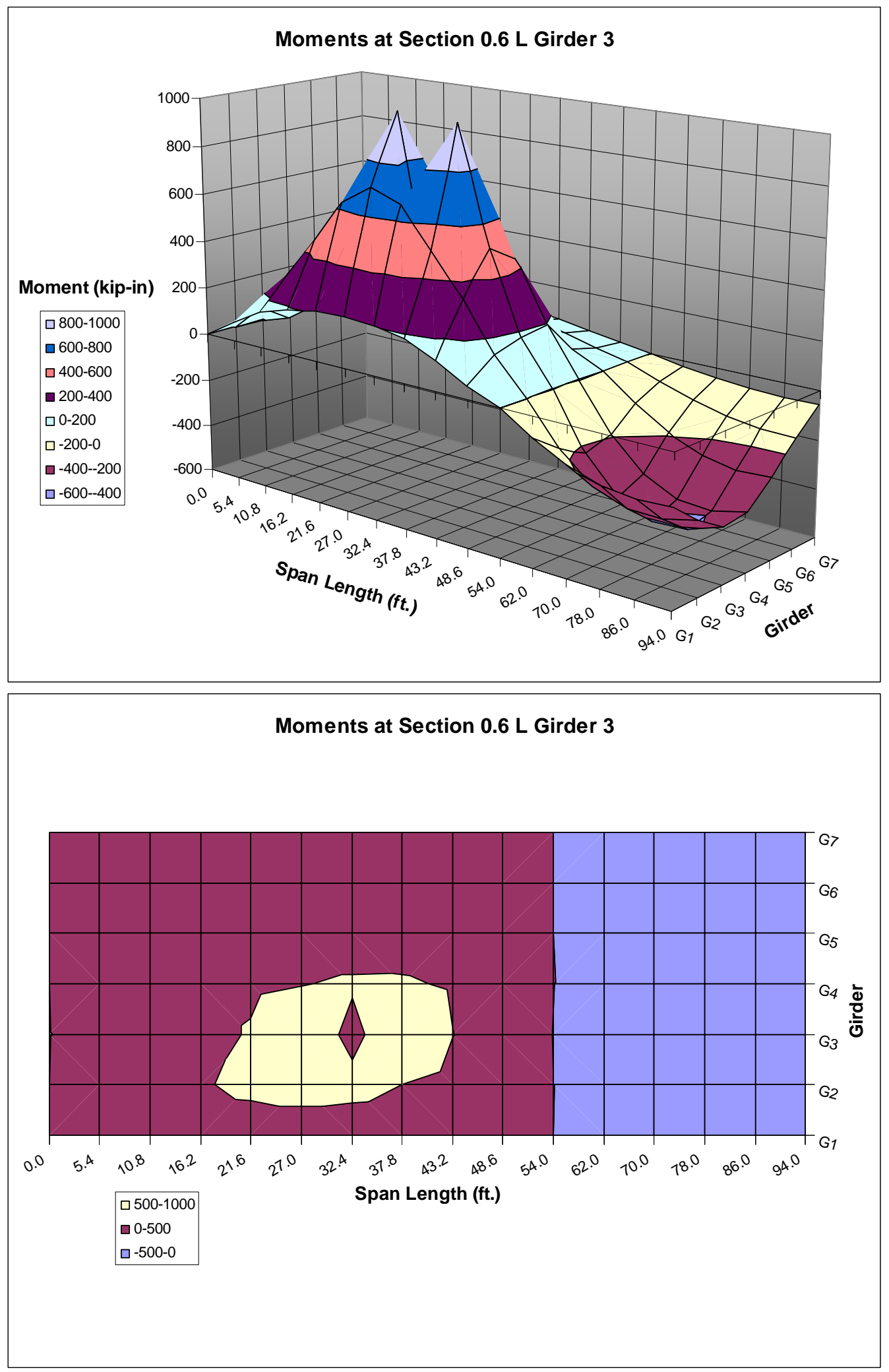

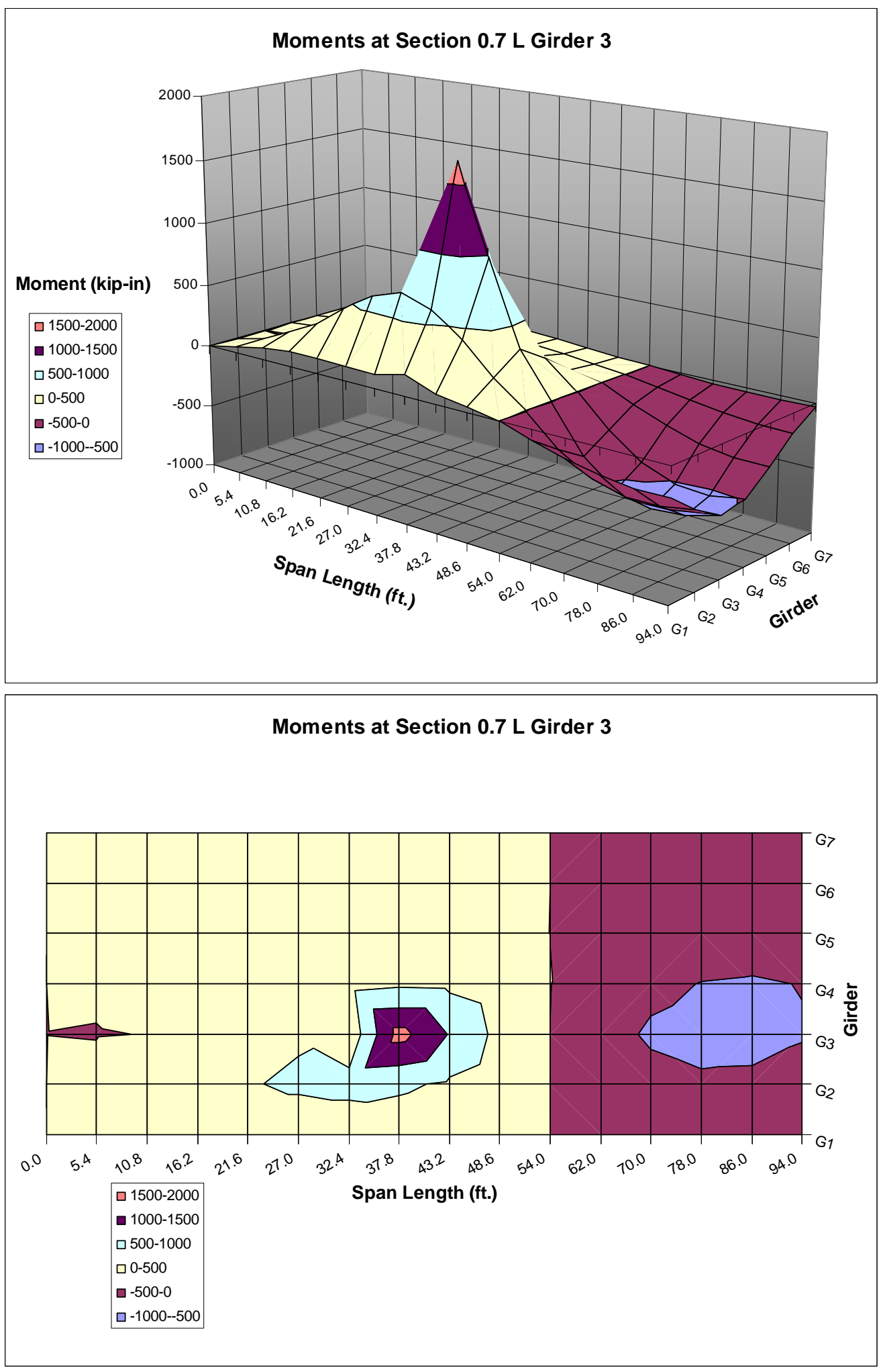

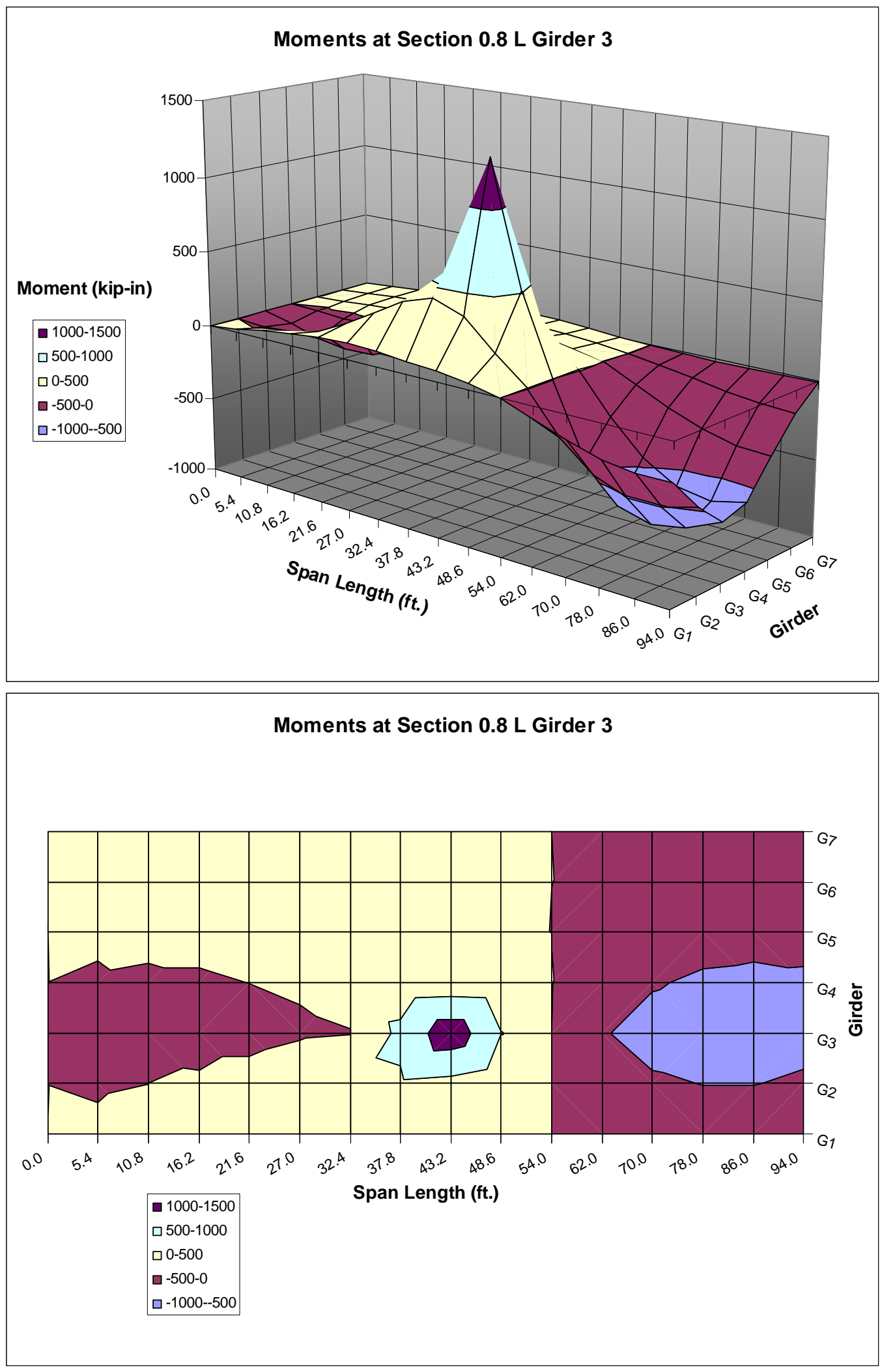

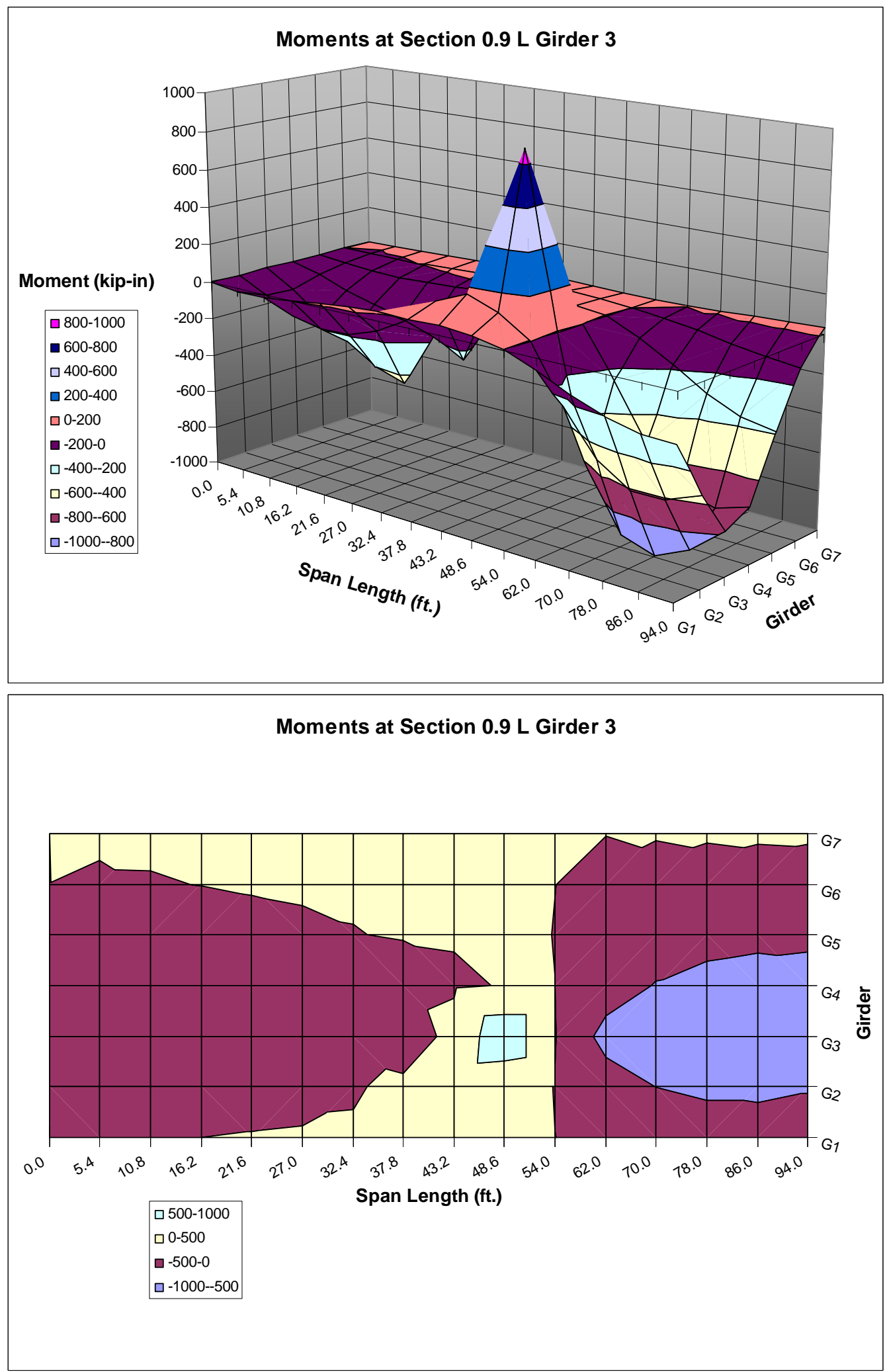

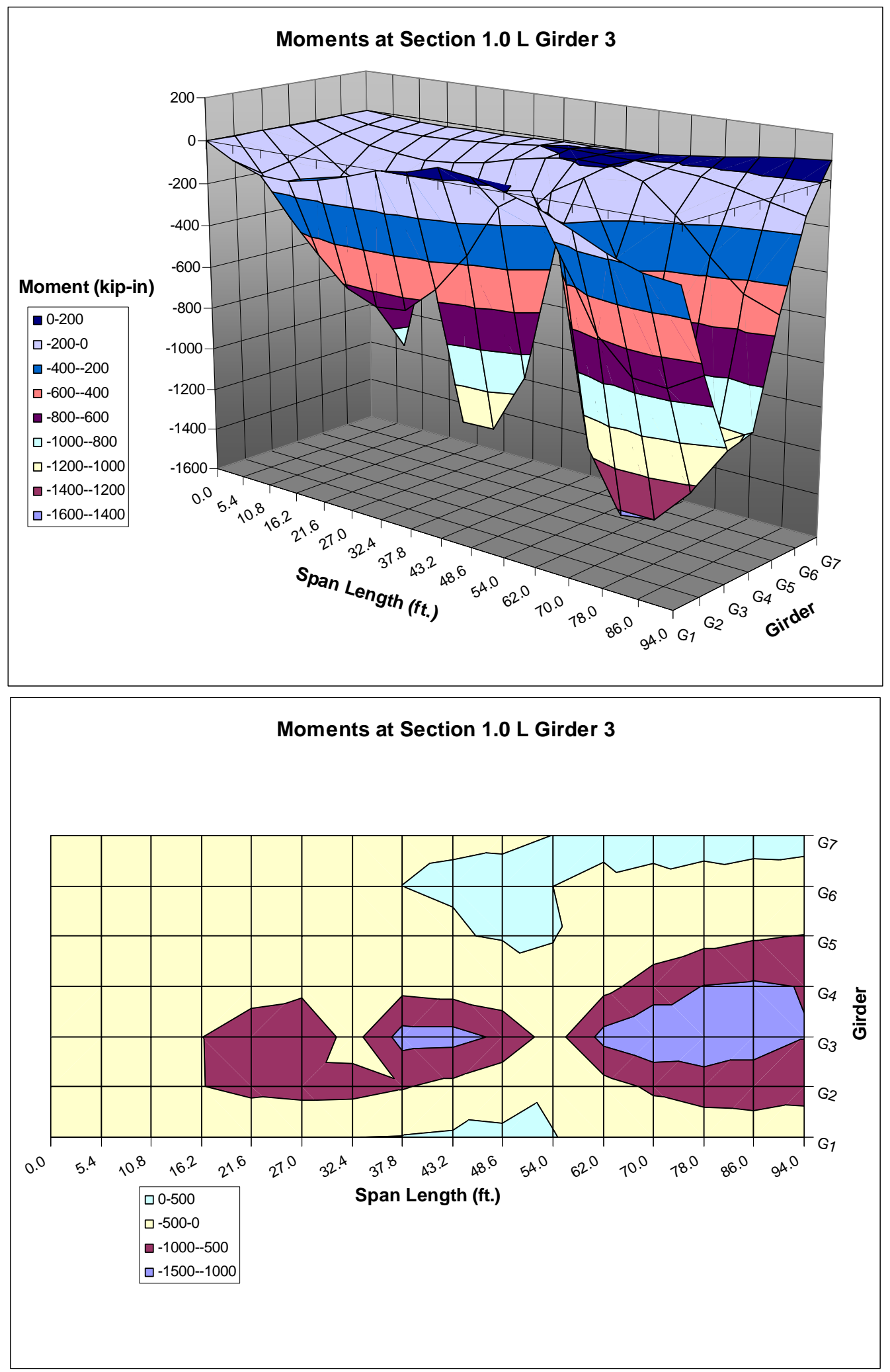

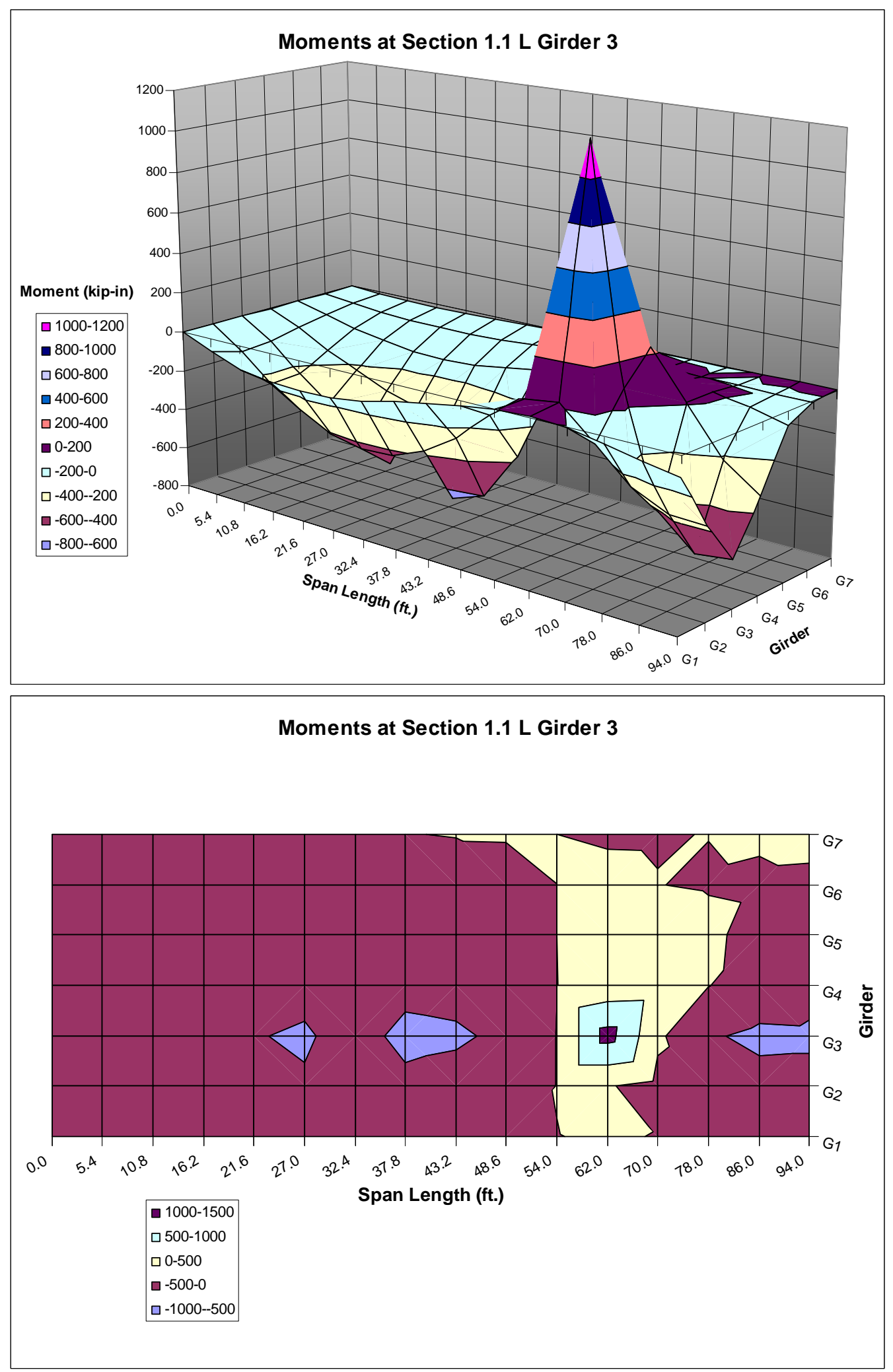

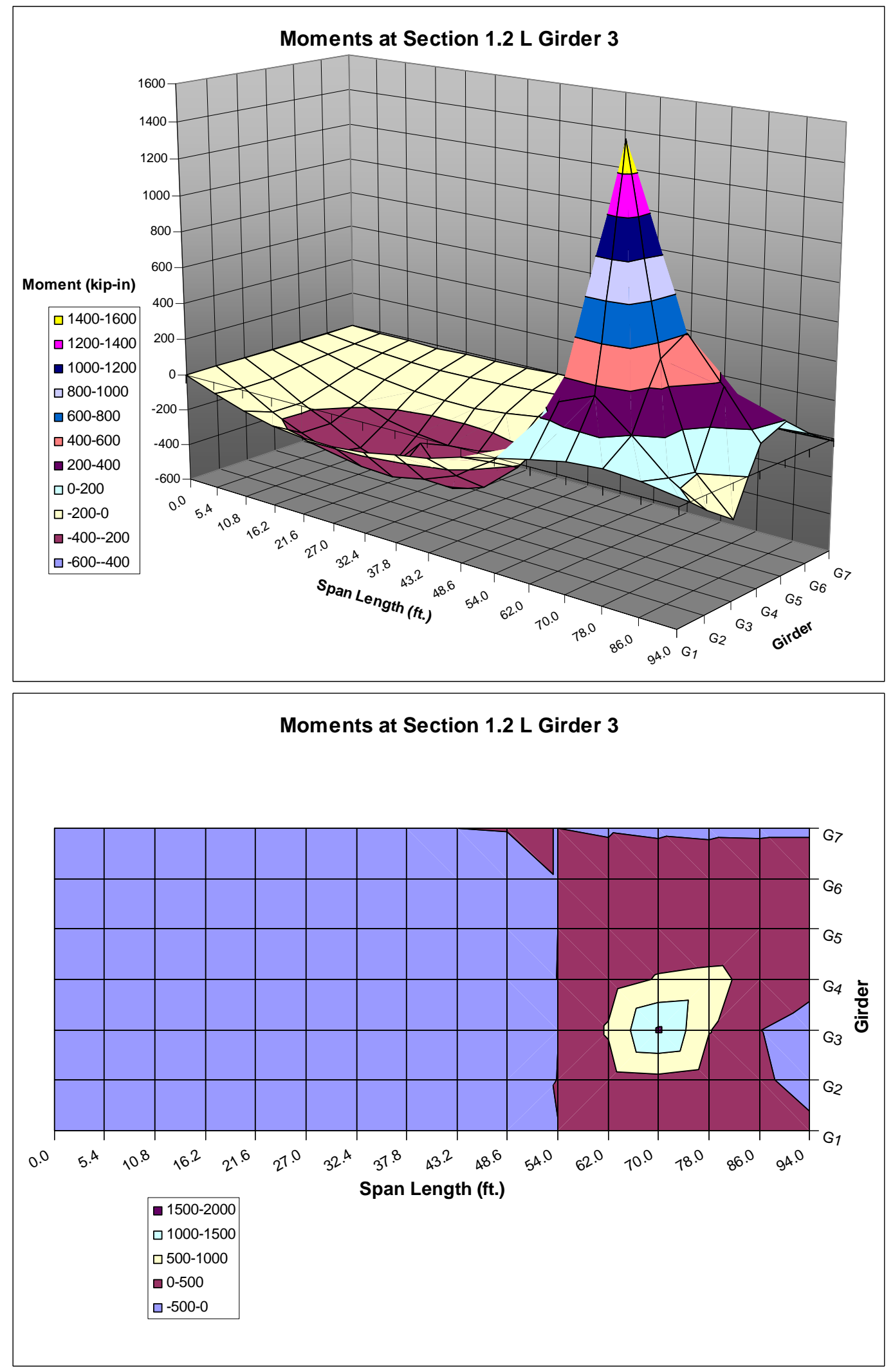

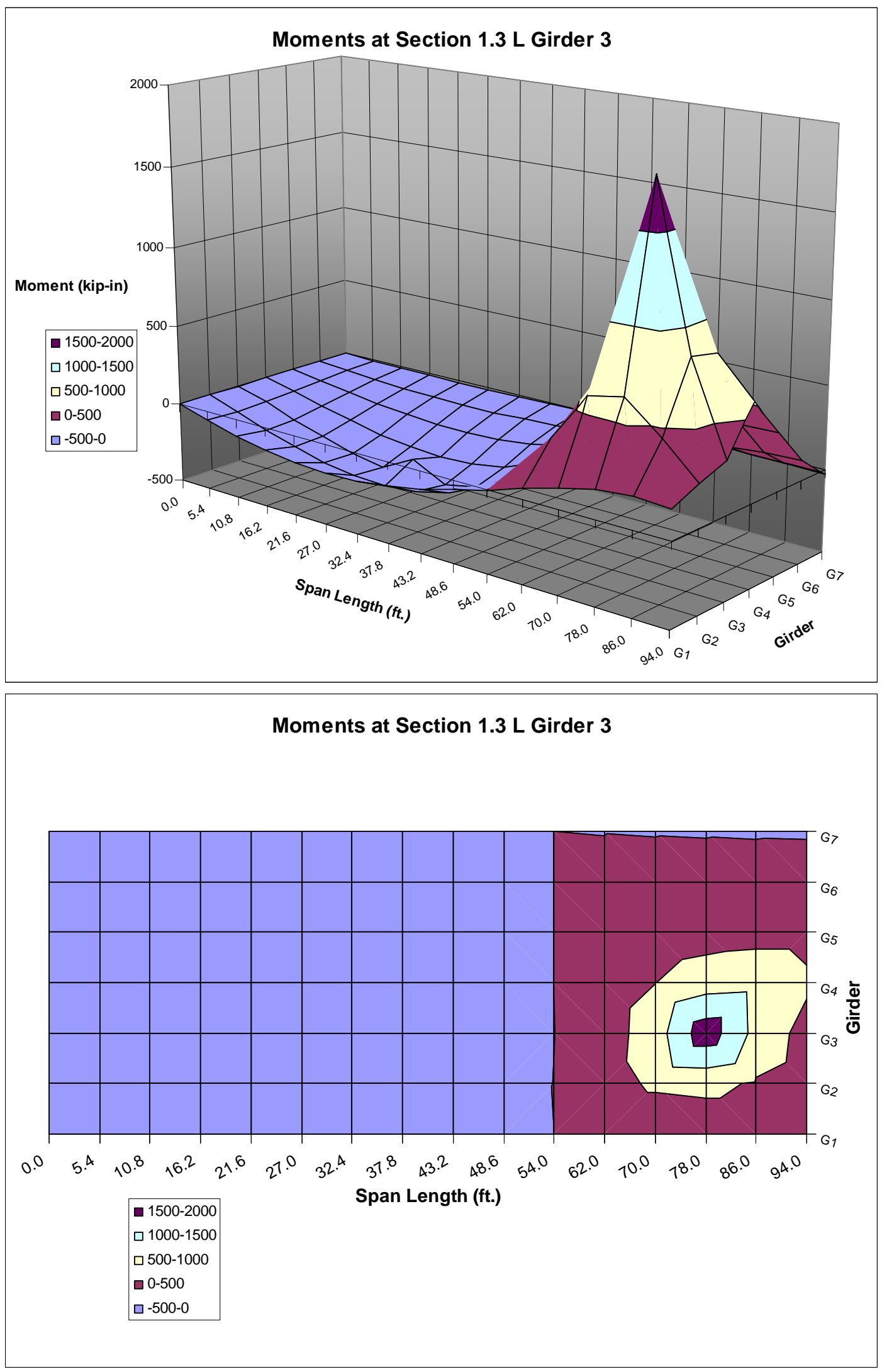

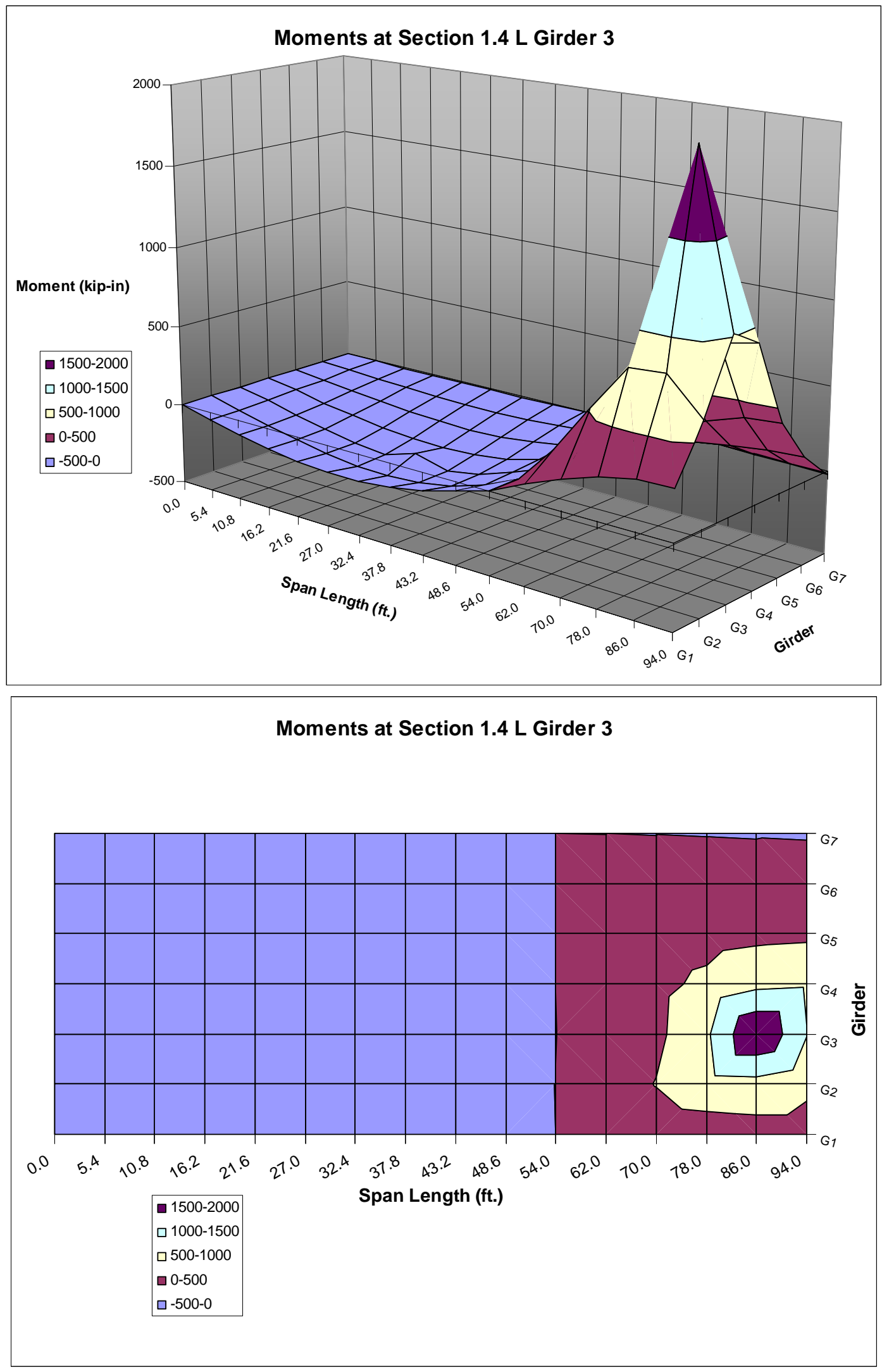

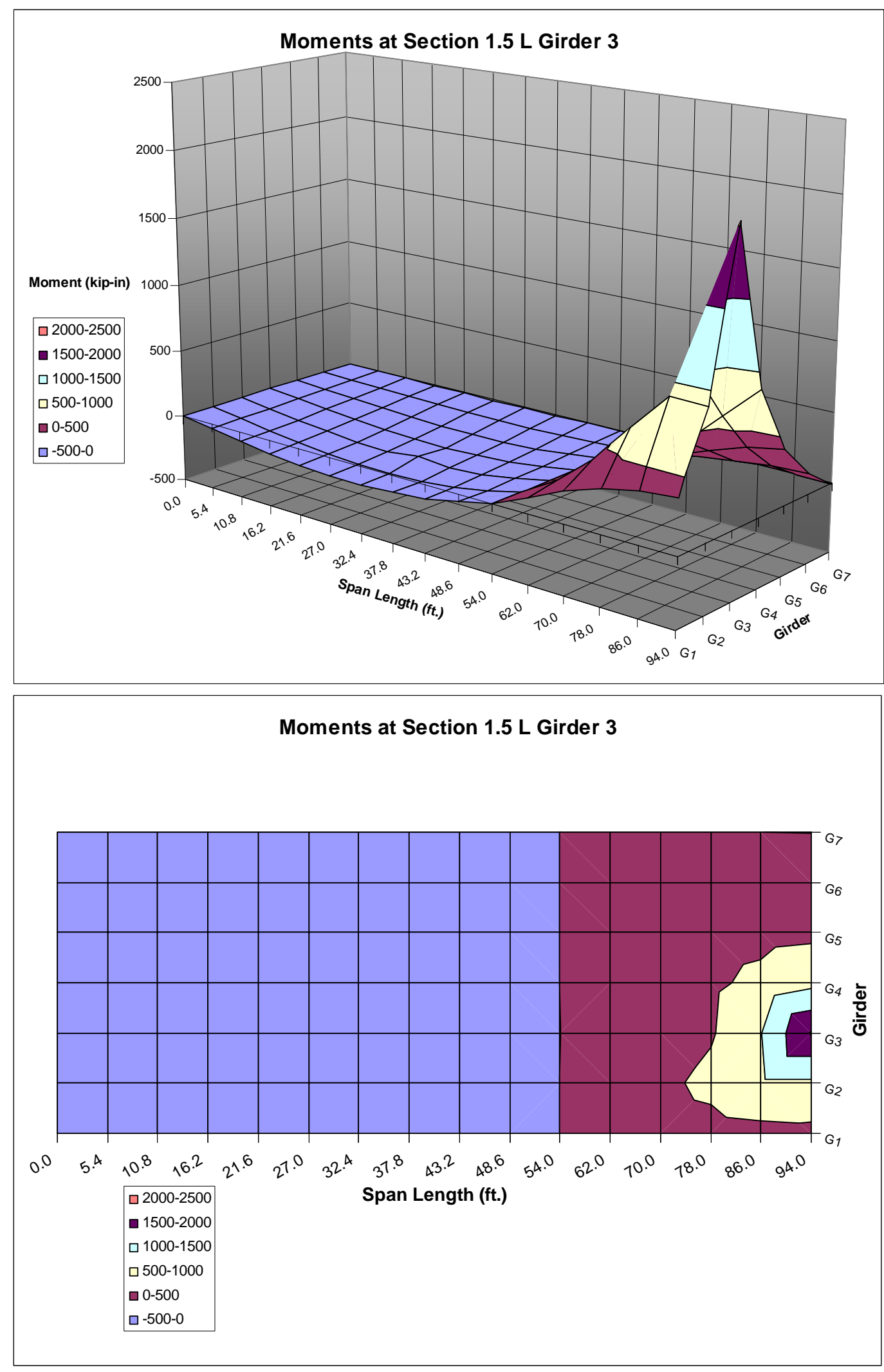

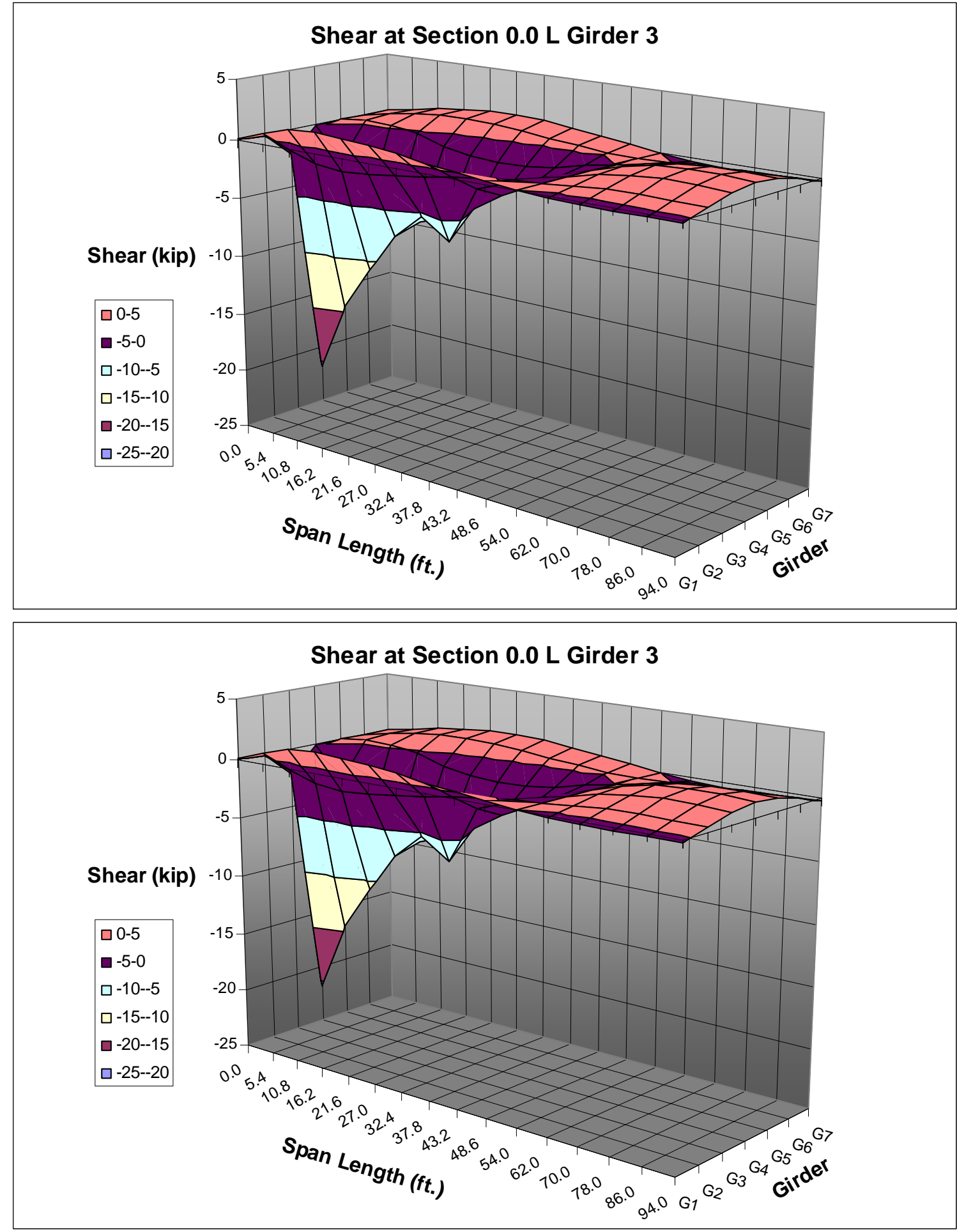

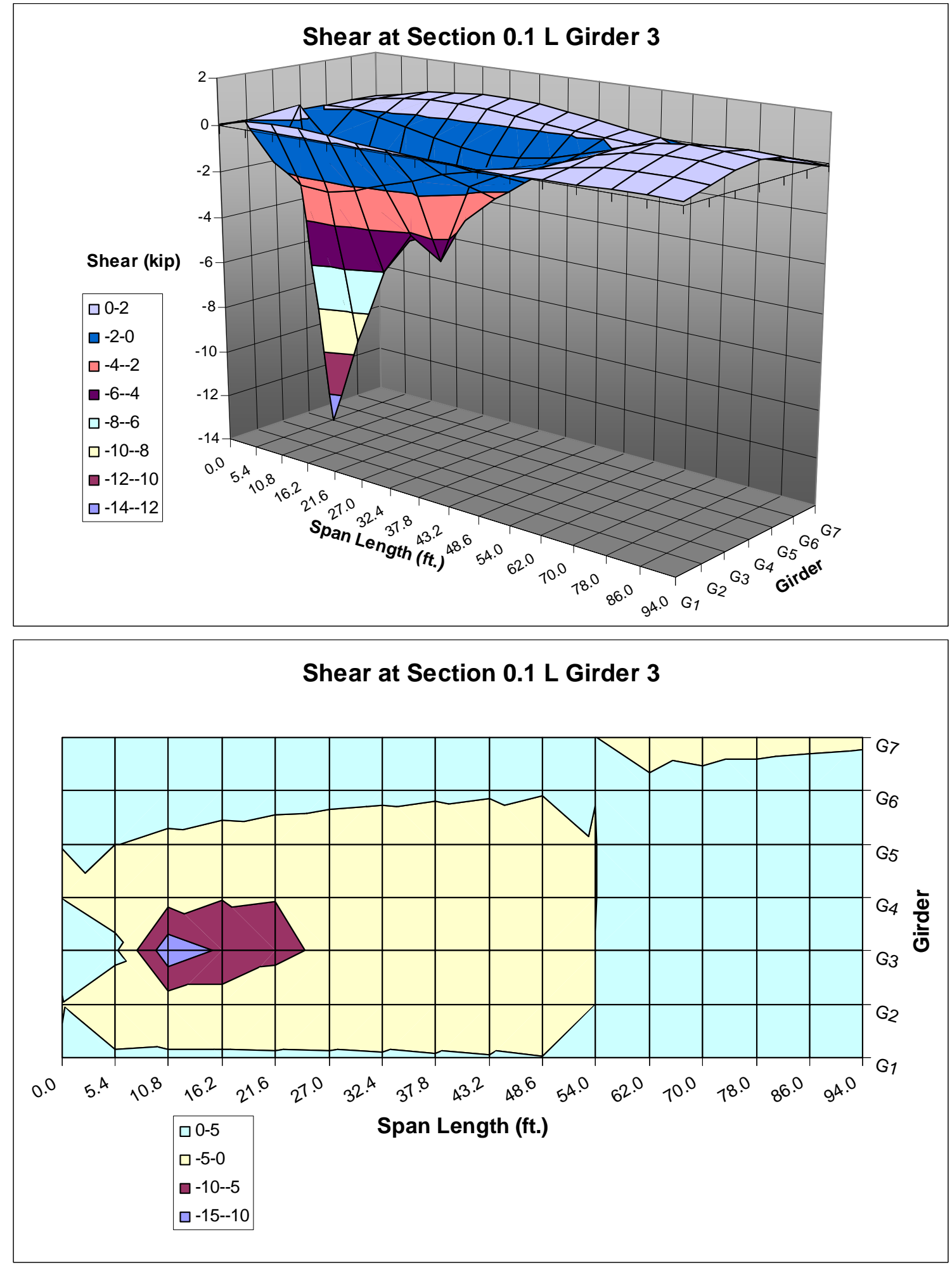

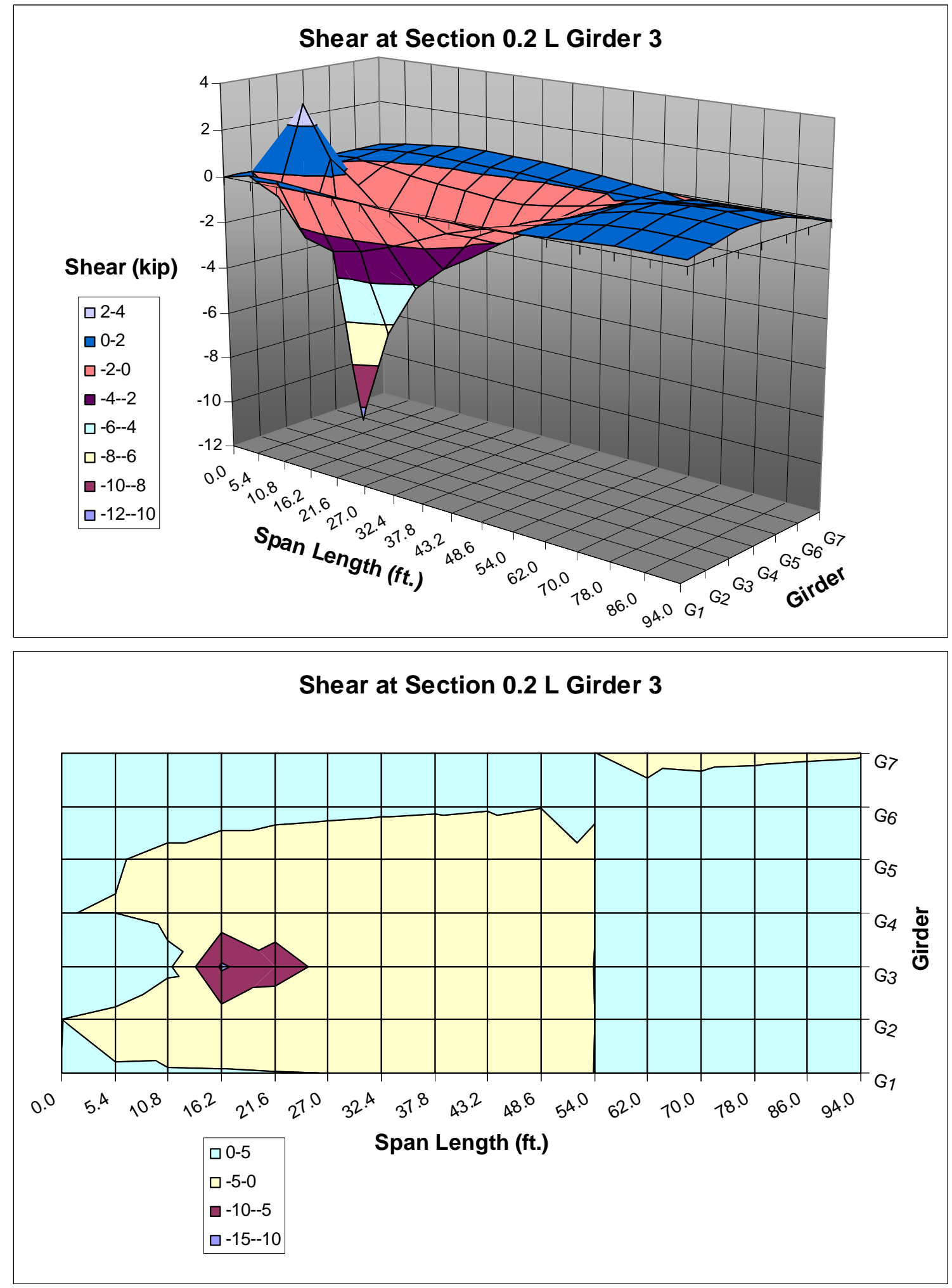

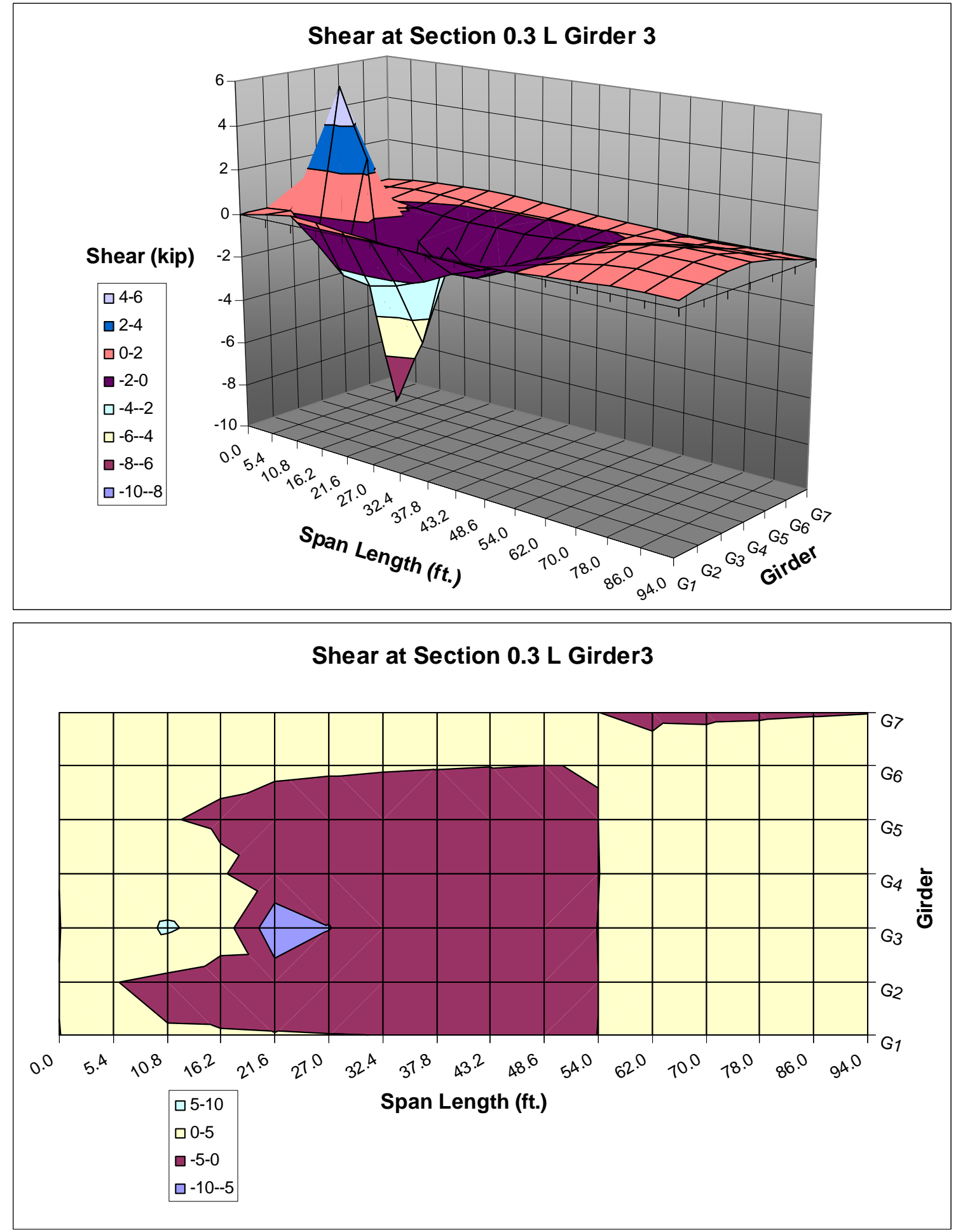

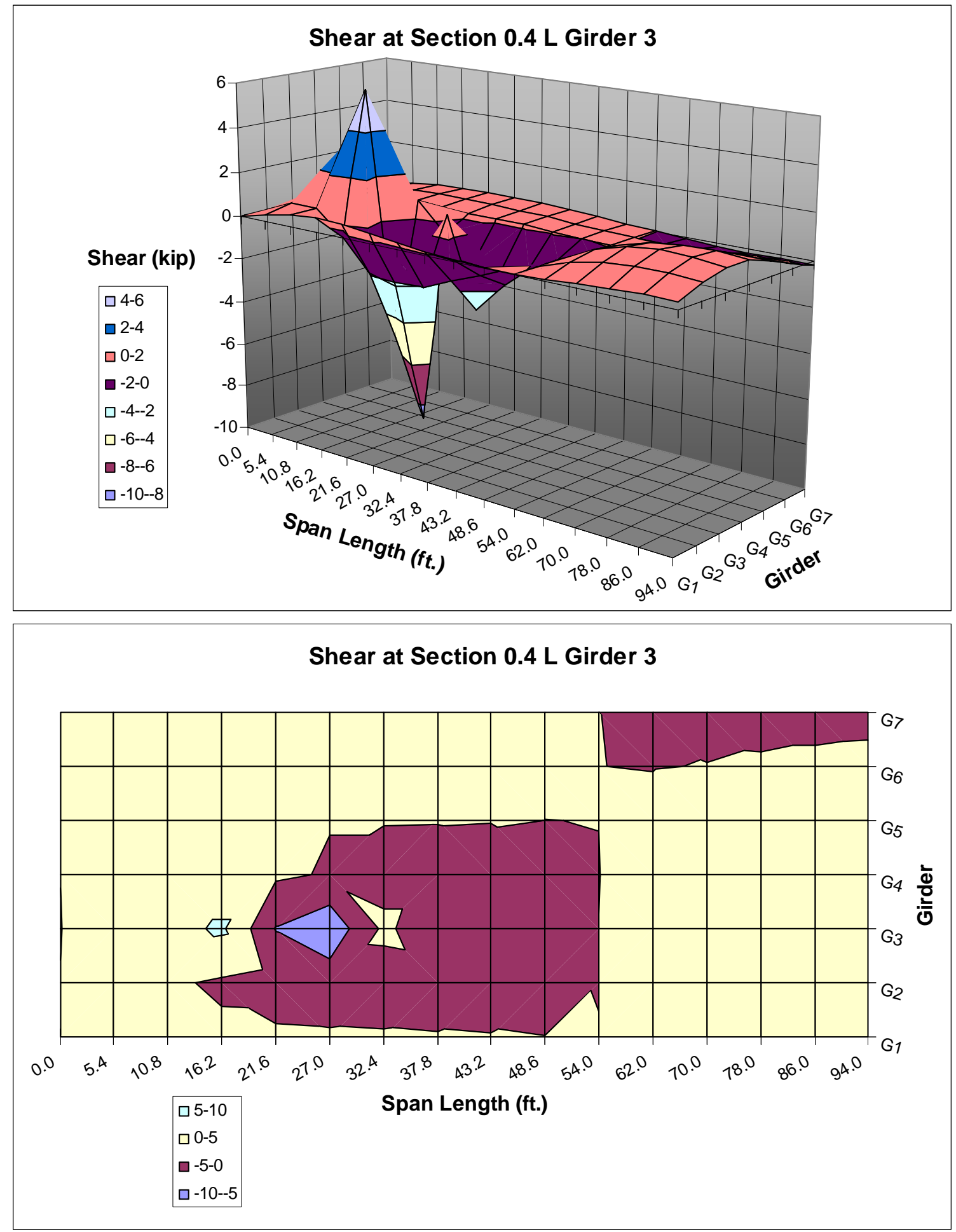

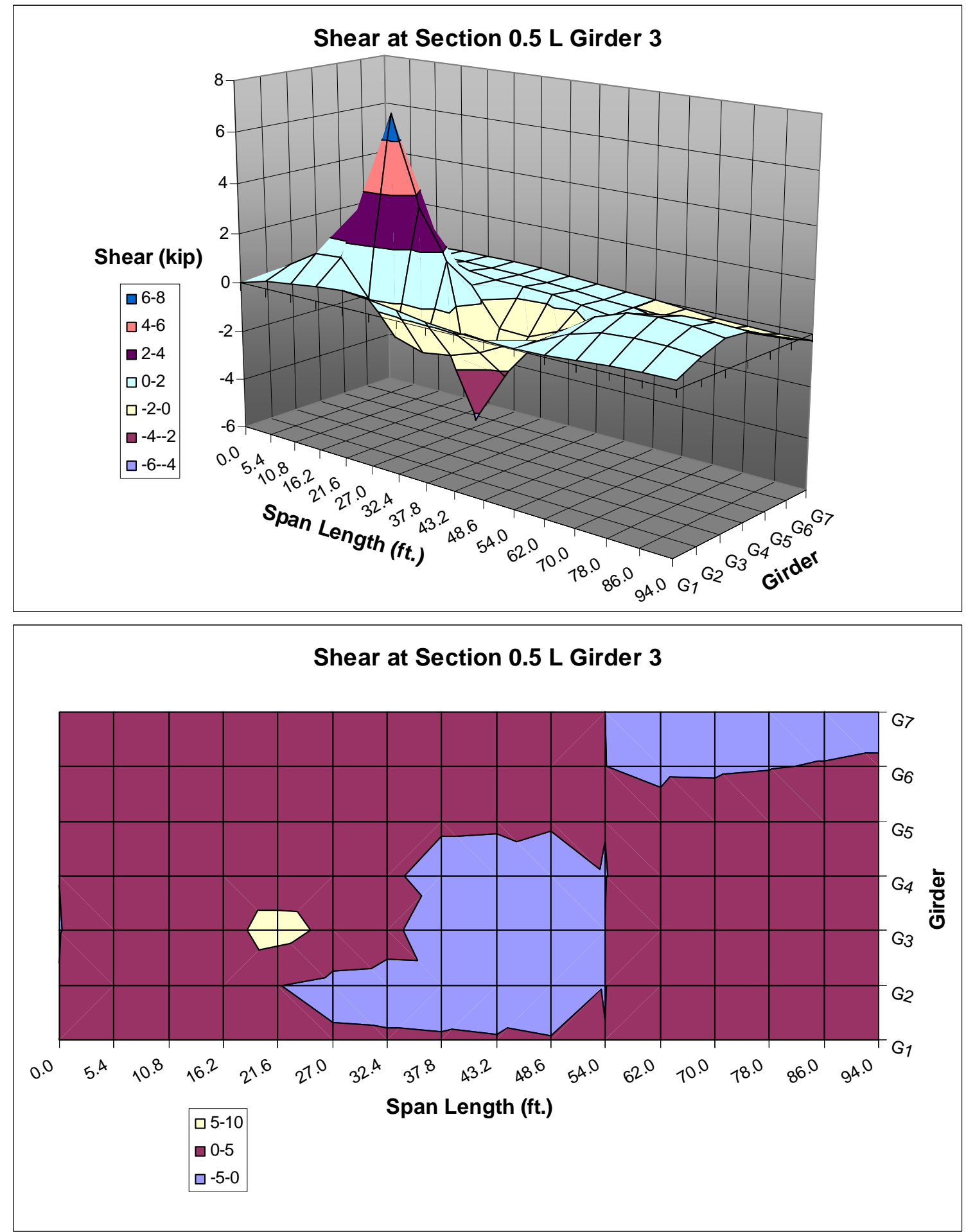

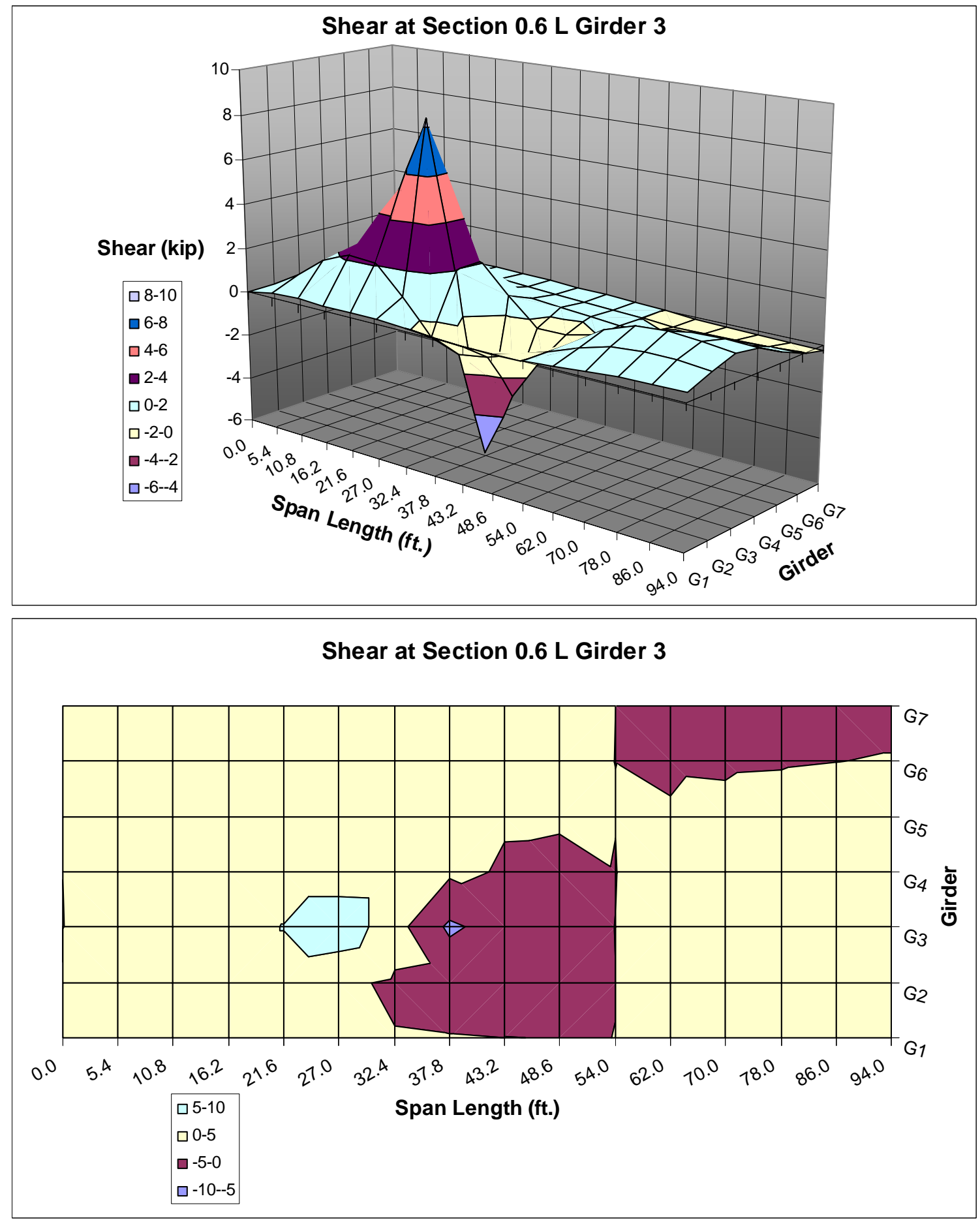

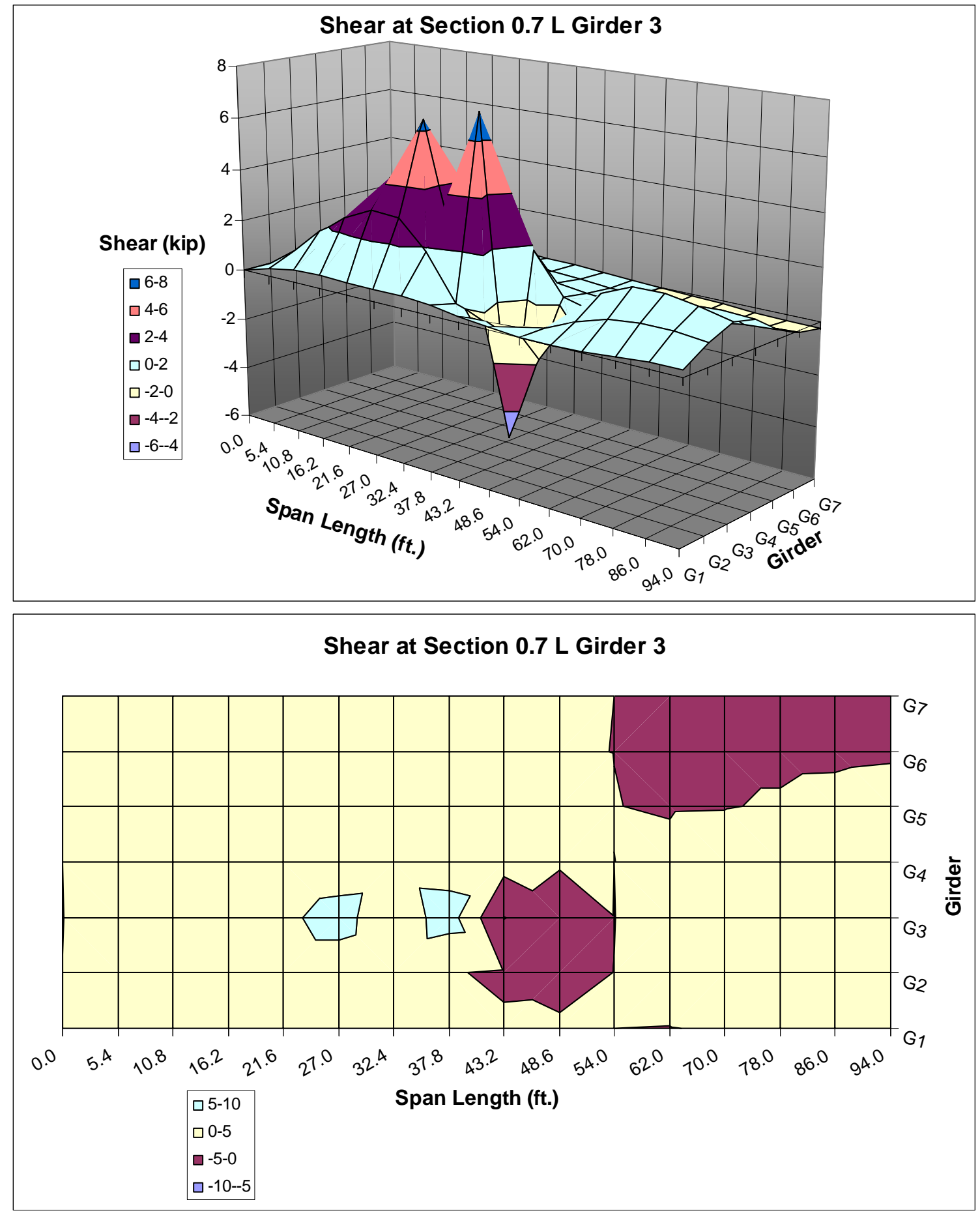

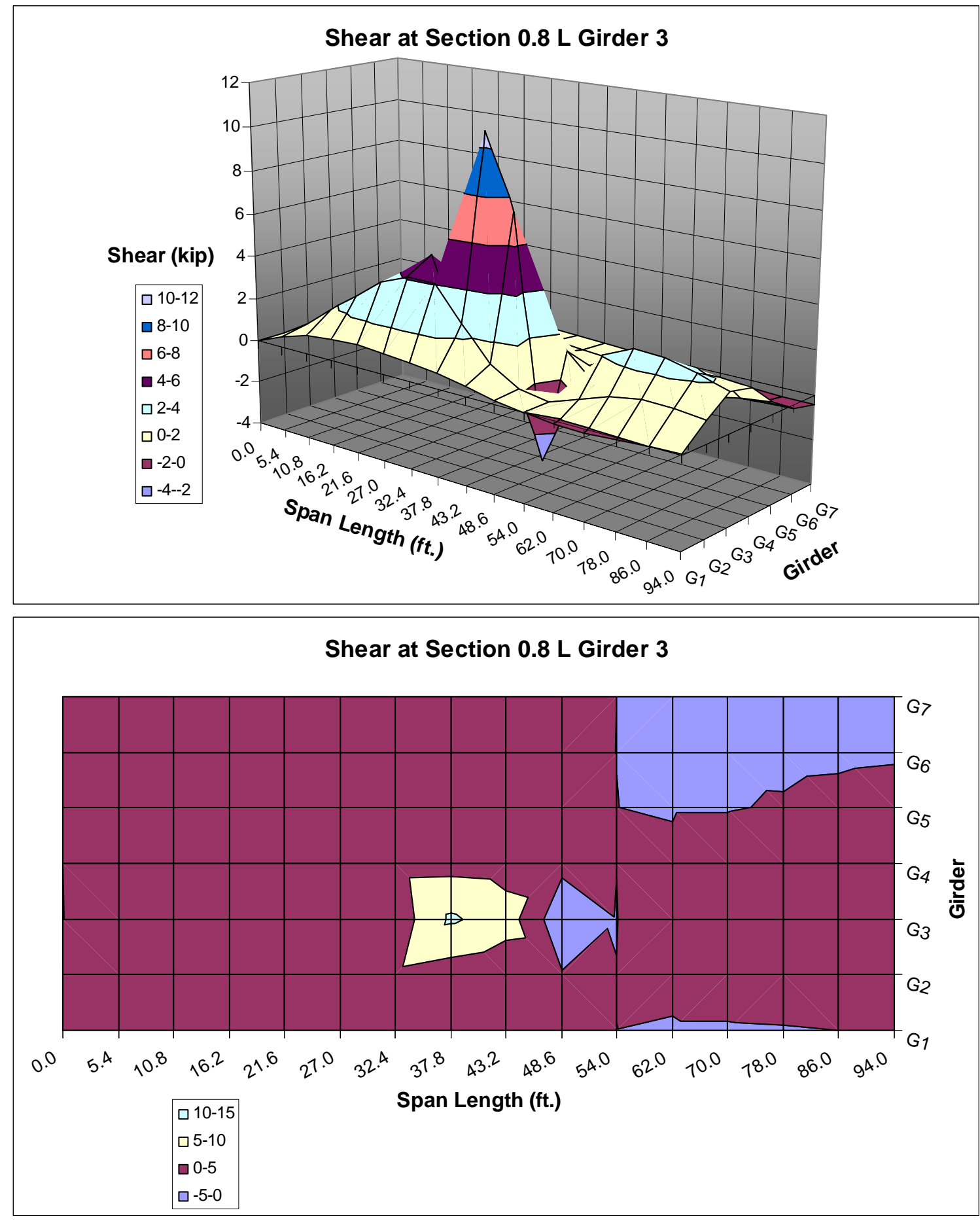

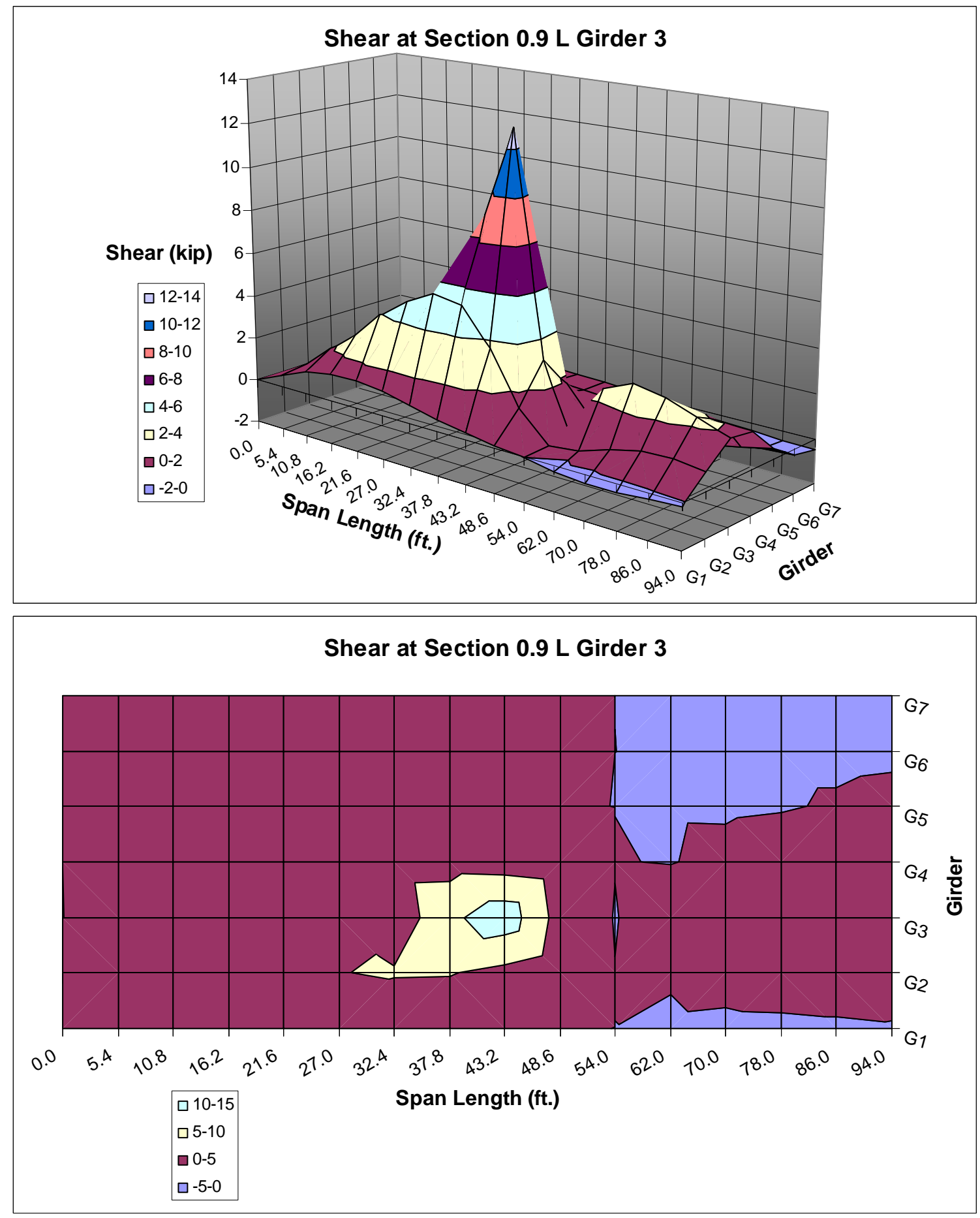

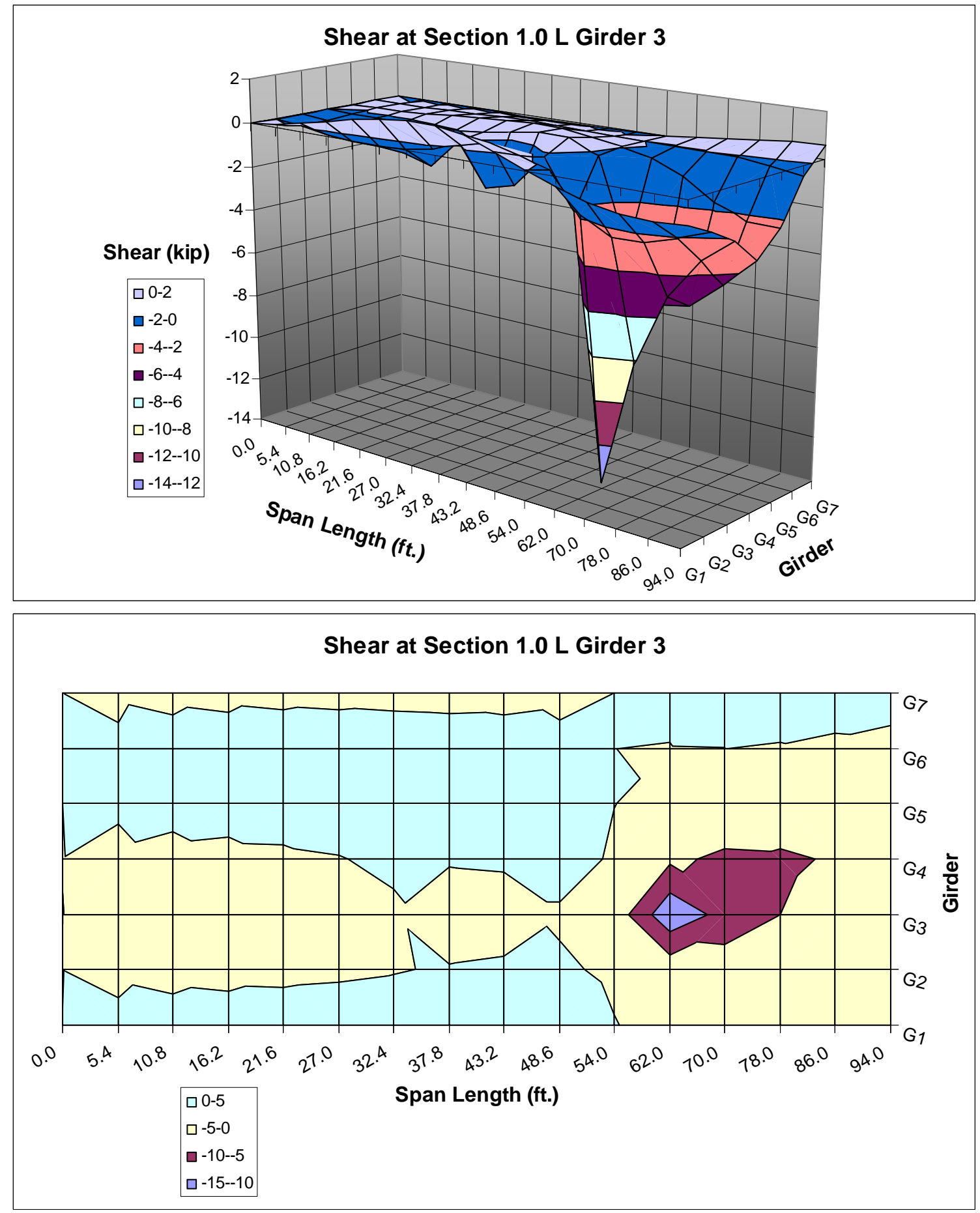

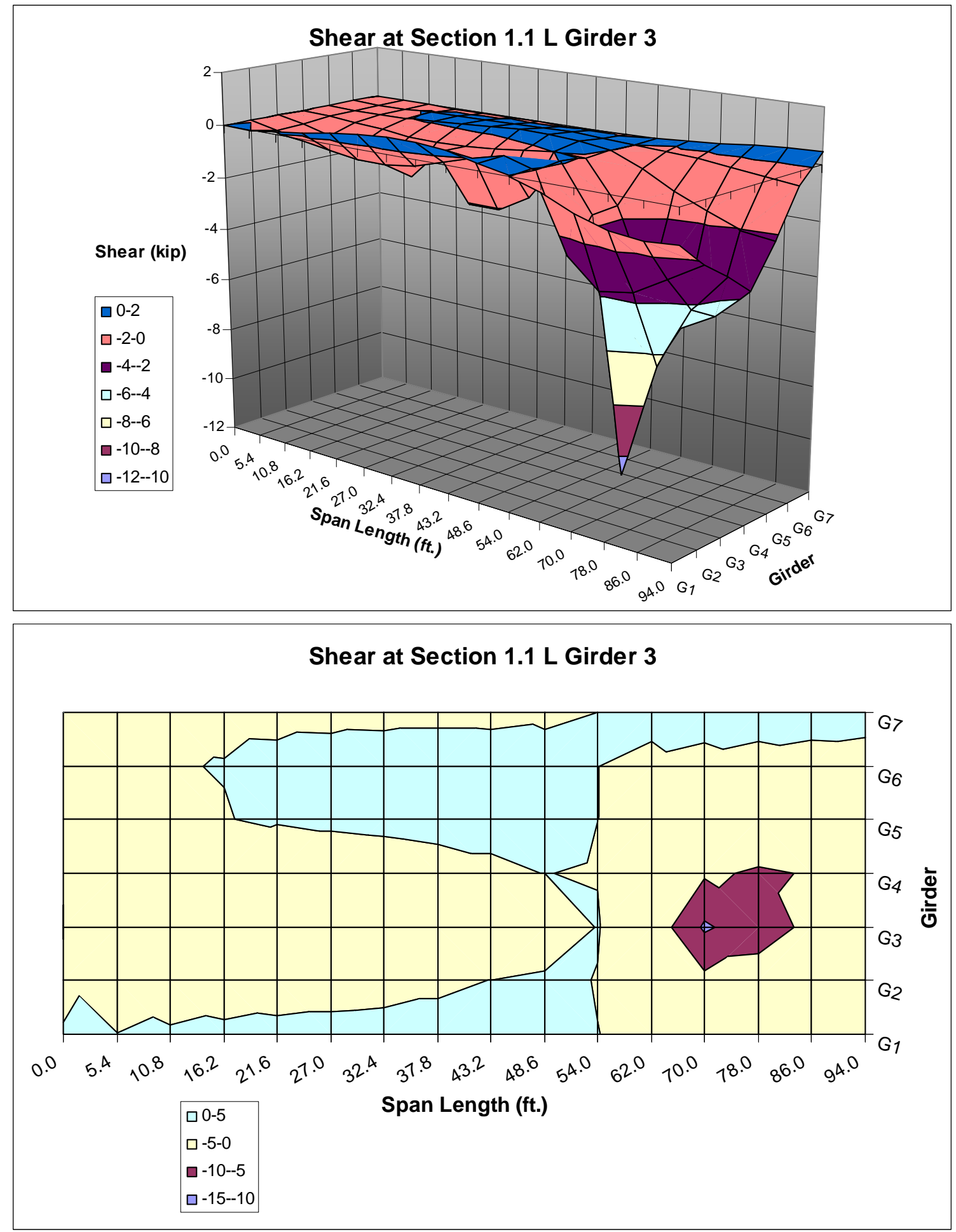

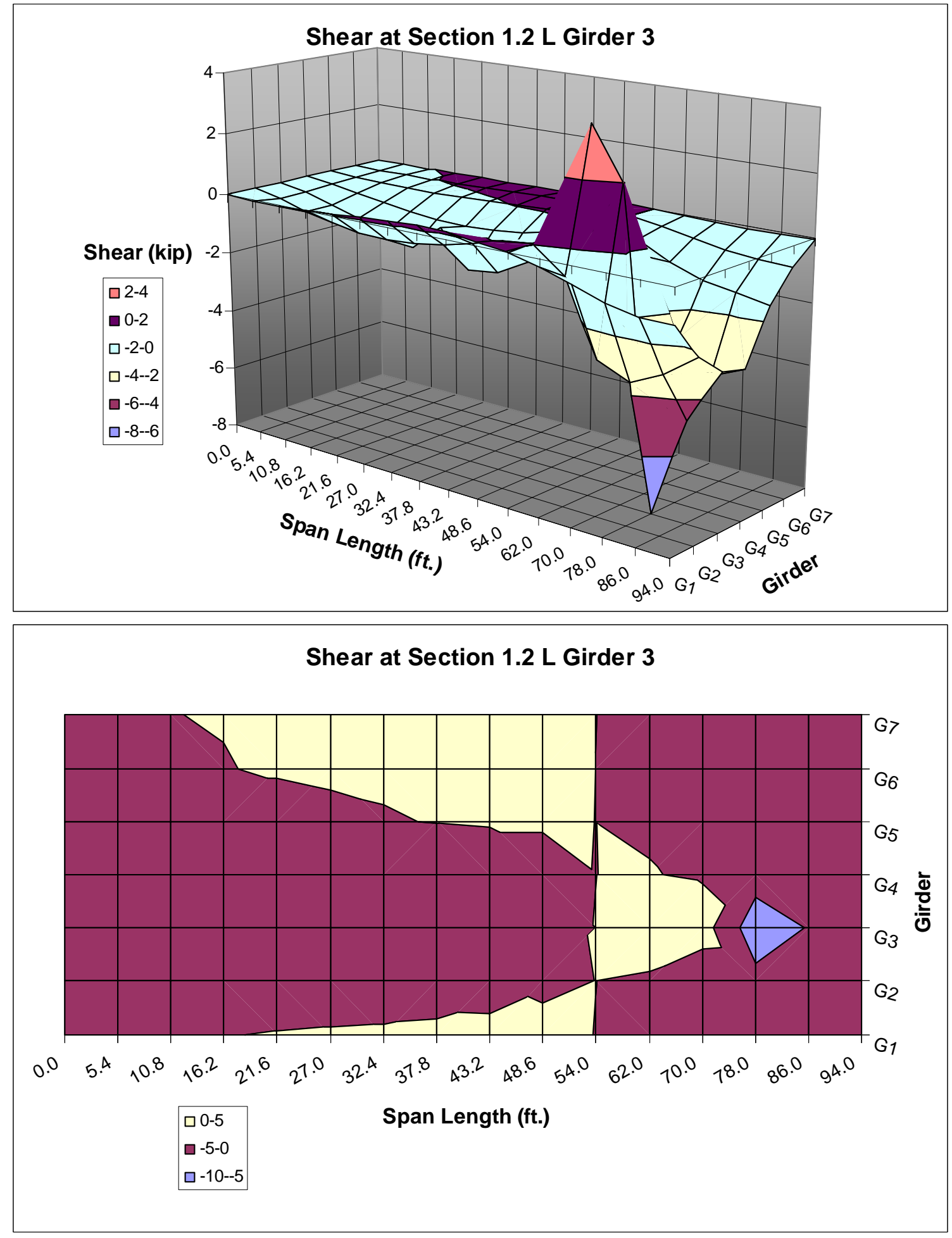

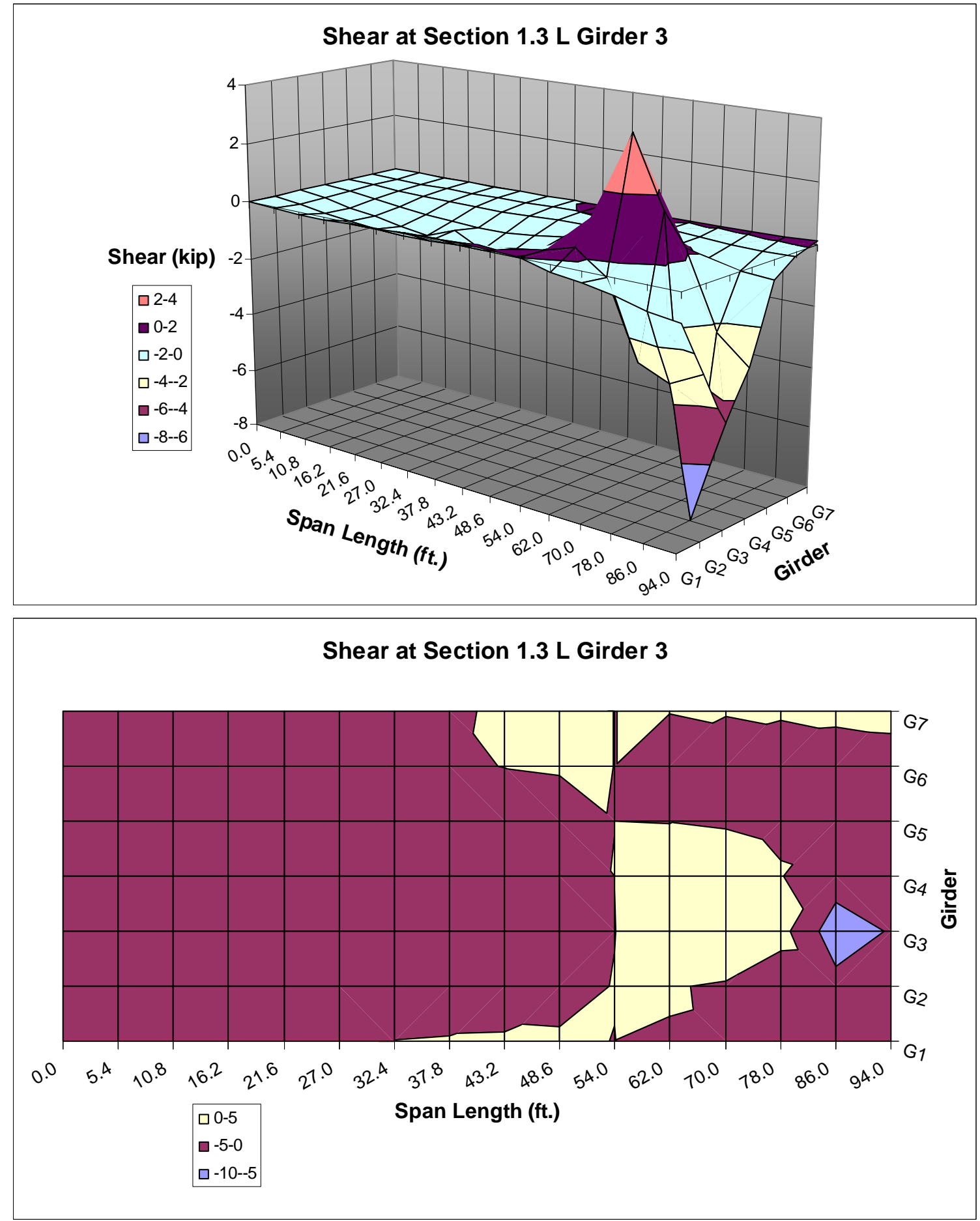

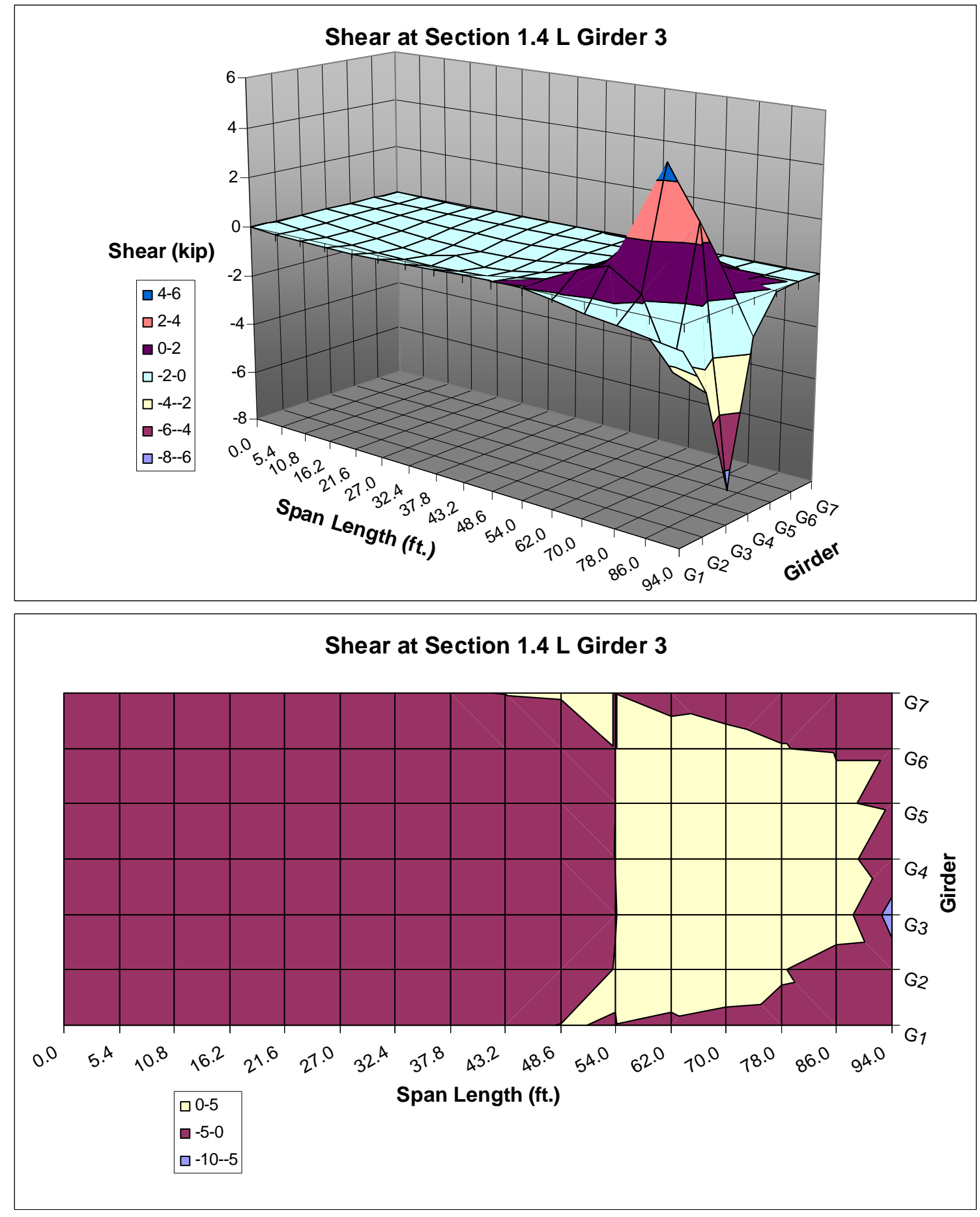

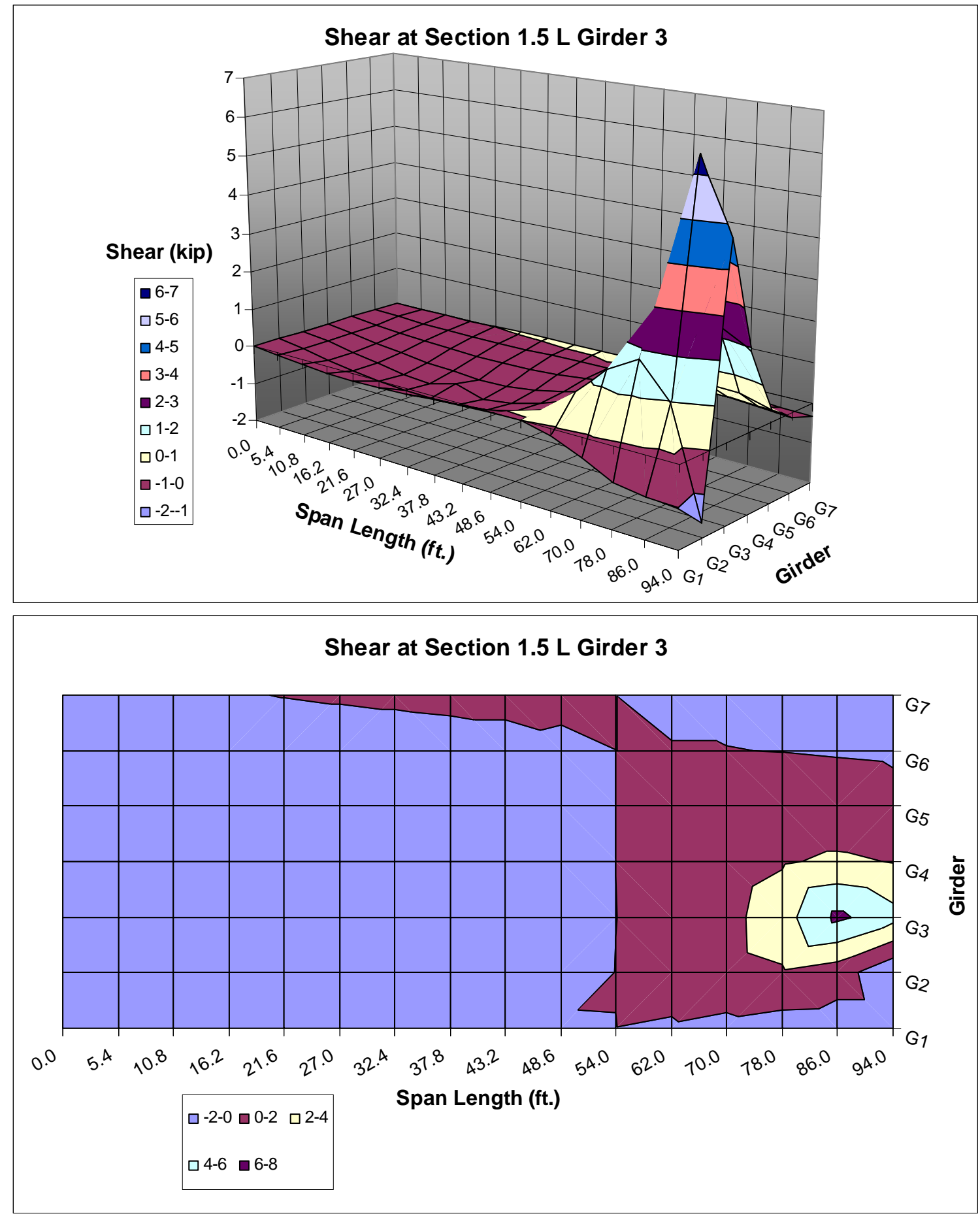

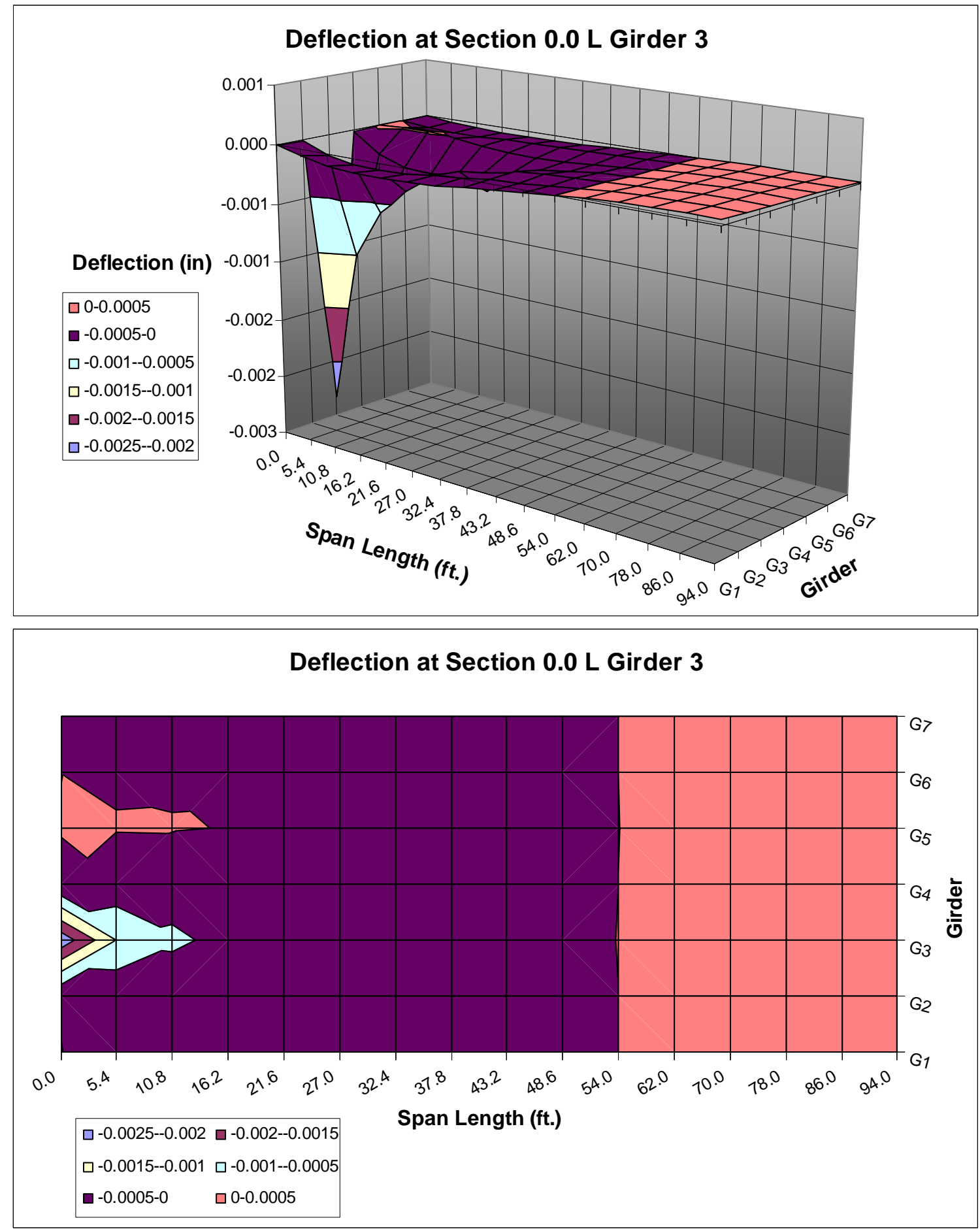

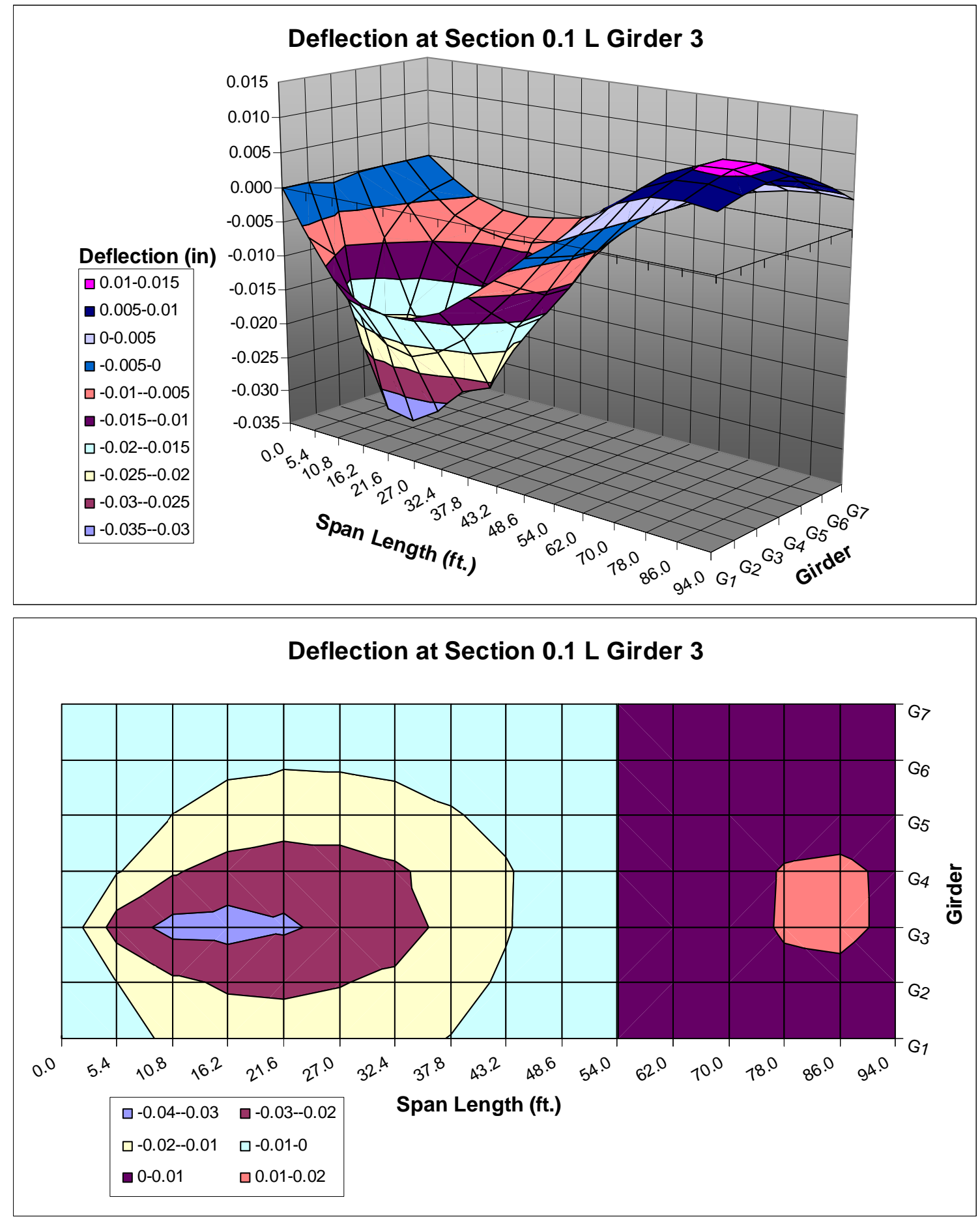

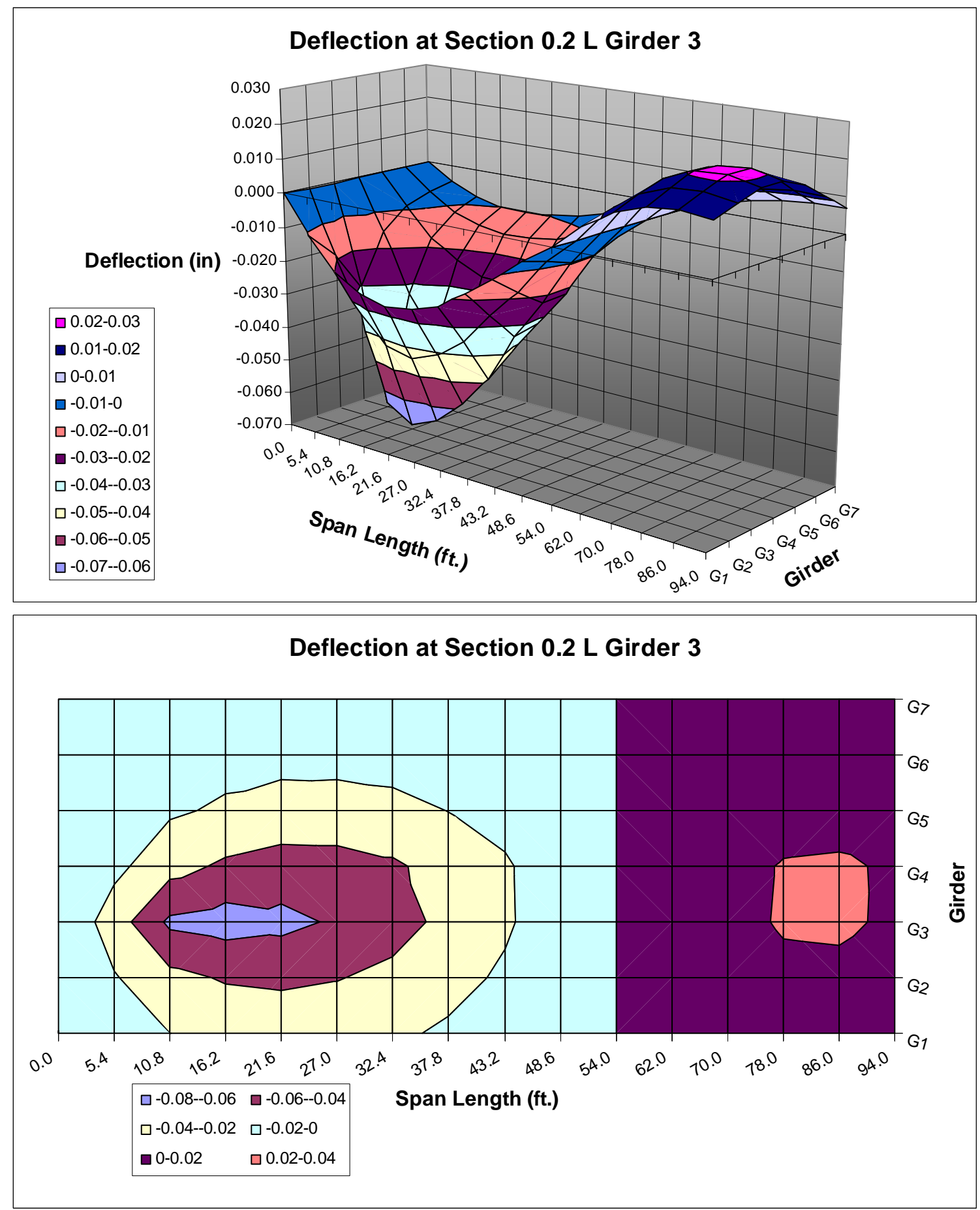

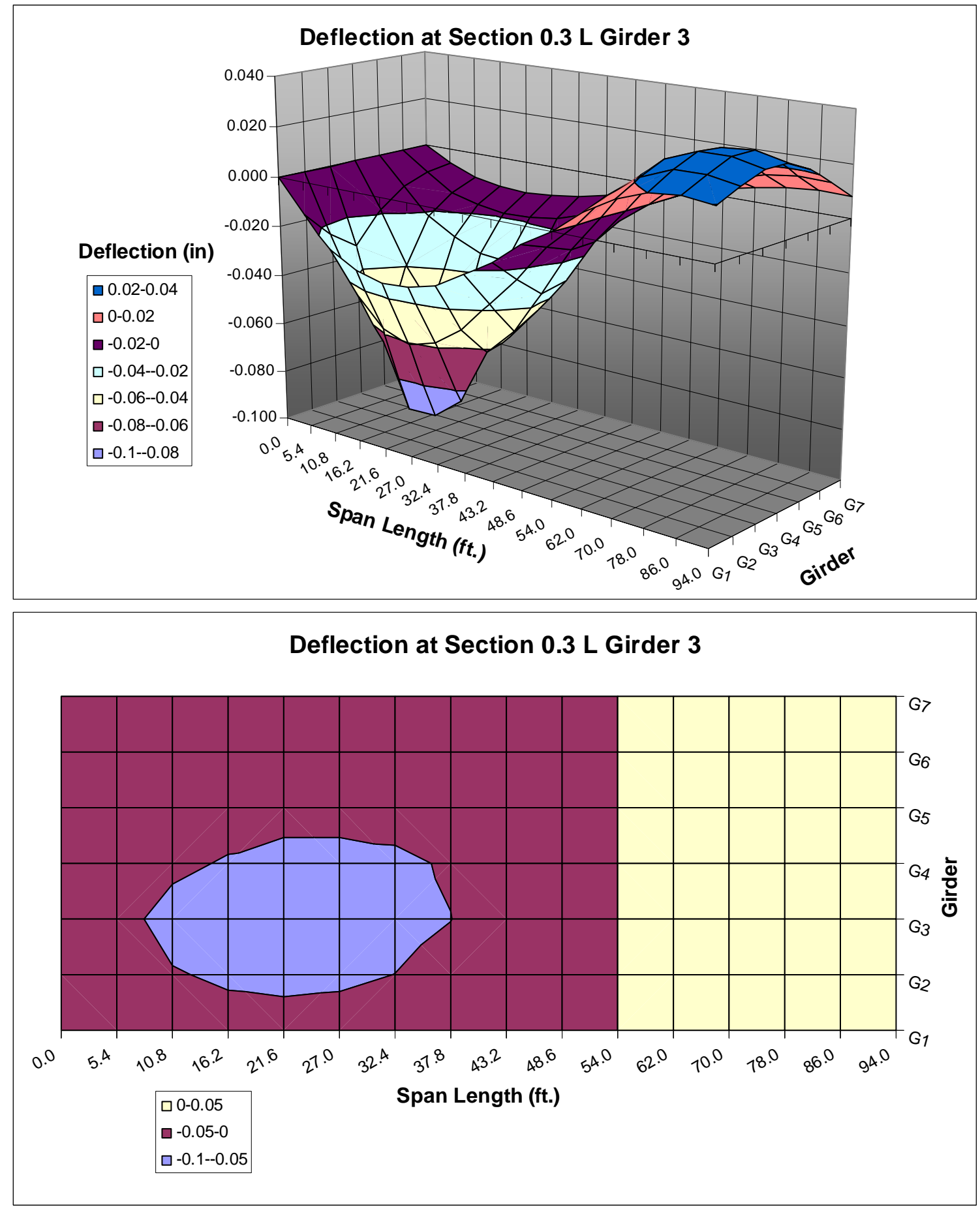

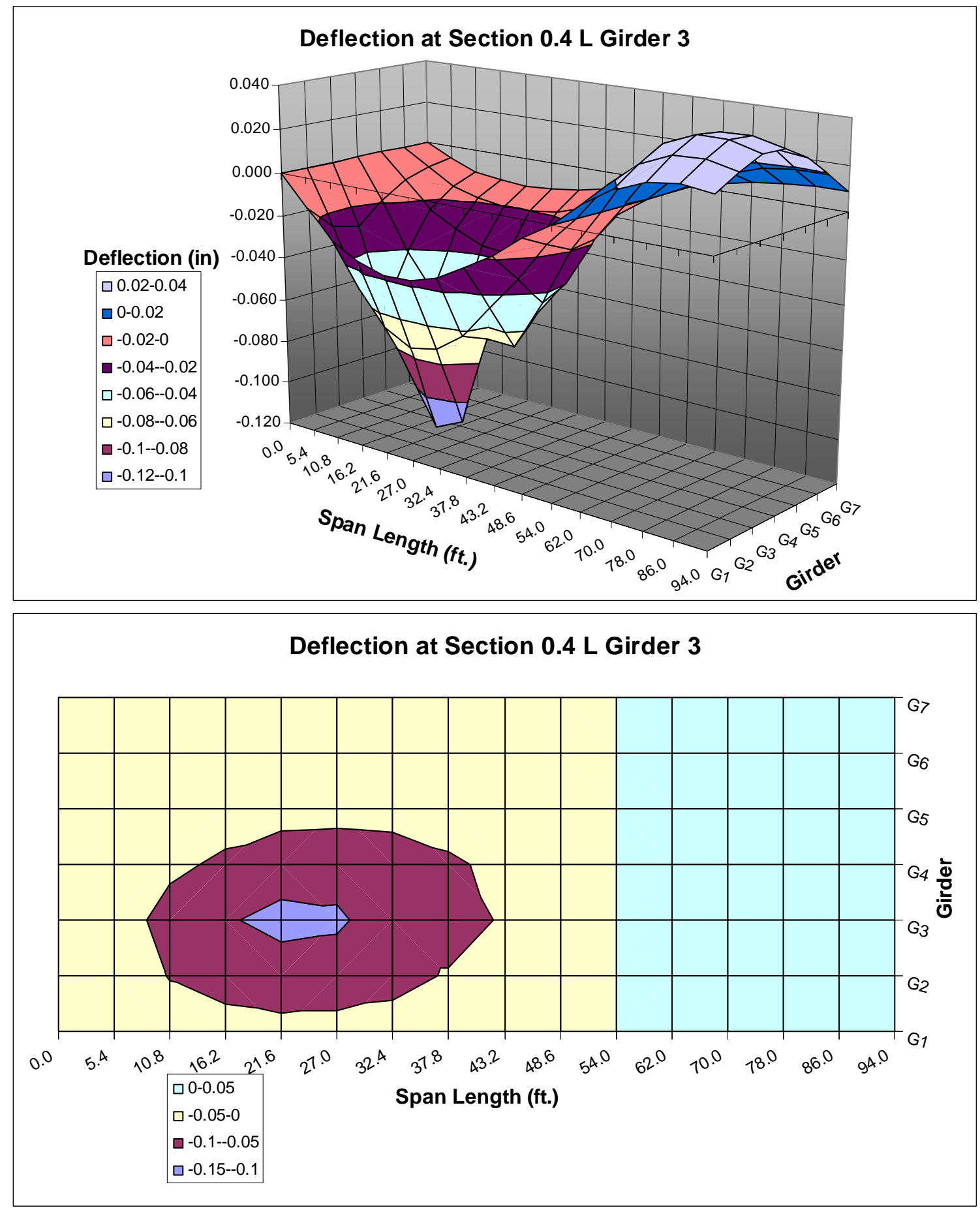

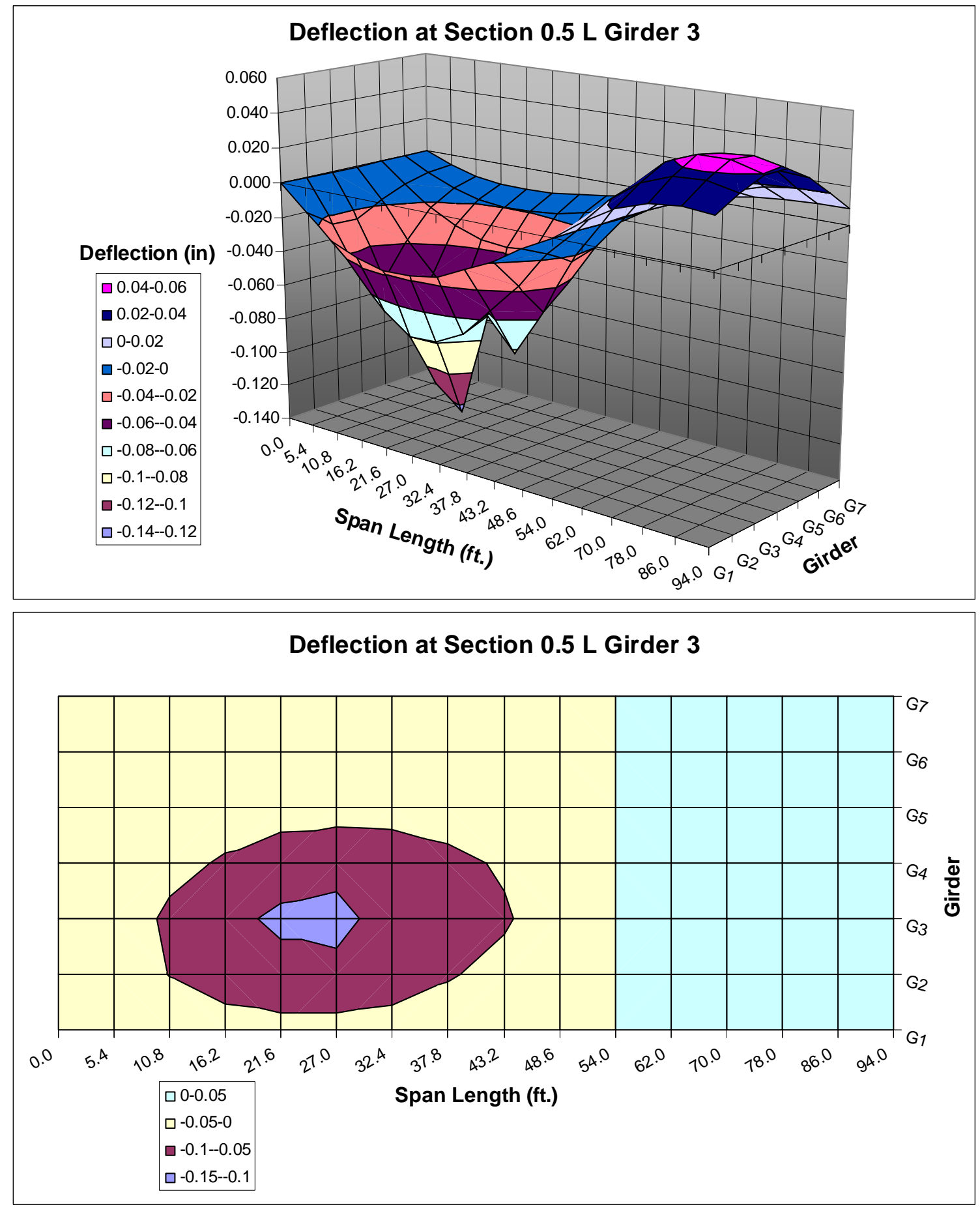

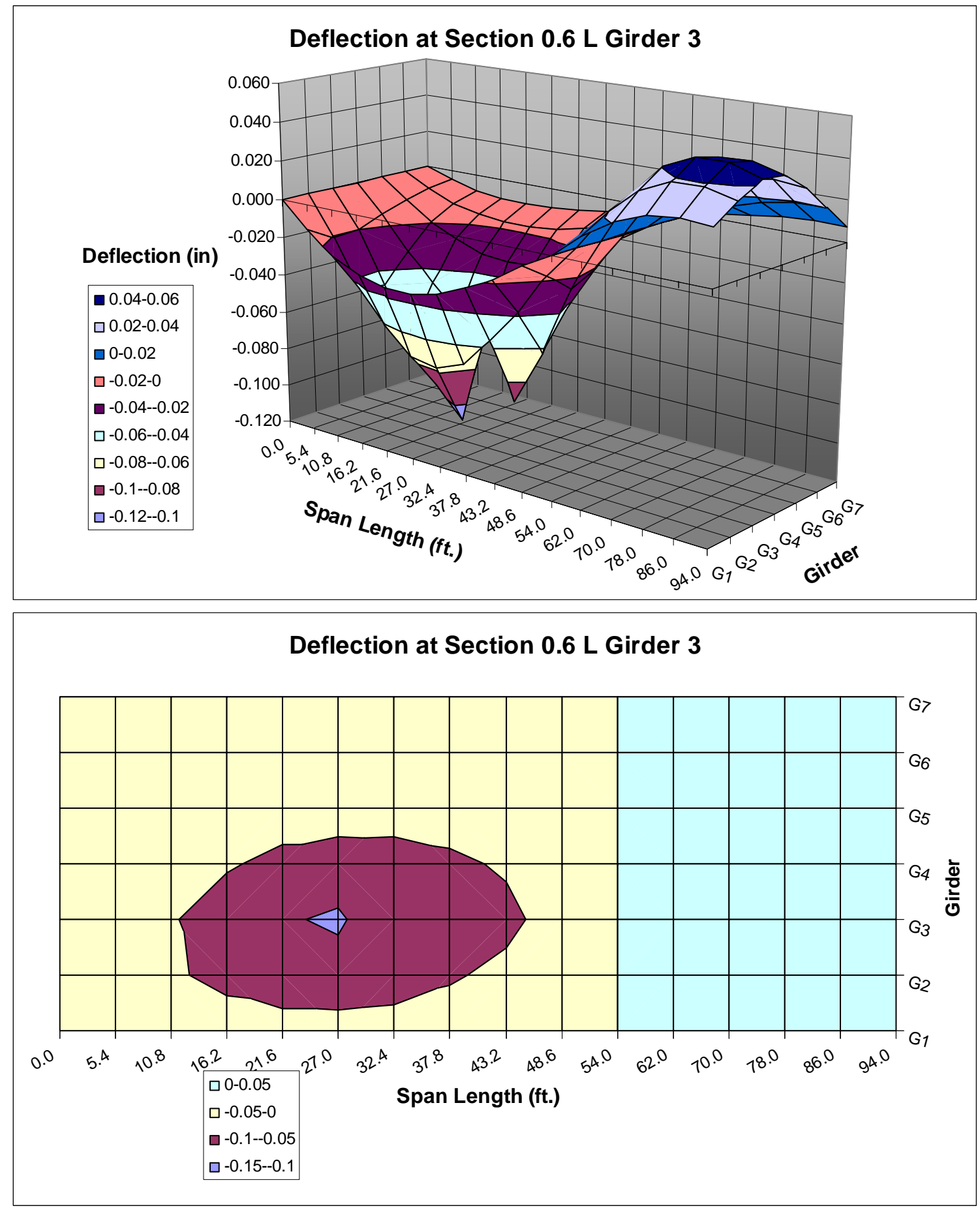

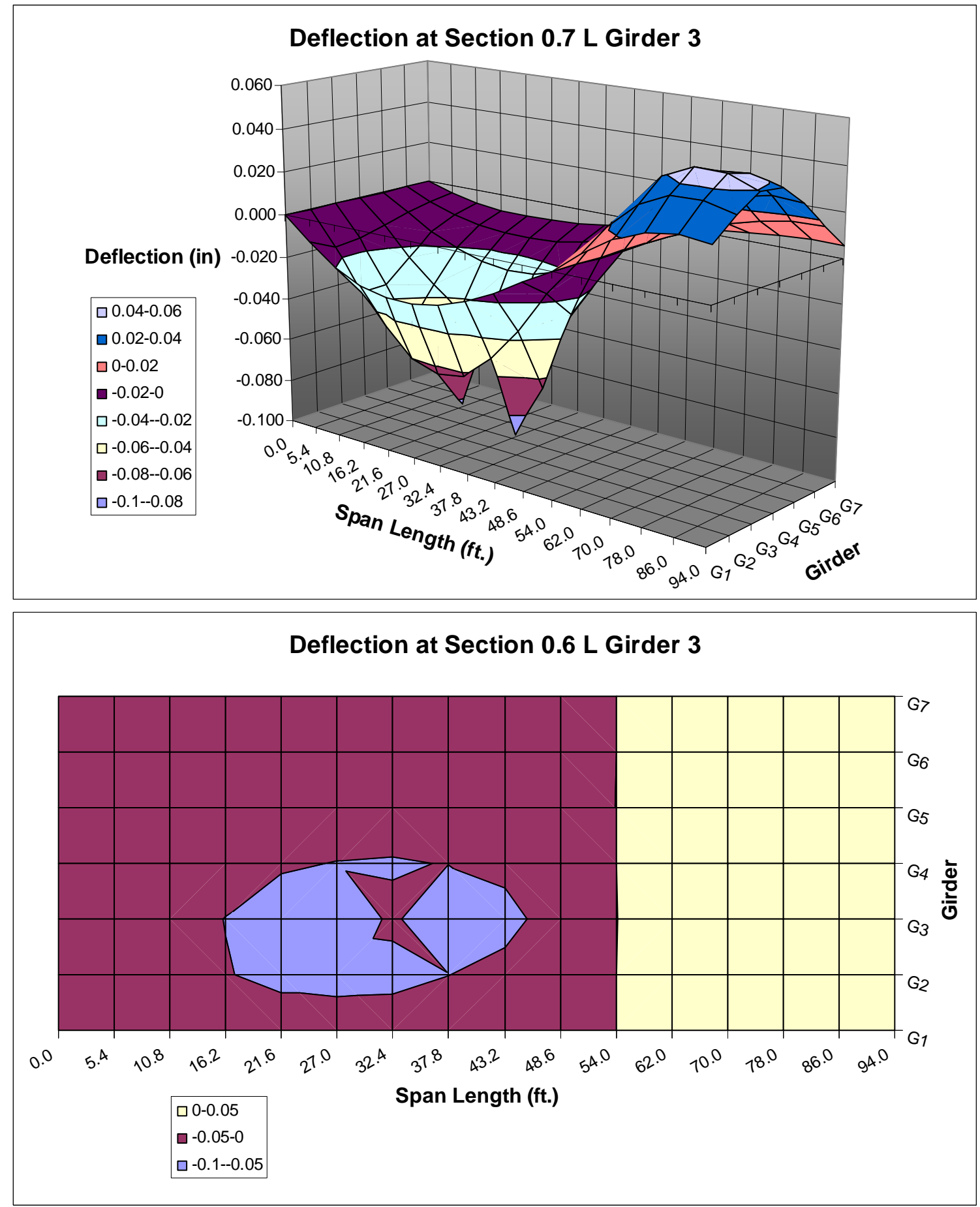

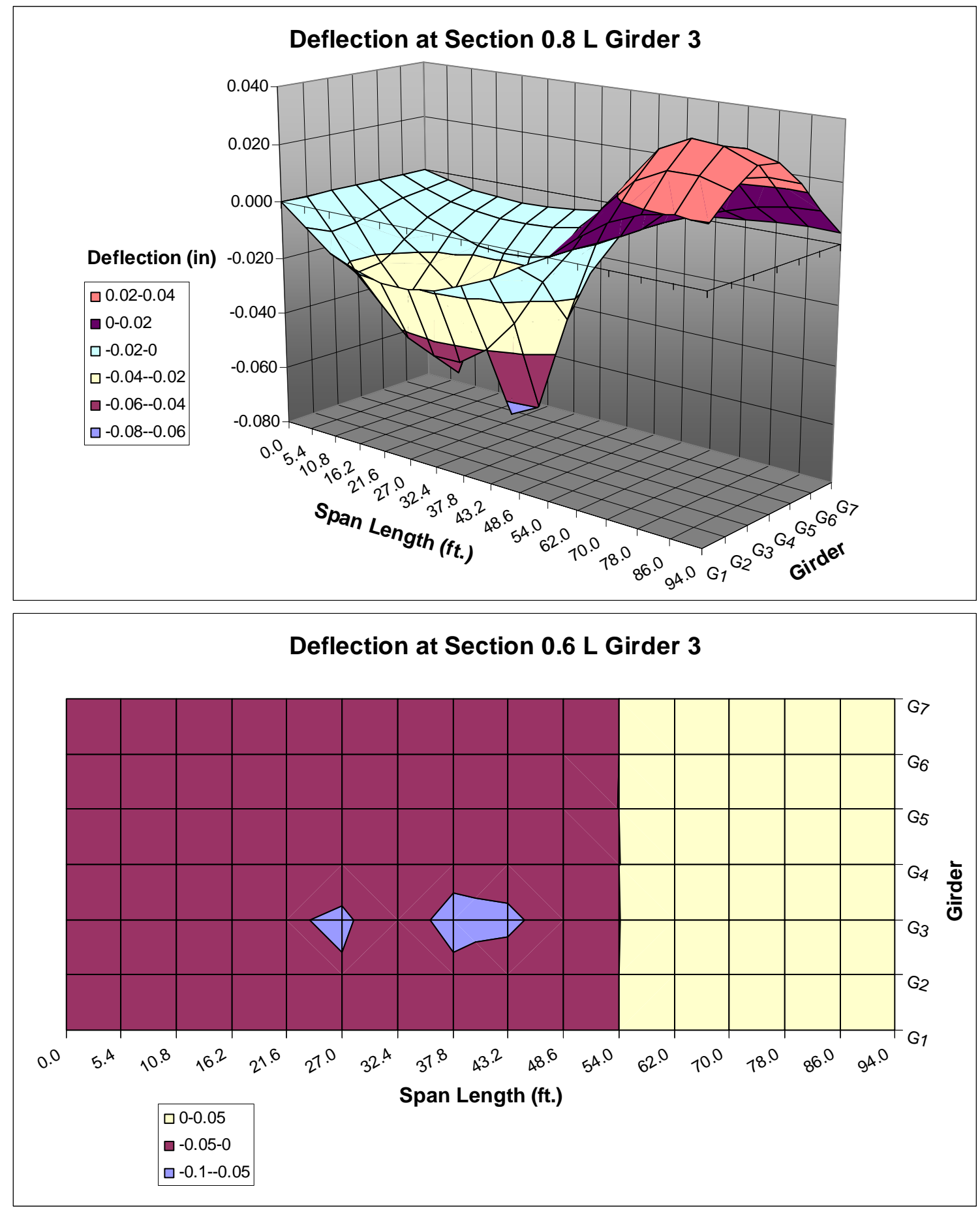

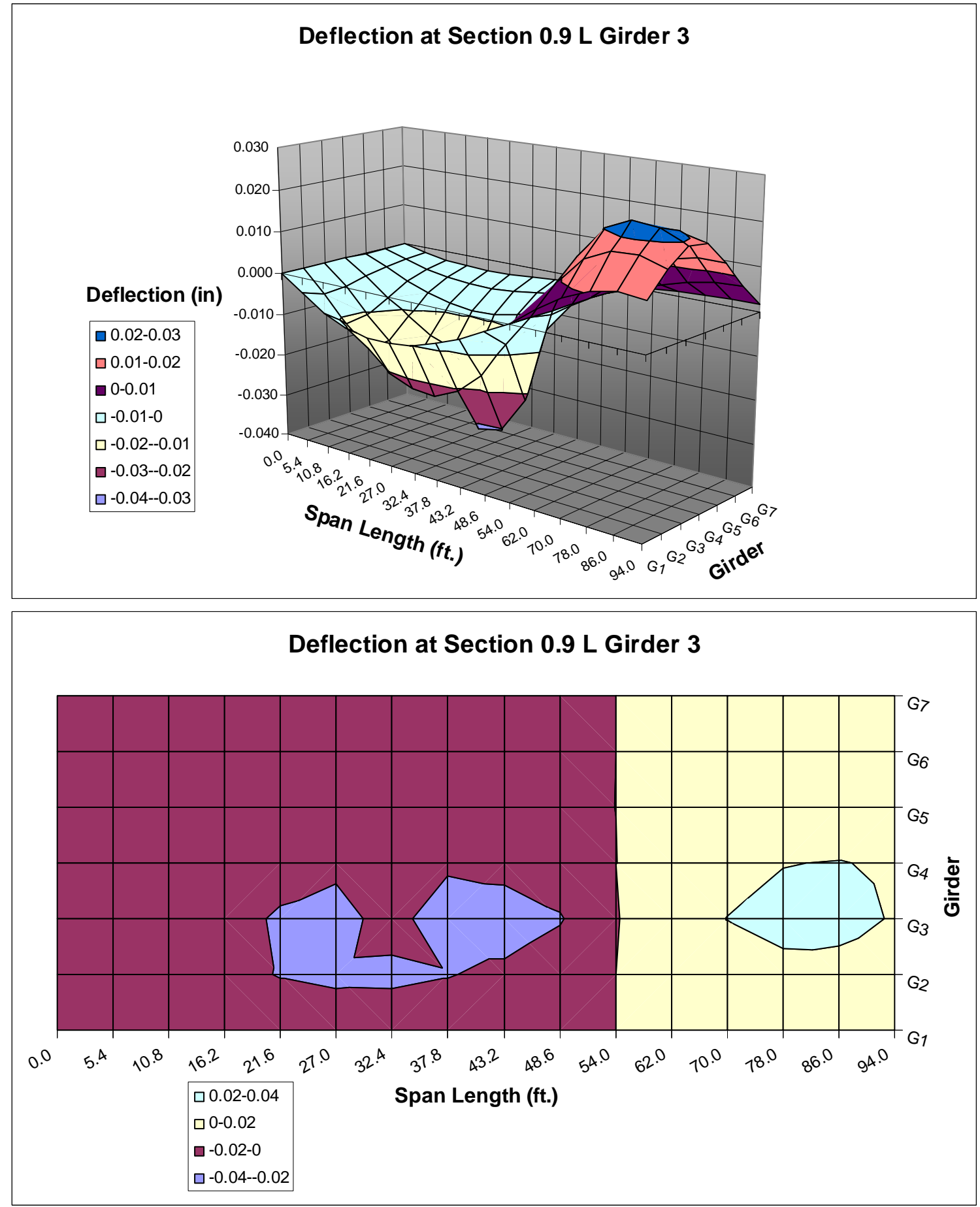

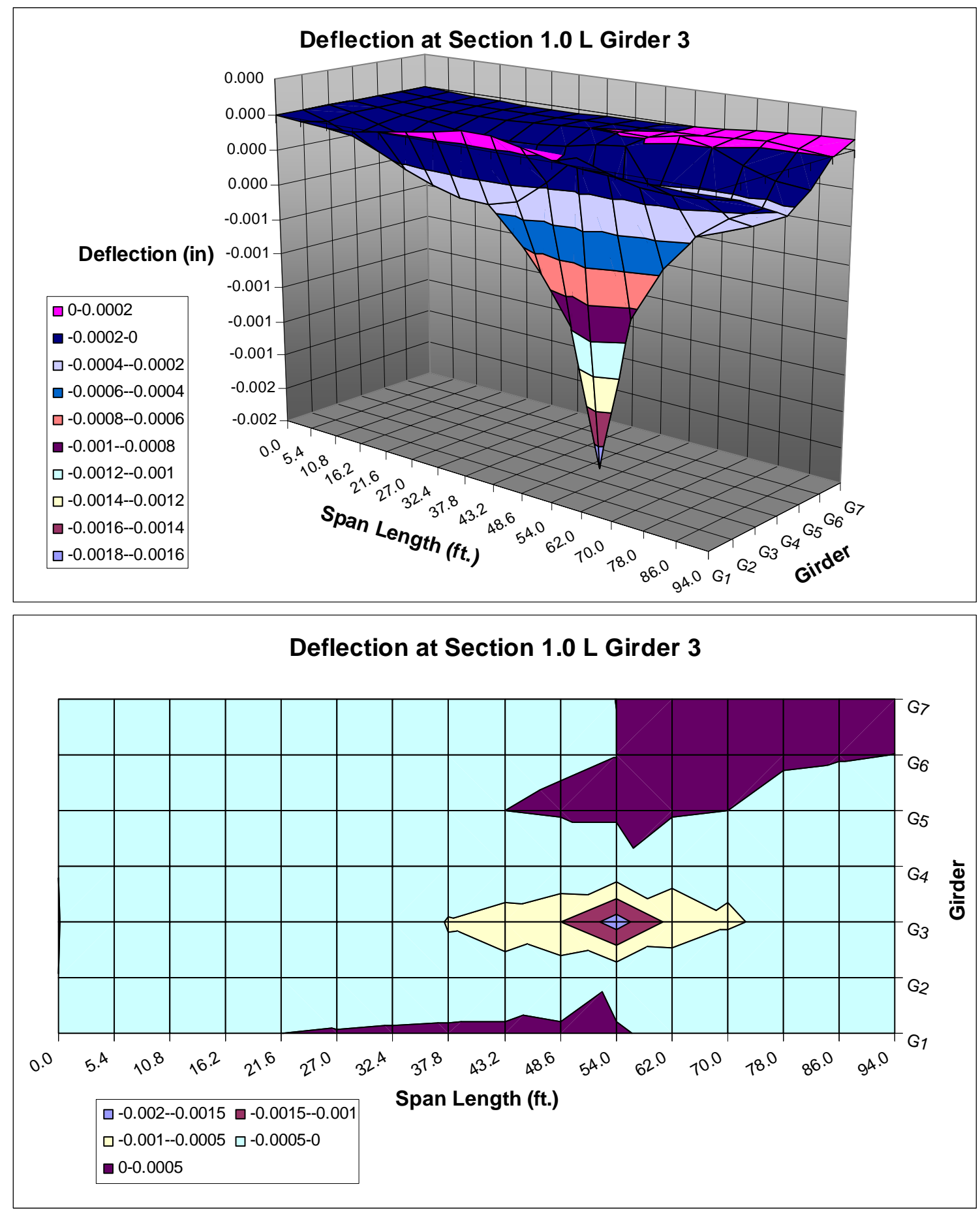

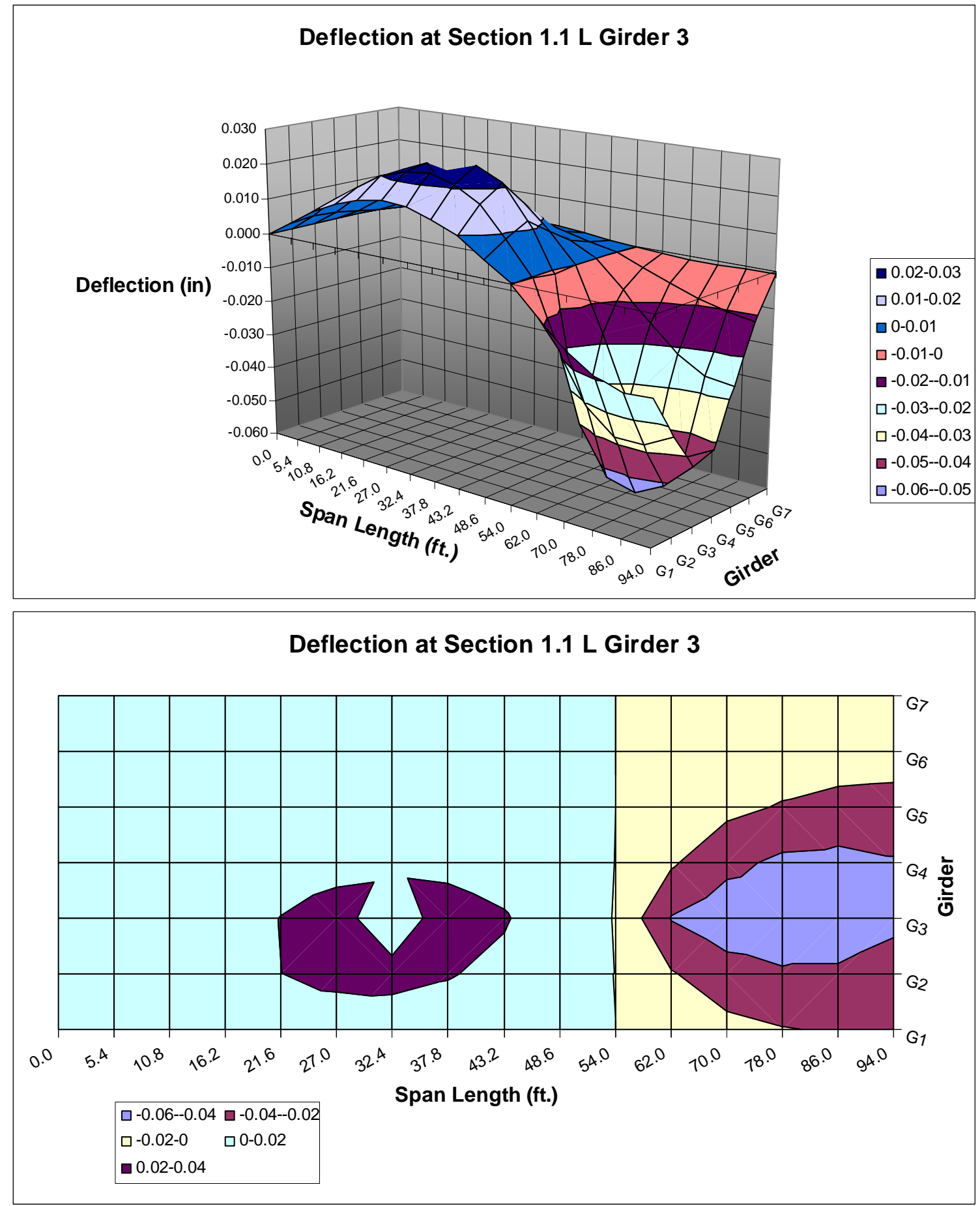

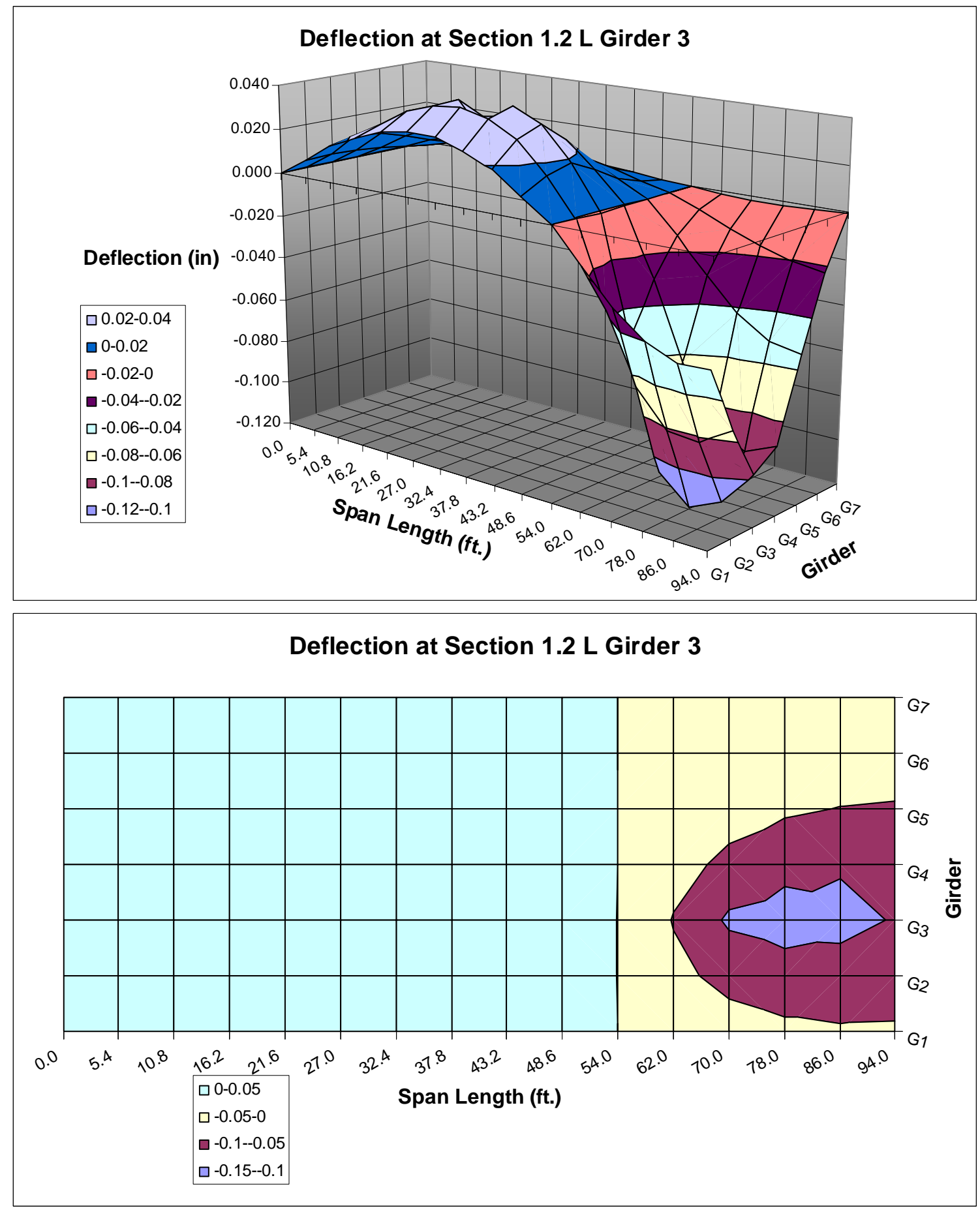

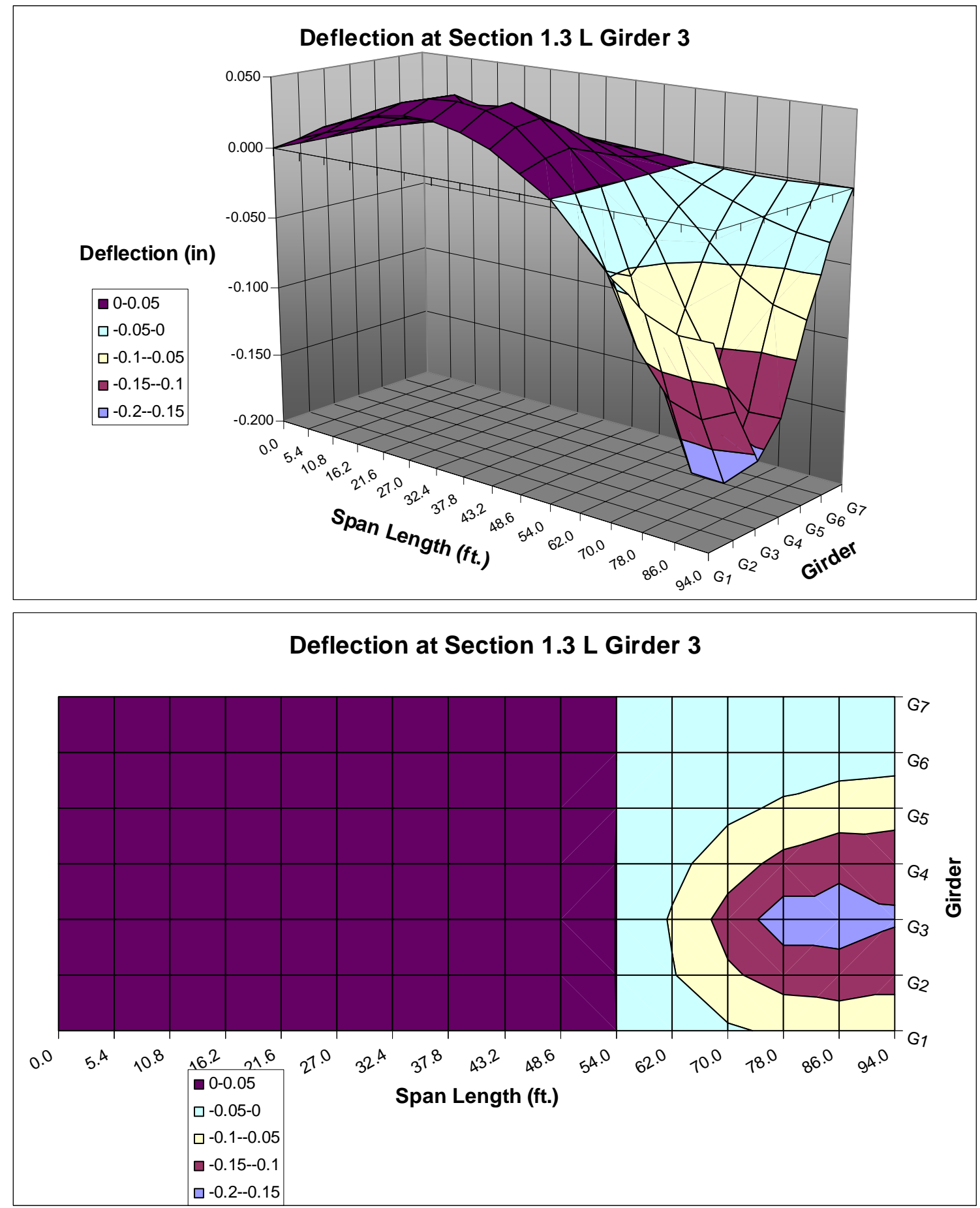

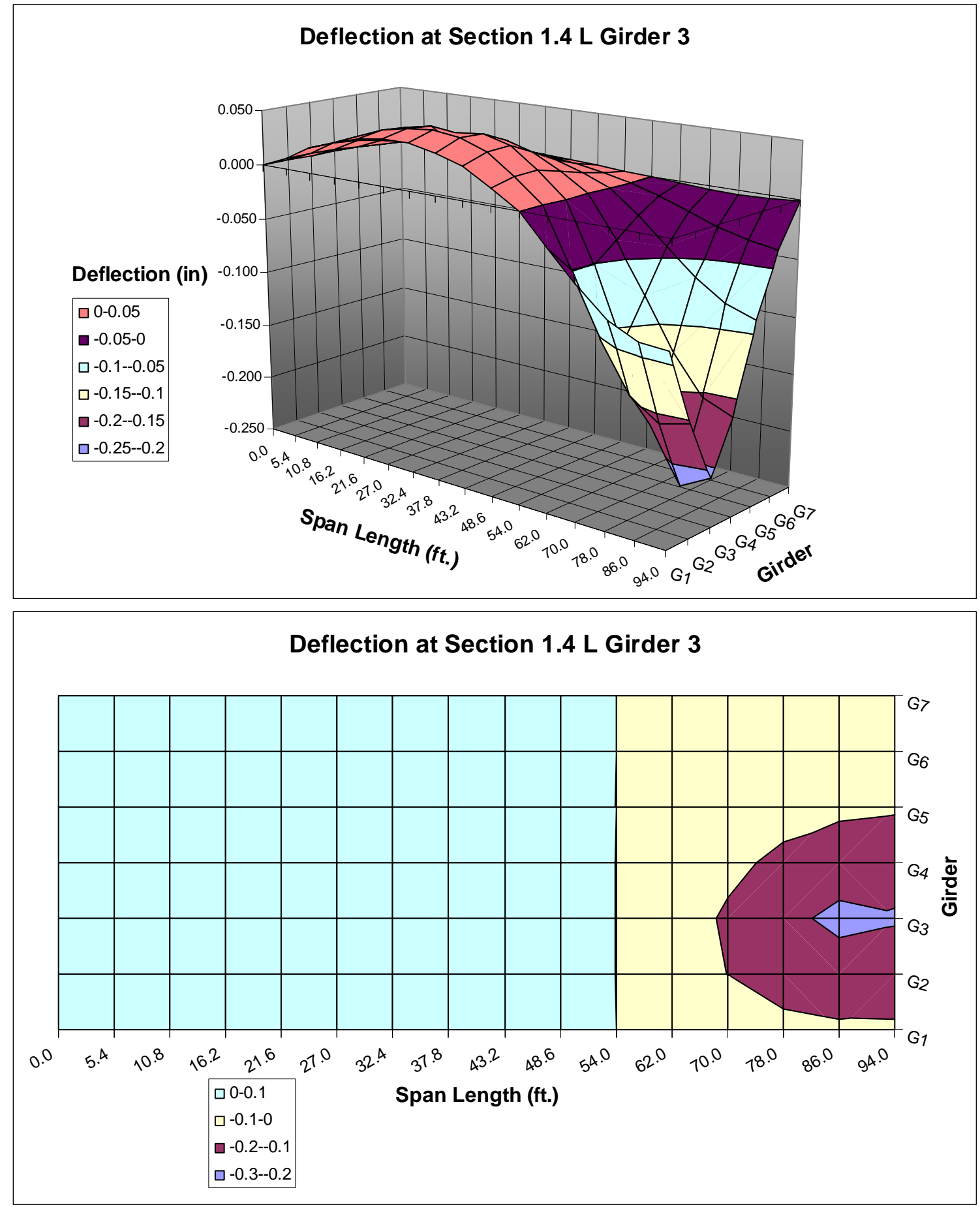

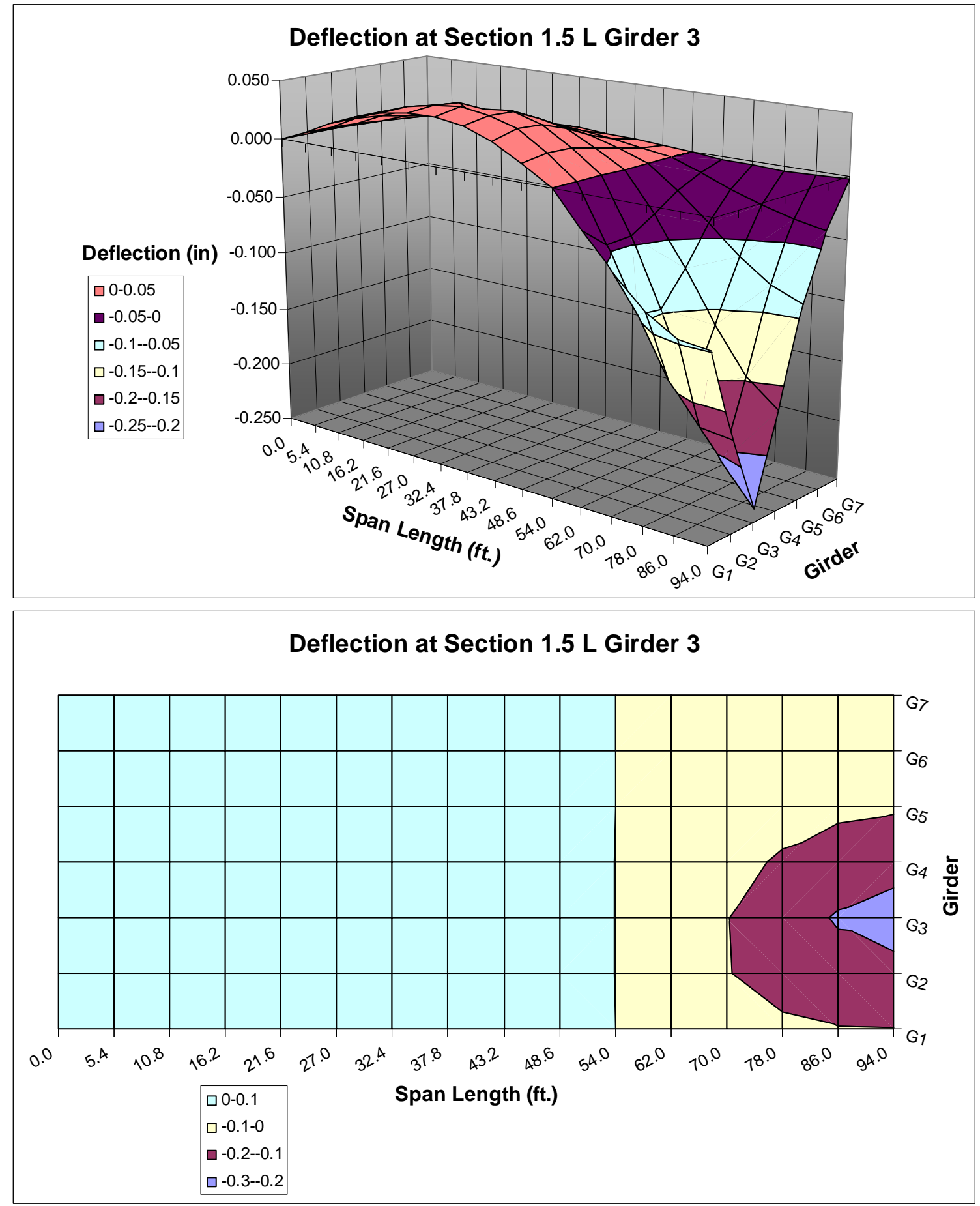

John 